UNIVERSIDAD DE LEÓN

DEPARTAMENTO DE PSICOLOGÍA, SOCIOLOGÍA Y FILOSOFÍA

PROGRAMA DE DOCTORADO DE PSICOLOGÍA

Y CIENCIAS DE LA EDUCACIÓN

\title{
MITOS Y REALIDADES ACERCA DE LA VIOLENCIA DE GÉNERO: ENTRE EL AMOR Y LA DOMINACIÓN
}

TRABAJO DE INVESTIGACIÓN PARA LA OBTENCIÓN DEL TÍTULO DE DOCTORA POR LA UNIVERSIDAD DE LEÓN

\section{BELÉN CASTAÑóN DEL POZO}

Directora: Ana Isabel Blanco García. Doctora en Sociología. Catedrática de Escuela Universitaria, departamento de Psicología, Sociología y Filosofía, Universidad de León. Presidenta del Seminario Interdisciplinar de Estudios de las Mujeres de la ULE.

León, España 


\section{DEDICATORIA:}

Este trabajo está dedicado a todas las mujeres que en el mundo y a lo largo de la historia, han sido o están siendo habitadas, por algún terrorista doméstico. 


\section{AGRADECIMIENTOS:}

A Ana Isabel Blanco García, directora de esta tesis, por razones obvias.

Al Ayuntamiento de León, a la Oficina Municipal de Información a las Mujeres y a Teresa Gutiérrez Álvarez, concejala de Bienestar Social, Mujer y Escuelas Infantiles por el PSOE, en el momento de realización de esta tesis, por facilitar todos los recursos a su alcance y eliminar barreras, para sacar adelante tanto este proyecto, como otros relacionados.

A las Asociaciones de Mujeres, Isadora Duncan y ADAVAS de León, que posibilitaron mi desarrollo profesional en el campo de la mujer y los malos tratos.

A las nueve mujeres que colaboraron desinteresadamente en el trabajo, por permitir esta intromisión en sus recuerdos y regalar testimonios repletos de dolor y esperanza.

A todos y todas aquellos/as, compañeros/as y amistades, que con sus acciones y actitudes han apoyado y estimulado en el día a día, la realización de este trabajo.

A toda mi familia, también a los que ya no están, no sólo por alentarme en esta tarea, sino también por comprender, disculpar y respetar mis ausencias. A Clara y a Jesús, por haber soportado sin reproches este tiempo de dedicación al trabajo, en detrimento de nuestro tiempo de ocio y por compensar la fatiga y los sinsabores con tanto amor y alegría. 


\section{TABLA DE CONTENIDO.}

Página

$\begin{array}{ll}\text { INTRODUCCIÓN } & 1\end{array}$

$\begin{array}{ll}\text { CAPÍTULO I MARCO TEÓRICO } & 7\end{array}$

$\begin{array}{ll}\text { 1.- Concepto de Mito } & 7\end{array}$

1.1.- Mitos más frecuentes acerca de la violencia de género. 11

1.1.1.- A las víctimas de la violencia de género les gusta que las 12 maltraten, son mujeres masoquistas y provocadoras.

1.1.2.- Las víctimas de la violencia de género padecen trastornos 22 psicológicos, están locas.

1.1.3.- Los maltratadores son enfermos mentales.

1.1.4.- La violencia de género, sólo se da en familias desestructuradas, con bajo nivel económico.

1.1.5.- Los maltratadores están sometidos a estrés laboral.

1.1.6.- Los maltratadores abusan de sus parejas a causa del alcohol u otras sustancias.

1.1.7.- Lo que ocurre en una familia es un asunto privado, mejor no denunciar.

1.1.8.- Siempre se exagera la realidad cuando se habla de violencia contra las mujeres.

1.1.9.- Las feministas odian a los hombres y las casas de acogida rompen matrimonios.

1.1.10.- Hay muchos hombres maltratados.

1.1.11.- Si tienen hij@s es mejor que aguanten. 
2.1.- En busca de una definición.

2.2.- Medidas contra la violencia de género. Historia de una ley.

2.3.- Los datos.

2.4.- Explicaciones teóricas sobre la violencia de género.

2.5.- La mecánica: el ciclo de la violencia.

3.- Concepto de Amor.

3.1.- ¿Qué es el amor romántico?

3.2.- Mitos y falsas creencias acerca del amor. Los celos.

3.3.- La interiorización de la ideología del amor romántico.

4.- Concepto de Dominación.

4.1. Micromachismos:

CAPÍTULO II EXPOSICIÓN Y DISCUSIÓN DE RESULTADOS.

1.- Decisiones metodológicas.

2.- Diseño de la investigación.

3.- Hipótesis de trabajo.

4.- Objetivos.

5.- Presentación de los hallazgos.

5.1.- Tiempo de estudio.

5.2.- Fechas de realización de entrevistas.

5.3.- Número de escenarios e informantes.

5.4.- Análisis de resultados.

5.4.1.- Acerca de la violencia de género. 
5.4.3.- Realidades acerca de la violencia contra las mujeres.

5.4.4.- Estrategias utilizadas para salir de la relación de maltrato:

CAPÍTULO III

CONCLUSIONES

BIBLIOGRAFÍA

ANEXO I

ANEXO II 


\section{ÍNDICE DE TABLAS Y CUADROS}

Página

Cuadro 1 Víctimas de violencia de género según grupo de edad 92

Cuadro 2 Media de edad de víctimas mortales año 2009

Cuadro 3 Víctimas mortales según grupos de edad 94

Cuadro 4 Denuncias por Violencia de Género 95

Cuadro 5 Víctimas de nacionalidad extranjera 99

Cuadro 6 Víctimas mortales según nacionalidad 100

Cuadro 7 Víctimas mortales por violencia de género año $2009 \quad 107$

Cuadro 8 Rueda de control y poder 143

Cuadro 9. Tiempo invertido en la realización de las entrevistas 173

Cuadro 10 Fechas de realización de las entrevistas 173

Cuadro 11 Mitos acerca de la violencia de género 175

Cuadro 12 Mitos acerca del amor romántico 196

Cuadro 13 Realidades acerca de la violencia contra las mujeres 210 


\section{RESUMEN:}

En la base de este trabajo, se encuentra la inquietud por descubrir, cuáles fueron las estrategias que utilizaron las nueve mujeres que conforman el estudio, para salir de la violencia que imperaba en sus relaciones de pareja.

Nos motivó el afán por conocer cómo consiguieron sobrevivir, durante cuánto tiempo estuvieron sometidas, cuántos intentos de separación hubo antes del definitivo, cómo protegían a sus hijos e hijas del maltrato, por qué permanecían al lado de sus maltratadores y un largo etc. de cuestiones a las que se les ha venido dado respuesta, desde el imaginario social, con un discurso anacrónico y patriarcal repleto de mitos, que como veremos a lo largo de este trabajo, poco tiene que ver con la realidad que describen las nueve mujeres que conforman nuestro estudio.

Se optó por un enfoque holístico, en el que hubo cabida para la persona en sí misma. Se buscó el análisis de la experiencia de maltrato como un todo, teniendo en cuenta circunstancias personales, sociales, culturales, económicas...

Desde un punto de vista fenomenológico se analizaron tanto las respuestas que se desprendían de las cuestiones planteadas en la entrevista que sirvió de guía, como la actitud que mostraron las entrevistadas ante dichas cuestiones. Nos referimos a la observación de gestos, expresiones,... todo lo que comprende la comunicación no verbal y que aportó información igualmente valiosa. 


\section{INTRODUCCIÓN:}

Con el presente trabajo se pretendió dar continuidad al DEA expuesto en esta misma universidad, en octubre del año 2008, que lleva por título La seducción del machismo en la adolescencia y su influencia en la violencia de género. Aunque se trata de trabajos independientes, hay un tronco común que vertebra ambas investigaciones, en el que se amalgaman los conceptos que aquí se exponen. Ese tronco común es la búsqueda de una explicación a las dinámicas que subyacen en el mantenimiento de una relación de maltrato y a la posibilidad de su disolución.

El principio básico que sustenta ambos estudios, se sitúa en el esfuerzo por visibilizar y comprender la violencia contra las mujeres desde la perspectiva feminista, intentando arrojar luz acerca de los factores que impiden o favorecen la citada disolución de la relación con el maltratador. Consideramos que es importante destacar el esfuerzo del feminismo, desde sus orígenes, poniendo en evidencia las teorías universalistas capaces de distorsionar la realidad de las mujeres.

"El feminismo es capaz de percibir las trampas de ciertos discursos, y, en este sentido, el feminismo no es una alternativa teórica más, sino que actúa como conciencia crítica resaltando las tensiones y contradicciones que encierran dichos discursos. Estas contradicciones se hacen patentes cuando se enfrentan a las vindicaciones emancipatorias del discurso feminista" (Amorós, 1995, p.142)

Lo que subyace a toda investigación feminista es el objetivo de comprender y revelar características de las mujeres, frecuentemente ignoradas o mal entendidas en culturas en las que la información es 
controlada por los hombres. Con este propósito, el feminismo se esfuerza por adoptar un sistema de trabajo que haga visibles las experiencias de mujeres.

Según Mies (1983), Lather (1988), Stanley (1990) las feministas argumentan que para que una investigación sea feminista debe, de algún modo, contribuir al movimiento, dando a conocer ya sea las maneras en que se controla a las mujeres en una cultura dominada por los hombres, o simplemente el carácter de las experiencias de las mujeres en culturas que otorgan una importancia primordial a las necesidades masculinas. Diferentes investigadoras sostienen diversos puntos de vista sobre qué se puede considerar un aporte a la lucha contra la opresión. Muchas afirman que la investigación debe estar íntimamente ligada a la acción, lo que puede lograrse comprometiendo a las participantes a generar proyectos dirigidos a cambiar la situación de la población femenina.

Este trabajo lleva como título, Mitos y Realidades acerca de la Violencia de Género: entre el Amor y la Dominación. En él, se trata de:

1.Hacer una revisión de la literatura científica sobre los conceptos (Mito, Violencia de Género, Amor y Dominación) que desde nuestro punto de vista explican la permanencia y/o ruptura de una relación en la que las mujeres son víctimas de violencia por el mero hecho de serlo.

2.Realizar un estudio descriptivo, desde el punto de vista de la investigación cualitativa, utilizando la técnica de la entrevista en profundidad, en este caso, entrevistas semiestructuradas, realizadas a nueve mujeres que han sido víctimas de violencia de género, con objeto de comprobar si las explicaciones que tanto desde la literatura científica, como desde la opinión pública, acerca de por qué se produce, se mantiene o se destruye dicha relación, coinciden con las experiencias vividas por estas mujeres en concreto. 
3.Conjugar objetivos, hipótesis de trabajo y metodología, para buscar, si las hubiere, explicaciones alternativas, a la realidad de la violencia contra la mujer, de las que se ofrecen desde los mitos y las creencias populares asentadas en la sociedad.

La hipótesis de la que se parte surge de la duda acerca de las afirmaciones predominantes en la actualidad, que culpabilizan a las mujeres víctimas de su situación. Hablamos de la doble victimización de las mujeres maltratadas.

Torres Falcón (2001, p.225) afirma al respecto: "Además del maltrato de sus esposos o compañeros, durante mucho tiempo las mujeres han tenido que soportar que trabajadores sociales, terapeutas, abogados y jueces, entre otros, las acusen de provocadoras"

Uno de los factores socioculturales más importantes de riesgo, para la ocurrencia de la violencia contra las mujeres en las relaciones de pareja, son precisamente, las actitudes favorables que justifican el maltrato desde el patriarcado.

Los modelos multicausales que se barajan en la actualidad Heise (1998), Heise y García Moreno (2003), Sanmartín, Farnós, Capel y Molina (2000),Fondo Internacional de Ayuda a la Infancia de las Naciones Unidas (UNICEF) (2000) y Organización de las Naciones Unidas (ONU) (2006), para dar explicación al maltrato, han llegado a la conclusión de que no hay una causa única que explique la violencia contra las mujeres sino que ésta surge de la convergencia de factores específicos en el contexto general de las desigualdades de poder en los niveles individual, grupal, nacional y mundial, de modo que la violencia contra las mujeres funciona como un mecanismo para mantener la autoridad de los hombres y los límites de los 
roles de género masculinos y femeninos, en definitiva, como un mecanismo para el mantenimiento del sistema patriarcal ${ }^{1}$.

Se atribuyen a las mujeres, características de personalidad 0 síndromes patológicos como el de la indefensión aprendida o la personalidad masoquista, la dependencia o el amor. Pensamos que con independencia de estos factores, es la dominación del varón sobre la mujer, y no el amor romántico, la dependencia emocional o cualquier otra característica "interna" de las mujeres, el elemento que dificulta e impide la separación de una pareja en la que existen malos tratos. Siendo éste el planteamiento de trabajo, el objetivo primordial va encaminado a reconocer las estrategias que ellas utilizan para liberarse de esa dominación subyugante, razón por la que se han elegido como informantes mujeres de diferentes edades, clases sociales y niveles educativos, que comparten la circunstancia de haber puesto fin a su relación de pareja. En uno de los casos, la mujer mantiene la convivencia con su pareja, no obstante hemos querido contar con ella en este estudio porque aún compartiendo espacio físico con su maltratador, psicológicamente se encuentra distanciada de él.

Un recorrido por la tabla de contenidos, muestra la estructura y ordenación de la exposición:

En primer lugar, en la dimensión teórica del trabajo, se lleva a cabo una revisión de la literatura científica de los términos que conforman el propio título: Mito, Violencia de Género, Amor y Dominación. (cap.l)

\footnotetext{
1 Varela (2005, p.177) cita a Dolors Reugant (1996) quien define el patriarcado como "forma de organización política, económica, religiosa y social basada en la idea de autoridad y liderazgo del varón, en la que se da el predominio de los hombres sobre las mujeres; del marido sobre la esposa; del padre sobre la madre, los hijos y las hijas; de los viejos sobre los jóvenes y de la línea de descendencia paterna sobre la materna. El patriarcado ha surgido de una toma de poder histórico por parte de los hombres, quienes se apropiaron de la sexualidad y reproducción de las mujeres y de su producto, los hijos, creando al mismo tiempo un orden simbólico a través de los mitos y la religión que lo perpetúan como única estructura posible"
} 
En segundo lugar (cap.II), en la dimensión práctica del trabajo, encontramos el análisis de las entrevistas cuyo guión se encuentra recogido en el Anexo I.

El trabajo concluye con la redacción de las conclusiones que se desprenden del análisis de las entrevistas, recogidas íntegramente en el Anexo II. (cap.III)

Homenajear a las víctimas de violencia de género es posible desde el recuerdo a las hermanas Mirabal, porque fue su historia de muerte la que señaló el 25 de Noviembre, como fecha insignia para la lucha contra la violencia hacia las mujeres.

El 25 de Noviembre fue declarado el Día Internacional Contra la Violencia hacia las Mujeres en el Primer Encuentro Feminista para América Latina y el Caribe, celebrado en Bogotá, Colombia, en Julio de 1981. Ya en esta fecha, mucho antes de que las instituciones y los gobiernos se pusieran a trabajar contra la violencia de género como una realidad sistemática que abarcaba desde agresiones domésticas a violaciones, desde tortura sexual a violencia de Estado, incluyendo abusos a mujeres prisioneras políticas. Dieciocho años después, en 1999, Naciones Unidas reconocía oficialmente el 25 de Noviembre como Día Internacional para la Eliminación de la Violencia contra las Mujeres.

Patria, Minerva, María Teresa y Debé nacieron en Ojo de Agua, en la región de Cibao de la República Dominicana. Eran hijas de Enrique Mirabal y María Mercedes Reyes y se las apodaba "las mariposas". Eran activistas políticas y símbolos muy visibles de la resistencia a la dictadura de Trujillo y fueron encarceladas repetidamente por sus actividades revolucionarias en defensa de la democracia y la justicia. El 25 de Noviembre de 1960, Minerva, Patria y María Teresa fueron asesinadas por miembros de la policía secreta de Trujillo. Las tres mujeres se dirigían a Puerto Plata a visitar a sus maridos encarcelados. Sus cuerpos fueron encontrados en el fondo de un precipicio con los huesos rotos y signos de que habían sido estranguladas. La noticia 
de estos asesinatos conmovió y escandalizó a la nación. El brutal asesinato de las hermanas Mirabal impulsó al movimiento anti-Trujillo. El dictador fue asesinado el 30 de Mayo de 1961 y su régimen cayó poco después. Las hermanas se han convertido en símbolos de la resistencia, tanto popular como feminista. 


\section{CAPÍTULO I}

\section{MARCO TEÓRICO}

\section{1.- Concepto de Mito}

Entender el concepto de mito es fundamental en este trabajo, porque los mitos sustentan y legitiman las creencias que la sociedad maneja cuando justifican el fenómeno de la violencia de género. ${ }^{2}$

Es necesario desmontar el mito, porque la creencia en el mismo impide centrar la atención en el foco del problema, desde un punto de vista científico, es decir, empíricamente comprobable, dirigiendo así las soluciones hacia medidas periféricas, que lejos de resolver el problema, lo mantienen en el tiempo y lo justifican.

2 La Real Academia Española (RAE) define a la creencia como el firme asentimiento y conformidad con algo. La creencia es la idea que se considera verdadera y a la que se da completo crédito como cierta Puede considerarse que una creencia es un paradigma que se basa en la fe, ya que no existe demostración absoluta, fundamento racional o justificación empírica que lo compruebe. Por eso la creencia está asociada a la religión, la doctrina o el dogma. 
El mito es una creencia que se muestra como una verdad absoluta e inflexible. Por esta razón, posee una gran carga emotiva y es capaz de aglutinar en su esencia, sentimientos irracionales que calan en la sociedad.

De este hecho se han percatado los grupos de mujeres y las organizaciones feministas que trabajan en el campo de la violencia desde un enfoque de género. El feminismo, desmarcándose del mito y prestando especial atención a la socialización y al aprendizaje infantil, busca el equilibrio de poder entre mujeres y hombres, en la creencia de que ésta es la mejor opción para luchar de forma eficaz contra la violencia de género.

Carcedo Cabañas y Molina Subirós (2001, p. 04) lo reflejan de la siguiente manera: "Las organizaciones feministas han afirmado que algunos de los planteamientos que tratan de explicar la violencia por las adicciones 0 los problemas económicos del agresor, son en realidad mitos. No solo contradicen la realidad, sino que la ocultan, impiden su comprensión, y por tanto, obstaculizan la posibilidad de enfrentar adecuadamente el problema. La socialización de género, la agresividad masculina o el aprendizaje infantil de la violencia, que sin duda alimentan y propician la agresión contra las mujeres, no son casuales. Tienen un trasfondo común más profundo, que es precisamente la estructura social de inequidad entre los géneros. Es este desbalance de poder lo que permite y facilita el aprendizaje y la práctica de la violencia de los hombres hacia las mujeres."

Para una aproximación al concepto de mito, es inevitable recurrir a Eliade (1968). El autor, en esta obra, define el mito con la intencionalidad de hacerlo cercano y accesible a las personas no especializadas en el tema, pero a la vez procurando que dicha definición sea aceptada por los/as especialistas. La cuestión que se plantea es si se podrá elaborar una única definición, que sea capaz de englobar o abarcar los diversos tipos de mitos que se hacen presentes en todas las sociedades, arcaicas y tradicionales. Esta tarea se presenta harto complicada, partiendo de la concepción de mito como una realidad cultural compleja, susceptible de ser abordada e 
interpretada desde muy diversos puntos de vista, que simultáneamente se complementan entre sí.

Analizaremos la definición de mito que ofrece Elíade para ahondar en el concepto, y trataremos de poner esta definición, en sintonía con el tema central de este trabajo.

"El mito cuenta una historia sagrada; relata un acontecimiento que ha tenido lugar en el tiempo primordial, el tiempo fabuloso de los comienzos. Dicho de otro modo: el mito cuenta cómo, gracias a las hazañas de los Seres Sobrenaturales, una realidad ha venido a la existencia, sea ésta la realidad total, el Cosmos, o solamente un fragmento; una isla, una especie vegetal, un comportamiento humano, una institución. Es, pues, siempre el relato de una creación: se narra cómo algo ha sido producido, ha comenzado a ser. El mito no habla de lo que ha sucedido realmente, de lo que se ha manifestado plenamente. Los personajes de los mitos son Seres Sobrenaturales. Se les conoce sobre todo por lo que han hecho en el tiempo prestigioso de los comienzos. Los mitos revelan, pues, la actividad creadora y desvelan la sacralidad (o simplemente la sobre-naturalidad) de sus obras. En suma, los mitos describen las diversas, y a veces dramáticas irrupciones de lo sagrado (o lo sobrenatural) en el Mundo. Es esta irrupción de lo sagrado la que fundamenta realmente el Mundo y la que le hace tal como es hoy día. Más aún: el hombre es lo que es hoy, un ser mortal, sexuado y cultural, a consecuencia de las intervenciones de los seres sobrenaturales." (Eliade, 1968, p.12)

En esta definición se revelan algunas de las claves acerca del mito, que puestas en conexión, con el tema que nos ocupa, la violencia de género, pueden explicar parte de la situación que sufren las mujeres víctimas de malos tratos, estigmatizadas por la creencia de la sociedad en los mitos. El autor señala en la definición, cuestiones relevantes para la violencia de género. Dice del mito que: "Cuenta una historia sagrada", es decir incuestionable, como todo lo sagrado; habla de la ocurrencia del mito 
en "el tiempo primordial", es algo asentado y perdurable a través del tiempo y de su devenir; habla de "las hazañas de los seres sobrenaturales", grandes gestas llevadas a cabo por seres inalcanzables. También señala el autor en su definición, que el mito "no habla de lo que ha sucedido realmente", por el contrario todo apunta a que se ha de creer tal y como se relata; Por último comenta, que "Ios mitos describen las diversas, y a veces dramáticas irrupciones de lo sagrado en el Mundo", es decir, tienen un carácter creador, salvador y reparador, y gracias al mito las personas somos lo que en realidad somos.

Se puede observar, cómo esta definición, discurre en paralelo al discurso sostenido por la cultura patriarcal que alimentándose del mito que rodea la ideología machista, gesta, tolera y justifica la violencia contra las mujeres.

En esta tradición patriarcal, los hombres, al igual que en el mito, son sobrenaturales, su comportamiento es incuestionable porque ha sido así desde el inicio del tiempo, además las actividades que ellos ejecutan, siempre tendrán más valor que las realizadas por mujeres, las que han de sentirse afortunadas porque él les permite permanecer a su sombra.

No acaban aquí las semejanzas, cuando Eliade habla de la función principal del mito, volvemos a encontrarnos con paralelismos entre dicha función y la propia del maltrato, es decir, el mito tiene valor en tanto en cuanto hace patente el modelo a imitar y no sólo eso, sino que se alardea de las gestas imposibles causando en quien escucha de forma pasiva, la admiración, el temor y la gratitud.

Es posible que los mitos proporcionen modelos de conducta humana atemporal, que se transmitan, casi de forma inalterable, a través de la historia. Tomando esta premisa como válida, podemos pensar que si estos modelos son conocidos y estudiados, según se manifestaron en otro tiempo, nos podrán ayudar a comprender la conducta humana del momento actual. 
Según Eliade (1968) En nuestra sociedad, encontramos el arraigo del mito en la Edad Media donde se sabe que la cultura mitológica estaba muy presente en todos los estamentos sociales; la caballería, los oficios, los clérigos, los campesinos. Adoptan un mito de origen de su condición y hacen esfuerzos por imitar el modelo ejemplar que les sirve de guía. $Y$ es aquí donde se empieza a elaborar una mitología sobre la mujer y el amor romántico, de esto se encargan los trovadores que se ven obligados a teñir de un barniz cristiano su discurso, para enmascarar sus actuaciones.

Lo que haremos a continuación será conectar la violencia de género que sufren las mujeres con las falsas creencias al respecto, que se encuentran instaladas en el imaginario social del siglo XXI y que de alguna manera, están basadas en los mitos arcaicos en la medida en que se transmiten de generación en generación y son incuestionables funcionando como dogmas de fe, que impiden su superación, a pesar de las evidencias que muestra la otra cara de una realidad cada vez más presente en nuestro entorno, la de la víctima.

Puesto que parece evidente la conexión existente entre la aceptación de los mitos y el mantenimiento de las relaciones de pareja violentas, haremos un recorrido por los mitos más extendidos en nuestra sociedad, acerca de la violencia contra las mujeres, que representa en la actualidad, una de las principales causas de muerte entre las mujeres del siglo XXI.

\section{1.- Mitos más frecuentes acerca de la violencia de género.}




\subsection{1.- A las víctimas de la violencia de género les gusta que las maltraten, son mujeres masoquistas y provocadoras.}

Las víctimas de la violencia de género, han sido históricamente caracterizadas como mujeres masoquistas a las que les gusta ser maltratadas, sin embargo, la evidencia no soporta esta teoría anacrónica. Lo cierto es que las víctimas de violencia de género, buscan desesperadamente que el abuso acabe y adoptan diferentes estrategias de supervivencia. Kirkwood (1999) recoge testimonios al respecto, que dejan en evidencia este primer mito.

En algunos casos, el silencio también puede ser una maniobra de supervivencia y soportar el maltrato para que el maltratador no ataque a los hijos e hijas, se convierte en una estrategia de adaptación empleada por la víctima, pero eso no significa que a la víctima le guste ser maltratada.

La primera teoría sobre palizas en el matrimonio surgida de los estudios psicológicos de Deutsch y Horney, ofrecía una explicación que se centraba en el extremo masoquismo femenino y las desviaciones psicológicas que las mujeres golpeadas ostentaban ${ }^{3}$. Pleck (1987), recoge que el legado de Freud tuvo un peso específico en los supuestos psicológicos predominantes, sostenidos en los años 1960 acerca de la violencia contra las mujeres. Freud consideraba como fruto de la imaginación de sus pacientes femeninas los presuntos recuerdos de abuso sexual e incesto que éstas le relataban. A partir de aquí Freud desarrolla la teoría de que las niñas desean inconscientemente llevar a cabo experiencias

3 El psicoanálisis conecta el concepto de masoquismo con el de mujer golpeada o violada. Deutsch y Horney (1991). 
sexuales con sus padres y de adultas satisfacen esta necesidad a través de la creación de fantasías. Al entender los informes de incesto como el resultado de la inmadurez femenina, Freud inició la creación de la imagen de la mujer masoquista. Fue esta imagen la que resurgió en los años 1960 durante los primeros debates sobre mujeres golpeadas.

Gayford (1975) publica un estudio sobre 100 esposas golpeadas que vivían en refugios. Las mujeres daban muchas razones prácticas y económicas para permanecer con sus parejas e ilustraban lo severo del trauma experimentado a través de datos sobre intentos de suicidio. A pesar de ellos, Gayford se detenía más en el factor del trasfondo personal, a saber: si la mujer había tenido relaciones sexuales antes de su matrimonio, si había tenido relaciones ilícitas o si había quedado embarazada por otros hombres. Sin hacer una comparación con la respuesta femenina en las relaciones no violentas, llega a la conclusión de que las palizas tienen un correlato en características tales como la promiscuidad. De este modo construyó un perfil de la mujer golpeada que incluía una multitud de conductas consideradas culturalmente desviadas y al hacerlo, dio a entender que éstos eran factores causales del abuso.

"El trabajo de Gayford fue popularizado y apoyado por Pizzey (1974), fundador del primer refugio para mujeres. Debido al fácil acceso a su trabajo, a principios y mediados de la década de 1970, Gayford y Pizzey llegaron a ser los "expertos" más conocidos en el tema de la mujer golpeada y sus conclusiones fueron, durante muchos años, la base para la comprensión popular británica sobre el tema. A parte de la crítica mencionada, el trabajo de Pizzey y Gayford puede ser cuestionado con respecto al grado en el cual era generalizable. Ambos investigadores basaban sus análisis en las condiciones psicológicas de mujeres que vivían en refugios, en particular en ChiswickWomen's Aid. El hacinamiento y las malas condiciones eran especialmente problemáticas en los refugios que se levantaban en la primera etapa del movimiento. Esto combinado con el temor por parte de la mujer a la ira de su esposo y los obstáculos prácticos 
de vivir sin él, puede haber contribuido a un estado temporal de trauma psicológico durante el tiempo en el cual se las estaba estudiando. No queda claro si Pizzey o Gayford intentaron distinguir entre los rasgos psicológicos que éstas ostentaban como una reacción a tener que vérselas con la vida de un refugio y aquellos que se atribuían al masoquismo en las personas como individuos." Kirkwood, (1999, p. 25)

En otro orden de cosas, el androcentrismo con el que se ha contemplado, y se sigue contemplando el mundo, incluido el campo de la salud mental, han hecho un flaco favor a todas las mujeres que han manifestado síntomas por estrés postraumático, después de haber sufrido violencia. Dichos síntomas han sido interpretados, al antojo de los hombres, que en nombre de la ciencia, decidieron que los mismos, eran características de personalidad previa de la mujer que los presentaba y no secuelas a posteriori, por haber sufrido un maltrato de la índole que este fuera.

Poner en cuestión o culpabilizar a la víctima, de forma generalizada y automática, únicamente se observa en este tipo de delitos, siendo impensable en cualquier otro, por ejemplo en un atraco a un banco, un atropello en un paso de cebra, o un atentado terrorista.... La pregunta es ¿Por qué en los ataques a mujeres las cosas se ven de otra manera?

Rojas Marcos (1995, p.36) lo explica de la siguiente forma: "Los profesionales de la salud mental han manifestado cierta tendencia a culpabilizar a la víctima de los malos tratos mediante el razonamiento de que la agresión masculina satisface la necesidad de sufrir de la mujer, a quien se achacaba una personalidad dependiente, perdedora 0 autoderrotista. E propio Freud consideraba el masoquismo una expresión de naturaleza femenina. En 1985, la psiquiatría oficial cuenta entre sus diagnósticos con el de personalidad masoquista, clasificando como enfermas mentales a las personas que se emparejan con un terrorista doméstico o permanecen en relaciones explotadoras en las que son habitualmente maltratadas" 
El concepto de Trastorno de la Personalidad por Dependencia, se define (American Psychiatric Association : Manual Diagnóstico y Estadístico de los Trastornos Mentales (1994) (DSM IV), del siguiente modo, incluyéndolo dentro de los Trastornos de Personalidad del Grupo C. Necesidad general y excesiva de que se ocupen de uno que ocasiona comportamiento de sumisión y adhesión y temores de separación, que empieza al inicio de la edad adulta y se da en varios contextos, como lo indican cinco (o más) de los siguientes ítems:

- Tiene dificultades para tomar las decisiones cotidianas si no cuenta con un excesivo aconsejamiento y reafirmación por parte de los demás.

- Necesidad de que otros asuman la responsabilidad en las principales parcelas de su vida.

- Tiene dificultades para expresar el desacuerdo con los demás debido al temor a la pérdida de apoyo o aprobación.

- Tiene dificultades para iniciar proyectos o para hacer las cosas a su manera (debido a la falta de confianza en su propio juicio o en sus capacidades más que a una falta de motivación o de energía)

- Va demasiado lejos llevado por su deseo de lograr protección y apoyo de los demás, hasta el punto de presentarse voluntario para realizar tareas desagradables.

- Se siente incómodo o desamparado cuando está solo debido a sus temores exagerados a ser incapaz de cuidar de sí mismo.

- Cuando termina una relación importante, busca urgentemente otra relación que le proporcione el cuidado y el apoyo que necesita. 
- Está preocupado de forma no realista por el miedo a que le abandonen y tenga que cuidar de sí mismo.

En el caso de las mujeres maltratadas se observa cómo los ítems anteriormente expuestos no corresponden a su realidad, desmarcándose así de esta categoría. Ellas no es que tengan dificultad para tomar las decisiones cotidianas, no es que tengan la necesidad de que otras personas asuman sus responsabilidades, no es que tengan dificultad para expresar el desacuerdo, no es que tengan dificultades para iniciar proyectos; es que no se les permite llevar a cabo nada de esto. Ellas no pueden buscar protección en quien las está maltratando, es una paradoja, al igual que no se sienten mal cuando están solas, sino todo lo contrario, su particular infierno empieza cuando están en compañía de la pareja maltratadora, saben cuidar de sí mismas, así como de sus hijos/as y cuando ponen fin a esa relación son conscientes del beneficio que supone.

Las sospechas acerca del desequilibrio mental de las mujeres que sufren malos tratos, quedaría disipadas si lográramos dar respuestas a la siguiente cuestión: ¿Por qué unas mujeres son capaces de abandonar a sus parejas maltratadoras y otras no?

Gelles (1976) aporta algunas apreciaciones al respecto. Descubrió que el grado de violencia o la intensidad de las agresiones es un factor de distinción entre las mujeres que abandonan la relación de maltrato y las que no.

En primer lugar este autor señala que cuanto más grave es la agresión, mayor es la probabilidad de que la mujer abandone y busque ayuda fuera del hogar. En segundo lugar, cuantos menos recursos tiene una mujer y más atrapada está en el matrimonio, menor es la probabilidad de que aún recibiendo malos tratos abandone a su pareja. De ahí la importancia de que las mujeres tengan cierta independencia para la solución e incluso para que la situación no se produzca. Pero ninguno de estos dos factores 
está ligado a la personalidad de las víctimas, sino a situaciones socioestructurales.

Es Torres Falcón (2001) la que elabora el estudio explicativo más aproximado, de lo que sucede entre las parejas que tienen una relación de maltrato. Esta autora habla del síndrome de la mujer maltratada, diciendo que lo padecen las mujeres maltratadas que viven una situación de terror y angustia. Señala que los rasgos más característicos son: culpabilidad, baja autoestima, confusión, incapacidad de concentrarse, trastornos en los hábitos alimenticios y de sueño, sensación de no poderse comunicar con los demás, disfunciones sexuales, timidez, depresión, furia o miedo prolongado. Habría que incluir otras somatizaciones, entre ellas el cansancio constante y la sensación de debilidad.

"Si la sociedad considera que el matrimonio es una especie de carrera para la mujer y que, por lo tanto, es prácticamente su única responsabilidad, además de ser responsabilidad exclusivamente suya, no es difícil suponer que cuando las cosas no marchan bien las mujeres sientan que fracasaron, que no lograron construir una buena pareja y que todo ello de alguna manera es su culpa. El peso de estos mensajes, que se escuchan continuamente desde la infancia en las familias de origen, repercute de manera directa en la autoestima de las mujeres maltratadas". (Torres Falcón, 2001, p. 1709)

La autora, continúa su argumentación formulando varias preguntas, ¿por qué permanecen en una relación que implica un coste tan alto como la pérdida de la autonomía, de la autoestima y hasta de la integridad física? ¿Por qué aman a quien las maltrata? ¿Por qué no pueden dejarlo o por qué regresan con él después de una breve separación? ¿Por qué olvidan o minimizan las amenazas y la misma violencia? ¿Por qué se quedan atrapadas en la circularidad de la dinámica del maltrato? La autora establece una especie de paralelismo interesante, entre dos problemáticas, por un lado la situación a la que son sometidas las personas tomadas como 
rehenes en caso de terrorismo y por otro la situación que viven las mujeres sometidas al terrorismo doméstico.

Se trata de dar respuesta a los interrogantes anteriormente planteados, analizando al detalle el llamado Síndrome de Estocolmo definido originalmente para explicar el vínculo emocional que algunos rehenes desarrollan hacia sus captores, al grado de visitarlos en la cárcel una vez que han sido liberados y sus captores aprehendidos, y de darle seguimiento a su proceso legal. Este modelo busca explicar las respuestas psicológicas de las mujeres maltratadas por analogía con los rehenes, respuestas que a primera vista parecen contradictorias. Si una persona o grupo de personas son atrapadas por casualidad, como sucede con los rehenes, lo lógico sería que una vez liberadas trataran de estar lo más lejos posible de sus captores y que hablaran de ellos con resentimiento, coraje, indignación o furia. Sin embargo, hay ocasiones en que pasa todo lo contrario y muestran un sincero interés por lo que a sus captores les suceda en prisión. ¿Por qué? ¿Qué mecanismos operan en esa relación para que se produzcan esas consecuencias? El llamado síndrome de Estocolmo busca analizar la situación en conjunto y no las características de cada persona, a fin de mostrar de qué manera los desequilibrios extremos del poder llegan a generar un fuerte vínculo emocional. Para que se presente el síndrome se requieren al menos las tres condiciones siguientes:

- Una persona amenaza con matar o producir un daño considerable a otra y se percibe que tiene la capacidad de hacerlo. Cuando se trata de terrorismo, nadie duda que los captores, con armas de alto poder, puedan ocasionar lesiones extremas y; por supuesto, la muerte. En las relaciones de maltrato, los hombres golpeadores no solamente amenazan sino que producen daños que al principio no son tan serios pero que van siendo cada vez más graves. Si en algún momento sus víctimas pensaron "Él no lo haría" "Sería incapaz de hacerme daño", estas ideas se esfuman ante el primer 
episodio de golpes. A partir de entonces, las mujeres no sólo sospechan sino que saben a ciencia cierta que se encuentran en una situación de peligro progresivo.

- La persona amenazada no puede escapar porque ha sido aislada del exterior. En el caso de los terroristas, de ahí deriva precisamente su poder; en eso consiste tener rehenes: en asilarlos del exterior y utilizar su liberación como el principal instrumento de negociación. En el caso de las mujeres maltratadas, la dinámica de la violencia entraña un aislamiento que puede ser más simbólico que real y por ello mismo más eficaz. Las mujeres están aisladas en el terreno emocional y a veces también en el físico. A medida que el maltrato va cumpliendo sus fases cíclicas, la relación se confina en una especie de aislamiento. Por coraje, por ansiedad, por culpa, por vergüenza o por cualquier otra razón, las mujeres maltratadas están cada vez menos comunicadas con sus amigas e incluso con su familia. Esto no es sólo una consecuencia sino una de las manifestaciones del maltrato psicológico; la violencia consiste también en eso, en producir aislamiento y alejar cualquier posible contacto o ayuda del exterior.

- La persona amenazadora muestra hacia la amenazada cierta amabilidad que opera como refuerzo intermitente. La gentileza no es continua ni el maltrato permanente. Se va de un lado a otro, sin que la víctima conozca los motivos de tales cambios en el trato. La amabilidad del agresor queda totalmente manifiesta en la fase llamada luna de miel. Con respecto a los rehenes, algunos testimonios revelan que el mismo hombre que los amenaza con un arma potente, los insulta, les impide ir al baño y no les da de comer, pero en otro momento se acerca y les ofrece un cigarrillo, por ejemplo. Con ese comportamiento tan simple parecen esfumarse todas las agresiones anteriores; 
se convierte en el bueno de la película tan sólo por mostrar un lado amable.

A este respecto Torres Falcón argumenta: "Este modelo, más que ofrecer una explicación exacta del motivo por el cual una relación de maltrato puede prolongarse (a veces durante varios años), permite reconocer la complejidad de la situación y las dificultades que deben enfrentar las mujeres para poder salir de ella”. (Torres Falcón, 2001, p.176)

Ante las afirmaciones que sitúan la provocación de la mujer, como causa y objeto del maltrato, se levantan voces que ponen de relieve la inconsistencia de esta postura.

Los hombres que maltratan a las mujeres se apuntan enseguida, qué duda cabe, al modelo explicativo de la provocación, para así poder justificar su conducta ante sí mismos y ante los demás; este argumento alimenta una pauta ya existente de negación y minimización de los abusos. Y además aplican este planteamiento a la propia agresión, en el mismo momento de cometerla. Los hombres continúan considerando que tienen el derecho de esperar que la mujer esté a su disposición para satisfacer todas sus necesidades.

Los maridos maltratan a sus esposas y les echan la culpa por ello, ya sea porque la mujer ha hecho algo o porque no lo ha hecho, y a menudo la causa de su violencia es, según el momento, la misma cosa y exactamente su opuesta.

Ptacek (1988, p. 151) se posiciona al respecto afirmando que "La mujer maltratada se encuentra en un callejón sin salida, porque cuanto más le da, él más le exige y, si intenta captar sus deseos, él cambia las reglas en cualquier momento con el fin de tener una excusa para tratarla con violencia: Nadie provoca a un hombre que apalea a su mujer. La golpea cuando tiene ganas, por cualquier razón y en cualquier momento". 
Al colocar el acento en las características de las mujeres maltratadas, podemos pensar que de una $u$ otra manera son ellas quienes provocan la violencia, que no hacen nada para impedirla o bien que tiene motivos conscientes o inconscientes, para permanecer en una relación de maltrato. A esta explicación se le da el nombre de precipitación de la violencia ${ }^{4}$. Muchos hombres, interpretan como provocación cualquier actitud de las mujeres que ellos desaprueben, olvidando que cada quien es responsable de sus propios actos.

Torres Falcón se hace eco del concepto de precipitación de la violencia y alude a términos relacionados al mismo, como son responsabilidad de actuaciones o motivación inconsciente.

"La tesis de la precipitación de la víctima va un poco más allá y señala que la provocación es inconsciente, con lo cual entramos en un terreno resbaladizo, porque si en efecto se trata de una motivación inconsciente, sólo la propia víctima o su terapeuta pueden determinarlo, tal vez meses o años después de haber iniciado un trabajo psicoanalítico. Es importante subrayar, por un lado que si existen motivaciones inconscientes es imposible demostrarlo y, por otra parte, que esta tesis olvida uno de los postulados básicos del modelo individual en el cual se inscribe: que cada quien es responsable de sus actos". (Torres Falcón, 2001, p. 224)

Detrás de esta postura que culpa a las víctimas existe una actitud que justifica el maltrato. Al descargar de toda responsabilidad al agresor y desplazar la culpa hacia las víctimas, se condona la violencia.

Para finalizar con el mito que nos ocupa acerca de la provocación de las mujeres hacia sus parejas para ser maltratadas y que si son maltratadas es porque a ellas les gusta, sólo nos resta tener presente que tanto los efectos psicológicos del abuso, como las estrategias que las mujeres

\footnotetext{
${ }^{4}$ Precipitación de la violencia: algunas mujeres llegan a resultar golpeadas porque con sus actitudes son capaces de reducir el deficiente autocontrol masculino de sus parejas. (Torres Falcón, 2001)
} 
maltratadas han puesto en marcha para sobrevivir, no evidencian el presunto masoquismo del que son acusadas.

Mañas Viejo (2005, p.131) apunta que "Es importante recordar que las formas de afrontar las situaciones estresantes son muchas y diversas y no sólo las estrategias activas son afrontamiento. Así, es relativamente frecuente que las mujeres maltratadas que permanecen en la relación abusiva empleen estrategias pasivas y/o evitativas, lo cual ha sido en ocasiones interpretado erróneamente como masoquismo, cuando en realidad no es más que una estrategia de supervivencia".

\subsection{2.- Las víctimas de la violencia de género padecen trastornos psicológicos, están locas.}

Como quedó patente en la exposición del mito anteriormente expuesto (A las víctimas de la violencia de género les gusta que las maltraten, son mujeres masoquistas y provocadoras), abundan las teorías que consideran a la mujer como psicológicamente desviada. Buscan la explicación de los abusos que sufre en la propia personalidad de la mujer, (Dobash y Dobash,1992), basándose en conceptos tales como el masoquismo para explicar la sumisión y el sufrimiento como forma de vida, o la impotencia aprendida, que pretende explicar por qué una mujer maltratada no abandona al hombre que abusa de ella.

En la actualidad, la explicación más aceptada y extendida acerca del no abandono de la relación de maltrato, por parte de las mujeres que sufren violencia, la ofrece Walker (1980), quien afirma que la mujer también está implicada en lo que esta autora denominó el ciclo de la violencia, no con 
referencia a la transmisión generacional, sino a los tres estadios de la violencia:

"Acumulación, explosión y fase de arrepentimiento o luna de miel, porque se supone que ella ha participado en la situación a partir de una conducta aprendida y que esta la vincula con el que abusa de ella, distorsiona su visión de lo que es normal y, según dice, la lleva a creer que nada podrá detener las palizas, por lo que no se muestra receptiva cuando se le ofrece ayuda." (Walker, 1980, p. 530)

El ciclo de la violencia, descrito por la investigadora estadounidense, explica y nos ayuda a entender cómo se produce y se mantiene la violencia en la pareja. Walker trabajó en una casa refugio para mujeres maltratadas y observó que muchas mujeres describían un patrón muy parecido en el proceso de maltrato y que este tenía una forma cíclica, que se desarrollaba en tres fases: la fase de tensión, la fase de agresión y la fase de conciliación, arrepentimiento o de "luna de miel". El desarrollo de este ciclo se expone en el Capítulo I, Apartado 2.5 de esta investigación.

El ciclo de la violencia explica por qué algunas mujeres retiran la denuncia, que interponen en la fase de agresión, al encontrarse un hombre que se arrepiente, promete cambiar y que está en plena fase de "luna de miel". También explica por qué las mujeres, después de verbalizar que están sufriendo violencia o de iniciar la toma de decisiones para terminar con la relación, le disculpan, minimizan su comportamiento violento o lo justifican, volviendo de nuevo a la situación anterior.

"Con el tiempo, la fase de agresión se repite más a menudo o se está todo el tiempo entre la tensión y la agresión, sin apenas "fase de conciliación". Cuando esto sucede, es cuando muchas mujeres deciden pedir ayuda. A veces, hasta llegar a este momento, han pasado muchos años. Si este ciclo no se rompe a tiempo, las agresiones se repetirán con más frecuencia y más intensidad, con mayor gravedad y riesgo para la mujer" (Ruiz-Jarabo Quemada y Blanco Prieto, 2005, p.48) 
Sin embargo, es posible romper el círculo de la violencia cuando de manera paralela a la relación abusiva, existen unas condiciones psicosociales protectoras (Díaz Aguado y Martínez Arias, 2001)

- Adquirir habilidades alternativas a la violencia que permitan afrontar el estrés y resolver conflictos sociales con eficacia.

- Poder expresar a otras personas las emociones suscitadas por el maltrato.

- Establecer relaciones afectivas positivas alternativas con otras personas que le permitan cambiar sus sentimientos y expectativas sobre la vida y las personas que le rodean.

- Rechazar y condenar toda forma de violencia, incluida la propia sufrida en la infancia.

- Comprometerse a no reproducir la violencia.

Desde la Psicología, a esto que describe Leonore Walker, se le denomina indefensión aprendida y hace referencia a la condición psicológica en la que un sujeto aprende a creer que está indefenso, que no tiene ningún control sobre la situación en la que se encuentra y que cualquier cosa que haga es inútil. Como resultado, permanece pasivo frente a una situación displacentera o dañina, incluso cuando dispone de la posibilidad real de cambiar estas circunstancias. ${ }^{5}$

La Indefensión aprendida fue postulada por el psicólogo Martin Seligman (1967). Seligman exponía a dos perros, encerrados en sendas jaulas, a descargas eléctricas ocasionales. Uno de los animales tenía la posibilidad de accionar una palanca con el hocico para detener esa descarga, mientras el otro animal no tenía medios para hacerlo. El tiempo de la descarga era igual para ambos, ya que la recibían en el mismo momento, y cuando el primer perro cortaba la electricidad, el otro también dejaba de recibirla. En cualquier caso, el efecto psicológico en ambos animales era muy distinto; mientras el primero mostraba un comportamiento y un ánimo normal, el otro permanecía quieto, lastimoso y asustado, con lo que la importancia de la sensación de control en el estado de ánimo parecía demostrada. Incluso cuando la situación cambiaba para el segundo animal, y ya sí podía controlar las descargas, era incapaz de darse cuenta y seguía recibiendo descargas sin intentar nada para evitarlo. 
Dobash y Dobash (1992) han confeccionado una lista de más de treinta defectos de personalidad atribuidos a las mujeres maltratadas, desde debilidad del ego a propensión a manipular y desde impulsos autodestructivos a tendencia a evitar los enfrentamientos, categorías que en muchos casos son mutuamente contradictorias a lo largo del continuo pasivo/agresivo o indecisión/dominancia. Este tipo de teorías se alimenta de la tradición individualista que ha guiado la investigación psicológica y la práctica clínica en Estados Unidos, y de una realidad: el diagnóstico de padecer algo parecido al síndrome de la mujer apaleada o a un trastorno postraumático a consecuencia del estrés. Puede ser, para una mujer en Norteamérica, la única forma de conseguir que el seguro cubra la asistencia sanitaria o el asesoramiento psicológico que necesite.

"Estas etiquetas representan un problema, porque ponen énfasis en la pasividad y en el trastorno psicológico, en lugar de incidir en la actuación en defensa propia; sin embargo, el estado actual de las leyes deja tan pocas opciones a las mujeres, que los abogados tienen que utilizar esos conceptos cuando son de alguna utilidad. Sería mucho más constructivo basar la defensa en el intento de auto protegerse de la mujer y centrarse en los abusos perpetrados por el hombre, en lugar de hacer hincapié únicamente en la supuesta enfermedad de la víctima". (Dobash y Dobash, 1992, p.228)

La herramienta con la que cuenta la psicología para diagnosticar trastorno o enfermedad mental es insuficiente en estos casos, los test no diagnostican la propensión de personalidad que conduce al maltrato.

Así lo corrobora Hoff (1990, p.22) en la siguiente cita "Los test psicológicos se han revelado inútiles para encontrar diferencias de personalidad significativas entre mujeres maltratadas y otras que no han

La teoría de la indefensión aprendida ha sido utilizada para explicar el mecanismo de la depresión. Cuando estamos deprimidos -dirían los defensores de esta relación-, percibimos que nuestra situación vital es dolorosa, y no distinguimos ninguna solución ni ninguna posible vía de escape a nuestro alcance; nos sentimos mal y no podemos hacer nada para cambiarlo. 
sufrido esa experiencia. Incluso cuando algún estudio ha demostrado que existen diferencias ente las mujeres que han sufrido malos tratos y las demás, éstos pueden ser el efecto más que la causa de los abusos".

Otra formulación más reciente de este planteamiento es la afirmación de que las mujeres "aman demasiado" y son adictas a la excitación y el peligro que representa la violencia, por lo que la buscan en las sucesivas relaciones que entablan.

La evidencia apunta en sentido contrario y Pahl (1985, p. 62)lo recoge de la siguiente manera: "Ninguna de las mujeres acogidas en refugios a las que se entrevistó volvieron a padecer violencia cuando iniciaron una relación estable con otra pareja, en claro contraste con aquellas que sí la sufrieron al reiniciar la relación con el mismo hombre que las había maltratado, aunque si hay razones para creer que los hombres violentos van de una relación a otra y se comportan con violencia en todas ellas".

Esta característica de la mujer maltratada como mentalmente enferma proviene de la asunción de que las víctimas de violencia de género deben estar enfermas, de lo contrario no soportarían el abuso. Las teorías más recientes demuestran que la mujer maltratada resiste el abuso en una variedad de formas. Además, la mayoría de las víctimas de la violencia de género no padecen enfermedades mentales a priori, pero a posteriori a menudo sufren efectos psicológicos, como trastornos de estrés postraumático o depresión, como resultado de haber sido maltratadas.

Las teorías tradicionales presuponen que las mujeres con una autoestima adecuada no permitirían ser objeto de abuso por sus parejas sentimentales. En realidad, se está demostrando que las víctimas de la violencia doméstica no comparten ninguna otra característica más que ser mujeres. La teoría de que una autoestima baja produce que las víctimas se ven implicadas en una relación de maltrato tiene poco soporte empírico, por el contrario, algunas víctimas pueden experimentar una reducción de su 
autoestima como resultado de haber sido sometidas a maltrato, puesto que los agresores con frecuencia degradan y humillan a las víctimas.

No hay por tanto nada parecido a un retrato robot de la víctima. Coincidimos con Barea (2004, p.30) cuando afirma: "Las secuelas de los malos tratos (depresión, angustia, inseguridad, baja autoestima, dependencia) son interpretadas por gran parte de la sociedad como demostración de que ella tiene una personalidad previa enfermiza y está mal de los nervios, cuando en realidad este comportamiento es casi siempre consecuencia de los malos tratos vividos. Exceptuando los casos en que se han recibido malos tratos anteriores, no existe un retrato robot de la víctima de la violencia de género, ni hay un tipo de mujer predispuesto a serlo, de la misma forma que no existe ningún tipo de persona predispuesto a sufrir el Síndrome de Estocolmo. Cualquier persona sometida a un largo proceso de descalificaciones, críticas, insultos y agresiones físicas y sexuales, acaba desarrollando una sintomatología parecida: estrés postraumático, depresión, etc."

No hay una sintomatología psicológica común a todas las mujeres maltratadas. De hecho, los síntomas y rasgos que éstas presentan son las secuelas de la victimización sufrida y no corresponden a una patología, sino a las huellas que deja la violencia en todo ser humano; huellas diferentes según la personalidad del agresor que determina su forma de agredir, la personalidad y situación socioeconómica de la víctima, y la respuesta del medio cuando ella pide ayuda. Hemos de tener en cuenta que la violencia contra las mujeres no es un hecho aislado que se da de forma esporádica, sino que es un todo, un cúmulo de situaciones y circunstancias que facilitan la ocurrencia del maltrato. No podemos olvidar que a medida que avanza la escalada de violencia cambia el estado de ánimo de la mujer maltratada y a medida que aumenta la intensidad de la violencia, se observan en ella claras transiciones emocionales. Cada salto en la escalada del maltrato provoca una variación en el estado mental y emocional de la mujer. Sería interesante analizar, más que la psicología de la víctima de maltrato, el 
entorno, al que pertenece; es decir, la red de apoyos con la que cuenta en la toma de decisiones que le permitan salir de la situación de maltrato.

Popularmente se utilizan calificativos como histéricas, para denominar a las mujeres presas del pánico que les infunden sus parejas maltratadoras. Pero un recorrido por tal denominación y el origen de dicho término nos demuestra que es una denominación incorrecta.

La palabra histeria proviene del griego hystera y significa matriz; por tanto, propio de mujeres. En época de Freud se creía que los hombres no se comportaban así.

A raíz de la guerra de Vietnam se observó que los excombatientes presentaban sintomatología histérica. Considerando que era indigno llamar histéricos a los héroes de la patria, y viendo que en realidad dicha sintomatología provenía de una vivencia traumática, se eliminó la denominación histeria del DSM 3 y se desglosó en nuevos diagnósticos psiquiátricos como: estrés postraumático, conversión, somatización, trastornos disociativo.

Gracias a los excombatientes de Vietnam las mujeres maltratadas ya no son calificadas de histéricas y disponen de un criterio diagnóstico muy útil en los juicios de malos tratos. Cuando en un peritaje forense se concluye que la mujer maltratada sufre estrés postraumático, se está admitiendo que su estado mental no es casual ni debido a la locura, sino originado por un trauma, es decir, que puede ser muy bien la secuela psicológica de las agresiones de su pareja.

Otros trastornos psicológicos, provocados muchas veces por los malos tratos son la fatiga crónica, los trastornos de los hábitos alimenticios y los abusos de sustancias como el alcohol, los psicofármacos, etc.

La sociedad es cómplice del maltratador y elabora un "retrato robot" de la mujer maltratada como buscando una predisposición previa en algunas mujeres. Se trata de intentar demostrar que algunas nacen predestinadas 
para los malos tratos, o incluso que buscan ese tipo de situaciones casi a propósito.

Cárdenas y Ortiz (2005) analizan el binomio malos tratos y trastornos psicológicos. Ellas dicen que hay muchas mujeres que presentan síntomas psicosomáticos o depresivos y están muy confusas. Sienten mucha vergüenza y se culpan por todo lo que pasa en su relación, tienen su autoestima muy baja y no se creen con derecho a exigir nada. Piensan que cuando el hombre ostenta el poder no es probable que esté interesado en cambiar la situación y la mujer, posiblemente, lo hará cuando haya llegado a una situación extrema.

Podemos pensar que las mujeres que han sufrido maltrato, pueden llegar a quedarse atrapadas en su papel de víctimas porque asocian ese rol con otros que consideran positivos, roles de género, transmitidos culturalmente: ser buena conlleva aguantarlo todo, no importa el sacrificio con tal de que la familia permanezca unida. Es decir, para ser una buena mujer se debe estar dispuesta a darlo todo por la familia, en especial por los hijos/as; se debe ser prudente para no enfadar al hombre y se debe ser sacrificada. Todo esto se consigue ensalzando la maternidad y el rol de ama de casa. Cambiar estos valores no está resultando fácil porque pensar en ellas mismas significa, en su escala de valores, dejar de ser buena y convertirse en alguien egoísta que antepone su felicidad a la de sus hijos/as y su pareja.

Las autoras sitúan el foco de atención en las responsabilidades de las personas implicadas en el maltrato "La persona que agrede debe tomar el control sobre su violencia. $Y$ la que es agredida necesita responsabilizarse de su seguridad no exponiéndose al maltrato". (Cárdenas y Ortiz , 2005, p.150)

El trabajo de Mañas Viejo (2005) también se sitúa en la defensa de la salud mental de la mujer que sufre maltrato, analizando la sintomatología 
que pueda presentar como consecuencia de la relación de maltrato y no previa a la misma.

"Es importante analizar tanto los indicadores de malestar psicológico (miedos, ansiedad, tristeza, consumo de sustancias...) como los cambios cognitivos (atribuciones, expectativas...) y las dificultades de relación con personas distintas del agresor (miedos, dificultad para establecer relaciones de intimidad...) etc. y, a demás, es importante partir de la base de considerar (al menos inicialmente) todas estas respuestas como consecuencias de las agresiones vividas. Ello permitirá superar uno de los prejuicios con los que en ocasiones se ha encarado el trabajo con las mujeres maltratadas y es el de considerar que la psicopatología que presentan era previa a la relación de abuso e, incluso, causa de esta”. (Mañas Viejo, 2005, p.131)

Para concluir la exposición de este mito, no podemos olvidarnos de que esta problemática tiene un alto precio, en la mayoría de los casos las secuelas del maltrato no son de carácter físico sino psicológico, algunas mujeres maltratadas contemplan el suicidio como su única salida. $Y$ las mujeres que pierden la vida de esta manera, aunque muertas a causa de la violencia de género, no son consideradas como asesinadas por sus parejas y no figuran en las estadísticas como tal.

Barea (2004, p.55) señala que "La agresión verbal puede ser tan dañina y destructiva como la física. No es necesario que haya una clara agresión física o sexual para que la mujer viva en el terror y sufra graves secuelas psicológicas. La destrucción sistemática de su autoestima y poder, las amenazas y el control pueden llevar a la mujer a ver el suicidio como un descanso. De la tristeza ha pasado al miedo. Poco a poco, sin saber cómo, se ha ido encontrando cada vez más angustiada, no duerme bien, está sobresaltada, Si antes estaba triste, ahora tiene miedo. Una vez comienza la estructura cíclica, la escala es casi imparable. Cuando agredir se vuelve una costumbre, la intensidad se hace cada vez mayor, aunque nunca se llegue al maltrato físico". 


\subsection{3.- Los maltratadores son enfermos mentales.}

Encontramos en el discurso popular, la defensa de los planteamientos psicológicos que atribuyen a la enfermedad, física 0 psicológica, el fenómeno de la violencia contra las mujeres. Constan ejemplos de ello, tanto en prensa escrita, como en tv, etc. Así queda reflejado en el siguiente artículo publicado en el diario La Vanguardia el 14 de Agosto del 2008 en relación a la agresión sufrida por Violeta Santander a manos de su, entonces pareja, Antonio Puerta ("Prisión incondicional para el agresor de Jesús Neira. El estado de salud del profesor universitario empeora") Es significativo el texto que acompaña al titular "El juez pidió informes sobre el estado de salud de Neira y los presuntos problemas psíquicos del agresor" El presunto agresor de Neira se presentó en el juzgado de Majdahonda poco después de las 10 de la mañana, Pero no fue hasta las 12:15, cuando declaró ante el juez. La demora se produjo por la petición de este de reclamar informes actualizados tanto del estado de salud de Neira como del de Antonio Puerta, a raíz de la declaración de su compañera sentimental, Sandra. Esta justificó el pasado martes el comportamiento de Antonio Puerta en que tiene problemas psiquiátricos. También se indicó ayer que el agresor de Neira tiene problemas con las drogas...

Algunos autores defienden teorías diferentes basadas en el elevado número de casos que se producen en la sociedad actual.

\footnotetext{
${ }^{6}$ La Vanguardia 14/08/2008. 2o Edición. Pág. 21. Ref: 2103513. Tirada 259419
} 
Como expone Mullender (2000, p.66) "Sería difícil afirmar científicamente que hay una cantidad tan elevada de hombres enfermos. Menos útil, y difícilmente científico, sería atribuir la violencia al pecado. Parece difícil entender que lleven conductas correctas a excepción de la relación de pareja, que si está enfermo y por tanto sin responsabilidad sobre sus actos, pueda controlar y decidir el momento del ataque, el lugar y las partes del cuerpo que elige".

Por su parte Bograd (1988, p.17) afirma que "Las investigaciones han buscado una patología individual masculina basada a veces en anormalidades orgánicas o en alteraciones de la bioquímica del cerebro y más frecuentemente en disfunciones psicológicas, pero no se han hallado pautas consistentes en este sentido".

También Ptacek(1988, p.139) se posiciona en esta misma idea y señala que "La enorme influencia de tales teorías, en el sentido de que permiten que los profesionales que también son hombres puedan llevar a cabo su trabajo sin tener que cuestionarse en un sentido más amplio la naturaleza de la relación hombre/mujer".

En la literatura científica abundan más las explicaciones psicológicas que las fisiológicas y éstas tienden a centrarse en la ira incontrolable que procede de conflictos familiares sin resolver, en reacciones primitivas agresivas, en el temor soterrado del que va de matón, en la inseguridad del hombre a causa de su dependencia de la mujer o en cualquier otra forma de estrés interno.

Al respecto, Dobash y Dobash (1992, p.237) puntualizan que "Desde esta perspectiva, el hombre no es malo, sino que está loco o triste; y si está emocionalmente trastornado, entonces no es plenamente responsable de sus actos. Puede que considere que la sociedad, su pareja y él mismo deben perdonar lo que ha hecho; en realidad, es posible incluso que llegue a considerarse una persona de gran calidad moral, por el hecho de estar dispuesto a iniciar una terapia". 
No podemos conformarnos con una justificación individual, de un hecho socialmente tan extendido y frecuente como es la violencia de género. Esta actitud eximiría de responsabilidad a la educación y la cultura patriarcal en la que crecen y se desarrollan las personas. Esta es una herencia a la que debemos renunciar cuanto antes, las actuaciones individuales no son válidas para resolver una problemática tan compleja que requiere soluciones integrales.

Bograd (1988, p.17), utilizando un razonamiento lógico afirma que "Por encima de todo, el maltrato de las mujeres está demasiado extendido como para ser considerado la conducta desviada de unos pocos hombres; es mucho más probable que se trate de una situación continuada en línea con la psicología y las acciones masculinas"

Por su parte, Barea coloca fuera del campo de la salud, la actitud del maltratador común, evidenciando como causa del maltrato la pérdida de poder sobre la mujer.

"El maltratador común, no está loco ni es un enfermo sino que se cree superior a la mujer. Es un sexista sin una patología psiquiátrica concreta, que puede haber sufrido o presenciado violencia doméstica cuando era pequeño. Se comporta normalmente mientras no hay tensiones o conflictos y/o mientras no siente que la mujer tiene o puede tener más poder que él". (Barea 2004, p.16)

El maltrato radica sobre todo en un afán de control del maltratador hacia su víctima, sin diferencias en el nivel socioeconómico o cultural del mismo, aunque sí es frecuente observar una socialización inadecuada basada en la superioridad del hombre sobre la mujer, que se pone de manifiesto en el ámbito familiar, puesto que fuera de éste, su funcionamiento puede ser perfectamente normalizado, llegando incluso a resultar agradable y amable para el resto de las personas de su entorno, como seguramente lo fue en su día para su compañera, cuando pretendía seducirla. 
En la mayoría de los casos no tienen comportamientos agresivos fuera del ámbito familiar. La conducta pública de los agresores suele ser muy diferente de su conducta privada: con otras personas son amables y correctos, e incluso con la víctima al principio de la relación. Es importante que la familia, las amistades, los compañeros/as de trabajo, y sobre todo la justicia, no desconfíen de la credibilidad de la víctima basándose en el comportamiento y la imagen pública del maltratador.

El maltrato proviene de la creencia cultural y social de la superioridad del hombre sobre la mujer, por la que los hombres se otorgan el derecho para controlar a la mujer usando cualquier medio, incluso la violencia. Hay prejuicios sociales latentes difíciles de erradicar: se da por supuesto que frente al hombre, la mujer suple su falta de inteligencia con astucia; en los medios de comunicación se la asocia a temas frívolos o de mujeres; laboralmente todavía está discriminada en cuanto a acceso al trabajo, sueldo y categoría. Pegar a la mujer estaba permitido hasta hace muy poco en todos los países. Ella era una posesión del marido, al igual que los hijos/as.

Barea (2004, p.91) concluye "La violencia es una forma efectiva de conseguir control sobre sus parejas $y$, en general, hay pocas consecuencias sociales negativas para esta conducta. Él consigue que ella se calle, que le obedezca, sin tener que esforzarse en razonar, pactar o ceder en algo".

Es necesario desligar el maltrato de los problemas de salud mental, tanto de la víctima como del maltratador. Sin por ello olvidar que el maltrato continuado pone de manifiesto secuelas psicológicas en las víctimas, inexistentes antes de que se produjera el mismo.

Así Cárdenas y Ortiz (2005, p.127), revelan que "No es frecuente que ejercer el maltrato sobre la pareja tenga una relación directa con la psicopatología. No acostumbran a ser enfermos mentales, diagnosticados como psicóticos paranoides. Ahora bien, las personas que estén implicadas en una relación de pareja donde tratar mal sea el común denominador, podrán presentar síntomas asociados, tales como la depresión, problemas 
en el control de la ira, impulsividad, baja autoestima, inestabilidad emocional, etc."

Lo que lleva a un hombre a maltratar a una mujer, no es una psicopatología determinada, porque eso significaría que lo que les sucede, al respecto del maltrato, es curable; sino su afán de control y la forma errónea que tiene de entender la masculinidad hegemónica en la que se han educado.

Torres Falcón (2001, p. 218) se hace algunas preguntas acerca de la patología que presentan los maltratadores. "El modelo individual centrado en el agresor justifica la violencia a través de la psicopatología. Habría que preguntarse en qué consiste esa psicopatología y quién la define como tal”.

Huyendo de la etiqueta de enfermo para el maltratador, es legítima la idea de terapia para éste, pero no dirigida a la rehabilitación psicológica de una posible enfermedad, sino a la adquisición de responsabilidad de su actuación maltratante intolerable y la reeducación psicosocial del maltratador.

Mañas Viejo se detiene en la polémica sobre la conveniencia de la aplicación de terapia a los maltratadores para conseguir la asunción de responsabilidades.

“Los programas de atención a los hombres que han ejercido violencia contra las mujeres surgieron a finales de la década del 70, en los Estados Unidos y Canadá. Su objetivo fue complementar los programas de atención y prevención de la violencia hacia las mujeres, teniendo en cuenta que la responsabilidad primaria de dicha violencia corresponde a quienes la ejercen.

Desde un comienzo quedó claro que no se trataba de un tratamiento para una enfermedad, sino de un proceso que procuraba la responsabilización frente a la violencia y el cambio en las relaciones abusivas hacia las mujeres". (Mañas Viejo, 2005, p.137) 
Por lo anteriormente expuesto, se puede afirmar en cuanto a los varones maltratadores, que en general no son locos ni psicópatas. En la mayoría de los casos no tienen comportamientos agresivos fuera del ámbito familiar y dentro de éste, utilizan la violencia no por pérdidas de autocontrol, sino por la necesidad que sienten de controlar a la mujer con la que mantienen una relación.

\subsection{4.- La violencia de género, sólo se da en familias desestructuradas, con bajo nivel económico.}

Blanco García (2006), señala que Las teorías de la anomía ${ }^{7}$ toman como punto de partida el hecho de que la proporción de familias violentas es mayor entre las clases más bajas, lo que les conduciría a mayores niveles de frustración y provocaría mayor número de conductas violentas hacia las víctimas más fáciles (mujeres y menores). Esto unido a que su acceso a recursos sociales alternativos es menor, daría como resultado una tasa mayor de violencia de género.

Las teorías subculturales ${ }^{8}$ también se centran en las familias de clase baja, pues para ellas la violencia sería una norma dentro de la cual han sido

$7 \quad$ La anomia se refiere a la ausencia de un cuerpo de normas que gobiernen las relaciones entre las diversas funciones sociales que cada vez se tornan más variadas debido a la división del trabajo y la especialización, características de la modernidad. Entendiendo modernidad como el conjunto de instituciones y modos de comportamiento que surgieron en Europa a partir del S. XVI que transformaron la realidad de la época y cuyos principios rectores son la fe en el progreso y el empleo de la razón humana como promotora de la libertad. (Durkeheim, 1998)

$8 \quad$ En su etimología, subcultura alude a lo que está en posición inferior a la cultura. Si bien muchas veces es usado el término en este sentido, en otros casos se utiliza para diferenciar los usos y costumbres de ciertos grupos, del de los grupos dominantes, sin que esto signifique que su valor 
socializados. Algunos autores combinan las anteriores explicaciones de la anomía y las subculturales para explicar por qué el fenómeno se produce con mayor frecuencia entre las clases más desfavorecidas. Las teorías del aprendizaje social y las de la asociación diferencial, también insisten en la existencia de un exceso de definiciones favorables hacia el uso de la violencia en determinados contextos, lo que conllevaría un aprendizaje de cómo y cuándo utilizarla como algo perfectamente normal.

La autora también refiere que "aunque no podamos decir que el fenómeno quede reducido a las clases sociales bajas, lo cierto también es que estadísticamente se golpea más a las mujeres de clase baja que a las de las clases acomodadas (la probabilidad de ser golpeadas es seis veces mayor para las primeras). La explicación parece estar asociada a los sentimientos de frustración y falta de poder que tienen los varones de clase baja y en último extremo por tanto, está relacionado con la desigual distribución de la riqueza" (Blanco García ,2005, p.11)

Los datos sobre casos de violencia están muy por debajo de los números reales en todos los estratos sociales y es más probable que sean las mujeres con un nivel socioeconómico alto las que más oculten el problema a la policía y a otros servicios, y es posible también que los hombres que abusan de ellas tengan más cuidado en causarles daños físicos que no sean visibles o que recurran sobre todo al maltrato psicológico (Pagelow, 1981). En las entrevistas realizadas a personas de la población general, las diferencias por clase prácticamente desaparecen.

Los datos numéricos recogidos en las estadísticas, aunque son fiables, no pueden hacerse eco de todas las particularidades de los casos de violencia de género y esto lo explica Mullender cuando dice:

sea menor, por ejemplo las llamadas "tribus urbanas". Sin embargo por ser minorías, es frecuente que sufran discriminación.

En sentido peyorativo, el concepto de subcultura surgió de los estudios de la Escuela de Chicago sobre grupos marginales, de jóvenes delincuentes, pandilleros y vagabundos (Merton, 1964) 
"Frecuentemente, las investigaciones muestran resultados contradictorios: familias desestructuradas pueden dar hijos que aborrecen la violencia, y chicos con estudios en países del primer mundo pueden tener similares actitudes y prácticas violentas que otros de países con menos recursos". (Mullender, 2000, p.64)

Este dato nos da pié a reforzarnos en la idea de que más que un problema de características individuales, estamos ante un problema de transmisión de valores que va muy ligado a la socialización de las personas.

Parece claro que todos los tipos de violencia se dan en todas las clases sociales. En las clases bajas se evidencia más fácilmente la violencia física, pero parece que no hay un rasgo típico, ni perfil del maltratador. Lo que tienen en común todos los maltratadores es el tener o haber mantenido una relación afectiva con la víctima.

De ahí que Barea (2004, p.74) preste especial atención al maltratador señalando que "Múltiples trabajos de investigación en muchos países coinciden en concluir que cualquier mujer, independientemente de su nivel cultural, económico, edad o raza, puede llegar a desarrollar las secuelas propias del maltrato si se la somete a un trato degradante continuado. No es ella quien crea el problema, sino el agresor. Es en él en quien hay que poner el énfasis".

Existen trabajos recogidos por Cárdenas y Ortiz que ponen de manifiesto datos referentes al maltrato en la sociedad finlandesa que echan por tierra la falsa creencia que defiende la escasez de violencia de género en los países más desarrollados, o en las clases sociales más acomodadas.

"Podríamos creer que las sociedades más adelantadas en la igualdad de la mujer sufrirían menos maltrato doméstico, pero para nuestra sorpresa, no es así: las estadísticas nos dicen que en Europa el mayor número de muertes por violencia doméstica se da en los países nórdicos. Recientemente nos sorprendía la noticia de que Finlandia está a la cabeza 
de mujeres asesinadas por sus compañeros sentimentales. Un país con un alto nivel de vida, donde la mujer ha alcanzado cotas muy altas de puestos de responsabilidad y de poder. No podemos, entonces, poner todo el peso en la cultura, y menos de una forma simple o reduccionista". (Cárdenas y Ortiz, 2005, p.42)

Aunque la violencia de género está presente en todos los estratos sociales, estas autoras ofrecen una explicación que arroja luz al mito de la violencia de género asociada a las clases más bajas de la sociedad.

"La pobreza, la marginación y la precariedad son tierra de cultivo para el maltrato. Pero la violencia es sólo un síntoma más de la miseria, no su atributo principal. Sabemos que el maltrato está presente en todos los sectores de la población, pero son los más deprimidos los que suelen llamar la atención de los servicios sociales, que intervienen en ellos con frecuencia. Escandalosas peleas, que provocan que los vecinos acaben llamando a la policía, o niños que muestran conductas preocupantes en la escuela, son señales de alarma que movilizan a los profesionales. Las clases sociales más altas tienen mecanismos para ocultar sus diferencias, guardan más las apariencias y se pueden permitir adquirir ayudas que disminuyan la tensión, por lo que es menos usual que generen intervenciones externas". (Cárdenas y Ortiz, 2005, p.44)

Necesariamente hay que hacer alusión una vez más a Cárdenas y Ortiz con respecto al bagaje sociocultural que arrastra cada persona, bagaje que cobra gran relevancia cuando se forma una pareja nueva, pues lo aprendido en las respectivas familias de origen ha de conjugarse para llevar una convivencia armónica. La situación ideal se produce cuando la familia de cada miembro de la pareja funciona como fuente de apoyo y elemento de freno ante situaciones complicadas de resolución de conflictos, esto ayuda a que el maltrato no se instale en la casa. No cabe duda, una mujer respaldada por los suyos, tiene mayor capacidad de poner límite a su pareja y se siente capaz de afrontar situaciones nuevas. El deber de la familia es 
educar a sus miembros conforme a las reglas de la comunidad y en el caso de que estas no sean asumidas ejercer presión, así se evitaría la intervención, a otros niveles, de otras instituciones

"El grupo social por excelencia, donde se transmiten los patrones culturales, es la familia. Cómo se deben comportar una mujer, un hombre o una pareja, lo aprendemos mayoritariamente en el seno de nuestra familia, con la educación que nos dan nuestros padres, con el ejemplo de su relación conyugal y sus roles femeninos y masculinos. Cuando se forma una pareja, lo hace a partir de dos universos distintos, de dos culturas familiares que se encuentran y que incluyen distintas expectativas de lo que ha de ser la pareja. La complejidad, está servida". (Cárdenas y Ortiz, 2005, p.45)

Es sabido que la pobreza en el mundo tiene rostro de mujer, y esto tiene mucho que ver con la violencia ejercida hacia ella por parte de sus parejas. Las mujeres pueden ser pobres o ricas, pero eso no necesariamente indica que tengan algún control del dinero. En muchas ocasiones, aunque los maridos sean ricos las mujeres siguen siendo pobres.

Torres Falcón (2001, p.146) se refiere a la violencia económica en los siguientes términos: "Al igual que en la violencia física y la violencia sexual, en la económica se advierte con claridad que la dirección del maltrato doméstico es del hombre hacia la mujer. La desigualdad entre los géneros se expresa de manera indudable en la economía y se nota en todos los espacios sociales. Las estadísticas de Naciones Unidas no pueden ser más elocuentes: obtener $10 \%$ del ingreso mundial y poseer el $1 \%$ de la propiedad coloca a las mujeres en posición subordinada. Esta desigualdad económica se reproduce en el interior de los hogares con desagradables consecuencias".

Sin prestar atención a la clase social, muchas mujeres dedican su tiempo a atender al marido, educar a los hijos e hijas y cuidar de que todo el engranaje de la casa funcione bien. Esta es una tarea que requiere gran dedicación, es un trabajo a tiempo completo, carente de vacaciones, ni 
festivos, por el que no se recibe ninguna compensación económica, ni pensión de jubilación. Es el trabajo invisible por excelencia, puesto que sólo se nota si no se lleva a cabo. Es significativo que aunque las mujeres incursionen en el mercado laboral y generen recursos, la carga doméstica no disminuye, y por lo regular no se comparte con los maridos. Esto también es violencia, porque nace de la desigualdad entre las personas.

La violencia dentro de la pareja existe independientemente de la clase social a la que se pertenezca o el lugar del mundo del que se trate. $Y$ así lo refleja esta autora en la siguiente cita:

"Hay creencias que apuntan que la violencia es privativa de una determinada clase social o de personas de bajo nivel educativo o cultural. Es cierto que en algunas condiciones la violencia es más visible; a las mujeres ricas puede costarles más trabajo formular una denuncia o intentar salir de la relación, precisamente por el entorno, la crítica y el temor a desclasarse. Cuando lo hacen quizá recurren a profesionales privados y no a centros gubernamentales u organizaciones sociales." (Torres Falcón, 2001, p.177)

Existe una explicación a la continuidad en la pareja, a pesar del maltrato, basada en la precariedad económica a la que se ven abocadas, un gran número de mujeres, cuando deciden poner fin a su relación. Mañas Viejo (2005, p.38) recoge esta reflexión al respecto: "Las mujeres maltratadas sufren un empobrecimiento material tanto durante la relación en la que apenas son dueñas de nada, como después. El empobrecimiento se agrava con la ruptura, ya que entonces la mujer prácticamente ha de empezar desde cero: cambio de residencia, asunción de las cargas familiares, mal estado de salud, paro, etc. Esta situación de desamparo ha llevado a muchas mujeres a sobrellevar en silencio el peso del maltrato".

\subsection{5.- Los maltratadores están sometidos a estrés laboral.}


Es improbable que el estrés sea la causa de los malos tratos, la violencia de género, como ya hemos señalado en apartados anteriores, no tiene en cuenta la clase socioeconómica y tampoco se puede achacar a problemas de salud mental. Un hecho evidente de esta afirmación es que si el estrés fuera causa de violencia de género, los maltratadores agredirían a sus jefes y compañeros o compañeras de trabajo, además de a sus parejas. La violencia de género se instala en las relaciones de pareja porque la sociedad minimiza el abuso y porque el agresor sabe que puede conseguir lo que quiere mediante el uso de la fuerza, sin necesidad de hacer frente a consecuencias serias para él.

Bien es cierto, que encontramos un mayor número de mujeres maltratadas en familias que sufren situaciones de tensión o problemas económicos. Por el contrario, cuanto más democrática sea la familia con respecto a los principios de poder y autoridad, encontramos una menor incidencia de casos de mujeres maltratadas.

En la literatura encontramos autores/as que ponen de relieve la falta de consistencia del argumento que explica la violencia contra las mujeres a causa de la pérdida de control del maltratador. Dichas explicaciones no encajan con aquellos hombres que maltratan a pesar de su vida exitosa 0 fácil. Recogemos citas al respecto de Bograd (1988), Ptacek (1988) y Gelles (1979)

Los abusadores caen en contradicciones: mientras dicen que su violencia está más allá del control racional, al mismo tiempo admiten que esa violencia es deliberada y justificada. Otra contradicción consiste en restar importancia a las lesiones causadas a las mujeres y al temor infundido en ellas. Pensamos que los abusos tienen que ver con el control, pero no con su pérdida, sino con la utilización que de él se hace para dominar la voluntad de la mujer a la que se maltrata. 
"Este tipo de hombre quiere maltratar y aterrorizar a su pareja, quien, según él, le ha provocado, y se siente con derecho a castigarla si no la considera una buena esposa. Habitualmente es capaz de parar antes de matarla, a diferencia de otros que se dejan llevar por la ira" (Bograd, 1988, p.17)

"La pérdida de control, como excusa para justificar acciones que requieren tiempo para llevarlas a cabo, como por ejemplo escribir una serie de cartas amenazadoras o acechar a la mujer y su nueva pareja (Ptacek, 1988, p. 145)

"Los hombres se vuelven individualmente abusivos como respuesta a las presiones sociales y del entorno, como por ejemplo la pobreza, la precariedad del alojamiento, la mala calidad de vida, el desempleo o la explotación laboral, el racismo, el fracaso en los estudios, los deseos materiales insatisfechos en una sociedad comunista y/o la falta de esperanza en el futuro" (Gelles 1979, p. 25)

Si se considera que las presiones conducen a la frustración y al estrés y que esto a su vez desemboca en violencia contra las mujeres, aquellos hombres con más éxito y más dinero, al verse liberados de la presión por conseguir tales objetivos, no maltratarían; sin embargo, no sucede así y lo habitual es que cuando las violencia empieza sigue una pauta en escalada.

No se puede negar que la precariedad económica o la falta de recursos, favorece la aparición de la violencia de género, lo cual no se convierte de forma automática en la justificación que libera de la responsabilidad de la agresión al maltratador.

"Con esto no se pretende decir que los problemas materiales no tengan importancia, ni que el desempleo, la pobreza y la falta o precariedad de alojamiento no sean factores que influyan en los abusos (quizá porque representan, por ejemplo, una amenaza al papel dominante del hombre en el hogar, sino que no excusan a los maltratadores de la responsabilidad que 
tienen acerca de sus actos, ni explican por qué muchos hombres que tienen que hacer frente al desempleo y a la pobreza no maltratan por ello a las mujeres. Uno de los problemas metodológicos de ciertas investigaciones es que algunas de ellas han utilizado para el estudio muestras de mujeres acogidas en refugios y éstas provienen en muchos casos de entornos pobres" (Pahl 1985, p.43)

No es sorprendente que a menudo las mujeres de entornos más desfavorecidos, hagan hincapié en que los problemas relacionados con el dinero y la vivienda han tenido mucho que ver con el estrés y las peleas, mientras que las que disponen de ahorros, ingresos propios o ayuda económica de su familia, aunque también sufren malos tratos, generalmente no acuden a los refugios, sino que suelen escapar de su situación de otra forma. (Smith, White y Holland, 2003)

La pérdida de control puntual, asociada a un episodio de estrés concreto, que lleva a una agresión contra la mujer, no explica el abuso a todos los niveles (psicológico, físico y/o sexual) que padecen las mujeres maltratadas.

"Las teorías psicosociales no han podido explicar por qué el estrés tiene que desembocar necesariamente en la violencia y, en concreto, en la violencia masculina, por qué son prácticamente siempre los hombres los que pegan a las mujeres, cuando estas son sus iguales a nivel social y no sus enemigas de clase " (Ericksson, Nenola, Muhonen Nilsen \& Nordisk, 2002, p. 134)

Las desigualdades sociales en función del género se plasman en la violencia de género. Esta es, además, la única explicación que puede abarcar de manera satisfactoria la naturaleza de los abusos, tanto en cuanto a su persistencia como a su pauta de escalada y la combinación de control físico, sexual y emocional que representan. Una pauta que no se corresponde simplemente con la pérdida de control en un momento determinado a causa del estrés. 
"Las mujeres son, en un número desproporcionadamente mayor, el objetivo de los abusos físicos y de la coerción por parte de los hombres" (Bograd, 1988, p.19)

No está permitido justificar la agresión hacia la mujer a causa de una pérdida de control del varón, sino por todo lo contrario, por deseo de mantenimiento de ese control y poder hacia ella. Las llamadas pérdidas de control son controladas. El hombre violento agrede cuando la mujer es más vulnerable, en situaciones de mayor aislamiento. En otros contextos y con otras personas no se descontrolan o lo hacen mucho menos.

"Es habitual imputar la violencia a estados episódicos de pérdida de control. Claro está que lo extraño es que la pérdida de control y la tensión interior no se descarguen más que contra las mujeres o contra los hijos e hijas y no, por ejemplo, contra la empresa, sobre todo si pensamos que la escasez económica o las dificultades en el trabajo pueden -y sin duda lo hacen - estresar a los hombres (pero también a las mujeres). Además, los ataques de ira y de violencia contra las mujeres son normalmente controlados. No es, en definitiva, una cuestión de pérdida de control sino de mantenimiento del control y del poder sobre la mujer". (Mullender, 2000, p.66)

Algunas profesiones presentan mayor propensión a utilizar la violencia como método de resolución de conflictos. Para estas personas el bloqueo de la pérdida de control sería más complicado. Las armas que utilizan pueden ser los puños, un arma blanca o de fuego, las palabras, la imposición del silencio, la seguridad material de las hijas e hijos, hacer algo que la humille, obligarla a realizar algo que no desea, ignorarla cuando ella le presta atención, menospreciarla, desautorizarla delante de las hijas e hijos y cualquier cosa que le sirva a su objetivo, que es la utilización y el dominio.

"Las personas que trabajan en profesiones donde el uso de la violencia es frecuente (policía, guarda de seguridad, militares, etc.), tienen un problema añadido. Se observa que los hombres que maltratan, si además 
tienen una profesión de este tipo, experimentan más dificultad en identificar como problema la familiaridad con que recurren a la violencia en casa y, por lo mismo, son más resistentes a cambiar."(Cárdenas y Ortiz, 2005, p.77)

Hay que tener en cuenta las falsas creencias que se extienden en el sistema de valores ligado a la violencia y se basan tanto en el componente genético del maltratador, como en las clases sociales o culturales, o en el amor romántico que impregna toda la relación en perfecta armonía con la dominación y la posesión masculina. La frustración, como explicación y no como justificación, a la violencia de género, asocia el maltrato a factores deficitarios en el plano social, económico, familiar que pueden ocasionar frustración, la cual lleva al maltratador a una incapacidad para mantener el estereotipo de virilidad impuesto por la cultura machista hegemónica.

"El mito de que los hombres son violentos por naturaleza, hace alusión a la información genética de cada individuo. En realidad se trata de una conducta aprendida que la sociedad puede estimular o inhibir. En este sentido, se debería revisar cómo se construye en cada cultura la idea de lo que debe ser un hombre; podría comprobarse que en muchos lugares el prototipo de masculinidad está directamente asociado a diversas formas de violencia". (Torres Falcón, 2001, p.178)

Las circunstancias que pueden conjugarse para ocasionar frustración son múltiples. Quienes se aferran a esta explicación han insistido en factores económicos tales como el desempleo, el hacinamiento, la pobreza. También se mencionan aspectos sociales, como el aislamiento, la falta de amigos, los conflictos con la familia de origen, las dificultades en el trabajo, el estrés. Los hombres se sienten abrumados con una serie de problemas y ante la incapacidad de manejarlos desahogan la tensión ejerciendo maltrato hacia su esposa y sus hijos e hijas.

"Muy cerca de la idea de inadaptación social se ha mencionado como causa de la violencia la incapacidad de manejar la frustración. Según esta idea, el hombre que actúa violentamente lo hace porque no soporta ciertas 
condiciones de su vida y entonces estalla. Cuando no es capaz de mantener cierto autocontrol se vuelve iracundo: grita, ofende, destruye objetos, golpea”. (Torres Falcón, 2001, p. 220)

En la cultura patriarcal, algo que puede ocasionar frustración es la imposibilidad de mantener el estereotipo de virilidad. El hombre desempleado, que vive en condiciones de precariedad económica, no puede cumplir con el papel de proveedor y principal sostén de la familia. La violencia actúa entonces como un recurso para mantener el dominio, el control y el poder.

\subsection{6.- Los maltratadores abusan de sus parejas a causa del alcohol $u$ otras sustancias.}

Con frecuencia se ha utilizado la excusa del abuso de sustancias, para justificar la conducta agresiva del maltratador. Sin embargo diferentes autores y autoras, demuestran que los maltratadores no necesitan el consumo de alcohol o drogas para abusar de sus parejas. Es cierto que las drogas $\mathrm{y}$ el alcohol disminuyen las inhibiciones $\mathrm{y}$ producen un comportamiento más impredecible, de manera que el abuso de estas sustancias puede aumentar la frecuencia o la severidad de los episodios de violencia en algunos casos.

Con respecto al consumo de alcohol, se piensa que es un factor presente en al menos el 50\% de los episodios de violencia conyugal. (Gelles y Strauss, 1988)

Torres Falcón (2001), lleva a cabo un exhaustivo análisis al respecto haciendo interesantes reflexiones desde novedosos enfoques, como por 
ejemplo el hecho de focalizar la atención en el agresor y sus características o circunstancias, más que en la víctima de la violencia de género, como viene siendo habitual. Se analizan sus actitudes, formas de vida, comportamientos y, en particular, las circunstancias en que se desencadenó la violencia.

El consumo de alcohol y drogas es una de las razones más citadas al abordar la violencia familiar. La señalan por igual los agresores y sus víctimas, las personas cercanas a la familia, los estudiosos/as del tema y también, desde luego, algunos especialistas. El borracho que golpea es una figura común en el imaginario social.

El binomio alcohol y malos tratos, se encuentra arraigado en nuestra cultura. Están contrastados los síntomas físicos que provoca ingerir alcohol: lentitud de reflejos, dificultad para hablar de manera articulada, para caminar y, en casos extremos, para mantener el equilibrio. Sin embargo perdura la pregunta de si el alcohol provoca o no comportamientos violentos, es decir, si efectivamente hay una relación de causa y efecto entre el alcohol y la conducta violenta.

Muchos hombres únicamente maltratan o golpean a sus parejas cuando están ebrios, estando sobrios son amables y sociables. Así se demuestra que el alcohol es, sin duda, un factor a tener en cuenta al estudiar las causas del fenómeno de la violencia familiar, sin llegar a la justificación de la misma por este motivo.

Por otra parte, en multitud de casos no se hace patente esa conexión entre alcohol y violencia. En la literatura encontramos numerosos testimonios sobre hombres abstemios que se muestran violentos con sus mujeres ${ }^{9}$. Las actitudes de acoso permanente, de control de los movimientos

Torres Falcón, M. (2001). La violencia en casa. Buenos Aires: Paidós

Cárdenas y Ortiz (2005). Entre el amor y el odio. Madrid: Síntesis

Kirkwood, C. (1999). Cómo separarse de su pareja abusadora. Buenos Aires: Granica 
de la mujer, de usar a los hijos/as para manipular, de chantaje y de amenazas, no tienen ninguna relación con el consumo de alcohol.

¿Qué es entonces lo que sucede? ¿Algunos hombres se vuelven violentos y otros no, cuando se encuentran bajo los efectos del alcohol? El consumo de alcohol, debe tomarse en cuenta y en efecto es uno de los factores que intervienen en la dinámica de la violencia, pero no es determinante. Hay suficiente investigación empírica para sostener con seguridad que hay alcohol en familias no violentas y violencia en familias que viven libres del influjo de la bebida.

Algunos hombres se vuelven violentos sólo cuando ingieren alcohol, pero este comportamiento no se debe propiamente al consumo de la bebida sino a otras razones. El alcohol desinhibe, baja las defensas y permite que el individuo realice determinadas conductas que en otras circunstancias habría reprimido. El alcohol no produce la violencia: no es que no hubiera existido antes, sino que estaba reprimida. Además de desinhibir, el alcohol proporciona una excusa para comportamientos inadmisibles. Por ello es frecuente escuchar, de boca de un agresor, expresiones como "Estaba muy borracho", "No lo recuerdo", "No supe lo que hacía", "El alcohol me vuelve loco". Las víctimas emiten frases similares: "Bebe y se transforma", "No lo reconozco", "Actúa como poseído". (Torres Falcón, 2001)

Otra de las cuestiones novedosas a tener en cuenta, planteada por Torres Falcón, es la imagen que proyecta la mujer cuando bebe, pues nada tiene que ver con la del hombre en las mismas circunstancias. Ella dice que en realidad, el nexo entre alcohol y violencia sólo se aplica a los hombres violentos. Las mujeres que consumen alcohol rara vez golpean al marido o a los hijos/as cuando están bajo su efecto; es más, si ellas lo consumen ésta es una justificación más para maltratarlas. 
"No conocemos casos de mujeres que por el alcohol se involucren en una riña callejera con otras mujeres y que cada una saque del bolso una navaja; no conocemos mujeres que por estar alcoholizadas persigan a los hombres o les tiendan trampas para violarlos o asesinarlos. Ni siquiera sabemos de mujeres que regresen a sus casas a altas horas de la noche, azoten la puerta y exijan a gritos ser atendidas con una cena caliente y después esperen del marido disponibilidad sexual. Pero si los conociéramos, ¿cómo reaccionaríamos? Este conjunto de reflexiones y ejemplos muestra que hay normas sociales para el consumo del alcohol diferenciadas por sexo. La valoración de los mismos hechos y actitudes cambia radicalmente según se trate de hombres o de mujeres". (Torres Falcón, 2001, p. 216)

Hay que señalar el hecho del control que manifiestan los hombres que han bebido fuera del hogar, absteniéndose de golpear a las personas con las que se relaciona hasta llegar a su casa, que es donde descarga su ira y de especial modo contra su mujer.

$\mathrm{Si}$ algunos hombres se comportan de manera violenta en el hogar sólo cuando están bajo los efectos del alcohol, conviene recordar que esos mismos hombres no tienen las mismas actitudes en otras circunstancias sociales, siendo capaces de ejercer control sobre sus impulsos violentos, aunque también se encuentren bajo los efectos del alcohol.

Straus, M., Gelles, R. and Steinmetz, S. (1980) por su parte concluyen que la proporción de violencia de los varones hacia las mujeres es tres veces mayor en los bebedores que en los abstemios. No obstante conviene tener prudencia a la hora de afirmar taxativamente que el alcohol es la causa de la violencia familiar pues la gran mayoría de los varones que beben no golpean a sus mujeres.

El consumo de alcohol u otras sustancias, proporciona a los agresores la excusa adecuada ante las mujeres que esperan el milagro de la rehabilitación, pretendiendo encontrar un hombre diferente si éste 
abandonase el consumo. Ellas desconocen la intencionalidad: él no agrede porque consume, sino que consume para agredir con mayor facilidad.

"Lo más probable es que la bebida sea, en el caso de algunos hombres, una variable que influya en su comportamiento: los hombres beben para conseguir el valor o el permiso para ser violentos, o para tener una excusa a la que recurrir después de producido el suceso. A veces hay mujeres que creen en esta excusa y albergan la esperanza de que el hombre cambie si deja de beber. Pero los hombres se valen de la bebida para desinhibirse del freno que ya han decidido pasarse por alto con antelación" (Gelles, 1974, p. 117)

Algunos autores defienden la idea de la violencia, previamente existente, en los hombres que agreden, incluso sin haber bebido.

El hombre que es violento estando ebrio también lo puede ser estando sobrio, demostrando que el alcohol sólo alimenta una violencia ya existente. (Kaufman, 1989)

En cuanto al alcohol y a las drogas, en el Eurobarómetro y en otras investigaciones son consideradas causas fundamentales de los malos tratos. Un factor decisivo en la violencia contra las mujeres. Sucede, sin embargo, algo parecido a las influencias familiares: ni explica todos los casos, ni muestra las razones por las cuales muchos hombres que beben no agreden a sus mujeres. De hecho, diversos estudios muestran que muchos hombres no están borrachos en el momento específico de la violencia (HagemannWhite y Gardlo, 1997). En todo caso, el alcohol hace salir una violencia que ya existe.

Aunque el alcohol y otros tóxicos producen desinhibición y la violencia se agrava, no son la causa. El alcohol no hace violento a un hombre que no lo es aunque sí hace que la violencia sea más extrema. De todos los hombres juzgados por violencia hacia la mujer, sólo un porcentaje bajo (5\% según la Asociación de Juristas Themis) se han asociado al diagnóstico 
síndrome de dependencia al alcohol. Además son violentos también cuando no beben. Ya decía Séneca: "La embriaguez no crea los vicios; no hace más que ponerlos en evidencia".

Esta creencia, como la de estar sometido a gran tensión psíquica, y la mayoría de las atribuidas a los hombres violentos, sirven para justificar su conducta y restarle responsabilidad.

"Las personas que recurren a la violencia suelen tener poca conciencia de sus estados afectivos y experimentan dificultades para tender puentes entre su parte emocional y su parte racional. Ello puede conducirles a pasar de la emoción a la actuación de forma impulsiva, sin ser conscientes de qué es lo que les ha llevado a actuar de determinada manera. Una palabra, un gesto o una actitud de su compañera la interpretan como una amenaza o como un daño, lo que desencadena toda una gama de emociones que les llevan a actuar impulsivamente. Evidentemente, si alguien piensa que el otro le pertenece, es más que probable que, ante determinadas conductas, se sienta ofendido o maltratado, lo que puede alimentar algunas emociones concretas como rabia, tristeza o miedo a ser abandonado. Cuando estas emociones aumentan de intensidad, resultan desbordantes y difícilmente controlables". (Cárdenas y Ortiz, 2005, p.74)

Parece claro que el abuso de estas sustancias no es la causa de la violencia de género, el seguimiento de un programa de desintoxicación por parte del maltratador, no elimina eficazmente la violencia doméstica. Estos programas pueden ser útiles en combinación con otros programas de intervención sobre el maltratador.

"Cuando se utiliza cualquier sustancia, el objetivo es sentir nuevas sensaciones para salirse de sí mismo o para escapar de la realidad. Cuando se empieza a trabajar con parejas y personas con problemas de violencia, el primer paso es obtener un compromiso de autocontrol y, si hay utilización de sustancias, este compromiso no es firme ni fiable. Se pueden tener muy buenas intenciones, pero si se han consumido drogas, se da más fácilmente 
rienda suelta a las pasiones y a las sensaciones, que hay que domesticar en el proceso de cambio. El control de la violencia, por tanto, no puede estar disociado del control de la drogodependencia o del alcoholismo". (Cárdenas y Ortiz, 2005, p.127)

\subsection{7.- Lo que ocurre en una familia es un asunto privado, mejor no denunciar.}

Ninguna situación que dañe de este modo a un ser humano puede considerarse privada. Es un delito y está tipificado en el Código Penal. A pesar del compromiso personal que implica y la dificultad diagnóstica que en muchos casos supone, lo cierto es que hay obligación legal y, por supuesto, moral de indagar y manifestar, siempre respetando la decisión de las mujeres.

Decir que es un asunto privado implica también desestimar el miedo de la mujer, colocándola de igual a igual con su agresor, en su casa, lugar donde ella es más vulnerable y tiene más riesgo.

Considerar la violencia contra las mujeres como un fenómeno privado fomenta que esta sea entendida como un derecho del varón, legitimado por la herencia patriarcal. En la actualidad, la violencia de género se contempla como una cuestión incómoda, admitiéndose que forma parte de la cotidianeidad y la intimidad de algunas familias, lo que justifica la no intervención. Como consecuencia, las víctimas no denuncian el 100\% de las agresiones, tanto por miedo, como por vergüenza, así como por desconfianza en las ayudas a las que se tiene acceso. Como consecuencia podemos pensar que las cifras oficiales posiblemente sólo son la punta del iceberg. 
Se puede responsabilizar, de parte del silencio que envuelve a los malos tratos, a la sociedad que facilita que se viva como normal la dominación y el maltrato. También el aislamiento propicia que se normalicen actitudes, como el control sobre la pareja o la justificación de episodios violentos.

"Cuando el maltrato entra por la puerta, existe la tendencia a guardar el secreto, porque los trapos sucios se lavan dentro. Todos los participantes en el juego saben, aunque no se haya explicitado, que hay cosas de las que fuera no se puede hablar. Y claro, van pasando los años con la sensación de que es inevitable y que la vida es asi". (Cárdenas y Ortiz , 2005, p.123)

Blanco García, pone de manifiesto que hay quien culpa a la evolución de la institución familiar de ese supuesto incremento de maltrato. Para estas personas algo está fallando ahora en las familias y sería la causa de que los malos tratos sean cada vez más frecuentes. Lo cierto es que potenciar la imagen bucólica de la familia tradicional, conduce directamente a distorsionar la realidad de la convivencia. La familia presenta dos vertientes, una positiva que implica cuidados y protección de sus miembros; y otra negativa que va unida a la forma de resolución de conflictos y tensiones que inevitablemente se producen en todas las familias. No podemos obviar el sistema que rige la familia, cuyo poder se encuentra distribuido de forma desigual en una clara jerarquía y va unido al principio de autoridad que alguien ostenta. (Blanco García, 2006)

Pues bien, aunque sea difícil de reconocer, puesto que tendemos a idealizar la familia como el lugar del cariño, de los cuidados y de la seguridad de sus miembros frente al duro mundo exterior, lo cierto es que tal como los expertos en violencia familiar afirman, la familia es la institución social más violenta con excepción de la policía y el ejército. (Gelles y Strauss, 1988)

En esta misma dirección, se pronuncia Rojas Marcos diciendo que "a diferencia de la mayor parte de las organizaciones en las que los intereses y actividades son reducidos, la familia como grupo primario que es, 
comprende prácticamente todo. Esto significa que hay muchas más cuestiones sobre las que discutir, y además mucho más tiempo en el cual se puede producir la interacción. Una exposición más extensiva incrementa la probabilidad de que surjan desacuerdos, irritaciones, violaciones de la privacidad, etc., y que con ello, se incremente el riesgo de que aparezcan conductas violentas". (Rojas Marcos, 1995, p.29)

Este autor señala en la misma cita otra característica relacionada con esa cara negativa de la familia, es su privacidad.

"En nuestra sociedad lo que ocurre en el hogar son asuntos privados y esto tiene dos consecuencias negativas: aísla a sus miembros de la protección que la sociedad puede prestarles e impide a las víctimas de abusos buscar ayuda externa a sus problemas". (Rojas Marcos, 1995, p.29) y continúa exponiendo: "La agresión sádica, repetida y prolongada, se produce sobre todo en situaciones de cautiverio. Sucede especialmente cuando la víctima es prisionera o incapaz de escapar de la tiranía de su verdugo y es subyugada por la fuerza física o por imposiciones económicas, legales, sociales o psicológicas. Estas condiciones se dan en las cárceles, en los campos de concentración, en ciertos cultos religiosos, en burdeles y, con mucha frecuencia, en la intimidad familiar, porque en ella las cadenas y los muros no se ven con claridad, son casi siempre invisibles, aunque no menos reales o insuperables".

Esta descripción de la cara oscura de la institución familiar ha de servirnos como marco para intentar entender o explicar lo que en principio puede parecer inexplicable, un sinsentido que muchas veces tendemos a atribuir a situaciones patológicas desde el punto de vista psicológico y que en algunos casos serán efectivamente su producto, pero que en la mayor parte de ellos tienen que ver con nuestra organización sociocultural.

Al tratar de desmontar el mito de la privacidad de los asuntos de familia, como excusa para ocultar el maltrato, solemos hacer alusión al aprendizaje de los niños y niñas que presencian o sufren violencia en sus 
hogares, diciendo que ellos y ellas probablemente estén aprendiendo un modelo que posteriormente podrán reproducir, con facilidad, cuando formen parejas en su vida adulta.

En palabras de Mullender (2000, p.71) "Uno de los factores que muchas investigaciones subrayan como predictor de violencia es haberla experimentado en la infancia. Así, hogares violentos generarían nuevos hogares con hombres violentos, en un ciclo imposible de cortar. No se puede negar la influencia de las familias en la socialización de los hijos e hijas. Lo que sí puede discutirse es que ser testigo o víctima de la violencia en el hogar durante la infancia cause inevitablemente violencia futura: no sólo buena parte de los hombres que la han sufrido no son violentos - en realidad, la mayoría en casi todas las investigaciones- sino que la mayor parte de quienes agreden y de las mujeres que son víctimas provienen de hogares no violentos".

Con respecto a la denuncia cuando se produce el maltrato, sabemos que las víctimas de la violencia de género son las mujeres, y que este tipo de violencia se alimenta de unas creencias que tienen que ver con la institución del patriarcado. ¿Deben las mujeres denunciar a sus agresores? ¿Tiene esto algún efecto positivo en la conducta de sus parejas? ¿Decrece el número de agresiones tras la denuncia? Según un estudio realizado en Minneapolis en 1981 por su departamento de policía, parece claro que cuando se produce el arresto del agresor, se reduce la incidencia de posteriores ataques. ${ }^{10}$

\footnotetext{
${ }^{10}$ El Proyecto de Indulto de Illinois se centra en garantizar clemencia a las mujeres maltratadas en prisión por herir o matar a sus cónyuges abusivos. Margaret Byme, directora del Proyecto, fundó el grupo en la década de 1990. Desde su concepción, abogados, profesores, estudiantes de derecho y simpatizantes, han luchado para conseguir el indulto de decenas de mujeres maltratadas en el sistema penitenciario de Illinois.
} 
A pesar de las denuncias, las mujeres no tienen una protección real, son escasas las órdenes de alejamiento y se quebrantan con frecuencia, la mayor parte de los asesinatos se producen después de la denuncia. No se trata de desaconsejar la denuncia, aunque se hace necesario planificar una estrategia acerca de dónde irá después, con qué recursos cuenta, cuáles son las medidas de protección a su alcance, cómo podrá seguir recuperándose. Las mujeres precisan atención jurídica, apoyo psicológico, formación laboral y en la mayor parte de los casos, apoyo económico.

Se cree que el simple hecho de llamar a la policía (aunque no haya arresto) ya tiene un efecto disuasorio. (Sherman y Berk, 1984)

Otros estudios (Langan e Innes, 1986) llegan a la misma conclusión.

Estudios posteriores Dunford, Huiznga y Elliot (1990), Sherman (1981), Sherman y Smith (1992), Pate y Hamilton (1992) matizan estos resultados, que de tomarlos como concluyentes, nos llevarían casi automáticamente a generalizar el arresto como medida. Concretamente lo que se ha obtenido es que los agresores desempleados que habían sido arrestados, incrementaron sus agresiones, mientras que los ocupados las disminuyeron, lo que parece estar relacionado con los efectos que la etiqueta negativa tiene en ellos.

La aportación fundamental del feminismo a la violencia doméstica ha sido, además de la denuncia, provocar el paso desde la privacidad a la agenda política y a la agenda pública, llevar a la calle y a los medios de comunicación lo que sucede en la intimidad de la casa y exigir soluciones.

"El camino no ha sido fácil, no sólo por las dificultades que el feminismo ha tenido para presentar sus temas como claves para la sociedad, sino también porque la violencia ha sido y es uno de los asuntos en los que con cierta facilidad las instituciones políticas han asumido los aspectos externos del problema, sin cuestionar a fondo sus raíces". (Posada kubissa 2001, p.31) 
Lo cierto es que la mujer maltratada que decide denunciar a su pareja, precisa de apoyos que mantengan su decisión.

"Cuando la mujer se da cuenta por primera vez de que su pareja la maltrata suele hablar con alguien. No es verdad que las mujeres maltratadas no lo digan o no pidan ayuda; lo que ocurre es que la respuesta que reciben de los conocidos y de la sociedad en general es fría, tópica, y las disuade de continuar en su denuncia de la violencia de género". (Barea, 2004, p.184)

Resulta imprescindible la necesidad de sacar a la luz los casos de violencia de género, para así ceder la responsabilidad de resolución del asunto a otras personas o instituciones situadas fuera del ámbito familiar.

"Existe la idea de que la violencia conyugal es un asunto privado y que, por lo tanto debe resolverse en el mismo lugar donde se produce, o sea en el hogar y a puerta cerrada. Con estas afirmaciones se desestima la intervención de terceros -sea a título individual o institucional- y se acentúa el aislamiento en que viven las víctimas. Expresiones como la ropa sucia se lava en casa, tienen también el efecto de perpetuar una obligación femenina de aguantar silenciosa y resignadamente cualquier agresión y de hacer sacrificios en aras de conservar un matrimonio o una familia que, lejos de ser la pequeña comunidad de amor y armonía que se presenta como ideal, representa el encierro de un malestar que se vive y retroalimenta entre las cuatro paredes que delimitan la escenografía". (Torres Falcón, 2001, p.177)

\subsection{8.- Siempre se exagera la realidad cuando se habla de violencia contra las mujeres.}


Frecuentemente nos encontramos ante un error de concepto, en el sentido de creer que si la mujer no abandona al hombre que la maltrata, entonces la violencia que soporta no debe ser tan intolerable. En realidad el maltrato es progresivo y cuando se inicia puede que una mujer piense que lo ocurrido ha sido un hecho puntual y que no se volverá a repetir, por ello tiende a restarle importancia.

Sólo con la perspectiva que da el tiempo, la mujer comenzará a ser consciente de que el primer incidente, lejos de ser un suceso puntual, marcó el comienzo de la escalada de violencia. En ese momento y haciendo uso de la lógica, se abriría un interrogante ¿por qué el violento no permite que ella abandone la relación? Sin embargo, el hecho ampliamente extendido de formular la pregunta de por qué no se marcha ella, tiene que ver con la tendencia generalizada de culpabilizar a la víctima.

Desde nuestro punto de vista, el tratamiento debe ir dirigido exclusivamente a los responsables del acto delictivo, los maltratadores y no a quienes sufren sus consecuencias, las víctimas. De este modo recaería la condena en quien comete el delito y no en quien lo sufre.

Sabemos que desde el primer momento, la mujer desea el cese de la violencia, pero no de la relación, bien porque todavía ama a su pareja, bien porque se siente comprometida con él. Los periodos de aparente calma entre los episodios violentos consiguen que la mujer albergue la esperanza de que éstos no vuelvan a producirse. Para que una mujer abandone la relación de maltrato, es condición sine qua non que adquiera conciencia de ser mujer maltratada.

"Uno de los obstáculos para que las mujeres se marchen de casa y busquen ayuda externa es que, éstas no se definen a sí mismas como las mujeres maltratadas que son. Es posible que una mujer crea que no conoce a nadie que pase o haya tenido que pasar por lo mismo que ella y no se atreva a ponerle un nombre a su experiencia. Puede que los mensajes culturales, familiares y/o religiosos hayan calado en ella, en el sentido de 
creer que su situación es parte del matrimonio y no debe poner por delante de éste sus propias necesidades o su seguridad personal." (Mullender, 2000, p.87)

En el trabajo de Blanco García (2006), Violencia de Género: Víctimas, Verdugos y Propuestas de Actuación, se expone que, curiosamente, las mujeres que han sido víctimas de delitos de maltrato por sus parejas se convierten en aquellos sujetos a los que se les aplica el tratamiento y esta situación es bien patente en las casas de acogida, es decir, en este caso la prevención o tratamiento va dirigido a modificar las conductas de las propias víctimas, lo que nos hace inferir que algún papel desempeñan en la comisión del acto.

Hemos de tener presente que no es fácil abandonar una relación, porque al margen de las cuestiones emocionales, la parte práctica de la decisión obliga a las mujeres a resolver su situación en el plano económico.

"A lo largo de la ocurrencia de los malos tratos, surgen obstáculos importantes para marcharse de casa. Con frecuencia, la mujer no tiene a dónde ir o no sabe que existen lugares a los que puede recurrir. Lo más probable es que la mujer no tenga dinero propio o que no conozca sus derechos con respecto a los bienes del matrimonio, o que sienta un miedo justificado a la pobreza y el aislamiento que esperan a una madre sola con sus hijos. Puede que le preocupe perder su casa y todas sus posesiones al marcharse.

Otro de los temores que atenazan a estas mujeres es la posibilidad de perder a sus hijos, en el caso, por ejemplo, de que se los lleve con ella sin disponer de un alojamiento adecuado; o de que necesite ayuda externa para cuidarlos; o de que los deje en casa con el marido." (Mullender, 2000, p.89)

Encontramos mujeres de todas las nacionalidades compartiendo la experiencia del maltrato. En contextos sociales, económicos y culturales 
dispares, es posible advertir el maltrato en sus diversas modalidades y en el control económico que sufren las mujeres.

Indiscutiblemente y a tenor de los resultados estadísticos, el tema de la violencia de género, cobra cada vez más protagonismo en el ámbito de lo público. No obstante a pesar de lo objetivo o lo cuantificable, a pesar de las sentencias judiciales y las órdenes de alejamiento quebrantadas, aún hay quien se cuestiona si el fenómeno está tan extendido como parece, o si en realidad nos encontramos frente a simples disputas de pareja, con demasiado pábulo en los medios de comunicación.

La violencia física, aunque resulta generalmente más evidente y hay mayor conciencia sobre ella, no siempre es más grave que otras formas de violencia: psíquica, económica, sexual..., todas ellas tienen el mismo objetivo que es condicionar, limitar o doblegar la voluntad de la mujer, además de ser métodos de violencia que suelen darse de forma simultánea.

El proceso, la estrategia de maltrato tiene por objeto dominar sistemáticamente a una de las partes: la víctima, la mujer. Ésta cada vez es más débil, está más deteriorada, se siente más indefensa. El maltratador, en cambio, cada vez va más lejos y actúa con más saña, como si la violencia se alimentara a sí misma como consecuencia del refuerzo positivo que supone. Con el acto violento consigue cada vez más fácil su deseo, lo que unido a la escasa penalización de su conducta, hace que descubra su impunidad.

"La violencia en los hogares tiene una historia nada reciente. La premisa de que la violencia -específicamente la violencia en la familia- va en aumento, si no es falsa, por lo menos sí es cuestionable. Una cosa es que cada vez se hable más del tema y otra muy distinta que el fenómeno sea nuevo". (Torres Falcón, 2001, p.19) 


\subsection{9.- Las feministas odian a los hombres y las casas de acogida rompen matrimonios.}

Los recursos como las casas de acogida, han de entenderse como la oportunidad para rehacer la propia vida, más que como la última alternativa para la mujer víctima; por eso es importante que estos centros partan de un objetivo práctico basado en la independencia. Independencia necesariamente abordada tanto desde el ámbito económico y laboral, como desde el afectivo-emocional. La búsqueda activa del empleo, que tiene como meta la incorporación de la mujer al mundo del trabajo, se convierte en una de las estrategias fundamentales para la independencia, no sólo de carácter económico, sino también la de carácter psicológico.

Cabe señalar que en la década de 1970 la violencia contra las mujeres en la pareja comenzó a denunciarse de forma específica como problema y nació en Inglaterra el denominado movimiento de mujeres maltratadas, con el establecimiento de una primera casa de acogida (1971), que fue seguida por la apertura de una segunda en Holanda (1974) y luego por muchas más en Estados Unidos. Jovani Roda, Marti Ferrer, Segarra Gali y Tormo Jarque, (1994) y Pagelow (1987).

A finales del siglo $X X$, una vez más, las feministas llevan a la agenda política estas cuestiones y es a partir de la segunda mitad de la década de 1980, cuando la atención general comenzó a dirigirse hacia estas cuestiones, cuando las feministas europeas comenzaron a presionar a sus gobiernos para que reformaran las leyes sobre violencia contra las mujeres y para que crearan o ampliaran las redes de casas de acogida y los mecanismos de atención a las víctimas (Anderson y Zinsser, 2000)

Una vez más en este trabajo, se hace alusión al movimiento feminista reconociéndole el mérito de haber hecho visible, tanto el problema social como las consecuencias personales que implica la violencia de género. 
"La respuesta fundamental del feminismo a la violencia doméstica ha sido, además de la denuncia, provocar el paso desde la privacidad a la agenda política, a la agenda pública, llevar a la calle y a los medios de comunicación aquello que sucedía entre las cuatro paredes de las casas y exigir soluciones. El camino no ha sido fácil, no sólo por las dificultades que el feminismo ha tenido para presentar sus temas como claves para la sociedad, sino también porque la violencia ha sido y es uno de los asuntos en los que con cierta facilidad las instituciones políticas han asumido los aspectos externos del problema, sin cuestionar a fondo sus raíces". (Posada Kubissa, 2001, p.31)

La línea básica del pensamiento feminista ha analizado la violencia como fruto de la estructura patriarcal de la sociedad que incluye familia, relaciones sociales, ideología y política. En el ámbito familiar, a las mujeres se les transmite una determinada visión de su destino basada sobre todo en la condición de esposas y madres, otorgándoles unos roles y unos espacios determinados.

Como dice Álvarez (2001, p.165), "la violencia contra la mujer es el instrumento universal del patriarcado para sustentar los privilegios masculinos".

Ante la violencia contra las mujeres, las organizaciones feministas han trabajado tanto en su denuncia como en la organización de centros y entidades para luchar, acoger y ayudar a las mujeres. En los años setenta del siglo XX, las asociaciones feministas consideraban esta acción como una más en una visión más amplia relacionada con el cambio social y cultural, como se correspondía al movimiento feminista de aquellos años. Pasado el tiempo, las administraciones han puesto más medios y han subvencionado frecuentemente a estas entidades feministas que, por otro lado, también han ido evolucionando, desde movimientos sociales hacia organizaciones de un servicio social. 
Marugán y Vega (2001), analizan la evolución del pensamiento y acción de los grupos feministas respecto a la violencia contra las mujeres. A partir del derecho al propio cuerpo, con el debate sobre el aborto como centro, se insiste cada vez más en la libertad de las mujeres a vivir tranquilas en cualquier espacio y en cualquier tiempo. Las agresiones se convierten en uno de los centros de la lucha feminista en los ochenta.

"El código penal acabó siendo el eje central del trabajo feminista de finales de los 80 . Parte de las reivindicaciones se asumieron formalmente en los textos legales, las administraciones tuvieron una participación mucho más activa, especialmente a través de los distintos Institutos de la Mujer, y los medios de comunicación (más que las organizaciones feministas) han sido los que han trasladado el tema a la opinión pública". (Marugán y Vega, 2001, p.124)

"El movimiento feminista pasó, a finales de los 90, de ser el movilizador principal de las conciencias acerca de este problema, a un enunciador de segundo orden, cediendo ante el nuevo papel de los medios de comunicación". (Marugán y Vega, 2001, p.127)

Las teorías feministas más actuales van en tres direcciones:

- Analizar qué funciona y qué no a la hora de reducir la violencia, por ejemplo las casas de acogida o los servicios sociales.

- Examinar el sistema político y judicial, y su funcionamiento.

- Reelaborar el significado de la violencia contra las mujeres como ataque a los derechos humanos y sus implicaciones concretas.

La familia es un mito que aparece en la literatura, películas, publicidad... Se muestra solo lo positivo de la familia ocultando el resto, y así muchas personas piensan que es sólo en su familia donde las cosas van mal. Pero las familias no siempre fomentan la individualidad, el respeto a las diferencias, ni se motiva, ni se protege. Todavía es habitual el cachete 
porque "se lo estaba buscando" o los castigos porque son "malas", "por su bien". Esto lo aplica el hombre violento a la mujer sobre la que considera que tiene derecho a educar y corregir.

La mayor parte de las violaciones a menores se realizan por el padre, el hermano, el tío, el abuelo o por un conocido próximo a la familia. Las mujeres tienen más peligro en la casa que fuera de ella, tienen más riesgo con los maridos o parejas actuales o pasadas, que con los extraños. Por lo que no es razonable dar por hecho que la familia y allegados ayudan y apoyan a la mujer.

"Cuando a Lorente Acosta (2005) le preguntan cuáles son las características, el perfil del agresor él lo tiene claro; el perfil del agresor es: hombre, varón de sexo masculino. Dice que no hay un perfil, no hay una conducta, una alteración, un rasgo psicológico que le lleve a maltratar, a ejercer la violencia continuada y sistemática como mecanismo y elemento de control. No existe esa patología. Pueden existir elementos, rasgos, o trastornos o enfermedades de la personalidad o mentales que puedan favorecer la respuesta impulsiva, la dificultad para el autocontrol, etc., pero el ejercicio sistemático, continuado y mantenido de la violencia para obtener beneficios no deriva de una patología sino que deriva de una voluntad, y esa voluntad es la que desarrolla el agresor cuando quiere conseguir esos objetivos basándose en la violencia". (VV.AA, 2009, p. 36)

En ocasiones, es la familia la que inculca a la mujer que es ella la máxima responsable de mantener la familia unida, que debe cuidar no solo de las hijas e hijos sino también del marido y hasta acusan a la propia hija o hermana de no saber complacer lo bastante, de no ser adecuada, de provocar parte o toda la situación.

"Los servicios sociales o centros de atención a la mujer, servicios gestionados por los ayuntamientos, pueden brindar una ayuda eficaz. En estos centros se recibe el apoyo para poder verse a sí misma y ver la relación desde otra perspectiva para valorar cuál es la mejor salida. 
Dependiendo de la gravedad de la situación, si la mujer necesita protección podrá ir a una casa de acogida, como un paso intermedio hacia la separación definitiva y la independencia”. (Cárdenas y Ortiz, 2005, p.151)

\subsubsection{0.- Hay muchos hombres maltratados.}

Estamos ante el mito del síndrome del hombre maltratado. Cuando se habla del tema de la violencia de género en público, ya sea en una emisora de radio, una conferencia o un curso, es frecuente la intervención de alguien interesándose por los hombres maltratados. Estas intervenciones afirman que hay casi tantos como mujeres y que, por otra parte, las mujeres suelen maltratar más psicológicamente.

Vamos a intentar aclarar de dónde proviene el mito del hombre maltratado por la mujer, y qué ocurre en realidad con los malos tratos ejercidos por mujeres.

Straton (2010), profesor de la Universidad de Portland, participa con varios artículos en la valiosa web europea "European Men Profeminist" (www.europrofem.org). Según explica Straton, es tal el encarnizamiento supuestamente humanitario y científico del Lobby masculino, que pretenden que se desvíen parte de los fondos dedicados a la asistencia a mujeres maltratadas y a casas de acogida, a servicios y casas para hombres maltratados por las mujeres. Por otra parte, están dedicando tiempo y dinero a investigaciones pseudocientíficas que intentan demostrar que los malos tratos son equiparables entre hombres y mujeres. El ataque más vengativo contra la seguridad de la mujer es el mito de que el hombre es maltratado con la misma frecuencia que ella. 
Straus, Gelles y Steinmetz (1980) publicaron en Estados Unidos estudios de conflictos entre esposos, obteniendo que las tasas de violencia eran casi las mismas para hombre y mujer. Presentaron como prueba los resultados del CTS, primer instrumento psicométrico que supuestamente media violencia física y psicológica entre hombre y mujer.

Straus presenta un conjunto de preguntas que no discriminan entre intento y efecto. Iguala a una mujer que empuja a su pareja en defensa propia al hombre que la tira por las escaleras. Etiqueta a una madre de violenta si defiende a su hija del acoso sexual del padre. Combina categorías como "pegar" e "intentar pegar" a pesar de la importante diferencia entre ellas. Como sólo estudia un año de convivencia, iguala a una simple bofetada de la mujer al hombre, con quince años de terrorismo doméstico, el CTS ignora la diferencia entre una bofetada dolorosa y un puñetazo que causa una lesión permanente.

Straus sólo entrevistaba a uno de los componentes de la pareja. Otros estudios que entrevistaron independientemente a los dos componentes encontraron que sus relatos sobre la violencia no concordaban.

Excluyó incidentes de violencia que ocurrieron después de la separación y el divorcio; aunque en ellos se contabilizaron un 75,9\% de agresiones, siendo el 93,3\% de las veces el agresor el hombre según el Departamento de Justicia de Estados Unidos.

El estudio de Straus se basó en lo que decían los participantes, sin tener en cuenta que está demostrado que los hombres que maltratan niegan o minimizan su maltrato en un $50 \%$.

Finalmente, el CTS no incluye la agresión sexual como una categoría, aunque hay muchas más mujeres violadas por sus maridos que sólo pegadas. Ajustando las estadísticas de Straus y corrigiendo estos fallos sale una proporción de 16 a 1 para la violencia del hombre a la mujer. Según la 
policía y los tribunales, del 90 al $95 \%$ de las agresiones son hechas por los hombres a sus parejas.

Straus dijo que las mujeres denunciaban más el maltrato, por lo que la muestra podía estar sesgada.

Por supuesto, los pocos hombres (4\%) auténticamente maltratados por sus mujeres son dignos de compasión, pero es mucho más lógico y sensato focalizar nuestra atención y trabajo en el vasto problema de la violencia masculina (96\% de la violencia doméstica).

Aunque hombres y mujeres pueden pegarse unos a otros, las mujeres inevitablemente sufren unas consecuencias físicas mayores. Además, las mujeres maltratadas sufren más consecuencias emocionales y psicológicas que los hombres.

¿Cuáles son las diferencias entre el maltrato masculino y el femenino?

Según Bagshaw y Chung (2000) de la Universidad South Australia, las formas en las que las víctimas masculinas experimentan la violencia doméstica difieren de cómo la experimentan las mujeres. Los hombres...

- Relatan que no vivían en un continuo estado de terror de la agresora.

- No tenían experiencias previas de malos tratos.

- Raramente experimentaron violencia después de la separación.

- No se sentían intimidados o temerosos, sino más bien coléricos ante la violencia de ella.

Aunque hay evidencias de que ambos, hombre y mujer, se comportan a veces violentamente en sus relaciones, la naturaleza y las consecuencias de la violencia de la mujer no son equivalentes en absoluto a las del hombre.

- La violencia del hombre es más severa. 
- Es más probable que las mujeres sean asesinadas por su pareja actual o anterior, que por otras personas.

- La mayoría de homicidios de hombres son realizados por otros hombres, en lugares públicos y casi siempre con la excusa del alcohol.

- Las principales razones por las que el hombre mata a su pareja mujer son porque ella lo deja y por celos. Sin embargo, las mujeres que matan a sus parejas tienen una historia previa de violencia doméstica con ellas, en más del $70 \%$ de los casos. La mitad de los asesinatos al marido ocurre como reacción a una amenaza inmediata de ataque por parte de él.

- La violencia psicológica del hombre hacia la mujer consiste en control, humillación y dominación, por medio del miedo y la intimidación.

- La violencia psicológica de la mujer hacia el hombre consiste en una expresión de la frustración en respuesta a su dependencia, estrés o rechazo a aceptar una posición sumisa de menos poder.

- Análisis de los datos sobre homicidios sugieren que las mujeres usan la violencia principalmente como defensa propia, y en segundo lugar como represalia después de años de brutal victimización. Además, es seis veces más probable que las mujeres sean lesionadas a que lo sean los hombres.

The Illinois Clemency Proyect es un proyecto para la liberación de prisión de mujeres maltratadas que han matado o lesionado a sus compañeros maltratadores. En su página web ${ }^{11}$, entre otras muchas cosas, presentan algunos datos sobre mujeres que han matado a sus compañeros

${ }^{11} \mathrm{http} / / /$ clemencyproject.com/ Revisado el 22 de diciembre del 2011 
maltratadores y hacen un acertado análisis de las diferentes defensas posibles de una mujer maltratada cuando mata a su compañero.

- El $90 \%$ de las mujeres que están en prisión por matar a un hombre habían sido maltratadas por ese hombre.

- La condena media (en Michigan) para un hombre que mata a su compañera es de 2 a 6 años. La condena media para una mujer que mata a su compañero es de 15 a 17 años.

- Los fiscales y jueces mostraban su desconocimiento de la violencia de género, cuando repetidamente recriminaban a la mujer maltratada por no dejar a su compañero. Una mujer maltratada que consigue finalmente dejar la relación, antes suele haber hecho de cinco a siete intentos de irse, solamente irse; nunca es tan fácil para estas mujeres como sugiere el fiscal. El vínculo traumático puede no ser la única razón para que la mujer se resista a dejar al maltratador. Ella puede tener la convicción, totalmente razonable, de que si lo deja la lesionará o matará.

- Según Sir William Blackstone, cuando un marido mata a su mujer es comparable a matar a un extraño; pero cuando ella lo mata a él es comparable a traición por matar al rey.

Existe el mito de que muchas mujeres maltratadas matan a sus maltratadores cuando ellos están dormidos. En realidad, el $70 \%$ de las mujeres maltratadas que matan a sus maltratadores lo hacen durante una confrontación con él. Se puede, por tanto, considerar defensa propia.

Si se da el caso de que él está durmiendo, alguien podría pensar que la amenaza no es inminente.

Según la ley, a la mujer no se le permite defenderse con un arma hasta que el maltratador la pegue lo bastante severamente para que quede 
claro que es inminente la muerte o un daño corporal grave. Llegado ese momento ella ya estará totalmente indefensa. Los principios tradicionales de la defensa propia están hechos por y para hombres, y se supone que los contendientes tienen fuerza y tamaño parecidos. El caso en que él duerme debería considerarse defensa propia que la mujer lo mate si ella actúa bajo la creencia honesta y razonable de que en el momento en que él despierte la matará y de que si ella espera estará mucho menos capacitada para defenderse.

"Gestos sutiles que pueden no significar una amenaza para un extraño, pueden ser reconocidos por la mujer maltratada como un signo de que está en un peligro grave e inmediato. Los maltratadores llevan a veces objetos que no son considerados como armas letales (puños, llaves, libros, botellas, comida caliente, etc.), pero que la investigación y el sentido común dicen que pueden ser amenazantes, y mucho más si la persona que lo esgrime es alta y fuerte". (Barea, 2004, p.222)

La sociedad ha adoptado, de forma generalizada, la creencia de que quienes ejercen la violencia psicológica en mayor medida son las mujeres, se piensa que los hombres golpean, pero las mujeres agreden de forma más insoportable, ellas son celosas, posesivas, humillan, ofenden, ridiculizan... son ejecutoras de tortura emocional. Cabe preguntarse qué hay de verdad en esta creencia tan extendida y la respuesta ha de tener presente las relaciones de poder que implican desigualdad en la pareja.

"Se conocen muchos casos de mujeres psicológicamente maltratadas, pero muy pocos de hombres, por lo que la afirmación de que las mujeres son más violentas en el terreno del asedio y el abuso verbal no es más que una especulación". (Torres Falcón, 2001, p.135)

En cuanto a los celos se refiere, se observa cómo se esgrime este argumento en contra de las mujeres, como una de las supuestas causas de maltrato hacia los hombres, sin embargo, a poco que nos detengamos en los hechos reales que marcan el funcionamiento de gran parte de las parejas, 
estadísticamente se contempla que son ellos los que protagonizan las infidelidades, socialmente aceptadas, por otra parte, constituyendo una forma de conseguir status, mientras que las mujeres aprenden a tolerarlas fingiendo que no existen. Sin embargo la otra cara de la moneda, la encontramos en los hombres celosos que son capaces de terminar con la vida de sus compañeras, porque se consideran dueños de ellas.

\subsubsection{1.- Si tienen hij@s es mejor que aguanten.}

Horno Goicoechea (2005), como psicóloga responsable de los programas de violencia contra la infancia de Save the Children ${ }^{12}$ y coordinadora estatal de la investigación "Atención a los niños y niñas víctimas de violencia de género", del programa de prevención de abuso y explotación sexual infantil y de la campaña "Corregir no es pegar" contra el castigo físico a los niños y niñas ${ }^{13}$; asegura que en los últimos años, tanto en el ámbito estatal así como en las distintas Comunidades Autónomas se han tomado las medidas específicas para afrontar el fenómeno de la violencia de género, que discurre paralelo al de la violencia contra los niños y niñas y cuya dimensión lo ha convertido en motivo justificado de alarma social.

Las medidas tomadas van en la misma línea de las demandas que Save the Children y otras organizaciones que trabajan en la erradicación de la violencia contra la infancia llevan años demandando: una legislación

\footnotetext{
${ }^{12}$ www.savethechildren.org/ Revisado el 22 de diciembre del 2011

${ }^{13}$ La campaña "Corregir no es pegar" es una iniciativa de la organización Save the Children y el Ministerio de Trabajo y Asuntos Sociales cuyo objetivo es sensibilizar y formar a madres y padres, profesionales de los ámbitos sanitario, educativo y social, medios de comunicación e instituciones con competencias en materia de infancia y familia sobre la necesidad de erradicar el castigo físico a los niños y promocionar las alternativas de disciplina existentes
} 
adecuada, protocolos de actuación conjunta que garanticen una intervención coordinada interdisciplinar e interinstitucional eficaz, la dotación de los recursos necesarios y suficientes, la profesionalización y formación específica de los y las profesionales responsables de la atención, la rapidez en los procedimientos y la priorización de la actuación cara a las víctimas.

Todo ello es para Save the Children motivo de esperanza, puesto que prueba que cuando la conciencia y la decisión política se unen, los cambios son posibles, tanto más cuando hablamos de niños y niñas cuya protección ha de ser responsabilidad prioritaria de las instituciones involucradas.

Cuando se habla del "síndrome de mujer maltratada"14 se reconoce que estas situaciones "afectan también a los menores que se encuentran dentro de su entorno familiar..." Sin embargo, el desarrollo de la Ley y de los recursos que su aplicación y puesta en marcha ha generado, ha llevado a Save the Children a una preocupación básica: la atención a los menores hijos e hijas de mujeres víctimas de violencia de género.

Save the Children entiende que los niños y niñas, hijos e hijas de las mujeres víctimas de violencia de género son víctimas directas de la misma, de violencia psicológica y a veces también física. Los niños y niñas son víctimas de la violencia de género. Lo son como víctimas directas de violencia en muchas ocasiones, como víctimas indirectas porque presencian la violencia entre sus padres o simplemente porque viven en un entorno donde las relaciones violentas y el abuso de poder, que justifica, legitima y desencadena la violencia como parte de las relaciones afectivas personales, internalizando un modelo negativo de relación que daña su desarrollo. Ven y sufren a una madre maltratada, en vez de protectora. Ven y sufren un padre maltratador, en vez de protector.

\footnotetext{
14 Exposición de motivos de la Ley Orgánica 1/2004 de Medidas de Protección Integral contra la Violencia de Género. (España. Ley Orgánica 1/2004 de Medidas de Protección Integral contra la Violencia de Género)
} 
En este punto resulta significativo constatar que la conciencia de víctima necesaria en mayor o menor medida, para entrar en contacto con el sistema, no ha de ser consonante entre las madres y los niños y niñas. Una mujer puede dar el paso y ser consciente de la violencia de su pareja y sus hijos e hijas no serlo, y viceversa, existen niños y niñas conscientes de ser víctimas de violencia de género pero que difícilmente pueden tomar medidas para salir de ello si sus madres no llegan a hacer consciente el problema y toman las medidas necesarias para ello.

Si entendemos a los niños y niñas como víctimas, es necesario dar el siguiente paso y plantearnos si el sistema que hemos creado para atender a las víctimas de la violencia de género atiende y contempla de forma suficiente y adecuada sus necesidades. Hemos de entender que garantizando los derechos de las mujeres víctimas de violencia de género, protegemos los de sus hijos e hijas pero hacen falta medidas adicionales específicas para atender sus necesidades.

Todos los profesionales entrevistados en el marco de la investigación desarrollada por Save the Children, los congresos en los que se ha participado y los grupos de trabajo de profesionales del sistema de protección a la mujer, reconocen que las niñas y niños son víctimas de la violencia de género, en todos los casos psicológica y a veces también física directa.

Pero es interesante un dato más allá, darse cuenta que el cuadro de síntomas que describen y que se cita a continuación es similar al de un menor víctima de maltrato físico o emocional. $Y$ además, existe una percepción generalizada del riesgo de que los niños repitan patrones de violencia vividos en su familia como uno de los efectos que se evalúan como más graves.

Los efectos de la violencia de género en los niños y niñas identificados por los profesionales son los siguientes (Congreso: Abordaje Integral de la Violencia de Género, 2007): 
- Problemas de socialización: aislamiento social, dificultad para establecer relaciones personales conductas agresivas 0 auto agresivas...

- Problemas escolares: bajo rendimiento, problemas de atención y concentración, agresiones entre iguales (como víctimas y como agresores)

- Síntomas de estrés postraumático: trastornos del sueño, fobias, trastornos alimenticios, ansiedad, ataques de pánico...

- Conductas regresivas.

- Síntomas depresivos y de ansiedad.

- Alteraciones de desarrollo afectivo: modelos de vinculación erróneos en los que violencia y amor van unidos, manejo del poder sobre otros...

- Rechazo a la madre: culpándole por no haberles protegido, culpándole de la separación y de las medidas de protección, incluido el ingreso en el centro.

- Conductas agresivas y retadoras a otros (madre, educadores u otros niños) Los primeros días los niños y niñas parecen excesivamente inhibidos, pero en la segunda o tercera semana surgen los conflictos y las conductas agresivas.

- Parentalización de los niños: asunción de roles adultos en un intento de proteger a sus madres...

- Gran apego a los profesionales.

- Evaluación constante del compromiso de los profesionales en busca de la seguridad. 
- Combinación del rechazo a la madre con la proyección en una educadora de "la madre ideal".

- Internalización de roles violentos o de género equivocados: hemos de ser cuidadosos y no creer que los patrones de género se transmiten por el sexo. Hay niñas que reproducen patrones de agresión y niños de víctima.

Existen secuelas que arrastrarán a lo largo de su vida, los adultos/as que en su infancia hayan vivido situaciones de violencia de género. Emparejarse, para estas personas, no va a resultar una tarea sencilla, puesto que suelen mostrar fuertes lazos de unión con el/la progenitora, y para ésta compartir con otra persona a su hijo/a, puede ser vivido como una gran pérdida, lo cual no va a facilitar el camino para las relaciones de pareja.

"Son chicos carenciados en la protección hacia sí mismos y hacia los otros, con muchas dificultades para aceptar los límites y con necesidad de sentirse queridos incondicionalmente, como únicamente los padres lo saben hacer. Asimismo, estos niños/as no saben cómo manejar sus emociones. Han crecido con el miedo metido en el cuerpo y ésta es una funesta experiencia, que sobrepasa la capacidad del niño de regular las emociones. El miedo es una emoción que prevalece sobre las otras y provoca un estado de alerta y el paso a la acción a través de mecanismos poco controlables". (Cárdenas y Ortiz, 2005, p.52)

El comportamiento violento aprendido en la niñez suele aflorar en la vida adulta. No obstante la hipótesis del comportamiento aprendido, deja abiertos caminos que invitan a continuar en la línea de la investigación metodológica, porque con lo que se conoce hasta ahora, sólo es posible afirmar que algunos hombres reproducen el comportamiento violento que observaron en su infancia y que algunas mujeres se relacionan con hombres golpeadores, tal como lo hicieron sus madres. Es decir, haber presenciado o 
sufrido violencia en una etapa temprana de la vida es un factor que puede influir en el comportamiento posterior, pero no es el único ni es determinante.

"La tesis de los comportamientos aprendidos señala que las causas de la violencia están en la niñez, porque los menores presencian la violencia entre sus padres o bien porque la sufren directamente. El comportamiento se repite de generación en generación. De acuerdo con esta idea, los niños aprenden que la violencia es una prerrogativa del padre que podrán ejercer cuando sean adultos, en tanto que las niñas interiorizan una suerte de resignada aceptación ante la inevitabilidad del maltrato. Unos y otras, en sus relaciones de pareja, reproducen lo que aprendieron en la infancia. En apoyo de esta idea se señala que en varias investigaciones ha podido comprobarse que una tercera parte de los hombres golpeadores habían sufrido maltrato en su infancia."(Torres Falcón, 2001, p. 229)

\section{2.- Concepto de Violencia de Género.}

Comenzaremos este apartado haciendo una aclaración conceptual que creemos esencial para entender el resto del contenido, según Blanco García (2006) Violencia y agresividad, no son sinónimos. La agresividad es una potencialidad de todo ser vivo, que les permite vencer dificultades, abrirse camino en la vida y reproducirse sobre la tierra. La violencia, por su parte, es un producto característicamente humano, es decir cultural, que se compone de una serie de conductas destinadas a obtener el control y la dominación sobre otras personas. Actúa por tanto, mediante el uso de operaciones que causan daño o perjuicio físico, psicológico o de cualquier otra índole. Como es un producto humano, construido socialmente, podemos 
evitarla y al analizarla debemos situarla en el terreno de lo contingente. Es decir, lo inevitable es la agresividad, pero no la violencia.

$(O N U, 1993)^{15}$ Define la violencia de género como: todo acto de violencia basado en la pertenencia al sexo femenino que tenga o pueda tener como resultado, un daño físico, sexual o psicológico para la mujer, así como las amenazas de tales actos, la coacción o la privación arbitraria de la libertad, tanto si se produce en la vida pública como en la privada. Los trabajos más recientes nos invitan a intentar una aproximación más precisa de la definición de violencia de género.

\section{1.- En busca de una definición.}

En el Informe de la Comisión para la Investigación de Malos Tratos a Mujeres, celebrado en Madrid el 30 de noviembre del 2005, queda constancia que en España llevamos trabajando desde hace treinta años para erradicar la violencia que se ejerce contra la mujer por el mero hecho de serlo, y el trabajo que se ha desarrollado a lo largo de estos años, ha sido en el ámbito de la intervención con las mujeres que han sufrido el maltrato de manera directa en dos ámbitos: relaciones de pareja y agresiones sexuales. Sin embargo, no llevamos mucho tiempo trabajando en el cambio del modelo de relaciones entre hombres y mujeres, en la educación en igualdad, en la educación no sexista, que los informes reconocen como la mejor fórmula para prevenir la violencia contra la mujer.

\footnotetext{
${ }^{15}$ www.un.org/es/rights/ Revisado en diciembre del 2011
} 
A continuación, describimos diversas formas de violencia contra las mujeres. No son definiciones legales, sino aproximaciones conceptuales, que pueden facilitar su comprensión.

La mayoría de la literatura sobre el tema, coincide en señalar que la violencia contra las mujeres adopta principalmente tres formas: física, psicológica y sexual. (Bosch y Ferrer, 2002)

Existen malos tratos cuando la violencia que se ejerce contra la mujer se lleva a cabo en el ámbito familiar o doméstico, por personas de su entorno: marido, compañero, padre, hijos o hermanos.

\section{Los malos tratos pueden ser:}

Psíquicos: aquellos actos o conductas que producen desvalorización o sufrimiento en las mujeres. Pueden comprender amenazas, humillaciones, exigencia de obediencia, tratar de convencer a la víctima de que ella es la culpable de cualquier problema. Así mismo, incluye conductas verbales coercitivas como los insultos. El aislamiento, el control de las salidas de casa, descalificar o ridiculizar la propia opinión, humillaciones en público, así como limitar y retener el dinero, son formas de maltrato.

Físicos: este tipo de violencia comprende cualquier acto no accidental, que provoque o pueda producir daño en el cuerpo de la mujer, tales como: bofetadas, golpes, palizas, heridas, fracturas, quemaduras...

Sexuales: siempre que se imponga a la mujer una relación sexual contra su voluntad. Si bien, cuando en esa relación se produzca una penetración forzada, se considera violación.

Estos tres tipos de violencia, física, psíquica y sexual suelen combinarse y es muy difícil separar o encontrar solamente uno de los tres tipos en una pareja donde existe violencia.

Otros tipos de violencia son: 
Las agresiones sexuales, que comprenden aquellas conductas sexuales donde se utiliza la fuerza o intimidación.

La violación comprende toda penetración, por la vagina, el ano o la boca, usando la fuerza o intimidación. También se considera violación la penetración con objetos. Cuando una mujer haya sido forzada a realizar estos actos por un amigo, compañero o esposo, se considera igualmente violación.

Los abusos sexuales a menores, hacen referencia a las actitudes y comportamientos que un adulto realiza para su propia satisfacción sexual, con una niña, niño o adolescente, empleando la manipulación emocional como chantajes, engaños, amenazas, etc. $Y$ en algunos casos, la violencia física. Los abusos sexuales contra las niñas abarcan comportamientos como el exhibirse desnudo delante de la menor con el fin de excitarse sexualmente, observar a la niña vestirse o desvestirse o cuando está en el baño. Tocarla, besarla, o agarrarla..., así como forzarla a tocar al adulto, realizar sexo oral, vaginal o anal. Obligarla a ver imágenes o películas, efectuar exploraciones médicas innecesarias con el fin de que el profesional se excite sexualmente, etc. Se llama incesto cuando los abusos sexuales son llevados a cabo por el padre, el padrastro, un hermano o cualquier pariente cercano.

El acoso sexual comprende todo comportamiento sexual considerado ofensivo y no deseado por la persona acosada desarrollado en el ámbito laboral, docente o similar, utilizando una situación de superioridad o compañerismo y que repercute en sus condiciones de trabajo o estudio, creando un entorno laboral o de aprendizaje hostil, intimidatorio o humillante.

Sin embargo, y aunque ésta sea la diferenciación más común, tomando como base la propuesta del Consejo de Europa (1997), frecuentemente se añaden a éstas otras formas de violencia, dando lugar a la descripción de los siguientes tipos: 
Violencia física: Toda acción realizada voluntariamente que provoque o pueda provocar daños y lesiones físicas en las mujeres. Incluye el uso de la fuerza física o de objetos para atentar contra su integridad física (empujones, tirones de pelo, bofetadas, golpes, patadas, pellizcos, mordiscos, mutilación genital, tortura, asesinato...)

Violencia sexual: Cualquier atentado contra la libertad sexual de la mujer por el que se obliga a soportar actos de naturaleza sexual o realizarlos. Incluye cualquier acto o expresión sexual realizado contra su voluntad que atente contra su integridad física o afectiva como bromas, expresiones groseras, comentarios desagradables, llamadas telefónicas obscenas, propuestas sexuales indeseables, forzarla a ver pornografía, cualquier acto o relación sexual no consentida por la mujer (acoso, violación, incesto), cualquier relación o acto sexual que la mujer considere humillante o doloroso o la obligación de prostituirse.

Violencia psicológica: Acción, normalmente de carácter verbal o económico, que provoca o puede provocar daño psicológico en las mujeres. Incluye el empleo de mecanismos de control y comunicación que atentan contra su integridad psicológica, su bienestar, su autoestima o su consideración, tanto pública como privada, ante las demás personas, como podría ser: denigrarla, despreciar lo que hace, hacer que se sienta culpable, tratarla como si fuera una esclava, hacer comentarios desatentos sobre su físico, humillarla en público o en privado, crearle una mala reputación, obligarla a rendir cuentas sobre sus relaciones o contactos con otras personas, obligarla a romper sus amistades, prohibirle habar con personas del otros sexo, mostrar celos de las amistades de ella, limitar su espacio vital o no respetarlo, bromas y chistes machistas o de contenido denigrante, infravaloración de sus aportaciones o ejecuciones, insultos públicos 0 privados, las amenazas y la intimidación, el chantaje emocional, las amenazas de suicidio si la pareja manifiesta su deseo de separarse, etc. 
Violencia económica: Desigualdad en el acceso a los recursos compartidos. Incluye negarle y/o controlar su acceso al dinero común, generar dependencia económica, impedir su acceso a un puesto de trabajo, a la educación o a la salud, negarle los derechos de propiedad, etc.

Violencia estructural: Barreras intangibles e invisibles que impiden el acceso de las mujeres a los derechos básicos. Incluye la negación de la información inherente a los derechos fundamentales y las relaciones de poder en los centros educativos o de trabajo.

Violencia espiritual: Destrucción de las creencias culturales o religiosas de las mujeres mediante el castigo, la ridiculización o la imposición de un sistema de creencias ajeno al propio. Incluye el sometimiento e invisibilidad de las creencias culturales o religiosas de las mujeres o el analizarlas desde una perspectiva etnocéntrica.

Por otra parte, y también como consecuencia de la definición de la ONU, mencionada anteriormente, se considera que la violencia contra las mujeres no sólo adopta diferentes formas, si no que se da o puede darse en distintos contextos (Heyzer, 2000), son actos que se cometen tanto en el ámbito de las relaciones de pareja, como en el ámbito de la sociedad en general, como por ejemplo:

- Violencia en la familia (violencia doméstica): relaciones de pareja o noviazgo.

- Violencia en los conflictos armados.

- Violencia en la sociedad: agresiones sexuales y explotación y tráfico de mujeres.

- Violencia en el ámbito laboral: acoso sexual y bullying/mobbing

- Violencia en los medios de comunicación.

- Violencia institucional (perpetrada o tolerada por el estado) 
- Violencia en las tradiciones culturales.

Aún teniendo en cuenta las aclaraciones anteriores debemos poner de manifiesto que la definición de violencia de género más ampliamente aceptada es la de las Naciones Unidas, que es a la que nos ceñiremos en el presente trabajo, y que en su resolución de 20-12-1993 expone:

Artículo 2: Se entenderá que la violencia contra la mujer abarca los siguientes actos, aunque sin limitarse a ellos:

a) La violencia física, sexual y psicológica que se produzca en la familia, incluidos los malos tratos, el abuso sexual de las niñas en el hogar, la violencia relacionada con la dote, la violación por el marido, la mutilación genital femenina y otras prácticas tradicionales nocivas para la mujer, los actos de violencia perpetrados por otros miembros de la familia y la violencia relacionada con la explotación;

b) La violencia física, sexual y psicológica perpetrada dentro de la comunidad en general, inclusive la violación, el abuso sexual, el acoso y la intimidación sexual en el trabajo, en instituciones educacionales y en otros lugares, la trata de mujeres y la prostitución forzada;

c) La violencia física, sexual y psicológica perpetrada o tolerada por el Estado, dondequiera que ocurra.

Así definida, vemos cómo, la violencia contra las mujeres, es un fenómeno que interviene en todas las esferas de la vida; se desarrolla en la familia, influye en las formas de establecer las relaciones sexuales, afecta al mundo del trabajo, las formas de ocio, la cultura y los estilos de vida. A pesar de que con la democracia se produjo una quiebra de la legitimidad del patriarcado, lo cierto es que todavía estamos en un proceso de transición en el que, aunque el patriarcado ha perdido su legitimidad, no deja de tener vigencia. Ciertas formas extremas de violencia contra las mujeres pueden 
interpretarse como los últimos estertores de un sistema que se resiste a desaparecer.

\section{2.- Medidas contra la violencia de género. Historia de una ley.}

Durante los años 1998 y 1999, las organizaciones de mujeres que trabajaban en el estudio de la violencia de género y en la atención a las víctimas, plantean la necesidad de una Ley Integral contra este tipo de violencia. Su planteamiento es que se trata de un problema de Estado y que es necesario afrontarlo con políticas en todos los ámbitos.

En la campaña electoral del 2000 el Presidente del Gobierno, José María Aznar en aquel momento candidato del Partido Popular, se comprometió en una reunión con la Plataforma de Mujeres Artistas celebrada en el Palacio de la Moncloa el 9 de Febrero del 2000, a poner en marcha una Ley Integral en caso de llegar a gobernar, durante la campaña en diversas ocasiones también Javier Arenas asumió públicamente la propuesta.

En el mismo sentido se manifestó el PSOE, y así el Grupo Parlamentario Socialista presentó una moción en el mes de junio de ese año pidiendo al Gobierno que llevara a la Cámara una iniciativa legislativa en cumplimiento de este compromiso común. La moción fue rechazada.

EI PSOE inició los trabajos de elaboración de una Proposición de Ley Integral Contra la Violencia de Género, en la que participaron personas expertas en el ámbito jurídico (penal, civil, procesal, laboral), así como en el sanitario y educativo y sobre todo contó con las aportaciones de quienes 
desde el movimiento de mujeres llevaban años luchando contra la violencia de género.

El Grupo Parlamentario Socialista presentó además una proposición no de ley que pedía la creación de una Delegación del Gobierno contra la violencia de género, con rango de Secretaría de Estado. Esta propuesta también fue rechazada.

Estas dos iniciativas del PSOE, son importantes porque llevan el problema de la violencia contra las mujeres al mayor rango, tanto administrativo como en cuanto a derechos se refiere.

Regular las medidas contra la violencia por la Ley Orgánica significa que convertimos el vivir sin violencia en un derecho de las mujeres que el Estado tiene la obligación de cumplir. Significa que las personas tiene derecho a ser educadas en igualdad, que quienes atenten contra este derecho serán castigados, que las mujeres tienen derecho a su recuperación y a ser acogidas adecuadamente, por tanto nunca puede pasar que no puedan acceder a una Casa de Acogida porque no hay plazas, que tienen derecho a las ayudas económicas que regula la ley, por tanto nunca puede pasar que se acaban las ayudas porque no hay partida presupuestaria suficiente, que tienen derecho a la atención adecuada y especializada por parte de policía, jueces, personal sanitario y la comunidad en general.

Esta propuesta también es importante porque es integral, es decir afecta a todos los ámbitos que tienen que ver con la violencia de género, desde la prevención a la protección, a la atención sanitaria, social, laboral, etc. Y además hace posible la coordinación judicial.

Su debate tiene lugar el día 10 de Septiembre del 2002, con el siguiente resultado: 165 votos en contra, 151 a favor. Todos los grupos políticos apoyan la iniciativa a excepción del Grupo Popular que votó en contra. Mientras tanto las organizaciones de mujeres, constituidas en Red de Organizaciones Feministas contra la violencia de género, presentan en 
Madrid su campaña a favor de una "Ley Integral contra la violencia de género".

Además el día 4 de Septiembre del 2002, IU presentó una Interpelación Urgente al Gobierno, para su debate en pleno, con el objeto de que explique el balance de las medidas puestas en marcha hasta ahora y las que piensa adoptar para acabar con la violencia de género. Fruto de esta interpelación el día 11 de Septiembre presenta una moción.

Ante esto, todos los grupos políticos presentan enmiendas, pero sólo dos Grupos Parlamentarios plantean una enmienda de adicción a la moción que hace referencia a una ley integral. Estos grupos son Coalición Canaria y el Grupo Parlamentario Socialista. El PP por su parte presentó una enmienda, pero estas enmiendas a la moción no se aprobaron, porque ante las enmiendas presentadas, IU retiró su moción y se negoció un texto alternativo con el siguiente contenido:

"El Congreso de los Diputados aprueba construir, mediante el procedimiento reglamentariamente establecido, una Subcomisión, en el seno de la Comisión correspondiente, para concretar en el plazo máximo de 4 meses, la articulación de un Acuerdo entre todas las fuerzas con representación Parlamentaria, con el fin de formular medidas legislativas que den una respuesta integral frente a la violencia de género"

Este texto, aunque fue aprobado por todos los grupos de la Cámara, no conlleva implícitamente la puesta en marcha de una Ley integral contra la violencia.

"La ley Orgánica 1/2004, de Medidas de Protección Integral contra la Violencia de Género, sin embargo, no es, pese a su rotundo título y pese a las manifestaciones de su Exposición de Motivos, una Ley contra la violencia de género, en el sentido amplio recogido en la Conferencia de Beijing ${ }^{16}$, sino

\footnotetext{
${ }^{16}$ En la IV Conferencia Mundial sobre las Mujeres celebrada en Beijing (China), en Septiembre de 1995 , se reconoce que la violencia contra las mujeres es un obstáculo para la igualdad, el desarrollo
} 
una ley contra la violencia de género en el ámbito de las relaciones de afectividad, presentes 0 pasadas. Esto ha originado, determinadas confusiones en algunos sectores, que han hecho equivalente el concepto de violencia de género con el ámbito regulado por esta Ley, excluyendo del concepto y, por ello, desdibujándolo, pese a su firme asentamiento en la comunidad internacional, otros supuestos de violencia de género". (Marín López, 2007, p.167)

La Ley Integral expresa, inicialmente, la firme voluntad del legislador de incorporar a nuestro ordenamiento los compromisos internacionales previamente asumidos, coherentes con la afirmación de la titularidad de todos los derechos humanos por parte de todas las personas, sin distinciones basadas en factores de discriminación, y ello a través de una ley que, por primera vez, aborda la lacra de la violencia contra las mujeres en el ámbito doméstico de forma integral y multidisciplinar.

La publicación de las leyes, y, desde luego, también la de las penales, no supone el automático cambio de costumbres, egoísmos, comodidades y distribución de papeles jerarquizados construidos durante siglos, por lo que , sin perjuicio de la inmediata efectividad de las leyes, se exige un esfuerzo individual y colectivo en la común contribución a la construcción de una sociedad basada en nuevos valores, que no defina artificialmente la identidad de mujeres y varones de forma diferenciada y que afirme, por el contrario, la existencia de seres autónomos y libres, todos ellos titulares por igual de los mismos derechos y libertades.

No son las modificaciones que introduce la Ley en materia penal, de menor alcance del que, desde algunos sectores, se pretende conferirle, la estrella de la reforma legislativa sino que lo es su afirmado carácter integral, con concretas medidas al respecto y, muy especialmente, el acento que pone en una educación en los valores de igualdad entre hombres y mujeres

y la paz de los pueblos, impidiendo que las mujeres disfruten de sus derechos humanos y libertades fundamentales. 
y de corresponsabilidad en las tareas domésticas, en el respecto de los derechos y libertades fundamentales de todas/os, en el ejercicio de la tolerancia y de la libertad y en la educación en la resolución pacífica de los conflictos que permita la convivencia pacífica entre seres iguales, en la que el mero nacimiento con determinados atributos biológicos no implique la carga de roles de sometimiento y subordinación previamente atribuidos.

Todas las personas expresamos, en las manifestaciones de nuestra vida, determinados valores, también a través del lenguaje que sirve para nombrar el mundo y conformar la realidad a través de los valores que visibilizamos. De ahí que la modificación de pautas de comportamiento haya de alcanzar también, inexcusablemente, al lenguaje que utilizamos todos los días, lo que nos tiene que hacer reflexionar sobre si nombramos el mundo en femenino y en masculino, en función de las realidades y personas a las que nos queremos referir, o si continuamos utilizando un falso masculino genérico que por asentado que esté, resulta asimétrico o excluyente, por lo que sirve a mantener la discriminación. Por eso no es un tema menor en la batalla contra el prejuicio y a favor de la igualdad.

El pasado 29 de Junio, se cumplió el Sexto Aniversario de la creación de los Juzgados de Violencia sobre la Mujer por la Ley Orgánica de Mediadas de Protección Integral contra la Violencia de Género.

Se impone un balance, que en líneas generales es positivo, al haberse mejorado cualitativamente la respuesta judicial e institucional hacia las víctimas de la violencia de género, lo que evidencia el pleno acierto del legislador al diseñar en la ley la creación de estos Juzgados especializados.

En estos seis años de su andadura se han cumplido parte de los objetivos del legislador:

1) Garantizar la tutela judicial efectiva e inmediata a las mujeres que sufren violencia en el ámbito de la pareja o ex pareja, otorgándoles 
medidas cautelares de protección para garantizar sus derechos fundamentales básicos: la vida, la integridad física y la libertad.

2) Una mayor eficacia en la investigación y enjuiciamiento de los delitos de violencia de género, consiguiendo hacer desaparecer la sensación de impunidad que durante muchos años ha acompañado el fenómeno criminal de la violencia machista.

3) Terminar con la dispersión judicial al actuar de forma especializada y asumiendo una doble competencia penal y civil para la resolución de los conflictos que atañen a una misma víctima.

Cabe anticipar en este momento, sin embargo, la existencia de asignaturas todavía pendientes, seis años después de la promulgación de la Ley Integral:

1) Proceder a la comarcalización para posibilitar la creación de más Juzgados de Violencia sobre la Mujer exclusivos, esto es, aquellos cuyo conocimiento se centra exclusivamente en la instrucción de los delitos, enjuiciamiento de faltas, adopción de medidas cautelares, sentencias de conformidad en caso de delitos y resoluciones de asuntos civiles de derecho de familia en supuestos de violencia contra las mujeres, con competencias en varios partidos judiciales próximos geográficamente. Esta es una cuestión inaplazable, frente a la realidad actual en la que 375 del total de 458 Juzgados de Violencia sobre la Mujer, el $82 \%$, compatibilizan esta materia con cualesquiera otras propias de un Juzgado de Instrucción o de Primera Instancia e Instrucción, lo que genera muchas disfunciones debido a la sobrecarga de trabajo y a la imposibilidad de actuar como verdaderos órganos especializados y con los medios necesarios. 
2) La generalización de las Unidades de Valoración Forense Integral y su constitución efectiva, con la plantilla adecuada para abordar en plazo razonable los diferentes contenidos que les corresponden, algunos tan urgentes como la valoración pericial de la situación de riesgo de las víctimas.

3) El Insuficiente desarrollo de la obligación de poner en marcha los programas de rehabilitación de los condenados por delitos de violencia machista, cuyo seguimiento es voluntario para los que se encuentran cumpliendo pena privativa de libertad, no puede dejar de ser valorado como insuficiente compromiso de la Administración Penitenciaria con la asunción de las obligaciones derivadas de la Ley Integral

4) La introducción de reformas técnicas legislativas puntuales que, respetando la filosofía de la Ley, avalada por el Tribunal Constitucional en su esencia y en la concreta redacción efectuada de determinados tipos penales, permitan superar disfunciones detectadas desde los primeros momentos y una mejor efectividad en la aplicación de la Ley.

Comas d'Argemir i Cendra (2006), Vocal del Consejo General del poder Judicial, Presidenta del Observatorio contra la Violencia Doméstica y de Género, sostiene que, gracias a la aplicación de esta Ley en estos años, se está logrando una mejor coordinación de todas las Administraciones Públicas comprometidas en la erradicación de la gravísima lacra social de la violencia de género. ${ }^{17}$

Pero lo que es relevante y significativo es la reflexión del párrafo 64 del Informe del Secretario General de Naciones Unidas, del 6 de Julio del 2006: "A pesar de las complejidades y los desafíos, el progreso hacia el fin de la violencia contra la mujer ha comenzado".

\footnotetext{
${ }^{17}$ Disponible en: www.observatorioviolencia.org/noticias.php.
} 
La Ley Orgánica, 1/2004 de medidas de protección integral contra la violencia de género, también establece en su artículo 4, que el sistema educativo español incluirá entre sus fines la formación en el respeto de los derechos y libertades fundamentales y de la igualdad entre hombres y mujeres, así como en el ejercicio de la tolerancia y de la libertad dentro de los principios democráticos de convivencia.

La ley desarrolla los objetivos específicos adecuados a cada edad para lograr la erradicación de los obstáculos que dificultan la plena igualdad entre hombres y mujeres en nuestra sociedad.

Para concluir este apartado, sólo resta decir que la Ley Orgánica 1/2004, de 28 de diciembre, de Medidas de Protección Integral contra la Violencia de Género, aprobada por unanimidad por todos los grupos políticos con representación parlamentaria, entró en vigor en enero de 2005. Si se compara la media anual de homicidios por violencia de género en los años anteriores y posteriores a la entrada en vigor de dicha Ley, se observa un descenso en el número de crímenes, del 8,3\%. Sin embargo, evaluar la eficacia de la Ley Orgánica 1/2004 y de su impacto social y de cada una de sus medidas en base a las cifras de víctimas mortales se considera inadecuado, puesto que no es posible determinar la cifra de las mujeres que han salvado su vida en base a los recursos que la Ley Integral pone a su disposición. ${ }^{18}$

\section{3.- Los datos.}

18 España, Observatorio Estatal de Violencia Sobre la Mujer (2010). III Informe Anual. Madrid : Ministerio de Sanidad, Política Social e Igualdad 
El Primer Informe del Observatorio Estatal de Violencia contra la Mujer, señala que, la manifestación de maltrato se da en mujeres de todas las edades, clase social, situación laboral, tamaño del municipio en el que residen, nivel educativo, posicionamiento ideológico u opciones religiosas, a pesar de que dicha manifestación tiene diferentes magnitudes.

La violencia en las relaciones de pareja en la población española en general y en la población adolescente y joven en particular, supone, en la actualidad, uno de los problemas sociales más serios con los que se enfrenta la sociedad de nuestros días.

Uno de los primeros abordajes de la violencia contra las mujeres que ofrecen resultados representativos de España es el estudio del Instituto de la Mujer en el año 1999 y el año 2000: "La violencia contra las mujeres. Resultados de la macro encuesta". Uno de los datos más preocupantes es la distribución por edades, es decir, de las mujeres que sufren malos tratos el $36,4 \%$ se sitúan en el grupo de 18 a 30 años, como se puede observar en la siguiente tabla.

Cuadro 1. Víctimas de violencia de género según grupo de edad 2005-2008

\begin{tabular}{lcc}
\hline & TOTAL & \% \\
\hline TOTAL & 328443 & $100 \%$ \\
Menores de $\mathbf{1 8}$ años & 6663 & $2,1 \%$ \\
De $\mathbf{1 8}$ a $\mathbf{3 0}$ años & 116642 & $36,4 \%$ \\
De 31 a 50 años & 169,221 & $52,8 \%$ \\
Mayores de 50 años & 28120 & $8,8 \%$ \\
No consta & 7807 & \\
\hline
\end{tabular}

Fuente: III Informe anual del observatorio estatal de violencia sobre la mujer 2010

En el año 2009 hubo 55 víctimas mortales, la media de edad de las mismas fue de 41 años, como así se refleja en el siguiente gráfico. 
Cuadro 2. Media de edad de víctimas mortales año 2009

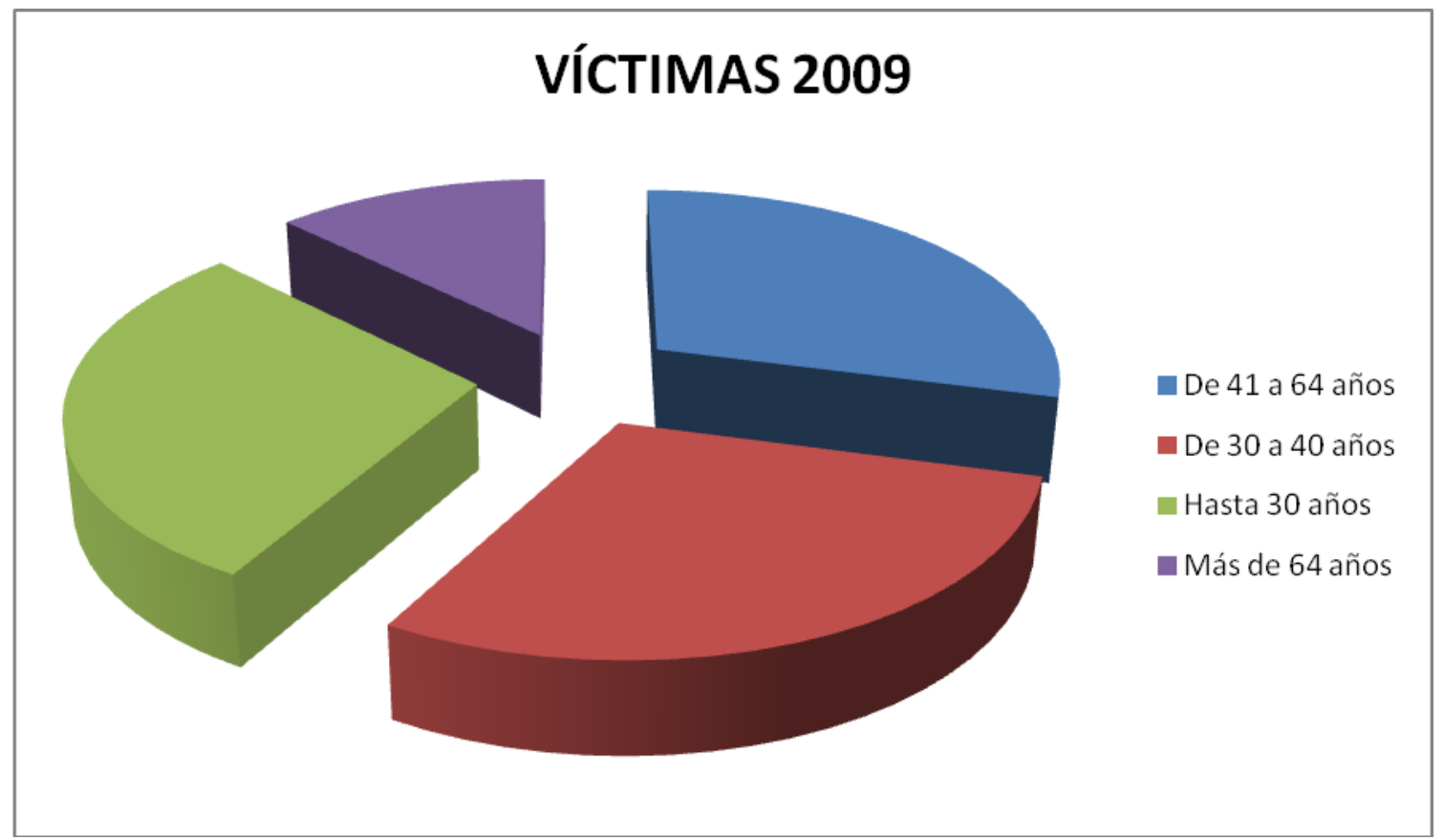

Fuente: III Informe anual del observatorio estatal de violencia sobre la mujer 2010

La revisión de las investigaciones realizadas en los diversos países sobre la violencia en las relaciones de pareja sostienen que la violencia entre las parejas de adolescentes y de jóvenes son significativas, e incluso su magnitud es superior a la de las parejas adultas (Jackson, Cram y Seymour, 2000). Específicamente en el estudio de Kury, Obergfell-Fuchs y Woessner (2004) las jóvenes determinan que son objeto de más ataques violentos que las mujeres de mayor edad, en concreto entre un $12,5 \%$ y un $28 \%$. De la misma forma, otros autores como Smith, White y Holland (2003) o Fritz y O'Leary (2004) han apoyado la reducción de la agresión a lo largo del ciclo vital de las personas.

La Organización Mundial de la Salud (OMS)(1998) informó que el $30 \%$ de las estudiantes universitarias habían revelado algún tipo de violencia en sus relaciones de pareja, y con el tiempo, las agresiones verbales se convertían en agresiones físicas. Esta investigación coincide a grandes rasgos con el Servicio de Violencia Familiar de Bilbao que muestra que el 
$22 \%$ de los casos registrados, los problemas de violencia empiezan durante el noviazgo (Echeburúa, Corras y Amor, 1999). Datos extraídos de otros países revelan que en el $72 \%$ de los casos atendidos en los últimos años, se detecta que la violencia se inicia también en este periodo de tiempo (Trujano y Mata, 2002).

El Instituto de la mujer aporta datos estadísticos más recientes que ponen en conexión la violencia de género con los diferentes grupos de edad que la sufren. Las cifras obtenidas indican que lamentablemente, la violencia contra la mujer aumenta cada año, y en los colectivos más jóvenes no son una excepción.

Cuadro 3. Número de víctimas mortales por violencia de género según grupos de edad.

\begin{tabular}{lcccccccc}
\hline & TOTAL & $\mathbf{2 0 0 3}$ & $\mathbf{2 0 0 4}$ & $\mathbf{2 0 0 5}$ & $\mathbf{2 0 0 6}$ & $\mathbf{2 0 0 7}$ & $\mathbf{2 0 0 8}$ & $\mathbf{2 0 0 9}$ \\
\hline TOTAL & 469 & 71 & 72 & 57 & 68 & 71 & 75 & 55 \\
$\begin{array}{c}\text { Menos de } \\
\text { 16 años }\end{array}$ & 3 & 0 & 3 & 0 & 0 & 0 & 0 & 0 \\
De 16 a17 & 4 & 1 & 1 & 1 & 0 & 0 & 1 & 0 \\
De 18 a 20 & 22 & 0 & 5 & 4 & 2 & 2 & 4 & 5 \\
De 21 a 30 & 108 & 16 & 13 & 14 & 15 & 19 & 20 & 11 \\
De 31 a 40 & 132 & 27 & 17 & 15 & 27 & 15 & 15 & 16 \\
De 41 a 50 & 85 & 15 & 9 & 10 & 9 & 15 & 18 & 9 \\
De 51 a 64 & 49 & 4 & 10 & 3 & 5 & 9 & 11 & 7 \\
Más de 65 & 63 & 7 & 12 & 10 & 10 & 11 & 6 & 7 \\
No consta & 3 & 1 & 2 & 0 & 0 & 0 & 0 & 0 \\
\hline Fuente: III Informe anual del observatorio estatal de violencia sobre la mujer \\
2010
\end{tabular}

Los datos estadísticos que manejamos en tres áreas: denuncias, estadísticas de muertes y atenciones; reflejan que la violencia contra la mujer en edades menores de 30 años tiene unas dimensiones que requieren de una atención especial, por varias razones, pero la fundamental es porque reflejan que los avances en materia de violencia contra la mujer en las relaciones de pareja son pequeños todavía, es decir, no hemos sido capaces de modificar el esquema violento, instaurado en las raíces de nuestra 
sociedad y basado en la estructura de poder y supremacía en las relaciones del hombre sobre la mujer.

Los datos de denuncias establecen que la curva es ascendente, lejos de producirse una disminución de la violencia sexista en las mujeres jóvenes. Desde luego hay que resaltar que en términos absolutos el dato es escalofriante, el $40 \%$ de las denuncias son de mujeres menores de 30 años Cuadro 4. Denuncias por Violencia de Género

\begin{tabular}{ll}
\hline TOTAL & $\mathbf{2 6 8 4 1 8}$ \\
\hline 2007 & 126298 \\
2008 & 142125 \\
2009 & 135540 \\
\hline
\end{tabular}

Fuente: III Informe anual del observatorio estatal de violencia sobre la mujer 2010

Más de la cuarta parte de las mujeres que fallecieron en 2009 por violencia de género habían denunciado a su agresor (14-25\%), aunque una de las catorce denuncias fue retirada por la víctima.

Del total de mujeres que fallecieron por violencia de género en 2009, 13 habían solicitado medidas de protección, $(23,6 \%)$, de las cuales 11 obtuvieron dichas medidas $(20,0 \%)$

De las 11 mujeres que tenían medidas de protección, 3 de ellas renunciaron a sus medidas y 2 tenían caducadas dicha protección en el momento de su asesinato, por lo que tan sólo 6 de las mujeres que murieron en 2009 tenían medidas de protección en vigor.

De estas 6 víctimas, 3 mujeres minimizaron el riesgo y en los otros 3 casos el quebrantamiento se produjo sin el consentimiento de las víctimas.

Durante 2009, llegaron a los juzgados un total de 135.540 denuncias por violencia de género, lo que implica una media mensual de 11.295 denuncias y una media diaria de 371 denuncias. 
En el 2009 se ha producido un ligero descenso del número de denuncias por violencia de género si se compara con la cifra registrada de denuncias en 2008, año en el que se interpusieron 142.125

En los últimos años estamos asistiendo a cambios políticos y sociales importantes, la incorporación masiva de la mujer al mundo laboral y la presencia de mujeres en el sistema educativo universitario es cada vez mayor, al igual que en otros ámbitos que hasta el momento había permanecido muy alejados de las expectativas femeninas ${ }^{19}$.

Todo ello nos puede hacer adoptar la falsa percepción de un cambio, cambio irreal que no se está produciendo a todos los niveles. Tomemos un ejemplo, si como ya es notorio, las mujeres pueden y acceden de hecho a la Universidad en igualdad de condiciones con sus compañeros varones y salen con una preparación que las habilita para el ejercicio profesional, es en la incorporación al mundo laboral cuando se mantiene el modelo tradicional que remarca las diferencias entre ambos sexos, y vemos como los puestos directivos en las empresas los sustentan hombres, cómo la mayoría de los dirigentes políticos de las diferentes naciones son hombres y lo que es peor como el salario, en igualdad de condiciones, es hasta un $30 \%$ más bajo para ellas. $^{20}$

Los porcentajes más elevados de mujeres que han sufrido violencia de género en la encuesta de 2006 se dan en las mujeres con Bachiller elemental (7,2\% de maltrato) o Bachiller superior (7,7\%), También es algo superior la proporción en el caso de las que tenían estudios universitarios $(6,5 \%)$. Entre las mujeres con menor nivel de estudios, en cambio, la proporción de maltratadas por la pareja o ex pareja alguna vez en la vida era del $4,7 \%$, inferior a la media $(6,3 \%)$. Más de la mitad de las mujeres que

\footnotetext{
${ }^{19}$ Véase la tabla sobre el nivel de estudios terminados, elaborada por El Instituto de la Mujer.

${ }^{20}$ Véase página web del Instituto de la Mujer.
} 
manifestaron haber sufrido maltrato de género tenía Bachiller elemental o Bachiller Superior.

Por lo dicho anteriormente, podemos concluir que la discriminación de género, en nuestra sociedad, desde una perspectiva feminista, es un hecho que tiene su origen en la sociedad patriarcal ${ }^{21}$ y a su vez se ve reforzada por las diferentes fases de socialización que van consolidando los roles sociales diferenciados por razón de género, cuyos principales agentes son la familia, la escuela, los medios de comunicación de masas, etc., pues son los que van a contribuir de manera relevante a la formación de modelos sociales que son determinantes en la formación de la personalidad de los individuos.

"El reconocimiento del papel crucial que la escuela puede y debe desempeñar en la superación del sexismo y la violencia de género es hoy generalizado en nuestra sociedad, que suele destacar la necesidad del cambio generacional desde la educación como la herramienta fundamental para superar estos problemas. Pero llevar a la práctica este principio es más difícil de lo que suele suponerse. No basta con que la escuela no sea sexista, sino que exige contrarrestar influencias que proceden del resto de la sociedad, erradicando un modelo ancestral de relación, basado en el dominio y la sumisión, que tiende a reproducirse de una generación a la siguiente a través de mecanismos fuertemente arraigados". (Díaz Aguado Jalón y Carvajal Gómez, 2011, p.15)

21 "Analizar el patriarcado como un sistema político supuso ver hasta dónde se extendía el control y dominio sobre las mujeres. Buena parte de la riqueza teórica del feminismo de las últimas décadas procede de aquí. Al darse cuenta de que ese control patriarcal se extendía también a las familias, a las relaciones sexuales, laborales... las feministas popularizaron la idea de que lo personal es político. Es cuando se organizan los grupos de autoconciencia y, con ellos, un nuevo descubrimiento: las mujeres se dieron cuenta de que aquello que cada una pensaba que sólo le ocurría a ella, que tenía mala suerte, que había hecho una mala elección de pareja o cualquier otra razón, no era, sin embargo, nada personal. Eran experiencias comunes a todas las mujeres, fruto de un sistema opresor". (Varea, 2005, p. 177) 
Mención especial merece la vulnerabilidad de la mujer inmigrante ante la violencia de género, de sobra es sabido que la violencia contra las mujeres puede estallar en cualquier rincón y en todas las capas de la sociedad. Pero existe un colectivo especialmente susceptible al maltrato: las inmigrantes, en especial las que se hallan en situación irregular o han llegado tras un proceso de reagrupación familiar.

Los agresores se aprovechan de su indefensión emocional, jurídica y económica, no conocen a nadie, no son independientes ante la justicia y no tienen permiso de trabajo, para someterlas y mantenerlas bajo su yugo.

En los últimos años España se ha configurado como un país de inmigración procedente de muchos lugares del mundo. No obstante, las agresiones mortales de género muestran una evidente sobrerrepresentación de víctimas de nacional extranjera.

Entre el 1 de enero de 2003 y el 31 de diciembre de 2009 se desconoce tanto la nacionalidad concreta como el continente de nacionalidad de la víctima en 2 casos. De acuerdo con la información disponible, en ese periodo hubo 327 víctimas españolas y 142 extranjeras. La proporción de víctimas extranjeras es del $30,3 \%$.

Desde el 1 de Enero de 2003 hasta el 31 de Diciembre de 2009, sin considerar a españolas, según continente, la mayoría de las víctimas de nacionalidad extranjera eran iberoamericanas $(50,7 \%)$, seguidas de las nacionalidades de países de la Unión Europea $(25,4 \%)$ y africanas (12,7\%). 
Cuadro 5. Víctimas de nacionalidad extranjera

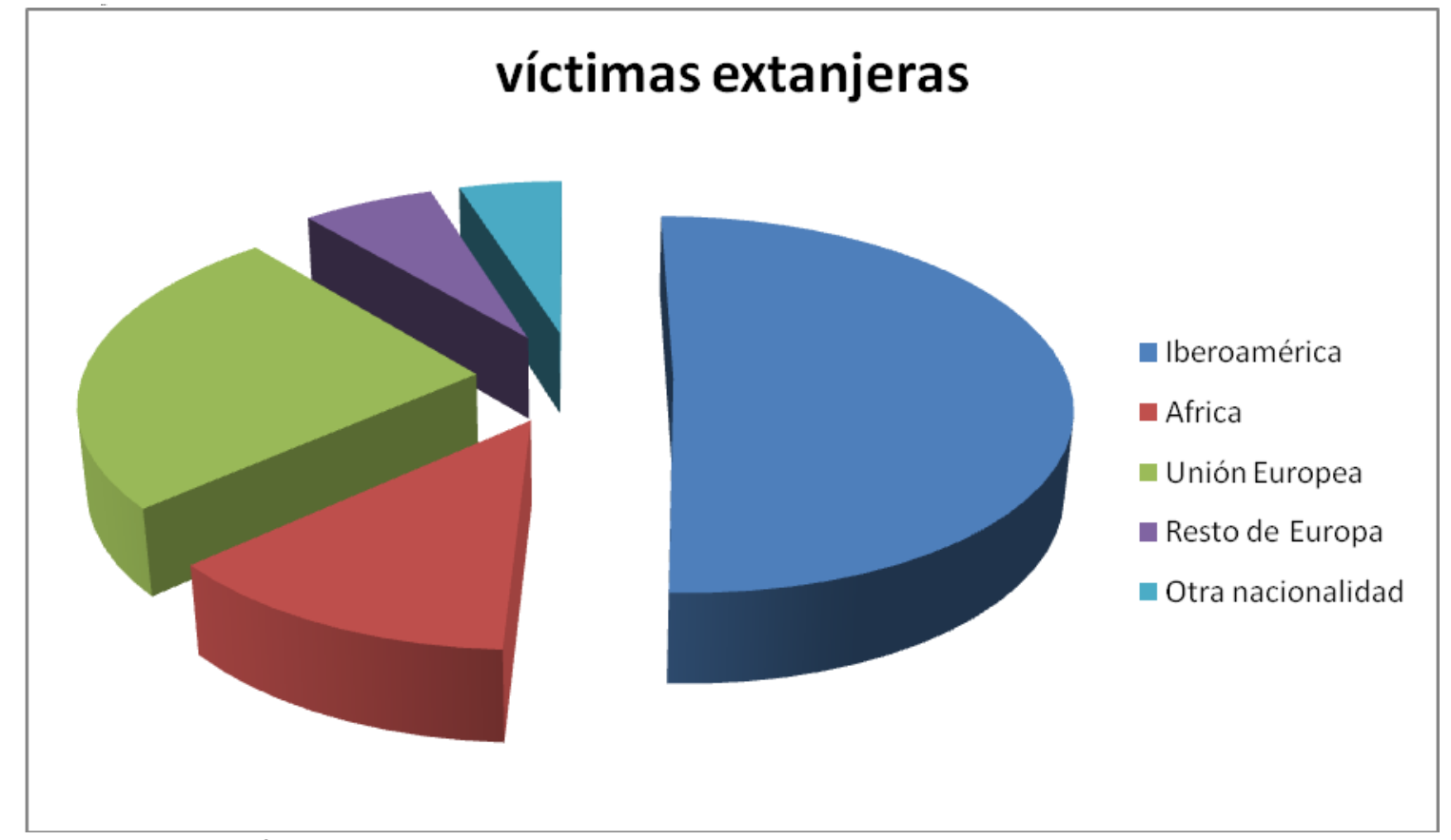

Fuente: III Informe anual del observatorio estatal de violencia sobre la mujer 2010

Las extranjeras, sobre todo las latinoamericanas, que son las que tienen mayor presencia en España, provienen de estructuras socioculturales fundamentadas en el patriarcado. Las mismas pautas que sus parejas reproducen aquí. Pero también hay algunos españoles casados con extranjeras que siguen esos mismos patrones. $Y$ cuando ellas llegan aquí y quieren desprenderse de las cadenas machistas y ser independientes, ellos sienten que pierden el control. Cuando ellas se rebelan, da comienzo la escalada de violencia. Él se convierte en agresor, y el mecanismo de la violencia de género se pone en marcha.

En 1999 fueron siete (el 14\%), de un total de 54 mujeres asesinadas, según datos del Instituto de la Mujer. Años después, en 2009, tras el fenómeno migratorio, las víctimas extranjeras se elevaron a 21 (el 27,6\%), entre las 76 muertes registradas. Estos datos reflejan que la mayoría de mujeres asesinadas por sus cónyuges o ex parejas son de nacionalidad española, pero descubren otra realidad paralela, diferente, y demuestran la 
sobreexposición y la sobrerrepresentación de las víctimas extranjeras, en palabras del delegado del Gobierno para la Violencia de Género, Miguel Lorente Acosta. De los 22,8 millones de mujeres que hay en España, 2,1 millones son inmigrantes, (el 9,2\%). Teniendo en cuenta este porcentaje, ahí va el dato preocupante: la tasa de extranjeras asesinadas por millón de mujeres inmigrantes fue de 13,18 en 2007 , mientras que la misma cifra respecto las víctimas nacionales fue de 2,05.

Los agresores se aprovechan de la situación de precariedad afectiva y económica de sus víctimas, haciéndoles ver que ellos son lo único que tiene. A ello se añade la falta de redes sociales de apoyo.

Los casos en que la víctima inmigrante es irregular o ha llegado a España reagrupada son aún más difíciles y delicados. De entrada, estas mujeres perciben a las administraciones públicas más como una amenaza que como una protección; tienen miedo a no ser creídas, a que la denuncia pueda afectar a su proceso de regulación y a la normativa de extranjería. La autorización de residencia de las reagrupadas está condicionada a la convivencia con su pareja, y no tienen permiso para trabajar.

Otro de los obstáculos de la mujer inmigrante en situación irregular es que se le exige la denuncia para acceder a centros de acogida 0 tratamientos psicológicos. Y muchas veces ellas, por miedo, la retiran. Finalmente por ser irregulares, no pueden acceder a las ayudas económicas para las víctimas de violencia de género con orden de protección judicial y sin ingresos. $Y$ si quieren trabajar, les ocurre lo mismo que a las reagrupadas, es decir, necesitan una oferta de trabajo.

Cuadro 6. Víctimas mortales por violencia de género según nacionalidad

\begin{tabular}{lllllllll}
\hline & TOTAL & $\mathbf{2 0 0 3}$ & $\mathbf{2 0 0 4}$ & $\mathbf{2 0 0 5}$ & $\mathbf{2 0 0 6}$ & $\mathbf{2 0 0 7}$ & $\mathbf{2 0 0 8}$ & $\mathbf{2 0 0 9}$ \\
\hline TOTAL & 469 & 71 & 72 & 57 & 68 & 71 & 75 & 55 \\
ESPAÑOLA & 324 & 62 & 54 & 41 & 48 & 43 & 42 & 34 \\
EXTRANJERA & 143 & 9 & 16 & 16 & 20 & 28 & 33 & 21 \\
NO CONSTA & 2 & & 2 & & & & & \\
\hline
\end{tabular}


Fuente: III Informe anual del observatorio estatal de violencia sobre la mujer 2010

\section{4.- Explicaciones teóricas sobre la violencia de género.}

“Una explicación sociológica más comprehensiva, de la violencia contra las mujeres, debe necesariamente tomar en cuenta la perspectiva feminista o de género. Según esta aproximación, todas las formas de violencia contra las mujeres, o violencia de género, guardan relación entre sí, tienen continuidad entre ellas y están relacionadas con el patriarcado, es decir, con la desigualdad de género. La investigación feminista ha puesto de manifiesto cómo la consideración cultural de las mujeres como seres inferiores, que es el eje de la ideología patriarcal, está relacionada con la violencia que los hombres ejercen sobre ellas. Desde este punto de vista, el hombre es superior y debe poner de manifiesto su poder sobre las mujeres, incluso mediante la violencia. Un acto de dominio sobre las mujeres, no sería otra cosa pues, que una manifestación legítima de una situación que se formula como naturalmente construida". (Blanco García, 2007, p.6)

Para el desarrollo de esta cuestión nos basaremos en el trabajo de Blanco García (2006)

"Centrándonos ahora en las explicaciones teóricas que se han elaborado para explicar la violencia doméstica, diremos que hay una serie de teorías de raíz psicoanalítica, psicosocial o conductual, que atribuyen la culpa de los malos tratos a factores individuales, sean estos psicológicos 0 fisiológicos, que afectan tanto a la víctima como al agresor, lo que tiene el efecto de despolitizar el problema, al situarlo en el terreno individual y 
enviándolo al terreno profesional, terapéutico. Estos enfoques potencian la conveniencia de ser tratado institucionalmente, pero de manera privada. Es decir, se elude el componente estructural que la cuestión requiere, para poder ser entendida en su totalidad. Dentro de estos enfoques individuales hay quien centra su explicación en las características de los varones y otras que lo hacen en las de las mujeres. Las que se centran en el comportamiento de los hombres los tratan, bien como enfermos o psicológicamente trastornados, Maynard (1993), Dobash y Dobash (1998), Bograd (1998), Ptacek (1998). Otras aluden a un supuesto ciclo de transmisión generacional de la violencia, según el cual el agresor ha aprendido una conducta que posteriormente reproduce. El alcohol o el consumo de drogas en general suele ser también una de las explicaciones más aceptadas, así como las que se refieren a la pérdida ocasional del control sobre sus actos, a estallidos de ira incontrolados o a una combinación de factores psicosociales que serían los que causan tal cantidad de estrés en los hombres que les llevaría a comportarse de esa manera. Cualquiera de estas situaciones tiene que ver con el control, pero como señala muy acertadamente McConell: "no con perderlo, sino con utilizarlo para dominar la voluntad de otra persona: la mujer maltratada" (Blanco García, 2006, p. 48)

Por lo que se refiere a las teorías de corte individualista, que se centran en las características de la víctima, es decir de las mujeres, se han ofrecido explicaciones que van, desde las que consideran que ellas to merecen o lo provocan por su comportamiento, (son provocadoras) a las que las presentan como masoquistas, es decir adictas a la violencia; las que atribuyen el hecho de no salir de esa situación a factores culturales o tienden a minimizar el alcance de los abusos, pues argumentan que, si fueran tan graves sería lógico pensar que la mujer no lo soportaría. Todas ellas tienen en común un efecto perverso que es culpabilizar a la víctima de lo que le está ocurriendo, eludiendo fijar la mirada en el contexto social y animando a 
las mujeres a creer en esos mensajes y a sentirse lo bastante culpables como para seguir soportando los malos tratos.

Como formuló Ryan (1971), a las víctimas se les echa la culpa por los fallos de sus superiores sociales, y esta tendencia se ve completada con la solución de centrarse solamente en la víctima, que es la que adoptan los que tienen el poder para articular respuestas ante el problema.

La mirada sociológica nos hace insistir en la idea de que, para poder entender estas situaciones, es necesario acudir al concepto de socialización diferencial, basándonos en la existencia de un modelo masculino tradicional que se apoya en dos conceptos: la restricción emocional y la obsesión por los logros y el éxito. En el marco de una sociedad patriarcal, la identidad masculina se construiría como negación de todo lo que es culturalmente definido como femenino. Por otra parte y desde una perspectiva ecológica, Strauss, Gelles y Steinmetz (1980) se centran en los conceptos de poder y género dentro del ámbito familiar que convierten a la familia en una organización jerárquica en la que la violencia es un modo que utilizan los más fuertes para mantener el control de la relación.

Este modelo ecológico, se articula en torno a la relación que se establece entre cuatro niveles sociales:

1) I macrosistema, que comprende la organización social, con sus jerarquías establecidas e inamovibles y su distribución desigual de poderes, así como las creencias y los estilos de vida. De él parten las concepciones del deber ser, en este caso de lo que hombres y mujeres deben tener y hacer y de cómo deber ser la familia. Se refiere pues, a los estereotipos de género dentro de la familia (y de otras instituciones sociales) y establece las prescripciones de rol. Igualmente, en este nivel, se establecen las concepciones acerca del poder y el uso de la fuerza para hacer frente a los conflictos. 
2) El exosistema, y está integrado por las instituciones que actúan de mediadoras entre la cultura y el espacio individual: escuelas, iglesias, medios de comunicación, órganos judiciales, legislación, etc. Las creencias, los valores culturales que emanan del microsistema no son entidades abstractas, sino que se transmiten, fortalecen, recrean y modifican a través de estas instancias concretas en las que se produce la interacción cotidiana. Las figuras de autoridad que operan dentro de estas instituciones, (maestros, sacerdotes, psicólogos, jueces, padres) son los transmisores de esos mandatos sociales y sirven de enlace entre los mandatos sociales y los sujetos individuales.

3) El microsistema, y se refiere a las relaciones cara a cara. En este espacio se concretan los mandatos sociales sobre el deber ser en situaciones cotidianas. La familia es uno de los lugares privilegiados para esa concreción, en la medida en que, como grupo primario que es, se caracteriza por esa interacción cercana, continuada y con una elevada carga afectiva. En ella se despliegan y controlan los mandatos sociales que emanan de los dos niveles anteriores. En ella se aprende a ser hombre o mujer concreto y se hacen patentes las relaciones de poder y jerarquía establecidas en los niveles anteriores. Señalar, como lo han hecho algunos autores con anterioridad que, la familia es, después del ejército y el Estado, una de las instituciones más violentas es una imagen que se resiste a hacerse pública y ésta es una de las razones por las que todavía resulta muy difícil calificar estos comportamientos como puramente delictivos. Gelles y Cornwell (1985) y Giddens (2001), nos recuerdan cómo es más probable que una persona sea atacada físicamente, golpeada, abofeteada o azotada en su 
propio hogar por otro miembro de la familia, que en cualquier otro lugar o por cualquier otra persona en nuestra sociedad.

4) Finalmente, estaría el nivel individual, que se refiere a las maneras en que cada individuo percibe y conceptualiza el mundo, las emociones, las ansiedades, los conflictos y las pautas de relación con los demás. Aunque es cierto que de este nivel emana la diversidad humana, las diferencias individuales, en definitiva, la libertad de cada ser humano para poder elegir entre una conducta u otra, e incluso para innovar, no lo es menos, que este ámbito no puede entenderse sin hacer referencia a los tres niveles anteriores; es esta interrelación la que nos permite comprender el comportamiento individual concreto y es desde ella desde donde debemos partir, a la hora de explicar por qué un hombre en particular, se comporta de manera violenta contra una mujer, en este caso contra la mujer que ama.

En definitiva, este modelo sociocultural toma en cuenta las características de la sociedad en su conjunto, y de las diversas instancias que emiten mandatos específicos para regular el comportamiento de cada persona. Entender por tanto, por qué se produce la violencia contra las mujeres, sea en el ámbito doméstico o en otros contextos sociales, implica poner los comportamientos individuales en relación con los roles y estereotipos sexuales que emanan del macrosistema, se transmiten a través de las instituciones del exosistema y se concretan en las relaciones cara a cara del microsistema.

Combinando esta aproximación ecológica con una perspectiva feminista, nos damos cuenta de que la violencia en el hogar se produce porque en él hay unas relaciones jerarquizadas que responden a una organización social patriarcal. Dichas relaciones no se generan en cada familia, sino que son el reflejo de estructuras sociales más amplias, por lo que el maltrato a las mujeres dentro de una relación familiar no puede ser 
contemplado como algo individual, ni un asunto que compete sólo a la familia. Es por el contrario, la afirmación de un orden social particular, que tolera la subordinación de las mujeres y el uso de la violencia en su contra.

Desde esta óptica, no sería una conducta desviada, ya que es promovido por un orden social basado en la desigualdad y que tiene interés en mantener y perpetuar esos esquemas de dominación. La sociedad no quiere hacer frente a una situación que percibe como de la vida privada, cuando no hay delitos íntimos ni privados, el delito, cuando es, es siempre público. Sin embargo, la realidad se aleja bastante de esta afirmación, y lo cierto es, que como sabemos, la violencia contra las mujeres es el crimen encubierto más extendido del mundo.

Según la OMS (2002), se documenta que casi la mitad de las mujeres que mueren por homicidio son asesinadas por sus maridos o parejas actuales o anteriores, un porcentaje que se eleva al 70\% en países donde no hay altos índices de delincuencia, problemas graves de seguridad, ni conflictos armados. En el mismo informe se señala que una de cada cuatro mujeres será víctima de violencia sexual por parte de su pareja en el curso de su vida. En una tercera parte o en más de la mitad de los casos se producen también abusos sexuales. En algunos países, hasta una tercera parte de las niñas han sufrido una iniciación sexual forzada.

En España los datos son también alarmantes. Desde 1999 hasta octubre de 2010 el número de mujeres fallecidas como víctimas de la violencia de género asciende a 1038. Sin embargo, esto es sólo la punta del iceberg, ya que sabemos que la cifra negra de este tipo de delitos es muy abultada. No tenemos datos fiables sobre cuántas mujeres están sufriendo tortura y violencia cotidiana en sus casas, aunque esto no tenga como resultado la muerte; no sabemos cuántas mueren como consecuencia de lesiones o enfermedades que tengan que ver con el maltrato continuado, ni el número de ellas que ante el sufrimiento, se suicidan. 
Cuadro 7. Víctimas mortales por violencia de género año 2009.

\begin{tabular}{lc}
\hline Año 2009 & No de \\
& Víctimas \\
\hline Enero & 0 \\
\hline Febrero & 5 \\
\hline Marzo & 5 \\
\hline Abril & 2 \\
\hline Mayo & 9 \\
\hline Junio & 5 \\
\hline Julio & 6 \\
\hline Agosto & 6 \\
\hline Septiembre & 6 \\
\hline Octubre & 6 \\
\hline Noviembre & 0 \\
\hline
\end{tabular}

Fuente: III Informe anual del observatorio estatal de violencia sobre la mujer 2010

En el año 2009 se produjeron 55 crímenes por violencia de género; dicha cifra es la más baja registrada en el periodo comprendido entre 2003 y 2009. El mes de mayo fue el mes en el que se contabilizaron mayor número de víctimas (9) y en los meses de enero y noviembre fueron meses sin víctimas mortales.

En el informe de la Delegación del Gobierno para la Violencia de Género se presentan datos, desde el 1 de enero de 2003, basados e informes individualizados relativos a las víctimas mortales por violencia de género en los términos de la Ley Integral (mujeres muertas a manos de su pareja o ex pareja) 
Los datos de 2003 a 2005 proceden del Instituto de la Mujer, siendo su fuente la información facilitada por los medios de comunicación. Los datos de 2006, 2007, 2008 y 2009 proceden de la propia Delegación del Gobierno para la Violencia de Género, que contabiliza cada caso de acuerdo a los informes emitidos por las Delegaciones y Subdelegaciones del Gobierno y por las Unidades de Coordinación y Unidades de Violencia contra la Mujer, las cuales en la actualidad, dependen funcionalmente del Ministerio de Sanidad, Política Social e Igualdad. Estas Unidades recaban los datos de cada suceso de las Fuerzas y Cuerpos de Seguridad del Estado o Policía Autonómica y, complementariamente, de órganos jurisdiccionales y Fiscalía.

La heterogeneidad y previsible disparidad de criterios a lo largo del tiempo en los sistemas de recogida de información, así como la limitada significación estadística de las cifras de crímenes por violencia de género, obligan a utilizar con prudencia los datos que recoge este informe que, no obstante, intenta tener carácter exhaustivo. En ese sentido, conviene señalar que, a mayor desagregación de los datos, menor significación de los mismos. Cada caso se refiere a las circunstancias de un determinado crimen $y$ todos ellos tienen el mismo valor social.

¿Qué pueden hacer las mujeres maltratadas ante tal estado de la cuestión? A este interrogante parece que en los últimos tiempos se ha dado como solución casi única el acudir a solicitar ayuda o asistencia institucional pues, no hay referencia alguna sobre mujeres que salieron de su hogar y lograron superar la situación por sí solas o con ayuda de sus familiares y/o amigos.

No obstante, hemos de dar cuenta de un cambio significativo en la literatura reciente, pues ya contamos con relatos de mujeres que han superado la situación, Suñer (2002), Zubiaur (2003), Berbel( 2004) así como de algunos manuales que representan un cambio decidido de postura frente a la cuestión. Barea (2004), Ruiz-Jarabo y Blanco Prieto (2005). 
Aunque el completo tratamiento del tema en la literatura, no deja lugar a la duda, sí conviene reseñar que el/la niño/a aprende e interioriza el modelo familiar observado. Así, los varones pueden aprender que la violencia es un medio lícito de resolver los conflictos y las niñas pueden asumir el maltrato como algo "normal" en una pareja. De este modo el modelo sexista, que genera la violencia, se perpetúa y transmite de generación en generación.

Gelles y Straus (1988) Ilegaron a decir que la familia es la institución más violenta de nuestra sociedad, con excepción del ejército en tiempos de guerra.

Los estudios sobre violencia en general reflejan que la exposición a modelos violentos especialmente en la infancia y adolescencia conduce a la justificación y al incremento del riesgo a ejercerla.

De este modo, parece existir una predisposición de las víctimas de violencia sexista dentro de su familia a convertirse a su vez en padres abusadores. Es la teoría de la transmisión intergeneracional (Kaufman, 1989)

\section{5.- La mecánica: el ciclo de la violencia.}

Tal y como hemos señalado a lo largo de los apartados anteriores, en nuestra sociedad el amor $y$, especialmente, el amor romántico, se ha convertido en la base de una de las instituciones sociales básicas como es la familia. Y este amor romántico ofrece a las personas un modelo de conducta que cuando falla, produce frustración y desengaño y es uno de los factores que contribuyen a favorecer y mantener la violencia contra las mujeres en la pareja Garrido (2001), González y Santana (2001), Lagarde (2005), 
Sanmartín, Molina y García (2003), Sampedro (2005). O dicho en palabras de Flecha, Puigvert y Redondo (2005): La violencia de género está intrínsecamente ligada a nuestro imaginario social sobre el amor, los modelos amorosos y los modelos de atractivo, a como nos hemos socializado y nos socializamos continuamente en ellos.

Debemos resaltar, entre los factores de vulnerabilidad a la violencia contra las mujeres en la pareja, el concepto de amor romántico, con su carga de altruismo, sacrificio, abnegación y entrega que todavía se les inculca a las mujeres. Esta forma de amar puede generar angustia y sometimiento a la pareja.

Y esto es así porque, como señalan González y Santana (2001), quienes asumen este modelo de amor romántico y los mitos que de él se derivan, cosa que ocurre particularmente entre las mujeres, como hemos ido viendo, tienen más probabilidades de ser víctimas de violencia y de permitirla puesto que consideran que el amor y la relación de pareja, es lo que da sentido a sus vidas y que romper la pareja, renunciar al amor es el fracaso absoluto de su vida, y no la promesa de una vida mejor; que como el amor todo lo puede han de ser capaces de allanar cualquier dificultad que surja en la relación y/o de cambiar a su pareja, incluso aunque sea un maltratador irredento, lo que las lleva a perseverar en esa relación violenta; que la violencia y el amor son compatibles 0 , incluso que ciertos comportamientos violentos son una prueba de amor, lo que es empleado por víctimas y agresores para justificar los celos, el afán de posesión y/o los comportamientos de control ejercidos por su maltratador como una muestra de amor, llegando, incluso a sugerirse que el amor sin celos no es amor, y trasladando la responsabilidad del maltrato a la víctima por no ajustarse a dichos requerimientos. En definitiva, y como señalan estas mismas autoras: "un romanticismo desmedido puede convertirse en un serio peligro" (González y Santana, 2001, p. 46) 
El modelo de familia basado en modelos patriarcales de relación, ejercicio de poder del varón principal sobre las mujeres y los menores, puede propiciar en las mujeres la sobrevaloración, del matrimonio y de la realización personal a través del afecto y en los varones el desvío de la agresividad de lo público a lo privado. Ello facilitaría tanto en los hombres como en las mujeres el aprendizaje de modelos violentos de relación, ejercidos por ellos y padecidos por ellas, y relaciones asimétricas de dominación y toma de decisiones que incrementarían el grado de violencia hacia las mujeres. (Martín, 1999)

Diversas investigaciones han señalado la presencia de creencias irracionales sobre la relación de pareja y el uso de la violencia entre las maltratadas y los maltratadores. Fernández-Montalvo y Echeburúa (1997, 1998), Sarasúa , Zubizarreta, Echeburúa y Corral (1994), han estudiado los modelos de amor que suscitan más acuerdo (Ubillos, 2001), han determinado la gran vigencia de los mitos sobre el amor romántico entre la población general de nuestro entorno, Barón y Martínez-línigo (2001), Centro de Investigaciones Sociológicas (CIS), (1995), Yela (2002 y 2003) han mostrado la confusión reinante, incluso entre población de jóvenes universitarias que consideran que los abusos o la violencia pueden ser entendidos como actos de amor, Henton, Cate, Koval, Lloyd y Christoher (1983), Oliver y Valls (2004), Rosen y Bezold (1996)

"Cuando en aras del amor, se sacrifican los valores, la libertad o la dignidad; cuando se quiere más al otro que a una misma, algo no funciona; "ama al prójimo como a ti mismo". Cuando a la vez se ama y se teme a la pareja, algo muy grave está ocurriendo. Eso no es amor, sino dependencia y sumisión". (Barea, 2004, p.146)

Entramos de esta manera y quizá a una edad demasiado temprana en el ciclo de la violencia. 
"La violencia de género tiene estructura cíclica; en la mayor parte de relatos la víctima describe que después de la agresión el compañero suaviza su conducta y sus palabras, y que esa aparente tranquilidad acaba cuando, sin motivo, él vuelve a cargarse de ira hasta que explota en una nueva agresión. Según datos de Estados Unidos el $47 \%$ de los varones que agreden a sus parejas repiten la acción al menos tres veces al año. (Barea, 2004, p.50)

Aunque la mayor parte de la literatura al respecto habla de ciclos, entendemos que, sería más correcto hablar de una espiral de violencia, puesto que cada vez que se repite el ciclo aumenta, tanto la intensidad, como la frecuencia del maltrato.

El ciclo de la violencia, descrito por la investigadora estadounidense Leonore Walker (1980) explica y nos ayuda a entender cómo se produce y se mantiene la violencia en la pareja. Walker trabajó en una casa refugio para mujeres maltratadas y observó que muchas mujeres describían un patrón muy parecido en el proceso de maltrato y que este tenía una forma cíclica, que se desarrollaba en tres fases: la fase de tensión, la fase de agresión y la fase de conciliación, arrepentimiento o de "luna de miel".

1.- La fase de tensión se caracteriza por una escala gradual de tensión que se manifiesta en actos que aumentan la fricción y los conflictos en la pareja. El hombre violento expresa hostilidad, pero no en forma explosiva. La mujer intenta calmar, complacer o, al menos, no hacer aquello que le pueda molestar a la pareja, en la creencia irreal de que ella puede controlar la agresión. Pero esta sigue aumentando y se producirá la agresión.

2.- Fase de agresión, en la que estalla la violencia psíquica, física y/o sexual. Es en esta fase cuando la mujer suele denunciar los malos tratos y en la que puede decidirse a contar lo que le está pasando. 
3.- Fase de conciliación o "luna de miel", en la que el hombre violento se arrepiente, pide perdón, le hace promesas de cambio o le hace regalos. Este momento supone un refuerzo positivo para que la mujer mantenga la relación. También le permite ver el "lado bueno" de su pareja, fomentando la esperanza de que puede llegar a cambiar.

El ciclo de la violencia explica por qué algunas mujeres retiran su denuncia, que interponen en la fase de agresión, al encontrarse un hombre que se arrepiente, promete cambiar y que está en plena fase de "luna de miel”. También explica por qué las mujeres, después de verbalizar que están sufriendo violencia o de iniciar la toma de decisiones para terminar con la relación, le disculpan, minimizan su comportamiento violento o lo justifican, volviendo de nuevo a la situación anterior.

"Con el tiempo, la fase de agresión se repite más a menudo o se está todo el tiempo entre la tensión y la agresión, sin apenas "fase de conciliación". Cuando esto sucede, es cuando muchas mujeres deciden pedir ayuda. A veces, hasta llegar a este momento, han pasado muchos años. Si este ciclo no se rompe a tiempo, las agresiones se repetirán con más frecuencia y más intensidad, con mayor gravedad y riesgo para la mujer." (Ruiz-Jarabo Quemada y Blanco Prieto, 2005, p.48)

Sin embargo, es posible romper el círculo de la violencia cuando de manera paralela a la relación abusiva, existen unas condiciones psicosociales protectoras (Díaz-Aguado, 2003):

- Adquirir habilidades alternativas a la violencia que permitan afrontar el estrés y resolver conflictos sociales con eficacia.

- Poder expresar a otras personas las emociones suscitadas por el maltrato.

- Establecer relaciones afectivas positivas alternativas con otras personas que le permitan cambiar sus sentimientos y expectativas sobre la vida y las personas que le rodean. 
- Rechazar y condenar toda forma de violencia, incluida la propia sufrida en la infancia.

- Comprometerse a no reproducir la violencia.

El primer amor suele ser maravilloso y devastador. El sufrimiento y el placer que provoca, atormenta y obnubila dejando escaso margen para hacer otra cosa, nada más que enamorarse. Se pierde la noción del tiempo y la percepción se distorsiona porque sólo vemos lo que queremos ver, a una persona idealizada que en realidad no existe.

La fuerza de esta emoción nos expone, nos hace vulnerables y a merced de alguien desconocido, sin la capacidad objetiva de discriminación entre lo positivo y lo negativo de la relación. Sin embargo, somos capaces de desarrollar la capacidad de sobreponernos al primer amor, que marcará una etapa de nuestra vida que jamás se repetirá y que nos sirve como experiencia.

\section{3.- Concepto de Amor.}

\section{1.- ¿Qué es el amor romántico?}

"El amor es un sentimiento universal, pero la forma en que expresamos el amor, y el cómo lo expresamos con alguien en concreto es cultural, es una forma social. El amar a alguien no obliga necesariamente a ser pareja, se tienen visiones muy distintas de la pareja y cada cual querrá imponer su criterio y se puede generar mucha violencia y ser pareja no obliga 
necesariamente a convivir, porque así como para ser pareja se tienen que llegar a acuerdos, también tiene que haberlos para la convivencia, porque si no, esta puede ser un infierno en vez de una forma de relación que favorezca el bienestar y el desarrollo mutuo". (Ruiz Jarabo Quemada y Blanco Prieto, 2005, p.13)

Hemos querido comenzar este apartado haciendo alusión a la definición de amor que ofrecen Ruiz Jarabo Quemada y Blanco Prieto, porque en ella, las autoras ya se desmarcar del concepto más tradicional de amor romántico, desvinculando amor y convivencia, hablando de acuerdos para evitar la violencia y haciendo mención a una forma de relación en la que el desarrollo sea mutuo, es decir, la tendencia se dirige hacia la consecución de relaciones igualitarias.

No obstante, es fundamental comenzar aclarando el término amor, desde un punto de vista academicista y para ello utilizamos al diccionario ideológico feminista de Victoria Sau, que a su vez recoge otras acepciones del término, realizadas por diferentes autoras.

Sau (1990, p.36) recurre a María Moliner (1966-67) para definir el amor de la siguiente manera:

"Sentimiento experimentado por una persona hacia otra, que se manifiesta en desear su compañía, alegrarse con lo que es bueno para ella y sufrir con lo que es malo. Lo mismo que amar es sustituido en el lenguaje familiar y corriente por querer, amor es sustituido por cariño cuando no se emplea para designar ese sentimiento en abstracto; pero en frases de sentido abstracto como el amor maternal o el amor entre marido y mujer, es de uso corriente; y cuando se aplica a conceptos elevados, como en el amor de Dios, el amor al prójimo, el amor a la patria o el amor a la humanidad, la palabra amor es insustituible". (Sau, 1990, p. 36) 
Si ubicamos ésta definición de amor en el tramo de edad de la adolescencia $^{22}$, en cierta medida, estamos hablando de confusión, de inexperiencia, de intensidad en los sentimientos y de necesidad de acumular vivencias con la mayor brevedad posible. Con este propósito vemos útil remitirnos a la obra de Consuelo Barea. Esta autora identifica el amor con la adicción y describe cómo esta puede llevar a su vez al maltrato.

"El amor de pareja tiene una primera fase, el enamoramiento, en la que es normal un comportamiento similar al adictivo por parte de ambos componentes de la pareja. En esta fase se sufre una dependencia intensa de la otra persona y se vive como insoportable la posibilidad de ruptura. Se trata de un proceso fisiológico al que siguen un clímax de pasión y una tranquilidad afectiva más o menos duradera”. (Barea, 2004, p. 145)

En la adolescencia, la modificación del cuerpo de forma abrupta y no armónica, las tensiones generadas por los cambios hormonales, dificulta la adaptación y generan conflictos emocionales. La presencia de jóvenes del sexo opuesto, que hasta poco antes de la llegada de la adolescencia, resultaban indiferentes y hasta molestos, produce una sensación nueva y compleja de manejar, pues es capaz de monopolizar todos los sentidos y dificulta el prestar atención a cualquier otra cosa.

Pero la atracción física no es suficiente para enamorarse. El enamoramiento abarca a la persona en su totalidad, cómo es, cómo habla, cómo camina, qué dice, su nivel de seguridad y confianza en sí misma, su capacidad de escuchar, de entender y de aceptarse tal cual es.

\footnotetext{
22 Para la Organización Mundial de la Salud, la adolescencia es el período comprendido entre los 10 y 19 años y está comprendida dentro del período de la juventud -entre los 10 y los 24 años-. La pubertad o adolescencia inicial es la primera fase, comienza normalmente a los 10 años en las niñas y a los 11 en los niños y llega hasta los 14-15 años. La adolescencia media y tardía se extiende, hasta los 19 años. A la adolescencia le sigue la juventud plena, desde los 20 años hasta los 24 años.
} 
Sangrador (1993), nos recuerda que el amor puede entenderse como actitud (amor como actitud positiva o atracción hacia otra persona, que incluye una predisposición a pensar, sentir y comportarse de un cierto modo hacia esa persona), como una emoción (amor como sentimiento o pasión que incluye, además, unas ciertas reacciones fisiológicas) o como una conducta (cuidar de la otra persona, estar con ella, atender sus necesidades,...)

Tal como resumen Ubillos, Silva, Páez y Zubieta (2003) los factores que determinan el inicio y el fin del amor dependen de si el acento se pone en el sujeto que siente el amor, en el objeto hacia el que se dirige el amor o en la situación en la que surge. De este modo se manejarán, sobre todo, dos modelos teóricos basados en:

- Explicaciones sociobiológicas que inciden en la funcionalidad biológica del comportamiento amoroso para la persistencia de la especie. En opinión de Ubillos y cols. (2003), estas predicciones de la teoría sociobiológica sobre la diferencias de género en los comportamientos sexuales y amorosos de hombres y mujeres coinciden con los planteamientos de las teorías de roles según los cuales las mujeres son socializadas en roles comunales, pasivos y de subordinación, mientras los varones son socializados en roles agentes, activos y de dominio.

- Explicaciones que ponen el acento en los condicionantes culturales del amor como construcción social. El amor es un fenómeno universal aunque su significado pueda variar sensiblemente de un entorno cultural a otro e incluso a través del tiempo.

Como señalan González y Santana (2001) ó Ubillos y Barrientos (2002), el amor también ha sido explicado desde otros puntos de vista, entre lo que destacan la teoría del apego de Bolwby (1980), considerando que las relaciones amorosas que la persona mantiene en su adultez se basan en el estilo de apego (seguro, evitativo, ansioso-ambivalente) o calidad de la 
relación de esa persona cuando era niña con la persona principal que le cuidó durante la infancia.

"En la visión feminista, el amor es histórico, está condicionado por las épocas y las culturas, está especializado por géneros, tiene normas y mandatos diferentes para los varones y las mujeres, y va de la mano con el poder. El vínculo entre el poder y el amor es central en la visión feminista del amor" (Lagarde, 2005, p.359)

Cabe la posibilidad de encontrar dos tipos de amor diferentes que se suceden en el tiempo. (Taylor, 1994)

- El amor sexual o pasional, compuesto por fuertes sentimientos incontrolables de atracción hacia la persona deseada y ansiedad y malestar en su ausencia; elevados niveles de activación fisiológica y deseo sexual; pensamientos obsesivos sobre la persona amada y patrón conductual que incluye expresión de los afectos, apoyo físico y emocional o aceptación incondicional.

- El amor romántico no pasional compuesto por pensamientos de necesidad, cuidado y confianza en la pareja: sentimientos de bienestar y dificultad de concentración y conductas de intimidad, apoyo y tolerancia hacia la otra persona.

Desde una perspectiva patriarcal, el amor entre dos grandes colectivos sexuales: las mujeres y los hombres, es imposible, y lo es tanto en cuanto por definición se admite, que el amor sólo es posible entre iguales. Esto entra en contradicción con la idea del amor imposible entre hombres, ya que de ellos se espera que luchen entre sí para mantener el orden del cual su manifestación primaria es la posesión del territorio y de las propias mujeres. En todo caso los hombres admiran a los "mejores" de entre ellos para una mayor aproximación al modelo propuesto de lo que significa ser viril. 
La sociedad patriarcal, estructurada sobre los valores de violencia, enfrentamiento y lucha, habla mucho del amor sin duda por encontrarse éste ausente. El hombre no debe amar a la mujer, a ninguna mujer, las madres es una excepción, porque amar al inferior, al subordinado, equivale a hacerse su igual y debilitarse. De ahí que el varón desee en lugar de amar.

Esta puntualización, nos remite a la imposibilidad del amor en una sociedad erigida sobre relaciones de poder. El amor es negado permanentemente por quienes detentan el poder. El amor, así pues, cuando se piensa que pueda ir más allá de la mera satisfacción del instinto sexual, es calificado de inadecuado o ridículo.

Puesto que el amor no está legitimado por las normas patriarcales, se puede decir que el amor es un concepto en formación. Distintas disciplinas, como la Historia, la Filosofía, la Literatura, la Psicología, nos permiten rastrear cómo ha sido y sigue siendo el proceso de formación de este sentimiento, cuya eclosión habrá de significar un salto cualitativo en las relaciones humanas.

Ahondando en el origen del amor, suele considerarse que el amor romántico surge en los siglos XII y XIII con la tradición del amor cortés entre los trovadores (González y Santana, 2001) y (Yela, 2000). El amor cortés ensalzaba el amor como auténtica base de la relación entre un hombre y una mujer, desvinculando amor y sexo (de hecho se trataba habitualmente de un amor platónico y espiritual).

Estos prototipos presentes en las novelas de caballería medievales han llegado casi intactos hasta nuestros días en forma de cuentos, canciones e incluso libros o películas cuyas heroínas, o princesas, tienen como objetivo prioritario lograr el amor en forma de "príncipe azul", dedicando a ello gran cantidad de esfuerzos y energías.

Volviendo a la actualidad, cabe señalar, que obviamente, el hecho de que en las sociedades occidentales modernas una de las instituciones 
sociales básicas, como es la familia, se fundamente en el matrimonio y éste, a su vez, en el amor romántico, no es en absoluto ajeno al interés despertado por esta cuestión en diferentes ámbitos científicos y, entre ellos, en la psicología social (Sangrador, 1993)

La diferencia hombre/mujer, excusa para el desamor, se convierte por esto mismo en paradigma de los sentimientos humanos en general. $Y$ desde dicho paradigma se puede afirmar lo siguiente:

- El amor cuya dirección va del hombre a la mujer no es tal sino una lucha por conquistarla a ella, para obtener su amor. Desesperado por entender que en buena ley no se puede amar al agresor, el hombre lucha para que la mujer le ame a pesar de todo, es decir, a pesar de que lo lógico es que no lo ame. Es el amor paradójico.

- Según el paradigma de amor del hombre, las mujeres quedan clasificadas en tres categorías: esposa, amante, prostituta. Cualquier otra categoría es sólo una variación de estas tres. $Y$ ninguna el amor en plenitud.

- La posición desigual, asimétrica, de hombres y mujeres, produce los siguientes efectos sobre el amor:

1) Lo impide

2) Si lo hay, lo hace trágico

3) Si lo hay, lo hace vergonzoso

4) Si lo hay, lo hace tímido, débil, miserable.

Hay hombres que prescinden del amor de las mujeres, aunque a veces pueden tener una madre, una hija o una hermana cuyo afecto no valoran como tal porque no son compañeras sexuales, pero de cuyo amor se alimentan. Hay hombres también que se ganan el amor de una mujer con promesas, regalos y otras formas externas permitidas a los varones para 
solicitar amor; cuando esto falla también lo solicitan fingiéndose indignos del mismo. Como esto último sólo sucede en situaciones privadas, el orgullo viril en lo público queda a salvo. Generalmente cuando el hombre ha obtenido el amor-limosna de la mujer, cambia su actitud inicial por la de desprecio. El varón encuentra a menudo más placer en el propio forcejeo para obtener amor que en el disfrute del amor mismo, lo cual no es de extrañar si la estructura de base está montada sobre la lucha y no sobre la comprensión.

El amor que toma la dirección mujer-hombre es cualitativamente diferente. Consciente o inconscientemente, lo sepa ella misma o no, la mujer aprendió in illo tempore a amar al hombre como hijo y como hermano-propio y/o de las demás mujeres, como individuo a solicitar, mucho antes de que el macho humano tomara el poder y la oprimiera. La doble condición de todo hombre de individuo patriarcal y, a la vez, de "nacido de mujer", permite que la mujer pueda amar al hombre, a pesar de las circunstancias adversas para su sexo.

Desde esta óptica podría decirse que la esposa, o la pareja, están condenadas a no ser amadas y sí sólo sexualmente deseadas.

La primera referencia a la aproximación entre los sexos, la encontramos en el siglo XII en Francia, es un movimiento cultural denominado amor $\mathrm{fi}^{23}$. Se da por supuesto que este amor sólo puede existir fuera del matrimonio, ya que las condiciones de este último son incompatibles con tal sentimiento. El amor es, pues, adúltero.

En el siglo XIX el amor romántico es en parte una vuelta al amor cortés de romance. Forma parte del movimiento artístico y literario de la época. Pero, como en Tristán e Isolda, si hay amor hay tragedia. La reunión de los conceptos de amor y muerte es propiamente masculina y de base misógina; incapaces de resolver la paradoja de amar a quien a la vez se oprime, los

\footnotetext{
${ }^{23}$ Movimiento que surge cuando mujeres letradas de la época, abren salones y se impone la moda de la poesía lírica y el amor refinado
} 
románticos prefieren a veces el suicidio como solución al problema. O el crimen contra la mujer.

El siglo $X X$ trae consigo una nueva ola de rechazo a la mujer, esta vez con la excusa de que es feminista. El hombre se presenta como irreprochable y si tiene algún fallo la culpable es ella, por tener personalidad y resultar, por lo tanto, castradora. El matrimonio burgués, por otra parte, pretende que se vaya al mismo por amor. Por primera vez en la historia hombres y mujeres pasan mucho tiempo juntos y en espacios pequeños en los que es inevitable encontrarse: las viviendas. Y ellas, las mujeres, ocupan además un espacio exterior que, de masculino, se ha convertido en mixto.

En el patriarcado el hombre se avergüenza de amar a la mujer; teme el juicio de los demás varones y que le consideren débil o afeminado. Para defenderse del peligro de amar, él la tilda a ella de sentimental y se ríe de sus sentimientos como de una debilidad.

Las falsas creencias del amor irracional conducen a errores que asociados a la renuncia, (generalmente por parte de ellas), y a la sumisión femenina, perpetúan los mitos del amor que perdura y que no en pocas ocasiones desemboca en la agresión hacia la mujer.

El amor es una construcción cultural y cada período histórico ha desarrollado una concepción diferente del amor y de los vínculos que deben existir o no entre el matrimonio, el amor y el sexo (Barrón, Martínez-Íniigo, De Paul y Yela, 1999) y (Yela, 2003). Así, en la antigua Grecia las relaciones afectivas (heterosexuales, pero sobre todo homosexuales) estaban fuertemente relacionadas con la esfera sexual y claramente separadas del matrimonio donde únicamente la mujer debía ser fiel a su marido y donde el sexo tenía como finalidad la procreación; durante el Imperio Romano, el placer erótico estaba también separado del matrimonio y ligado a conquistas esporádicas y ocasionales; en la Alta Edad Media el amor, el matrimonio y el placer sexual eran vistos como tres entidades independientes que eran satisfechas en relaciones diferentes; entre los siglos XVI y XVIII continuaban 
existiendo de forma simultánea el matrimonio de conveniencia y el amor romántico no sexual (cuyo origen era el amor cortés medieval); desde los inicios del siglo XIX surge la conexión entre los conceptos de amor romántico, matrimonio y sexualidad que llega hasta nuestros días (Barrón et al., 1999). Y a lo largo de las últimas décadas en la cultura occidental esta relación se ha ido estrechando cada vez más, llegando a considerarse que el amor romántico es la razón fundamental para mantener relaciones matrimoniales y que "estar enamorado/a" es la base fundamental para formar una pareja y para permanecer en ella (Simpson, Campbell y Berscheid, 1986) y (Ubillos , 2001), de modo que el amor romántico se hace popular y normativo, el matrimonio aparece como elección personal y el amor romántico y la satisfacción sexual deben lograrse en el matrimonio (Barrón et al., 1999) y ( Yela, 2003)

Posteriormente Stemberg (1989) sugiere que la combinación de tres elementos (intimidad, pasión y compromiso), generaría diversas posibles clases de amor: Simpatía, donde existe intimidad, pero no amor ni compromiso (por ejemplo, los amigos y amigas que tenemos); el enamoramiento, donde existe pasión, pero no intimidad ni compromiso (por ejemplo, las relaciones basadas en la atracción física); sólo compromiso, donde existe compromiso, pero no intimidad ni pasión (por ejemplo, aquellas parejas cuya relación se mantiene en el tiempo por diversas razones, pero en las que se ha perdido la pasión y la intimidad); amor romántico, que incluye intimidad y pasión pero donde no hay compromiso por lo que es difícil el mantenimiento de la relación en el tiempo; amor de compañeros/as, que incluye intimidad más compromiso pero sin pasión; amor loco, que incluye pasión más compromiso, pero sin intimidad o conocimiento entre los miembros de la pareja como ocurre en las relaciones cinematográficas; amor completo, que incluye intimidad, más pasión, más compromiso y que constituiría la situación ideal, según este modelo.

Para finalizar este apartado, y dado nuestro particular interés por el tema en el marco de esta investigación, recogemos las ideas que aparecen como 
más características de lo que el amor romántico implicaría para los miembros de la pareja, según resume Ferreira (1995)

- Entrega total a la otra persona.

- Hacer de la otra persona lo único fundamental de la existencia.

- Vivir experiencias muy intensas de felicidad o de sufrimiento.

- Depender de la otra persona y adaptarse a ella, postergando lo propio.

- Perdonar y justificar todo en nombre del amor.

- Consagrarse al bienestar de la otra persona.

- Estar todo el tiempo con la otra persona.

- Pensar que es imposible volver a amar con esa intensidad.

- Sentir que nada vale tanto como esa relación.

- Desesperar ante la sola idea de que la persona amada se vaya.

- Pensar todo el tiempo en la otra persona, hasta el punto de no poder trabajar, estudiar, comer, dormir, o prestar atención a otras personas menos importantes.

- Vivir sólo para el momento del encuentro.

- Prestar atención y vigilar cualquier señal de altibajos en el interés o el amor de la otra persona.

- Idealizar a la otra persona no aceptando que pueda tener algún defecto.

- Sentir que cualquier sacrificio es positivo si se hace por amor a la otra persona. 
- Tener anhelos de ayudar y apoyar a la otra persona sin esperar reciprocidad ni gratitud.

- Obtener la más completa comunicación.

- Lograr la unión más íntima y definitiva.

- Hacer todo junto a la otra persona, compartirlo todo, tener los mismos gustos y apetencias.

Obviamente estamos frente a un conjunto de mitos e ideas y creencias irracionales, frente a un modelo de conducta imposible de seguir y, por tanto, que fácilmente desembocará en desengaños y frustraciones.

\section{2.- Mitos y falsas creencias acerca del amor. Los celos.}

Un mito no es más que una creencia, aunque se halla formulada de tal manera que aparece como una verdad y es expresada de forma absoluta y poco flexible. Este tipo de creencias suelen poseer una gran carga emotiva, concretan muchos sentimientos, y suelen contribuir a crear y mantener la ideología del grupo, y por ello suelen ser resistentes al cambio y al razonamiento.

Tal y como señala Yela (2003), podemos considerar que los mitos románticos son el conjunto de creencias socialmente compartidas sobre la "supuesta verdadera naturaleza del amor", y, al igual que sucede en otros ámbitos, también los mitos románticos suelen ser ficticios, absurdos, engañosos irracionales e imposibles de cumplir. 
Este autor realiza una revisión de los principales mitos románticos, sus orígenes y sus posibles consecuencias negativas que resumimos a continuación (Yela, 2003)

- Mito de la media naranja, o creencia de que elegimos a la pareja que teníamos predestinada de algún modo y que ha sido la única elección posible. Este mito tiene su origen en la Grecia Clásica (con el relato de Aristófanes sobre las almas gemelas) y se intensifica con el amor cortés y el romanticismo. La aceptación de este mito podría llevar a un nivel de exigencia excesivamente elevado en la relación de pareja, con el consiguiente riesgo de decepción, o a una tolerancia excesiva en el marco de esa relación, al considerar que siendo la pareja ideal hay que permitirle más o esforzarse más (uno/a mismo/a) para que las cosas vayan bien.

- Mito del emparejamiento o de la pareja, creencia de que la pareja heterosexual es algo natural y universal y que la monogamia amorosa está presente en todas las épocas y todas las culturas. Este mito fue introducido por la Cristiandad. La aceptación de esta creencia dará lugar a conflictos internos en todas aquellas personas que se desvíen de algún modo de esta creencia normativa (personas que no están emparejadas, que lo están con personas de su mismo sexo...)

- Mito de la exclusividad, o creencia en que es imposible estar enamorado/a de dos personas a la vez. La aceptación de esta creencia puede suponer conflictos internos para la persona (dudas,...) además de evidentes conflictos relacionales.

- Mito de la fidelidad, o creencia de que todos los deseos pasionales, románticos y eróticos deben satisfacerse exclusivamente con una única persona, la propia pareja, si es que se la ama de verdad. 
- Mito de los celos, o creencia de que los celos son un signo de amor, e incluso el requisito indispensable de un verdadero amor. Este mito es también introducido por la Cristiandad y constituye un garante de la exclusividad y la fidelidad, anteriormente comentadas. Este mito suele usarse habitualmente para justificar comportamientos egoístas, injustos, represivos y, en ocasiones, violentos.

- Mito de la equivalencia, o creencia en que el amor y el enamoramiento son equivalentes $y$, por tanto, si una persona deja de estar apasionadamente enamorada es que ya no ama a su pareja y, por ello, lo mejor es abandonar la relación. Las investigaciones sobre el tema han mostrado que los procesos psicológicos e interpersonales característicos de las fases de enamoramiento intenso van modificándose con el tiempo, dando lugar a procesos de otro tipo. Aceptar este mito supone no reconocer la diferencia entre una cuestión y otra y no reconocer como natural esa transformación, lo que puede llevar a vivirla de modo traumático.

- Mito de la omnipotencia o creencia de que el amor lo puede todo y por tanto si hay verdadero amor no deben influir los obstáculos externos o internos sobre la pareja, y es suficiente con el amor para solucionar todos los problemas. La aceptación de este mito puede generar dificultades en tanto en cuanto puede ser usado como una excusa para no modificar determinados comportamientos o actitudes o puede llevar a una valoración negativa de los conflictos de pareja dificultando su afrontamiento.

- Mito del libre albedrío, o creencia de que nuestros sentimientos amorosos son absolutamente íntimos y no están influidos por factores socio-biológico-culturales ajenos a nuestra voluntad y 
conciencia. Este mito se expande durante el Renacimiento, el Barroco y posteriormente durante el Romanticismo. Aceptar este mito supone no reconocer las presiones biológicas, sociales y culturales a las que las personas estamos 0 podemos estar sometidas, lo cual puede llevar a consecuencias negativas (exceso de confianza, culpabilización...)

- Mito del matrimonio o de la convivencia, creencia de que el amor romántico pasional debe conducir a la unión estable de la pareja y constituirse en la única base de la convivencia de la pareja. Tal como ya hemos comentado anteriormente, a finales del s. XIX se inicia una corriente que vincula por primera vez en la historia los conceptos de amor romántico, matrimonio y sexualidad y a partir de la cual el amor romántico se hace normativo, el matrimonio deja de ser concertado y pasa a ser por amor y no sólo el amor romántico si no también la satisfacción sexual debería darse en el matrimonio.

- Mito de la pasión eterna o de la perdurabilidad, esto es, creencia de que el amor romántico y pasional de los primeros meses de una relación puede y debe perdurar tras años de convivencia. Este mito surge muy ligado a esta nueva corriente ya que si amor, pasión y matrimonio van unidos y se pretende que el matrimonio sea duradero, la pasión y el amor deben serlo también.

A todos los posibles problemas derivados que se han comentado para todos y cada uno de los mitos descritos, cabría añadir, como hace Altable (1998), la crítica desde una perspectiva de género en tanto en cuanto una parte importante de ellos han sido impulsados desde los estamentos religiosos, pero también desde otros estamentos de la sociedad patriarcal para reforzar el papel pasivo y de subordinación de la mujer al varón 
(sacralizando la pareja y el matrimonio, dándole carácter de destino irreductible, reforzando la pasividad y el papel de cuidadora, etc.)

No podemos finalizar este apartado sin antes hacer una mención especial al problema de los celos, pues los celos y su consideración como requisito del verdadero amor, constituyen uno de los mitos ligados al amor romántico.

Los celos son una experiencia emocional compleja negativa, compuesta por al menos tres emociones básicas: la ira, la tristeza y el miedo. Surgen ante la percepción de que una relación valiosa o significativa está amenazada y puede llegar a perderse o a deteriorarse como consecuencia de la aparición de una tercera persona, con independencia de que la amenaza sea real o imaginaria y que puede tener manifestaciones conductuales o fisiológicas diversas, dependiendo de las diferencias individuales, sociales, culturales, etc. (Barón y Martínez-Íñigo, 2001) y (Cantó, García Leiva y Gómez- Jacinto, 2005)

Los celos y su consideración como requisito del verdadero amor, constituyen uno de los mitos ligados al amor romántico. Como señalan Barrón y Martínez-Íñigo (2001), el contenido de algunas obras de las creencias y mitos del amor romántico aportarían claros indicios para comprender la conexión entre romanticismo y celos. Así, entre las creencias románticas están, como ya se ha comentado, la exclusividad (sólo se puede amar a una persona), la mitificación del sexo (como sinónimo de amor) o la predestinación (hay una persona destinada para cada uno/a de nosotros/as y capaz de satisfacer nuestros deseos)

En relación a las diferencias en la manifestación de los celos, se han sugerido, por ejemplo, que algunas de las expresiones conductuales de los celos estarían relacionadas con la emoción dominante en cada caso, de modo que si la emoción predominante fuera la ira, los celos se manifestarían de modo explosivo con acciones de agresividad, ofensas verbales 0 conductas violentas dirigidas hacia la persona con la que se mantiene la relación o hacia "la tercera persona"; en cambio, si la emoción predominante 
fuera la tristeza serían frecuentes acciones como el llanto, el retraimiento o el consumo de alcohol o drogas; $y$, finalmente, si predominara el miedo a la pérdida serán frecuentes acciones tendentes a restablecer la relación (grandes gestos,...) (Chóliz y Gómez, 2002)

Entre las variables más empleadas para explicar las diferencias individuales en la expresión de los celos se halla el género. Así por ejemplo, Canto Ortiz, García Leiva y Gómez Jacinto (2009) resumen los resultados de diversas investigaciones sobre el tema según los cuales, ante el descubrimiento de que su pareja está teniendo una relación con otra persona, los hombres tenderían a mostrar sentimientos de cólera (que en algunos casos llegan a expresar violentamente) y a abandonar la relación, mientras las mujeres tenderían a mostrar sentimientos de depresión, culpándose a sí mismas y tratando de recuperar a su pareja; por otra parte, los hombres se preocuparían más ante una infidelidad sexual, mientras que las mujeres mostrarían más preocupación ante una infidelidad emocional. Buunk (2005), Gómez, Canto y García-Leiva (2001)

Desde una perspectiva genética y evolucionista, sostenida por autores como Buss, Larsen, Wsten y Semmelroth (1992), se ha sugerido que estas diferencias son el resultado de los distintos mecanismos adaptativos que los hombres y las mujeres han puesto en práctica a lo largo de su evolución. De acuerdo con ello, para garantizar la transmisión de sus genes, los hombres habrían necesitado una pareja sexualmente fiel evitando así el riesgo de invertir recursos en un descendiente que no fuera propio (motivo por el cual les inquietaría más la infidelidad sexual que la emocional); por su parte, para garantizar el aporte de recursos para ellas y sus descendientes las mujeres necesitarían una pareja que les fuera fiel emocionalmente y estuviera dispuesta a hacer esa inversión (motivo por el cual las inquietaría más la infidelidad emocional que la sexual).

Desde un punto de vista evolucionista, también se han analizado las características del rival, señalando, como remarca Yela (2000) que en caso 
de celos la persona trata de evaluar si su rival le supera en ciertas características y los análisis sobre el tema han detectado diferencias de género en las características del rival que provocan celos, de modo que, en general, las mujeres son más sensibles al atractivo físico del rival (que sería la característica que los hombres más valorarían en una pareja) mientras los hombres son más sensitivos hacia el estatus y la dominancia social del rival (que son las características que las mujeres más valorarían en una pareja).

Como señala García-Leiva (2001), desde un punto de vista cultural el análisis de las características del rival ha sido estudiado como un proceso de comparación social en el que se pone en juego el auto concepto de la persona.

Para concluir, una reflexión acerca de los celos de Bosch y Ferrer (2002). El mito popular que relaciona los celos y el amor constituye un grave problema en el ámbito de la violencia contra las mujeres en la pareja al remitir al terreno de los sentimientos algo que no es más que una forma de poder y de dominación y que se convierte en una estrategia de control más de las diversas que emplean los maltratadores.

\section{3.- La interiorización de la ideología del amor romántico.}

¿Cómo se llegan a interiorizar las anteriores creencias y por tanto a convertirlas en motivaciones y justificaciones de una acción determinada?

La socialización es el proceso, que se inicia en el momento del nacimiento y perdura durante toda la vida, a través del cual las personas, en interacción con otras personas, aprenden e interiorizan los valores, las actitudes, las expectativas y los comportamientos característicos de la 
sociedad en la que han nacido y que le permiten desenvolverse en ella (Giddens, 2001). Se trata pues del proceso por el que las personas aprenden y hacen suyas las pautas de comportamiento social de su medio socio-cultural. En el caso de que la persona no siga las pautas de comportamiento social establecidas se habla de desviación social.

Según la teoría de la socialización diferencial, las personas, en su proceso de iniciación a la vida social y cultural, y a partir de la influencia de los agentes socializadores, adquieren identidades diferenciadas de género que conllevan estilos cognitivos, actitudinales y conductuales, códigos axiológicos y morales y normas estereotípicas de la conducta asignada a cada género (Barton y Walker, 1983)

Una de las claves de la fuerza del proceso de socialización diferencial radica, precisamente, en la congruencia de esos mensajes emitidos por los diferentes agentes socializadores. Estos mensajes repetidos, recibidos durante la socialización y diferentes para uno y otro sexo son interiorizados por cada persona que "los hace suyos" y acaba pensando y comportándose en consecuencia.

Concretamente, los diferentes agentes socializadores (el sistema educativo, la familia, los medios de comunicación, el uso del lenguaje, la religión) tienden a asociar tradicionalmente la masculinidad con el poder y la racionalidad con aspectos de la vida social pública, como el trabajo, la política... y la feminidad a aspectos de la vida privada y la subordinación al varón, la pasividad, la dependencia, la obediencia... (Alcántara, 2002) y (Pastor, 1996). Así, de una forma explícita unas veces e implícita y sutil y, por tanto, más difícil de contrarrestar otras, se transmite un mensaje androcéntrico, considerando que el hombre es lo importante y el protagonista, mientras la mujer desempeña un papel secundario y de comparsa, considerando, en definitiva, que lo masculino tiene mayor valoración que lo femenino. 
Las claves de esta socialización diferencial serían las siguientes (Cabral y García, 2001) y (Poal, 1993): A los niños, chicos, hombres se les socializa para la producción y para progresar en el ámbito público y, en consecuencia, se espera de ellos que sean exitosos en dicho ámbito, se les prepara para ello y se les educa para que su fuente de gratificación y autoestima provenga del mundo exterior. En relación a ello: se les reprime la esfera afectiva; se les potencian libertades, talentos y ambiciones diversas que faciliten la autopromoción; reciben bastante estímulo y poca protección; se les orienta hacia la acción, hacia lo exterior y lo macrosocial; se les orienta hacia la independencia; y el valor del trabajo se les inculca como una obligación prioritaria y definitoria de su condición. A las niñas, chicas, mujeres se las socializa para la reproducción y para permanecer en el ámbito privado, desarrollando y potenciando las cualidades y habilidades necesarias para desempeñar con éxito los roles a los que estaban destinadas: ser esposas y madres, $\mathrm{Y}$, en consecuencia, se espera de ellas que sean exitosas en dicho ámbito, se las prepara para ello y se las educa para que su fuente de gratificación y autoestima provenga del ámbito privado. En relación a ello: se fomenta en ellas la esfera afectiva; se reprimen sus libertades, talentos y ambiciones diversas que faciliten la autopromoción; reciben poco estímulo y bastante protección; se las orienta hacia la intimidad, hacia lo interior y lo microsocial; se las orienta hacia la dependencia; y el valor del trabajo no se les inculca como una obligación prioritaria y definitoria de su condición.

Recordemos el cuento del Conde Lucanor del marido que se casa con mujer brava. Pues como a la mujer brava no se lo han contado en su casa, se lo cuenta el marido la misma noche de su casamiento. Se sienta a la mesa y dice: "señor perro, venid y traedme la cena". Y la esposa, que lo está contemplando con cara de "atrévete a decirme algo" se queda un tantico asombrada de que el marido le pida al perro que le ponga la cena. Entonces, el marido, airado, repite: "señor perro, os he dicho que me pongáis la cena". $Y$ como el perro no lo hace, se levanta, coge la espada y deja al perro 
deshecho. Calmadamente se sienta de nuevo y apunta: "señor caballo, venid a ponerme la cena". El señor caballo ni a la tercera responde, ni le pone la cena, de ahí que el marido se levanta, destroza al caballo allí mismo y ya en una habitación por completo ensangrentada, con la mejor de las voces, dice: "Señora mujer, parece que nadie quiere ponerme la cena". La señora mujer, que hasta entonces era mujer brava, sin que nadie le tenga que decir nada, rápidamente le pone, temblorosa, la cena.

Así se doma la braveza, pero la femenina. El modelo es antiguo y véase que el varón no ejerce sobre su mujer violencia, sólo apunta la que tiene y la que es permitida. Pero ¿cómo se doma la braveza masculina? De antiguo sólo nos viene la receta de la paciencia y el agrado.

Si hacemos alusión a este antiguo cuento del Conde Lucanor, es porque la historia hoy en día no ha variado en su esencia, muchas jovencitas que presumen de indómitas, sucumben inevitablemente ante los imperativos del varón al que aman sin ningún tipo de fisura. Quizá nadie las obligue explícitamente a la obediencia, pero ellas acaban entrando en la dinámica del control, que en un principio se disfraza de preocupación, de sentimiento de protección y de amor sin límites, firmando tácitamente acuerdos imposibles de mantener en el tiempo, que las conducirá al maltrato, ya en esas primeras relaciones de pareja.

Tal como exponen Hunt, Sowell y Santana (2004), hay cada vez un mayor interés y una mayor preocupación en la sociedad actual respecto al fenómeno de la violencia en las relaciones de pareja de jóvenes y adolescentes. Las estadísticas realizadas en los últimos años por los organismos públicos y privados de diferentes países demuestran que la violencia en las relaciones de pareja es un hecho frecuente.

Durante el proceso de socialización aprendemos lo que significa enamorarse, qué sentimientos debemos tener y cuáles no, de quién sí y de quién no debemos enamorarnos, qué o quién es atractivo y qué o quién no, lo cual suele coincidir con los patrones de rol de género tradicionales, como 
debe ser la relación entre los dos miembros de la pareja (asimétrica, igualitaria,...), etc. $\mathrm{Y}$, evidentemente, aprendemos también todos los mitos sobre el amor imperantes en nuestra cultura, (Duque, 2006), (Flecha, Puigverte y Redondo, 2005) y (Sampedro, 2005)

El modelo de amor romántico que se nos propone como modelo cultural de amor a las mujeres a lo largo del proceso de socialización implica una renuncia personal, un olvido de nosotras mismas, una entrega total que potencian comportamientos de dependencia y sumisión al varón.

La desvalorización de lo femenino y la sobrevaloración de lo masculino están basadas en el modelo social de feminidad y masculinidad sostenido en las sociedades patriarcales por un entramado de mitos y estereotipos que facilitan la violencia contra las mujeres. (Aumann e Iturralde, 2003)

Los/as niños/as y jóvenes se socializan diferencialmente en el marco de una cultura de violencia presente en el entorno (juegos, juguetes, películas, deportes...) Así mientras existe una correlación histórica y cultural entre masculinidad, violencia, agresividad y dominio, fomentando este tipo de comportamiento como prueba de virilidad; la socialización de las mujeres y las niñas incorpora elementos (pasividad, sumisión o dependencia) que las hacen precisamente más vulnerables al padecimiento de comportamientos violentos como víctimas. En palabras de Nogueiras (2005), La desvalorización de lo femenino, la falta de poder y de reconocimiento de su autoridad han contribuido también a que las mujeres se conviertan en víctimas de violencia.

A las chicas se las socializa en el amor y la dependencia transmitiéndoles que ellas tienen una responsabilidad, que la relación se mantenga y que la relación de pareja es básica para su supervivencia y su felicidad (la pareja es su refugio en un mundo convulso y es, al mismo tiempo, su misión); en cambio, a los chicos se les socializa en la autonomía y la independencia. Es decir, según Oliver y Valls (2004), en la socialización actual de los chicos y chicas estadounidenses continuarían imperando los 
modelos de socialización diferencial tradicional según los cuales el papel de las mujeres en el marco de la pareja y las relaciones afectivas es de subordinación y cuidado y el de los varones es de dominación e independencia. Los modelos que nos llegan a través de las series de televisión, películas e incluso libros y contenidos de internet dirigidos a público adolescente y post-adolescente parecen confirmar estas reflexiones.

Por su parte, en una investigación llevada a cabo por Altable (1998) con jóvenes de nuestro entorno se observó que igualmente los roles sentimentales de actividad-pasividad seguían también pautas tradicionales de género de modo que las chicas tendían a mostrar en las relaciones sentimentales que construían un rol pasivo y con predominio del amor, mientras los chicos eran mayoritariamente activos y las preferían a ellas pasivas y en sus historias predominaba el sexo, aunque se observaban algunas tendencias al cambio, sobre todo en las ciudades y entre las clases medias cultas.

Investigaciones recientes en nuestro país confirman en la actualidad estos hallazgos. Así, por ejemplo, Moreno Marimón, González y Ros (2007) observan en estudiantes universitarios/as que las chicas se caracterizan por mostrar una idealización del amor y una entrega incondicional a la relación amorosa, una valoración de la autorrenuncia por satisfacer a la otra persona, un elevado sentimiento de protección y cuidado del otro por encima de la satisfacción de sus propias necesidades e intereses, un concepto del amor que implica sacrificio del yo, identificación con el otro y entrega total a sus deseos, y un deseo de conservar los vínculos de pareja por encima de cualquier otro tipo de consideraciones. En cambio los chicos muestran una disposición mucho menor a la renuncia total, el sacrificio personal y la entrega y una mayor contención emocional. 


\section{4.- Concepto de Dominación.}

En el diccionario básico de la lengua encontramos como sinónimos del término dominación o dominar, las siguientes palabras: someter, conquistar, destacar, reprimir, predominar, desarrollar y obedecer. Esta terminología conduce en esencia a la forma de entender la familia tradicional, en la que un miembro, el varón, está autorizado para ejercer dominación sobre la mujer. Obviamente este tipo de familia se asienta sobre los pilares de una sociedad patriarcal que no sólo permite, sino que también legitima, el maltrato hacia las mujeres en general por parte de los hombres que lo ejercen. Es el movimiento feminista el responsable de visibilizar y denunciar esta situación que alcanza carácter de delito y vulnera los derechos humanos.

"Un elemento importante de la crítica feminista a la institución del matrimonio y la familia heterosexual de dos progenitores, fue mostrar las maneras en las que ésta apoya y refuerza una estructura en la cual las mujeres son oprimidas. Una de las ilustraciones más gráficas de esta violencia en la familia son las palizas sufridas por las mujeres. De modo que, desde este punto de vista, los golpes se ven como un problema que se ha desarrollado a partir de una ideología social y de estructuras que refuerzan a la familia tradicional." (kirkwood, 1999, p.44)

En la década de 1850 se realizaron en Gran Bretaña varias reformas sociales que, junto con el aumento de oportunidades en la educación, señalaron los inicios de una nueva actitud hacia las mujeres que iba a otorgarles mayor libertad de la que habían tenido anteriormente. Así, por ejemplo, en 1852 una ley del parlamento puso fin al derecho del marido a obligar a su mujer a cohabitar con él al dictar auto de habeas corpus contra cualquiera que le diera refugio y en 1857 fue promulgada una primera ley de 
divorcio. Sin embargo, esta ley que permitía al marido divorciarse de su mujer por adulterio, le exigía a ella probar que él era culpable de violación, sodomía o bestialidad, o de adulterio juntamente con incesto, bigamia, crueldad o abandono y un marido todavía tenía derecho a secuestrar y encerrar a su mujer. ${ }^{24}$

Así pues, las feministas del s. XIX y la denominada "primera ola del feminismo" (1850-1950) ya consideraban la "brutalidad masculina" como una cuestión candente e iniciaron la lucha por el reconocimiento de este problema, por la instauración de reformas legales, incluyendo la legalización de la separación y el divorcio, y por el establecimiento de medidas de apoyo para las víctimas. (De Miguel, 2005) y ( Vives, Martín y Frau, 2005)

Las feministas del siglo $\mathrm{XX} y$, especialmente, el movimiento de liberación de las mujeres, iniciado en la década de 1960, ampliaron su campo de denuncia centrándose en nuevos aspectos de la condición femenina y, entre ellos, en la violencia contra las mujeres, primero en la violencia de tipo sexual y después en la que ocurría en las parejas (Anderson y Zinsser, 2000) y ( Heise, 1998)

Como señala Ana de Miguel (2005), dos obras clásicas de esa época, Política sexual (Millet, 1969), y Contra nuestra voluntad: hombres, mujeres y violación (Brownmiller, 1975), contribuyen de modo decidido a cambiar la consideración de la violencia contra las mujeres de problema personal a problema social estructural cuyo origen está en el patriarcado y cuya finalidad es mantener la situación de manifiesta desigualdad.

"R.E. y R.P. Dobash fueron las primeras, en su libro de 1980 Rethinking Violence Against Women. Dobash y Dobash se centran en qué significan las ideas tradicionales y cómo esas ideas apoyan a la institución

${ }^{24}$ Así permaneció hasta una nueva modificación legal en 1891. 
del patriarcado dentro de la cual el abuso sobre la esposa es una forma más destacada del control de la mujer por parte del hombre. Argumentan también que la familia y la posición de las mujeres como esposas, son parte de esta institución." (Kirkwood, 1999, p. 44)

A partir de entrevistas a 137 mujeres golpeadas, Dobash y Dobash registran una cantidad de descubrimientos que indican que las palizas son un modo mediante el cual los hombres controlan a las mujeres y parte de un sistema de control más amplio. Por ejemplo, demostraron que el aislamiento social de las esposas es característico de los matrimonios en los que el varón es proclive a golpear. Con frecuencia los varones incrementan el cultivo de sus vínculos extra hogareños, al tiempo que el contacto de las mujeres con sus amistades decrece a lo largo de su relación en pareja. Además Dobash y Dobash documentaron que las mujeres no son pasivas, o desvalidas, sino que buscan muchas formas de ayuda para reducir lo peligroso de su situación aunque el tipo de ayuda solicitada o recibida sea insuficiente. En síntesis, Dobash y Dobash afirman que los golpes son el producto de un sistema reflejado en leyes históricas acerca de la propiedad masculina y el matrimonio, como así también en los actuales papeles sociales de los sexos y en las estructuras que garantizan la dominación de los hombres sobre las mujeres. Dado que el abuso se da en este contexto patriarcal, es producto del mismo y lo refuerza, es más propio definirlo como abuso a la mujer o abuso a la esposa que como violencia familiar. Las dos primeras expresiones revelan la dirección de la violencia y, por ende, identifican la posición de las mujeres dentro de la relación, haciéndose eco de la histórica sumisión femenina en general. Por el contrario, la última fórmula, más ambigua, oculta el nexo entre la opresión social de las mujeres y sus experiencias particulares de maltrato, tan bien documentadas, por otro lado, en el trabajo de Dobash y Dobash (1980).

Catherine Kirkwood, utiliza la siguiente definición de poder y control. Para esta autora "Existe el control de una persona sobre otra, cuando aquella tiene más dominio sobre la conducta o los puntos de vista de 
la segunda que ella misma. El poder es la suma total de recursos personales y externos que se emplean para lograr el control."(Kirkwood, 1999, p.93)

Mullender (2000) en su libro La violencia doméstica, recoge una definición de Russell de 1990 que pone en franca conexión la violencia que sufren las mujeres con la dominación que su pareja ejerce sobre ellas. "La violencia sexual y física a menudo es parte de una conducta dominante que incluye la violación marital” (Russelll, 1982)

"Soportar ataques graves y constantes tiene consecuencias psicológicas. El sufrimiento emocional crónico no es una reacción anormal, sino normal, ante este tipo de situaciones." (Dobash, Dobash, Wilson y Daly, 1992, p.144)

Entre las tácticas de control que utilizan los hombres se incluye el abuso emocional, esto es, toda palabra o acción dirigida a debilitar la fuerza interna de la mujer y socavar su autoimagen y su autoestima. No es inusual que aquellas que consiguen sobrevivir consideren que, de todas las penalidades que han tenido que pasar, lo más destructivo ha sido la humillación y la degradación.

"Los malos tratos físicos se pueden prolongar desde cinco minutos hasta dos horas, pero el efecto del abuso emocional persiste las veinticuatro horas del día, incluso mientras duermes." (Mullender, 2000, p.48)

(Kirkwood (1999) Recoge una cita de Marilyn Frye (1983) donde nos recuerda que "tenemos una predisposición cultural a definir la coerción en términos de avasallamiento fisco. Sostiene que la manipulación de las opciones de una mujer por otra persona, hecha de tal modo que la alternativa más atractiva a su alcance resulte ser adecuarse al deseo de esa persona, es la manera más predominante en que se ejerce la violencia. Pero este aspecto no es reconocido por la definición de abuso que se basa solamente en la fuerza corporal. Lo mismo sucede con la definición del 
control. Por ejemplo: la tan frecuentemente planteada cuestión de ¿por qué una mujer no se separa de su pareja abusadora en el período durante el cual ella no está físicamente impedida de hacerlo? Encara el tema en términos concretos e ignora la amplia dimensión de control ejercido con tácticas mentales o emocionales." (Kirkwood, 1999, p.94)

De todas las formas de abuso, la violencia física o la anticipación de que ésta se va a producir es el elemento clave que sirve para perpetuar los malos tratos. Por ello, el Proyecto de Intervención de Abusos Domésticos, en Duluth, Minnesota, ilustra los abusos como una rueda, donde el maltrato físico hace girar todos los ejes; esta rueda se mueve hacia un objetivo principal que es el poder y el control del hombre sobre la mujer. Entre los radios de esa rueda se encuentran todas las formas de abuso que este trabajo aborda para dejar patente sobre quién recae la responsabilidad del maltrato y sobre quién las consecuencias del mismo, a pesar de mitos y falsas creencias ligadas al sistema de valores imperante.

Las claves de esta rueda se encuentran en los radios de la misma, claves invisibilizadas en referencia al maltrato contra las mujeres, claves definidas en términos de poder:

Amenazas: Proferir amenazas, o llevarlas a la práctica para herirla emocionalmente. Amenazarla con llevarse a los hijos e hijas, con suicidarse, o con informar en su contra a los Servicios Sociales.

Intimidación: Infundirle temor por medio de miradas, actos y gestos, de alzar la voz, romper objetos y destruir sus pertenencias.

Abuso emocional: Degradarla o hacer que se sienta mal consigo misma, ponerle apodos ofensivos. Hacerle creer que está loca. Utilizar estrategias psicológicas perversas.

Aislamiento: Controlar lo que hace, a quien ve, lo que habla, a donde va. 
Negar, culpar, desvalorizar: Minimizar el abuso sin tomar los intereses de la víctima en serio, negar que el abuso ha ocurrido, culpar a la víctima de causar el comportamiento abusivo. Muchas veces quien agrede justifica sus agresiones por conductas de la víctima, sin asumir su responsabilidad en la agresión.

Utilización de hijos e hijas: Hacerla sentirse culpable con respecto a los niños y niñas. Utilizar a éstos para enviarle mensajes agresivos. Servirse de las visitas para hostigarla

Privilegios de ser hombre: Tratarla como una sirviente. Tomar él todas las decisiones "importantes". Actuar como el "rey de la casa".

Control económico: Impedirle que pueda conseguir o mantener un empleo. Obligarla a pedirle dinero, asignarle una cantidad de dinero. Quitarle el dinero. 
Cuadro 8. Rueda de control y poder.

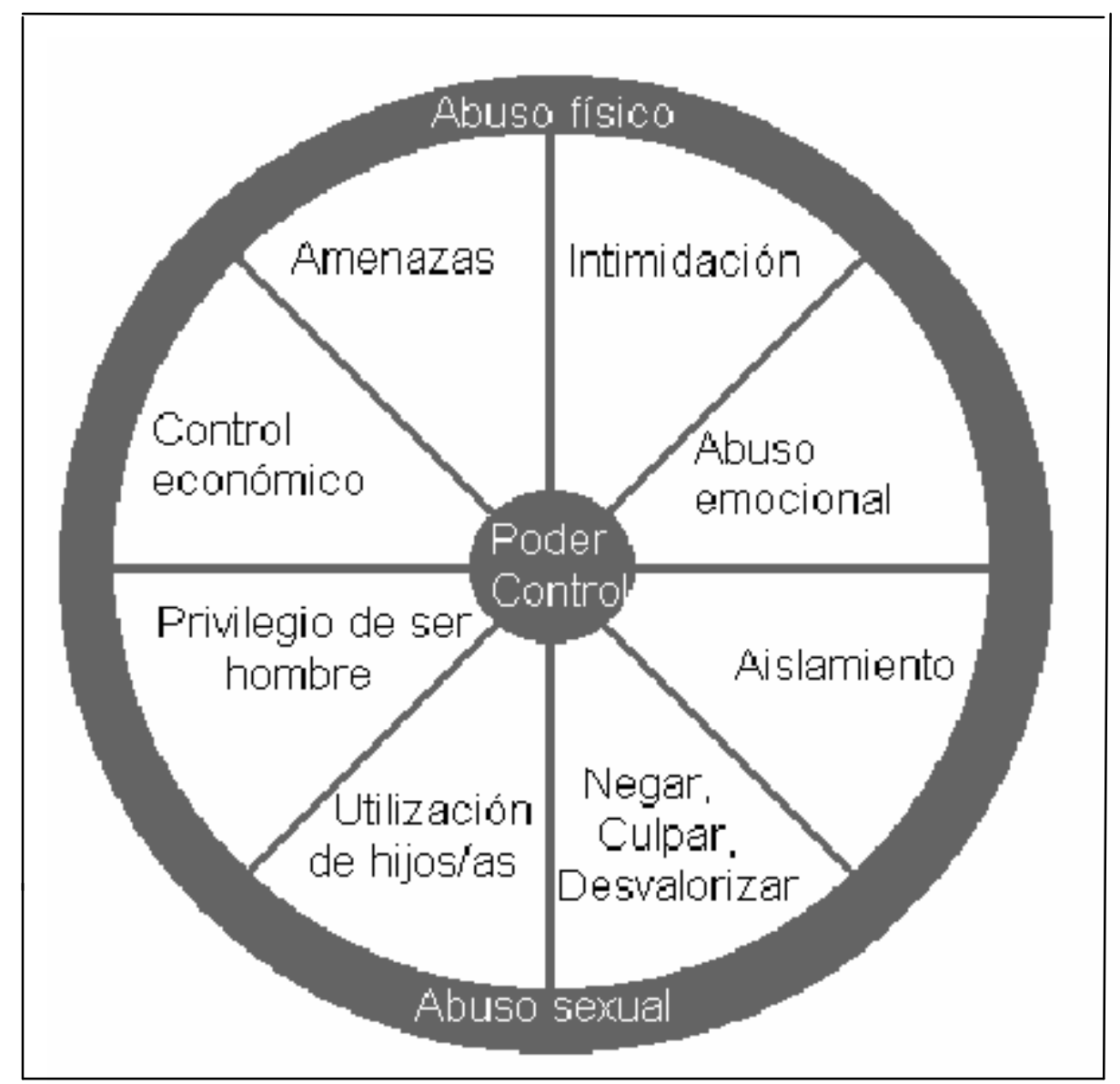

Fuente: (Pence, 1987, p.12)

Si bien la dominación masculina adopta formas y argumentos distintos en función de las diferentes culturas, las mujeres pueden aprender unas de otras porque hay aspectos comunes a todas ellas, por ejemplo el hecho de que sean otras personas distintas de las propias mujeres quienes definan el papel de ésta en la familia y la sociedad. Y comparten además las limitaciones y las responsabilidades asociadas a la crianza de los hijos (Hanmer, 1978) 
Resulta de gran importancia relacionar la violencia contra las mujeres con la posición de subordinación que como género tienen en las sociedades.

"Fue el movimiento de mujeres mundial, y en particular el movimiento feminista, el que en la segunda mitad del siglo XX conceptualizó la violencia contra las mujeres como un problema de poder, específicamente como el desbalance de poder entre los géneros. Este es uno de los referentes para marcar el terreno y delimitar una de las fronteras, la más básica, entre las diversas posiciones existentes al respecto. Es también el primer puntal en el que se sustenta la propuesta de Grupos de Autoayuda de Mujer no estás sola." (Carcedo Cabañas y Molina Subirós, 2001, p.03)

Estas autoras hacen un repaso por los distintos ámbitos, en los que puede asentarse el freno, para que la dominación de las mujeres siga siendo posible.

"En la relación de pareja y en el seno de las familias se encarnan las relaciones de poder de una sociedad patriarcal y sexista que cuenta con todo un aparataje institucional. Por eso, hemos afirmado que lo personal es político y lo político es personal, como una forma de eliminar la tradicional división entre lo público y lo privado. Hemos hablado de las leyes hechas por los hombres para mantener su dominación de género; de la policía como guardiana de ese orden patriarcal; de las instituciones estatales, insensibles al dolor y a las necesidades de las mujeres maltratadas; de la educación que acuña hombres agresores y mujeres desempoderadas; de las iglesias con sus discursos de perdón; de la moral judeocristiana de culpa y renuncia a la felicidad en este mundo; y de la mística femenina de sacrificio a favor de los otros, en que somos educadas las mujeres. Y también de la estructura de propiedad y de crédito, que coloca los recursos económicos en manos masculinas; de la estructura política formal que excluye a las mujeres de las decisiones y de los controles; y de las costumbres y tradiciones que son 
prácticas estereotipadas, ritos de mantenimiento del orden establecido entre géneros." (Cardedo Cabañas y Molina Subirós, 2001, p.07)

El poder del hombre sobre la mujer, se alimenta de relaciones basadas en el dominio, nacidas de falsas creencias sobre la necesidad de pertenencia que sienten las mujeres, cuando piensan que por sí mismas no tienen ningún valor ante el mundo.

Marcela Lagarde piensa que "para las mujeres, amar es colocar al otro en el lugar de ser lo más importante del mundo, más importante que una misma. Decimos: sin ti me muero y eso significa que la sustancia de mi vida está en ti, no en mí, que mi vitalidad depende de tu existencia, no de la mía, que mis pensamientos están habitados por ti, que mi amor está monopolizado por ti. Es lo que algunas autoras han llamado la colonización de las mujeres a través del amor. Te coloniza otra persona, te habita. No solamente habita entre tus cuatro paredes, sino que habita tu cuerpo, tu subjetividad, tus anhelos, tus pensamientos. En la colonización amorosa, una persona ejerce poderes de dominación sobre la otra." (Lagarde, 2005, p.31)

Desde el feminismo se hace visible la dominación padecida por las mujeres, cuando se hace posible la solidaridad entre las mismas, dejando así al descubierto, la tiranía del patriarcado. Esa solidaridad funciona a modo de escudo protector entre las propias mujeres.

La sororidad es la gran aportación del feminismo a la cultura contemporánea, a la cultura del nuevo siglo. La sororidad es la última de las grandes pautas del feminismo, que hoy ya empieza a ser retomada por grupos, movimientos y colectivos que se plantean establecer una nueva ética entre las mujeres.

"En esta nueva ética entre las mujeres no hemos eliminado las causas de la competencia. Sin embargo, y a pesar de que subsisten esas causas, por voluntad y por libertad, decidimos no competir más entre 
nosotras. Y esta decisión es una innovación en la cultura y en la convivencia. $Y$ tiene un principio posible, realizable, sencillo: para poder crear la sororidad entre las mujeres, basta que por un tiempo, por unos años, hasta que se vaya generalizando por todas partes, hasta que ya se nos vuelva costumbre, nos comprometamos a dejar de ser misóginas. Nada más, basta eso." (Lagarde, 2005, p.109)

El feminismo ha jugado un papel importante en la lucha contra la dominación masculina y para que quede constancia de la terminología machista que no podemos olvidar, para poder combatir, de nuevo recurrimos al diccionario ideológico feminista (Sau, 1990) que aunque entre sus términos, no figura el de dominación, podemos aproximarnos al mismo a través de otros allí recogidos y relacionados, como por ejemplo: derecho de pernada, dote, machismo, marido o miedo. Estos términos evidencian la cultura contra la que hemos de luchar, fuertemente instaurada en la sociedad.

Es de referencia obligada, antes de concluir este apartado, citar la obra de Pierre Bordieu (2000), La Dominación Masculina. En este libro Bordieu establece una comparativa entre las costumbres asociadas al género de la sociedad Cabileña y las costumbres, igualmente asociadas al género, de las sociedades occidentales más desarrolladas.

El autor señala las coincidencias androcéntricas que se transmiten y perduran a pesar del paso del tiempo. Estas coincidencias las traslada de una sociedad primitiva y ancestral a la nuestra moderna y contemporánea. Esto lo hace recordando que lo que en la historia aparece, como eterno, sólo es el producto de un trabajo de eternización que incumbe a instituciones interconectadas entre sí, como son la familia, la iglesia, el estado...

“Las relaciones entre los sexos están menos transformadas de lo que una observación superficial podría hacer creer y que el conocimiento de las estructuras objetivas y de las estructuras cognitivas de una sociedad androcéntrica especialmente bien conservada (como la sociedad cabileña, 
tal como yo pude observarla a comienzos de los años sesenta) ofrece unos instrumentos permanentes para entender algunos de los aspectos mejor disimulados de lo que son estas relaciones en las sociedades contemporáneas más adelantadas económicamente, hay que preguntarse, en efecto, cuáles son los mecanismos históricos responsables de la deshistoricización y de la eternización relativas de las estructuras de la división sexual y de los principios de división correspondientes. (Bourdieu, 2000, p. 07)

También este autor hace alusión a la utilización de la violencia simbólica como método de dominación.

"Y siempre he visto en la dominación masculina, y en la manera como se ha impuesto y soportado, el mejor ejemplo de aquella sumisión paradójica, consecuencia de lo que llamo la violencia simbólica, violencia amortiguada, insensible e invisible para sus propias víctimas, que se ejerce esencialmente a través de los caminos puramente simbólicos de la comunicación y del conocimiento o, más exactamente, del desconocimiento, del reconocimiento o, en último término, del sentimiento".(Bourdieu ,2000, p.12)

Bourdieu hunde las raíces del patriarcado, responsabilizando del mismo a tres instancias: la escuela, la familia y la iglesia.

"El trabajo de reproducción quedó asegurado, hasta una época reciente, por tres instancias principales, la Familia, la Iglesia y la Escuela, que, objetivamente orquestadas, tenían que actuar conjuntamente sobre las estructuras inconscientes." (Bordieu, 2000, p.107)

De la familia, dice Bordieu que es la que asume el principal papel en la reproducción de la dominación. En ella, parece que es donde se impone la experiencia precoz de la división sexual del trabajo. Por su parte la iglesia, habitada por un profundo antifeminismo, es la responsable de la visión pesimista de las mujeres y de la feminidad, inculcando una moral pro familia, 
enteramente dominada por los valores patriarcales, especialmente por el dogma de la inferioridad natural de las mujeres. La escuela, finalmente, incluso cuando está liberada del poder de la iglesia, sigue transmitiendo los presupuestos de la representación patriarcal (basada en la homología entre la relación hombre/mujer y la relación adulto/niño).

Para terminar de orquestar las actuaciones de estas instituciones, que juegan en contra de las mujeres, Bourdieu, pone su punto de mira y responsabiliza al Estado, que ha respaldado y hecho posible que esta desigualdad perdurara a través de los años.

"Para completar el censo de los factores institucionales de la reproducción de la división de los sexos, convendría tomar en consideración el papel del Estado, que ha acudido a ratificar e incrementar las prescripciones y las proscripciones del patriarcado privado con las de un patriarcado público, inscrito en todas las instituciones encargadas de gestionar y de regular la existencia cotidiana de la unidad doméstica. Sin alcanzar el grado de los Estados paternalistas y autoritarios (como la Francia de Petain o la España de Franco), realizaciones perfectas de la división ultraconservadora que convierte a la familia patriarcal en el principio y en el modelo del orden social como orden moral, basado en la preeminencia absoluta de los hombres respecto a las mujeres, de los adultos respecto a los niños, y de la identificación de la moralidad con la fuerza, con la valentía y con el dominio del cuerpo, sede de las tentaciones y de los deseos, los Estados modernos han inscrito en el derecho de la familia, y muy especialmente en las reglas que regulan el estado civil de los ciudadanos, todos los principios fundamentales de la división androcéntrica." (Bourdieu, 2000, p.109)

Al movimiento feminista, hay que agradecerle, además de otras cuestiones, el evitar que se haya impuesto de una forma obvia, la dominación masculina en la sociedad de nuestro tiempo. El cuestionamiento de las evidencias va acompañado de las profundas transformaciones que ha 
conocido la condición femenina, sobre todo en las categorías sociales más favorecidas: por ejemplo, el mayor acceso a la enseñanza secundaria y superior, al trabajo asalariado, y a partir de ahí, a la esfera pública, o también, el distanciamiento respecto a las labores domésticas ${ }^{25}$ y las funciones de reproducción., especialmente con el retraso en la edad de contraer matrimonio y de procrear, la disminución de la interrupción de la actividad profesional con motivo del nacimiento de un niño, así como el aumento de las tasas de divorcio y la disminución de las tasas de nupcialidad.

"Uno de los caminos más importantes en la condición de las mujeres y uno de los factores más decisivos de la transformación de esa condición es sin duda alguna el aumento del acceso de las muchachas a la enseñanza secundaria y superior, que, en relación con las transformaciones de las estructuras productivas (especialmente el desarrollo de las grandes administraciones públicas o privadas y de las nuevas tecnologías sociales de encuadramiento), ha provocado una modificación muy importante de la posición de las mujeres en la división del trabajo. Se observa, pues, un fuerte incremento de la representación de las mujeres en profesiones intelectuales o la administración y en las diferentes formas de venta de servicios simbólicos -periodismo, televisión, cine, radio, relaciones públicas, publicidad, decoración-, así como una intensificación de su participación en las profesiones próximas a la definición tradicional de las actividades femeninas (enseñanza, asistencia social, actividades relacionadas con la medicina)." (Bourdieu, 2000, p. 113)

\footnotetext{
25 Un factor no despreciable de cambio es, sin duda, la multiplicación de los instrumentos técnicos y de los bienes de consumo que han contribuido a aliviar las tareas domésticas, cocina, lavado, limpieza, compras, etc.(como lo demuestra el hecho de que el tiempo dedicado al trabajo doméstico ha disminuido uniformemente tanto en Europa como en Estado Unidos), aunque el cuidado de los niños sigue siendo más difícilmente reducible (si bien más compartido), pese al desarrollo de las guarderías infantiles.
} 


\subsection{Micromachismos:}

Para concluir este apartado referido a la dominación masculina, es imprescindible detenerse en los micromachismos, término acuñado por Luis Bonino (1995-1996)

Este psicólogo propone el concepto de micromachismo para referirse a aquellas conductas sutiles y cotidianas que constituyen estrategias de control y microviolencias que atentan contra la autonomía personal de las mujeres y que suelen ser invisibles o incluso, estar perfectamente legitimadas por el entorno social. Se refiere, por tanto a las prácticas de dominación masculina en la vida cotidiana, que incluyen un amplio abanico de maniobras interpersonales que tienen como objetivo:

- Mantener el dominio y su supuesta superioridad sobre la mujer objeto de la maniobra.

- Reafirmar o recuperar dicho dominio ante una mujer que se "rebela".

- Resistirse al aumento de poder personal o interpersonal de una mujer con la que se vincula, o aprovecharse de dichos poderes.

Estos comportamientos son "micro-abusos" y "micro-violencias" y son efectivos porque el orden social imperante los ratifica, porque se ejercen reiteradamente hasta llevar a una disminución importante de la autonomía de las mujeres y porque muchas veces son tan sutiles que pasan inadvertidos para quien los padece y/o para quien los observa.

Con objeto de describirlos adecuadamente, este autor estableció una tipología de los micromachismos clasificándolos en tres categorías: 
- Los micromachismos coercitivos (o directos) incluyen aquellos en los que el hombre usa la fuerza moral, psíquica, económica o de su personalidad, para intentar doblegar a las mujeres y convencerlas de que la razón no está de su parte. Entre los micromachismos coercitivos, Bonino describe los siguientes: intimidación, toma repentina del mando, apelación al argumento lógico, insistencia abusiva, control del dinero, uso expansivo del espacio físico.

- Los micromachismos encubiertos (de control oculto o indirecto) incluyen aquellos en los que el hombre oculta su objetivo de dominio. Algunas de estas maniobras son tan sutiles que pasan especialmente desapercibidas, y por ello pueden llegar a ser más efectivas que las anteriores. Entre los micromachismos encubiertos, Bonino describe los siguientes: maternalización de la mujer, maniobras de explotación emocional, terrorismo, paternalismo, creación de falta de intimidad, engaños, autoindulgencia sobre la propia conducta perjudicial.

- Los micromachismos de crisis suelen utilizarse para establecer el reparto previo y mantener la desigualdad de poder en momentos tales como el aumento del poder personal de la mujer por cambios en su vida o por la pérdida de poder del hombre por razones físicas o laborales. Entre los micromachismos de crisis, Bonino describe los siguientes: seudoapoyo a las tareas de la casa, desconexión y distanciamiento, hacer méritos, dar lástima. 


\section{CAPÍTULO II}

\section{EXPOSICIÓN Y DISCUSIÓN DE RESULTADOS.}

\section{1.- Decisiones metodológicas.}

"Nuevas teorías traen nuevos enfoques, es decir, nuevas metodologías", (Marsal, 1977b, p.287)

Ciertamente según este autor, "la otra acepción en que se usa normalmente el término metodología es equivalente al de técnicas de investigación social". Y añade: "la sociología, y las ciencias sociales en general, han ido desarrollando un instrumental para la investigación social, muchas veces independiente de las orientaciones teóricas" (Marsal,1977b, p.288)

Podemos definir el término metodología como el modo en que son enfocados los problemas para buscarles una respuesta. En las Ciencias Sociales, se aplica, este término, a la manera de realizar la investigación, es decir, los supuestos, los intereses y los propósitos que nos llevan a elegir una metodología determinada. Podemos hacer, a groso modo, una distinción entre las metodologías positivistas y las fenomenológicas, las primeras buscan los hechos o causas de los fenómenos sociales con independencia de los estados subjetivos de los individuos (cuestionarios, inventarios, estudios demográficos), mientras que las segundas, entienden los fenómenos desde la propia perspectiva del actor, la realidad que importa es 
la que las personas consideran como importante (observación participante, entrevista en profundidad). ${ }^{26}$

La utilización adecuada de cualquier técnica de investigación social (cualitativa o cuantitativa) requiere un trabajo previo de toma de decisiones, que se han de plasmar en un diseño específico en el que se conjuguen los objetivos del estudio y la metodología del mismo. En nuestro estudio, hemos optado por un enfoque cualitativo porque sus diseños son flexibles y abiertos, lo que favorece la recogida de información.

La metodología cuantitativa, se refiere en su más amplio sentido a la investigación que produce datos descriptivos: las propias palabras de las personas, habladas o escritas y la conducta observable. La metodología cualitativa, a semejanza de la metodología cuantitativa, consiste en más que un conjunto de técnicas para recoger datos. Es un modo de encarar el mundo empírico.

- La investigación cualitativa es inductiva: el diseño de investigación es flexible. Los investigadores/as comienzan sus estudios con interrogantes sólo vagamente formulados.

- El investigador/a ve el escenario y a las personas en una perspectiva holística: son consideradas, las personas, como un todo. El investigador/a estudia a las personas en el contexto de su pasado y de las situaciones en las que se hallan.

- Los investigadores/as cualitativos son sensibles a los efectos que ellos/as mismos causan sobre las personas que son objeto de su estudio. Actúan de un modo natural y no intrusivo.

- Los investigadores/as cualitativos tratan de comprender a las personas dentro del marco de referencia de ellas mismas, se

$26 \quad$ Vallés, M. (1999). Técnicas cualitativas de investigación social. Madrid: Síntesis.

D’Ancona (1996). Estrategias y técnicas de investigación social. Madrid: Síntesis. 
identifican con las personas que estudian para poder comprender cómo ven las cosas.

- El investigador/a cualitativo ve las cosas como si estuvieran ocurriendo por primera vez. Nada se da por sobreentendido.

- Para el investigador/a cualitativo todas las perspectivas son valiosas. Este investigador/a no busca "la verdad" sino una comprensión detallada de las perspectivas de otras personas. A todas se las ve como a iguales.

- Los métodos cualitativos son humanistas si estudiamos a las personas cualitativamente, llegamos a conocerlas en lo personal y a experimentar lo que ellas sienten en sus luchas cotidianas en la sociedad.

- Los investigadores/as cualitativos dan énfasis a la validez en su investigación. Están destinados a asegurar un estrecho ajuste entre los datos y lo que la gente realmente dice y hace. Las evaluaciones cualitativas están siempre sujetas a los errores del juicio humano.

- Para el investigador/a cualitativo, todos los escenarios y personas son dignos de estudiar.

- La investigación cualitativa es un arte.

\section{Enfoques teóricos principales}

- Interaccionismo simbólico: atribuye una importancia primordial a los significados sociales que las personas asignan al mundo que las rodea.

- La etnometodología: se refiere al tema u objeto de estudio. Ponen entre paréntesis o suspenden su propia creencia en la realidad para estudiar la realidad de la vida cotidiana. Mediante el examen del sentido común, el etnometodólogo trata de entender cómo las personas "emprenden la tarea de ver, descubrir y explicar el orden en el mundo en el que viven. 
A menudo y a la hora de hablar acerca de las diferentes herramientas existentes en los proyectos de investigación, se establece un debate entre el enfoque cuantitativo vs cualitativo, tratando de establecer criterios de exclusión entre una y otra aportación, sin enfatizar en una cuestión clave como es el hecho de que cada una de ellas planea sobre espacios de cobertura diferentes (Alonso, 1988) a la hora de explorar la realidad del individuo o grupo de referencia observado.

"Ambas perspectivas metodológicas, la explicativa y la comprensiva o, dicho de otro modo, la corriente cuantitativa y cualitativa, abordan el estudio de la realidad con técnicas diferentes para la recogida y análisis de datos. Así, mientras que en la cuantitativa, la recogida de datos presenta técnicas muy estructuradas y sistematizadas previamente, a través de cuestionarios estandarizados con preguntas predefinidas, en la cualitativa, la recogida de datos no está previamente definida quedando sometida a la interacción del proceso comunicativo entre el investigador y el investigado". (Olaz, 2008, p.16)

"Las técnicas cuantitativas recurren a modelos matemáticos, que son per se sistemas axiomáticos -abstractos y formalizados- (Cicourel, 1982, p.36), auxiliándose de técnicas estadísticas y cálculos probabilísticos como instrumentos puestos al servicio de la investigación. Con ellos mide el fenómeno en la muestra y generaliza esta medida para la población en general, con un margen de error controlado (Guardiola, 2000, p.191) Por el contrario, la metodología cualitativa no pretende realizar generalizaciones, aun siendo consciente de esta limitación, procediendo durante el análisis a encontrar la estructura subyacente en los discursos y el sentido dado a los mismos. Por todo ello, la lógica que reposa en ambas es diferente: si la cuantitativa busca la generalización y en esta dirección destacan los aspectos coincidentes, en la cualitativa, por el contrario, se resaltan los elementos que son divergentes" (Díaz Martínez, 1996, p.116) 
Por ello, una de las principales diferencias entre ambas técnicas radica en el hecho de que las técnicas cuantitativas basan su esencia en preguntas cerradas, favoreciendo que el investigador/a imponga su visión de la realidad a la persona investigada, mientras que desde el punto de vista cualitativo es la persona entrevistada quien marca, a través del desarrollo discursivo, su apreciación de la realidad ante el investigador/a y, por consiguiente, nuevas vías de acceso a la comprensión del fenómeno.

"En el cuestionario estandarizado, prototipo de la investigación cuantitativa, a la hora de realizar su diseño, es posible encontrar contenidos homogéneos, de estructura similar y cerrados; no obstante, en las entrevistas en profundidad, la heterogeneidad en cuanto a contenidos, la flexibilidad en su estructura y la elasticidad en las posibles respuestas marca algunos de sus elementos más ricos y diferenciadores. Esto se debe, en gran parte, a que en las técnicas cualitativas el marco de investigación es abierto y de una mayor y aparente fragilidad, no imponiéndose las cuestiones y aspectos a tratar al sujeto investigado, como ocurre en un cuestionario estandarizado que, de algún modo, se encuentra teledirigido por el propio investigador". (Olaz, 2008, p.18)

La entrevista, entendida como un proceso comunicacional basado en la interactividad de al menos dos interlocutores/as, es una situación cotidiana en la que, a priori, toda persona cuenta con experiencias previas para participar en ella. Sin embargo en la concepción de la entrevista, para esta investigación, se ha tenido en cuenta que las relaciones interpersonales, se producen en un contexto institucionalizado, donde las interlocutoras parten de una posición inicial de la que a su vez, derivan unos papeles o roles cuyo conocimiento posibilitó una comunicación construida en un espacio psicológico, favorable a la investigación, semejante a la experiencia propia, de un laboratorio científico, donde se generó un acto no natural de comunicación, susceptible de aprendizaje, razón por la cual en la entrevista, la entrevistadora, se abstuvo de influenciar las respuestas de las 
entrevistadas y evitó el pronunciar cualquier juicio de valor que pudiera distorsionar la perspectiva o el discurso de las mismas.

Mayntz, Holm, Hübner (1975) señalan cómo las entrevistas pueden clasificarse de diferentes modos, atendiendo a:

- El grado de estandarización, se pueden diferenciar entre las "Entrevistas no Dirigidas(Cualitativas, no Estructuradas)", "Entrevistas Intensivas o en Profundidad" y "Entrevistas por Medio de Cuestionario Estandarizado"

- El modo de realización, se puede distinguir entre "Entrevista Oral" y "Entrevista por Escrito" o "Autoadministrada"

- El número de intervinientes, se puede establecer otra subdivisión: "Entrevistas Individuales" y las "Entrevistas o Discusiones en Grupo".

Atendiendo a esta clasificación, en el presente trabajo se optó por una entrevista donde se combinaron las preguntas abiertas y las cerradas, formuladas y contestadas de forma oral e individual.

Así la Entrevista No Dirigida se empleó, en este caso, con fines exploratorios, tratando de obtener las primeras informaciones delimitando el problema de la investigación. Una vez explicitado el tema sobre el que se desea tratar -tarea muchas veces larga y tediosa- la entrevistada conversa más libremente con la entrevistadora, quien interviene realizando matizaciones y aflorando cuestiones complementarias con objeto de garantizar una mínima coherencia en el discurso que se realiza.

Aunque no debe caerse en reduccionismos acerca de la elección entre preguntas abiertas y cerradas, siguiendo el esquema de García Ferrando (1989, p. 57) citando a Lazarsfeld (1972), se tratarán de justificar las características del porqué las preguntas abiertas se consideran más adecuadas para este trabajo: 
- Cuando los objetivos de la entrevista pretenden explorar la opinión de un experto acerca de un tema, es más recomendable dar lugar a que fluyan sus manifestaciones, de modo que no se vean "encorsetadas" por la estructura de una pregunta cerrada. Del resultado de sus respuestas a una pregunta abierta, es posible construir o delimitar un espacio que, posiblemente en el futuro, ayude a precisar la realidad a través de un cuestionario estandarizado mediante preguntas cerradas.

- El grado de conocimiento o el nivel de información que la población posee sobre el tema de las preguntas en la fase inicial de una investigación, es suficientemente disperso como para que la heterogeneidad de respuestas tenga cabida sobre la base de una pregunta cerrada.

- El grado en que el tema ha sido pensado previamente por los entrevistados/as, es diferente de la realización masiva de exploraciones vía cuestionario estandarizado, en las que la reflexión previa incluso ni ha tenido lugar de una manera premeditada, produciéndose muchas veces en ese mismo momento.

En la entrevista en profundidad, objeto preferente de este trabajo, la entrevistadora cuenta con un guión aproximativo de aquellas cuestiones sobre las que se quiere profundizar (Ver guión de entrevista. Anexo I). Estas cuestiones no se encuentran formalmente estandarizadas, aunque sí responden a ciertos criterios de ordenación. Si la propia dinámica lo exige, la entrevistadora podrá formular alguna cuestión adicional.

Dentro de la entrevista en profundidad, la batería de preguntas, ocupa un lugar central dentro del proceso global de la investigación, aunque bien entendido, como un guión vertebrador que dinamizará el desarrollo de dicha entrevista. 
El guión se convierte en un medio, más que en un fin, permitiendo construir el marco de relación en el que la entrevistadora y la entrevistada interactuarán. Es, por tanto, otra perspectiva diferente a la del cuestionario asociado a la encuesta y que normalmente se cumplimenta sin que, en ocasiones, esté presente el entrevistador/a.

En el contexto de la entrevista en profundidad. Se han utilizado diferentes tipos de preguntas:

- Preguntas de Sondeo: “¿Qué opinas acerca de...?”, “¿Cuál es tu idea sobre...?" ayudan a la apertura de la entrevistada e impiden respuestas monosilábicas.

- Preguntas de Comprobación: “¿Por lo que anteriormente has dicho, quieres indicar...?", "¿A qué te refieres cuando enfatizas que...?", permiten comprobar si se ha entendido el mensaje recibido y comprobar la comprensión acerca del tema sometido a las manifestaciones de la entrevistada.

- Preguntas de Ampliación: "¿Podrías comentar algo más acerca de...?”, “¿Qué más detalles conoces...?” facilitan la exploración de otros temas relacionados que amplían la información.

- Preguntas de Concreción: "¿Qué aspectos concretos señalarías sobre...?”, “¿Podrías sintetizar en algún punto concreto...?”, favorecen la particularización de los temas tratados en algún aspecto concreto.

- Preguntas de Relanzamiento: "Enlazando con la pregunta anterior ¿Qué más señalarías...?”, “¿Podrías hablarme nuevamente sobre el aspecto... que antes has mencionado...?", permiten relanzar ciertos aspectos ya comentados y que, pese a todo, cobran una mayor dimensión con relación a otros temas. 
Conviene advertir que, antes de diseñar el guión-cuestionario, se extremaron al máximo todas aquellas precauciones que permitieron desarrollar con posterioridad el proceso de investigación. No es obvio indicar que el diseñar el guión es quizás una de las fases más frágiles y que más puede comprometer el contenido, alcance y dimensión de las posteriores conclusiones a realizar.

Según Olaz (2008), el proceso de construcción de las preguntas en una entrevista, es una de las partes más sensibles y vulnerables en el desarrollo del proceso de investigación. La formulación de cuestiones busca una triple finalidad:

- Establecer un proceso comunicacional entre entrevistador/a y entrevistado/a, favoreciendo un clima de interactividad que enriquezca el desarrollo de la entrevista.

- Conocer la opinión contrastada del entrevistado/a en cuanto al estudio que se está realizando, como punto de arranque en la formulación, contrastación y verificación de las hipótesis de trabajo.

- Generar una corriente empática que permita la proactividad, a través de la cual se garantice cierto grado de sensibilidad y compromiso hacia el tema tratado.

Para que estos fines puedan ponerse en práctica, es necesario contemplar una serie de aspectos que ayuden a potenciar los temas a tratar. Al menos son seis los aspectos que, cuando menos, deberían considerarse: el "presunto" grado de conocimiento del entrevistador sobre el tema tratado, el lenguaje empleado, el marco de referencia, el clima afectivo, los aspectos ergonómicos y las condiciones ambientales que a continuación se desarrollan: (Olaz, 2008, p. 33)

- El "presunto" grado de conocimiento que del tema tratado tiene el entrevistado, dado que de lo contrario, podría incurrirse en situaciones en las que éste podría sentirse "insultado" al considerar que las 
preguntas quedan por debajo de su nivel de conocimientos. Por otra parte, podría darse el efecto inverso, al entender el entrevistado que las cuestiones exceden a su conocimiento del tema $\mathrm{y}$, por consiguiente, se le pudieran estar poniendo a prueba, con lo que se podría bloquear en ambas direcciones el curso de la entrevista.

- El lenguaje empleado o como los términos empleados deben ser compartidos tanto por el entrevistador como por el entrevistado. Caso de que, por alguna razón, se introdujeran nuevos términos, estos deberían ser enmarcados para poder ser asimilados y empleados en justa correspondencia. Pese a todo, no siempre es posible establecer una homogeneización en el lenguaje. En este caso, el entrevistador debería esforzarse mínimamente por hablar el mismo lenguaje que el entrevistado, pero sin llegar a un tono exagerado ya que ello supondría una desnaturalización del flujo comunicativo. Ante estas situaciones es preferible combinar ciertas dosis de observación, naturalidad y empatía como recurso que permita la dinamización de la entrevista.

- El marco de referencia, es decir, la relevancia de las cuestiones que se presentan al entrevistado, así como los niveles de información que éste pueda tener acerca del tema sobre el que se le pregunta. Dado que esta cuestión no es sencilla de determinar, deberán establecerse esquemas indirectos de aproximación. El primero de ellos es invitar al entrevistado a que explicite el marco desde el que se originan sus respuestas. Otra opción consiste en dar instrucciones al entrevistado acerca del marco de referencia que el investigador considera oportuno y, una tercera vía sería delimitar de lo abstracto a lo concreto o de lo concreto a lo abstracto, el espacio que se desea analizar.

- El clima afectivo adecuado para desarrollar la entrevista, eliminando las tensiones que pueden generarse como resultado de la relación de 
poder entre el entrevistador y el entrevistado. Continuando con este argumento, la empatía entendida, según la explicación dada por Goleman como "mecanismo por el que se es capaz de conocer los sentimientos de la otra persona, sentir lo que ésta está sintiendo y responder compasivamente a los problemas que le aquejan", (Goleman, 2006, p.85), son vitales para crear una atmósfera adecuada.

Otros aspectos tales como las conductas no verbales, estudiadas tiempo atrás por Davis (1987), pueden contribuir notablemente a un mejor desarrollo de la entrevista, sin que por ello deba interpretarse necesariamente como una vía indirecta de manipulación. La posibilidad de recurrir a la imitación de posturas sigue siendo un recurso que favorece la creación de una atmósfera adecuada, siempre y cuando se realice de forma selectiva y atemperada, ya que, de otro modo, podría interpretarse por el entrevistado como una imitación burda y ofensiva hacia lo que comunica y lo que es peor hacia su persona.

- Los aspectos ergonómicos como, por ejemplo, el uso de un mobiliario adecuado: mesas redondas, sillas con respaldos abatibles, regulables en altura, etc..... También contribuyen a potenciar la comunicación entre entrevistador y entrevistado.

- Las condiciones ambientales (luminosidad, temperatura y grado de humedad) igualmente adquieren relevancia en la cantidad y calidad de un discurso que, por definición, es irrepetible.

También en esta investigación se han analizado diferentes tipos de comunicación porque a menudo empleamos dos grandes tipos de comunicación a la hora de relacionarnos con nuestros semejantes: la verbal y la escrita. 
Intuitivamente, puede convenirse que una cuestión es lo qué se dice y otra bien distinta y, a menudo, puede que de forma divergente, cómo se dice. Piénsese por un momento, en la cantidad de tipos de comunicación que pueden emplearse conscientemente o no, en función de la combinación de nuestros recursos comunicativos: la palabra y los sonidos.

De este modo pueden precisarse cuatro tipos de comunicación:

- Comunicación Verbal Oral: presencia de palabras y sonidos.

- Comunicación Verbal Escrita: presencia de palabras y ausencia de sonidos.

- Comunicación Gestual: ausencia de palabras y sonidos.

- Comunicación Paralingüística: ausencia de palabras y presencia de sonidos.

En otro orden de cosas, hemos querido respetar las diferentes fases de la entrevista en profundidad. Las fases que, en principio, se consideran más importantes son las siguientes: el contacto inicial, la apertura, el desarrollo y el cierre de la entrevista.

A continuación se significan los aspectos más relevantes en cada una de estas fases.

- Fase I: El Contacto Inicial. Esta fase es de vital importancia dado que es en ella donde se define la situación y se establece el marco dentro del que transcurrirá la entrevista. El objetivo de esta fase consiste en "suavizar el ambiente", de modo que la entrevistada sienta una homogeneidad de estatus o incluso la percepción de que es considerada como alguien de quien se quiere aprender.

- Fase II: La Apertura. Tiene su punto de partida con la formulación de la primera pregunta. Dicha pregunta debe ser realizada genéricamente con relación al tema que se va a tratar y servirá de 
referencia, ya que definirá el hilo conductor del resto de las cuestiones, dará pistas a la entrevistada del tipo de respuestas que se esperan obtener y permitirá aflorar temas que después podrán ser retomados por la entrevistadora.

Las preguntas deberán ser lo suficientemente abiertas al inicio, para paulatinamente abordar cuestiones más concretas. Es decir, la entrevista deberá construirse buscando aproximaciones sucesivas a los contenidos más relevantes que se vayan suscitando.

Del resultado del diseño, desarrollo y materialización de esta pregunta inicial, dependerá el éxito de la fase de desarrollo de la entrevista, razón por la cual es necesario extremar al máximo la atención.

- Fase III: El Desarrollo. Es la parte central de la entrevista y la de mayor duración en el tiempo. Su objetivo consiste en conseguir la máxima información sobre el tema investigado, no ya sólo desde un punto de vista cuantitativo (número de respuestas), sino cualitativo (matices obtenidos en las respuestas obtenidas). Estos objetivos se obtienen cuando la entrevistada se implica en el diálogo expresándose en un lenguaje que le es propio, al haber reducido aquellos aspectos que presuntamente podían generar tensión en sus intervenciones.

Por todo ello, aun por obvio que parezca, es necesario reconducir cuantas veces sea necesario a la entrevistada sobre el tema a tratar, evitando en lo posible divagaciones que no conduzcan a nada efectivo. De igual modo, es importante situarse en el plano del discurso y evaluar si la entrevistada ha agotado el tema, aspecto que tiene su indicador cuando se suceden repeticiones de una misma idea o comienza a imperar el silencio.

Otro aspecto importante, inscrito en el desarrollo comunicativo, es el uso que se quiera o se pueda dar a los "silencios". Manejar los 
silencios de la entrevistada, no es una cuestión fácil de realizar, pero puede permitir siempre y cuando haya sido bien modulado, provocar la reacción de la interlocutora. En otras ocasiones el silencio puede provocar cierta sensación de ansiedad. En esta situación, es aconsejable prolongar unos segundos la pausa o el silencio y, en caso de mantenerse, mejor emplear la reformulación del tema, dando un rodeo o haciendo una derivación que permita volver al punto anterior de una manera más tranquila.

Adicionalmente es conveniente atender a las posibles muestras de cansancio y nerviosísimo, para evitar que la entrevista concluya con rapidez.

Casi por último, es necesario controlar el exceso de empatía (excesiva identificación con la entrevistada) porque si puede ayudar a identificar de manera más profunda ciertas cuestiones, también propiciar cierta pérdida de subjetividad.

De igual modo, una postura totalmente alejada y distante de la entrevistada, puede permitir ganar en perspectiva, pero no así en proximidad humana.

- Fase IV: El Cierre. Una vez agotada la fase anterior comienza la fase de Cierre. Para ello, en ocasiones, la entrevistadora puede hacer una breve síntesis de las conclusiones más importantes, no obstante, esta situación debería abordarse lo más al final que se pueda, ya que ello podría implicar la reanudación del proceso de interactividad, eternizándose el cierre.

Como en la Fase I de Contacto Inicial, lo oportuno es nuevamente extremar la cortesía agradeciendo el tiempo y la dedicación dispensada de forma relajada (evitando la rapidez desmesurada)

Es importante dejar la "puerta abierta", ante posibles nuevos contactos en el futuro y asegurar a la entrevistada que el resultado de 
sus apreciaciones y valoraciones figurarán en el más estricto anonimato. Igualmente deberá significarse como en su momento se le enviará el resultado del estudio realizado, como contraprestación a su colaboración.

Buceando en la obra de Gorden (1975) se puede añadir un conjunto de criterios muestrales de naturaleza práctica. La selección concreta y final de las entrevistadas se efectúa atendiendo a las respuestas ofrecidas ante tres preguntas clave. Estas preguntas criterio son:

- ¿Quiénes tienen la información relevante?

- ¿Quiénes están más dispuestas a informar? ( atendiendo a un criterio de accesibilidad)

- ¿Quiénes son más capaces de comunicar la información con precisión?

En el trabajo que nos ocupa, se elige a un grupo de nueve mujeres que se ajustan a estos tres criterios. Se trata de mujeres víctimas de malos tratos, que reconocen haberlo sido y tienen en su haber multitud de experiencias para poder relatar y están dispuestas a hacerlo. La accesibilidad a ellas, por parte de la entrevistadora, es relativamente sencilla puesto que a todas se las conoce desde una perspectiva profesional y dentro del ámbito de los malos tratos. Por último son nueve mujeres con buena capacidad de comunicación y cierta facilidad para la expresión de emociones.

Gorden (1975) también habla de barreras o "inhibidores" de la comunicación interpersonal y hace distinción a cuatro inhibidores que pueden rebajar la disposición de las entrevistadas a dar información o a ser entrevistadas incluso. Estos son:

- La falta de tiempo (sobre todo en las personas más ocupadas) 
- La amenaza al ego (o temor a que la información trascienda y se vuelva en su contra.

- La etiqueta (o autocensura psicosocial)

- El trauma (o sentimiento desagradable que se revive al rememorar algunas experiencias.

En nuestro estudio, estos inhibidores también se encontraron presentes, por lo que se trató de solventar cualquier obstáculo, adaptándonos a las entrevistadas, en la medida de lo posible, ocasionándoles el menor trastorno posible en sus rutinas ordinarias, asegurándoles la confidencialidad en todo momento, respetando su deseo de no abordar los temas especialmente dolorosos y potenciando su propia autoestima al valorar el esfuerzo que hacen colaborando en este proyecto.

\section{2.- Diseño de la investigación.}

Para el desarrollo de este trabajo se optó por la entrevista en profundidad por diferentes razones que a continuación se detallan:

- Las entrevistas se basaron en un guión elaborado en torno a los mitos y realidades señalados en el capítulo 1 , en el que se redactaron preguntas con los temas clave, pero lo suficientemente abiertas como para ordenar y abordar dichas cuestiones de la forma que mejor se adaptara a las características de las entrevistadas, teniendo en cuenta el desarrollo de la propia entrevista. No hay una secuencia de preguntas cerrada para todas las entrevistadas. 
- Se consideró que este tipo de entrevista, era el formato más adecuado para la obtención de información, en relación a los objetivos planteados en este trabajo, dado el carácter distendido de la dinámica generada en la propia entrevista.

- Las nueve entrevistadas han estado expuestas a situaciones de maltrato.

- Las entrevistadas han sido elegidas porque la entrevistadora conoce sus historias de maltrato, bien por haber sido tratadas psicológicamente en consulta, bien por haber sido alumnas de un curso sobre Violencia de Género, impartido por ella misma desde el Ayuntamiento de León, en Octubre del 2010. En todo caso ellas acceden libremente a participar en el estudio.

- La entrevista se centra en las experiencias subjetivas de maltrato de las participantes, con el propósito de contrastar la hipótesis de trabajo.

- Se buscan respuestas espontáneas y libres, se trata de explorar las implicaciones afectivas y la carga emocional de las respuestas de las entrevistadas para determinar si la experiencia tuvo significación central en sus vidas.

\section{3.- Hipótesis de trabajo.}

Se inicia este apartado teniendo presente la hipótesis de trabajo que sirve de hilo conductor al mismo, dicha hipótesis se formula en los términos siguientes:

Es la dominación del varón sobre la mujer, la verdadera dificultad que impide la separación de una pareja en la que se han instalado los malos 
tratos como forma de relación, quedando así, en un segundo plano la cuestión del amor.

Se ha realizado, en el capítulo I, relativo al desarrollo conceptual, una revisión teórica de la literatura acerca de los términos implicados en esta situación victimizadora: mito, amor, violencia de género y dominación

Se mantiene, en el ámbito de la subcultura de la vida en pareja, es decir; en valores, normas, creencias y símbolos, una idea de amor romántico, en la que prima la desigualdad entre los miembros de la pareja ${ }^{27}$, y que se manifiesta en las interpretaciones de las situaciones, que llevarían a los actores sociales masculinos implicados, a justificar conductas violentas contra las mujeres y a las mujeres a aceptar conductas de sumisión ante los varones. Todo ello avalado por los mitos y las falsas creencias acerca de la violencia de género a los que se tienen que enfrentar las mujeres que quieren salir de la situación de maltrato.

Teniendo presente esta idea, que impregna el imaginario social, se desea describir lo más detalladamente posible, las estrategias empleadas por algunas mujeres que han sido víctimas de violencia de género y han conseguido escapar de las relaciones en las que ocurrían los malos tratos. Para ello se ha utilizado la metodología cualitativa, que nos permite ahondar en los relatos de estas mujeres desde su propia subjetividad y así describir la forma en la que han sido capaces de salir del maltrato, rompiendo el ciclo de la violencia.

Hay que señalar que el propósito de la investigación no es exclusivamente la validación de la hipótesis, sino la descripción de las circunstancias personales de un grupo de nueve mujeres víctimas de malos tratos, su interpretación personal acerca de los motivos por los que se mantuvieron y posteriormente rompieron dicha relación, así como las estrategias concretas para poner fin a la misma. Fueron elegidas por

27 Desigualdad que se sustenta en los elementos culturales de la ideología patriarcal. 
muestreo no azaroso entre las mujeres que acuden en busca de ayuda, a la Oficina Municipal de Atención a las Mujeres del Ayuntamiento de León, atrapadas durante años en una espiral de violencia de la que la mayoría ya había logrado escapar ( de las nueve informantes elegidas, ocho ya se habían separado de sus maltratadores). Se decidió incluir a una mujer que mantiene la convivencia con su pareja maltratadora, para observar las circunstancias que impiden la disolución de la relación. La accesibilidad a las mismas se consiguió a través de la Oficina Municipal de Atención a las Mujeres. La muestra es estratificada, cubriendo diferentes variables, como edad, nivel de estudios, clase social, nacionalidad o lugar de origen y etnia.

Se analizarán los resultados obtenidos mediante la utilización de entrevistas en profundidad, efectuadas a dichas mujeres, comparando sus relatos con las creencias al respecto. En este caso, la entrevista semiestructurada, se convierte en un elemento clave para la investigación que nos ocupa. Se consideró oportuno recabar los datos mediante dicha herramienta cualitativa, porque nos permite obtener la información en primera persona acerca de las motivaciones, pensamientos, presiones, que mantenían o padecían las mujeres entrevistadas. Esto es, se intentó desvelar sus "definiciones de la situación", así como las circunstancias objetivas que obstaculizaban la ruptura.

Así mismo, se optó por este tipo de entrevista como forma específica de investigación cualitativa, para acceder con mayor facilidad a la información acerca de la complejidad de las vivencias de las mujeres que habían sufrido malos tratos, sus sentimientos, creencias y acciones después de separase de sus parejas maltratadoras. Eso motivó que los encuentros fuesen abordados a modo de conversaciones distendidas, a pesar de tener como base o referencia, un cuestionario de preguntas obligadas sobre el tema que nos ocupa, para así alentar a las entrevistadas a relatar lo que les había sucedido. Se pensó que frente a un cuestionario con preguntas cerradas, ellas responderían de forma más estandarizada, lo que iría en detrimento de la información a recabar. 


\section{4.- Objetivos.}

Nos planteamos, como objetivo principal, el descubrir las estrategias utilizadas por algunas mujeres víctimas de violencia de género, para romper la relación con sus parejas maltratadoras y además:

- Verificar la conexión entre los cuatro conceptos expuestos en el desarrollo teórico del trabajo: mito, violencia de género, amor y dominación.

- Contraponer la realidad de mujeres víctimas de violencia de género, al mito, que habita en la sociedad, al respecto.

- Mostrar la capacidad de superación de mujeres que luchan por modificar su propia realidad y la de sus hijos e hijas víctimas de la violencia, al margen de mitos y falsas creencias que la sociedad maneja acerca de la violencia contra las mujeres.

\section{5.- Presentación de los hallazgos.}

Partiendo de una perspectiva teórica fenomenológica, hemos llevado a cabo un estudio cualitativo de investigación inductiva y holística donde consideramos a las personas participantes como un todo, teniendo en cuenta los posibles efectos que causamos sobre ellas que son nuestro objeto de estudio. Así mismo tenemos que tener la capacidad de empatizar con sus diferentes problemáticas para poder entender su particular punto de vista, teniendo también en cuenta que no puede haber un único enfoque válido, sino que se trata de comprender y analizarlos todos. 
No podemos olvidar que los métodos cualitativos son humanistas y esto nos permite llegar a conocer el interior de las personas, sus inquietudes y batallas cotidianas.

La actividad consistió en la realización de una entrevista individualizada en profundidad a nueve mujeres víctimas de violencia de género. En dichas entrevistas quedan al descubierto, los sentimientos, ideas y creencias de todas las participantes, acerca del amor romántico y su relación con la violencia de género. Sondeando, además, mediante preguntas estratégicamente diseñadas, los mitos más frecuentes que están instalados en nuestra sociedad, en contraposición a la realidad del maltrato que ellas han vivido.

La entrevista tipo, a la que se hace referencia, se encuentra en el Anexo I. Hay que tener presente que sólo se trata de un guión aproximado de entrevista, puesto que dependiendo de la fluidez de la conversación con cada mujer, este guión se ve modificado ajustándose al discurso de cada una de ellas.

\section{1.- Tiempo de estudio.}

El tiempo utilizado en las diferentes entrevistas no estuvo estipulado de antemano, cada mujer hizo uso del tiempo que le fue necesario, para exponer su vivencia acerca del maltrato, sin ningún tipo de horario preestablecido.

En la realización de las entrevistas, se invirtieron un total de 11 horas, 5 minutos y 8 segundos. Como queda reflejado en la siguiente tabla. 
Cuadro 9. Tiempo invertido en la realización de las entrevistas.

\begin{tabular}{lccc}
\hline ENTREVISTAS & HORAS & MINUTOS & SEGUNDOS \\
\hline 1 O & 1 & 11 & 07 \\
2 E & 1 & 03 & 32 \\
3 RP & 1 & 08 & 39 \\
4ㅇ MJ & 0 & 48 & 50 \\
5 AM & 0 & 52 & 53 \\
6 A & 2 & 54 & 39 \\
7ㅇ C & 0 & 41 & 40 \\
8 D & 1 & 06 & 04 \\
9 R & 0 & 54 & 28 \\
TOTALES & 6 & 277 & 292 \\
\hline
\end{tabular}

\section{2.- Fechas de realización de entrevistas.}

Las entrevistas fueron realizadas en el mes de Marzo del 2011, como así se refleja en la tabla siguiente.

Cuadro 10. Fechas de realización de las entrevistas

\begin{tabular}{ll}
\hline ENTREVISTAS & FECHA \\
\hline 1ㅇ O & $14 / 03 / 2011$ \\
2ㅇ E & $15 / 03 / 2011$ \\
3ㅇ RP & $15 / 03 / 2011$ \\
4ㅇ MJ & $17 / 03 / 2011$ \\
5ㅇ AM & $18 / 03 / 2011$ \\
6ㅇ A & $21 / 03 / 2011$ \\
7으 & $23 / 03 / 2011$ \\
8ㅇ D & $23 / 03 / 2011$ \\
9ㅇ R & $28 / 03 / 2011$ \\
\hline
\end{tabular}

\section{3.- Número de escenarios e informantes.}

El escenario elegido para desarrollar las entrevistas fue, en ocho de los nueve casos, el despacho donde habitualmente, desarrolla su 
actividad profesional como psicóloga en el Ayuntamiento de León, la entrevistadora. Sólo en un caso, la entrevistadora acude al domicilio de la entrevistada, donde se efectúa el trabajo, por imposibilidad de desplazamiento de esta mujer al despacho.

La población elegida es un grupo de nueve mujeres víctimas de malos tratos, con situaciones personales heterogéneas, tanto en cuanto a nivel social, económico y cultural se refiere. La media de edad de las participantes se sitúa en 41,2 años y oscila entre los 26 años de la más joven y los 55 de la más mayor.

\section{4.- Análisis de resultados.}

\subsection{1.- Acerca de la violencia de género.}

1) A las víctimas de la violencia de género les gusta que las maltraten, son mujeres masoquistas y mujeres provocadoras.

2) Las víctimas de la violencia de género padecen trastornos psicológicos, están locas.

3) Los maltratadores son enfermos mentales.

4) La violencia de género sólo se da en familias desestructuradas, con bajo nivel económico.

5) Los maltratadores están sometidos a estrés laboral.

6) Los maltratadores abusan a causa del alcohol u otras sustancias.

7) Lo que ocurre en una familia es un asunto privado, mejor no denunciar.

8) Siempre se exagera la realidad cuando se habla de violencia contra las mujeres.

9) Las feministas odian a los hombres y las casas de acogida rompen los matrimonios. 
10) Hay muchos hombres maltratados.

11) Si tienen hij@s es mejor que aguanten.

Cuadro 11. Mitos acerca de la violencia de género.

\begin{tabular}{|c|c|c|c|c|c|c|c|c|c|c|c|}
\hline & MITO & MITO & MITO & MITO & MITO & MITO & MITO & MITO & MITO & MITO & MITO \\
\hline & 1 & 2 & 3 & 4 & 5 & 6 & 7 & 8 & 9 & 10 & 11 \\
\hline ENTREVISTA1 & & & & & & & & & & & \\
\hline ENTREVISTA2 & & & & & $\sqrt{2}$ & & & & & & $\checkmark$ \\
\hline ENTREVISTA3 & & & & & & & & & & & $\checkmark$ \\
\hline ENTREVISTA4 & & & & $v$ & & & & & & & \\
\hline \multicolumn{12}{|l|}{ ENTREVISTA5 } \\
\hline ENTREVISTA6 & & & & & & & & & & & $\checkmark$ \\
\hline ENTREVISTA7 & & & & & & & & & & & $\checkmark$ \\
\hline \multicolumn{12}{|l|}{ ENTREVISTA8 } \\
\hline ENTREVISTA9 & & & & & & & & & & & \\
\hline
\end{tabular}

FRAGMENTOS DE ENTREVISTAS QUE CONFIRMAN O REFUTAN ESTOS MITOS:

1) A las víctimas de la violencia de género les gusta que las maltraten, son mujeres masoquistas y mujeres provocadoras

No hay ninguna entrevistada que confirme este mito, ellas hacen referencia al mismo en los siguientes términos:

Entrevista ํㅜ 1- O.

- (P) Tú dices que te sentías asqueada

- (R) Sin ganas de vivir, no sabía si tirarme por la ventana o qué hacer, es que no...

- (P) ¿En ese momento qué imagen tenías de ti misma?

- (R) Acabada, acabada, acabada. Una mujer acabada, sin ilusiones, acabada. 
- (R)Quería marcharme, coger a las niñas y marcharme, pero ahí también me paró mi madre

- (P) ¿Qué cosas de las que tú hacías, le ponían de mal humor?

- (R) Nada, él iba al bar o a ver a su mamita y ya venía cambiado.

- (P) Cuando llegaba a casa, ¿se metía contigo por alguna cosa en concreto?

- (R) Al principio no, después, igual pasaba y me empujaba

- (P) ¿Te empujaba sin más, sin mediar palabra?

- (R) Sí y me miraba y se reía

\section{Entrevista ํㅜ 2- E.}

- (R) .... cuando estábamos bien... incluso cuando estábamos en reunión con más gente estaba bien, era entrar en casa, cerrar la puerta y empezar a insultar, a empujarte, a humillarte, a despreciarte, es que era no querer volver a casa, porque cuando estás con más gente no pasaba, entonces era un poco angustioso, jel hay que volver a casa! Y cuando estábamos nosotras en casa que él llegaba... (toma aire muy profundamente) un estrés tremendo..., porque llegaba y... ¿a ver qué pasa hoy?, porque nuestra vida era normal, estaban las actividades y cuando llegaba él a casa ¿a ver qué pasa hoy? ¿a ver por donde sale? ¿a ver qué ocurre?...

- (R) Me veía fatal, fatal, fatal,... pero mal, no sé explicarlo, me veía muy mal de todo, no me veía, como un monstruo, fea, yo es que creo que soy una persona normal, pero me veía mal, no salía ni a la calle para que no me viese la gente, no me pueden ver así, no valgo nada, no me puede ver la gente así, que no tengo nada de fuerzas, que no....

\section{Entrevista ํㅡ 3 - R.P.}

- (R) Al principio lloraba, al principio lloraba, yo nunca reclamaba, yo lloraba mucho porque yo no quería hacer, o sea, lo que a mí no me gusta es el pleito, el lío, el estar reclamando, no me gusta. Entonces lloraba de impotencia porque yo tengo un genio muy fuerte, pero me lo tragaba, eso me daba impotencia, me daba rabia, porque decía "porqué", tenía miedo que al reaccionar de esa manera, si reclamaba me pudieran quitar la niña, o me puede hacer algo a mí, entonces tenía miedo. Era eso, miedo, a que me pueden hacer algo, no sé, algo así.

- (R)... al principio fue fatal, fue fatal, te iban como absorbiendo, como queriéndome... Yo tengo el carácter muy fuerte..., porque tanto él como mi suegra fueron a P., para casarnos ¿no? Y ellos vieron como yo era realmente y a mí me daba la sensación de que no querían que yo fuese así aquí, como queriéndome, 
pues eso, minimizar, aplacar y querer ser ellos los que mandaran sobre mi persona. Es una sensación muy horrible

\section{Entrevista ํㅜ 4 - M.J.}

- (P) ¿Por qué se enfadaba contigo? ¿Qué clase de cosas le ponían de mal humor?

- (R) Por cualquier cosa, yo recuerdo que estando viviendo juntos, él me pidió huevos fritos, ni le gustaban muy hechos ni poco hechos, tenía que ser un término medio y porque me pasé, cuando vino me pegó una paliza que bueno.... Me agarró de los pelos, de últimas y me arrastró por el pasillo, se metió su hermano, ese día se metió también su hermano y le agredió también a él. Por pequeñeces, por cosas que no tenían sentido ninguno, pero él enseguida se encendía.

- (P) ¿Tú en esos momentos, cómo te sentías?

- (R) Pues muy sola, muy sola. No sé, yo veía que no podía hacer nada por solucionarlo, porque yo decía, si me voy de con él, ya sé dónde voy a acabar, en casa de mi madre, y yo sabía que con mi madre tampoco podía contar porque tampoco me quería

- (P) ¿Él era tu salida?

- (R) Yo era lo único que tenía, yo pensé que era lo único que tenía. Mi madre, pero es que mi madre nunca me quiso con ella, entonces yo tenía que quedarme con él.

\section{Entrevista ํㅜ 5 - A.M.}

- (P) ¿Él se alteraba?

- (R) Él sí

- (P) ¿Tú no entrabas a eso?

- (R) No, yo prefiero siempre perder de mi punto de vista, aunque bueno... en algún momento se lo decía o le exponía lo que yo creía, pero... por no llegar a más, yo siempre me he callado.

- (P) ¿Cómo te sentías en ese momento? Tú dices que estabas con una gran depresión, bastante medicada y él insultándote. ¿Cómo te sentías?

- (R) Fatal, hundida. Hundida hasta el punto que me quise suicidar

\section{Entrevista ํㅜ $6-$ A.}

- (R) Me veía una mujer que tenía que fingir delante de todo el mundo, porque mi padre sufría en silencio porque no podía hacer nada y me veía sufrir mucho a mí y mi padre sufría mucho, entonces yo tenía que fingir para que mi padre no sufriera aunque yo sabía que sufría. Mi madre no se enteró nunca, mi madre no se enteró 
nunca de lo que me pasaba, intenté hablarlo con ella una vez y no me quiso escuchar

- (P) ¿Por qué se enfadaba contigo? ¿Qué cosas no le gustaban de ti?

- (R) Pues que yo estuviera en un estatus más alto, siendo su pareja y él en un estatus más inferior, porque se relacionaba con el mundo del vinoteo, del chateo, que lo único que hay en su mundo es el vino y el futbol y para de contar

Entrevista $n^{\circ}$ 7- C.

- (R) Lo veía venir, ese día ya lo sabía, pero había veces que venía de trabajar y ya sólo por la manera de llamar al timbre ya sabías... buf... cómo viene

- (P) ¿Y a lo mejor no se había "puesto"?

- (R) No, probablemente no porque venía de trabajar, pero ya sólo por la manera de llamar al timbre ya...

- (P) Ya sabías tú que algo iba a pasar

- (R) En casa se acojonaba hasta el tato

- (P) ¿Y los niños también?

- (R) También

- $(\mathrm{P})$ ¿Cómo te sentías en ese momento? Cuando estabas conviviendo con él ¿qué pensabas de ti misma? ¿Qué sentías?

- (R) Que yo me quería ir de allí

- (P) ¿Tus sentimiento era de huida, de salir corriendo?

- (R) Sí, a veces hasta pensé que me quería morir y todo, porque ya no le aguantaba más, porque no me veía capaz de salir de allí, porque claro te llega a comer la cabeza. Yo llegué a pensar que a dónde vas a ir tú con los niños, a trabajar y a todo.... No, no, no

\section{Entrevista no 8 - D.}

- (P) ¿Qué tipo de cosas le irritaban a este hombre? ¿qué es lo que no le gustaba de ti?

- (R) Pues no le gustaba de mí que tuviera amistades, que mi tiempo lo compartiera con alguien que no fuera él le molestaba, aunque fuera con mi hija, le daba igual, no quería. La familia, contra menos hablara con ella, mejor y luego sin ningún motivo, él llegaba a la casa y no había motivo ninguno. Yo no sé porqué, llegaba a la casa y... (él le decía a ella) "esto está lleno de mierda, esa porquería no me la como..." tiraba la comida, decía que la ropa se la tenía que lavar él porque yo la dejaba sucia... no sé... (ella intenta razonar en sus pensamientos, como si tratara de hacerle recapacitar a él) "trabajamos los dos... tenemos tanta carga, que no tenemos familia, nos tenemos que echar una mano los dos...todo lo contrario", bueno era un acoso conmigo constante. Lo que peor llevaba era que tuviera una amistad o tuviera algo, le volvía loco, es que no podía y me decía "tú sal, tú sal" Cuando llegaban 5 minutos antes de salir ya estaba... "¿A dónde vas?, porque a mí 
me dejas solo, porque yo para eso no vengo..." Lo de siempre "porque tú no ves lo que yo he hecho por ti, porque yo estoy aquí solo y tú tienes amigos, tienes a tu hermano y a R. "Y al final tenía que llamar a alguien para decir, "mira que no salgo"

- (R) ¡Puf...! ¿cómo me sentía? ¿cómo explicarte?, pues me sentía que no era nada, estaba vacía por dentro, ni tenía amigos, ni podía expresarme con mi madre, tenía que llamar a mi madre a escondidas, yo me sentía vacía, es que nada me hacía ilusión, con lo alegre que yo soy, yo siempre he sido muy alegre, muy... con muchas ganas de vivir y mucha ilusión, y yo ahí no tenía ilusión, ni ganas de nada, yo tenía ganas de morirme

- (P) ¿Cómo te veías a ti misma? ¿Qué imagen tenías de ti misma?

- (R) No sé, una mujer mayor, me veía vieja, vieja, fea, sosa, me veía fatal y es a día de hoy que mis amigas me dicen "ilo que has cambiado, no pareces tú!" No sé, ni me arreglaba, ni nada, bueno eso de pintarme ni se me ocurriera porque "¿dónde vas tú pintada al trabajo?, no, no, tú de pintarte no". Yo ni me pintaba ni me arreglaba, nada, era un levantarme y un empezar, bueno venga...

\section{Entrevista no $9-R$.}

- (P) ¿Qué clase de cosas le hacían enfadarse para que se pusiera así contigo?

- (R) Sobre todo, yo me he dado cuenta ahora, de que era, cuando empezaba yo a subir, a tener un trabajo bien..., después de sacar el carnet de conducir... Él te animaba, pero después... cuando él veía que tú ibas consiguiendo cosas, como que no.

- (P) ¿Le fastidiaban tus logros?

- (R) Sí, sí, sobre todo cuando él no los tenía

- (P) ¿Cómo te sentías en aquel momento?

- (R) ¡Puf...! es que llegas a no sentir

- (P) ¿No sentías?

- (R) No

- (P) Nada. ¿Cómo te veías...? Se te llenan los ojos de lágrimas $R$.

- (R) Es que eso fue...Terrible, el no sentir

- (P) ¿Cómo te veías a ti misma cuando te mirabas al espejo?

- (R) ¡Puf...! me veía como me veía él, me veía inútil, me veía mala madre, me veía fea, me veía... todo

\section{2) Las víctimas de la violencia de género padecen trastornos psicológicos, están locas.}

No hay ninguna entrevistada que confirme este mito, los desmienten con rotunda decisión. 
- (P) ¿Antes de conocerle a él habías estado a tratamiento psicológico?

- (R) No, no, no, yo era muy contenta, muy alegre.

\section{Entrevista $\mathrm{n}^{\circ}$ 2- $\mathrm{E}$.}

- (P) ¿Antes de conocer a tu marido estuviste a tratamiento psicológico?

- (R) Si

- (P) ¿Antes de conocerle a él?

- (R) ¡Ah no!, antes no, antes no. Estaba pensando después de la separación

\section{Entrevista nํㅜ 3- R.P.}

- (P) ¿Esto antes de conocerle a él, nunca te había pasado? (En el párrafo anterior expone diferente sintomatología psicológica que ella presenta en la actualidad)

- (R) Nunca me había pasado

Entrevista nํ 4 - M.J.

- (P) ¿Antes de conocer a esta persona, estuviste alguna vez a tratamiento psicológico?

- (R) No

\section{Entrevista nº 5 - A.M.}

- (P) Tú ahora dices que te encuentras a tratamiento psicológico, pero antes de haberle conocido ¿estuviste también?

- (R) No, nunca. Yo era una persona muy alegre

- (P) ¿Tú eras alegre antes de conocerle?

- (R) ¡Puf! Estaba el día bailando, estaba con la música, cantando a todo gas, muy, muy alegre. Y eso se fue apagando, se fue apagando. Yo cuando teníamos así, de juntarnos un grupo de parejas o de novios o luego ya de casados, digamos que yo era la chispa del grupo, la más fea, la más pequeña, pero la que daba un poco de chispa y con el paso del tiempo eso se apagó, no soy yo ni mi sombra

\section{Entrevista no $6-\mathrm{A}$.}

- (P) Antes decías que tuviste que visitar a un psicólogo y de hecho estás en tratamiento todavía, tanto tu hija como tú. ¿Antes de conocer a P., tú tuviste que visitar psicólogos? 
- (R) No, para nada

Entrevista nำ $7-\mathrm{C}$.

- (P) ¿Estuviste alguna vez a tratamiento psicológico?

- (R) No

- (P) ¿Nunca tuviste ningún trastorno, ni ningún problema?

- (R) No

Entrevista nํ 8-D.

- (P) ¿Antes de conocerle tuviste problemas psicológicos?

- (R) No, no

Entrevista nํ $9-R$.

- (P) ¿Tuviste algún tratamiento psicológico antes de conocerle a él?

- (R) No

\section{3) Los maltratadores son enfermos mentales.}

No hay ninguna entrevistada que confirme este mito. Sus comentarios al respecto lo desmienten.

Entrevista $\mathrm{n} \times 1$ - O.

- (P) ¿Y él había estado a tratamiento psicológico antes de conocerte a ti?

- (R) Que yo sepa no, pero tiene traumas por la madre, si le tratan... no sale del bar, su madre dice..., me echa la culpa a mí, que le desgracié la vida...

Entrevista $\mathrm{n}^{\circ} \mathrm{2}-\mathrm{E}$.

- (P) ¿Y él, había estado a tratamiento (psicológico) antes de conocerte a ti?

- (R) No tengo ni idea, pero después de estas cosas, salió a la luz que había tenido robos con agresión, o sea con violencia

Entrevista nํ 3 - R.P. 
- (P) Y él ¿había estado a tratamiento psicológico antes de conocerte a ti?

- (R) Que yo sepa, no. Yo qué sé

\section{Entrevista ำ 4 - M.J.}

- (P) ¿Y él antes de conocerte a ti? (En el párrafo anterior se hace alusión en la entrevista a tratamientos psicológicos)

- (R) No, que yo sepa, tampoco.

\section{Entrevista ํㅜ 5 - A.M.}

- P) Y él ¿tuvo algún tratamiento psicológico antes de conocerte a ti?

- (R) Que yo sepa no, que yo sepa.

\section{Entrevista $n^{\circ}=6-A$.}

- (R) Como ir al psicólogo significa estar loco ¿cómo iba a ir? Él era el que tenía que haber necesitado el psicólogo, pero bueno tenía que haberlo necesitado toda la familia, que era una familia desestructurada. Ahí es que no había por donde coger las cosas, yo... para mí era muy extraña, no... yo me eduqué de otra forma, entonces...

\section{Entrevista nำ 7 - C.}

- (P) ¿Y él, antes de conocerte a ti? (En el párrafo anterior se habla de tratamientos psicológicos)

- (R) Ni antes ni después, porque él no tiene ningún problema, "la que estoy loca soy yo" (según él, utiliza la ironía), bueno de hecho se lo dijo a... que yo tenía algún tipo de problema psicológico, que me iba de casa cuando se me antojaba y volvía cuando me daba la gana y como él era muy buena persona, ahí se quedaba esperándome, a que volviera (lo dice con ironía)

\section{Entrevista nㅇ 8 - D.}

- P) ¿Y él, sabes si los tuvo? (Nos referimos a problemas psicológicos)

- (R) Yo creo que no, lo que pasa es que él no es que tenga problemas psicológicos, a ver... no lo sé, nunca fue al psicólogo, pero yo creo que el problema que él ha tenido es que ha visto eso en su casa, a lo mejor, no sé...

\section{Entrevista no $9-R$.}

- (P) ¿Y él antes de conocerte a ti, tuvo algún tratamiento psicológico?

- (R) Sí

- (P) ¿Qué le pasaba? 
- (R) Tenía crisis de ansiedad, tenía crisis de pánico

- (P) ¿Pero esto antes de conocerte a ti?

- (R) No, bueno eso no lo sé, eso no lo sé

- (P) Esto que dices que tenía crisis de ansiedad y ataques de pánico

- (R) Eso le pasó estando conmigo, sí, pero es porque tenía mucho miedo a la muerte

- (P) ¿Y eso, algo que él tenía en su cabeza?

- (R) Eso son cosas de él, yo me pasaba las noches hablando con él, calmándole, claro, para eso yo era maravillosa, en esos momentos, yo era la única persona que le podía ayudar. Una vez que se le pasaba... ancha es Castilla

- (P) Es decir, que antes de conocerte tú no sabes, pero sí que mientras estuviste casada con él, tuvo que visitar... ¿hizo terapia?

- (R) Bueno sí, vino a L. un par de veces, le dieron una cinta, pero él luego no hizo nada, realmente no hizo nada

\section{4) La violencia de género sólo se da en familias desestructuradas, con bajo nivel económico.}

Sólo una entrevistada refleja en su discurso la falta de apoyos y apego familiar arrojando indicadores de desestructuración familiar y falta de recursos económicos, el resto de las entrevistadas pertenecen a familias normalizadas en este aspecto.

\section{Entrevista no 4 - M.J.}

- (R) Tengo madre y 8 hermanos

- (P) ¿Son para ti un apoyo?

- (R) No, para nada

- (P) ¿Nunca lo han sido?

- (R) Nunca, nunca. No nos hemos criado juntos, entonces no sentimos los unos por los otros y mi madre.... Nunca.... El hecho de llamarla madre, porque me ha tenido, no por otra cosa

- (R) Es que... es que es muy fuerte. Yo ahora me pongo a pensar en el apoyo que tuve de mi madre y digo ¡es muy triste! ¡No sé porqué la llamo madre!

\section{5) Los maltratadores están sometidos a estrés laboral.}

Sólo en una entrevista se refleja la existencia de estrés laboral en el maltratador, pero la entrevistada no la indica como la causa de la violencia de género. 


\section{Entrevista no $2-\mathrm{E}$.}

- (P) ¿Tu marido sufría estrés en el trabajo?

- (R) Sí

- (P) ¿Y piensas que eso puedo influir, a la hora de llegar a casa y ponerse de esa manera y agredirte?

- (R) No lo sé

\section{6) Los maltratadores abusan a causa del alcohol u otras sustancias.}

Seis entrevistadas mencionan el abuso de alcohol en sus parejas maltratadoras, ellas admiten ser maltratadas de igual manera, cuando ellos no han consumido alcohol u otras sustancias. En los seis casos el alcohol funciona como desinhibidor de la conducta agresiva que también se muestra, aunque en menor medida, en estado sobrio de los maltratadores.

Entrevista ํㅜ 1- O.

- (R) Hombre..., por lo menos no tengo que aguantar, sus borracheras, y que esté diciendo por debajo "eres una puta, eres una zorra, eres... una perra, si quieres te abro la ventana para que te tires"

- (P) ¿Eso cuando estaba borracho?

- (R) Y cuando tenía resaca, después ya no hablaba, se sentaba en el sofá y no había nadie en casa. Es el día de hoy que en el sofá donde se sentaba él no me puedo sentar.

\section{Entrevista nำ2- E.}

- (R) Al día siguiente, es como si no hubiese pasado nada, no se acordaba de nada o no quería acordarse, yo ya eso no lo sé, él hacía como si no hubiese pasado nada, cuando yo le decía "es que no me encuentro bien porque ayer me has dicho esto y me duele el brazo porque me has tirado de él, me has empujado" "eso no fue nada, eso fue porque no me dejabas pasar" No le daba importancia y... y le decía "es que siempre llegas bebido, ¿No te das cuenta de que bebes?" "Que no tomo más que un par de cubatas, que eso no me sienta mal, ¿tú me has visto alguna vez caerme 
contra las paredes?" "No te caes contra las paredes, pero aunque no te caigas contra las paredes estás mal, estás borracho porque lo que estás haciendo, si me dices que encima no te acuerdas, estás mal, había que buscar ayuda" $Y$ me decía que sí, que iba a intentar buscar ayuda, que eso, pero no... no lo hizo nunca, pedía perdón al día siguiente "venga anda, que no pasa nada, que no lo vuelvo a hacer", y eso sí me lo decía mucho, pero no... siempre volvía

\section{Entrevista ํㅜ 4- M.J.}

- (P) ¿Él consumía alcohol o drogas?

- (R) Él sí, él bebía bastante y luego empezó a fumar eso que se llama costo.

- (P) ¿Cuándo bebía o fumaba costo pasaba algo, quiero decir, era peor, mejor...?

- (R) Era igual, él era lo mismo sin beber que bebiendo, era lo mismo, pegar, me pegaba igual, se levantaba de la cama, iba y me pegaba, o sea que...

\section{Entrevista nำ6- A.}

- (R)... Mi marido es alcohólico, entonces eh.... Él nunca consideró que es alcohólico, para él salir de trabajar y tomarse 6 ó 7 vinos y luego venir, comer e irse a jugar la partida, jugaba la partida y se tomaba a lo mejor dos o tres cubatas, luego venía a casa y cogía y... "que voy a hacer la compra, que voy yo, si te quedas pintando o cualquier cosa, ya voy yo" poco a poco me fue relegando y salía a tomarse los vinos, otra vez por la tarde, hasta las 9 de la noche. ....

Tuvimos muchas discusiones porque llegaba a tomarse la friolera de unos 25 cubatas por la noche, diarios, gin -tonic, que huelo a gin-tonic y me dan nauseas, hoy día, no lo puedo evitar. ... llegó a presumir delante de los amigos de tomarse 25 cubatas.

- (R)....llegó a la hora de la cena, (no venía borracho) estaba la cena preparada y me dice "¿todavía sigues aquí? ¿cuándo te piensas marchar?" "No me voy a ir, cuando te pase el enfado hablamos "es que no estoy enfadado, es que no te quiero ver ni delante" Le dije "¿qué es que hay otra persona?" Dijo "No, no hay nadie" "Si hay otra persona me puedes decir que estás enamorado de otra persona, somos civilizados y se puede hablar" "Que no te tengo que dar explicaciones de ningún tipo, pero tú ¿quién te piensas que eres? Pero tú ¿quién te crees que eres?, mira sepárate porque te daba" "no tienes valor, ni siquiera para eso porque eres un cobarde" $Y$ esa noche nos quedamos en casa, yo me acuerdo que él se fue a dormir para la cama, yo estuve viendo un rato la tele, luego me fui para la cama y cuando estaba en la cama, él me abrazó, y le dije "P., por favor" "Ni por favor, ni puñetas" y me violó (lo dice muy bajo, casi no se oye). Me sentí tan sucia, tan sucia, tan sucia, que lo único que recuerdo fue humillación,... 


\section{Entrevista ํㅜ 7- C.}

- (R) Sí, cuando se ponía de cocaína, al día siguiente estaba que no había quien...

- (P) ¿Y tú ya lo veías venir?

- (R) Lo veía venir, ese día ya lo sabía, pero había veces que venía de trabajar y ya sólo por la manera de llamar al timbre ya sabías... ¡buf... cómo viene!

- (P) ¿Y a lo mejor no se había "puesto"?

- (R) No, probablemente no porque venía de trabajar, pero ya sólo por la manera de llamar al timbre ya...

- (P) Ya sabías tú que algo iba a pasar

- (R) En casa se acojonaba hasta el tato

\section{Entrevista no 9- R.}

- (P) ¿Él bebía?

- (R) Sí, la bebida no hace eso, porque cuando estaba calmado era cuando estaba "pedo", es cuando estaba tranquilo, y claro, al día siguiente, era cuando había que prepararse, por si no había dinero para salir él, había que prepararse también

- (P) ¿A ti te agredía estando sereno?

- (R) Si, siempre, si, si, si.

7) Lo que ocurre en una familia es un asunto privado, mejor no denunciar.

Salvo dos mujeres que no denunciaron, las siete restantes denunciaron a sus parejas por violencia de género. De las dos que no denuncian, el motivo para R.P. es porque minimiza el daño, "solo" sufre violencia psicológica y M.J. no lo hace por miedo.

\section{Entrevista ํㅜ 3- R.P.}

- (P) ¿Nunca le has denunciado, verdad?

- (R) No, no. Es que no ha habido cosas como para denunciarlo... 
Entrevista nㄴ- M.J.

- (P) ¿Denunciaste a este hombre en alguna ocasión?

- (R) No

- (P) Nunca

- (R) No, no, no... (lo dice como asustada, reviviendo el miedo), ni se me pasó por la cabeza.

\section{8) Siempre se exagera la realidad cuando se habla de violencia contra las mujeres.}

No hay ninguna entrevistada que confirme este mito. Las nueve lo desmienten con rotundidad.

Entrevista $n \div$ 1- O.

- P) ¿En algún momento sentiste la necesidad de exagerar tu historia para que la gente te creyera?

- (R) No, yo conté lo que era, si me creían o no me creían me daba igual, es lo que hay.

\section{Entrevista nำ2- E.}

- (P) ¿Sentiste alguna vez la necesidad de exagerar tu historia para hacerla más creíble?

- (R) No, al contrario, lo contrario, siempre suavizo y digo lo bien... lo buena persona que es cuando está bien, al contrario, siempre le dejo como se ha comportado cuando está bien, se comportaba fenomenal, era normal, y cuando ha estado así, y ahora los últimos tres años, era un infierno total que no se salía y no se salía y no se salía, cada vez era menos espacio, antes era una semana de estar bien, que casi cogías fuerzas para volver a tirar, pero ahora era cada dos días y ya te quedas sin fuerzas. En tres años se ha vuelto horrible, horrible, horrible... se volvió horrible

Entrevista nํ3- R.P.

- (P) Alguna vez, cuando le cuentas esto a tu hermana, o a alguna otra persona de tu confianza, ¿sientes la necesidad de exagerar para que te crean? 
- (R) No, yo creo que no hay necesidad de exagerar, porque lo que me ha hecho ya es bastante... para mí por lo menos... bastante doloroso, como para exagerarlo. No creo que esté bien tampoco, poner a una persona así... se cuenta lo que realmente se ha vivido, porque exagerar para qué...

\section{Entrevista no 4- M.J.}

- (P) En alguna ocasión, ¿tuviste la necesidad de exagerar tu historia para que fuera creíble?

- (R) No, no, yo creo que no me ha hecho falta

- (P) No te ha hecho falta nunca

- (R) No, no,..., las cosas son como son y punto

\section{Entrevista no 5- A.M.}

- (P) ¿Tuviste en alguna ocasión, A.M., la necesidad de exagerar tu historia para hacerla más creíble?

- (R) No, no me gusta exagerar las cosas, no, no soy así.

\section{Entrevista $\mathrm{n}^{\circ} 6-\mathrm{A}$.}

- (R) Siempre lo oculté, todo lo que pude, pero luego me di cuenta, ellos me lo han contado, de que hacían que se iban y escuchaban todo (se refiere a su hijo e hija)

\section{Entrevista $\mathrm{n}^{\circ}$ 7- C.}

- (P) ¿Tuviste la necesidad, no sé si en el momento de la denuncia, o en alguna otra ocasión, de exagerar la historia para que la gente te creyera?

- (R) No, me da igual que me crean o no, es algo que tampoco me importa mucho, el que me quiera creer que me crea y el que no que no me crea. Simplemente algún día se verá quién tiene razón y quién no y de hecho se está viendo. Yo no tengo ningún parte de incidencias en la policía, él ya tiene dos

\section{Entrevista $\mathrm{n} \times 8-\mathrm{D}$.}

- (P) ¿Sentiste alguna vez la necesidad de exagerar tu historia para que te creyeran?

- (R) Yo es que nunca he querido contarlo, por no sé, que la gente me viera diciendo... "oye mira, que pena, pobrecilla, ha sufrido malos tratos" o porque no me 
crean. Por qué lo voy a contar si tampoco tengo fotos, no tengo fotos, ni nada que demuestre, es lo que te estoy contando...

- (P) Te pueden creer o no creer, ¿eso es lo que quieres decir?

- (R) Exactamente, y como que cada vez, yo me ponía a pensarlo... Si yo ahora lo cuento, pasas el mal rato de contarlo, revivirlo todo y encima para que luego a lo mejor, sientan pena o te critiquen o te pongan una etiqueta que no...

Entrevista nํ $9-R$.

- (P) Te vas a la comisaría acompañada por ella, luego aparecen tus amigos. ¿Te has sentido, no sé si en aquel momento o ahora al revivirlo, sientes la necesidad de exagerar tu historia para que la gente te crea?

- (R) No, yo muchas veces, muchas cosas he tenido que no contarlas porque dirán, esta está loca, ¿cómo le pudo pasar eso y estar ahí?, porque lo que más rabia me da es cuando dicen "¿cómo pudiste seguir?", eso me da una rabia que no puedo con ello, a ti te quería yo haber visto ahí, a ver si hubieras seguido o no. Bueno... pues infórmate de a ver cómo es la cosa, yo lo entiendo porque me lo tuvisteis que explicar por qué yo seguía ahí, pero no sé, no es tan fácil, no es fácil

\section{9) Las feministas odian a los hombres y las casas de acogida rompen los matrimonios.}

No hay ninguna entrevistada que confirme este mito. Dos de ellas han vivido en casa de acogida, pero su discurso al respecto no se ajusta al mito.

\section{Entrevista nํ 4- M.J.}

- (P) ¿Estuviste en casa de acogida?

- (R) Sí, en F., estuve 10 días y verdaderamente, aquello me pareció catastrófico.

- (P) ¿Por qué? ¿cómo te sentías allí?

- (R) Muy mal

- (P) ¿Ya había nacido el niño?

- (R) Sí, sí, sí,... yo fue por lo que me marché, porque yo veía que en casa de mi madre, mi madre no nos quería, o sea que...

- (P) Ni al niño, ni a ti

- (R) No, no, no... Entonces marché y aquello me pareció una casa de locos más que un centro de acogida y llamé a mi hermana, a una de mis hermanas y le dije que por favor hablara con mamá, a ver si podía acogerme... y sí, sí...

- (P) Aguantaste 10 días, a los 10 días te volviste y es donde dices que tu madre te abre la puerta y ahí te dejó... ¿pero tú entraste? 
- (R) Sí, yo entré, pero ahí te das cuenta que no eres bienvenida, porque es que ni al niño me lo miró, te das cuenta de que no eres bienvenida. Yo enseguida me puse en manos de la asistenta social de P., M.J., muy maja, y sí, sí, me ayudó a conseguir una ayuda económica para independizarme yo

\section{Entrevista ำ 7- C.}

- (P) ¿Cómo acabas en la casa de acogida, C.? Porque tú tienes familia, que en otras ocasiones te recogían en su casa ¿por qué una casa de acogida?

- (R) Porque estaba en A. y me iba a buscar

- (P) Necesitabas salir de A.

- (R) Yo creo que no lo dejé antes, porque nunca salí de A., a ver, me había ido al pueblo, pero cuando me iba al pueblo, cogía a los niños, se los llevaba y claro... él sabía que yo iba a volver, porque si él va y se lleva a los niños, sabe que matemáticamente, en cuanto entre por la puerta de casa en A., a la hora, estoy ahí, no voy a dejar a los niños con él, y eso... no te dejaba, no te dejaba, hasta que no volvías y volvías con miedo o acojonada o porque te había convencido o por mil cosas, pero era entrar por la puerta y decir "¿qué hago yo aquí? Si yo aquí no quiero estar"

- (P) ¿Entonces acudes a la casa de acogida...?

- (R) Acudo al CEAS de A. y me dicen que es un maltratador y que tengo que salir de la casa, que tengo que salir de allí, que me van a buscar una casa de acogida, espero tres semanas

- (P) ¿En tu casa, con él?

- (R) No, en casa de mi tía... pero bueno, las dos primeras nada, ni se inmutó, ni se acordó de mí, ni de sus hijos, ni de nada que se le pareciera. Luego ya la última sí, ya fue cuando fui otra vez al CEAS y les dije que miraran a ver si lo aligeraban porque ya me estaba... acosando ya... del todo y fue cuando me vine para $L$.

\section{0) Hay muchos hombres maltratados.}

No hay ninguna entrevistada que confirme este mito, aunque en muchas ocasiones ellos intentan culpabilizarlas. Hablan de ello en los siguientes términos:

\section{Entrevista $\mathrm{n}^{0}$ 1- $\mathrm{O}$.}

- (P) ¿Tú pareja, en algún momento se sintió maltratado por ti?

- (R) No él, por ejemplo, igual me hablaba o eso y claro yo había veces que ya o aguantaba y... le pegaba cuatro voces porque lo que no es normal es que vaya al servicio y mee en el suelo o haga cosas que jolina, o que se meta con las niñas, hay días que bueno... no eres de piedra, y... se me fue el santo al cielo.

- (P) Estábamos diciendo que si él consideraba que tú le maltratabas.

- (R) No, él por ejemplo cuando veía cosas de estas en los semáforos, de mujeres maltratadas, enuncias, o algo, cambiaba la tele, justo pusieron una en 
la puerta de mi madre y yo me quedé así mirando para ella y él me hablaba para que no mirara.

- (P) ¿Un anuncio quieres decir?

- (R) Sí

\section{Entrevista nำ2- E.}

- (P) ¿Piensas que él en algún momento, él se pudo sentir maltratado por ti?

- (R) No

- (P) ¿Nunca manifestó nada en ese sentido?

- (R) No

\section{Entrevista ํㅜ 3- R.P.}

- (P) ¿Él considera que es él la víctima, que tú eres una maltratadora con respecto a él?

- (R) Sí, yo creo que sí. (Se ríe), muchas veces me lo ha hecho sentir , como que yo soy la mala, como que él es muy bueno, porque se llama $S$. y se apellida $S$. y yo soy la mala

- (P) ¿Se llama S. S?

- (R) (Se ríe con grandes carcajada) S. G. S. además.

- (P) ¡Ah, S. G. S!

- (R) (Continúa riéndose) Sí, entonces dice... "pero si yo soy un santo" "Lo serás, yo no sé tu madre tanta la redundancia de decir tanto S." porque yo no sé, si yo soy la mala, pienso mal o qué pasa. A veces, por eso te digo, de repente, es que yo soy un poco malilla con él, pero no, la realidad es esa.

- (P) Pero... ¿él te lo dice así?

- (R) No, así tal cual te lo dice "pero si yo no te hago nada, yo no sé cómo quieres que te trate, yo te trato como una reina" Le digo "Si la reina Sofía es tratada así, yo no creo que esté en el palacio 11 años aguantándole al rey, no lo sé"

- (P) A lo que yo me refería, es si él te decía, "Eres tú la que me maltratas a mí"

- (R) Yo soy la que siempre está encarándole las cosas, yo soy la que le está pinchando siempre, yo siempre soy la mala, soy la mala, según su punto de vista.

Entrevista nํ 4- M.J.

- (P)... Este hombre, el padre de tu hijo, ¿sentía que eras tú la que le maltratabas? decías antes que él te culpaba

- (R) ¡Ah, sí, yo creo que sí!, que él se pensaba que yo le estaba maltratando psicológicamente, porque él te venía y te decía "iEs que mira por lo que me haces pasar, has estado ahí toda la tarde hablando con mi tío y yo que sé, o vas en pantalón corto y estás toda la tarde hablando con mi tío!" Y yo decía "¡Jo... pues igual, pues igual yo estoy un poquitín..." Sí me lo hacía pensar, el hecho de que toda la culpa era mía y yo sí que llegué a pensar que igual psicológicamente le hacía daño. 


\section{Entrevista nํ 5- A.M.}

- (P) Tú cuentas esta historia de malos tratos psicológicos y de amenazas de muerte, pero yo te pregunto ¿A. en alguna ocasión se sintió maltratado por ti, pensó que eras tú la que le maltratabas?

- (R) No

- (P) ¿Nunca te lo manifestó?

- (R) No

\section{Entrevista $\mathrm{n}^{\circ} 6-\mathrm{A}$.}

- (P) ¿Él consideró en alguna ocasión que el maltratado era él?

- (R) Para nada.

\section{Entrevista $n^{\circ}$ 7- C.}

- (P) Volviendo al padre de tus hijos ¿Él se sintió en algún momento maltratado por ti?

- (R) Me imagino, no sé... yo creo que no, pero yo qué sé...

- (P) Alguna vez te verbalizó... Él te decía que la culpa era tuya

- (R) Sí, la culpa era mía, yo provoco, yo le sacaba de quicio, yo era muy mala, yo era un pendón, yo cien mil cosas

- (P) ¿Te sientes una mujer maltratadora?

- (R) No, creo que no, tengo muy mala leche, no lo voy a negar, tengo mala leche, es un defecto muy malo, pero vamos... maltratadora no, creo que no.

\section{Entrevista nํ $8-D$.}

- (P) Él ¿en alguna ocasión se ha considerado maltratado por ti?

- (R) No. ¿Él por mí? (muy extrañada)

- (P) Sí

- (R) No, ¿qué dices?, demasiado bien me he portado yo. No, no, no.

\section{Entrevista no $9-R$.}

- (P) ¿Tu ex marido, se consideraba en aquel entonces un hombre maltratado por ti? ¿Pensaba que tú eras la maltratadora?

- (R) Sí, sí, sí

- (P) ¿Te echó a ti la culpa en alguna ocasión?

- (R) Sí, sí, sí 


\section{1) Si tienen hij@s es mejor que aguanten.}

Las cuatro entrevistadas que en un principio confirman el mito, avanzando en la entrevista se puede observar como ellas mismas llegan a la conclusión de que no les ha compensado permanecer unidas a una persona que maltrata, ni siquiera por I@s hij@s.

\section{Entrevista n- 2- E.}

- (P) Y tú E. ¿por qué permanecías a su lado? ¿Qué clase de cosas te ataban a él?

- (R) Sobre todo mis hijas

- $(P)$ Las niñas ¿por qué?

- (R) Porque quería que estuviesen bien, que ellas estuviesen bien, y es lo que más miedo me daba, que como nos amenazaba tanto, "que a la calle, que sin nada" yo sólo quería que las niñas estuviesen bien, que estudiasen, que se formasen y es lo que...

- (R) Sí, exactamente, pero yo necesitaba protegerlas de alguna manera y dije hasta aquí se ha llegado y.... me da igual, no tener que comer o vivir debajo del puente, es que me daba igual todo, en ese momento sólo quería que mis hijas no sufriesen más, porque no vivían, era llorar continuamente, ya está bien

- (P) ¿Te lo pedían ellas?, "mamá sepárate"

- (R) Me decían muchísimas veces "porqué aguantas esto", mucho tiempo, y porqué... yo decía "bueno anda, ya se le pasará..." y seguías. Y el desencadenante fue meterse con ellas

\section{Entrevista ํㅜ 3- R.P.}

- (R) Eso sí, yo a mis hijos no les dejo por nada del mundo, si me tengo que sacrificar yo, me sacrifico, pero a mis hijos no, de momento ahora están muy pequeños y mientras yo les pueda educar y estar con ellos, estaré con ellos, aunque yo me sacrifique, pero... $\mathrm{Y}$ bueno, eso fueron las primeras veces, pero luego en el trascurso del tiempo que he estado acá hubo muchas, muchas veces.

- (P) En relación a tu hija y tu hijo ¿qué piensas?, piensas, en relación a lo que comentabas antes, que tu gente, familia, amigas, te dicen que los niños así no están bien ¿tú qué piensas? 
- (R) Yo también lo pienso, porque ya te digo, yo estaba acostumbrada a vivir en un ambiente tan diferente a este. Y yo a mis hijos los veo como muy desvalidos como personas, aun siendo niños, como personas, porque si a mí me pasa algo es que los niños se quedan en la nada, porque yo a él no le veo responsable, pero si a mí me pasa algo, él los lleva con su madre y según es él, a mí me da mucha pena decirlo, pero creo que a él no le han educado como debería de ser ¿sabes?, entonces yo qué podría esperar para mis hijos

\section{Entrevista ํㅜ 6- A.}

- $(\mathrm{P})$ ¿Por qué permanecías a su lado, A? ¿Qué te ataba a él?

- (R) Yo creo que en primer lugar los hijos y yo creo que en el fondo yo lo quería, pero llegó un momento que llegó el desamor y llegó el costumbrismo y como llegó un momento en que el objetivo era que yo necesitaba ese dinero para que mis hijos tuvieran una cultura, porque yo no quería que se quedaran...

\section{Entrevista ํㅜ 7- C.}

- (P) ¿Qué te mantuvo a su lado? ¿Por qué tanto tiempo?

- (R) Primero porque se puso mala mi madre y bueno... tampoco aquel momento me parecía el concreto para... para sacar el bombazo, y bueno... me callé y seguí. Luego tuve al niño y dije "bueno cambiará"

- (P) ¿Al mayor?

- (R) Sí, pero no cambió nada y luego me quedé embarazada de la niña y seguimos igual. Empecé a trabajar y bueno... mi plan era... a ver... no era hacer esto, era trabajar y una vez que tuviera trabajo y tal y una independencia económica, dejarlo, pero luego claro... me quedé embarazada de D. y ahí la jorobamos, que de los 9 meses, estuve 7 llorando

- $(\mathrm{P})$ ¿Por qué?

- (R) Porque para mí, quedarme embarazada de D. fue lo peor, porque M. ya tenía 5 años, B. 8, ya me veía yo libre, con más tiempo para ir a trabajar, buscar un trabajo, para todo, los niños eran ya más mayores, D. me trastocaba todos los planes

- (R) Yo creo que no lo dejé antes, porque nunca salí de A., a ver, me había ido al pueblo, pero cuando me iba al pueblo, cogía a los niños, se los llevaba y claro... él sabía que yo iba a volver, porque si él va y se lleva a los niños, sabe que matemáticamente, en cuanto entre por la puerta de casa en A., a la hora, estoy ahí, no voy a dejar a los niños con él, y eso... no te dejaba, no te dejaba, hasta que no volvías y volvías con miedo o acojonada o porque te había convencido o por mil cosas, pero era entrar por la puerta y decir "¿qué hago yo aquí? Si yo aquí no quiero estar" 
5.4.2.- Acerca del amor romántico.
1) La media naranja
2) El emparejamiento
3) Exclusividad
4) Fidelidad
5) Celos
6) Equivalencia
7) Omnipotencia
8) Libre albedrío
9) Matrimonio
10)Pasión eterna 
Cuadro 12. Mitos acerca del amor romántico

\begin{tabular}{|c|c|c|c|c|c|c|c|c|c|c|}
\hline & $\begin{array}{c}\text { MITO } \\
1\end{array}$ & $\begin{array}{l}\text { MITO } \\
2\end{array}$ & $\begin{array}{c}\text { MITO } \\
3\end{array}$ & $\begin{array}{c}\text { MITO } \\
4\end{array}$ & $\begin{array}{c}\text { MITO } \\
5\end{array}$ & $\begin{array}{c}\text { MITO } \\
6\end{array}$ & $\begin{array}{c}\text { MITO } \\
7\end{array}$ & $\begin{array}{c}\text { MITO } \\
8\end{array}$ & $\begin{array}{c}\text { MITO } \\
9\end{array}$ & $\begin{array}{c}\text { MITO } \\
10\end{array}$ \\
\hline $\begin{array}{c}\text { ENTREVISTA } \\
1\end{array}$ & & $\sqrt{ }$ & & & & & & $\sqrt{ }$ & $\bar{\checkmark}$ & \\
\hline $\begin{array}{c}\text { ENTREVISTA } \\
2\end{array}$ & & & & & & & & & $\checkmark$ & \\
\hline $\begin{array}{c}\text { ENTREVISTA } \\
3\end{array}$ & & & & & & & & & & \\
\hline $\begin{array}{c}\text { ENTREVISTA } \\
4\end{array}$ & & & & & & & & & $\checkmark$ & \\
\hline $\begin{array}{c}\text { ENTREVISTA } \\
5\end{array}$ & $\checkmark$ & $\checkmark$ & & $\checkmark$ & & & $\checkmark$ & $\checkmark$ & $\checkmark$ & \\
\hline $\begin{array}{c}\text { ENTREVISTA } \\
6\end{array}$ & & $\checkmark$ & & & & & $\checkmark$ & $\checkmark$ & & \\
\hline $\begin{array}{c}\text { ENTREVISTA } \\
7\end{array}$ & & & & & & & & $\checkmark$ & & \\
\hline $\begin{array}{c}\text { ENTREVISTA } \\
8\end{array}$ & & & & & & & & & & \\
\hline $\begin{array}{c}\text { ENTREVISTA } \\
9\end{array}$ & & & & & & & & & & \\
\hline
\end{tabular}

FRAGMENTOS DE ENTREVISTAS QUE CONFIRMAN O REFUTAN LA CONEXIÓN ENTRE AMOR Y VIOLENCIA DE GÉNERO:

\section{1) La media naranja}

Aunque todas las entrevistadas mencionan este mito, después de haber pasado por la experiencia de maltrato, sólo una de ellas lo mantiene.

Entrevista no 5- A.M. 
- (P)... ¿Tú piensas A. M., que tu pareja, A., en aquel momento era tu complemento ideal, la persona con la que ibas a envejecer?

- (R) Siempre

- (P) Lo pensaste

- (R) Siempre

- (P) ¿Y a día de hoy?

- (R) Hombre, lo veo imposible, pero sigo pensándolo

- (P) ¿Sigues pensando que es el hombre de tu vida?

- (R) Si

\section{2) El emparejamiento}

Tres entrevistadas confirman este mito.

\section{Entrevista no 1-O.}

- (P) ¿Tú piensas que la situación ideal de cualquier mujer es estar emparejada?

- (R) Si te va bien, sí. Yo reconozco que si quiero estar con una pareja, que me va a costar mucho confiar en un hombre, yo tengo un amigo que se ha separado y quiere estar conmigo, pero yo no estoy preparada para estar con él.

\section{Entrevista no 5-A.M.}

- (P) ¿Piensas que la situación ideal para ti, es la de estar emparejada, que si no tienes una pareja como que no tienes valor?

- (R) A ver, una pareja cualquiera no. No, no, prefiero estar yo sola

- (P) ¿Pero te gustaría estar emparejada?

- (R) Con mi marido sí

\section{Entrevista $n^{\circ}$ 6-A}

- (P) A día de hoy, A., ¿tú piensas que la situación ideal de cualquier mujer es estar emparejada?

- (R) Yo por ejemplo, te digo una cosa, yo... me encantaría tener pareja, yo soy mujer de vivir en pareja, vivo sola porque no me queda más remedio, pero si tuviera una pareja... eso sí... ahora sí que escojo muy mucho, tiene que tener unas cualidades muy especiales. 


\section{3) Exclusividad}

No hay ninguna entrevistada que confirme este mito, opinando al respecto lo siguiente:

\section{Entrevista ํㅜ 1- O.}

- (P) ¿Piensas que las mujeres sólo podemos amar a un hombre en la vida y después de ese, todo lo que pueda venir ya no va a ser lo mismo?

- (R) No, antes, sí, yo pensaba que yo no iba a rehacer mi vida. Yo creo que sí se puede, pero... ¿con quién?

\section{Entrevista ํㅜ 2- E.}

- (P) ¿Tú crees que las mujeres somos capaces de amar después de haber pasado por todo esto?

- (R) Sí, hay personas que merecen la pena

\section{Entrevista no 3- R.P.}

- (R) Si, estuve soltera hasta treinta y tantos años y estaba perfectamente. No creo que porque estés sola, vayas a estar mal

- (P) Por el contrario, ¿piensas que las mujeres sólo podemos amar a un hombre?

- (R) No, hombre, no, eso es una mentira. (Se ríe con grandes carcajadas). No, yo estuve enamorada otras veces y muy enamorada, y mucho más que esta vez, creo yo, pero oye... así es la vida ¡Que le vamos a hacer! No siempre se puede tener lo que uno quiere. Yo antes de él, estaba ya para casarme pues...Hombres, hombres...

\section{Entrevista no 4- M.J.}

- (P) ¿Y crees que las mujeres cuando nos enamoramos de una persona, luego ya no podemos enamorarnos de nadie más?

- (R) Yo creo que no

\section{Entrevista no 5- A.M.}

- (P) ¿Piensas que las mujeres somos de un solo hombre? 
- (R) ¡Hombre!, mi educación me dice que sí, pero vamos... lo que ves alrededor... eso está muy pasado, no. Tienen el mismo derecho las mujeres que los hombres de tener una o varias relaciones, las cosas han cambiado, por supuesto.

\section{Entrevista no 6- A.}

- (P) ¿Tú piensas que las mujeres sólo podemos amar a un hombre y que después de haber amado a un hombre, todo lo que nos venga, ya no es válido?

- (R) No, no, no... para nada. Vamos a ver, yo creo en el amor, de hecho cuando hay una pareja que si puede haber una reconciliación y se puede unir una pareja y no se puede romper, soy partidaria de que se unan y no se rompa, porque no hay mejor cosa que compartir la vida con alguien, las alegrías y las penas

\section{Entrevista $n^{0}$ 7- C.}

- $(\mathrm{P})$ Continuamos con ideas románticas ¿Piensas que las mujeres sólo podemos amar a un hombre y después de ese, ya nada va a ser igual?

- (R) No, no

\section{Entrevista nำ 8- D.}

- (P) ¿Crees que las mujeres nos enamoramos una vez de un hombre y después de eso no somos capaces de amar a nadie más?

- (R) ¡Hombre!, yo no sé si lo que sentí por él fue amor, estoy todavía en proceso de estudio, pero creo que es muy difícil, no sé decirte ni un no, ni un sí, creo que es... Te queda el escollo, que te queda. Una vez que te entregas, yo en el caso me entregué tanto... y luego yo pienso que ya no te entregas igual... es la desconfianza, aunque supongo que con el tiempo pasará, no sé, es que tampoco te creas tú... yo he estudiado... he leído en el proceso ese, pero lo que pasa después ya no lo sé

\section{Entrevista no 9- R.}

- (P) ¿Crees que las mujeres cuando amamos a un hombre, después de ese ya no hay más?

- (R) No

- (P) ¿Tenemos capacidad para...?

- (R) Sí, sí 


\section{4) Fidelidad}

Sólo una entrevistada confirma el mito de la fidelidad, pero lo hace con reservas, ubicándose en la realidad del s. XXI, en cuanto a las relaciones se refiere.

Entrevista oㅜ 5- A.M.

- (P) ¿Piensas que las mujeres somos de un solo hombre?

- (R) ¡Hombre!, mi educación me dice que sí, pero vamos... lo que ves alrededor... eso está muy pasado, no. Tienen el mismo derecho las mujeres que los hombres de tener una o varias relaciones, las cosas han cambiado, por supuesto.

\section{5) Celos}

No hay ninguna entrevistada que confirme este mito, lo refutan con los siguientes argumentos:

Entrevista ํㅜ 1- O.

- (P) ¿Qué opinas de los celos? ¿Piensas que son buenos en una relación?

- (R) Mi ex, aparentemente no era celoso, yo un poquito. Eso de que se queden mirando para chicas o eso... no me gusta... pero tampoco es no...

- (P) ¿Pero son necesarios en una pareja?

- (R) No, hombre..., si tienes alguno, pero que no es una virtud, no... Yo no creo que estén bien eso, pero bueno...

\section{Entrevista ํㅜ 2- E.}

- (P) Vamos a hablar de celos ¿crees que los celos son buenos en la pareja?

- (R) No, no creo que sean buenos

- (P) No los has mencionado en toda la entrevista.

- (R) No, no, no. No había problema de celos, yo creo que no, al menos eso yo no lo vi

Entrevista ํㅜ 3- R.P. 
- (P) ¿Qué opinas de los celos? ¿piensas que tienen que formar parte de la pareja? ¿Son un componente más?

- (R) No, yo pienso que los celos..., yo no sé, no todo el mundo piensa lo mismo, pero para mí los celos son una tontería, si tu quieres a una persona y confías en ella, no tienes porqué sentir celos. Ahora que tú se lo digas para que la otra persona se sienta importante, pues se lo dices, pero no... sentir celos.... Si tú estás con una persona es porque confías en esa persona, porque la quieres, y porque sabes que esa persona es digna de tu confianza, si vas a sentir celos... no, yo no lo veo

\section{Entrevista nํ 4- M.J.}

- (P) ¿Qué piensas de los celos M.J., piensas que son buenos para la pareja?

- (R) No que va, es una desconfianza total

\section{Entrevista ํㅜ 5- A.M.}

- P) ¿Qué opinas de los celos? ¿piensas que son necesarios en una pareja para que funcione la relación?

- (R) A ver, una cosa con color, como se suele decir, pero no, creo que no son buenos

\section{Entrevista $n^{\circ}$ 6- A.}

- $(\mathrm{P})$ De los celos ¿qué opinas? ¿Crees que son buenos en una relación?

- (R) Es un arma de doble filo, porque el que bien te quiere, te hace sufrir, me parece una tontería. El que bien te quiere no te hace sufrir, vamos a ver, el decir, es que me pega porque se cela porque me quiere mucho, eso es algo que nos han contado y nos han metido en la cabeza

\section{Entrevista $n^{\circ}$ 7- C.}

- (P) Dame tu opinión con respecto a los celos ¿qué piensas de ellos? ¿Son necesarios en una pareja para que funcione?

- (R) Hombre, yo pienso que no, yo pienso que una pareja para que funcione, lo principal es el respeto

\section{Entrevista ํㅜ 8- D.}

- (P) Y los celos ¿son buenos o no para una relación de pareja? 
- (R) No, que no, que no... cuando yo quiero a alguien, quiero en confianza, cuando yo quiero a alguien, yo pienso que si tu lo haces, ya me estás engañando a mí, pero también te estás engañando a ti mismo, si me estás diciendo que me quieres y te estás yendo con otra persona... antes era celosa, pero para qué, de qué te vale, los celos no te valen para nada, si tiene que estar contigo estará y si no que no esté

\section{Entrevista no 9- R.}

- (P) Cuéntame ¿qué opinas de los celos?

- (R) Los celos, es envidia, es...

- (P) ¿Son buenos en una relación?

- (R) No, no, no

- (P) ¿Mejor no?

- (R) No, no. Eso es que no hay confianza, no hay... no hay esto... ¿cómo se dice?... no hay respeto, no hay nada, nada. Tiene que haber total libertad de todo

\section{6) Equivalencia}

No hay ninguna entrevistada que confirme este mito, sus opiniones así lo confirman.

\section{Entrevista ํㅜ 1- O.}

- (P) ¿Sería necesario estar siempre demostrando el amor con la misma intensidad?

- (R) Yo creo que habrá de todo un poco, no lo sé...

- (P) ¿Sería bueno que estuviésemos siempre al $100 \%$ con la otra persona?

- (R) Yo creo que eso no existe, yo creo que no... Siempre habrá momentos buenos y malos, pero si te quiere esa persona, ves que te apoya, tampoco va a estar ahí abrazándote y mua, mua, mua... todo el día... pero bueno que te apoye, que esté contigo, que te demuestre que te quiere que te apoye...

\section{Entrevista $\mathrm{n}^{\circ}$ 2- $\mathrm{E}$.}

- (P) ¿Sentías o sientes que el amor se tendría que demostrar siempre con la misma intensidad?

- (R) ¡No hombre!, hay momentos mejores y peores, pero no tiene porque humillarte ni desvalorizarte, y pegarte mucho menos, pero siempre hay momentos mejores y peores, es la vida misma 


\section{Entrevista nํ 3- R.P.}

- (P) ¿Piensas que el amor debería estar siempre en la misma intensidad, al $100 \%$ que dices tú?

- (R) No, yo creo que tiene sus altibajos, pero no tan bajos, hay que estar ahí, ahí, pero no tan bajo

\section{Entrevista nำ 4- M.J.}

- (P) Antes hablabas de la intensidad en tu matrimonio, con el primer hombre no llegaste a casarte, con el segundo, y decías que las cosas fueron bajando en intensidad ¿piensas que el amor tiene que estar siempre al 100\%?

- (R) Bueno... no al $100 \%$, pero sí creo que... a ver...no sé lo que me preguntabas o como explicarlo

- (P) Inténtalo

- (R) A ver, yo pensé que siempre iba a ser tan especial como al principio, el hecho de ver... no sé cómo decirte...

- (P) Te estoy entendiendo

- (R) Es muy difícil, es muy difícil, yo creo que entre lo mucho y lo poco hay un término medio

- (P) ¿Y él pasó de un extremo a otro?

- (R) Abajo total, entonces...

- (P) No conociste el término medio.

- (R) No

\section{Entrevista nำ 5- A.M.}

- (P) ¿Y qué piensas sobre el amor? ¿Crees que tiene que mostrarse siempre con la misma intensidad en una pareja?

- (R) Yo pienso que hay momentos, pienso... mi forma de ser, y lo que te digo... la educación, y no es lo mismo, los dos primeros años que es todo vida y dulzura y de novios, que luego una vida constante, día a día, día a día, día a día. Pues tienes tus altos y tus bajos. Y días que tienes ganas de más carantoñas que otras. Ahora sí, claro que te gusta que te den una caricia, que te den un beso, o que tengan un detalle. Pero bueno... tienes tus altos y tus bajos

\section{Entrevista $n^{\circ}$ 6- A.}

- (P) ¿Ha de mostrarse siempre con la misma intensidad? (nos referimos al amor)

- (R) No siempre, no tiene porqué, pero sí demostrarse. A mí no me vale que me diga te quiero si no me lo demuestras, porque las palabras las lleva el viento, yo lo que quiero es demostraciones, eso es lo que he aprendido 


\section{Entrevista no 7- C.}

- (P) Respecto al amor ¿piensas que ha de mostrarse siempre con la misma intensidad?

— (R) Tenemos altos y bajos

\section{Entrevista no 8- D.}

- (P) ¿Piensas que el amor se tiene que manifestar siempre con la misma intensidad?

- (R) Yo pienso que no, yo pienso, yo... que para querer tienes que dar sin pensar en recibir, porque si no... yo doy porque yo quiero dar, si luego recibo..., pero no el hecho de dar por recibir, por narices, es lo mismo que el voluntariado, es decir, yo doy porque quiero, si luego recibo cariño en ese caso, más agraciado eres y más bonito, yo pienso que se hace, más bonito, cuando yo recibo y no te lo esperas... es mucho más... obligar a que te quieran.

\section{Entrevista no 9- R.}

- (P) ¿Qué piensas R. de la intensidad con la que se ama? ¿Tenemos que amar siempre con la misma intensidad?

- (R) No, yo tengo que amar con menos intensidad

- (P) Tú es que amas mucho

- (R) Demasiado, lo doy todo, no dejo nada para mí, entonces ahí es cuando la cago, entonces prefiero no tener nada

- (P) ¿Piensas que el amor tiene que manifestarse siempre con la misma intensidad? $¿ \mathrm{O}$ crees que tiene altos y bajos?

- (R) Sí, sí, todas las relaciones empiezan... todas las relaciones tienen una intensidad al principio, pero luego se va relajando, siempre igual más o menos

\section{7) Omnipotencia}

Dos entrevistadas confirman el mito de la omnipotencia del amor.

\section{Entrevista nํ 5- A.M.}

- (P) ¿El amor lo puede todo?

- (R) Eso creía yo 
- (P) ¿Tú pensabas eso?

- (R) Sí

- (P) ¿Y ahora qué piensas?

- (R) Pues sigo opinando como la gente de antes, que tiran más dos tetas que dos carretas.

\section{Entrevista ํㅜ 6- A}

- (P) ¿Piensas que el amor lo puede todo?

- (R) Sí. El amor mueve montañas

\section{8) Libre albedrío}

Cuatro entrevistadas confirman el mito del libre albedrío, no obstante en la primera entrevista se observan contradicciones al respecto, tanto en cuanto ella misma no puede entender cómo se ama a alguien que agrede.

\section{Entrevista nำ 1- O.}

- (P) ¿Una se puede proponer dejar de amar a una persona o no?

- (R) ¿Cómo, como...?

- (P) ¿Piensas que si te lo propones puedes dejar de querer a esa persona, o no, dices, el amor es así y cuando llega, llega y no se puede pensar con la cabeza, simplemente, te dejas llevar?

- (R) Yo creo que eso se siente, se siente o no se siente,...

\section{Entrevista no 5- A.M.}

- (P) ¿Tú piensas que amar a una persona es involuntario, que no se puede hacer nada para evitarlo, que cuando surge el amor surgió y no depende de la voluntad?

- (R) Yo creo que sí

\section{Entrevista ํㅜ 6-A}

- (P) ¿El amor es algo que no se puede dominar? ¿No se puede controlar?

- (R) No, es un sentimiento

- (P) ¿Es un sentimiento, qué no tiene nada que ver con la voluntad?

(R) Evidentemente, tú un sentimiento lo tienes y no lo puedes controlar,... 


\section{Entrevista ํㅜ 7- C.}

- (P) ¿Piensas que es inevitable amar a una persona? ¿Es algo involuntario?

- (R) Pienso que sí, que es involuntario

\section{9) Matrimonio}

Cuatro entrevistadas confirman este mito.

Entrevista ํㅜ 1- O.

- (R) Habrá otras formas de demostrar el afecto, yo..., mi sueño desde pequeña era tener una pareja, no sé si casarme o no casarme, pero tener un apoyo conmigo en casa.

- (P) ¿Podemos decir que para ti, si es una buena opción la vida en pareja?

- (R) Sí, pero bueno... haciéndolo con cabeza, no tan joven como yo, que mira me estrellé.

\section{Entrevista nำ2- E.}

- (P) ¿Piensas E. que si se quiere a una persona lo más natural es acabar conviviendo con ella, o casándose?

- (R) Cuando quieres a una persona quieres estar con ella, compartir con ella

- (P) ¿Piensas que es la situación ideal cuando se quiere a alguien?

- (R) Cuando se quiere a alguien, yo creo que cuando quieres a alguien estás a gusto con ella, te sientes bien, y quieres estar mucho tiempo con ella. Si.

\section{Entrevista nำ 4- M.J.}

- (P) Y piensas que si dos personas se quieren y tienen una buena relación ¿lo normal es que vivan juntas, o se casen o lo que sea?

- (R) Hombre, pues yo creo que sí.

- (P) ¿Sí?

- (R) Yo creo que sí.

Entrevista no 5- A.M. 
- (P) Si te enamoras de alguien ¿lo ideal sería casarse con ese alguien o convivir?

- (R) ¡Hombre!, si la otra persona quiere como tú, sí.

- (P) Sería la situación ideal

— (R) $\mathrm{Si}$, yo soy muy de familia, muy de... si.

\section{0)Pasión eterna}

No hay ninguna entrevistada que confirme este mito, después

de la experiencia de maltrato, opinan de la siguiente manera:

\section{Entrevista ํㅜ 1- O.}

- (R) Si..., o sea, tampoco era un amor loco, yo veía que estaba muy a gusto, que me quería, que me apoyaba, le veía como el hombre con el que moriría.

- (P) Y ahora ¿ha cambiado la percepción que tienes de él?

- (R) Yo no le quiero ni ver, ya no quiero saber más de él.

\section{Entrevista ํㅜ 2- E.}

- (P) ¿Teníais planes de futuro... envejecer juntos..., ver pasar la vida...?

- (R) Sí

- (P) ¿Y ahora qué piensas acerca de todo eso?

- (R) Nada (rompe a llorar y es incapaz de parar)

\section{Entrevista nํㅜ 3- R.P.}

- (R) Los sentimientos han variado mucho. Yo pienso que cuando uno se casa, es porque le tienes amor, respeto, admiración a una persona y puedes... a ver... amor yo que sé, del $100 \%$ quedará un $50 \%$ creo yo, ya no estoy ni segura, el respeto, pues si él no se da a respetar como debe ser, como marido, yo qué puedo decir, no es que no le respete, yo le respeto, porque es mi hogar y tal, pero ya no es lo mismo que al principio, yo siento que del $100 \%$ que había en general, ahora queda un $50 \%$ y esto es

\section{Entrevista nํ 4- M.J.}

- R) Yo creo que estaba enamorada, pero quererlo no.

- (P) ¿Estabas enamorada, pero no le querías?

- (R) No, yo creo que son pasos diferentes. O sea, querer a una persona, no te importa como es físicamente esa persona, yo estaba enamorada de esta persona, 
lo veía muy guapo, veía que atraía a muchas chicas y a mí eso, el hecho de que se hubiera fijado en mí...

- (P) Te alagaba

- (R) Sí, sí, pero yo luego, después de haberlo dejado, no sentí, no sentí, o sea, no me dio pena, no me dio cosa de decir "!ay ya no estamos juntos, que tristeza!" No, no, no, nada, para nada.

\section{Entrevista nำ 5- A.M.}

- (P) ¿Tú piensas A.M. María, que tu pareja, A., en aquel momento era tu complemento ideal, la persona con la que ibas a envejecer?

- (R) Siempre

- (P) ¿Lo pensaste?

- (R) Siempre

- (P) ¿Y a día de hoy?

- (R) Hombre, lo veo imposible

\section{Entrevista ํㅜ 6- A.}

- (R) Yo creo que como empezamos de niños, tan jovencines... costumbre, porque si me dices... yo a P. le quise muchísimo, yo a P. lo adoraba, daba la vida por él, quizás por eso le perdoné tanto, porque yo decía, cambia, nunca mostró maldad, la maldad que yo empecé a ver fue a raíz de... porque para él eran prioritariamente sus amigos y su entorno de amigos, a mí me llegó a decir "para mí son más importantes mis amigos que mis hijos" A mí eso... son muchas puñaladas, muy dolorosas que te quedan clavadas, no se olvidan, no se olvidan, son puñales clavados

\section{Entrevista ํㅜ 7- C.}

- (P) ¿Pensaste en algún momento que este hombre era el hombre de tu vida?

- (R) No

- (P) ¿Nunca lo pensaste?

- (R) Hombre lo pensé con 17 años, a lo mejor sí, pero yo con 20 ya sabía que no

\section{Entrevista $\mathrm{n}^{0}$ 8- D.}

- (R) Es que ahora yo creo que no me llegué nunca a enamorar, sí que le quise, le tuve mucho cariño, pero enamorarme no.

- (P) Cuando pasa todo esto, tú dices que empiezas a sentir pena, como que te sientes culpable

- (R) Sí, claro, cuando se termina siento mucha rabia, siento mucho coraje, mucho asco, en ese momento le tenía demasiado coraje, estaba yo demasiado alterada porque terminas cogiendo sus hábitos, me sentía agresiva... bueno estuve muchísimo tiempo sin poder decir su nombre, o sea, no quería ni verle, ni hablar de 
él, ni nada, pero luego ya... mira, no le guardo rencor, fue parte de mi vida pasada, que pasó y que merezco vivir otra

Entrevista $\mathrm{n}^{\circ}$ 9- $\mathrm{R}$.

- (R) Vamos, es que cualquier película de estas románticas, no se puede comparar con el año de noviazgo, o sea, insuperable, o sea...

- (P) ¿ldeal?

- (R) Bueno... impresionante

- (P) ¿Y ahora qué piensas de todo eso?

- (R) Pues que fue bonito mientras duró, un año y se acabó, de veinte, uno

\subsection{3.- Realidades acerca de la violencia contra las mujeres.}

1) Edad

2) Nacionalidad

3) Ciclo de la violencia

4) Dependencia económica

5) Presencia de violencia de género en la familia de origen de él

6) Presencia de violencia de género en la familia de origen de ella

7) Micromachismos y autoestima de la mujer

8) Aislamiento social 
Cuadro 13. Realidades acerca de la violencia contra las mujeres.

\begin{tabular}{cccccccccc}
\hline & ENTR.1 & ENTR. 2 & ENTR.3 & ENTR.4 & ENTR.5 & ENTR.6 & ENTR.7 & ENTR.8 & ENTR.9 \\
\hline EDAD & 34 & 42 & 42 & 38 & 51 & 55 & 36 & 26 & 47 \\
NACIONALIDAD & ESP. & ESP. & OTRA & ESP. & ESP. & ESP. & ESP. & ESP. & ESP. \\
CICLO DE LA & $\checkmark$ & $\checkmark$ & & $\checkmark$ & $\checkmark$ & $\checkmark$ & $\checkmark$ & $\checkmark$ & $\checkmark$ \\
VIOLENCIA & & & & & & & & & \\
DEPENDENCIA & $\checkmark$ & $\checkmark$ & $\checkmark$ & $\checkmark$ & $\checkmark$ & $\checkmark$ & $\checkmark$ & $\checkmark$ & $\checkmark$ \\
ECONÓMICA & & & & & & & & & \\
V.G. EN LA FAMILIA & & & & & $\checkmark$ & & $\checkmark$ & $\checkmark$ & $\checkmark$ \\
DE ÉL & & & & & & & & & \\
V.G. EN LA FAMILIA & & $\checkmark$ & & $\checkmark$ & $\checkmark$ & & $\checkmark$ & & \\
DE ELLA & & & & & & & & & \\
MICROMACHISMOS & $\checkmark$ & $\checkmark$ & $\checkmark$ & $\checkmark$ & $\checkmark$ & $\checkmark$ & $\checkmark$ & $\checkmark$ & $\checkmark$ \\
AISLAMIENTO & $\checkmark$ & $\checkmark$ & $\checkmark$ & $\checkmark$ & $\checkmark$ & $\checkmark$ & $\checkmark$ & $\checkmark$ & $\checkmark$ \\
SOCIAL & & & & & & & & & \\
\hline
\end{tabular}

FRAGMENTOS DE ENTREVISTAS QUE MUESTRAN LA REALIDAD ACERCA DE LA VIOLENCIA CONTRA LAS MUJERES:

\section{1) Ciclo de la violencia}

Ocho entrevistadas reflejan con fidelidad el ciclo de la violencia, observándose en todos los casos cómo, este ciclo es tan difícil de romper que se convierte en el principal responsable de la perdurabilidad de este tipo de relaciones.

Entrevista ํㅜ 1, O.

- (P) ¿Luego mostraba arrepentimiento?

- (R) Al principio sí, después ya no.

- (P) ¿Había reconciliaciones entre vosotros?

- (R) Él no me hablaba, yo no le hablaba, se calmaba la cosa, mi madre me decía "tú no le hables, tú háblale, tú no le hables...", pero había días que no se podía menos... 


\section{Entrevista $n^{0}$ 2, E.}

- (P) ¿Había reconciliaciones?

- (R) Reconciliaciones..., regalos..., viajes..., el último fue por estas fechas el año pasado, de hecho, nos fuimos, otro perdón, "os llevo de viaje, vamos ahora en semana santa" que el año pasado fue en marzo, "vamos a la playa", pedía perdón a mí y a las niñas, en realidad. Él si sabía lo que hacía cuando pedía perdón y hacía, pero no le daba importancia, no le daba importancia y estaba bien tres días, dos y después era vuelta a empezar.

- (P) Incluso cuando estabais de vacaciones o salíais por ahí, en esos periodos de reconciliación

- (R) Cuando estábamos fuera, no, estaba bien.

- (P) ¿A ti te hacía pensar que podía haber cambiado?

- (R) Exactamente

- (P) Volvíais a casa y ¿qué pasaba?

- (R) Volvíamos a lo mismo

- (P) Vuelta a la realidad

- (R) A la misma historia, es que es eso, cuando estábamos bien... incluso cuando estábamos en reunión con más gente estaba bien, era entrar en casa, cerrar la puerta y empezar a insultar, a empujarte, a humillarte, a despreciarte, es que era no querer volver a casa, porque cuando estás con más gente no pasaba, entonces era un poco angustioso, el jhay que volver a casa! Y cuando estábamos nosotras en casa que él llegaba... (toma aire muy profundamente) un estrés tremendo..., porque llegaba y... ¿a ver qué pasa hoy?, porque nuestra vida era normal, estaban las actividades y cuando llegaba él a casa ¿a ver qué pasa hoy? ¿a ver por donde sale? ¿a ver qué ocurre?...

- (P) ¿Cuánto tiempo solía durar la calma, en tu casa, las reconciliaciones?

- (R) De que nos agredía.... Lo que te he dicho dos, tres días.

- (P) Dos, tres días y otra vez a empezar

- (R) Y otra vez a empezar, alguna vez era un poco más largo, estaba una semana bien, yo no notaba nada extraño, no insultaba, no agredía, incluso se duchaba, que también los olores que traía, fíjate, con todo eso que mueve él, actividad y olores de.... Incluso eso, los días que quería amansar las cosas y que claro, además se acostumbró a que yo cediese, ¿para qué estar más? Si después de una semana volvíamos a estar hasta que eso..., podía hacer lo que le diera la gana, estaba hundida, estaba hundida, no tenía autoestima, no tenía nada, era una mierda, realmente cuando me lo decía me lo creía, no valía para nada, me manipulaba, me anulaba y yo ni me enteraba, es que no me enteraba, es que para mí ya era ipuf... bueno...! "Si tú lo dices que soy una mierda y que no valgo nada y que no sé hacer nada, vale..."

- (R) No, al contrario, lo contrario, siempre suavizo y digo lo bien... lo buena persona que es cuando está bien, al contrario, siempre le dejo como se ha comportado cuando está bien, se comportaba fenomenal, era normal, y cuando ha estado así, y ahora los últimos tres años, era un infierno total que no se salía y no se salía y no se salía, cada vez era menos espacio, antes era una semana de estar bien, que casi cogías fuerzas para volver a tirar, pero ahora era cada dos días y ya te quedas sin fuerzas. En tres años se ha vuelto horrible, horrible, horrible... se volvió horrible

- (P) Se precipita un poco todo en estos tres últimos años

- (R) Horrible, los tres últimos años, horrible, porque antes, lo que te comento... Era un poco más espaciado. Era un poco más espaciado, cogías fuerzas para seguir aguantando (lo subraya), pero en los tres últimos años, ya ni era buena persona por el día, es que ya... "estás mal porque no habrás dormido, yo no he hecho nada, te lo estás inventando, te lo estás inventando, si yo no he hecho nada, lo has soñado, 
tú, tú..." Ya no era ni por el día, ya no vivías ni por el día, porque antes el día era bueno, en los últimos años ya no era el día bueno, ya no salía (se ríe nerviosa), no compartía, no quería estar con nadie por no tener nada de nada, era maldad totalmente, era malo, malo, malo...

\section{Entrevista no 4, M.J.}

- (P) ¿Qué pasó esa primera vez, cuando te tira contra esa puerta y la rompe a golpes contigo? ¿Cómo fue su reacción en ese momento y qué pasa después?

- (R) Nada, él... yo marché... yo recuerdo que ese día iba yo sangrando por las narices por la calle, pero en ese momento no piensas que vas sangrando, piensas en lo que te ha pasado, que te has sentido un poquitín..., es muy difícil explicarlo. Entonces yo recuerdo que sí, que al día siguiente él vino con un detalle..., que no recuerdo ahora cuál fue...

- (P) Con un regalo

- (R) Sí, con un regalo y dijo que.... Me echó a mí la culpa y bueno, que él no me iba a poner más la mano encima... Que me quería muchísimo y todas estas cosas.

- $(\mathrm{P})$ Después de la agresión, dices que la primera vez vuelve con un regalo, medio arrepentido, medio echándote a ti la culpa, ¿siguió pasando eso? ¿cada vez que te pegaba se arrepentía?

- (R) No, luego ya no, luego ya no, en ningún momento.

- (P) ¿No había periodos de calma en tu casa?

- (R) No, que va, que va

- (P) ¿Esto era continuo?

- (R) Sí, estando ya en T. era continuo, y lo mismo venía por la tarde y te daba, y venía por la noche, porque él marchaba, y andaba con unas y con otras... y venía por la noche y después de abusar de ti, te volvía a pegar otra vez.

\section{Entrevista ํㅜ 5, A.M.}

- (P) ¿Cada cuánto pasaba esto?

- (R) No sé decirte, Belén

- (P) ¿Cada día se enfadaba por algo? O no, ¿teníais épocas buenas?

- (R) Sí, sí, teníamos épocas buenas. Pero bueno... él en cuanto yo dejé de trabajar, pues digamos que era un continuo, porque empezó a faltarme directamente. Yo tampoco me daba cuenta

- (P) ¿Empezó a insultarte?

- (R) Me llamaba gocha, me llamaba... pues de todo

- (P) ¿Y eso antes nunca había pasado?

- (R) Digamos que no.

\section{Entrevista ํㅜ 6, A.}

- (P) A., cuando él te hacía todas esas cosas, que antes describías, decías que había momentos de reconciliación...

- (R) Luna de miel, luna de hiel

- (P) ¿Eso cómo era? ¿Cómo funcionaba en tu pareja?

- (R) Pues al principio, de que pasaba todo esto, llegaba la etapa del arrepentimiento, procuraba..., me decía "he visto un vestido más bonito en $R$, que si te lo compras y 
tal... te puede quedar muy bonito ¿por qué no te lo compras?" Yo le decía ,si me es igual, yo mi pasión, eran mis hijos, volqué mi vida en mis hijos

\section{Entrevista ํㅜ 7, C.}

- (P) ¿Había periodos de calma en tu casa?

- (R) ¡Si hombre!, después de la tempestad, estaba muy tranquilo, muy enamorado y muy pacífico

- (P) ¿Cuánto duraba eso?

- (R) Ahora al final, cada vez menos, era una calma muy... "yo te quiero mucho, pero es que eres una borde, eres una asquerosa, contigo no se puede ni hablar, es que yo lo intento, pero tú nunca haces nada, es que tú..., es que tú... es que tú..."

\section{Entrevista ํㅜ 8, D.}

- (P) Después de que pasaba esto, después de una agresión, ¿Él mostraba arrepentimiento o había un periodo de calma en tu casa, intentaba conquistarte?

- (R) Sí, sí... además si eran regalos caros mejor. Sí, pero tampoco yo he visto un arrepentimiento... sí que tuvo mucho arrepentimiento cuando yo decidí separarme y cuando fue la última vez que me puso la mano encima, hasta que me separé, después de los dos meses esos que eran insultos constantes, pero no sé, te insultaba y a lo mejor al rato venía y te mostraba como que él quería ¿sabes? "yo te quiero", pero tampoco, él nunca me ha pedido perdón por el hecho de que me haya puesto la mano encima, a día de hoy nunca me ha pedido perdón por eso, nunca, nunca, él decía que sí... que no volvía a pasar, que ... pero pedir perdón, no lo ha pedido nunca

- (P) ¿Había periodos de calma?

- (R) Sí, había periodos, pero ya a lo último no, tuvimos un año, desde que mi madre se fue, que la cosa fue peor, cuando él vio que yo me quedé sola. Cuando él vio que mi madre se fue, él aprovecho esa oportunidad, ahí como si fuera el amo, tú en la casa, tú no te muevas de la casa, porque la casa es para ti y tenía que ir a comprar "no bajes, voy yo", pero bueno, "si voy ahí..."'no, no, no, voy yo " y yo "vale"

\section{Entrevista no 9, R.}

- (R) Yo es que puse todo, todo, todo, todo... es que no podía poner ya más, porque no tenía más y yo que sé... a mí me parecía lo mejor del mundo, lo mejor que me había pasado, él me lo hacía ver de esa manera y luego, de repente, desde la primera vez que me dio... yo ahí luego ya... siempre estuve alerta, pero claro, siempre piensas que las cosas se van a solucionar, que van a cambiar, que... siempre piensas que las cosas van a cambiar, entonces en esos periodos en que las cosas van bien, crees que están cambiando y no está cambiando nada, nada, no cambia nada, simplemente hay un periodo de descanso y luego viene otra cosa peor

- (P) Otra tormenta 
- (R) Sí, pero peor a la anterior, siempre es peor, porque como ya te conoce más y ya sabe tus puntos débiles, te hace todavía más daño, porque puede hacértelo, entonces cada

\section{2) Dependencia económica}

Todas las entrevistadas mencionan como hándicap para su separación la cuestión económica, puesto que la dependencia en ese aspecto estuvo presente durante toda la convivencia, aunque algunas de ellas contaban con ingresos propios.

Entrevista $n^{0} 1,0$.

- (R) Yo quería mi trabajo, volver a mi trabajo, volver a mi trabajo, pero tuve un parto muy fastidiado de la pequeña, me separaron la pelvis, yo me quejaba y me recetaban termalgín, me hicieron rehabilitación y mejoré, pero yo no podía andar casi. Entonces esperé un poco, al año y ya dije esto no puede ser, no puede ser, llamé a la empresa a ver si me cogían, "espera un poco, no sé qué, no sé cuánto" (respuesta de la empresa) Yo quería integrarme otra vez al trabajo, porque si no ¿qué?, yo no podía permitir que me quitaran el piso. En diciembre, cuando yo me quería separar antes de navidad, pensé en volver a integrarme a mi puesto de trabajo, lo que pasa es que me daban largas, entonces estaba la crisis y no me cogieron, por la dichosa crisis, pero estaba pensando en integrarme, pensaba en la economía, pero cuando dije, me separo porque me pegó, ya no te aguanto, ni una más, me da igual el dinero, mi madre, el cura bendito y todo lo demás, de verdad. Hablando claramente, lo mismo me dio.

\section{Entrevista ํำ 2-E.}

- $(P) \ldots$ ¿hubieras permanecido más tiempo a su lado porque te proporcionaba un bienestar económico, o llegó un momento que no te compensó?

- (R) No, no, compensar no, no vivíamos, no disfrutábamos de nada realmente, no vives, no disfrutas, tienes mucho dinero, bueno mucho dinero, él tenía una buena nómina, pero no lo disfrutas, no vives, no puedes... no estás bien para disfrutar de nada, de nada, simplemente vives con miedo, comes normal y vives porque tienes que vivir, pero no disfrutas de nada, no era calidad de vida, ni vida siquiera, era una mala vida

- (R) Denunciar, si, tenía que haberlo hecho antes, pero no lo hacía porque siempre me decía, "como me denuncies me voy a quedar sin trabajo y no sé qué", pues eso, y si que tienes la cosa y dices....pues sí... No lo haces por no hacerle daño, por no tener problemas. 
- (P) Y porque para ti es una cadena supongo, él se queda sin trabajo, las niñas, quiero decir, es una cadena, en la que lo piensas todo

- (R) Si, si, lo piensas todo, es una cadena, exactamente ¿de qué vives?

\section{Entrevista no 3-R.P.}

- (R)..., en cuestión del dinero yo pienso que eso de que yo me ponga a trabajar, me ha dado un poco de libertad, ¿sabes? Porque claro yo dependía mucho de él, ahora aunque no sea mucho lo que yo tenga, pero él ve que soy independiente nuevamente, que ya no dependo tanto de él y eso como que le da un poco de temor

- (P) ¿Te ata a su lado la cuestión económica?

- (R) Sí, yo creo que también un poco ¿sabes?, aunque no mucho, pero un poco, si.

\section{Entrevista n-4-M.J.}

- (P) ¿Y el dinero?

- (R) El dinero, él trabajaba

- (P) ¿Y lo manejaba él o tú?

- (R) Él, él, él.

- (P) ¿Tú trabajabas?

- (R) Sí, yo también trabajaba

- (P) Y tu dinero ¿quién lo manejaba?

- (R) Lo manejaba él

\section{Entrevista nํ5- A.M.}

- (P) Verte en la cama le molestaba ¿qué más le molestaba?

- (R) Sí, mi posición, de que como te he dicho, igual me volví cómoda, el hecho de que supuestamente ya no ganaba dinero. Que yo le decía, que bueno... ya no estaba en activo, pero una ayuda en casa, con lo que yo ganaba... teníamos para nuestra hipoteca, quedaba su sueldo libre. Pues él que no, que no valía para nada, vamos...

- (P) En el momento que dejas de trabajar, tú ahí sí que notas....

- (R) Fue a peor, fue a peor

\section{Entrevista ํㅜ 6- A.}

- R)...estaban mis hijos, que estaban empezando en la universidad, yo sabía que iba a terminar explotándonos en las manos en cualquier momento, pero yo quería llegar por lo menos a pagar la universidad, porque mi sueldo no me daba para ello, yo quería que mis hijos, porque son muy inteligentes, sacaran por lo menos la titulación,... 


\section{Entrevista $\mathrm{n}^{0}$ 7-C.}

- (P) ¿Qué tipo de maltrato sufrías? ¿malos tratos físicos, psicológicos, sexuales...?

- (R) Psicológicos principalmente, cuando el psicológico no funcionaba porque soy muy turriona y muy cabezona y a mí no me calla nadie tampoco, era el físico y luego el económico, el económico era el que más, también le gustaba utilizarlo mucho, el dejarte en casa toda la semana con los niños sin dinero. De hecho yo estuve con él conviviendo 15 años y yo no estaba en las cuentas del banco

- (P) ¿Él manejaba el dinero?

- (R) Sí

- (P) ¿Incluso el tuyo cuando tú lo ganabas?

- (R) No, es que cuando yo lo ganaba, no me daba ni un duro para nada, ni para comprar para comer, ni para vestir a los niños, ni para nada. O sea que...

- (P) ¿No eras dueña de tu propio dinero?

- (R) Si era dueña, pero para comer, para vestir a los niños y para llevar la casa y ya está, y no le dijeras que necesitabas dinero porque "a ver dónde has metido tu sueldo hija de puta"

- (P) La cuestión económica ¿te frenó a la hora de separarte?

- (R) Sí

\section{Entrevista no8 - D.}

- (P) ¿Y el manejo del dinero?

- (R) Él también

- (P) ¿Incluso el tuyo?

- (R) Incluso el mío

- (P) D., ¿la cuestión económica de alguna manera bloqueó tu separación, te dificultó?

- (R) Sí, porque cuando mi madre se va y yo me quedo sola en casa y voy viendo tantísimos detalles, porque es como que viviera en una cárcel, todo tenía que ser con su consentimiento, todo era a base de que él me dejara, o me diera dinero. Entonces claro, yo el verme querer salir y no poder...

- (P) Económicamente te sentías atada

- (R) Si que me sentía atada, me sentía muy atada

\section{Entrevista $\mathrm{n}^{0}$ 9- $\mathrm{R}$}

- (P) ¿La cuestión económica dificultó tu separación? ¿Tú pensaste mucho en el dinero a la hora de separarte? 
- (R) Sí, vamos... mucho no, pensé que era un problema añadido al problema que ya tenía, pero vamos, para mí el dinero no era importante, yo sabía que tenía familia y que no me iba a faltar ni un techo, ni comida y a mi hijo tampoco. O sea, que no tenía problema, que podía trabajar en cualquier cosa, lo he hecho siempre, en lo que me dejó él trabajar, porque había que... entonces claro, normalmente eran pequeños trabajos, que no requieran mucho tiempo, que...

3) Violencia de género en la familia de origen de él:

En cuatro entrevistas, las mujeres confirman este mito, sus parejas maltratadoras, eran fiel reflejo de lo que habían visto en sus familias de origen.

\section{Entrevista ํㅜ 5- A.M.}

- (P) Y los padres de A. ¿Tú sabes si entre ellos había maltrato?

- (R) De pegarla no, voces sí. Mi suegro también fue un hombre, de dar muchas voces.

- (P) ¿Como su hijo?

- (R) Si

\section{Entrevista ํㅜ 7- C.}

- (P) En su familia de origen ¿su padre maltrataba a su madre?

- (R) Si

\section{Entrevista no8 - D.}

- (R)... La diferencia que hay, es que a él no le decían nada, no le decían que fuera malo, no porque en su casa se ha vivido eso, su padre ha pegado a la madre durante muchos años, psicológicamente lo sigue haciendo ahora, de puta para arriba, todos los días, por lo menos hasta el momento que yo dejé esa casa, entonces claro... yo ahora comprendo, él al decirme que si yo era una guarra, que si era una puta o si estaba sucio... yo ahora lo entiendo... no es que él lo viera mal, o lo viera bien, son los hábitos que ha aprendido en su casa ¿Qué me iba a decir?, pues lo que ha oído, ahora lo veo así, cuando antes no lo entendía, decía "pero bueno... ¿qué me está diciendo?, yo qué sé, voy a seguir limpiando porque se ve que esto no está bien" pero ahora me doy cuenta de que no, después de psicólogos y de charlas y de cosas que ya vas viendo, con gente que vas hablando... son patrones que se tienen y él los tenía, él los tiene, el hermano los tiene, el otro hermano los tiene porque todos son así, porque la hermana, al marido no, pero a las niñas, las tiene fritas y los otros tres hermanos son iguales que él, ¿Entonces qué va a hacer? 
Entrevista no $9-R$.

- (P) Sí, pero la pregunta es ¿él presenció ese maltrato? ¿él vio como su padre maltrataba a su madre?

- (R) Pues... seguramente. Maltrato de palabra sobre todo, de palabra a lo mejor, sí

- (P) Maltrato psicológico

- (R) Sí, lo que pasa que mi suegra era una mujer tan... "va, no pasa nada" y siempre tapaba y tapaba

4) Violencia de género en la familia de origen de ella:

Cuatro entrevistadas afirman haber presenciado violencia en su familia de origen.

\section{Entrevista nำ 2-E.}

- R) Mi madre y mi hermana, mucho, mi hermano menos, porque bueno... tengo menos relación con él, pero me ha apoyado mucho mi madre, mi hermana, lo entienden y apoyan porque, por desgracia, mi padre era también un poco alcohólico y mi madre, lo entiende, la situación de humillación, a lo que llegan de desvalorización, de insultos, de todo lo que hacen, porque lo vivió, claro, era otra época, pero lo vivió también.

- (P) ¿Tú viste malos tratos en tus padres?

- (R) Sí

- (P) ¿Viste a tu padre agrediendo a tu padre?

- (R) Sí, muchas veces.

Entrevista no 4 - M.J.

- (P) ¿Entre tu padre y tu madre, tú viste alguna vez malos tratos $\mathrm{M} \mathrm{J}$ ?

- (R) Yo sé que entre ellos si los hubo, mi padre si pegaba a mi madre, pero a mí nunca me pegaron, ninguno de los dos.

Entrevista $\mathrm{n}^{\circ} 5$ - A. M.

- (P) ¿Tú viste alguna vez que tu padre maltratara a tu madre? 
- (R) Nunca lo vi y mi madre sí lo alegó en su separación. Que era una mujer maltratada

\section{Entrevista $\mathrm{n}^{0}$ 7- C.}

- (P) Yo sé que no quieres hablar de tu padre, ¿pero tú en tu familia de origen viste algún tipo de maltrato?

- (R) No, yo no lo sufrí, mi padre bueno... sí, pero era del alcohol, de la bebida (le incomoda hablar de su padre)

\section{5) Micromachismos y autoestima de la mujer:}

\section{En todas las entrevistadas aparecen los micromachismos que}

\section{desembocan en la pérdida de la autoestima.}

\section{Entrevista nำ1-O.}

- (P) ¿En casa, quién se ocupaba de la compra, de las niñas, un poco de la intendencia de la casa?

- (R) Yo

- (P) En algún momento, por todo esto que te pasó con él, ¿llegaste a dudar de tu capacidad como madre, ama de casa, administradora del dinero?

- (R) Yo sólo pensaba que estaba acabada, que estaba acabada y que estaba acabada... Yo me acuerdo que me decía mi madre, "haz algo de comida" y yo, si no sé cocinar, no me acuerdo y mi madre.... "tú, tú, tú, tú... pero si sabías cocinar y cocinabas muy bien", mamá que no me acuerdo de cocinar.

\section{Entrevista no 2-E.}

- (P) ¿Cómo estás de salud E?

- (R) Bien, estoy algo deprimida, duermo mal, estoy a tratamiento, pero de salud en general me encuentro bien, con fuerzas y ... intentando salir adelante aunque con todo esto, vamos, lo que más fuerza me dan, son mis hijas que ves que tienes que estar ayudando a salir adelante, porque... porque se puede, porque se vale, vamos, porque valgo y porque me lo dicen muchísimas personas, aunque en la cabeza tienes grabado que eres una mierda y que no vales nada y que, y que, no sabes hacer nada, pero intentas tener fuerza para salir adelante, además, es eso, que tengo buena salud a pesar de lo que me ha pasado, esto, después del maltrato, pues psicológicamente estaba hundida y todo lo que me puede pasar de esto, creo que se va a superar, porque es solamente por maltrato, te quedas sin fuerzas, tienes una ansiedad tremenda, un descontrol de todo, que no sabes por dónde empezar a vivir, porque no sabes vivir, porque te han destrozado, la vida, realmente te la destroza, anímicamente, personalmente y todo, pero... pero bueno... tienes que.... 
- (P) ¿Cómo te sentías mientras estabas viviendo con él? ¿Llegaste a creerte todo eso que él te decía? ¿Interiorizaste el discurso, de tal manera que lo hiciste tuyo?

- (R) Sí, sí, sí, yo estaba convencida de que no valía nada, que no valía, que no sabía por qué vivía, porque no valía nada, no era nada, no hacía nada bien ¡Puf...!, es una humillación la que tienes dentro que no... que te crees todo lo que te dice, eres un asco, un asco de persona, no tienes...

- (P) Me decías antes, que toda la intendencia de tu casa, la comida, la compra, las niñas, las actividades... eras tú, siempre

- (R) Sí

- (P) ¿Y así continúas?

- (R) Sí, claro (lo dice con una amplia sonrisa, con orgullo de sí misma)

- (P) ¿En algún momento dudaste de tus capacidades para hacer eso? Si se supone que siempre lo hiciste bien, que fuiste buena madre, que administrabas bien el dinero, que a tus niñas no les faltaba de nada. ¿Llegaste a dudar si lo estabas haciendo bien?

- (R) Dudaba de que supiese hacer las cosas, pero cuando él lo decía, porque cuando él no estaba en casa, yo veía que yo las cosas las hacía, que no... que funcionaba todo, realmente cuando... ¿qué era cuando él estaba así que yo no sabía hacer nada? Yo lo veía, incluso después de que el abogado le dijo que se fuese de casa, funcionaba todo igual de bien, incluso mejor por la tranquilidad, por no tener el miedo este de cuando llega a ver qué pasa, pero bueno... él ayudaba también en casa alguna vez, cuando estaba bien, colaboraba.

\section{Entrevista nำ 3-R.P.}

- (P) ¿Quién se ocupa de los niños, de la ropa, de la comida, de la casa, de la intendencia familiar?

- (R) Yo siempre, desde siempre, yo, yo, yo, yo. Ahora cuando yo estuve haciendo el curso, como él está en el paro, se encargó él, hizo de amo de casa y creo que se dio cuenta del trabajo

- (P) O sea que te ocupas tú de todo esto

- (R) Yo me ocupo de todo, de los niños, de la comida, de la casa, de todo.

- (P) En algún momento, mientras él te oprime o te dice cosas, aunque sea a través de su madre, ¿tú has sentido que no eres válida, por ejemplo haciendo esto, te has sentido o mala persona, o mala madre o mala trabajadora...?

- (R) No, no me he sentido valorada. Yo no he sentido que no haya hecho las cosas bien, porque siempre estaban bien hechas

\section{Entrevista no-4-M.J.}


- (P) ¿Quién tomaba las decisiones importantes en esa relación?

- (R) Él siempre todo, él siempre

- (P) Él decidía

- (R) Hasta lo que me tenía que poner de ropa, él era el que decía lo que había que comer, lo que había que beber, lo que había... lo que te tenías que poner.... Todo.

- (P) Sin embargo de la casa, las compras,... Dices que te ocupabas tú, comentas que te monta un número porque cocinas unos huevos que no son de su agrado ¿eras tú la que te ocupabas de la casa y esas cosas?

- (R) Sí.

- (P) ¿En algún momento dudaste de ti misma? Decías que tenías la idea de que la culpa era tuya. ¿Dudabas de tus capacidades?

- (R) Sí, sí, sí. Siempre, siempre. Yo creo que me lo hizo creer él, porque yo después de un tiempo, te das cuenta de que son cosas sin sentido y que no... que hay otras maneras de solucionar las cosas.

\section{Entrevista nำ 5- A.M.}

- (R) Porque, a ver, yo no es que me diera cuenta, ni mucho menos..., yo me encontraba muy bien, jamás tuvimos ningún problema... pero por lo que me ha dicho gente, que me ha consultado, que me ha visto, me tenía, digamos, un poco anulada. Era como él decía, dónde él decía, lo que él quería. Si yo quería comprar unas sábanas, a pesar de estar trabajando,... "espera que este mes no se puede... o para el mes que viene... o no las necesitas" En cuanto a eso, en cuanto a ir por ahí un día a comer, pues tampoco se podía, el ir de vacaciones tampoco se podía, el salir con mis hijos un momento puntual a comerme una hamburguesa, te to he contado yo en algunas ocasiones, ya les decía antes de entrar, que el postre era una taza de leche en casa, que no se podía,... Cuando en ese momento estábamos los dos trabajando. A pesar de pagar una hipoteca, teníamos una solvencia los dos y nos lo podíamos permitir

- (P) Pero él decidía que no

- (R) Eso es

- (R) Sí, porque de hecho te dicen que eso es cosa tuya, que me tendría que haber hecho valer... Y ya que yo en aquel momento me lo ganaba... Porque yo una vez que dejé de trabajar, él todavía peor, claro según él no hacía nada, ni lo de casa ni nada, según él

- (P) Tirabas de tus hijos

- (R) Sí claro y de mi casa y de la comida a su hora cuando él llegaba y... yo entonces hacía más que hago ahora.

— (P) Cuando él te insultaba y empezó a faltarte al respeto... ¿Ahí empezaste a dudar o no?

- (R) Simplemente le decía que ¿qué era lo que pedía de mí? A ver... no sé... le tuve que fallar en algo para que buscara a otra persona ¿no?, pero yo era lo que él decía, tenía mi casa atendida, a mis hijos atendidos ¿qué me pedía? No lo entendía. No lo entiendo todavía. 
- (P) Cuándo él te insulta, cuando él te increpa, te dice "eres una gocha, no te levantas de la cama, no haces las cosas..." ¿Tú empezaste a creerte que eras tan gocha como él decía, que no te ocupabas de tus hijos...?

- (R) Sí, en aquel momento sí

\section{Entrevista no 6- A.}

- (R) Que seguí pagándola, pero cuando tuve que mandar a mis hijos... yo dije "M, yo no puedo pagar, lo siento mucho, pero yo no puedo, a mí mil pesetas, dos mil..." para mí era un sacrificio, bueno... ahí ya empezamos a hablar de euros, porque claro, yo te puedo decir, cuando yo me separé, como hacía tantísimo tiempo que yo no utilizaba dinero... tenía que venir mi hija conmigo de compras porque no sabía pagar, no conocía los euros, no sabía distinguir los euros. Entonces claro... si yo pagaba con un billete de $5 €$ o con $1 €$, bien, pero como llegáramos a los céntimos ya me perdía, porque no manejaba el dinero, yo estuve un año sin tocar dinero, entonces tenía que venir mi hija conmigo y pagarme ella "mira mamá, esto con esto y con esto..." enseñarme como a una señora mayor, enseñarme como a una señora mayor y luego en casa practicarlo para hacerlo

- (P) Entonces ¿quién manejaba...?

- (R) Me anuló totalmente

\section{Entrevista nำ 7-C.}

- (P) ¿Quién se ocupaba de la casa, la comida, la compra, los niños?

- (R) Yo

- (P) ¿Siempre?

- (R) Siempre

- (P) ¿En alguna ocasión dudaste de tu capacidad para hacer eso?

- (R) Sí

- (P) ¿Pensaste que lo estabas haciendo mal?

- (R) Siempre lo he pensado, que lo estaba haciendo fatal, jvamos que era una inútil perdida!, lo tenía clarísimo. (Para él) Todo estaba siempre mal hecho

\section{Entrevista $\mathrm{n} \cong 8-\mathrm{D}$.}

- (P) ¿Quién se ocupaba de las cosas de la casa, la compra, la comida, la niña...?

- (R) Mira, de las cosas de la casa me ocupaba yo, él hacía la cena, porque yo volvía tarde, pero bueno hacía la cena, pero muy restregado "porque yo hago la cena" y luego la compra, si podíamos hacerla los dos, para él mejor, porque es que yo no sabía comprar, yo no sabía comprar

- (P) ¿En algún momento te llegaste a creer o dudaste de tus capacidades para ser buena madre, buena trabajadora, buena...?

(R) Sí, sí, sí, sobre todo de casa, yo pensé que no sabía ni fregar, bueno y el tema de la comida, ni hacer de comer, ni ir a la compra, que yo no tenía ni idea, de hacer la compra yo, ni idea. Llega un momento que tanto te lo repiten que al final te lo terminas creyendo,...

\section{Entrevista no 9- R}


- (P) ¿Quién se ocupaba de la casa, de la compra, del niño...?

- (R) Yo

- (P) Siempre

- (R) Sí, porque las pocas veces que se tuvo que ocupar él, era "Sí, sí, yo, yo" Dos días

- (P) Sin embargo decías que sí que te hizo dudar de tu labor de madre, de ama de casa...

- (R) Sí, si él hacía un día la comida, eso era la leche y había que pregonarlo, no te decía hazlo así, pero te lo daba a entender, fíjate, no había un dios que comiera aquello, pero bueno, había encima que... Yo sí, yo bueno, cuando empezó, "mira yo trabajo, tú no trabajas, pues haces la comida..." pero no hacía nada, lo hacía yo todo

\section{6) Aislamiento social:}

Todas las mujeres entrevistadas experimentaron aislamiento social en sus relaciones de pareja.

Entrevista nำ-O.

- (P) Las relaciones sociales ¿cambiaron mucho? Las amistades que tenías antes, de casada, con lo que tienes ahora. ¿Qué pasó con tu red social?

- (R) Yo con mi ex me fui separando de todas mis amigas, cuando me he separado, en mujeres maltratadas, que ves de todo, gente que dice la verdad, gente que no la dice... y me hice mis amigas, pero hubo varias que me fallaron, me metieron muchas mentiras y me utilizaban, entonces, empecé un poco a... y bueno salgo con este chico, me lo paso bien, bailo.

\section{Entrevista ํำ 2-E}

- (P) ¿Qué tipo de insultos de profería?

- (R) Puf... De todo,... mucho puta.

- (P) Si

- (R) Puta, siempre en la boca, hija de puta mucho y... en ese momento, además, no me veía apoyada porque no se lo decía a nadie, no podía decírselo a nadie, y te vas encerrando y.... y...

- (P) Eso era lo siguiente que te quería preguntar, cuando a ti te empiezan a pasar estas cosas, tú ¿lo cuentas E. o te lo callas?

- (R) No lo cuento, no lo cuento, porque me da vergüenza, me daba vergüenza, es que te encierras, yo dejaba hasta de salir, porque no, no... como que... al ver a la gente que te lo iba a notar, que te..., que te... estabas mal... que no...( lo dice llorando)

- (P) Cuando te mirabas al espejo ¿Qué imagen veías reflejada de ti misma? 
- (R) Me veía fatal, fatal, fatal,... pero mal, no sé explicarlo, me veía muy mal de todo, no me veía, como un monstruo, fea, yo es que creo que soy una persona normal, pero me veía mal, no salía ni a la calle para que no me viese la gente, no me pueden ver así, no valgo nada, no me puede ver la gente así, que no tengo nada de fuerzas, que no....

\section{Entrevista no 3-R.P.}

- (R) Exactamente, físicamente no, yo creo que él, a ver... es que no quiero justificarlo, porque justificación no tiene ninguna, pero a ver, yo pienso que si tú sabes que hay una persona que la has encontrado tú libre en su país o donde ella haya estado y ves que ha trabajado, que se ha estado desenvolviendo, bien, la traes para aquí y la metes en un lugar donde ves que no hay nada y le dices, "mira, lo tienes todo". ¿Cómo le puedes decir a una persona que lo tiene todo, si no tiene nada? ¿sabes? Y si te da dinero, te da lo mínimo y con eso tú tienes que hacer maravillas. Entonces yo creo que por ahí, no más, ya te está cortando las alas. No te informa de nada, no te dice "mira, esto es así, esto es así, esto es así..." Yo venía de un país diferente a éste, diferente, aunque siempre explico, dicen que mi país es un país tercermundista, y de tercermundista no tiene nada ¿sabes? Porque la gente allá es muy instruida, la gente allá, serán de repente, yo no quiero decir que no haya gente que no sea pobre, porque es que la hay, pero son sectores, ¿sabes?, yo vivo en una ciudad grande, en una ciudad donde la gente, la mayoría, por no decir todos, tienen educación e instrucción, yo no sé, la gente ésta que es muy pobre, muy pobre, es la gente de la sierra de P., yo vivo en la costa, él me veía que venía de un estrato social diferente a donde él me estaba metiendo a mí, y no me informaba de nada. Yo en la luna, yo decía "pero ¿a quién le digo, oye?", a dónde yo iba, siempre me miraban con una cara como diciéndome "¿para qué quieres saber? o ¿a ti que te importa?" Si él era mi marido, quién mejor que él para darme una información, entonces le decía "¿dónde queda...?" es que me sentía tan enclaustrada en la B. que le decía "¿Dime donde queda la estación de autobuses?"... "Ah mira, queda... te vas por acá... das la vuelta.... Y ya está" Como si yo fuera una ignorante, cómo le dices a una persona una cosa así. Podía llevarme, mira "vas por esta calle, cruzas aquí, das la vuelta y ya está..."

(P) Indicarte

(R) Exactamente

- (P) Pero no, de forma vaga...

- (R) Exactamente... "y si yo me quiero ir a Madrid ¿cómo me voy?" "Pues vas a la estación de autobuses" “¿Pero dónde está la estación de autobuses?" No, de siempre, trataba de cortarme cualquier información, cualquier cosa. Mira, me fueron minimizando, él y su madre, de tal manera, que llegó un momento en que yo me sentía tan pequeñita, que yo decía "aquí el mundo me come" Yo tenía hasta miedo de salir de la casa. Yo venir de vivir en una casa grande, te estoy hablando, no de un piso, sino de una casa, a meterme, eso no era ni un piso, era cualquier cosa, entrabas y era un pasillo, una habitación, otra habitación y la cocina y ya está. Es que yo me sentía fatal, yo decía "muero, aquí muero, de verdad, muero, muero, pero muero" y ahí tenía que estar, porque no podía salir, porque no sabía dónde estaba, hasta que poco a poco, yo iba saliendo, cuándo él iba a trabajar, yo salía. No porque me dijera que no salga "puedes salir", pero claro, a pesar de que L. B. era pequeña, yo me sentía fatal, me sentía perdida ¿sabes?, entonces yo salía, iba más o menos mirando cosas y así por mi cuenta, hasta que ya iba saliendo un poco más, pero al principio fue fatal, fue fatal, te iban como absorbiendo, como queriéndome... Yo tengo el carácter muy fuerte..., porque tanto él como mi suegra fueron a P., para casarnos ¿no? Y ellos vieron como yo era realmente y a mí me 
daba la sensación de que no querían que yo fuese así aquí, como queriéndome, pues eso, minimizar, aplacar y querer ser ellos los que mandaran sobre mi persona. Es una sensación muy horrible

\section{Entrevista nㄴ-M.J.}

- (R) Estando ya en T. fue todo peor, las palizas de continuo..., violaciones....Sí, sí, sí. Yo llegó un momento que no he sido capaz de mirar a la gente a la cara hasta hace muy poco, porque siempre me he sentido inferior a todo el mundo, siempre.

- (P) ¿Y tú lo achacas al maltrato vivido en ese momento?

- (R) Todo, todo

- (P) ¿Tú en esos momentos M.J, cómo te sentías?

- (R) Pues muy sola, muy sola. No sé, yo veía que no podía hacer nada por solucionarlo, porque yo decía, si me voy de con él, ya sé dónde voy a acabar, en casa de mi madre, y yo sabía que con mi madre tampoco podía contar porque tampoco me quería

\section{Entrevista nํ 5- A.M.}

- (P) Y tú, después de escucharle reñir o dar voces ¿cómo te sentías?

- (R) Me metía mucho... o sea, me metía en mi trabajo en principio y luego con mis hijos, o sea como que....

- (P) Intentabas mantenerte ocupada ¿quieres decir?

- (R) Exacto, olvidar lo que pasaba, sí.

\section{Entrevista $n^{\circ}$ 6- A.}

- (R)... no me dirige la palabra nadie porque todo el mundo, se encargó muy mucho de decirle "que no se os ocurra a nadie mirar a mi novia porque hay hostias por el medio" palabras textuales, a compañeros de trabajo amenazarles que no me mirara nadie a la cara que se las encontraban, no con él, con él y con 20 más. Yo cuando me enteré de todo esto, yo alucinaba en colores "estoy saliendo con un mafioso, es que esto parece de la mafia" yo decía "bueno... esto es una tontería" Pues me lo dijeron y era verdad, yo alucinaba, " ¿Tú crees que algún chico se va a atrever a sacarme a bailar?, cuando a los 2 minutos tengo pegado a un hermano tuyo para que no me saque a bailar nadie", porque si llevaba un vestido con un poco de escote, venía el hermano y me decía "¿dónde vas con ese vestido tan escotado?" y yo decía "¿Y yo por qué tengo que darte a ti explicaciones?"'Es que vas enseñando todo" "¿Y a ti que más te da?"'pues ya se lo diré yo a mi hermano que no te permita andar con esas cosas" Eso me pasó a mí, claro que si es hoy, le meto el vestido por la boca, pero entonces... 
- (R) ...Cortábamos mucho, íbamos al instituto y tenía amenazados a toda la clase, que no se acercara a mí nadie, entonces me decían, siempre me dijeron mis amigos ¿qué había visto yo en ese hombre para casarme con él? Pues no lo sé, no sé lo que vi en él....

- (R)... Yo había estado trabajando en el motel de P., lo inauguré yo y yo estaba de administrativo allí y claro... con los camareros que había allí, unos chavales encantadores, hacíamos un equipo... una unión... de maravilla" Los amenazó a todos uno por uno, que no se metieran ninguno en el medio que iban 20 por ellos....

\section{Entrevista $\mathrm{n}^{0}$ 7- C.}

- (R) Se me cerraba el estómago, tenía constantemente como un nudo en el estómago, un dolor, ganas de vomitar, que con el tiempo se me quitó y empecé a dormir, que era incapaz de dormir por las noches y yo que sé... empecé a ser yo misma, a vestirme como me da la gana, a cortarme el pelo como me da la gana, a despeinarme como él decía, a tratar con gente, a salir, a yo que sé... a relacionarme, a... vivir un poco

\section{Entrevista nㅇ- - D.}

- (R) No, no, no... Al revés, si me pasaba algo, que a lo mejor me caía yo, un día que me caí por la escalera, él se reía y no veía que fuera nada malo, incluso, el tema de la violencia él no lo veía nada malo. El tema de la violencia, los amigos y la familia, que no tuviera amigos, que no tuviera familia, que no tuviera nada, así él podía... ¿sabes? Todo en la vida tenía que ser con él, entonces él cuando hacía algo así, pues no lo veía malo

- (R) Pues no le gustaba de mí que tuviera amistades, que mi tiempo lo compartiera con alguien que no fuera él le molestaba, aunque fuera con mi hija, le daba igual, no quería. La familia, contra menos hablara con ella, mejor y luego sin ningún motivo, él llegaba a la casa y no había motivo ninguno. Yo no sé porqué, llegaba a la casa y... "esto está lleno de mierda, esa porquería no me la como..." tiraba la comida, decía que la ropa se la tenía que lavar él porque yo la dejaba sucia... no sé... trabajamos los dos... tenemos tanta carga, que no tenemos familia, nos tenemos que echar una mano los dos...todo lo contrario, bueno era un acoso conmigo constante. Lo que peor llevaba era que tuviera una amistad o tuviera algo, le volvía loco, es que no podía y me decía "tú sal, tú sal" Cuando llegaban 5 minutos antes de salir ya estaba... "¿A dónde vas?, porque a mí me dejas solo, porque yo para eso no vengo..." Lo de siempre "porque tú no ves lo que yo he hecho por ti, porque yo estoy aquí solo y tú tienes amigos, tienes a tu hermano y a R. " $Y$ al final tenía que llamar a alguien para decir, "mira que no salgo" 
- (R) Puf... ¿cómo me sentía? ¿cómo explicarte?, pues me sentía que no era nada, estaba vacía por dentro, ni tenía amigos, ni podía expresarme con mi madre, tenía que llamar a mi madre a escondidas, yo me sentía vacía, es que nada me hacía ilusión, con lo alegre que yo soy, yo siempre he sido muy alegre, muy... con muchas ganas de vivir y mucha ilusión, y yo ahí no tenía ilusión, ni ganas de nada, yo tenía ganas de morirme

- (R) Sí, porque cuando mi madre se va y yo me quedo sola en casa y voy viendo tantísimos detalles, porque es como que viviera en una cárcel, todo tenía que ser con su consentimiento, todo era a base de que él me dejara, o me diera dinero. Entonces claro, yo el verme querer salir y no poder...

Entrevista no 9- R.

- (R)... Cuando veía ese periodo en el que te iba a machacar, lo sabías que te venía, tenías que estar sentada en el sofá, así (se cruza de brazos) y sin moverte. Bueno, yo me bloqueaba, yo me quedaba sentada en el sofá y arreando, procuraba ir a comprar cuando él no estaba, para que no supiera que iba a comprar, o... para que él me viera en casa y hacer de ama de casa. Si estaba trabajando en alguna cosa ipuf...!, cuando fue lo del gas, tenía que hacer reuniones de vecinos y a veces se alargaban por la noche, pues que de dónde venía, de estar con alguno, de yo qué sé, de lo que fuera, le daba igual, le daba lo mismo

\subsection{4.- Estrategias utilizadas para salir de la relación de maltrato:}

Cada persona tiene un límite interno que determina lo que puede permitir y lo que no en una relación. La frontera entre lo que se permite y lo que no, es variable para cada mujer que recibe maltrato. En algunos casos es la infidelidad, en otros es el maltrato hacia sus hijos e hijas,... lo que les hace reaccionar.

En este apartado se exploran, cuáles fueron los factores mantenedores de la relación y cuáles precipitaron la ruptura de la misma, para las nueve mujeres entrevistadas en la investigación.

Entrevistada ํㅜ 1-O. 
Mujer de 34 años, nacionalidad española, madre de dos niñas (3 y 6 años), separada desde hace dos años del padre de sus hijas, en paro y con estudios de bachiller

1) Factores mantenedores de la relación:

- Idealización del amor romántico

- Dependencia económica

- Ciclo de la violencia

- Aislamiento social (falta de apoyos familiares)

- Micromachismos

2) Factores precipitantes de la ruptura:

- Consumo de alcohol por parte de su pareja

- Episodio de violencia en presencia de sus hijas

- Temor a perder la vida a manos de su pareja

\section{Entrevistada $\mathrm{n}^{0} \mathrm{2}-\mathrm{E}$.}

Mujer de 42 años, nacionalidad española, madre de dos hijas (18 y 13 años), separada desde hace 10 meses del padre de las mismas, en paro y estudios primarios.

1) Factores mantenedores de la relación:

- Idealización del matrimonio como forma de vida

- Dependencia económica

- Ciclo de la violencia

- Haber presenciado violencia en su familia de origen

- Micromachismos

- Aislamiento social 
- Temor a desclasarse

2) Factores precipitantes de la ruptura:

- Violencia dirigida hacia sus hijas por parte de su pareja

- Apoyos familiares

- Consumo de alcohol por parte de su pareja

\section{Entrevistada ํㅜ 3-R.P.}

Mujer de 42 años, de nacionalidad no española, madre de una niña y un niño (8 y 5 años respectivamente), trabajo en economía sumergida (4 horas semanales) y estudios de bachiller.

1) Factores mantenedores de la relación:

- Dependencia económica

- Aislamiento social

- Micromachismos

2) Factores precipitantes de la ruptura:

Continúa la convivencia con su pareja y padre de su hija e hijo, a pesar del maltrato psicológico al que está sometida desde hace ya 11 años, fecha en la que contrae matrimonio en su país con un hombre español. Esta mujer describe estar atrapada físicamente en la relación, aunque no psicológicamente, verbaliza su deseo de salir de la misma, para ello precisa de unas condiciones económicas favorables, con las que ahora no cuenta.

\section{Entrevistada ํㅜ 4-M.J.}

Mujer de 38 años, nacionalidad española, madre de dos hijos y una hija (20, 15 y 8 años), 20 años separada de su primera pareja y padre de su 
hijo mayor, empleada en un supermercado de forma eventual y estudios primarios.

1) Factores mantenedores de la relación:

- Inmadurez en el inicio de la relación (13 años)

- Aislamiento social

- Dependencia económica

- Familia desestructurada (sin apoyos familiares)

- Presencia de violencia de género en la familia de origen de ella

- Ciclo de la violencia

- Micromachismos

- Idealización de la pareja

- Embarazo en la adolescencia

2) Factores precipitantes de la ruptura:

- Agresiones durante el embarazo

- Miedo a perder la vida, tanto ella como el bebé que esperaba

\section{Entrevistada nº 5- A.M.}

Mujer de 51 años, madre de dos hijos (18 y 19 años), 7 años separada del padre de ellos, jubilada por motivos médicos y estudios de bachiller.

1) Factores mantenedores de la relación:

- Idealización del amor romántico en general

- Ciclo de la violencia

- Aislamiento social

- Micromachismos 
- Violencia de género en ambas familias de origen

- Dependencia económica

2) Factores precipitantes de la ruptura:

- Infidelidad por parte de su pareja

\section{Entrevistada n 6 - A.}

Mujer de 55 años, madre de un hijo y una hija (33 y 29 años respectivamente), 7 años separada de su pareja y padre de él y ella, trabajo estable como administrativa, estudios de grado medio (diplomatura).

1) Factores mantenedores de la relación:

- Idealización de la pareja

- Idealización del amor romántico: omnipotencia e inevitabilidad

- Ciclo de la violencia

- Dependencia económica

- Micromachismos

- Aislamiento social (falta de apoyos familiares)

2) Factores precipitantes de la ruptura:

- Infidelidad por parte de su pareja

- Afán de superación

\section{Entrevistada ํㅜ 7- C.}

Mujer de 36 años, madre de dos niños y una niña (12, 8 y 4 años), separada desde hace un año del padre de sus hijos e hija, trabaja de forma eventual en dos sitios diferentes para completar la jornada laboral, estudios de bachiller. 
1) Factores mantenedores de la relación:

- Idealización del amor: inevitabilidad

- Amenazas dirigidas tanto a ella como a su familia

- Ciclo de la violencia

- Dependencia económica

- Aislamiento social

- Presencia de violencia de género en ambas familias de origen

- Micromachismos

2) Factores precipitantes de la ruptura:

- Apoyo familiar

- Colaboración de los servicios sociales (Casa de Acogida)

\section{Entrevistada no 8- D.}

Mujer de 26 años, madre de una niña de 4 años de edad, 14 meses separada del padre de su hija, trabaja como auxiliar administrativa de forma eventual, estudios de bachiller.

1) Factores mantenedores de la relación:

- Ciclo de la violencia

- Dependencia económica

- Micromachismos

- Aislamiento social

- Sentimiento de culpa

2) Factores precipitantes de la ruptura:

- Apoyo familiar

- Temor a perder la vida 
- Temor a perder a su hija

\section{Entrevistada no 9- R.}

Mujer de 47 años, madre de un hijo de 20 años, 4 años separada de su pareja y padre de su hijo, regenta un bar, estudios de bachiller.

1) Factores mantenedores de la relación:

- Ciclo de la violencia

- Dependencia económica

- Micromachismos

- Aislamiento social

2) Factores precipitantes de la ruptura:

- Agresiones a su hijo

- Temor a perder la vida, ella o su hijo.

- Apoyo familiar 


\section{CAPÍTULO III}

\section{CONCLUSIONES}

Para la elaboración de las conclusiones se tendrán presentes los resultados que se plasman en las tablas 11,12 y 13 del Capítulo II, apartado 5.4. En ellas se hace alusión a los mitos acerca de la violencia de género que se encuentran instalados en la sociedad (Tabla 11). También se tendrán en cuenta los mitos acerca del amor romántico (Tabla 12), que definen las primeras relaciones de pareja, como así quedó patente en el estudio previo (DEA), que lleva por título La seducción del machismo en la adolescencia: Influencia en la violencia de género. Por último se alude a los episodios reales de violencia, con los que conviven las víctimas de la violencia de género, que por su mecánica son responsables, en gran parte, del mantenimiento y retroalimentación de dicha violencia (Tabla 13).

Del mismo modo, se enmarcarán los relatos de las mujeres víctimas de violencia de género que conforman este estudio, dentro de las teorías expuestas a lo largo del trabajo acerca de mitos, violencia de género, amor o dominación. De esta forma se comprobará si la realidad de las experiencias de maltrato, que relataron las nueve entrevistadas, valida o no dichas teorías, además de comprobar si dicha realidad se corresponde con el imaginario social acerca de la violencia de género.

Por todo ello, es necesario tener presente la hipótesis de la que se parte en este estudio, que se redacta en los siguientes términos:

Es posible que la dominación del varón sobre la mujer, sea la verdadera dificultad que impide la separación de una pareja en la que 


\section{se han instalado los malos tratos como forma de relación, quedando así, en un segundo plano la cuestión del amor.}

A tenor de esta premisa lo prioritario fue la revisión conceptual, para clarificar los términos que se manejaron a lo largo del trabajo: mito, violencia de género, amor romántico y dominación. La revisión conceptual cobra sentido desde la necesidad de entender el vínculo que conecta dichos términos, con las estrategias empleadas por algunas mujeres, que siendo víctimas de violencia de género, consiguieron romper la dinámica de las relaciones en las que ocurrían los malos tratos y escapar de la dominación de sus parejas.

Con este planteamiento el objetivo se define por sí mismo: además de descubrir cuáles eran las estrategias utilizadas por algunas mujeres víctimas de violencia de género, para romper la relación con sus parejas maltratadoras, se quiso saber cuál era la conexión entre amor, dominación, violencia y mito; quisimos comprobar si el mito tiene un peso específico a la hora de tomar la decisión de separarse; y por último, poner de manifiesto, a través de testimonios reales, que la experiencia de maltrato, no incapacita para el funcionamiento normalizado en la sociedad, una vez rota la relación.

En el capítulo II, apartados 5.4.1., 5.4.2. y 5.4.3. se recogen fragmentos de entrevistas que invalidan tanto los mitos de la violencia de género, como los del amor romántico, dejando al descubierto la propia realidad de las mujeres víctimas que los refieren.

Haremos un recorrido por los mitos y por las realidades de estas nueve mujeres, comenzando por los mitos acerca de la violencia de género, siguiendo por los mitos acerca del amor romántico, para terminar con las realidades de las experiencias vividas durante la relación de maltrato. En este camino se irán insertando las conclusiones que se desprenden del análisis de las entrevistas realizadas. 


\section{Mitos acerca de la violencia de género:}

1.- A las víctimas de la violencia de género les gusta que las maltraten, son mujeres masoquistas y mujeres provocadoras: En ninguna entrevistada se encontró la confirmación de este mito. Ninguna de las nueve mujeres tenía conciencia de provocar en su pareja el estallido de violencia y ninguna de las nueve disfrutaba con el mismo. Es más todas deseaban terminar con la experiencia de maltrato lo antes posible.

La primera teoría sobre malos tratos dentro del matrimonio surgida de estudios psicológicos ofrecía una explicación que se centraba en el extremo masoquismo femenino y las desviaciones psicológicas que las mujeres golpeadas ostentaban. Elizabeth Pleck (1987) sugiere que el legado de Freud influenció en los supuestos psicológicos predominantes sostenidos en los años 1960. Pleck comenta que Freud consideraba como fruto de la imaginación de sus pacientes femeninas los presuntos recuerdos de abuso sexual e incesto que éstas le relataban. A partir de aquí Freud desarrollaba la teoría de que las niñas desean inconscientemente llevar a cabo experiencias sexuales con sus padres y de adultas satisfacen esta necesidad a través de la creación de fantasías. Al entender los informes de incesto como el resultado de la inmadurez femenina, Freud inició la creación de la imagen de la mujer masoquista. Pleck concluye que fue esta imagen la que resurgió en los años 1960 durante los primeros debates sobre mujeres golpeadas. Pleck cita a Deutsch y a Horney como los primeros psicoanalistas que aplicaron la teoría del masoquismo a las mujeres golpeadas o violadas. (Pleck, 1987)

Los resultados que arrojan nuestras entrevistas se alejan diametralmente de este tipo de teorías. En ningún caso encontramos indicios 
para afirmar que las mujeres buscaran ser golpeadas por sus parejas, que disfrutaran con el maltrato o provocaran ese tipo de situaciones. Por el contrario, todas intentaron acabar con el mismo a través del manejo de situaciones o estrategias como por ejemplo: el silencio, intentar agradar a su pareja, búsqueda de apoyos familiares, diálogo, volcarse en el cuidado de sus hijos e hijas, permanecer inmóviles, en el sentido más literal del término, en presencia del maltratador...

Después de haberlo intentarlo todo, las mujeres entrevistadas, coinciden en concluir, que de nada sirvieron sus esfuerzos, sus parejas las golpeaban de igual modo, al llevar a cabo cualquier tipo de conducta o su contraria.

2.- Las víctimas de la violencia de género padecen trastornos psicológicos, están locas: Ninguna de las nueve entrevistadas habían presentado trastornos psicológicos anteriores a la experiencia de maltrato.

"Los profesionales de la salud mental han manifestado cierta tendencia a culpabilizar a la víctima de los malos tratos mediante el razonamiento de que la agresión masculina satisface la necesidad de sufrir de la mujer, a quien se achacaba una personalidad dependiente, perdedora o autoderrotista. El propio Freud consideraba el masoquismo una expresión de naturaleza femenina. En 1985, la psiquiatría oficial cuenta entre sus diagnósticos con el de personalidad masoquista, clasificando como enfermas mentales a las personas que se emparejan con un terrorista doméstico o permanecen en relaciones explotadoras en las que son habitualmente maltratadas" (Rojas Marcos, 1995 p.36)

Atendiendo a los resultados de nuestra investigación, podemos concluir que de nuevo el planteamiento freudiano es erróneo. Ninguna de las nueve mujeres que integran el estudio había manifestado ningún tipo de trastorno psicológico, previo a la relación con su pareja maltratadora; 
ninguna tuvo necesidad de acudir a tratamiento psicológico antes de convivir con el maltrato. Sin embargo todas presentaron secuelas una vez finalizada la relación, todas precisaron tratamiento psicológico para superar la experiencia de maltrato y el estrés postraumático. El hecho de recibir ayuda psicológica les sirvió a todas ellas para iniciar o avanzar en su recuperación y afrontar el futuro de forma positiva. La relación entre una y otra variable sería pues, inversa.

3.-Los maltratadores son enfermos mentales: Ninguna de las entrevistadas refiere trastornos psicológicos en sus parejas. En ningún momento el comportamiento de ellos era anormal en otros ámbitos de su vida.

"Desde esta perspectiva, el hombre no es malo, sino que está loco o triste; y si está emocionalmente trastornado, entonces no es plenamente responsable de sus actos. Sería difícil afirmar científicamente que hay una cantidad tan elevada de hombres enfermos. Menos útil, y difícilmente científico, sería atribuir la violencia al pecado. Parece difícil entender que lleven conductas correctas a excepción de la relación de pareja, que si está enfermo y por tanto sin responsabilidad sobre sus actos, pueda controlar y decidir el momento del ataque, el lugar y las partes del cuerpo que elige". (Mullender, 2000 p.66)

Nos posicionamos a favor de la teoría de Mullender, pues resulta complicado entender cómo los maltratadores, si es que son enfermos mentales, son capaces de llevar una vida normalizada en otros ámbitos en los que se desenvuelven (trabajo, amistades...) hasta el punto de ser habitual la reacción de sorpresa e incredulidad, del entorno cuando se hace público el maltrato.

Ninguno de los nueve agresores de las mujeres entrevistadas, había recibido tratamiento psicológico, ni manifestaba trastornos al respecto. En 
ocasiones ellas llegaron a confundir el delito de la violencia de género, con algún tipo de trastorno mental, así intentaron acudir con ellos a terapias de pareja, de desintoxicación...ninguna lo consiguió.

\section{4.- La violencia de género sólo se da en familias desestructuradas, con} bajo nivel económico: De las nueve entrevistadas, sólo una de ellas refiere una familia desestructurada de origen, en la que no encuentra apoyos ni emocionales, ni económicos. Las ocho mujeres restantes, proceden de entornos familiares normalizados, pertenecientes a una clase social media.

"Podríamos creer que las sociedades más adelantadas en la igualdad de la mujer sufrirían menos maltrato doméstico, pero para nuestra sorpresa, no es así: las estadísticas nos dicen que en Europa el mayor número de muertes por violencia doméstica se da en los países nórdicos. Recientemente nos sorprendía la noticia de que Finlandia está a la cabeza de mujeres asesinadas por sus compañeros sentimentales. Un país con un alto nivel de vida, donde la mujer ha alcanzado cotas muy altas de puestos de responsabilidad y de poder. No podemos, entonces, poner todo el peso en la cultura, y menos de una forma simple o reduccionista". (Cárdenas y Ortiz, 2005, p.42)

Isabel Cárdenas y Dora Ortiz ofrecen un dato estadístico sorprendente, que sitúa el mayor número de muertes contabilizadas en nuestro continente, por violencia de género en los países del norte de Europa, sociedades supuestamente avanzadas y con alto poder adquisitivo.

Ocho de las nueve entrevistadas en este estudio, confirman esta teoría, invalidando así la creencia de que la violencia de género es un asunto de clases marginales y esto a pesar de que las nueve mujeres reciben en la actualidad o han recibido en el pasado, apoyo psicológico a través de la red de los servicios sociales y del Ayuntamiento de León. Además, todas 
coinciden en admitir, que para ellas resultó decisivo el sentir el respaldo de sus familias a todos los niveles.

Mención aparte requiere la cuestión educativa, porque si bien es cierto que para ser víctima de violencia de género, poco importa el nivel educativo que se posea, es obvio pensar que las mujeres con mejor preparación y cualificación profesional, tendrán menos dificultades para tomar la decisión de abandonar la relación de maltrato, pues se presumen para ellas mejores oportunidades y a más corto plazo la inserción en el mundo laboral, consiguiendo así independencia económica; que para aquellas que han de comenzar a formarse por exigencias del mercado de trabajo.

5.- Los maltratadores están sometidos a estrés laboral: Sólo en un caso, una entrevistada alude al estrés laboral de su maltratador, sin embargo no tiene la seguridad de que esta sea la causa de la violencia.

"Es habitual imputar la violencia a estados episódicos de pérdida de control. Claro está que lo extraño es que la pérdida de control y la tensión interior no se descarguen más que contra las mujeres o contra los hijos e hijas y no, por ejemplo, contra la empresa, sobre todo si pensamos que la escasez económica o las dificultades en el trabajo pueden -y sin duda lo hacen - estresar a los hombres (pero también a las mujeres). Además, los ataques de ira y de violencia contra las mujeres son normalmente controlados. No es, en definitiva, una cuestión de pérdida de control sino de mantenimiento del control y del poder sobre la mujer". (Mullender, 2000, p.66)

Estamos de acuerdo con Mullender cuando afirma que el estrés, lo padecen en igual medida hombres y mujeres, sin embargo las agresiones normalmente se producen en una dirección, del hombre hacia la mujer. Ocho de las nueve entrevistadas no admiten el estrés como factor 
desencadenante de las agresiones y la novena, aunque lo menciona en su discurso, no lo considera determinante. No obstante ellas, para rebajar este posible nivel de estrés de sus parejas, llevaron a cabo diferentes estrategias, como: intentar que los niños/as pequeños/as no molestaran en la casa, conseguir dinero extra a base de trabajo o privaciones varias, intentar agradar y atender todas las demandas de sus parejas... Nada daba resultado. Este punto refuerza además la afirmación de que en ningún caso disfrutan o buscan el maltrato.

\section{6.- Los maltratadores abusan a causa del alcohol u otras sustancias:}

Encontramos seis testimonios, de seis mujeres, que hablan del consumo abusivo de alcohol $u$ otras sustancias por parte de sus parejas maltratadoras. Es reseñable que las seis coinciden en que las agresiones ocurrían también aunque no hubiera habido consumo, incluso en algunas entrevistas queda de manifiesto que las agresiones se producían una vez habían remitido los efectos del alcohol.

Con respecto al consumo de alcohol, Gelles y Strauss (1988) estiman que éste es un factor presente en al menos el $50 \%$ de los episodios de violencia conyugal. Kantor y Strauss (1990) por su parte concluyen que la proporción de violencia de los varones hacia las mujeres es tres veces mayor en los bebedores que en los abstemios.

Puede ocurrir que la estadística acerca de los efectos del alcohol, tanto en cuanto a la probabilidad de aparición de episodios de violencia de género sea del $50 \%$. Sin embargo, no podemos olvidar que las parejas maltratadoras de las mujeres de nuestro estudio, capaces de golpearlas estando ebrios lo hacían también estando sobrios.

"El hombre que es violento estando ebrio también lo puede ser estando sobrio, demostrando que el alcohol sólo alimenta una violencia ya existente." (Kantor y Straus, 1987, p.224) 
Para paliar los efectos del alcohol u otras sustancias y evitar las agresiones, las mujeres de nuestro estudio intentaron: acompañar a sus parejas a terapias de desintoxicación, convencerles por la vía del razonamiento para el cese de su conducta de consumo, ocultar a los niños y niñas para que no presenciaran los episodios de embriaguez y violencia, guardar silencio cuando ellos llegaban a casa, incluso permanecer inmóviles para pasar desapercibidas. Pero de nada les sirvió.

El consumo excesivo de alcohol $\mathrm{u}$ otras sustancias euforizantes no es la causa directa del comportamiento violento, sino que incrementa la posibilidad de que éste se produzca y/o su gravedad.

\section{7.- Lo que ocurre en una familia es un asunto privado, mejor no} denunciar: De las nueve entrevistadas, siete denunciaron las agresiones y dos no lo hicieron. A las siete que denunciaron les movió el temor a perder su vida y una de las que no lo hizo, aunque también experimentó el mismo temor, creyó que si denunciaba sería aún peor y el propio miedo le impidió poner la denuncia. La otra mujer que no denunció explica que su maltrato se ciñe a lo estrictamente psicológico y por consiguiente difícil de comprobar empíricamente.

"Cuando el maltrato entra por la puerta, existe la tendencia a guardar el secreto, porque los trapos sucios se lavan dentro. Todos los participantes en el juego saben, aunque no se haya explicitado, que hay cosas de las que fuera no se puede hablar. Y claro, van pasando los años con la sensación de que es inevitable y que la vida es así". (Cárdenas y Ortiz, 2005, p.123)

Afortunadamente y gracias a la cada vez mayor información acerca del tema de la violencia contra las mujeres, la concienciación del delito que supone el golpear a una mujer y la existencia de recursos sociales, llevó a siete de las nueve entrevistadas a denunciar su situación, poniendo con ello un punto y final a su relación de pareja para empezar el largo proceso de 
recuperación. Para dar este paso, en todos los casos adquiere un papel decisivo, el apoyo familiar que aporta en los momentos más duros, sustento económico, cuidados físicos, estabilidad emocional, seguridad... Es por tanto el cambio que se produce en la sociedad en general a favor de la consideración de este asunto como un problema público, el que incide en la capacidad de romper la relación con el maltratador.

\section{8.- Siempre se exagera la realidad cuando se habla de violencia contra} las mujeres: Las nueve entrevistadas, no sólo no exageran su experiencia en el momento de narrarla, sino que omiten muchos detalles porque prefieren no recordar. El no hablar del tema también implica una estrategia para la superación y a la vez muestra lo complicado que puede resultar escapar de una relación de maltrato

"Este modelo, más que ofrecer una explicación exacta del motivo por el cual una relación de maltrato puede prolongarse (a veces durante varios años), permite reconocer la complejidad de la situación y las dificultades que deben enfrentar las mujeres para poder salir de ella". (Torres Falcón, 200, p.176)

Las nueve entrevistadas reconocen el silencio que rodeó su historia durante tiempo, hasta que la situación se hizo insostenible comenzando a temer por sus vidas o las de sus hijos e hijas. Es este temor y no otra cuestión, lo que les impulsa a pedir ayuda, haciendo pública su realidad.

\section{9.-Las feministas odian a los hombres y las casas de acogida rompen} Ios matrimonios: Ninguna de las entrevistadas mantiene esta opinión. Dos de ellas tuvieron que hacer uso de casa de acogida. Señalan que su relación de pareja ya estaba rota antes de ingresar en la casa. 
"Los servicios sociales o centros de atención a la mujer, servicios gestionados por los ayuntamientos, pueden brindar una ayuda eficaz. En estos centros se recibe el apoyo para poder verse a sí misma y ver la relación desde otra perspectiva para valorar cuál es la mejor salida. Dependiendo de la gravedad de la situación, si la mujer necesita protección podrá ir a una casa de acogida, como un paso intermedio hacia la separación definitiva y la independencia". (Cárdenas y Ortiz, 2005, p. 151)

Las casas de acogida han evolucionado desde su nacimiento hasta nuestros días, no obstante no son éstas las responsables de la ruptura de las parejas. En nuestro estudio, siete mujeres no utilizaron este recurso para salir de la relación y sin embargo rompieron con sus parejas igualmente y las dos que lo utilizaron, lo hicieron como única alternativa posible de subsistencia después de haber roto la relación con el maltratador y siempre teniendo en cuenta que esta era una solución transitoria, hasta conseguir la protección física necesaria y una independencia económica real.

10.-Hay muchos hombres maltratados: Ninguna de las entrevistadas refiere haber convivido con un hombre maltratado, muy al contrario, ellas intentan en todo momento complacerles para tratar de controlar así la ira y la agresividad de ellos.

Estamos de acuerdo con la teoría de Marta Torres Falcón, cuando afirma que sólo es una especulación el hablar de mujeres violentas. El comportamiento más agresivo que encontramos en las mujeres de nuestro estudio se refiere a la réplica o al reproche verbal a sus parejas, nunca a agresiones físicas como forma de respuesta.

"Se conocen muchos casos de mujeres psicológicamente maltratadas, pero muy pocos de hombres, por lo que la afirmación de que las mujeres son más violentas en el terreno del asedio y el abuso verbal no es más que una especulación". (Torres Falcón, 2001, p. 135) 
No obstante, en este punto debemos ser cautas a la hora de establecer afirmaciones concluyentes, pues si bien es cierto que la cifra conocida de estos sucesos es significativamente menor desde el punto de vista estadístico, el modelo tradicional de división de roles por género puede estar influyendo en el hecho de que la "cifra negra" de este delito sea más abultada.

11.-Si tienen hij@s es mejor que aguanten: Cuatro de las nueve mujeres entrevistadas refieren haber soportado el maltrato a la espera de que sus hij@s fueran avanzando en edad, para poder así proporcionarles un mayor bienestar económico. No obstante, las cuatro coinciden en reconocer que el esfuerzo resultó baladí, pues fue en detrimento del equilibrio emocional de sus hij@s, como así lo manifiestan Isabel Cárdenas y Dora Ortiz.

"Son chicos carenciados en la protección hacia sí mismos y hacia los otros, con muchas dificultades para aceptar los límites y con necesidad de sentirse queridos incondicionalmente, como únicamente los padres lo saben hacer. Asimismo, estos niños/as no saben cómo manejar sus emociones. Han crecido con el miedo metido en el cuerpo y ésta es una funesta experiencia, que sobrepasa la capacidad del niño de regular las emociones. El miedo es una emoción que prevalece sobre las otras y provoca un estado de alerta y el paso a la acción a través de mecanismos poco controlables". (Cárdenas y Ortiz, 2005, p.52)

En esta exposición queda de manifiesto la falsedad de los mitos que maneja la sociedad al hablar de violencia de género, ya que no se corresponden con las historias de violencia descritas por las nueve mujeres entrevistadas, víctimas de malos tratos. 
Mitos acerca del amor romántico:

1. La media naranja: Sólo una de las entrevistadas piensa que hay una persona predestinada a ser la pareja ideal y que es inevitable su elección.

2. Emparejamiento: Tres de las nueve entrevistadas piensan que la pareja heterosexual y la monogamia es la única forma de relación de pareja.

3. Exclusividad: En ninguna entrevista aparece este mito como posibilidad para una relación.

4. Fidelidad: Únicamente una entrevistada refleja este sentimiento como necesario en una relación de pareja.

5. Celos: No se encuentra ninguna entrevista donde se refleje que los celos son un signo de amor.

6. Equivalencia: Ninguna entrevistada refiere como equivalentes el amor y el enamoramiento.

7. Omnipotencia: En dos entrevistas se encuentra la creencia de que el amor lo puede todo y que habiendo amor se solventará cualquier diferencia.

8. Libre albedrío: Cuatro entrevistadas piensan que el sentimiento de amor es ajeno a la voluntad, capaz de dominarla, contra lo que no se puede luchar.

9. Matrimonio: En cuatro entrevistas aparece este mito como la única salida al amor, el matrimonio o la convivencia. 
10.Pasión eterna: Ninguna entrevistada piensa que se ha de amar, con la misma intensidad, durante todo el tiempo que dure la relación de pareja.

En lo que se refiere a este apartado, se puede concluir, que los mitos referidos al amor romántico que se encuentran arraigados en nuestra cultura, pierden fuerza en el caso de mujeres que han pasado por una experiencia de maltrato, adoptando, estas mujeres, una visión pragmática acerca de las cuestiones relacionadas con el amor.

Bien es cierto que existen mitos referidos al amor romántico, que irrumpen con más fuerza en el imaginario social, por ejemplo los que hacen alusión a lo inevitable del amor o el que defiende la idea del matrimonio o convivencia como meta final deseable entre dos personas que se quieren.

"Cuando en aras del amor, se sacrifican los valores, la libertad o la dignidad; cuando se quiere más al otro que a una misma, algo no funciona; "amar al prójimo como a ti mismo". Cuando a la vez se ama y se teme a la pareja, algo muy grave está ocurriendo. Eso no es amor, sino dependencia y sumisión". (Barea, 2004, p.146)

Las nueve mujeres entrevistadas fueron conscientes de que sus parejas no las amaban cuando las golpeaban, a pesar de que el discurso del maltratador trataba de convencerlas de lo contrario. Ellas a su vez dejaron de sentir hacia ellos amor, siendo el miedo y la dependencia económica los dos factores que las mantenían a su lado.

De forma clara, podemos concluir que nos encontramos ante relaciones de dominación y no de amor. 
Realidades acerca de la violencia de género:

1. Ciclo de la violencia: Ocho de las nueve entrevistadas, describen el ciclo de la violencia con gran precisión. El hecho de que él no siempre es "malo" con ellas o con sus hijos e hijas, el hecho de la existencia de momentos en los que trata de conquistarla de nuevo... es suficiente al principio para mantener la relación; cuando ellas toman conciencia de que esos momentos son cada vez menos y por el contrario aumentan en intensidad y frecuencia los episodios de violencia, es cuando da comienzo el proceso de ruptura de la pareja.

2. Dependencia económica: En las nueve entrevistas aparece esta realidad como hándicap a la hora de plantearse una separación. Ellos prefieren mujeres dependientes, sobre las que puedan ejercer control. Con este propósito dificultan o abiertamente impiden la inserción laboral de ellas, asegurándose una posición de superioridad o privilegio económico con respecto a la mujer. La desigualdad entre los géneros se aprecia de forma inequívoca en lo relativo a la economía.

3. Violencia de género en la familia de origen de él: Cuatro de los nueve maltratadores sufrieron o presenciaron violencia de género en sus familias de origen cuando eran niños. Esta cuestión facilita la reproducción de la violencia, así hogares violentos generan nuevos hogares con hombres violentos en un círculo difícil de cortar. Esta cuestión no es una ciencia exacta, por ello, en este estudio, nos hemos encontrado tanto a hombres violentos que provienen de 
hogares normalizados, como a hombres violentos con historia previa de violencia en sus familias de origen.

4. Violencia de género en la familia de origen de ella: Cuatro de las nueve mujeres maltratadas, sufrieron o presenciaron violencia de género en sus familias de origen. Al igual que en el punto anterior, esto no implica que de forma automática las niñas que han sufrido violencia en su infancia puedan llegar a padecerla en su vida adulta, puesto que nos encontramos a mujeres víctimas que nunca antes lo habían sido y a mujeres que habiendo sido víctimas en su infancia, la rechazan en su vida adulta.

5. Micromachismos: En todas las entrevistas aparecen, sin excepción los Micromachismos menoscabando la autoestima de la mujer. Las ideas tradicionales sobre las que se asienta el patriarcado favorecen la aparición y el mantenimiento de la violencia de género, el abuso sobre la mujer, siendo ésta, la forma más eficaz de ejercer control.

6. Aislamiento social: En las nueve entrevistadas aparece el aislamiento social como factor incapacitante para la búsqueda eficaz de recursos de ayuda. Esto va unido a la pérdida de autoestima y a cuestionarse el grado de responsabilidad que ella pueda tener sobre el maltrato que está recibiendo.

Teniendo en cuenta esta información se puede concluir que las mujeres víctimas, en este estudio, han tenido que luchar contra los 
mitos tanto de la violencia de género como del amor romántico, que se encontraban instalados, en mayor o menor medida en su repertorio conductual y sentimental.

Tanto los mitos acerca de la violencia de género, como los mitos acerca del amor romántico, no se sostienen en el mundo de lo real. A pesar de que los mitos dificultan la toma decisiones, las mujeres de esta investigación, fueron capaces de desmarcarse de sus estereotipos para elegir libremente el tipo de vida que deseaban tener.

Consideramos de interés, para transmitir a futuras generaciones, el hecho de hacer visible la realidad que rodea al maltrato, la realidad que atrapa en la violencia. Es imprescindible conocer el funcionamiento del ciclo de la violencia, sin permitir que un gesto amable del maltratador eclipse su agresión; Se ha de tener claro que la independencia económica hace libres a las personas para poder elegir la vida que se desea llevar; Se han de identificar los Micromachismos que pueden desembocar en violencia de mayor intensidad; y por último se ha de evitar el aislamiento social, teniendo en cuenta que el apoyo emocional, facilita la toma de decisiones.

Así pues podemos concluir que para las mujeres entrevistadas en este trabajo, hubo conexión entre mitos, violencia de género, amor y dominación. Pero esa conexión, habiendo pasado por la experiencia de maltrato, se debilita, hasta llegar a ser inapreciable en la mayoría de los casos.

La realidad de estas nueve mujeres nos lleva a concluir que fueron capaces de romper con la relación de maltrato cuando tomaron conciencia de que el control de la violencia no residía en ellas sino en quien la ejercía. Esto se refleja en el término de dominación, ya que es esta y no el amor quien mantiene una relación en la que está instalado el maltrato y de la que a la mujer no se le permite salir. 
Creemos que el paso que le falta por dar a nuestra sociedad en su conjunto, no es sólo contemplar la violencia contra las mujeres como un delito, sino deconstruir las creencias con las que la sociedad se explica las causas de este fenómeno.

Será necesario comenzar por una resocialización afectiva que modifique la conexión entre amor y dependencia, evidenciando la influencia que la dominación, conseguida a través de micromachismos de diversa intensidad, tiene en la situación de maltrato.

Sería interesante, para próximos trabajos tener en cuenta estas conclusiones y aplicarlas al tratamiento de los agresores, evitando así, la doble victimización a la que se ven sometidas las mujeres víctimas. 


\section{BIBLIOGRAFÍA}

Alcántara, M. (2002). De abnegada a maltratada: la socialización en la violencia de género. Málaga: Servicio de Publicaciones del Centro de Ediciones de la Diputación de Málaga.

Alonso Benito, L. (1988). Entre el pragmatismo y el pansemiologismo. Nota sobre los usos (y abusos) del enfoque cualitativo en sociología. Revista Española de Investigaciones Sociológicas, vol. 43, 157-168.

Álvarez, A. (2001). El feminismo como prevención de la violencia de género. Madrid: Instituto de Investigaciones Feministas.

Altable, CH. (1998). Penélope o las trampas del amor. Valencia: Nau.

American Psychiatric Association (Ed.). (1994) DSM IV : manual diagnóstico $y$ estadístico de los trastornos mentales. Barcelona : Masson

Amorós, C. (1995). Historia de la Teoría Feminista. Madrid: Instituto de Investigaciones Feministas de la Universidad Complutense de Madrid. Dirección General de la Mujer.

Anderson, B.S. y Zinsser, J.P. (2000). A history of their own. New York: Oxford University Press.

Auman, V. e Iturralde, C. (2003). La construcción de los géneros y la violencia doméstica. Buenos Aires: Paidós.

Bagshaw, D. y Chung, D. (2000). Women, men and domestic violence. Australia: University of South Australia.

Barea, C. (2004). Manual para mujeres maltratadas (que quieren dejar de serlo).Barcelona: Océano Ámbar.

Barón, A. y Martínez-Íñigo, D. (2001). Los celos: una perspectiva psicosocial. Madrid: Aljibe.

Barrón, Martínez-Î́igo, De Paul y Yela (1999). Romantic belief and myths in Spain. The Spanish Journal of Psychology, vol. 2(1), 64-67

Barton, L. y Walker, S. (Ed.). (1993). Race, class and education. London: Croom Helm.

Berbel, S. (2004). Sin cadenas. Nuevas formas de libertad en el S. XXI. Barcelona: Narceaediciones. 
Blanco García, A.l. (2005). Sobre la opacidad de género y la mística de la feminidad. En V. Maqueira DÁngelo (Ed.), Democracia, feminismo y universidad en el S. XXI. (p. 529-541). Madrid: Ediciones de la Universidad Autónoma de Madrid.

Blanco García, A.I. (2006). Violencia doméstica: la importancia de aprender a mirar. Barataria: Revista castellano-manchega de Ciencias Sociales, vol. 7, 41-62.

Blanco García A.I. y Marcos Santiago, R. (2006), Mujer y feminismo. En A. Lucas Marín (Ed.), Estructura social: la realidad de las sociedades avanzadas (p. 177-202), Madrid: Pearson Prentice Hall

Blanco García, A.I. (2007). Prevención de la violencia de género y crítica de la razón patriarcal: un reto para la postmodernidad. Tavira, vol. 23, 13-39.

Bograd, M. (1988). Feminist perspectives on wife abuse: an introduction. Beverly Hills: Sage

Bonino, L. (1995). Desvelando los micromachismos en la vida conyugal. Buenos Aires: Paidós.

Bonino, L. (1996). La violencia invisible en la pareja. Valencia: Generalitat Valenciana.

Bosch, E. y Ferrer, V. (2002). La voz de las invisibles. Las víctimas de un mal amor que mata. Madrid: Cátedra. Colección Feminismos.

Bourdieu, P. (2000). La dominación masculina. Barcelona: Anagrama.

Bowlby, J. (1980). Attachment and loss. Nueva York: Basic Books.

Brownmiller, S. (1975). Contra nuestra voluntad: Hombres, mujeres y violación. New York.: Simon and Schuster.

Buss, D.M., Larsen, R., Westen, D. y Semmelroth, J. (1992). Las diferencias de sexo en los cellos: la evolución, fisiología y psicología. Psychological Science, vol.3, 251-255

Buunk (2005). Diferencias de género en las características del rival que provocan celos debidos a la infidelidad emocional o sexual. Madrid: Biblioteca Nueva.

Cabral, B. y García, C. (2001). Deshaciendo el nudo del género y la violencia. Mérida, Venezuela: Otras Miradas.

Cantó, J., García-Leiva, P. y Gómez-Jacinto, L. (2005). Amor, relaciones y celos. Madrid: Biblioteca Nueva.

Canto Ortiz, J.M., García Leiva, P. y Gómez Jacinto, L. (2009). Celos y emociones: Factores de la relación de pareja en la reacción ante la 
infidelidad. Athenea Digital. Revista de Pensamiento e Investigación Social, vol. 15, 39-55.

Carcedo Cabañas, A. y Molina Subirós, G. (2001). Mujeres contra la violencia. Una rebelión radical. Embajada del Reino de los Paises Bajos: CEFEMINA

Cárdenas, I. y Ortiz, D. (2005). Entre el amor y el odio. Madrid: Síntesis.

Centro de Investigaciones Sociológicas (1995). Actitudes y conductas afectivas de los españoles. Revisado el 22 de diciembre del 2011 en www.cis.es/opencms/-Archivos/Boletines/07/BDO_7_index.html

Chóliz, M. y Gómez, C. (2002). Emociones sociales: enamoramiento, celos, envidia y empatía. Madrid: McGrawHill

Cicourel, A.V. (1982). El método y la medida en sociología. Madrid: Nacional.

Comas d'Argemir, D. (2006). Dones, les altres polítiques . Barcelona: Fundació Nous Horitzons

Consejo de Europa (1997). Informe del grupo de especialistas para combatir la violencia contra las mujeres.

Davis, K.E. (1987). Love styles and relationship quality: a contribution to validation. Journal of Social and Personal Relationships, vol. 4, 409-428

D’Ancona (1996). Estrategias y técnicas de investigación social. Madrid: Síntesis.

Deutsch y Horney (1991). Mothers of psychoanalysis. New York: Norton

Díaz Aguado, M.J.; Martínez Arias, R. (2001). La construcción de la igualdad y la prevención de la violencia contra la mujer. Madrid: Instituto de la mujer.

Díaz Aguado, M.J. (2003). Adolescencia, sexismo y violencia de género. Madrid: Papeles del Psicólogo.

Díaz Aguado Jalón, M.J. y Carvajal Gómez, M.I. (2011). Igualdad y prevención de la violencia de género en la adolescencia. Madrid: Ministerio de Sanidad Política Social e Igualdad. Gobierno de España.

Díaz Martínez, C. (1996). Les femmes et les hommes dans I'Union Europee. Portrait Statistique. REIS, vol. 75, 116

Diccionario Básico de la Lengua (1993). Madrid: Anaya.

Dobash and Dobash. (1992). Women, Violence and Social Change. London: Routldge and Kegan Paul.

Dobash, R.P., Dobash, R.E., Wilson, M., Daly, M (1992). The myth of sexual symmetry in marital violence. Social Problems, vol.39 (1), 71-91 
Dobash, R.E. y Dobash, R.P. (1998). Rethinking Violence Against Women. Thousan Oaks. Londres, Nueva Delhi: Sage.

Dunford, F., Huizga, D. y Elliot, D. (1990). The Role of Arrest in Domestic Assault: The Omaha Police Experiment: Criminology.

Duque, E. (2006). Aprendiendo para el amor o para la violencia. Las relaciones en las discotecas. Barcelona: El Roure.

Durkeheim, E. (1998). El suicidio. Buenos Aires: Grupo Editorial Tomo

Echeburúa, E., Corras, P. y Amor, P.J. (1999). Violencia familiar. Madrid: UNED

Eliade, M. (1968). Mito y Realidad. Barcelona: Labor.

Eriksson, M., Nenola, A., Muhonen Nilsen, M., Nordisk Ministerrad \&, N. R. 2002, Kon och vald I Norden, rapport fran en konferens I Koge, Danmark, 2324 november 2001, Gender and violence in the Nordic countries, report from a conference in Koge, Danmark, 23-24 november 2001, Kbh.: Nordisk Ministerrad, Kbh; Kobenhavn.

España, Comisión para la Investigación de Malos Tratos a Mujeres (2005). Informe de la Comisión para la Investigación de Malos Tratos a Mujeres

España, Congreso. Abordaje integral de la violencia de género (2007). Libro de actas. Zamora: Campus Universitario Viriato.

España, Observatorio Estatal de Violencia Sobre la Mujer (2010). III Informe Anual. Madrid : Ministerio de Sanidad, Política Social e Igualdad

España. Ley Orgánica 1/2004 de Medidas de Protección Integral contra la Violencia de Género

España. Ministerio de Sanidad, Política Social e Igualdad (2009). Violencia de género en los pequeños municipios del Estado Español. Madrid : Ministerio de Sanidad, Política Social e Igualdad

Fernández-Montalvo, J. y Echeburúa, E. (1997). Variables psicopatológicas y distorsiones cognitivas de los maltratadores en el hogar: un análisis descriptivo. Análisis y Modificación de Conducta, vol. 23, 151-178.

Fernández- Montalvo, J. y Echeburúa, E. (1998). Tratamiento cognitivoconductual de la violencia en el hogar: un caso clínico en un maltratador. Análisis y Modificación de Conducta, vol. 24, 579-614

Ferreira, G. (1995). Hombres violentos, mujeres maltratadas. Buenos Aires: Sudamericana 
Flecha, A, Puivert, L. y Redondo, G. (2005). Socialización preventiva de la violencia de género. Barcelona: Feminismo/s

Fondo Internacional de Ayuda a la Infancia de las Naciones Unidas (2000). La violencia doméstica contra mujeres y niñas. En Fonde Internacional de Ayuda a la Infancia de las Naciones Unidas (Ed.), Informe del Centro de Investigaciones Innocenti, 6. Florencia: Italia.

Fritz, P.A. y O'Leary, K.D. (2004). Physical and Psychological partner aggression across a decade: a growth curve analysis. Violence and victims,vol. 19, 3-16

Frye, M. (1983). The Politics of Reality: Essays in Feminist Theory. Nueva York: Crossing Press.

García Ferrando, M. (1989). La observación científica y la obtención de datos sociológicos. En M. García Ferrando (Ed.), El análisis social de la realidad social. Madrid: Alianza.

García-Leiva, P. (2001). Reacción de celos ante una infidelidad: diferencias entre hombres y mujeres y características de rival. Madrid: Psicothema

Garrido, V. (2001). Amores que matan. Acoso y violencia contra las mujeres. Valencia: Algar

Gayford, J.J. (1975). La práctica médica. Westminster: British Medical.

Gelles, J. (1974). The Violent Home: a Study of Physical Aggression between Husbands and Wives. Beverly Hills, CA: Sage.

Gelles, J. (1976). Abusedwives: why do they stay:Journal of Marriage and the family. New York: Simon and Schuster.

Gelles, J. (1979). Family Violence. Beverly Hills, CA: Sage.

Gelles, R.J. y Cornwell, C.P. (1985): Intimate violence in families, London: Sage.

Gelles, J. and Straus, M. (1988). Intimate Violence: the Definitive Study of the Causes and Consequences of Abuse in the American Family. New York: Simon and Schuster.

Giddens, A. (2001). La transformación de la intimidad. Madrid: Cátedra

Giddens, A. (2001). Sociología. Madrid: Alianza Editorial.

Goleman, D. (2006). Inteligencia social. La nueva ciencia de las relaciones humanas. Barcelona: Kairós. 
Gómez, J., Canto, J. y García-Leiva, P. (2001). Variables moduladoras de las diferencias de sexo en los celos. Revista de Psicología Social,vol. 16,3

González Méndez, R. y Santana Hernández, J.D. (2001). Violencia en parejas jóvenes: análisis y prevención. Madrid: Pirámide.

Gorden, R. (1975). Interviewing. Strategy, techniques and tactics. Illinois: Dorsey Press.

Hagemann-White, C. y Cardlo, S. (1997). Workshop Report. Interdisciplinary European Workshop: Family conflict and domestic violence. Loccum, Germany. Revisada el 22 de diciembre del 2011 en www. Umaine.edu/conflict/LoccumReport.htm

Hanmer, J. (1978). Violence and the social control of women. London: Croom Helm.

Heise, L. (1998). Violence against women: an integrated ecological framework. Violence Against Women, vol.4(3), 262-290

Heise, L. y García-Moreno, C. (2003). La violencia en la pareja. Washington DC: Organización Panamericana de la Salud

Hendrick, C. and Hendrick, S. (1986). A theory and method of love. Journal of Personality \& Social Psychology, vol. 50, 392-402

Henton, J., Cate, R., Koval, J., Lloyd, S. y Christopher, S. (1983). Romance and violence in dating relationships. Journal of Family, vol. 4,467-482

Heyzer, N. (2000). Trabajando por un mundo libre de violencia contra la mujer. Carpeta de Documentos del Foro Mundial de Mujeres contra la Violencia (pp. 13-24). Valencia: Centro Reina Sofía para el Estudio de la Violencia.

Hoff, L. (1990). Battered Women as Survivors. London: Routledge.

Horno Goicoechea, P. (2005). Programas de Violencia contra la Infancia. Revisada 22 de diciembre del 2011 en www.savethechildren.org

Horno Goicoechea, P. (2006). Atención a los niños y niñas víctimas de violencia de género. Intervención Psicosocial, vol. 15, 307-316.

Hunt, S., Sowell, R. y Santana, I. (2004). La violencia doméstica en los hispanos en el sureste de los Estados Unidos: un estudio y análisis de necesidades. Diario de la violencia familiar, Vol. 19(2), 107-115.

The Illonois Clemency Project. (n.d.). Revisada el 22 de diciembre del 2011 de http://clemencyproject.com/ 
Jackson, S.M., Cram, F. y Seymour, F.W. (2000). Violence and sexual coercion in high school students dating relations. Journal of Family Violence, vol 15, 23-36

Jovani Roda, E., Marti Ferrer, P., Segarra Gali, T. y Tormo Jarque, M.J. (1994), Mujeres maltratadas, mujeres mal tratadas (una experiencia de trabajo), Asparkia. Investigació Feminista, vol.4, 9-18.

Kantor, G. y Strauss, M. (1987), Social Problems. University of California Pres, vol 34 (3), 213-230.

Kantor, G. y Strauss, M. (1990), The drunken bum theory of wife beating. Physical Violence in American Familes: Risk Factors and Adaptions to Violence, Vol. 8, 203-224.

Kaufman, M. (1989). Hombres. Placer, poder y cambio. Santo Domingo: Centro de Investigación para la Acción Femenina.

Kirkwood, C. (1999). Cómo separarse de su pareja abusadora. Barcelona: Granica.

Kuri, H., Obergfell-Fuchs, J. y Woessner, G. (2004). The Extet of Family Violence in Europe. A comparaison of National Surveys. Violence Agaisnt Women, vol.10, 749-769

Lagarde, M. (1996). Género y feminismo. Desarrollo humano y democracia. Madrid: Horas y Horas.

Lagarde, M. (2005). Para mis socias de la vida. Claves feministas. Barcelona: Horas y horas.

Langan, P. e Innes, C. (1986). Predicting Domestic Violence Against Women: Bureau of Justice Statistcs Special Report.

Lather, P. (1988). Feminist perspectives on empowering research methodologies: Women's Studies International Forum.

Lazarsfel, P.F. (1972). Qualitative Analysis: Historical Critical Essays. Boston: Allyn \& Bacon.

Lorente Acosta, M. (2005). El agresor en la violencia de género: anatomía del maltratador. Gijón: Federación de Mujeres Progresistas.

Marsal, J.F. (1977b). La crisis de la sociología norteamericana. Barcelona: Península. 
Martín, E. (1999). La violencia que padecen las mujeres en sus relaciones de pareja. Madrid: Instituto de la Mujer.

Marín López, P. (2007). El papel de la jurisdicción frente a la violencia contra las mujeres: Obligaciones de jueces y juezas. En M.P. Vallejo \& G.L. Barrios Baudor (Ed.), Violencia de género: perspectiva multidisciplinar y práctica forense (pp. 230-277). Navarra: Thomson- Aranzadi.

Marugán, B. y Vega, C. (2001). El cuerpo contra-puesto. Discursos feministas sobre la violencia contra las mujeres. Madrid: Instituto de Investigaciones Feministas.

Mañas Viejo, C. (2005). Violencia estructural y directa: mujeres y visibilidad. Alicante: Feminismos.

Maynard, M. (1993). Violence towards women. En D. Richardson y V. Robinson (Ed.), Introducing women's studies: Feminist theory and practice (p. 99-122), Basingstoke: Mcmillan.

Mayntz, R., Holm, K., Hübner, P. (1975). Introducción a los métodos de la sociología empírica. Madrid: Alianza.

Merton, R. (1964). Teoría y estructuras sociales. Mexico: FCE

Mies, M. (1983). Towards a methodology for feminist research. London: Routledge and Kegan Paul.

Miguel de, A. (2005). Teoría feminista. De la ilustración a la globalización Madrid: Ediciones Minerva.

Millet, K. (1969). Sexual politic. Granada: The Second Chapter.

Mircea, E. (1968). Mito y realidad. Barcelona: Labor

Moliner, M. (1966). Diccionario de uso del español de María Moliner. Madrid: Gredos

Moreno Marimón, M., González, A. y Ros, M. (2007). Enamoramiento y violencia contra las mujeres. Palma de Mallorca: UIB.

Mullender, A. (2000). La violencia doméstica. Una nueva visión de un viejo problema. Barcelona: Paidós.

Nogueiras, B. (2005). Factores de vulnerabilidad en la violencia contra las mujeres. En B. Nogueiras, L. Bonino, y A. Arechederra (Ed.), La atención sociosanitaria ante la violencia contra las mujeres (p. 17-24). Madrid: Instituto de la Mujer.

Olaz, A. (2008). La entrevista en profundidad. Oviedo: Septem Ediciones.

Oliver, E. y Valls, R. (2004). Violencia de género. Investigaciones sobre quienes, porqué, y cómo superarla. Barcelona: El Roure. 
Organización de las Naciones Unidas (1993). Derechos Humanos. Revisada el 22 de diciembre del 2011 en www.un.org/es/rights/

Organización de las Naciones Unidas (1994). Declaración sobre la eliminación de la violencia contra las mujeres. Nueva York: Naciones Unidas.

Organización de las Naciones Unidas (2006). Estudio a fondo sobre todas las formas de violencia contra la mujer. Revisada el 22 de diciembre del 2011 en: http//www.intersindical.org/dones/Estudio_violencia ONU.pdf

Organización Mundial de la Salud (1998a). Salud Familiar y Reproductiva. División de Salud y Desarrollo. Violencia contra la mujer. Un tema de salud prioritario. En Organización Mundial de la Salud (Ed.). Washington DC: OMS/OPS

Organización Mundial de la Salud (1998b). Violencia contra la mujer. Revisada el 22 de diciembre del 2011, en: http//www.who.int/entity/gender/violencia/en/violencia_infopackl.pdf

Organización Mundial de la Salud (2002). Informe anual sobre la violencia y la salud. En Organización Mundial de la Salud (Ed.). Nueva York: Naciones Unidas.

Pagelow, M. (1981). Factors affecting women's decisión to leave violent relationships. Journal of Family Issues, vol 2(4), 391-414

Pagelow, M. (1987). Batteres Women: a historiacal research an some common mythsj. Journal of Agresion, Maltreatment and Traume, vol. 1, 95114

Pahl, J. (1985). Refuges for battered women: ideology and action. Feminist Review, vol. 19

Pastor, R. (1996). Significar la imagen: publicidad y género. Santiago: Universidad de Santiago.

Pate, A. y Hamilton, E. (1992). Formal and Informal deterrents to Domestic Violence: The Dade County Spouse Assault Experiment. American Sociological Review. vol.57(5)

Pence, E. (1987). In our Best Interest: A Process for Personal and Social Change. Duluth: Minesota Program Development.

Pizzey, E. (1974). Scream Quietly or the Neighbours Will Hear. Harmondsworth. Penguin.

Pleck, E. (1987). Domestic Turanny. Nueva York: Oxford University

Poal, G. (1993). Entrar, quedarse, avanzar. Madrid: S. XXI 
Posada Kubissa, L. (2001). Las hijas deben ser siempre sumisas. Discurso patriarcal y violencia contra las mujeres: Reflexiones desde la teoría feminista. Madrid: Instituto de Investigaciones Feministas.

Prisión incondicional para el agresor de Jesús Neira. (2008, 14 de agosto). La Vanguardia, p. 21.

Ptacek, J. (1988). Why do men batter their wives. Beverly Hills: Sage.

Rojas Marcos, A (1995). Las semillas de la violencia. Madrid: Espasa.

Rosen, K.H. y Bezold, A. (1996). Dating violence prevention: A didactic support for young women. Journal of Counselling e Development, vol 74 (5), 521-526

Ruiz-Jarabo, C., Blanco Prieto, P. (2005). La violencia contra las mujeres: prevención y detección. Madrid: Díaz de Santos.

Russell, D. (1982). Rape in Marriage. New York: Macmillan.

Ryan, W.(1971). Blaming the victim. London: Orbach and Chambers.

Sampedro, P. (2005). El mito del amor y sus consecuencias en los vínculos de pareja: Diseño 45. Revisado el 22 de diciembre del 2011 en www.pensameintocritico.org/pilsan0505.htm.

Sangrador, J.L. (1993). Consideraciones psicosociales sobre el amor romántico. Madrid: Psicothema.

Sanmartín, JL, Farnós, T., Capel, JL y Molina, A. (2000). Violencia contra las mujeres. Situación actual mundial. Valencia: Centro Reina Sofía para el Estudio de la Violencia

Sanmartín, J., Molina, A. y García, Y. (2003). Informe internacional 2003. Violencia contra la mujer en las relaciones de pareja. Estadísticas y legislación. Valencia: Centro Reina Sofía para el Estudio de la Violencia.

Sarasua, B., Zubizarreta, I., Echeburúa, E. y Corral, P. (1994). Perfil psicológico del maltratador a la mujer en el hogar. Madrid: Pirámide.

Sau, V. (1990): Diccionario ideológico feminista. Barcelona: Icaria.

Sherman, L. (1981). Experimento de Minneapolis de Violencia Doméstica (MDVE).Minneapolis: Fundación de la Policía y Departamento de Policía de Minneapolis.

Sherman, L. y Berk, R.A. (1984). Los efectos disuasorios específicos de arresto por asalto doméstico. American Sociological Review, vol 49(2), 261272 
Sherman y Smith (1992). Crime, Punishment, and Stake in Conformity: Legal and Informal control of Domestic Violence. American Sociological Review, vol. 57(5), 680-690.

Smith, P.H., White, J.W. y Holland, L. (2003). A Longitudinal Perspective on Dating Violence Among Adolescent and College-Age Women. American Journal of Public Health, vol. 93, 104-110.

Sigma Dos, Instituto de la Mujer. (2000). La violencia contra las mujeres: resultados de la macroencuesta. Madrid: Instituto de la Mujer.

Simpson, J.A., Campbell, B. y Berscheid. (1986). La asociación entre el amor romántico y el matrimonio. Personalidad and Social Psychology, vol, 30, 1198-1210

Stanley, L. (1990). Feminist Praxis. London: Routledge.

Sternberg, R. J. (1989). El triángulo del amor. Intimidad, pasión y compromiso. Barcelona: Paidós

Sternberg, R.J. (2000). La experiencia del amor. La evolución de la relación amorosa a lo largo del tiempo. Barcelona: Paidós.

Straton, J.C. (2010). Violence Women. Obtenida el 28 de enero del 2010 de www.europrofem.org

Straus, M., Gelles, R. and Steinmetz, S. (1980) Behind Closed Doors; Violence in the american Family. New York: Doubleday.

Suñer, M. (2002). Maltratadas. Hablan las supervivientes. Barcelona: Plaza y Janés.

Taylor, S.E. (1994). In Peplau L.A. y Sears D.O. (Ed.), Social psychology (8 $8^{\text {th }}$ ed.)London: Prentice Hall.

The Illonois Clemency Project (1990). Revisado el 22 de diciembre del 2011. En http://clemencyproject.com/

Torres Falcón, M. (2001). La violencia en casa. Mexico: Croma Paidós.

Trujano Ruiz, P. y Mata Velázquez, E. (2002). Relaciones violentas en el noviazgo: un estudio exploratorio. Psicología Conductual, vol 10, 389-408.

Ubillos, S. (2001). Amor, cultura y sexo. Revisada el 22 de diciembre del 2011 en http//reme.uji.es/artículos/aubils9251701102/texto.html.

Ubillos, S. y Barrientos, J. (2002). Relaciones interpersonales, atracción y amor. Buenos Aires: Pearson. 
Ubillos, S., Silva, M., Páez, D., y Zubieta, E. (2003). Relaciones íntimas: atracción, amor y cultura. Madrid: Pearson- Prentice Hall.

Varela, N. (2005). Feminismo para principiantes. Barcelona: Ediciones B

Vallés, M. (1999). Técnicas cualitativas de investigación social. Madrid: Síntesis.

Vives, C., Martín, M. y Frau, M.J. (2005). Actores promotores del tema de la violencia contra las mujeres en el espacio discursivo público. Feminismos, vol. 6, 147-158.

Walker, L. (1980). The battered woman. Nueva York: Harper \& Row

Yela, C. (2000). Placer, amor y diferencia de género. Madrid: Universidad Complutense de Madrid

Yela, C. (2002). El amor desde la Psicología Social. Ni tan libres ni tan racionales. Madrid: Pirámide

Yela, C. (2003). La otra cara del amor: mitos, paradojas y problemas. Encuentros en Psicología Social, vol. 1, 263-267

Zubiaur, P. (2003). Gritos silenciosos. El terrible testimonio de una mujer en un matrimonio aparentemente perfecto. Madrid: Maeva. 
ANEXO I

\section{ENTREVISTA EN PROFUNDIDAD:}

\section{DATOS DE IDENTIFICACIÓN:}

1. EDAD:

2. LUGAR DE PROCEDENCIA:

3. NACIONALIDAD /ETNIA:

4. № DE HIJOS/AS :
a) Edad
b) Sexo
c) ¿Con quién viven?
d) ¿Son hijos/as del maltratador?

5. LUGAR DE RESIDENCIA:

6. FAMILIA EXTENSA:

7. SITUACIÓN ECONÓMICA/LABORAL:

8. ESTUDIOS:

9. SALUD:

10. TIEMPO TRANSCURRIDO DESDE LA ÚLTIMA SEPARACIÓN EXPERIENCIA DE MALTRATO:

1. PRIMER INCIDENTE: DESCRIBIR LA SITUACIÓN:
a) ¿hubo agresión física?: lesiones o secuelas
b) ¿hubo agresión psicológica?: lesiones o secuelas 
c) ¿hubo agresión sexual?: lesiones o secuelas

\section{REACCIONES:}
a) De la víctima:
b) Del abusador:
c) ¿Lo contaste?
d) ¿Reacciones del entorno?

3. ¿HUBO ATAQUES POSTERIORES? REPETICIÓN Y FRECUENCIA:
a) ¿Qué tipo de cosas le hacían ponerse agresivo contigo?
b) ¿Qué pasaba cuando se ponía agresivo?
c) ¿Después de la agresión él mostraba arrepentimiento? ¿Intentaba conquistarte de nuevo? ¿Había reconciliaciones? ¿Cómo eran las reconciliaciones?
d) ¿Después de la agresión había periodo de calma? ¿Cuánto duraba el periodo de calma entre una agresión y otra?

\section{SENTIMIENTOS DE LA VÍCTIMA:}
a) ¿Cómo te sentías?
b) ¿Cómo te veías a ti misma cuando estabas a su lado?
c) ¿Cómo te ves ahora?
d) ¿Qué sentimientos tenías hacia él?
e) ¿Qué pensabas en relación a tus hijos/as?
f) ¿Quién tomaba las decisiones importantes?
g) ¿Cómo se manejaba el dinero de la familia?
h) ¿Tenías tu propio dinero? 
i) ¿Quién se ocupaba de la casa, los niños, la compra, comida, ropa...?

j) ¿En algún momento dudaste de tus capacidades o valores como persona, madre, trabajadora...?

\section{FALSAS CREENCIAS ACERCA DEL MALTRATO:}

a) ¿Qué clase de cosas, de las que tú hacías, le irritaban?

b) ¿Qué te mantuvo a su lado?

c) ¿Antes de conocer a tu pareja, visitaste a algún psicólogo/a?

d) ¿Tu pareja visitó a algún psicólogo/a?

e) ¿La cuestión económica dificultó la separación?

f) ¿Tu familia te sirvió de apoyo cuando te separaste?

g) ¿En tu familia de origen ha habido malos tratos? ¿En la de él?

h) ¿Tú pareja es un hombre sometido a estrés a causa de su situación laboral?

i) ¿Tú pareja consume alcohol u otras sustancias?

j) ¿Qué sucede cuando consume?

k) ¿Te costó comenzar a hablar del maltrato que sufrías?

I) ¿Denunciaste a tu pareja en alguna ocasión a causa del maltrato?

m) ¿Quién te animó a hacerlo? O por el contrario surge de ti la idea.

n) ¿Te han indicado o has sentido la necesidad de exagerar sobre tu historia de maltrato para hacerla más creíble?

o) ¿Has necesitado acudir a una casa de acogida para salir de la situación de maltrato?

p) ¿Cómo te sentías en la casa de acogida?

q) ¿Tu pareja se consideraba un hombre maltratado por ti? 
r) ¿Tus hijos/as presenciaron episodios de violencia?

\section{FALSAS CREENCIAS ACERCA DEL AMOR:}
a) ¿Creíste que tu pareja era tu complemento ideal? $Y$ ahora ¿qué piensas?
b) ¿Piensas que la situación ideal es la de estar emparejada?
c) ¿Crees que las mujeres sólo podemos amar a un hombre?
d) ¿Los celos son buenos en una relación de pareja?
e) ¿El amor ha de mostrarse siempre con la misma intensidad?
f) ¿El amor lo puede todo?
g) ¿Se puede evitar amar a una persona o por el contrario es algo involuntario?
h) ¿El amor ha de culminar en el matrimonio o la convivencia?

\section{RUPTURA DE LA PAREJA:}

1. DECISIÓN DE SEPARARSE:

a) ¿Quién toma la decisión de separase?

b) ¿Cuál fue el detonante para la separación?

c) ¿Cuántos intentos de separación hubo antes del definitivo?

d) ¿Qué cambios experimentó tu vida?

2. APOYOS CON LOS QUE CUENTA LA VÍCTIMA: 
SITUACIÓN ACTUAL:

1. ¿CÓMO ES AHORA TU SITUACIÓN?:
a) Salud
b) Vivienda
c) Economía y trabajo
d) Relaciones sociales
e) Relaciones familiares
f) Crianza de los hijos/as
g) Nuevas parejas

2. ¿CÓMO TE SIENTES AHORA CON RESPECTO A TI MISMA?: PLANES DE FUTURO: 


\section{ANEXO II}

ENTREVISTA № 1- O. (14/03/2011)

- $(\mathrm{P})$ ¿Cuántos años tienes?

- (R) 34

- (P) ¿Dónde naciste?

- (R) Aquí, en L.

- (P) Eres de aquí de L.

- (R) Bueno, viví unos años en S.A., pero... es $L$.

- (P) Eres Española

- (R) Sí

- (P) Me habías dicho que tienes dos niñas

- (R) Sí, de 6 y 3 años de momento

- (P) ¿Con quién viven las niñas?

- (R) Conmigo

- (P) Viven contigo, y ¿tú con quién vives?

- (R) De vez en cuando, a la pequeña, la llevo con mi madre, días salteados, cuando estoy un poco nerviosa o tengo problemas, va a dormir una noche o dos y...

- (P) ¿Sólo la pequeña?

- (R) Sólo la pequeña

- (P) ¿Y eso?

- (R) Uh..., porque la mayor creo que me necesita más, en los estudios y en todo. Cuando veo que se junta mucha hormona femenina en casa, porque la pequeña se altera mucho, claro es pequeña, quiere jugar, la otra se despista mucho y para centrar a la mayor tengo que ... (Hace un gesto con las manos, como de separarlas)

- (P) Las separas un poco

- (R) Sí

- (P) ¿Y te da resultado?

- (R) Sí. Y andan un poco con los celos

- (P) ¿Vivís las tres solas?

- (R) Sí

- (P) ¿Las niñas son hijas del que fue tu marido?

- (R) Sí

- (P) ¿El hombre que te maltrató es el padre de las niñas?

- (R) Sí

- (P) Vivís aquí en L. y ¿tienes familia que de alguna manera, te aporte apoyo?

- (R) Mis padres, mis padres me apoyan y están conmigo, pero mi madre al mismo tiempo me agobia mucho, tiene tanto miedo, que me llama cada dos minutos para cualquier cosa.

- (P) Miedo ¿por qué?

- (R) No lo sé, que me pase algo, que me engañen, que me... desaparezca, que...

- (P) ¿Tú madre siempre ha sido así o es a raíz de tu experiencia de maltrato?

- (R) Siempre fue así, incluso casada yo, ella siempre fue así.

- (P) ¿Protectora?

- (R) Sí, pero ahora, como que lo acentúa más.

- (P) ¿Y a ti eso te molesta mucho?

- (R) Hay días que sí. El sábado cogí un poco y me marche por la tarde, a las 7 de la tarde para darme una vuelta por todo L., no tenía a las niñas, puse el teléfono en 
silencio. Si no salieron chispas del teléfono, le faltó poco, ya me iba a salir a buscar con el coche y con la policía. Tampoco es eso, me llama cada muy poco y me pregunta cosas, pero después es para reñirme por algo, "no haces esto bien... no haces lo otro". Yo la entiendo, desde su punto de vista, pero me agobia.

- $(\mathrm{P})$ ¿Eres hija única?

- (R) Tengo una hermana mayor

- (P) ¿Ella también te apoya?

- (R) Ella está ahí, pero se mantiene un poco al margen. También un poco porque fue conmigo a la psicóloga del colegio y... cuando me pasó todo eso, le dijo que si yo le pedía apoyo, que me apoyara, pero que si no que no me agobiara.

- (P) Está siendo obediente

- (R) Sí, igual demasiado, porque hay veces que igual un apoyo más, pero bueno, bien.

- (P) A lo mejor, tú también puedes acercarte a ella y pedirle ayuda.

- (R) Sí, vive cerca de mí.

- (P) ¿Si te acercas a ella obtienes ayuda?

- (R) Sí, entre lo mucho de mi madre y eso, prefiero a mi hermana que no me agobia tanto.

- (P) ¿Y tu padre?

- (R) Mi padre me ayuda, si, lo que pasa que bueno..., él..., no sé..., no me agobia tanto como mi madre. Me gusta más la postura de mi padre.

- (P) Me decías, que en este momento, no estás trabajando fuera de casa

- (R) Estoy que me llevan los demonios

- (P) ¿Con anterioridad tuviste trabajo fuera de casa?

- (R) Yo antes de... cuando nació la mayor, a los 18 meses me puse a trabajar en C., mi ex no quería mucho, la verdad, pero yo soy muy cabezona y me puse a trabajar y bueno... dejé el trabajo ese y me puse a trabajar en una fábrica, de caramelos, aquí en L. y me quedé embarazada de la pequeña, entonces, pues claro, en una fábrica embarazada, no puedes hacer mucho, más que estorbar y me quedé de bajo, pedí la excedencia, mi ex quería que dejara por completo el trabajo y yo dije... pido la excedencia de 1 año y si veo que con las dos me es imposible pues pido más, pedí 2 años más, pero qué pasó, cuando la niña tenía 1 año ya me cansé de que me pegara, cuando venía bebido y ya quise trabajar, pero no pude porque no me dejaron entrar en la empresa, ni me dejaban salir, ni me firmaban los papeles para ir al paro, ni me cogían, hasta que no cumpliera la niña 3 años, entonces con UGT, me ayudaron a rescindir el contrato, porque yo allí estaba indefinida y me fui al paro.

- (P) ¿Cuál es tu situación económica?

- (R) El año pasado, La Junta me facilitó un trabajo, del Plan Dique, era una señora que tenía residencias, me hizo un contrato de 3 meses y medio y 2 meses no me los pagó, la liquidación tampoco, no pude cobrar paro, el sueldo todavía no lo he cobrado y claro, el banco, yo anduve muy justa y el banco no me perdona nada de nada, si no hay dinero, intereses. $Y$ esta señora ha abierto otra residencia, a ella no le hacen nada... yo las leyes no las entiendo mucho...

- (P) ¿El padre aporta un dinero para manutención de las niñas?

- (R) El año pasado estuvo 4 meses sin pasar nada, la hipoteca se desentendió y este mes no me ha pagado lo de las niñas, $275 €$ para las dos.

- (P) ¿Qué estudios tienes?

- (R) Lo que yo hice fue FP I y II de peluquería y FP I de estética

- (P) ¿Cómo te encuentras de salud?

- (R) Estoy nerviosa, tengo épocas muy nerviosa, ahora estoy nerviosa por el plan económico y eso me produce alergias que ni el propio de la alergia sabe de dónde me viene, porque me da alergia hasta el plátano, dice, esto lo desconocía, y todo es por los nervios, me lleno de granos, todo esto (se señala el pecho) y todo ha sido de lo mismo. 
- (P) ¿A qué se debe tanto nerviosismo?

- (R) Miedo a que me quiten el piso, que me lo quiten todo, yo vivo en un piso de protección oficial, pero si no lo pago me lo van a quitar y yo si el padre pasara lo que tiene que pagar iba tirando, pero él se desentiende de todo y lo que me da rabia, es que claro, yo me tiro por el piso, pero cuando el día de mañana él reclame su parte, la he pagado yo y él va a tener derechos y el abogado no me tira como me tiene que tirar.

- (P) ¿Cuánto tiempo hace que estás separada?

- (R) El día de navidad, 2 años.

- (P) ¿Tú te acuerdas de la primera vez que sentiste que este hombre te maltrataba?

- (R) Uh...Uh... El problema fue que... Él es hijo único, su madre es muy, muy acaparadora, bueno me han llegado a preguntar que si su madre pega a su padre y le ha pegado mucho desde pequeño.

- (P) La madre a tu ex marido

- (R) La madre a él, le protegía mucho

- (P) ¿Y le pegaba?

- (R) Y le pegaba en la cabeza, me lo han dicho, tías, la abuela. Yo al año de casarme, bueno antes, una vez, haciendo... intimidades (se ruboriza) le araño con una uña, sin querer, que arañas. Y levantó así el puño, como para darme (ella hace el gesto con el puño cerrado y en alto). Yo le digo ¿pero qué haces? Y él... "nada, nada, nada..." Ahí me di cuenta que esa reacción no era muy normal porque a ti te arañan, bueno, me arañaste, pero no pongo el puño para darte. $Y$ al año más 0 menos, fue cuando se murió su abuela, la familia se desarmó por completo, que si, que si la herencia, que si para aquí, que si para allá,... que si los hermanos de la madre, que si el propio abuelo, el padre de su madre, no quería ni ver a su suegra y mi ex como que no lo asumió todo. Esa noche se puso a beber mucho, era la fiesta, además del pueblo y me habían dicho las primas, que eran más pequeñas "quedaros a dormir aquí en el pueblo" y yo dije, vale nos quedamos a dormir, pero bebió tanto que él quería venir para L., pero yo le dije que no, no, yo no me voy para L., que has bebido y yo no me voy para L. Me dio dos golpes con la cabeza contra la ventanilla del coche que yo pensé que me había abierto, pero bueno era la primera vez que prácticamente... y bueno un poco, entre los problemas de la familia y todo pues me callé.

- (P) Y esa fue la primera vez que tú sentiste que ese era un comportamiento anormal.

- (R) La vez que me puso así el puño (vuelve a hacer el gesto), vi... esto no es normal, pero cuando la abuela bueno... un poco pues ha bebido, es mucho show lo de su abuela, que la familia se ponga mucho en contra de la madre, entonces pones un poco excusas.

- (P) En esa ocasión, cuando te dio los golpes contra la ventanilla del coche ¿te dejó alguna lesión?

- (R) No, no me miré tampoco, aparentemente no.

- (P) ¿Cuál es la reacción de él cuando te levanta el puño la primera vez?

- (R) Él se puso así, como diciendo "¿qué hago?", no sé... yo le dije “¿qué haces?", no sé

- (P) ¿Cuál fue tu reacción?

- (R) Me quedé confundida, no supe, no... y a lo mejor él también. No pensé que me iba a pasar todo lo que me ha pasado después.

- (P) ¿Cuándo lo cuentas?

- (R) Muy tarde, muy tarde, muy tarde..., pero luego a mi madre le contaba alguna cosa, cuando más fue un día que estábamos enfadados y me clavó un cuchillo aquí (señala su pierna)

- (P) ¿En la pierna?

- (R) En la pierna. Yo se lo conté a mi madre, mi madre no me apoyó. Ella dice ahora que sí, porque yo se lo echo en cara, pero no, cuando fue a decírselo, o cuando le 
decía que tenía discusiones, ella me decía que era una cosa normal, que venía borracho, que hacía cosas que no eran normales, me decía mi madre... "¿tú que te piensas casar y descasar cada dos días?, todos cojean de alguna pata", me decía mi madre, a ella no le gusta que cuente estas cosas, dice que la dejo mal a ella. Cuando me clavó el cuchillo, yo me metí en la cama, no me dejó marchar de la cama por la noche, y yo por la tarde al día siguiente, fue a urgencias a la C., claro, me intentaron sacar qué había pasado, y no quise decirlo, me cosieron además a lo vivo, estaba mal, con miedo, que no sabes a donde ir, ni qué hacer, ni nada y mi madre me decía, "no cuentes estas cosas que se ríen de ti, que no sé qué..." Entonces te paraliza un poco y no, no dije nada. Mi madre sólo me sabía decir, "no se lo digas a tu padre", fuimos además a la playa,... "tápatelo" (le decía su madre), yo con una tirita, "para que no lo vea tu padre, porque sabiendo cómo es tu padre, igual va y le arremanga y vale..." Después yo decía, me separo, me separo, me separo, no puedo más, yo no le aguanto, no puedo, no puedo porque eso eran las cosas más culpables, pero siempre había alguna cosilla, pero fue a una psicóloga y ella me decía que había otra chica como yo y que su consejo era que me separara porque a esa chica, al final la tuvieron que internar, no sé si sería verdad o sería un poco para hacerme reaccionar a mí o lo que fuera, no lo sé... porque yo era muy joven, no había tenido las niñas si quiera... y mi madre dijo. "bueno, que haga lo que quiera, que haga terapia de pareja, no sé qué... una terapia de pareja..." y yo dije, bueno... "que igual cambia, que igual cambia, que sólo es la bebida..." (decía su madre) $Y$ al final, pues fui a una terapia de pareja, lo que pasa que, la terapia de pareja, "hoy no puedo, mañana tampoco, hoy no puedo, hoy tengo que..." (Decía él), hasta hoy, y no fuimos.

- (P) ¿No llegasteis a ir nunca?

- (R) En ese tiempo fue cuando me quedé embarazada de la niña, de la pequeña.

- (P) ¿Qué le hacía ponerse agresivo?

- (R) El bar y su madre que le metía mucha cizaña en contra mía. Su madre le quería para ella. Cuando nos casamos... yo le veía tonterías... que me tenía como rabia, siempre metía cizaña y si me ayudaba a recoger la mesa o cualquier cosa, "anda maricón, ¿para qué está ella?, que lo haga ella que para eso está ella" (le decía a él su madre) (Ella pone un gesto en la cara despreciativo imitando a su suegra cuando pronunciaba la frase, cargado de odio hacia ella) Cosas así, picándole en contra mía, o "vete a saber que igual era una pelantrusca" (le decía a él su madre en relación a ella), siempre picándole. Yo, mi problema, fue su madre. Yo esas cosas..., estuvimos un tiempo, su madre y yo enfadadas y también le afectó, él no la quería ni ver en esa temporada, pero ya mi madre decía "dile que vaya a ver a su madre, porque te echan a ti la culpa", yo le decía vete a ver a tu madre, al final fue a ver a su madre, me convencieron para hacerme amiga otra vez de su madre, y como dicen, si quieres vencer al enemigo hazte su amigo. Me puso al hijo en contra, iba para el bar...

- (P) ¿Lo que le ponía agresivo era su madre, cuando le ponía en tu contra?

- (R) Iba al bar y reñía

- (P) Primero iba al bar, bebía y ¿qué pasaba luego?

- (R) Se ponía borracho, había días que igual venía y se ponía a mear en el servicio, pero por fuera, yo le decía ¿pero qué haces? Y él decía "para eso estás tú, para que lo limpies"

- (P) ¿Y eso siempre bajo los efectos del alcohol?

- (R) Sí, y cuando estaba de resaca también.

- (P) ¿Luego mostraba arrepentimiento?

- (R) Al principio sí, después ya no.

- (P) ¿Había reconciliaciones entre vosotros?

- (R) Él no me hablaba, yo no le hablaba, se calmaba la cosa, mi madre me decía "tú no le hables, tú háblale, tú no le hables...", pero había días que no se podía menos. Cuando nacieron las niñas, sobre todo la mayor, bueno... pero con la pequeña se acentuó más, venía y a coger a las niñas y hacer daño a las niñas para jorobarme, 
porque igual pasaba y me golpeaba, o igual yo estaba en el radiador detrás de la puerta, abría y la puerta y pumba, siempre me provocaba por alguna cosa, pero como ya eso ya ipuf...! Ya pasaba, me atacaba con las niñas, sigue haciéndolo.

- (P) ¿No había reconciliaciones o pedía disculpas?

- (R) Las primeras veces, me acuerdo que me firmó un papel y puso que no iba a volver a beber más, la siguiente vez que bebió lo cogí y se lo di, le dije te lo regalo, ya no lo quiero. Pero su madre le potenciaba, él no quería ir al bar y su madre le decía "vete al bar, qué haces en casa, vete hasta el bar", su madre es muy mala. Cuando yo me casé, me acuerdo que un amigo de él se iba a la legión y estaba la madre disgustada, claro, (se refiere a la madre del amigo), decía "iay madre! Que se me va para la legión" y le dijo mi suegra "cállate, que por lo menos sabes que cuando vuelva, vuelve, pero el mío se casó y no va a volver nunca más". O sea, qué idea tenía ella.

- (P) ¿Había periodos de calma en tu casa?

- (R) Sí

- (P) ¿Cuánto solía durar la calma?

- (R) Dos, tres meses, al principio, o más, depende, al principio más, después tres meses, a cuatro ya no llegaba. Si veía en el bar que la mujer de fulanito le hizo tal cosa, tal cosa, tal cosa, entonces él bebía y me venía a echar a mí la culpa, a reñirme a mí. ¿Qué culpa tengo yo de lo que haga fulanita?

- (P) ¿Tú cómo te sentías?

- (R) Asqueada

- (P) Defíneme asqueada

- (R) Cuando ya más, empecé, con la niña mayor estaba él ilusionado y bueno, pero con la pequeña, ya me pegó hasta embarazada en la barriga. Decía que ojalá me muriera pariendo, a la pequeña, cuando nació, yo creo que no la quería, ahora no lo sé, porque no le ves, pero yo creo que no y... la pequeña se parece más a él. Por parecerse a él, podía yo que sé, sentirse más... pues no, la mayor que es igual que yo.

- (P) Tú dices que te sentías asqueada

- (R) Sin ganas de vivir, no sabía si tirarme por la ventana o qué hacer, es que no...

- (P) ¿En ese momento qué imagen tenías de ti misma?

- (R) Acabada, acabada, acabada. Una mujer acabada, sin ilusiones, acabada.

- (P) ¿Y ahora?

- (R) Tengo mis... días

- (P) ¿Mejor o peor que antes?

- (R) Hombre..., por lo menos no tengo que aguantar, sus borracheras, y que esté diciendo por debajo "eres una puta, eres una zorra, eres... una perra, si quieres te abro la ventana para que te tires"

- (P) ¿Eso cuando estaba borracho?

- (R) Y cuando tenía resaca, después ya no hablaba, se sentaba en el sofá y no había nadie en casa. Es el día de hoy que en el sofá donde se sentaba él no me puedo sentar.

- (P) ¿Qué sentías por él?

- (R) ¿Cuándo?

- (P) Cuando le conoces y según va evolucionando la relación.

- (R) Mira, sus padres se llevaban muy mal, discutían mucho, yo me acuerdo que él decía, "si alguna vez te trato como mi padre, mi padre a mi madre, y mi madre a mi padre, prefiero morirme". Te comportas mucho peor que tus padres, tus padres nunca se han pegado, no creo.

- (P) ¿Qué sentías hacia él?

- (R) Yo al principio no quería salir con él.

- (P) ¿Eras muy joven?

- (R) Tenía 21 recién cumplidos

- (P) ¿Y él? 
- (R) 23 ó 24

- (P) No había mucha diferencia entre los dos.

- (R) No

- (P) ¿Qué sentimientos tuviste hacia él? ¿Por qué no querías salir con él?

- (R) Había salido con otro chico, me seguía gustando, me llevaba muy bien con él, pero bueno, lo que pasa, tuvo que hacer la mili, y para allá y para acá y nos enfadamos y... este es del pueblo de mi padre y ese chico también es del pueblo de mi padre, bueno era de aquí de T., pero del pueblo. Yo me acuerdo que cuando empecé a salir con este, que yo no quería salir con él (lo recalca), me decía mi prima, "te está mirando ese chico", que no me digas nada, que lo había dejado con el otro chico y lo que menos quiero es salir con nadie y ya me puse a salir y me acuerdo que me dijo mi prima, eso lo recordaba estos días, me dijo mi prima, "déjalo con él, por lo menos con R. te reías, era un cabrón, pero te reías, estabas contenta, has cambiado, ya no tienes la alegría que tenías antes". Eso me llamó la atención, pero yo va..., eso son cosas tuyas y me casé pronto, al año y medio me casé y el chico ese con el que salía antes, antes de esto, me dijo, "si querías darme celos, ya lo hiciste, déjalo a ese chico, déjalo" y yo..., no, no es para darte celos y tal, y me dijo "si te hace algún día algo dímelo", eso me llamó la atención, "dímelo, si te hace algo, y siendo como eres tú, te va a sacar hasta..." Pero bueno, me pensé que era por celos por lo que decía eso.

- (P) Fíjate O., que todavía no me has dicho lo que sentías por él.

- (R) No lo sé, es que me acaparó de una manera, que no me doy cuenta y ya después claro, que le quería, sí... al principio sí y si no le dejé era por eso, bueno hasta que me pegó. Luego ahí ya... dije.... Mira... Ya ahí ya...

- (P) A pesar de todo, mantuviste la relación.

- (R) Sí, un poco me empujaba mi madre. O me pagaba justo en fechas señaladas, a la boda de mi hermana fui acribillada entera. Esto (se señala una cicatriz en el párpado) es un arañazo de él, me dejó la piel colgando, la pegué así como pude y fue la madrina de mi hermana y fue hecha un Cristo. Lo hacía en las fiestas, navidades, o San Juan y San Pedro. Las vísperas, entonces mi madre... "Calla, porque nos vas a jorobar, nos vas a jorobar el día (le pone mucho énfasis a esa repetición), calla la boca, se van a reír de ti"

- (P) Cuando ya tienes a tus hijas ¿qué piensas en relación a ellas y a la vida que estáis llevando?

- (R) Quería marcharme, coger a las niñas y marcharme, pero ahí también me paró mi madre..., "que pierdes todos los derechos, ¿qué vas a hacer?, aguanta". La niña tenía tres meses, la pequeñina, la mangó muy gorda, muy gorda, era la noche de San Juan, muy gorda, tuve que llamar a la policía, la local, la verdad que me acojonaron ellos, me dieron el teléfono de ellos directo, pero me acojonaron, "piénsatelo bien, porque si pones la denuncia y la quitas después las matan, no se' qué, no sé cuánto". Me acojoné y me dijeron que cerrara la puerta y tal y si la puse, y tal y al día siguiente vino como si nada a las 9 ó las 10 de la mañana y empezó "ábreme la puerta", empezó la niña a llorar, la mayor, "abre a papá, abre a papá" y le abrí. Él dijo que a mí no me quería, que si volvía a casa era por las niñas, pues vale, como compañeros de piso. Él dormía en el salón, porque quería, porque yo no le mandé que marchara de la cama. Es el día de hoy que no puedo dormir en el trozo donde dormía él. Yo en mi sitio, en ese trozo, yo no soy capaz.

- (P) Del mismo modo que no te sientas en el sillón dónde se sentaba él.

- (R) No, se sienta la mayor, es que... tengo la tele del salón y la de la habitación y la tele de él, algunas veces veo los dibujos de la niña de refilón, pero no lo he sacado fuera, no lo he sacado fuera.

- (P) Tienes mucho por ahí todavía

- (R) ¡Uf...!

- (P) Cuando estabais juntos, ¿quién tomaba las decisiones importantes en la casa?

- (R) ¡Uf...! Para eso los dos, un poco, igual decía yo más porque me dejaba él, pero siempre lo hablábamos, si comprábamos esto, lo que tú quieras me decía él, 
cuando compramos la cocina, como tú quieras, o decía esto me gusta más así o a mí así, pero bien.

- (P) ¿El dinero quién lo manejaba?

- (R) Yo más, pero él me lo sacaba.

- (P) Explica eso

- (R) Yo era la que administraba, pero "dame para esto, dame para lo otro, dame para el bar, dame para..." La que lo llevaba era yo, pero él no estaba sin un duro.

- (P) El control del dinero lo llevabas tú, tú sabías si había o no, lo que se podía gastar o lo que no.

- (R) Sí, él me lo daba todo, cuando empeoró la situación, fue cuando se juntó a otro divorciado que trabajaba con él, más borracho que él y llegaba todos los días muy rato, no sé si era... porque mi suegro cuando llegaba decía, "este no sé si se toma algo porque esto no es normal, viene como una momia". Se juntó con ese otro y yo no sé si fumaban porros o era sólo el alcohol, ahí ya empezaba a decir bobadas, que si la ex mujer del otro le hacía no sé qué, venía y me lo decía a mí.

- (P) ¿Mantiene el trabajo?

- (R) No, trabajaba en la construcción, cuando nos separamos, estuvieron sin pagarle varios meses y ahí lo pasamos mal, pero bueno, yo no tengo la culpa, ahora está por cobrar un dinero, no sé si lo habrá cobrado, porque parte de ese dinero era también mío, pero...

- (P) ¿En casa quién se ocupaba de la intendencia, la compra, las niñas...?

- (R) Yo

- (P) ¿En algún momento llegaste a dudar de tus capacidades como madre, ama de casa, administradora del dinero?

- (R) Yo sólo pensaba que estaba acabada, que estaba acabada y que estaba acabada... Yo me acuerdo que me decía mi madre, "haz algo de comida" y yo, si no sé cocinar, no me acuerdo y mi madre... "tú, tú, tú, tú... pero si sabías cocinar y cocinabas muy bien", mamá que no me acuerdo de cocinar. Esto cuando me separé.

- (P) ¿Estando separada?

- (R) Sí me bloqueé, por un momento estuve, yo que sé, es que me quedé... no me cogían en mi trabajo, tenía una niña de 1 año y otra de 3 , él no me pasaba dinero... yo me separo en diciembre y los meses anteriores que él no cobró no sé ni lo que cobró, ni lo que no cobró, porque yo sé que estuvo diciembre en el paro y yo no lo sabía, yo me enteré en marzo, casi hasta febrero no me pasó pensión de las niñas ni nada.

- (P) ¿Qué cosas de las que tú hacías, le ponían de mal humor?

- (R) Nada, él iba al bar o a ver a su mamita y ya venía cambiado.

- (P) Cuando llegaba a casa, ¿se metía contigo por alguna cosa en concreto?

- (R) Al principio no, después, igual pasaba y me empujaba

- (P) ¿Te empujaba sin más, sin mediar palabra?

- (R) Sí y me miraba y se reía

- (P) ¿Cuándo hacía esto, estaba bebido?

- (R) Sí, cuando venía normal no se metía con nadie, igual bebía 1 ó 2 cubatas y no venía ofensivo, pero había otras veces que... a mí lo que más me jorobaba es que sabía que las gominolas a la niña, si las comía, no podía hacer caca, empezaba, "me duele, me duele, me duele" (su hija se quejaba) Y yo le decía, "no le traigas esas gominolas del bar que la niñas se pone mala, me traía esas gominolas del bar, se las metía él en la boca y miraba para mí y se reía...

- (P) ¿Por qué te mantuviste a su lado?

- (R) Por mi madre, no me sentí apoyada, sí, mi madre dice, claro el último día que ya lo denuncio, lo denuncio, lo denuncio...La llamé por teléfono y dije, haz lo que te dé la gana que yo voy y le denuncio. Yo esas navidades ya me quería separar y me decía, "sí, sí, te vas a separar, ja, ja, ja, ja..." (él se reía) Yo ya no aguanto más, yo le dije, esa noche buena, tú te llevas a la mayor a casa de tus padres y yo me voy 
con la pequeña a casa de mis padres, porque hasta esas navidades, celebrábamos la navidad en mi casa, para que ni sus padres ni los míos se quedaran solos y mi hermana incluida, todos para mi casa y allí montábamos... mis suegros se quedaban a dormir y eso..., pero ya el año ese dije no, no... ya no quiero fiestas, ni nada, ya no me veía yo fuerte, no... y sí, se la llevó, vino borracho el día de navidad por la noche, no borracho, borracho, pero había bebido algo, y venía muy sofocante, muy sofocante, fue la noche que pasó todo. La niña venía con el culín como esto (señala una carpeta roja que hay encima de la mesa), no le habían lavado, a los niños hay que lavarles todos los días, y a las niñas mucho más. "Me escuece, me duele mucho el culo" (se quejaba su hija) Y sí... se lo eché en cara, había pasado y golpe y ji, ji, ji... y para acá y para allá... y yo estaba detrás de la puerta de la cocina, tengo costumbre de ponerme allí, junto al radiador calentina, y pasaba y pumba en la puerta y pasaba y pumba y zorra, puta, perra y ya cuando me llamaba puta yo le decía que no soy puta (lo dice con mucho énfasis) y ahí empezó, me pegó delante de las niñas, yo tenía a la pequeña en los brazos y la otra mirando, la de 4 años mirando, que me iba a matar, que cualquier día me rajaba, yo llevé a las niñas para mi habitación y me cerré y al día siguiente puse la denuncia, le dije a mi madre, "me da igual lo que me digas que le voy a denunciar ya, yo prefiero morirme a seguir asi". Entonces dijo mi madre, "bueno te acompaño".

- (P) En ese momento, si te apoya tu madre

- (R) Porque vio que iba a ir igual

- (P) ¿Antes de conocerle a él habías estado a tratamiento psicológico?

- (R) No, no, no, yo era muy contenta, muy alegre.

- (P) ¿Y él había estado a tratamiento psicológico antes de conocerte a ti?

- (R) Que yo sepa no, pero tiene traumas por la madre, si le tratan... no sale del bar, su madre dice..., me echa la culpa a mí, que le desgracié la vida...

- $(\mathrm{P})$ ¿El dinero fue un impedimento para la separación?

- (R) ¿Antes de nacer las niñas?

- (P) En el momento de la separación

- (R) Yo quería mi trabajo, volver a mi trabajo, volver a mi trabajo, pero tuve un parto muy fastidiado de la pequeña, me separaron la pelvis, yo me quejaba y me recetaban termalgín, me hicieron rehabilitación y mejoré, pero yo no podía andar casi. Entonces esperé un poco, al año y ya dije esto no puede ser, no puede ser, llamé a la empresa a ver si me cogían, "espera un poco, no sé qué, no sé cuánto" (respuesta de la empresa) Yo quería integrarme otra vez al trabajo, porque si no ¿qué?, yo no podía permitir que me quitaran el piso. En diciembre, cuando yo me quería separar antes de navidad, pensé en volver a integrarme a mi puesto de trabajo, lo que pasa es que me daban largas, entonces estaba la crisis y no me cogieron, por la dichosa crisis, pero estaba pensando en integrarme, pensaba en la economía, pero cuando dije, me separo porque me pegó, ya no te aguanto, ni una más, me da igual el dinero, mi madre, el cura bendito y todo lo demás, de verdad. Hablando claramente, lo mismo me dio.

- (P) ¿Tú madre te acompaña a poner la denuncia?

- (R) Sí, bueno... sí..., sí, sí, sí

- (P) ¿Tú padre?

- (R) Sí, también

- (P) En ese momento, te apoyaron los dos

- (R) Sí, lo que pasa es que mi madre es un poco... (no quiere terminar la frase)

- (P) ¿Entre tus padres hubo alguna vez malos tratos?

- (R) No, mi padre se quedó sin padre a los 8 años, mi padre es de los que dicen que vale más una hostia que mil duros, y cuando me pegaba, me pegaba.

- (P) Tu padre a ti

- (R) $\mathrm{Si}$, yo entiendo que bueno, que había veces que no me portaba bien, pero tampoco la cosa es para tanto, pero bueno... mi madre me ha pedido perdón, porque yo fui a ADAVAS (Asociación de Ayuda a Víctimas de Agresiones Sexuales 
y Violencia de Género) y me decía "tienes que contar esto a la psicóloga, y esto no lo cuentes porque se ríen de 'ti y esto no sé qué..."

- (P) Te marcaba ella, un poco, lo que tenías que decir

- (R) Y después se quedaba donde la de ADAVAS y se ponía... ( hace el gesto de cruzar las manos y pone cara de ángel) Como que era buena y claro yo igual, estaba hasta el moño de todo y le contaba todo y sí, mi padre me pegaba..., sí.

- (P) Yo a lo que me refería, era si tú habías presenciado malos tratos de tu padre hacia tu madre.

- (R) Alguna vez tuvieron alguna discusión, pero no, nunca.

- (P) ¿Y hubo malos tratos en la familia de él?

- (R) Se llevan mal, siempre se han llevado mal. A mí me han preguntado que si mi suegra pegaba a mi suegro. Yo no puedo decir que sí, porque yo no lo vi, yo vi que ellos no se llevaban bien, pero hasta ahí. No porque yo no lo vi, y yo no puedo decir algo que no he visto.

- (P) Cuando sucede todo esto en tu pareja ¿lo achacas a estrés, presión, la crisis...?

- (R) Es igual, su madre, el bar, la crisis también le afectaría, pero él no lo veía, aunque no cobraba y eso, él llegaba a casa y "dame dinero para el bar, dame dinero, si no lo tienes lo pintas, lo sacas de donde quieras" (él le decía a ella), él teniendo para sus vicios y sus cosas no le importaba nada más. Pero ya de último, que le veía que estaba rabiado, que estaba como con ganas de matarme, yo le veía con ojos de querer matarme.

- (P) ¿Lo veías posible?

- (R) Sí, sí, sí, sí... yo si esas navidades no me separo, yo creo que ahora no estaba aquí. Así de claro te lo digo.

- (P) ¿Te cuesta un tiempo empezar a hablar de esto?

- (R) Yo nunca hablé nada hasta que ya reventó todo por todos los lados, con la única persona que lo hablaba era con mi madre y me mandaba callar, cuando empecé a hablar, mucha gente, les vino por sorpresa lógicamente.

- (P) ¿Y a tu madre, también tardaste en contárselo?

- (R) Yo a mi madre se lo contaba mucho, pero... "calla, él tiene el problema de la bebida, todos cojean de alguna pata..., ¿qué te piensas casar y descasar cada dos días? (era la respuesta que obtenía de su madre)

- (P) ¿Cuántas veces le denunciaste?

- (R) Aquella vez que fue la policía a mi casa, como me hablaron así los policías, que si denuncias, no denuncias, que si no se qué, que si no se cuantos, que si es cuando las matan, no oí mucho el contexto, sólo, me tan..., me acojoné más, me... la verdad es que me acojonaron los policías locales, eran muy jóvenes e imagínate, verte con una niña de 3 años y la otra de 1, pues les impactó, lo vi yo que se impactaron

- $(P)$ ¿Por qué? ¿qué vieron?

- (R) Eran los fuegos de L., era la noche de San Juan, imagínate, no se, yo aquel día estaba aturdida, estaba aturdida, no sabía qué hacer, le había estado hablando a las niñas, vino sofocante del pueblo, yo ni fui y me dice la niña mayor, "mamá, me dijo papá que te dijera una cosa", y digo dime..., "que eres una puta". Y sigue igual, y no ha cambiado, él sigue en el bar y ya le han llamado la atención porque alguna cosa las dice a las niñas o algo, pasa que la niña mayor es muy lista, la mayor uno de los días que fue le dijo que yo era tonta, fea y boba y yo tampoco estoy preparada para esas situaciones ¿sabes?, hay veces que sí, que estás preparada, te dicen los psicólogos, "dí esto, esto y esto", pero llega ese momento y le dices lo primero que te viene a la cabeza. El impulso ese y pumba, mal dicho, pero... le dije "le dices a tu padre que no soy ni fea, ni tonta, ni boba" Que igual no es así, mandarle el recado, no lo sé, yo me salió del alma, es que además estaba yo... Y me saltó con eso, porque también viene, que "papá no vive en casa porque pegó a mamá", ¿a qué coño se lo recuerda si esa niña ya está bien?, si hasta la niña pequeña, que la pilló con 1 año me lo viene diciendo, pero ¿qué saca? Si son muy pequeñas. La mayor lo vio todo y además le decía "papá no estés en el bar que 
después vienes malito", pasó sus cosas y yo la intenté tener al margen, ¿a qué coños las utiliza? Y cuando vino de APROME (Punto de Encuentro) justo se acordó de ese detalle, cuando me vio se acordó y dijo, espera, delante de la de APROME dijo, "que sepas que mi mamá no es ni tonta, ni boba, ni fea" Yo no sé si hice bien o hice mal, pero a mí me salió del alma eso y es que llega un momento que ya te harta.

- (P) ¿En algún momento sentiste la necesidad de exagerar tu historia para que la gente te creyera?

- (R) No, yo conté lo que era, si me creían o no me creían me daba igual, es lo que hay.

- (P) ¿Alguna vez, tuviste que utilizar una casa de acogida?

- (R) Yo quise irme a una casa de acogida hasta que yo estuviera bien porque mi madre me agobiaba mucho. Yo veía que si alguien estaba a mi lado y me ayudaba, iba a salir mucho mejor, porque yo me metía mucho en la cama, mi madre me convenció para que fuera a un psiquiatra y me dio pastillas, me quedé medio drogada, medio dormida, medio...

- (P) ¿Eso una vez separada?

- (R) Sí, me hubiera venido bien que una persona hubiera estado a mi lado, porque mi madre sólo era "y esto lo hicisteis mal, si me hubieras hecho caso a mí y si no te hubieras casado, porque patatín, si lo hubieras hecho antes, porque tú ya eras una guerrera de pequeña..." Iba para casa de mi madre e igual salía una mujer muerta y me decía mi padre, "mira, una como tú, mira donde está ahora" A mí me entraban unas diarreas...También en el matrimonio hubo cosas positivas, lo que pasa es que te centras en lo peor y tapa todo lo bueno porque yo estuve casi 10 años, entonces pues...

- (P) ¿Tú pareja, en algún momento se sintió maltratado por ti?

- (R) No él, por ejemplo, igual me hablaba o eso y claro yo había veces que ya o aguantaba y... le pegaba cuatro voces porque lo que no es normal es que vaya al servicio y mee en el suelo o haga cosas que jolina, o que se meta con las niñas, hay días que bueno... no eres de piedra, y... se me fue el santo al cielo.

- (P) Estábamos diciendo que si él consideraba que tú le maltratabas.

- (R) No, él por ejemplo cuando veía cosas de estas en los semáforos, de mujeres maltratadas, enuncias, o algo, cambiaba la tele, justo pusieron una en la puerta de mi madre y yo me quedé así mirando para ella y él me hablaba para que no mirara.

- (P) ¿Un anuncio quieres decir?

- (R) Sí

- (P) ¿Cuando te casas con él, piensas que es el hombre perfecto para tí?

- (R) Bueno, cuando me casé, si, me daba tranquilidad, si hombre, claro.

- (P) ¿Te casas convencida de que es tu media naranja?

- (R) Si..., o sea, tampoco era un amor loco, yo veía que estaba muy a gusto, que me quería, que me apoyaba, le veía como el hombre con el que moriría.

- (P) Y ahora ¿ha cambiado la percepción que tienes de él?

- (R) Yo no le quiero ni ver, ya no quiero saber más de él. Yo no soy como esas mujeres, porque claro, te metes en estos círculos, de gente como yo maltratada, y que van en busca de ellos, a meterse en los pisos de ellos y todo, porque eso se oye todo, yo no, yo cuando dije, no quiero más, no quiero más, mucha gente me lo ha dicho, que como yo de tener las ideas tan claras de que ya no quiero más...

- (P) Pusiste un punto y final a tu historia

- (R) Se acabó

- (P) ¿Tú piensas que la situación ideal de cualquier mujer es estar emparejada?

- (R) Si te va bien, sí. Yo reconozco que si quiero estar con una pareja, que me va a costar mucho confiar en un hombre, yo tengo un amigo que se ha separado y quiere estar conmigo, pero yo no estoy preparada para estar con él.

- $(\mathrm{P})$ ¿Con él por ser él, o quieres decir que no estás preparada para tener una nueva pareja? 
- (R) Para tener una relación, no, yo no sé, que no me fio. Porque mi ex era muy bueno y me quería mucho y me halagaba mucho y... "si te mueres tú, la vida no tiene sentido para mí y me muero yo... yo..." (le decía su marido a ella) Lo dicen todos, ¿quién dice la verdad y quién no?

- (P) ¿Tú le creíste?

- (R) Hombre... no es que me lo creyera, pero que te digan eso, pues... hombre... te halaga un poco.

- (P) Más siendo jovencita

- (R) Yo me casé con 22 años, imagínate

- (P) ¿Piensas que las mujeres sólo podemos amar a un hombre en la vida y después de ese, todo lo que pueda venir ya no va a ser lo mismo?

- (R) No, antes, sí, yo pensaba que yo no iba a rehacer mi vida. Yo creo que sí se puede, pero... ¿con quién?

- (P) ¿Qué opinas de los celos? ¿Piensas que son buenos en una relación?

- (R) Mi ex, aparentemente no era celoso, yo un poquito. Eso de que se queden mirando para chicas o eso... no me gusta... pero tampoco es no...

- (P) ¿Pero son necesarios en una pareja?

- (R) No, hombre..., si tienes alguno, pero que no es una virtud, no... Yo no creo que estén bien eso, pero bueno...

- (P) ¿Sería necesario estar siempre demostrando el amor con la misma intensidad?

- (R) Yo creo que habrá de todo un poco, no lo sé...

- (P) ¿Sería bueno que estuviésemos siempre al $100 \%$ con la otra persona?

- (R) Yo creo que eso no existe, yo creo que no... Siempre habrá momentos buenos y malos, pero si te quiere esa persona, ves que te apoya, tampoco va a estar ahí abrazándote y mua, mua, mua... todo el día... pero bueno que te apoye, que esté contigo, que te demuestre que te quiere que te apoye...

- (P) Dicen que el amor lo puede todo ¿tú qué piensas?

- (R) A ver, yo con los otros chicos que salí, pues bueno... yo que sé, es distinto, cada chico es un mundo y cada chica es un mundo.

- (P) ¿Piensas que el amor tiene un poder especial?

- (R) Te ayuda a hacer más cosas, a estar alegre, a tener,... no lo sé... Es que a mí esa relación me ha dejado cao.

- (P) ¿Una se puede proponer dejar de amar a una persona o no?

- (R) ¿Cómo, como...?

- (P) ¿Piensas que si te lo propones puedes dejar de querer a esa persona, o no, dices, el amor es así y cuando llega, llega y no se puede pensar con la cabeza, simplemente, te dejas llevar?

- (R) Yo creo que eso se siente, se siente o no se siente, yo creo que... conozco a una chica que puso la denuncia, la quitó, ahora se ha vuelto a casar con él y a ella la ha pegado y decía, es que es el amor de mi vida. A mí eso no me entra en la cabeza, a mí una persona que me quiere, (se equivoca, quiere decir, una persona que me agrede) no es el amor de mi vida, ni nada, una persona que me hace daño no es el amor de mi vida y yo no le quiero, ¿cómo puedo querer a una persona que me está pegando y que me está haciendo la vida imposible? Imposible. No me entra en la cabeza, pero bueno, se que lo hay, pero desde mi punto de vista no, yo en mi caso, la primera vez que me dio una paliza, ya no le sentía...

- (P) ¿Quieres decir que empiezas a verle de otra manera?

- (R) Le vi... no entiendo que una persona te pegue, no...

- (P) ¿Crees que cuando dos personas se quieren, lo normal es que convivan o se casen?

- (R) Habrá otras formas de demostrar el afecto, yo..., mi sueño desde pequeña era tener una pareja, no sé si casarme o no casarme, pero tener un apoyo conmigo en casa.

- (P) ¿Podemos decir que para ti, si es una buena opción la vida en pareja? 
- (R) Sí, pero bueno... haciéndolo con cabeza, no tan joven como yo, que mira me estrellé.

- (P) ¿Quien toma la decisión de separarse él o tú?

- (R) Yo lo hablaba con él, pero a él le daba la risa, decía...

- (P) No se lo creía

- (R) No, bueno de hecho, le dijo al policía que le había pillado por sorpresa, que no se lo esperaba, la verdad

- (P) ¿Es el día de navidad cuando tú tomas la decisión de separarte?

- (R) Cuando me pegó la última vez, al día siguiente le puse la denuncia, era un viernes y él hasta el lunes no apareció en comisaría.

- (P) ¿Por qué esa vez te decides a denunciar?

- (R) Le había dicho que la siguiente vez que me pegara no me lo iba a pensar, ya había ido a ADAVAS y había dicho que quería separarme, que no le quería jorobar la vida, que no le quería denunciar, pero que no aguantaba más, no tenía fuerzas ya, no tenía fuerzas, encima con las niñas, ¿qué panorama es ese?, que no, que la época más bonita, es la de unas niñas pequeñas y no quería que vieran a su padre así y menos pegarme y me dijo que la siguiente vez que lo denunciara, me ayudaron y sí, me dijo que aunque hiciera eso yo me tenía que poner en ayuda psicológica.

- (P) ¿Y lo hiciste?

- (R) Sí, estuve mucho tiempo, pero... yo sé es una carrera, unos estudios, una profesional, pero se les escapa muchas cosas del maltrato.

- (P) ¿A qué te refieres?

- (R) Sí, eso es mucha teoría, no... yo creo que para ser una buena psicóloga, tendría que pasar esto, vivirlo.

- (P) ¿Vivirlo para poder aconsejar?

- (R) Sí

- (P) ¿Sentías que esa persona no te estaba entendiendo?

- (R) Yo la veía muy profesional, te da unas pautas para que sigas, pero... después de separarte, yo no pensé que iba a tener un bajón tan fuerte, yo pensé que me iba a liberar y que por lo menos iba a tener tranquilidad al no ver a ese sin vergüenza viniendo como venía a mi casa, que yo no sabía cómo iba a entrar por la puerta, que yo, ya me temblaban hasta los... pelos, y yo no sabía de qué lado me iba a dar la bofetada ese día y... di en picado y se les escapan muchas cosas, muchas, muchas, muchas... lo que pasa es que...

- (P) ¿Tuviste varios intentos de separación antes del definitivo?

- (R) Sí, cuando vino la policía, pero siempre... Para la boda de mi hermana, también, lo que pasa que fue la boda, después parecía que se había hecho buenín, mi madre me decía "mira ya cambió..." No vi el apoyo suficiente.

- (P) ¿Cada vez que te pegaba intentabas separarte?

- (R) Sí

- (P) Después de la separación ¿qué cambios experimenta tu vida?

- (R) Que no me fio de la gente, aunque me lo pongan muy bonito...

- (P) ¿Te refieres a otros hombres?

- (R) En general, entre mi suegra y mi ex, no me fio de nadie. Siempre le doy la vuelta a las cosas para que no me dañen de ninguna de las formas.

- (P) Siempre estás con las alarmas encendidas.

- (R) Hombre... no siempre, pero por regla general, si

- (P) ¿Con qué apoyos cuentas además de tu familia?

- (R) El chico este que ahora... bueno..., me saca, voy con él a tomar un café, algo alguna vez, cuando no están las niñas a bailar un poco... pero... nadie más. Tengo, sí, sí, sí, sí, mi prima o eso que te llama, qué tal estás o cómo lo llevas, no... la gente...

- (P) ¿En este momento cómo estás de salud?

- (R) Pues con alergias raras 
- (P) ¿Tomas medicación?

- (R) No, hace muchísimo, sólo porque me dolía la cabeza, por culpa de mi madre, tomé unos cuantos, me hizo ir a un psiquiatra y me mandó tomar media pastilla, tomé $1 / 4$ y no me levantaba de la cama, si tomo media estoy todo el mes durmiendo... y... me habían mandado más porque se me quedaba la vista en blanco por la calle, ya me pasaba en julio, hasta diciembre que me separé, me mandaron al neurólogo de... al médico y me dijo que eso era de los nervios, me mandó una pastilla por la noche y otra por el día, y la del día la dejé, me acuerdo que la psicóloga me decía..., porque yo le decía a ella, yo no quiero tomar más pastilla y ella me decía "pues tienes que dejarlas", porque el neurólogo me había dicho que ya de por vida y yo decía es que yo noto la misma ansiedad que tenía antes, ahora con la pastilla, lo mismo me da tomar la pastilla que no, lo único por el dolor de cabeza, pero tengo miedo dejarla y que me vuelva, porque yo me quedaba con las niñas en blanco, yo iba por la calle y eso, me dice, tienes que ir dejándolas poco a poco y tal y me dio la de cabecera, que lo fuera dejando. $Y$ esa noche yo no sé que me pasó, se me olvidó la pastilla dichosa y no me dolió la cabeza y al día siguiente, dije, voy a probar a ver si no me duele la cabeza y hasta hoy. Si me duele la cabeza, como a una persona cualquiera, me toma un termalgín y ya está.

- (P) ¿Sigues viviendo en la misma casa que compartías con él?

- (R) Sí

- (P) ¿De trabajo nada? ¿Te liquidaron?

- (R) Sí

- (P) ¿Han cambiado tus relaciones sociales?

- (R) Yo con mi ex me fui separando de todas mis amigas, cuando me he separado, en mujeres maltratadas, que ves de todo, gente que dice la verdad, gente que no la dice... y me hice mis amigas, pero hubo varias que me fallaron, me metieron muchas mentiras y me utilizaban, entonces, empecé un poco a ... y bueno salgo con este chico, me lo paso bien, bailo.

- (P) ¿Cómo lo conociste?

- (R) Fue una historia muy larga, la amiga mía, esa queme hice en un curso por el plan dique, que yo pensé que era buena persona, pero es más mala que un demonio... pues me había metido una mentira muy grande, que su novio era catedrático, si su novio era muy educado, pero no era catedrático y ella estaba empeñada en que yo me liara con el amigo de él, pero que no, un paisano que debía tener 60 y pico años, pues mira, yo no quiero liarme con ninguno, el día que yo quiera liarme, me lío yo con el que yo quiera y si no quiero no quiero y no quiero... y bueno yo veía queme mentía mucho, me decía muchas mentiras, hasta que un día, salimos a bailar porque no estaban las niñas y estaba este chico que se acababa de separar hacía 2 ó 3 meses y en una de aquellas que yo me fui al servicio, él quería conocerme y tal y yo me fui al servicio y a él le dijo que por favor no me dijera la verdad porque yo no la sabía y él me dijo la verdad, que su novio estaba en la cárcel, que salí y entraba y el amigo estaba en la cárcel y ella no quería que yo me enterara.

- (P) ¿Y este chico es amigo de ellos?

- (R) No, él es funcionario de la cárcel, y es el que les abre y les cierra la puerta.

- (P) Antes mencionabas a una prima, ¿también te apoya?

- (R) Sí, bueno, pero... ya sabes, hoy te voy a llamar, o ven conmigo a tomar un café, pero no...

- (P) ¿Cómo es tu relación con las niñas después de la separación?

- (R) A ver, yo por mis niñas doy mi vida, pero también reconozco que cuando tengo el día chungo y ellas se pelean, les pego cuatro voces y desahogo, sé que no tengo que hacerlo, pero es que no puedo por menos y estoy intentando, se lo he dicho a la psicóloga, pero es que hay veces, que tienes problemas y que ellas se peguen, y además por una bobada, "que me miró, que me miró..."

- $(\mathrm{P})$ Me dices que no estás preparada para nuevas parejas 
- (R) Este chico, quiere y tal, pero es que le veo que es muy celoso, él nunca pegó a su ex mujer, ni nada...

- (P) ¿Cómo te definirías hoy?

- (R) Con ganas de luchar, me falta el trabajo, trabajo, el trabajo lo llevo mal

- (P) ¿Qué planes tienes para el futuro? ¿Cómo te ves pasado el tiempo?

- (R) Coger a mis niñas y marcharme de vacaciones a la playa y tener mi trabajo. Siempre soñé con tener niñas y hacerme como amiga de ellas, como si fuera su hermana, y si me llevo muy bien, me quieren mucho. Yo sé que hay días que decía tiro la toalla, se las doy a él, no puedo más, cuando ves que te dan bofetadas de todos los sitios y me acuerdo que... esto tiene que seguir para adelante... es que a veces se me va. 
ENTREVISTA № 2 - E (15/03/2011)

- (P) ¿Cuántos años tienes?

- (R) 42

- (P) ¿Dónde naciste?

- (R) Aquí en L.

- (P) ¿Tu familia es de aquí?

- (R) Mi padre sí, y mi madre es de A.

- (P) ¿Qué edades tienen tus hijas?

- (R) 18 y 13

- (P) ¿Viven contigo?

- (R) Sí

- (P) ¿Y son hijas del mismo padre las dos?

- (R) Sí

- (P) ¿Dónde vivís ahora $E$ ?

- (R) En el P X, en el que era el domicilio familiar que llaman

- (P) Y tu familia, E. ¿dónde está?

- (R) Mi madre, vive en M. A., mi hermana aquí muy cerquita en R. y S. y mi hermano para la zona del c.g., pero no sé cómo se llama la calle

- $(\mathrm{P})$ ¿No tienes padre?

- (R) No, no tengo, se murió hace un montón de años, veintipico años.

- (P) Tu madre y tu hermano y hermana, ¿Son para ti un apoyo E?

- (R) Sí. Mi madre y mi hermana, mucho, mi hermano menos, porque bueno... tengo menos relación con él, pero me ha apoyado mucho mi madre, mi hermana, lo entienden y apoyan porque, por desgracia, mi padre era también un poco alcohólico y mi madre, lo entiende, la situación de humillación, a lo que llegan de desvalorización, de insultos, de todo lo que hacen, porque lo vivió, claro, era otra época, pero lo vivió también.

- (P) Sabe por lo que estás pasando

- (R) Exacto

- (P) Me decías, que ahora no trabajas fuera de casa

- (R) No, no tengo trabajo

- (P) ¿Y estás buscando?

- (R) Lo busco, lo busco

- (R) Me comentabas también que estás intentado formarte porque, te encontraste después de la separación, que las puertas del mundo laboral se te bloqueaban precisamente por la falta de preparación.

- (P) Exactamente, no puedo, no tengo nada, me centré en la familia y no estudié y ahora se me cerraron muchas puertas.

- (P) ¿Cómo estás de salud $\mathrm{E}$ ?

- (R) Bien, estoy algo deprimida, duermo mal, estoy a tratamiento, pero de salud en general me encuentro bien, con fuerzas y ... intentando salir adelante aunque con todo esto, vamos, lo que más fuerza me dan, son mis hijas que ves que tienes que estar ayudando a salir adelante, porque... porque se puede, porque se vale, vamos, porque valgo y porque me lo dicen muchísimas personas, aunque en la cabeza tienes grabado que eres una mierda y que no vales nada y que, y que, no sabes hacer nada, pero intentas tener fuerza para salir adelante, además, es eso, que tengo buena salud a pesar de lo que me ha pasado, esto, después del maltrato, pues psicológicamente estaba hundida y todo lo que me puede pasar de esto, creo que se va a superar, porque es solamente por maltrato, te quedas sin fuerzas, tienes una ansiedad tremenda, un descontrol de todo, que no sabes por dónde empezar a vivir, porque no sabes vivir, porque te han destrozado, la vida, realmente te la destroza, anímicamente, personalmente y todo, pero... pero bueno... tienes que....

- (P) Pero estás luchando 
- (R) Tienes que salir adelante y tienes que luchar, exacto, tienes que luchar

- (P) ¿Cuánto tiempo llevas separada?

- (R) Va a hacer un año

- (P) Un año, no lo hace todavía

- (R) No, no lo hace

- (P) ¿Cuántos meses entonces?

- (R) 10

- (P) ¿Recuerdas la primera vez que tu marido te maltrató? ¿Cómo fue? ¿Qué pasó?

- (R) Pues... estoy intentado borrarlo de mi mente, pero...

- (P) Pero yo te lo hago traer a la memoria otra vez. ¿Qué pasó?

- (R) Ya casi ni... La vez más fuerte...

- (P) No. Te pregunto por la primera vez, la primera vez, luego me cuentas si tú quieres otras, pero en este momento, ¿tú recuerdas? El primer recuerdo que tienes de este hombre maltratándote, no sé si fue un maltrato físico, psicológico, no lo sé.

- (R) Fueron las dos cosas, psicológicamente, fue ..., bueno, ..., él bebía ya desde que éramos novios, pero bueno, pues lo que pasa, que no le das importancia porque era hasta divertido, porque hace el tonto y esas cosas, no le das importancia, pero seguía bebiendo después del matrimonio y ahí ya, después cuando quedé embarazada, él no estaba muy de acuerdo y bebía más los fines de semana y eso y ya empezó bastante mal y fue cuando estaba embarazada ya, cuando empezó a insultarme y a darme algún empujón, y a veces me daba por la espalda, tenía algún moratón en la espalda porque iba por el pasillo y ¡Pun! Me daba algún golpe, fue desde el principio, en el..., desde el principio del matrimonio, o sea... puf... yo quedé embarazada después de que llevábamos... 5 o 6 meses, hasta que quedé embarazada, de mi hija mayor, pues en el momento de quedar embarazada, como que no entraba en sus cánones de familia o que perdía libertad o no sé y empezó ahí más fuerte, y anteriormente aunque bebía yo no le veía maltrato mal, porque eso, se ponía tonto, pero hacía gracia porque hacía mucho el payaso y eso, pero lo ves de otra manera, a cuando ya... te insulta porque... porque algo que ha sucedido por ejemplo, en este caso los embarazos, no entran dentro de su, de su...

- (P) De sus planes

- (R) De su cabeza, de su rutina, si, de sus cosas, de su vida, de su vida...

- (P) ¿Qué tipo de insultos de profería?

- (R) ¡Puf...! De todo,... mucho puta. Puta, siempre en la boca, hija de puta mucho y... en ese momento, además, no me veía apoyada porque no se lo decía a nadie, no podía decírselo a nadie, y te vas encerrando y.... y...

- (P) Eso era lo siguiente que te quería preguntar, cuando te empiezan a pasar estas cosas, tú ¿lo cuentas E. o te lo callas?

- (R) No lo cuento, no lo cuento, porque me da vergüenza, me daba vergüenza, es que te encierras, yo dejaba hasta de salir, porque no, no... como que... al ver a la gente que te lo iba a notar, que te..., que te... estabas mal... que no...( lo dice llorando)

- (P) $\mathrm{Y}$ no se lo contabas a nadie, ni siquiera a tu madre, a tu hermana, a alguna amiga...

- (R) No. A nadie, al principio no se lo conté a nadie, después ya se lo conté a mi hermana, pero ya cuando había pasado bastante tiempo y.... y empecé a decírselo y ya, pues ves una salida, pero bueno...

- (P) ¿Cómo reacciona la gente de tu alrededor cuando empiezas a contarlo?

- (R) Decían que podía ser algo pasajero, que no... que hay que aguantar así, porque a veces los hombres tienen sus manías, y... y que si no lo hacía siempre, como era mi caso, que era más tarde- noche, porque por el día era... estábamos bien, era una vida normal, de salir de compras o a pasear, o vamos,...una vida rutinaria de pareja, de estar bien, o viendo una película o vas al cine, o tal, es más por la noche, pues aguantaba por eso, porque decías va, si es solamente..., al 
principio no era todos los días, solamente el fin de semana, es tal... pues vas aguantando

- (P) La primera vez que te agrede, que te empieza a insultar, o a pegar empujones, incluso puñetazos en la espalda, ¿él como reacciona, después cuando tú se lo haces notar, "oye, pero te das cuenta lo que has hecho", cual es su reacción?

- (R) Él, irse a la cama.

- (P) Se va a la cama y aquí no ha pasado nada, y tú ¿cómo reaccionas?

- (R) Llorando, lloraba mucho, llorando, llorando y con nervios..., intentaba tener siempre a mis hijas acostadas antes de que él llegase, para que no viesen todo lo que pasaba, aunque... claro, lo oían, lo oían porque se oye, las paredes son de papel.

- (P) No conseguías mantenerlas al margen

- (R) No, L. lo ha sufrido desde siempre, además, más tarde L., pero... (se pone a llorar)

- $(\mathrm{P})$ ¿Qué tipo de cosas le hacían ponerse agresivo contra ti? ¿por qué?

- (R) No había ninguna razón, ninguna razón, es que llegaba a casa ya exaltado, nervioso, cargado... ya no..., ni saluda, ni decía nada y ya empezaba a despotricar "vivís bien, sois... ahí unas chulas"

- (P) Se refería a las tres, a las niñas y a ti.

- (R) Si, si, si "Vivís bien, pero esto se acaba, porque no valéis para nada y lo único que hacéis es gastar mi dinero, y... sois una mierda, fuera de mi casa"( lo dice en voz muy baja)

- (P) ¿Os llegó a echar de casa en alguna ocasión?

- (R) Muchas veces nos echó de casa, muchas, nunca nos fuimos, pero muchas veces nos echó de casa a empujones, pero no salimos nunca. Hace unos años me reventó un oído de un tortazo y fue la policía y la ambulancia para llevarme al hospital y... fue otra intentona grande de separación que se volvió para atrás ... pero bueno, llegó la hora de ir al juzgado, porque denunció el hospital, yo no denuncié, denunció el hospital, al denunciar el hospital, él se encargó de ir a denunciar también, a ponerme una denuncia a mí, una denuncia falsa, como las que me está poniendo ahora, que me está haciendo, me está poniendo él denuncias y me está poniendo su familia, falsas totalmente, o sea..., tienen una imaginación muy grande, porque yo nunca sabría hacer lo que me están explicando, que cuando me llega la denuncia digo, iqué bien, que bien! Yo no puedo explicarme así, ni hacer lo que estáis escribiendo que es, pero eso... me puso una denuncia falsa para negociar que no siguiera adelante, y cuando fuimos al juzgado, antes de entrar, me dijo "di que no ha pasado nada, porque si no te vas a enterara, de esta no sales, porque..." y cuando entré a declarar dije que no había pasado nada. Y no pasó nada, siguió adelante.

- (P) Después de las agresiones, después de que él te agredía ¿cómo reaccionaba, mostraba arrepentimiento, intentaba camelarte?

- (R) No, eso era al día siguiente

- (P) ¿Qué pasaba?

- (R) Al día siguiente, es como si no hubiese pasado nada, no se acordaba de nada o no quería acordarse, yo ya eso no lo sé, él hacía como si no hubiese pasado nada, cuando yo le decía "es que no me encuentro bien porque ayer me has dicho esto y me duele el brazo porque me has tirado de él, me has empujado" "eso no fue nada, eso fue porque no me dejabas pasar" No le daba importancia y... y le decía "es que siempre llegas bebido, ¿No te das cuenta de que bebes?" "Que no tomo más que un par de cubatas, que eso no me sienta mal, ¿tú me has visto alguna vez caerme contra las paredes?" "No te caes contra las paredes, pero aunque no te caigas contra las paredes estás mal, estás borracho porque lo que estás haciendo, si me dices que encima no te acuerdas, estás mal, había que buscar ayuda" Y me decía que sí, que iba a intentar buscar ayuda, que eso, pero no... no lo hizo nunca, pedía perdón al día siguiente "venga anda, que no pasa nada, que no lo vuelvo a hacer", y eso sí me lo decía mucho, pero no... siempre volvía. 
- (P) ¿Había reconciliaciones?

- (R) Reconciliaciones..., regalos..., viajes..., el último fue por estas fechas el año pasado, de hecho, nos fuimos, otro perdón, nos dijo, "os llevó de viaje, vamos ahora en semana santa" que el año pasado fue en marzo, "vamos a la playa", pedía perdón a mí y a las niñas, en realidad. Él si sabía lo que hacía cuando pedía perdón y hacía, pero no le daba importancia, no le daba importancia y estaba bien tres días, dos y después era vuelta a empezar.

- (P) Incluso cuando estabais de vacaciones o salíais por ahí, en esos periodos de reconciliación

- (R) Cuando estábamos fuera, no, estaba bien.

- (P) A ti te hacía pensar que podía haber cambiado

- (R) Exactamente

- (P) Volvíais a casa y ¿qué pasaba?

- (R) Volvíamos a lo mismo

- (P) Vuelta a la realidad

- (R) A la misma historia, es que es eso, cuando estábamos bien... incluso cuando estábamos en reunión con más gente estaba bien, era entrar en casa, cerrar la puerta y empezar a insultar, a empujarte, a humillarte, a despreciarte, es que era no querer volver a casa, porque cuando estás con más gente no pasaba, entonces era un poco angustioso, el jhay que volver a casa! Y cuando estábamos nosotras en casa que él llegaba... (toma aire muy profundamente) un estrés tremendo..., porque llegaba y... ¿a ver qué pasa hoy?, porque nuestra vida era normal, estaban las actividades y cuando llegaba él a casa ¿a ver qué pasa hoy? ¿a ver por donde sale? ¿a ver qué ocurre?...

- (P) ¿Cuánto tiempo solía durar la calma, en tu casa, las reconciliaciones?

- (R) De que nos agredía.... Lo que te he dicho dos, tres días. Y otra vez a empezar, alguna vez era un poco más largo, estaba una semana bien, yo no notaba nada extraño, no insultaba, no agredía, incluso se duchaba, que también los olores que traía, fíjate, con todo eso que mueve él, actividad y olores de.... Incluso eso, los días que quería amansar las cosas y que claro, además se acostumbró a que yo cediese, ¿para qué estar más? Si después de una semana volvíamos a estar hasta que eso..., podía hacer lo que le diera la gana, estaba hundida, estaba hundida, no tenía autoestima, no tenía nada, era una mierda, realmente cuando me lo decía me lo creía, no valía para nada, me manipulaba, me anulaba y yo ni me enteraba, es que no me enteraba, es que para mí ya era ipuf... bueno...! "Si tú lo dices que soy una mierda y que no valgo nada y que no sé hacer nada, vale..."

- (P) ¿Llegó a agredirte sexualmente alguna vez $E$ ?

- (R) No, de violaciones y eso no.

- (P) Obligarte a mantener relaciones sin que tú quisieras, sin que tu consintieras

- (R) No, los borrachos no pueden. (lo dice risueña)

- (P ¿Cómo te sentías mientras estabas viviendo con él? ¿Llegaste a creerte todo eso que él te decía? ¿Interiorizaste el discurso, de tal manera que lo hiciste tuyo?

- (R) Sí, sí, sí, yo estaba convencida de que no valía nada, que no valía, que no sabía por qué vivía, porque no valía nada, no era nada, no hacía nada bien ¡Puf...!, es una humillación la que tienes dentro que no... que te crees todo lo que te dice, eres un asco, un asco de persona, no tienes...

- (P) Cuando te mirabas al espejo ¿Qué imagen veías reflejada de ti misma?

- (R) Me veía fatal, fatal, fatal, ... pero mal, no sé explicarlo, me veía muy mal de todo, no me veía, como un monstruo, fea, yo es que creo que soy una persona normal, pero me veía mal, no salía ni a la calle para que no me viese la gente, no me pueden ver así, no valgo nada, no me puede ver la gente así, que no tengo nada de fuerzas, que no....

- (P) Y ahora $E$ ¿cómo te ves después de 10 meses separada?

- (R) Me veo con ganas de salir a delante, estoy muy recuperada, me... intento buscar trabajo, porque he visto que lo necesitas, para que económicamente y 
psicológicamente, por relación, por autoestima, porque te haces valer..., pero bueno... no sé si llegaré a tener trabajo porque no tengo estudios, pero me veo bien, estupenda, divina de la muerte, antes me dolía un montón la cabeza, ahora me encuentro genial, me veo guapísima (lo dice riéndose ampliamente), me veo divina, me veo bien, con ganas de salir, con ganas de irme aunque sea yo sola a tomarme un café y leer el periódico, de estar fuera, de hacer algo, de vivir, no tenía ganas de vivir, vida social. Aunque realmente conoces gente, poca gente porque te has encerrado y los amigos, yo no confío, porque te das cuenta de que a lo mejor por otras cuestiones a él pueden sacarle algo más, yo no tengo nada que dar, beneficio, te quiero decir, él por su situación puede..., y es un manitas, puede ayudar a lo mejor más y por interés, que se mueve mucho la gente por el interés, que lo he visto ahora, porque hasta las personas que se lo había comentado, veo que siguen apoyándole y es apoyar a un maltratador y bueno... tengo mis amigas, que están casadas, que tienen una familia normal y una vida normal y bueno, las veo poco porque tienen su familia realmente, pero te cuesta volver a confiar en la gente, es lo que dices, vida social si, buscas vida social, pero no puedes confiar, no..., tienes ese miedo de hablar de algo, de algo...que después de la vuelta y te haga daño, que tampoco te ves con temas de conversación porque no has salido de tu hogar, tu vida son los niños, que ya no son niños, pero no tienes tampoco cultura para desarrollar nada..., nada..., a veces te cuesta hasta mantener una conversación sobre.... Pero mantenerla por la falta de atención que te crea el dolor, el maltrato que has sufrido, te crea una sensación de que no te concentras ni en una conversación, ni en una película, te pierdes, te pierdes, incluso a mí, cuando están hablando, si estamos con más gente, como algo me recuerde a lo que vivía, me pongo a llorar, me pongo a llorar y muchas veces me voy al baño hasta que se me pasa, porque hay situaciones que me recuerdan momentos, 0 a lo mejor solamente es una palabra o un chiste que te trae a la memoria cosas pasadas y me pongo malísima, por eso a veces no es vida social, es salir y estar tranquila y ver que no pasa nada, tener fuerzas de salir, de vivir, porque te encierras, y yo no tenía fuerzas para vivir, para salir, ni para nada. Era como una cárcel de cristal en la que fuera todo era muy bonito y dentro era un infierno, un calvario.

- (P) De todas las maneras, E., tú cuentas todo esto de tu relación de pareja, de tu matrimonio, pero realmente tuviste sentimientos hacia esta persona. ¿Qué sentías hacia él?

- (R) Yo le quería, yo le quería.

- (P) Mientras estaban sucediendo todas estas cosas ¿seguías queriéndole?

- (R) Mientras estaba pegando e insultando, no, pero cuando me pedía perdón y eso, yo le perdonaba porque le quería, le quería, quería que estuviese bien y salir adelante y volver a intentarlo y decía que no iba a volver a pasar y que no iba a volver a beber y yo le quería y tenía la esperanza de que pudiese ser así, como cuando estaba bien, porque cuando está bien, era una vida bonita y buena, yo quería tranquilidad, pero..., pero siempre volvía a lo mismo y al final ya no tienes sentimientos, ya lo haces por cuestión de que te amenaza, de miedo, lo haces por miedo, vuelves y sigues por miedo, por miedo mucho, yo tenía miedo a todo, a todo.

- $(\mathrm{P})$ ¿Y en relación a tus hijas?

- (R) Miedo también por ellas, exactamente

- (P) ¿Qué pensabas en relación a tus hijas y a él? ¿qué se te pasaba por la cabeza?

- (R) En este momento no lo recuerdo

- (P) Dices que sí que tenías miedo por ellas.

- (R) Si tenía miedo, si en general, tenía miedo, yo a ellas las metía en las habitaciones para que a ellas no las... a ellas nunca las pegó, sólo me pegó a mí. Ellas escuchaban las cosas, pero bueno... les he evitado lo más posible por miedo de.... (hay un silencio muy prolongado)

- (P) ¿Estaban dentro de la habitación cuando esto pasaba? ¿nunca se les ocurrió salir? 
- (R) Lo han visto, lo han visto, que me han pegado, lo han visto, pero yo enseguida les decía "ir a la habitación"

- (P) Y ellas te obedecían

- (R) Sí, sí y a veces me llevaban con ellas y dormía con ellas.

- (P) En tu casa E., mientras estuviste casada ¿Quién tomaba las decisiones importantes?

- (R) Él todo

- (P) Siempre

- $(\mathrm{R} \mathrm{Si}$

- (P) Y el dinero ¿Quién lo manejaba?

- (R) Él

- (P) ¿Tú no tenías tu propio dinero? ¿Le tenías que pedir para hacer la compra...?

- (R) No, la compra la pagaba con tarjeta

- (P) Tú tenías una tarjeta y podías disponer de ella, para comprar

- (R) Para gastar y eso no había problema

- (P) ¿Las cuentas las llevaba él?

- (R) Sí

- (P) ¿Te recriminaba si gastabas mucho?

- (R) En ocasiones sí, me decía que no llegaba el dinero a fin de mes porque había comprado o había hecho, pero en realidad el dinero no era problema

- (P) El dinero no era problema

- (R) Si, él tiene un sueldo bastante alto

- (P) Me decías antes, que toda la intendencia de tu casa, la comida, la compra, las niñas, las actividades... eras tú, siempre

- (R) Sí

- (P) ¿Y así continúas?

- (R) Sí, claro (lo dice con una amplia sonrisa, con orgullo de sí misma)

- (P) ¿En algún momento dudaste de tus capacidades para hacer eso? Si se supone que siempre lo hiciste bien, que fuiste buena madre, que administrabas bien el dinero, que a tus niñas no les faltaba de nada. ¿Llegaste a dudar si lo estabas haciendo bien?

- (R) Dudaba de que supiese hacer las cosas, pero cuando él lo decía, porque cuando él no estaba en casa, yo veía que yo las cosas las hacía, que no... que funcionaba todo, realmente cuando... ¿qué era cuando él estaba así que yo no sabía hacer nada? Yo lo veía, incluso después de que el abogado le dijo que se fuese de casa, funcionaba todo igual de bien, incluso mejor por la tranquilidad, por no tener el miedo este de cuando llega a ver qué pasa, pero bueno... él ayudaba también en casa alguna vez, cuando estaba bien, colaboraba.

- (P) ¿Qué clase de cosas le molestaban de ti? Cuando él te agredía ¿por qué era? ¿Qué es lo que verdaderamente le molestaba?

- (R) No lo sé. Todo imagino, no lo sé

- (P) ¿No llegaste a saberlo?

- (R) Yo creo que todo le molestaba, no lo sé, que estuviese ahí, que viviese.

- (P) ¿Por qué permanecías a su lado? ¿Qué clase de cosas te ataban a él?

- (R) Sobre todo mis hijas

- (P) Las niñas ¿por qué?

- (R) Porque quería que estuviesen bien, que ellas estuviesen bien, y es lo que más miedo me daba, que como nos amenazaba tanto, "que a la calle, que sin nada" yo sólo quería que las niñas estuviesen bien, que estudiasen, que se formasen y es lo que....

- (P) ¿Y por eso aguantas, para darles ese bienestar o ese futuro a tus hijas?

- (R) Exactamente

- (P) ¿Antes de conocer a tu marido estuviste a tratamiento psicológico?

- (R) Si 
- (P) ¿Antes de conocerle a él?

- (R) ¡Ah no!, antes no, antes no. Estaba pensando después de la separación

- (P) ¿Y él, había estado a tratamiento antes de conocerte a ti?

- (R) No tengo ni idea, pero después de estas cosas, salió a la luz que había tenido robos con agresión, o sea con violencia

- $(\mathrm{P})$ ¿Cuándo era chavalete?

- (R) Justo unos meses antes de casarnos

- (P) ¿Ya estabais de novios?

- (R) Si, si

- (P) ¿Cuánto tiempo estuvisteis de novios?

- (R) Estuvimos dos años y medio

- (P) Y esto pasó meses antes de casarte y tú sin enterarte

- (R) Yo no me enteré de nada porque fue en V., y yo aquí no sabía nada porque como se iba algún fin de semana porque sus padres vivían allí y eso, y yo no sabía nada, ni me dijo nunca nada, hasta ahora que con el tema de las denuncias ha salido que tenía eso, que había estado en la cárcel por robo con violencia.

- (P) ¿La cuestión económica dificultó la separación?, es decir, ¿fue un impedimento a la hora de separarte?

- (R) No entiendo

- (P) Quiero decir, ¿hubieras permanecido más tiempo a su lado porque te proporcionaba un bienestar económico, o llegó un momento que no te compensó?

- (R) No, no, compensar no, no vivíamos, no disfrutábamos de nada realmente, no vives, no disfrutas, tienes mucho dinero, bueno mucho dinero, él tenía una buena nómina, pero no lo disfrutas, no vives, no puedes... no estás bien para disfrutar de nada, de nada, simplemente vives con miedo, comes normal y vives porque tienes que vivir, pero no disfrutas de nada, no era calidad de vida, ni vida siquiera, era una mala vida

- (P) ¿Tu familia, en el momento de la separación, te sirve de apoyo?

- (R) Sí, me ayudaron económicamente porque nos llevó todo, nos dejó sin nada y me ayudaron como pudieron

- (P) ¿Cuándo dices que os llevó todo, a qué te refieres?

- (R) Pues que no nos daba nada de dinero, ni nada...

- (P) Estuvo un tiempo sin pasaros nada

- (R) Nada, nada. Yo saqué el dinero de los planes de estudio de las niñas, que después ahora me lo reclama, pero si no tienes dinero ¿qué haces, qué haces?, y... bueno

- (P) Tuviste ahí a tu familia ayudándote y apoyándote

- (R) Sí, si

- (P) Decías que en tu familia, en concreto tu madre, sabía un poco lo que te estaba pasando porque con tu padre, algo de esto pasó ella también.

- (R) Bueno, eran otros tiempos y era diferente, pero sí que sabía lo que pasaba con el alcohol

- (P) ¿Tú viste malos tratos en tus padres?

- (R) Sí

- (P) ¿Viste a tu padre agrediendo a tu padre?

- (R) Sí, muchas veces.

- (P) ¿Sabes si los padres de él tuvieron historia de maltrato?

- (R) No

- (P) ¿Qué no lo sabes o que no la tuvieron?

- (R) No lo sé, no lo sé, no lo sé.

- (P) ¿Tu marido sufría estrés en el trabajo?

- (R) Sí

- (P) ¿Y piensas que eso puedo influir, a la hora de llegar a casa y ponerse de esa manera y agredirte? 
- (R) No lo sé

- (P) Tú lo achacas al alcohol, más que al estrés laboral, por lo que comentas ¿no?

- (R) Sí, pero a lo mejor bebe por el estrés. No sé hasta qué punto es eso, no lo sé

- (P) ¿Y era consumir y ponerse agresivo? ¿Siempre iba unido?

- (R) En público, no. Cuando estábamos con más gente, no, no, nunca me agredió, ni nada. Era en casa

- (P) El maltrato sucedía de puertas para adentro de la casa

- (R) Como que él se desinhibía o cogía más fuerza o no sé

- (P) Porque ¿cuándo no bebía, él esto no lo hacía?

- (R) No, no, no

- (P) ¿A ti te costó, empezar a hablar de todo esto?

- (R) Sí

- (P) ¿Por qué, qué sentías, por qué no lo contabas?

- (R) Me sentía culpable

- (P) Te sentías culpable y por eso no hablabas

- (R) Yo tenía muy asumido que toda la culpa era mía, de todo lo que sucedía, como yo no hacía las cosas bien y que gastaba su dinero y eso, pues que la culpa era mía

- (P) ¿Lo creías realmente?

- (R) Sí, yo no hacía las cosas bien

- (P) Denunciaste una vez separada ¿sólo una vez?

- (R) Denuncié una vez separada y después otra vez que fue a recoger unas cosas en el trastero y me volvió a agredir

- (P) Dos veces, más la del hospital, cuando en una agresión te rompió el tímpano

- (R) Pero no se llevó a delante porque yo no denuncié, ahí denunció el hospital

- (P) ¿Quién te animó a poner la denuncia, o parte de ti la idea?

- (R) Salió de mí porque no podía más. Y además él se basaba en eso, como no denunciaba, como no denunciaba y que volvía porque no tenía nada que perder, no pasaba nada

- (P) No había consecuencias para él

- (R) Exactamente, y ahora que denuncio, como es después de la separación, la jueza lo toma como una riña normal y no lo da como malos tratos, porque se supone que después de separados ya no puede haber eso, pero ha seguido y.... la vez que me agredió en el trastero que fue en octubre, que llamé a la policía, dije "esto ya no lo aguanto más" y llamé a la policía, la jueza dijo que....... No me acuerdo, no me acuerdo....., (lo dice con mucho pesar, quiere recordar, pero no puede, está como perdida)

- (P) Tranquila

- (R) Pero bueno que él se basaba en que yo no denunciaba y pensó que esta vez tampoco iba a denunciar, y es que yo ahora, nada más que me haga algo, es que es lo que me ha dicho la policía

- (P) Lo primero que haces es denunciar

- (R) Denunciar, si, tenía que haberlo hecho antes, pero no lo hacía porque siempre me decía, "como me denuncies me voy a quedar sin trabajo y no sé qué", pues eso, y si que tienes la cosa y dices....pues sí... No lo haces por no hacerle daño, por no tener problemas.

- (P) Y porque para ti es una cadena supongo, él se queda sin trabajo, las niñas,..., quiero decir, es una cadena de consecuencias, en la que lo piensas todo

- (R) Sí, sí, lo piensas todo, es una cadena, exactamente ¿de qué vives?

- (P) ¿Sentiste alguna vez la necesidad de exagerar tu historia para hacerla más creíble?

- (R) No, al contrario, lo contrario, siempre suavizo y digo lo bien... lo buena persona que es cuando está bien, al contrario, siempre le dejo como se ha comportado cuando está bien, se comportaba fenomenal, era normal, y cuando ha estado así, y ahora los últimos tres años, era un infierno total que no se salía y no se salía y no se salía, cada vez era menos espacio, antes era una semana de estar bien, que 
casi cogías fuerzas para volver a tirar, pero ahora era cada dos días y ya te quedas $\sin$ fuerzas. En tres años se ha vuelto horrible, horrible, horrible... se volvió horrible

- (P) ¿Quieres decir que se precipita un poco todo en estos tres últimos años?

- (R) Horrible, los tres últimos años, horrible, porque antes, lo que te comento

- (P) Era un poco más espaciado

- (R) Era un poco más espaciado, cogías fuerzas para seguir aguantando (lo subraya), pero en los tres últimos años, ya ni era buena persona por el día, es que ya... "estás mal porque no habrás dormido, yo no he hecho nada, te lo estás inventando, te lo estás inventando, si yo no he hecho nada, lo has soñado, tú, tú..." (describe el discurso de él cuando ella le recriminaba su actitud) Ya no era ni por el día, ya no vivías ni por el día, porque antes el día era bueno, en los últimos años ya no era el día bueno, ya no salía (se ríe nerviosa), no compartía, no quería estar con nadie por no tener nada de nada, era maldad totalmente, era malo, malo, malo...

- (P) Las 24 horas

- (R) Las 24 horas, pero por eso, que decía que estaba loca, que él no lo había hecho, que... bueno

- (P) ¿Has necesitado acudir a casa de acogida, o no te hizo falta?

- (R) No

- (P) ¿Piensas que él en algún momento, él se pudo sentir maltratado por ti?

- (R) No

- (P) ¿Nunca manifestó nada en ese sentido?

- (R) No

- (P) Decías que tus hijas, si que han visto cosas

- (R) Si

- (P) Inevitablemente han presenciado episodios de violencia entre su padre y tú

- (R) Si, lo han visto y lo han oído, mucho

- (P) Vamos a centrarnos un poco, ya no en el tema del maltrato, sino la idea que tenemos en general, acerca del amor y la pareja ¿Vale? $Y$ te pregunto ¿tú pensaste que tu marido era tu complemento ideal, en aquel momento?

- (R) Sí

- (P) ¿Teníais planes de futuro... envejecer juntos..., ver pasar la vida...?

- (R) Sí

- (P) ¿Y ahora qué piensas acerca de todo eso?

- (R) Nada (rompe a llorar y es incapaz de parar)

- (P) ¿Estás bien? (asiente con la cabeza) ¿Continuamos con las preguntas? (vuelve a asentir con la cabeza ¿Tú pensabas o piensas que la situación ideal para cualquier mujer es tener una pareja o se puede vivir tranquila también sin ella?

- (R) Se puede vivir tranquila sin ella, lo que tienes que estar es bien y no necesitas a nadie que esté a tu lado torturándote y machacando, lo que necesitas es tranquilidad

- (P) ¿Tú crees que las mujeres somos capaces de amar después de haber pasado por todo esto?

- (R) Sí, hay personas que merecen la pena

- (P) Vamos a hablar de celos ¿crees que los celos son buenos en la pareja?

- (R) No, no creo que sean buenos

- (P) No los has mencionado en toda la entrevista.

- (R) No, no, no. No había problema de celos, yo creo que no, al menos eso yo no lo vi

- (P) ¿Sentías o sientes que el amor se tendría que demostrar siempre con la misma intensidad?

- (R) ¡No hombre!, hay momentos mejores y peores, pero no tiene porque humillarte ni desvalorizarte, y pegarte mucho menos, pero siempre hay momentos mejores y peores, es la vida misma

- (P) ¿Piensas que esos momentos difíciles se pudieron haber superado si realmente hubiera amor, es decir que el amor hubiera sido capaz de superarlo todo? 
- (R) Yo pienso que habría que haber solucionado el problema en sí

- (P) ¿Quieres decir, que lo del amor está muy bien, pero que había otras cosas detrás?

- (R) En mi caso sí.

- (R) ¿Entonces el amor no lo puede todo?

- (R) No, no lo puede todo, va a ser que no. (se ríe pillando la ironía)

- (P) Piensas que cuando amas a alguien, amas de forma incondicional, te haga lo que te haga.

- (R) No. Ahora mismo, no es así, yo antes no sé si pensaba que podía con todo, yo ahora mismo no pienso así, porque no puedes aguantar, ahora que lo piensas... No sé como aguanté todo lo que viví, no lo sé

- (P) Además en tu caso fueron muchos años.

- (R) Desde el principio, 20. Desde el principio, más esporádico y estos tres últimos años, más intensos, muy malos. Porque antes era muy esporádico, situaciones más puntuales, era más llevadero y el amor te ciega (se ríe). Piensas que puedes con todo

- (P) ¿Piensas que si se quiere a una persona lo más natural es acabar conviviendo con ella, o casándose?

- (R) Cuando quieres a una persona quieres estar con ella, compartir con ella

- (P) ¿Piensas que es la situación ideal cuando se quiere a alguien?

- (R) Cuando se quiere a alguien, yo creo que cuando quieres a alguien estás a gusto con ella, te sientes bien, y quieres estar mucho tiempo con ella. Sí

- (P) ¿Quién toma la decisión de separarse?

- $(\mathrm{R}$ Yo

- (P) ¿Qué es lo que te lleva a tomar esa decisión?

- (R) Lo que.... Yo estaba hundida, ya no veía, ni podía con mi vida, y lo que me hizo saltar la chispa para decir hasta aquí hemos llegado, es que él empezó a meterse con mis hijas y nunca las llegó a pegar, pero amenazándolas..., insultándolas...

- (P) ¿Recordaste que así empezó contigo? porque tú describes que en un principio fueron insultos, no entró directamente a la agresión.

- (R) Sí, exactamente, pero yo necesitaba protegerlas de alguna manera y dije hasta aquí se ha llegado y.... me da igual, no tener que comer o vivir debajo del puente, es que me daba igual todo, en ese momento sólo quería que mis hijas no sufriesen más, porque no vivían, era llorar continuamente, ya está bien

- (P) ¿Te lo pedían ellas?, "mamá sepárate"

- (R) Me decían muchísimas veces "porqué aguantas esto", mucho tiempo, y porqué... yo decía "bueno anda, ya se le pasará..." y seguías. Y el desencadenante fue meterse con ellas

- (P) ¿Con las dos?

- (R) Con las dos, más con la mayor, pero bueno...

- (P) ¿Cuántos intentos de separación tuviste antes del definitivo?

- (R) No lo recuerdo, pero por lo menos tres o cuatro

- (P) Tres o cuatro, a lo largo de estos años

- (R) Sí

- (P) ¿Qué cambios experimentó tu vida después de la separación? ¿Qué ha cambiado para mejor o para peor?

- (R) En principio para mejor, todo, me arrepiento mucho de no haber tenido huevos para hacerlo antes

- (P) ¿Sientes que has perdido el tiempo?

- (R) Sí, he perdido el tiempo, mucho...

- (P) Dices que lo tenías que haber hecho antes

- (R) Mucho antes, y realmente me dejé, me dejé y.... yo tenía mi vida centrada en mis hijas y lo otro, pues bueno... era algo que venía, un chaparrón, como que después salía un poco la luz del sol... y sí, me arrepiento mucho de no haberlo hecho antes. Desde que L. era pequeñita, que le tenía que haber dejado 
- (P) Cuando estabas embarazada, decías, que empiezas a ser consciente de que te está agrediendo realmente.

- (R) Empiezo a ser consciente y... mira, te voy a contar, cuando nació L, llevaba tal moña el tío, que casi no me puede subir al hospital, llegué al hospital y me salió la niña, estaba totalmente aquí (señala la parte baja de su vientre), en el coche iba aquí la cabeza y nació la cría y se marchó a dormirla a casa, me dejó sola (se ríe nerviosa)

- (P) A veces es mejor estar sola que mal acompañada, tú por eso no tengas pena (introducimos el sentido del humor)

- (R) ¡Ah sí, me quedé súper a gusto durmiendo! Son de esos días que no se olvidan, se quedan marcados, pues sí, desde eso, dices, vas borrando, no quieres pensar en nada de nada, para mí esto, es que ya ni recuerdo muchas cosas, quiero anularlo, es algo que pasó y ahora es una nueva vida, esto quiero anularlo, el disco duro borrarlo, pero sí, todo ha sido así

- (P) Es muy significativo lo que cuentas. ¿Ahora, con qué apoyos cuentas además de tu familia? Dices que tu madre, tu hermana también, tu hermano de aquella manera...

- (R) Si también está ahí, pero bueno, son hombres

- (P) Sí son hombres, pero hay hombres y hombres... (de nuevo introducimos el sentido del humor)

- (R) Mi hermano es muy bueno, pero es diferente, el apoyo es diferente

- (P) ¿Qué apoyos tienes, a parte de tu hermana y tu madre?

- (R) El más grande, mis hijas, porque como lo han sufrido todo, lo han visto, lo han vivido, pues entienden la situación, son mayores y a ellas nadie les puede decir lo que han visto o no han visto, lo que estoy haciendo o no haciendo, lo que estoy luchando, o sea, son mayores, que nadie puede decirles..., manipularlas, manejarlas, son adultas. Es un punto que digo, bueno, por lo menos son mayores, ya está, mira, nadie puede decirles, "es que tu madre era mala, tu madre hacía..." porque ellas lo han vivido, han estado conmigo, viviendo mi vida

- (P) Las dos partes, la que tú les puedas contar y...

- (R) No, yo no he contado nada, de esto no se habla

- (P) En casa no se habla

- (R) Sí, nada. Realmente lo que es, eso, se separan por esos motivos e intentamos que esto desaparezca de nuestra vida. Cuando nos toca ir al psicólogo, pues vamos al psicólogo y es el momento en el que estás ahí un poco otra vez. Si no, no se habla ni nada porque sabemos lo que hay, ellas están estudiando, necesitan estar centradas, y yo centrarme en otras cosas que en este momento es buscar trabajo y estudiar, que quiero estudiar porque me resulta difícil porque he perdido memoria y muchísima capacidad de retención, y.... incluso habilidad social con la gente, por lo que te comento de desconfianza, de.... Que no sabes cómo va a reaccionar la gente, porque casi todo el mundo lo sabe que estás separada por malos tratos y eso

- (P) ¿En el momento actual, tienes un buen estado de salud?

- (R) Yo creo que sí

- (P) Sigues viviendo en la misma casa, (a ella le gusta mucho su casa), ¿tienes idea de cambiar de casa o no?

- (R) Mientras mis hijas estén ahí, yo voy a estar ahí con ellas, soy la que les hace la comida, les limpia, les friega, les plancha....

- (P) Eres su madre

- (R) Exactamente

- (P) ¿Él pasará un dinero por las niñas?

- (R) Si, para la manutención de las niñas

- (P) ¿Con eso os llega?

- (R) No, pero bueno, hasta que encuentre trabajo ¿qué hago? 
- (P) Y en ello estás, así que es cuestión de tiempo. En cuanto a las relaciones sociales ¿qué pasó con las amistades de antes, has hecho amistades nuevas...?

- (R) Tengo a una amiga nueva por los cursos, pero no es íntima, puedes hablar, compartir cosas, pero no son amistades.... De antes tengo mis amigas, pero casadas, con su familia y que entienden la situación y me apoyan realmente, luego hay otras personas, que no es que no me apoyen, es que han desaparecido porque sí, por intereses, o porque piensan que hay que apoyar al maltratador

- (P) ¿Estás abierta a la posibilidad de una nueva pareja?

- (R) Si

- (P) Si surge un tío estupendo por ahí, le echamos el lazo (nos reímos las dos, pero ella inmediatamente se pone seria y dice lo siguiente)

- (R) No, yo no le echo el lazo a nadie, pero ¿por qué no? Igual que hay malas personas, hay buenas personas. No puedes decir...

- (P) Y tus hijas, que están tan unidas a ti ¿cómo lo verían, si de repente aparece una persona en tu vida?

- (R) No lo sé

- (P) Tiempo al tiempo

- (R) No entra en mis planes inmediatos, qué quieres que te diga, ojalá, ojalá que llegara el príncipe azul

- (P) Calla, calla, que se vuelven morados a los dos segundos

- (R) ¿Sí?

- (P) Si. ¿Cómo te sientes en la actualidad, contigo misma?

- (R) Me siento bien, pero bueno.... Necesito mucha más fuerza, pero me encuentro bien

- (P) ¿Qué planes tienes para el futuro? ¿Cómo te imaginas de aquí a un tiempo?

- (R) No me imagino nada, es que tengo muy poca imaginación, no tengo imaginación para verme de ninguna manera, simplemente ahora estoy tranquila, estoy bien, cierro la puerta cuando entramos en casa y es una tranquilidad inmensa y estoy bien y nada más

- (P) No te planteas nada más

- (R) Nada más, me voy a hacer mi pilates que me relaja y me des estresa y... es lo que me ayuda ahora, ir a pilates, al gimnasio, me gusta y no pienso en el futuro porque no puedo pensar en el futuro. No sé si mañana me va a caer una maceta en la cabeza, intento vivir el momento.

- (P) Bueno puedes pensar también que te va a tocar la lotería, no sólo que te va a caer una maceta en la cabeza

- (R) Si comprara el décimo a lo mejor, pero en principio no me va a tocar

- (P) Sí que decías que te apetece trabajar... y si que tienes ilusiones por formarte y abrirte camino en el mundo laboral.

- (R) Sí, quiero formarme. No tengo claro el futuro, el inmediato sí, formarme y hacer cursos y voy a intentar sacarme algo de estudios, aunque sea lo básico, pero este es el futuro inmediato, no a largo plazo, no sé lo que va a pasar de aquí a una semana.

- (P) Por mi parte E, sólo me resta darte las gracias porque esto se acaba, si tú no me cuentas nada más, agradecerte, de una forma inmensa, que hayas estado aquí, que se que te ha costado mucho, pero que mucho, esfuerzo, te lo he visto en la cara durante toda la entrevista, por eso te lo agradezco de forma especial, E. Sólo me queda despedirte y darte las gracias.

- (R) Gracias Belén.

- (P) Gracias a ti. 


\section{ENTREVISTA no $3-R P \quad(15 / 03 / 2011)$}

- (P) ¿Cuántos años tienes, R.P?

- (R) Ahora mismo 42 y voy a cumplir 43, el 8 de abril

- (P) ¿Vienes de P?, tu país es $P$.

- (R) $\mathrm{Si}, \mathrm{P}$.

- (P) ¿Tu nacionalidad cuál es?

- (R) P.

- (P) ¿No tienes nacionalidad española?

- (R) No, no la tengo, sólo $\mathrm{p}$.

- (P) ¿Y eso?

- (R) Por orgullo (se ríe abiertamente), orgullo tonto, ¿sabes?, cuando vine y me encontré con alguna cosa que no me esperaba dije "yo lo mío no lo quito por nada del mundo" y no es que vaya a quitar la nacionalidad p., pero claro en L. B., como que son más cerrados, así mucha gente (escucha comentarios) "ah claro, como en tu país no tenéis que comer, como en tu país no sé qué..." dije oye no y claro "vienes aquí porque acá vas a conseguir trabajo, te has casado por el interés, tu marido te ha sacado de pobre" (hace alusión a los estereotipos que ha escuchado en la calle acerca de las mujeres latinas). Entonces eso te da rabia y yo dije "para qué quiero la nacionalidad de una gente que no saben cómo soy y ya me están juzgando, no saben ni porqué me he casado ni como" ¿sabes?, era un poco orgullo, ahora si me lo pones ahora y dices, mira ha pasado tanto tiempo ¿por qué no pides la doble nacionalidad?, bueno me lo pensaría, ya no lo veo tan así, porque no es que ya no me digan esas cosas, pero ya me he hecho un poco al dolor, ya de tanto tiempo de estar aquí.

- (P) ¿Cuánto tiempo llevas en España?

- (R) Ya, 11 años

- (P) Y 11 años casada porque ¿ya viniste casada de tu país?

- (R) Si, sí, sí, me casé en P.

- (P) Te casaste en P. Tienes dos hijos, un hijo y una hija

- (R) Sí, una niña y un niño

- (P) ¿De qué edades?

- (R) B. tiene 8 y G. tiene 5

- (P) ¿Viven contigo?

- (R) Sí, vivimos todos juntos

- (P) De hecho vivís los 4, (su marido también), ¿alguien más en la casa?

- (R) No

- (P) ¿Son hijos de tu marido los dos?

- (R) Exactamente

- (P) ¿Vives aquí en L?

- (R) Si

- (P) Aunque vayáis a L. B. de vez en cuando

- (R) En verano vamos los fines de semana, pero vamos el sábado en la mañana y regresamos en la noche

- (P) ¿No os quedáis a dormir?

- (R) No yo nunca me quedo ahí

- (P) ¿Ni siquiera los niños?

- (R) No, nadie. Si no me quedo yo, los niños menos. A los niños no los dejo por nada del mundo. (Se ríe)

- (P) Toda tu familia está en $\mathrm{P}$.

- (R) Toda 
- (P) ¿No tienes aquí ningún apoyo familiar?

- (R) Nada, nada, nadie de mi familia está aquí.

- (P) Me comentabas que tu marido está en el paro

- (R) Sí, está en el paro

- (P) ¿Y tú qué haces?

- (R) Yo de momento, estoy trabajando en una casa, haciendo limpieza, lunes y jueves, dos días a la semana, dos horas cada día

- (P) ¿Qué estudios tienes?

- (R) Aquí le llaman administrativo, en mi país le llamamos secretariado

- (P) De hecho en tu país si que trabajabas como ...

- (R) En mi país yo era secretaria en una oficina, empecé trabajando, pues mira en lugar de ir poco a poco, empecé trabajando en una oficina de... papelera, hacían papel higiénico, que hay aquí, pues allá era una de las empresas más grandes, se llamaba sociedad paramon, ahora ya tiene otro nombre, empecé por ahí, de secretaria de gerencia, dicen que se empieza siempre por abajo, pero mira, yo empecé por ahí, suerte

- (P) ¿Cómo estás de salud?

- (R) No, oye, yo que sé, yo creo que de salud bien, una gripe de vez en cuando, pero bueno

- (P) Eso como todo el mundo. Me decías que llevas 11 años casada y ¿te has planteado la separación alguna vez?

- (R) Sí, ha habido momentos que sí, y muchos, muchos momentos. Tú mira, cuando nació mi hija, al medio año o así, quizás un año, sí. Pasaron muchas, muchas cosas que me hicieron decir, mira "mejor me quedo aquí" Porque a ver, yo tengo 11 años casada, pero cuando nació la niña marchamos a los dos meses a P., cuando la niña tenía dos meses marchamos a P. y yo ya no quería regresar. Ese año me lo pasé yo allí y mi marido también, nos fuimos los dos con la niña. $Y$ en ese tiempo, en ese lapso, al verlo a él que... o sea yo veía una persona inestable, de que "me quedo, me voy, me quedo, me voy..." y yo no soy así "o te quedas o te vas, pero decídete, porque no podemos estar en que me quedo o me voy"

- (P) Y eso estando en P.

- (R) Estando en P., entonces, fue ahí cuando me plantee por primera vez que me quería divorciar, esto no, para mí no es, así no se puede vivir. Estamos formando una familia y yo no me veo en un ambiente que me haga crecer como persona, prefiero quedarme en mi país, pero bueno, la niña estaba muy pequeña y yo no sé porqué los niños le agarran tanto cariño, creo que es porque es muy juguetón con los niños ¿sabes?, le gustan los niños, entonces los niños le agarran mucho cariño y siendo su hija, mayor aún, entonces, la niña tan pegada a él, lo que no es ahora tanto, lo era cuando estaba más pequeña ¿sabes? Y entonces este, él optó por venirse, pero la niña comenzó con sus líos de que gritaba y lloraba y tal y tuve que venirme, porque la niña no se iba a venir con él, eso de ninguna manera

- (P) Eso lo tenías claro

- (R) Eso sí, yo a mis hijos no les dejo por nada del mundo, si me tengo que sacrificar yo, me sacrifico, pero a mis hijos no, de momento ahora están muy pequeños y mientras yo les pueda educar y estar con ellos, estaré con ellos, aunque yo me sacrifique, pero... Y bueno, eso fueron las primeras veces, pero luego en el trascurso del tiempo que he estado acá hubo muchas, muchas veces. $Y$ creo que una de las cosas es la madre, la familia de él que se mete mucho, más que todo, la madre. Yo pienso que tú te casas y haces ya la vida entre tú y tu marido o viceversa ¿no? , pero en este caso no, somos tres, aparte de los niños

- (P) En la pareja sois tres

- (R) Él, su madre y yo

- (P) Sois un trío

- (R) Sí, pero yo estoy al final

- (P) Las prioridades son de esa manera 
- (R) Exactamente, él y su madre. Si pasa algo, él y su madre, si hay una decisión, él y su madre. Yo estoy siempre en un tercer plano, y esto es así, porque a veces si me entero de las cosas, es sin querer, porque alguien me lo dice, y entonces yo me quedo... "ah sí..." en blanco y bueno oye... Siempre es igual, eso no va a cambiar, eso seguirá siendo así

- (P) ¿Tú sientes que tu marido abusa de ti en cierta manera? Me decías que físicamente no, que nunca ha llegado a golpearte, pero...

- (R) Exactamente, físicamente no, yo creo que él, a ver... es que no quiero justificarlo, porque justificación no tiene ninguna, pero a ver, yo pienso que si tú sabes que hay una persona que la has encontrado tú libre en su país o donde ella haya estado y ves que ha trabajado, que se ha estado desenvolviendo, bien, la traes para aquí y la metes en un lugar donde ves que no hay nada y le dices, "mira, lo tienes todo". ¿Cómo le puedes decir a una persona que lo tiene todo, si no tiene nada? ¿sabes? Y si te da dinero, te da lo mínimo y con eso tú tienes que hacer maravillas. Entonces yo creo que por ahí, no más, ya te está cortando las alas. No te informa de nada, no te dice "mira, esto es así, esto es así, esto es así..." Yo venía de un país diferente a éste, diferente, aunque siempre explico, dicen que mi país es un país tercermundista, y de tercermundista no tiene nada ¿sabes? Porque la gente allá es muy instruida, la gente allá, serán de repente, yo no quiero decir que no haya gente que no sea pobre, porque es que la hay, pero son sectores, ¿sabes?, yo vivo en una ciudad grande, en una ciudad donde la gente, la mayoría, por no decir todos, tienen educación e instrucción, yo no sé, la gente esta que es muy pobre, muy pobre, es la gente de la sierra de P., yo vivo en la costa, él me veía que venía de un estrato social diferente a donde él me estaba metiendo a mí, y no me informaba de nada. Yo en la luna, yo decía "pero ¿a quién le digo, oye?", a dónde yo iba, siempre me miraban con una cara como diciéndome "¿para qué quieres saber? o ¿a ti que te importa?" Si él era mi marido, quién mejor que él para darme una información, entonces le decía "¿dónde queda...?" es que me sentía tan enclaustrada en L. B. que le decía "¿Dime donde queda la estación de autobuses?"... "Ah mira, queda... te vas por acá... das la vuelta... Y ya está" Como si yo fuera una ignorante, cómo le dices a una persona una cosa así. Podía llevarme, mira "vas por esta calle, cruzas aquí, das la vuelta y ya está..."

- (P) Indicarte

- (R) Exactamente

- (P) Pero no, de forma vaga...

- (R) Exactamente... "y si yo me quiero ir a Madrid ¿cómo me voy?" "Pues vas a la estación de autobuses" “¿Pero dónde está la estación de autobuses?" No, de siempre, trataba de cortarme cualquier información, cualquier cosa. Mira, me fueron minimizando, él y su madre, de tal manera, que llegó un momento en que yo me sentía tan pequeñita, que yo decía "aquí el mundo me come" Yo tenía hasta miedo de salir de la casa. Yo venir de vivir en una casa grande, te estoy hablando, no de un piso, sino de una casa, a meterme, eso no era ni un piso, era cualquier cosa, entrabas y era un pasillo, una habitación, otra habitación y la cocina y ya está. Es que yo me sentía fatal, yo decía "muero, aquí muero, de verdad, muero, muero, pero muero" y ahí tenía que estar, porque no podía salir, porque no sabía dónde estaba, hasta que poco a poco, yo iba saliendo, cuándo él iba a trabajar, yo salía. No porque me dijera que no salga "puedes salir", pero claro, a pesar de que L. B. era pequeña, yo me sentía fatal, me sentía perdida ¿sabes?, entonces yo salía, iba más o menos mirando cosas y así por mi cuenta, hasta que ya iba saliendo un poco más, pero al principio fue fatal, fue fatal, te iban como absorbiendo, como queriéndome... Yo tengo el carácter muy fuerte..., porque tanto él como mi suegra fueron a P., para casarnos ¿no? Y ellos vieron como yo era realmente y a mí me daba la sensación de que no querían que yo fuese así aquí, como queriéndome, pues eso, minimizar, aplacar y querer ser ellos los que mandaran sobre mi persona. Es una sensación muy horrible

- (P) ¿Este hombre no tiene padre? 
- (R) Padre no, sólo la madre

- (P) ¿Es hijo único?

- (R) Hijo único

- (P) ¿Entonces se puede decir que tú te has sentido maltratada psicológicamente?

- (R) Psicológicamente sí, yo creo que sí

- (P) ¿Y has tenido alguna secuela o algún daño por ello? ¿Has tenido que medicarte?

- (R) Medicarme, medicarme, no sé si habrá sido por eso, pero mira, hace dos o tres años, es que es una cosa tras otra, año, tras año, y tú dices bueno... levantarte y no tener ganas de nada, de saber que tienes que llevar la niña al colegio y no tienes ganas ni de levantarte, ni de nada, ni de comer, ni de ducharte. Dices "Bueno qué me pasa, algo no está bien". Llamas por teléfono a una amiga y decirle, "oye ¿me puedes llevar la niña al colegio por mí y la puedes traer? Eso pasó hace tres o cuatro año, o por ahí, y yo no sabía lo que me pasaba, decía "bueno estoy mal, algo tengo, yo que sé" y... pues esta chica, a la que le pedía el favor que me trajera a la niña me dijo "tú estás mal, porqué no vas al médico" $Y$ fue ella la que me sacó y me llevó al médico y dijo que estaba con un estrés impresionante y una depresión que tenía que salir ya, me recetaron ansiolíticos y no sé qué cosas más, estaba mal, mal, mal, muy mal, de esto de llorar y no saber porqué llorabas, yo estaba bien y de pronto unas lloraderas sin más. Yo creo que es arrastrar, aguantar tanto, tanto, tanto y ya no sabes y supongo que el cuerpo tiene que reaccionar de alguna manera

- (P) ¿Esto antes de conocerle a él, nunca te había pasado?

- (R) Nunca me había pasado

- (P) Y él ¿había estado a tratamiento psicológico antes de conocerte a ti?

- (R) Que yo sepa, no. Yo qué sé

- (P) ¿Cuándo es la primera vez, R.P., que tú eres consciente de que este hombre te está maltratando psicológicamente, que está ejerciendo sobre ti un control que no es normal?

- (R) Yo creo que siempre lo he sabido, yo creo que siempre lo he sabido, pero yo siempre he tratado, como te decía, tratar de... a ver, no echarme la culpa, no, sino de querer llevar las cosas en paz, de que funcionara, porque yo soy de la idea de que te casas para siempre, y tratar de sobrellevar la relación, pero ahora yo pienso que no se puede llevar una relación tu sola, si la otra persona no quiere. ¿sabes?, pero yo creo que siempre lo he sabido. Yo siempre me he dado cuenta, porque ya te digo, yo cada dos años voy a mi país, entonces yo esto lo he hablado con mis hermanos, yo tengo amigos psicólogos allá también y también me comentaban, me decían "eso se llama abusar de una persona psicológicamente, no te pega, pero a veces es peor lo psicológico que agarrarte y darte un bofetón, así es que reacciona" Me decían "reacciona" $\mathrm{Si}$, yo me doy cuenta, pero yo lo que quiero saber es qué puedo hacer, dame una solución, no me digas reacciona, porque yo me doy cuenta de lo que pasa, pero claro...

- (P) Dices que tú lo sabes desde hace tiempo, que él es así o tiene ese carácter, o lo que sea, pero ¿cuándo es cuando eres plenamente consciente, es decir, el primer incidente que a ti te hace saltar la alarma?

- (R) Pues mira, cuando salí embarazada de la niña, esto de que, por ahí empieza, salgo embarazada y con toda la felicidad le digo "iestoy embarazada!" "Ah, que bien" Es raro que te digan "ah que bien", como si fuese de todos los días

- (P) Una cosa fría

- (R) Sí, ya van pasando los meses, van pasando los meses, total que nace la niña, va mi suegra, la mira y dice "Ah esta niña no se parece a ti", se lo dice a él. Y él se queda así mirando y dice "pues le hacemos la prueba del ADN". Ahí te juro, que yo me sentí fatal, quizá no tiene nada que ver con lo que estamos hablando, pero yo me sentí muy mal porque dije, "vamos a ver ¿Cómo es eso de que vamos a hacer la prueba del ADN? ¿Qué está pasando aquí?, tú a mí me respetas, a ti no te importa 
lo que estás diciendo, pero para mí eso es una falta de respeto" Hacer una prueba de ADN significa que yo no le he sido fiel

- (P) Que tienes dudas

- (R) Exactamente ¿no?, porque, claro a ver, yo había viajado a mi país y yo vine predispuesta de quedarme embarazada, si antes yo no lo había hecho es porque yo misma me cuidaba y decía "no, no, no", pero cuando fui, mi familia me decían, atribuían mis quejas a "cómo estás sola, de repente necesitas una niña, ya es tiempo, como ya te has casado tienes que tener un niño y tal" Entonces yo vine predispuesta a quedarme embarazada y mira pues, "no me cuido y voy a tener un hijo" y fue así. Ni bien venir y quedarme embarazada. Y claro, entonces la madre dijo "mira, esta ya vino embarazada de allá" ¿sabes? Al principio la niña tenía muchos rasgos a mi familia, muy morenina, muy todo, a medida que fue pasando el tiempo, la niña fue cambiando y se parecía tanto a él y a mi suegra, que yo decía "mira no necesita....", pero bueno en ese momento yo le dije "mira yo no tengo que hacerle la prueba del ADN, hazle la prueba del ADN, pero yo agarro a mi hija y me voy de aquí, no me interesa donde, al monte más alto que hay, pero me voy" Porque yo sé que iba a salir positivo, que es hija de él, pero a mí no me va a venir a faltar al respeto. No le hicieron la prueba del ADN, ni nada, pero yo allí ya empecé a darme cuenta que él hacía todo lo que decía su madre, de que iba por encima de mí, era una cosa, muy... por ahí así y luego después sacaban a la niña sin mi autorización, siempre hacían lo que les daba la gana, yo no contaba para nada y esas cosas te hacen sentir que no está bien lo que están haciendo, porque si yo soy la madre tendrán que consultarme a mí ¿no?

- (P) ¿Y tú cómo reaccionabas ante esas cosas?

- (R) Al principio lloraba, al principio lloraba, yo nunca reclamaba, yo lloraba mucho porque yo no quería hacer, o sea, lo que a mí no me gusta es el pleito, el lío, el estar reclamando, no me gusta. Entonces lloraba de impotencia porque yo tengo un genio muy fuerte, pero me lo tragaba, eso me daba impotencia, me daba rabia, porque decía "porqué", tenía miedo que al reaccionar de esa manera, si reclamaba me pudieran quitar la niña, o me puede hacer algo a mí, entonces tenía miedo. Era eso, miedo, a que me pueden hacer algo, no sé, algo así.

- (P) ¿Y él como reaccionaba cuando te veía llorar?

- (R) "Siempre lo mismo", me decía, "siempre lo mismo, siempre lo mismo". La niña nació el 28 de Octubre y el primero de Noviembre, yo me acuerdo, día de los Santos, él se llama S., entonces todos estaban con sus mujeres porque era día festivo, no había que trabajar, pues él no, él agarró y se fue, como tiene al padre muerto, pues se fue a los difuntos con su madre, se fue, me dejó a mí, todos llegaron, porque era una habitación compartida en el hospital y la chica de al lado, estaba su marido, su suegra, todo el mundo, yo era la única que estaba sola con el niño y todos venían y me miraban como bicho raro. A las 7 de la noche llegó él con toda su familia. Cuando yo fui a dar a luz me hicieron el parto por cesárea, yo fui solita, me trajo al hospital, me dejó interna y se fue, se marchó. La niña no nació como se pensaba, nació a las 12 del día, yo estaba sola, quien firmó la autorización fui yo y a mí todo el mundo me decía "¿pero dónde está tu marido, tu familia?", yo solita. Entonces todo eso, o sea, ha ido de apoquito, tú dices ¿pero esto cómo es?, o sea, yo vengo acá, voy a tener un hijo, mi marido no está, son cosas que...

- (P) ¿Esto lo contabas en tu casa?

- (R) A mi hermana

- (P) ¿Hablabas por teléfono con ella?

- (R) Con mi hermana, a mi madre nunca, porque entonces le da un algo. Mi madre venía y no sé que hacía aquí. Yo nunca a mis padres se lo he contado, pero a mi hermana sí, mi hermana sabe, y por eso mi hermana dice, "mira yo veo que los niños tienen una calidad de vida como debe de ser, que tu vida no es como se supone que debería de ser..." y claro a ella le gustaría que yo estuviese allá ¿sabes?, porque claro ve que....

- $(\mathrm{P})$ ¿Vienen a visitarte? 
- (R) No, no, nunca

- (P) ¿A tu madre sigues sin contarle nada?

- (R) No, no, ella no sabe nada, son muy mayores, yo de verdad que a mi madre no me atrevo a decírselo, mi madre es muy, a ver, cómo te puedo decir, es una persona demasiado querendona con sus hijos y como que le toquen algo a uno, yo se que va a saltar, va a saltar porque va a reclamar y se va a poner mala ella, y yo prefiero evitarlo, prefiero evitarlo ¿sabes?

- (P) Entonces tu confidente es tu hermana

- (R) Es mi hermana, ella sí, ella qué te digo, es la que sabe todo desde un principio

- (P) ¿Qué tipo de cosas le molestan a tu marido de ti?

- (R) Eso también yo quisiera saber

- (P) Ni idea

- (R) Tú mira, tengo una amiga que es de P. también y tiene a su madre acá, y yo tengo una amistad muy grande con ellas desde hace mucho tiempo, entonces ella, pues se casó también con un español, pero la vida de ella es muy diferente a la mía, porque este chico es un muchacho muy, muy bueno y yo lo tengo en un concepto que no tiene nada que ver con mi marido y muchas veces yo les invito a casa a comer y ella va con su madre y una vez me dijo "pero bueno, tú que le has hecho a S., ¿por qué se pone así contigo?” Porque él con las demás personas es muy amable. Y un día le dijo "oye $S$. por qué tratas así a P., porque bueno a mí me dicen P., tengo tres nombres, R., M., y P., pero bueno Gloria (Oficina Municipal de Atención a las Mujeres) me dijo tú primer nombre por favor, pero los demás me dicen P. y dice "¿pero por qué la tratas así?" y él dijo "yo la trato como siempre". O sea, él con las demás personas es normal, está bien, llega alguien de visita y perfecto y si él va a P., es otra persona, cambia totalmente, lo ves en P. y todo el mundo dice, "Ah que bueno, mira te ha tocado la lotería, este chico tan bueno, por favor..." Viene para acá...

- (P) Así fue como tú le conociste

- (R) Exactamente yo lo conocí así, cuando vino para acá ¡Ay dios mío!

- (P) ¿Quién es este?

- (R) Exactamente ¿sabes?, entonces te quedas que dices ¿y ahora? A mí me cambiaron el marido, creo que en el avión, todo fue de venir de allá para aquí y aquí es otra persona, si vamos para allá cambia totalmente, es otra persona

- (P) Es curioso

- (R) Sí, sí. Tiene dos personalidades, yo le digo, "mira, vas a P. y eres de una manera, vienes para acá y eres de otra" Yo no sé si el frio le malogra el carácter, no sé si es el frio, yo no sé allá el clima es más caluroso, yo no sé

- (P) Bueno, eso me lo estás diciendo en broma ¿verdad?

- (R) (Se ríe) Sí, es una manera de divagar, porque es que de verdad, yo quiero encontrarle, quiero encontrarle una justificación a la manera de ser, porque él tiene momentos muy agradables. Yo con él nunca puedo tener una conversación como la estoy teniendo yo ahora contigo, si yo quiero conversar llamo por teléfono a una amiga y converso, yo con él no puedo conversar. Es esto que estoy conversando con él "ah sí que bien, ya..." se acabó, entonces yo no puedo tener una conversación de adulta, no puedo, no puedo, no se puede, es como un niño grande, por eso yo siempre digo que tengo tres niños en casa porque con él yo no puedo. Yo no puedo decirte que alguna vez me ha dejado sin comer, porque en ese sentido es muy responsable, él me llena la casa de comida, tal, tal, tal, y mira, por lo menos de los niños se preocupa de que tengan que estudiar, que tienen que ser... me ayuda con los niños cuando yo no estoy, si necesito esto... en ese sentido si, pero en otras cosas... El problema es conmigo, con ellos no, yo no sé que le habré hecho, yo también quisiera saber qué parte de mí es lo que no le agrada. Mira, yo a veces le digo, " yo no fui la apurada en casarnos", yo no vine aquí a decirle oye vamos a casarnos, fue él el apurado, yo recuerdo mucho que le dije "piénsalo bien, estamos para casarnos y estamos a tiempo, piénsalo bien, yo estoy muy segura de lo que vamos a hacer, pero yo a ti no te veo" Porque claro, cuando él estuvo solo 
bien, cuando conocí a su madre, cuando él ya fue para casarnos yo ya vi la cosa muy mal y entonces dije "mira piensa bien lo que vas a hacer porque a mí me da la sensación de que tú no estás seguro, que más bien te casas porque tu madre te está induciendo a que te cases" "Ah no, no, no, yo sí me quiero casar y nos casamos y nos casamos" "¿estás seguro?, mira que yo no tengo problemas" En ese sentido fui muy clara, y claro, es duro decirlo, pero yo muchas veces cuando estoy fatal con él yo le digo, "mira aquí el apurado por casarte fuiste tú", se lo echo en cara.

- (P) No entiendo una cosa, si su madre era, la que de alguna manera le empujaba a casarse ¿por qué ahora a ti no te acepta?

- (R) Porque yo pienso que ella vio que estando él aquí nunca se iba a casar ¿sabes?

- (P) ¿Eras su salida?

- (R) Yo era su salvación. Y ¿sabes qué pasa?, que ella pensó que yo viniendo para acá, ella me iba a dominar, ella iba a ser la señora siempre de la casa, y entonces ella iba a decir, esto es así, esto es allá, esto es acá y tú haces lo que yo digo y tal. Empezando que yo no fui a vivir a su casa, por ahí empezamos ¿no?, entonces el hijo salió de la casa, ya no vivía con ella

- (P) ¿En ese piso que describían antes?

- (R) No, no, no, ella vive en el pueblo, ella tiene su casa. Entonces ella pensó que yo iba a estar con ella ahí, pero yo dije que no. Si ella ya, cuando estuvo en P. me hizo papelones, con mi familia, yo dije "me voy a vivir allá con ella y muero, no, no, no" A mí no me importaba venir a vivir, al principio, tampoco en un sitio como ese, pero vamos en una casa decente, pero bueno, y entonces ya claro... ella quería que estuviésemos todos los días ahí con ella, que fuésemos a dormir, a comer y tal. Pues yo no, yo dije "yo me casé contigo, yo cocino, yo hago lo que haga falta" Es que yo allá en P. tampoco cocinaba, yo tenía una empleada que me hacía las cosas. Por eso te digo, son tantas cosas... De venir de tener comodidades a no tener ninguna, y encima hacerlas tú y encima que te miren de mala manera, que te critiquen, que te digan que eres una interesada, que eres una interesada no sé de qué, es que yo aquí no vine a quitarle nada a nadie, pero es que a nadie

- $(P)$ ¿En qué consisten vuestras discusiones? ¿Cuándo se altera, por qué es?

- (R) No, no. Gritarme no me grita, o sea, no es de gritar así, no, no. Soy yo la que más bien levanta la voz a veces y él se queda callado, su manera de defenderse es quedándose callado. Es como que yo hablo, como que estuviera loca, o sea, yo tengo la culpa, como que me quiere hacer sentir culpable. O sea, él dice una cosa, a mí no me parece porque yo sé que no está en su razón, que no es así y luego yo empiezo a decirle bonito y si no me entiende yo comienzo a gritar. Al final quien tiene la culpa soy yo porque grito, porque digo, porque tal... "Pero si aquí la que habla, la que armas el lío eres tú, yo no digo nada" "No claro no dices nada, sueltas la primera y después el resto que lo diga yo todo y..." ¿Y sabes otra cosa más?, yo me he dado cuenta y digo "mira si tú no estás conforme conmigo, no estás a gusto, porque cuando dos personas no están a gusto, no sé para qué están juntas, ¿no te parece mejor que nos divorciemos?"Entonces yo pienso que él quiere que yo le pida el divorcio, que yo sea y yo le digo "¿por qué no eres tú? !qué cómodo!, decir ella me abandonó, ella se largó y se llevó a los niños, pero yo no soy tonta y digo "aquí el que va a dar el paso eres tú" Siempre tengo que ser yo, yo soy la mala, ahí en la casa yo soy la mala, no lo dice, pero a veces me hace sentir que yo soy la mala.

- (P) En algún momento, después de que pasan estas cosas, ¿él muestra arrepentimiento, se siente arrepentido, te pide perdón?

- (R) No, no, no. Nunca dice nada, nunca, nunca. Mira, a mí me encanta la cocina, yo soy fanática, me pones en una cocina y me encanta cocinar, me relaja mucho además, cuando estoy muy tensa, muy nerviosa, me pongo a hacer comidas, que podía poner un restaurante, que me pongo como una máquina y entonces él.... Gracias a dios cocino bien. Mi amiga dice, porque muchas veces yo la llamo, ya veo tanta cosa que le digo "¿puedes venir un ratín, es que tengo comida para que lleves para una semana?, ella dice "¿otra vez?" Ya sabe que cuando yo cocino mucho es 
que estoy mal, entonces viene y dice "¿qué ha pasado?" y digo "nada, déjame a mí, son mis cosas" Ella dice "icocinas tan bien!", pero él eso no lo reconoce, porque muchas veces me he encontrado con ella y dice "estoy degustando lo que $P$. ha preparado" y él dice " $¿$ ah sí?" "Tienes una mujer que cocina muy bien y tal" "Bueno se deja comer y tal" (lo dice con mucho desdén)

- (P) ¿Nunca un halago?

- (R) Nunca, nunca, o sea, nunca te dice... o te pide disculpas.... No, no, no, nunca, nunca. O sea, como diciendo, es tu obligación. Es que no reconoce absolutamente nada

- (P) Ni sus propios errores, cuando tú le dices esas cosas sobre su madre, o lo que sea, él no acepta...

- (R) Como le diga algo sobre su madre, se me viene encima. Ahí sí que ya arde Troya, sí, sí, sí. Mira, tenía el niño de nacido una semana, creo y según ella vino a cuidarme, a cuidarme, mira, yo estaba con cesárea, salí del hospital y vine a cocinar para mí, para mi niña y él cocinaba para él y su madre y luego cuando él marchó a trabajar, pues yo tenía que cocinarle a la señora y a la semana marchó diciendo que me había venido a ayudar a cocinar, ¿en qué momento? yo quisiera saber, porque no sabe cocinar, porque no está acostumbrada, ha criado a su hijo a jamón y chorizo, que no está mal, pero cocinar no sabe y la que cocina en casa soy yo, y él no puede decir que no, que yo no sé cocinar, que no sé hacer mis cosas porque como le digo yo a él "yo he tenido todas mis comodidades allá, pero soy gracias a dios y gracias a mi abuela, una mujer completa, sé hacer muchas cosas en casa, que de repente, pues soy otra, trabajando todo el día, no, pero a mí desde pequeña me han enseñado a hacer cosas y a mí me gustaba aprender y que' quieres, o sea no....Pero no lo reconoce, no reconoce nada

- (P) Entonces cuando tú te enfadas, porque ves injusticias por su parte hacia ti ¿qué pasa después? ¿hay un periodo de calma?

- (R) A ver, si, no, hay tiempos de calma. Mira, a ver, cómo te explico. Estamos aquí, yo ya te digo que al pueblo yo no voy y en invierno menos, yo en verano voy casi todos los sábados, porque es más amplio, los niños juegan y tal, pero sólo los sábados en la mañana y en la tarde estamos en casa. Pero como vayamos al pueblo ya hay lío y si va él sólo también hay lío, es él marchar para su madre y cuando viene, por cualquier tontería, es que yo no sé lo que ella le dirá, pero sea, si yo hago un puntito así (señala una pizca de su dedo), se hace una avalancha que yo me quedo, de verdad, exhausta después de tanta discusión

- (P) Entonces, él sí discute ahí

- (R) A ver, la última vez que fue, fue al pueblo y entonces vino, ahorita mismo ni me acuerdo ni porqué fue, yo le dije algo y..."que si que mi madre, que si no se cuantos, que deberías estar agradecida a mi madre..." y yo le dije "pero vamos a ver.... Yo me he casado contigo no con tu madre, ¿por qué tengo que agradecerle cosas a tu madre?", es verdad, ahora él está en el paro y si nos ayuda, pero yo no tengo porqué rendirle pleitesía a la señora, yo le agradezco mucho, porque muchas veces se lo he dicho a ella también "yo te agradezco, a mí no me gusta esto, pero te tengo que agradecer", reconozco que sí que nos ayuda, pero de ahí a que yo le tenga que rendir pleitesía o estar a... como me dijo una vez ella, que yo tenía que besarle el trasero, imagínate tú, pero mira, yo hasta ese punto, yo no llego "si alguien tiene que hacer eso que lo haga tu hijo, yo ¿por qué?". Porque yo me casé con él, entonces cosas pequeñinas, se hacen enormes y... era lo que te decía, cuando el niño nació, ella vino y tal, y fue la fiesta del colegio de la niña, y entonces la niña quería que yo vaya, "mamá que tienes que ir", estaba que no podía ni caminar, pero bueno... a mí siempre me ha gustado, no pintarrajearme, pero sí arreglarme un poquito y estaba arreglándome y la oigo decir "¿y esta zorra donde se va a ir arreglándose así?". Estaba yo recién parida y la otra... "y esta zorra..." Yo me hice la que no le escuché ¿sabes? Pero son cosas que te clavan, que te duelen

- (P) Pero eso ¿qué se lo dijo a su hijo?

- (R) No me lo dijo a mí 
- (P) ¿No estaba su hijo delante?

- (R) No, él estaba trabajando.

- (P) ¿Como si fuesen sus pensamientos, dichos en voz alta?

- (R) Si, ella estaba allí a mi lado "y esta zorra donde va..."Mientras ella estuvo ahí, yo no dije nada, yo callada, yo siempre digo, que yo por educación, muchas veces me quedo callada, pero también le dije a él, "mira un día, se me va a salir el indio, y ese día que se me salga, de verdad, que va a ser peor que lo que pasó en Japón, es que no, no... yo no puedo más, hay días que...." Y esta última vez que fue la discusión que te digo, le dije "tú siempre me dices tu madre, tu madre, tu madre... yo muchas veces te he dicho, tu madre me insulta, tu madre me dice, tu madre, tu madre, tu madre..." y muchas veces delante de él y él siempre me dice "arréglate tú con mi madre", pero yo nunca he visto un marido que llegue... "oye mamá, ¿sabes qué? Por favor, no discutas así con ella, porque es mi mujer" Yo he visto casos así, pero él no... "tú arréglate con mi madre"

- $(\mathrm{P})$ ¿Cómo te sientes cuando pasan esas cosas? ¿Qué es lo que verdaderamente sientes?

- (R) ¿Qué siento? Pues mucha rabia. Mucha, mucha rabia, y al principio me sentía desamparada ¿sabes? Se supone que él es mi pareja, que me tiene que arropar en esos momentos, no, no, no... al contrario, como diciendo "mira ahí te las arregles, tú verás lo que haces"

- (P) ¿Eso continúa siendo así? ¿Te sigues viendo así?

- (R) Ya no, ya no, ya no

- (P) Ya no, ¿por qué? ¿qué ha cambiado?

- (R) Como que dentro de mí, algo ha madurado, yo que sé, o yo me he puesto un caparazón, parece. Cuando ella a mí me dice algo, yo como que no me dice nada y al principio yo no decía nada, pero ya hace no sé cuanto que tuvimos una bronca muy grande, a mí no me gusta faltarle al respeto a las personas mayores y menos siendo la madre de mi marido, para mí eso era inconcebible, pero bueno, ella se lo buscó y comenzó a decirme un montón de cosas, era para Navidad, una noche vieja o algo así y comenzó a decirme un montón de tonterías y yo no pude más y le falté al respeto verbalmente, le dije un montón de cosas que me había guardado desde el tiempo que me había casado y que me había callado, había habido insultos hacia mí, hacia mi familia, que mi familia, tranquilamente estaban allá en su país, en su sitio y nadie tiene por qué meterse y ella había hecho no sé.... Bueno y yo le dije "mira de mí puedes decir lo que te dé la gana, pero de mi familia no, y menos de mis padres y de mis hermanos". Mis padres son unos buenos señores y mis hermanos ya ni qué decir y ni ella ni nadie se va a meter, conmigo que diga lo que quiera, yo le dije "de mí puedes decir lo que te dé la gana, yo me defiendo, pero mientras ellos no estén, tú no vas a decir eso" Y fue la primera vez que le contesté, no le dije tacos, como dicen ustedes aquí, yo digo lisuras, acá dicen tacos, yo digo lisuras, no, no le dije, le levanté la voz, para mí, levantarle la voz a una persona mayor es como que no, pero bueno, ella se lo buscó y de ahí, como que fue un... me quedé a gusto, entonces ella, como que un poquito, se frenó. Entonces ahora ya no me dice tantas cosas, pero las veces que me lo dice, yo le contesto. Yo sé que después mi marido no me va a hablar, por lo menos en un mes no me habla, porque le da la razón a su madre y no me habla, le da la razón a su madre. Y yo para no, para que los niños no... no quiero que ellos se sientan mal, prefiero evitarlas, es por los niños, no por otra cosa, y esas cosas como que me han hecho tolerar un poco más la relación, ya no me siento como al principio, no, no, no...

- (P) ¿Qué sientes hacia tu marido?

- (R) Los sentimientos han variado mucho. Yo pienso que cuando uno se casa, es porque le tienes amor, respeto, admiración a una persona y puedes... a ver... amor yo que sé, del $100 \%$ quedará un $50 \%$ creo yo, ya no estoy ni segura, el respeto, pues si él no se da a respetar como debe ser, como marido, yo qué puedo decir, no es que no le respete, yo le respeto, porque es mi hogar y tal, pero ya no es lo 
mismo que al principio, yo siento que del $100 \%$ que había en general, ahora queda un $50 \%$ y esto es

- (P) En relación a tu hija y tu hijo ¿qué piensas?, piensas, en relación a lo que comentabas antes, que tu gente, familia, amigas, te dicen que los niños así no están bien ¿tú qué piensas?

- (R) Yo también lo pienso, porque ya te digo, yo estaba acostumbrada a vivir en un ambiente tan diferente a este. $Y$ yo a mis hijos los veo como muy desvalidos como personas, aun siendo niños, como personas, porque si a mí me pasa algo es que los niños se quedan en la nada, porque yo a él le veo responsable, pero si a mí me pasa algo, él los lleva con su madre y según es él, a mí me da mucha pena decirlo, pero creo que a él no le han educado como debería de ser ¿sabes?, entonces yo qué podría esperar para mis hijos

- (P) Tu miedo es ese, que tú faltes un día, siendo ellos pequeños, estén sin formar y que de alguna manera vuelvan a reproducirse los mismos patrones que esa mujer le inculcó a tu marido.

- (R) Exactamente, eso es

- (P) ¿Quién toma las decisiones en la casa?

- (R) Hasta antes que empezara el curso (hace alusión a un curso sobre violencia de género, al que ella asiste como alumna y que imparte la entrevistadora) él. ¡No sabes que bien me ha hecho este curso a mí, y no sabes que bien me hiciste tú!

- (P) ¡Qué bien, Gracias!

- (R) Es verdad, Belén, mira, ese día me acuerdo que llovió mucho, no me voy a olvidar nunca, es que llovió a chorros. Yo salía, no había llevado paraguas y salía yo y él estaba parado esperándome. Mira, yo tenía una bronca por dentro conmigo misma, yo decía "pero que tonta he sido, pero como es posible..." Y va el otro a esperarme con su paraguas porque yo no había llevado paraguas, no me gusta usar paraguas y entonces, así de frente le dije "¿para qué has venido?" "Por qué no tienes paraguas" (él respondió) "Bueno gracias"( le dice ella con mucho desdén) “¿qué te pasa?"(él estaba incrédulo) "En casa hablamos" (ella le contesta de forma muy árida) $\mathrm{Y}$ el otro venía hablando, pero yo lo tenía todo revuelto ¿sabes? Y entonces, pero a raíz del curso, él ha cambiado bastante, porque yo he cambiado. Es que tomar este curso me ha hecho mucho bien en todos los sentidos, en todo, en todo, en todo... Yo no sé , un día voy a ir a Gloria (coordinadora del curso al que se hace alusión) y le voy a agradecer, un día fui a ir a recoger el diploma y no la encontré, porque yo le iba a dar las gracias, porque no sabe ella, el bien que me ha hecho tomar el curso, porque yo ahorita estoy siendo lo que soy realmente, lo que he sido en mi país, hasta antes del curso era una chica apagada... un ama de casa, de estas que se resignan a todo... i qué le vamos a hacer! Cuando yo tomé el curso, todo fue tomar el curso, ya los primeros día, pero el día que tú fuiste, fue ya el clímax, eso ya fue como cuando van las olas más o menos, pero luego !pun! ya la marea, ahí se acabó ya, es que llegué a casa, tan envalentonada que me dijo "¿y a ti que te pasa?" "Siéntate" Yo nunca le había hablado así

- (P) Y él se sentó

- (R) “¿Pero qué pasa? ¿Qué tienes?”(le preguntaba él sin imaginar la revolución interior de ella) y le dije "mira, sabes quiero hablar contigo" (se pone muy seria, como reviviendo el momento del enfrentamiento después de haberse empoderado) el hombre se quedó de piedra, no lo creía, no se lo creía. Y a raíz de ese día le digo que se siente y que me escuche, apago la tele y me escucha, me escucha aunque a regañadientes, pero me escucha, lo que antes no hacía y tomaba él las decisiones, ahora no, ahora las tomamos los dos

- (P) ¡Qué bueno!,

- (R) Sí, sí, sí, ya te digo

- (P) ¿Y el dinero quién lo maneja en casa?

- (R) ¡Ay el dinero, el dinero! El dinero es un lío. Pues mira, como no hay mucho lo maneja él, no, bueno, lo manejamos los dos. A ver, es que depende...

- $(\mathrm{P})$ ¿También hay un antes y un después del curso? 
- (R) Bueno... no tanto, no varía mucho ahí. Pero vamos a ver, en cuestión del dinero yo pienso que eso de que yo me ponga a trabajar, me ha dado un poco de libertad, ¿sabes? Porque claro yo dependía mucho de él, ahora aunque no sea mucho lo que yo tenga, pero él ve que soy independiente nuevamente, que ya no dependo tanto de él y eso como que le da un poco de temor

- (P) ¿Qué llevas poco tiempo trabajando fuera de casa?

- (R) Si, cuando el curso también, coincidieron las dos cosas, fue empezar el curso y el trabajo a la vez, entonces él no sabe, no sabe... yo lo que no quiero es dejar de trabajar ¿sabes? Porque como yo deje, otra vez voy a estar a la dependencia de él y no quiero

- (P) ¿Te das cuenta como él dinero opera y articula las relaciones?

- (R) Sí, sí, sí, exactamente, y lo que tú nos dijiste, es que yo digo, mira, yo siempre te recuerdo, aunque te parezca mentira, yo no sé si habrá sido una casualidad, ¿qué fue una vez, sólo un día?, pero mira lo que ha servido

- (P) Una mañana que cundió mucho

- (R) No, no cundió nada, porque yo me quedé, así... lo que decías a mí me venía muy a tono. Yo decía, "sí, sí, sí, tiene mucha razón", o sea que... a mí me sirvió un montón, yo no puedo decir que no, que ha habido muchas cosas buenas que a mí me han servido de mucho para estos días de mi vida, en que bueno, nos volvemos a encontrar y estoy desahogándome, además de verdad, yo te agradezco bastante, yo no sé , creo que dios está poniendo en mi vida a personas, y mira que se lo pedí mucho "pon en mi vida a gente que me ayude a salir un poco hacia adelante" ¿Sabes qué pasa? Que te sientes estancada y que no hay manera, que vas para acá y que no... y de pronto, mira Patricia, no sé si la conoces, es la que nos dio todo el resto del curso, es una chica muy jovencita, pero muy responsable, entonces yo hablaba mucho con ella y de vez en cuando ella me llama por teléfono "¿Qué tal, cómo estás?..." Yo creo que era lo que necesitaba, gente que tenga un cierto nivel... no quiero menospreciar a nadie, pero es la realidad, cierto nivel de cultura, por decirlo así, con la que yo pueda entablar una conversación y no una conversación así tan superflua como "bueno hoy llueve... ¿qué me pondré?" No, yo quiero hablar de cosas que sean interesantes, que me ayuden a mí a salir adelante.

- (P) Yo te quería preguntar algo, estábamos hablando del dinero y tú decías que el dinero lo manejabais de forma diferente a las decisiones importantes, que siempre las tomaba él, parece ser que tú con respecto al dinero podías...

- (R) Bueno sí, al principio, yo una parte cómoda, porque recién llegué eran las pesetas, no eran euros y decía "iay dios, y ahora qué hago!" Creo que yo tuve la culpa en ese sentido porque le decía "mira llévalo tú porque yo me confundo un poco, me lío" y luego él se acostumbró a eso, pero ahí hubo un antes y un después, porque un amigo suyo le dijo "no puedes estar así, ella siempre sin dinero en la cartera, tienes que darle algo" y bueno soltaba, no mucho, pero soltaba. Todo esto también por la madre, porque tampoco le gustaba que yo manejase el dinero ¿sabes? Y le decía que no me diese, que yo eso lo escuché, pero bueno...

- (P) Y luego ¿empezó a darte?

- (R) Bueno, él siempre compró las cosas, y es como decirte, te doy una propina

- (P) ¿Y sigue así?

- (R) No, ahora no, no, no, no

- (P) ¿Desde que tienes tu propio dinero?

- (R) Desde que yo esto... y desde que esto que te digo, yo le dije "mira aquí no puedes ser siempre tú porque de repente yo tengo una urgencia, y no tengo nada en la cartera y ¿qué hago yo, voy a la vecina a que me preste?" "Ay, pues no lo había mirado asi'"'pues míralo así, porque los niños y yo necesitamos y no puede ser, yo no soy una hija" Ni cuando era hija

- (P) Y ahora con tu propio dinero ¿qué haces, lo manejas tú, se lo das a él?

- (R) No, no, lo manejo yo, lo manejo yo

- (P) ¿Quién se ocupa de los niños, de la ropa, de la comida, de la casa, de la intendencia familiar? 
- (R) Yo siempre, desde siempre, yo, yo, yo, yo. Ahora cuando yo estuve haciendo el curso, como él está en el paro, se encargó él, hizo de amo de casa y creo que se dio cuenta del trabajo. Porque claro "¿Qué haces?, si tú no haces nada, si te pasas el día mirando la tele, yo no sé, es que de verdad no sé qué haces ¿dices que has limpiado?, yo lo veo todo igual". Mira, yo por venganza lo hice, iba "oye ¿has limpiado?, ah, no, no, yo lo veo todo igual" Es que son niños, tú ordenas y al rato ellos lo desordenan todo otra vez, yo no sé cuantas veces él ordenaba y tú llegabas y esto... "¿pero dices que has ordenado?, pues yo lo veo igual" "No es que los niños..." Ah. Y un día le dije "¿Lo ves?, entonces no digas que yo no ordeno, que yo no limpio, yo ordeno, yo limpio, en el transcurso que tú traes los niños a comer, ellos terminan y se ponen a hacer cosas, a jugar, a jalar una cosa de aquí para allá ¿entonces?" "Ah, no, si, sí, si tienes toda la razón, me lo hacen a mí" Y en la cocina, hago tres comidas diarias, hasta eso él no llegó, hacía una y ya, pero yo suelo hacer tres comidas porque la niña es muy mala comedora, entonces si una no me la come, por lo menos un poquito de la otra, porque no le gusta comer de nada a esa niña, y si la ves es un palillo y entonces yo se lo hago, porque él también es muy ..., pero a eso le he malacostumbrado yo, porque bueno a mí me gustaba atenderlo bien, al principio, vienes enamorada y mira, a este niño, no le gusta comer los huesos, ah, pues le sacas el hueso, se lo pones bonito para que lo coma, ah mira que esto... y yo claro, lo malacostumbré y yo como una comida, porque hay cosas que yo no puedo comer y tengo que hacer para mí aparte y él una comida y a la niña, pues mira de las tres a ver cual le gusta. Por eso suelo hacer tres comidas diarias, tres, tres, tres.

- (P) ¿Te ocupas tú de todo esto?

- (R) Yo me ocupo de todo, de los niños, de la comida, de la casa, de todo.

- (P) En algún momento, mientras él te dice cosas, aunque sea a través de su madre, ¿tú has sentido que no eres válida, por ejemplo haciendo esto, te has sentido o mala persona, o mala madre o mala trabajadora...?

- (R) No, no me he sentido valorada. Yo no he sentido que no haya hecho las cosas bien, porque siempre estaban bien hechas

- (P) O sea, que tú por dentro, sí que lo sabes, perfectamente, lo que pasa es que él no te lo reconoce, pero tú eres consciente...

- (R) Exactamente, yo soy consciente de que las cosas las hago bien, porque yo soy de esas que dicen, cuando hagas las cosas hazlas bien hechas o no las hagas. Entonces yo se que hago el $100 \%$ por tratar de hacerlo lo mejor que se puede, ahora que si los demás no lo valoran ya...Al menos que yo esté equivocada, pero creo que no, si otros me lo dicen... yo creo que sí, que el que anda mal es él

- (P) Tanta gente no puede estar equivocada

- (R) Digo yo (se ríe satisfecha)

- (P) ¿Qué clase de cosas le molestan de ti? Cuando se pone a echarte en cara cosas ¿qué es lo que te dice?

- (R) ¿Sabes que pienso yo qué le molesta? El hecho de que él no puede lidiar conmigo en nivel... a ver cómo te explico. A él le molesta entablar una conversación conmigo ¿sabes?, eso le molesta de mí, que yo puedo hablar con otra persona, y él ve que yo converso con otra persona y a él eso le incomoda, le incomoda mucho, porque dices "¿y por qué?"

- (P) Quieres decir, como que se sintiera inferior

- (R) Algo así, si, si, si, si, incluso cuando va allá a P. y está con mi familia ¿sabes?, se siente... él trata, trata de... ¿cómo es la palabra?.... trata de...., ah, se me fue ahora mismo, trata de integrarse en el grupo, pero yo no tengo la culpa de que las cosas sean así, él me conoció de esa manera, entonces como que se siente como pez fuera del agua, porque no puede, no llega. Eso le molesta, eso le incomoda, como diciendo, pues... Me decía, yo no sabía lo que significaba ser pijo, en mi país le dicen a eso eres una pituca y entonces una vez me dijo "eres una pija" “ ¿Y eso qué significa?" para mí eso era una... "me está insultando, ¿qué me está diciendo este hombre?, ¿Qué me dices?" "Que eres una pija"'Vamos a ver, tranquilito, 
porque faltas de respeto no"''Yo no te estoy faltando al respeto, pero es que me pones... que eres así, que eres asá..."'Pues eso no es ser pijo, en mi país o eres una creída o eres una pituca, pero yo no creo que sea así tampoco, lo que pasa es que tengo una manera de ser y siempre va a ser así, yo no me considero una pija" Te digo como le decía a él, yo cuando estaba allá, estaba trabajando, estaba soltera y todos los meses me compraba ropa y los zapatos y lo que me daba la gana, claro, ahora no me puedo comprar nada de eso, pero antes yo me daba esos lujos, que mi papá decía que eso era botar el dinero, decía "tienes una manía tú..." renegaba siempre conmigo "es que eso es un vicio" Pues mira, yo vicios no tengo ninguno, pero para mi padre era un vicio y yo le digo "tu vicio es fumar... yo no tengo vicios acá ninguno, tú me quitaste el único que tenía, yo no fumo, yo no bebo, entonces pues..." Si el hecho de querer vestirte o arreglarte bien, o el hecho de expresarte, le llamas ser una pija, pues yo qué culpa tengo, si mi familia es así que culpa tengo, somos así, para mí no es así, es una manera de vivir y ya está

- (P) ¿Por qué estás a su lado? ¿por qué sigues con él?

- (R) Ah, por qué, esa es la gran pregunta, que yo también me la hago y no tengo respuesta, no sé si es por lástima hacia él, por miedo, yo que sé, a.... al qué dirán de la gente también puede ser o al no haber sido lo suficiente madura para poder mantener un matrimonio como debe de ser, creo que son miedos, creo que son miedos

- (P) ¿Te ata a su lado la cuestión económica?

- (R) Sí, yo creo que también un poco ¿sabes?, aunque no mucho, pero un poco, si. Te digo más, esta última vez que fui, me causó mucha gracia, tuve problemas con la aerolínea y entonces se vino él antes, porque todavía estaba trabajando, estaba trabajando y tenía que volver a trabajar, porque después que vino le dieron de baja en el trabajo y entonces yo me quedé porque fue en esta aerolínea que quebró y tuve un lío para regresar, entonces claro, yo tenía que regresar aquí en Enero, me pasé Febrero y todo Marzo casi, en Marzo, a finales de Marzo regresé y entonces ¿tú crees que me mandó un euro? Y yo con dos niños allá, y un niño enfermo. Yo no digo que mis padres no tengan dinero o que sean millonarios, pero es que yo ya estoy casada y tengo un marido y tengo dos niños, yo si voy sola no hay problema, pero yo tengo por delante dos criaturas. Entonces ¿Quiénes miraron por mí?, mis padres, mis hermanos... y yo no voy a ir a ser una carga para mi familia, eso me da un poco de temor, porque yo digo, claro... son 10 años u 11 de mi vida sin trabajar en mi país, yo llego y es como si fuese nueva otra vez

- (P) ¿Tendrías que empezar de cero?

- (R) Volver a empezar y volver a estudiar, porque allá, lo mismo que aquí, si tú vas a presentarte a un trabajo "¿Qué experiencia tiene?, ¿Qué ha hecho? Y ¿qué cursos y que tal y qué tal?..." Ama de casa, "pues váyase o póngase a estudiar" Entonces, por eso yo te digo, me quedo en el 2000, si yo sigo en el 2000, es que yo tengo que hacer algo, yo no me puedo quedar así, yo no soy así...

- (P) Si tú decidieras separarte ¿tu familia te apoyaría?

- (R) ¡Ay!, yo que sé, quizás sí, quizás no, yo no lo sé, es que en mi familia nunca hubo una separación, en mi familia nunca. Yo creo que todo el mundo tiene sus altibajos, pero así tan extremos como los míos, que te dicen, mira la decisión hay que tomarla y hay que tomarla. Te casas y como en todo matrimonio siempre hay altibajos, y los trato de superar, pero no sé cómo reaccionarían

- (P) ¿Tú viste alguna vez a tus padres atravesando situaciones similares a la tuya?

- (R) No, nunca, jamás. Mira yo le comentaba un día a mi madre, y no hace mucho, le decía "alguna vez tú has discutido con mi papá por algún tema? Y me decía "todos los matrimonios tienen discusiones, pero yo he discutido con tu padre muy pocas veces y las pocas veces que lo he hecho, nunca delante de ustedes porque a mí nunca me ha gustado..." Y es lo que pasa conmigo, a mí nunca me ha gustado que los niños se preocupen por las cosas que les pasan a los adultos. O sea que sin saberlo yo... eso es lo que quiero para mis hijos. Porque yo nunca he visto a mis padres discutir, yo puedo pensar "en qué momento mi padre le haya dicho algo así 
que a mi madre no le haya gustado. Ellos se tratan de viejo y vieja, siempre, siempre, pero de cariño porque siempre así se tratan, pero yo jamás les he escuchado que él le levante la voz o que ella... no, nunca. Por eso yo digo, esto no es manera de vivir, yo nunca he vivido así

- (P) ¿Tú sabes si en la familia de él, hubo alguna historia de malos tratos entre sus padres?

- (R) Mira, a mí siempre me hablan de que su padre era muy bueno, muy buena persona, pero aquí la mala persona es su madre. Porque esto de que cuando tú llegas y tú no conoces a nadie, pero todo el mundo te conoce a ti, porque eres la nueva. Yo, ahora mismo quisiera saber, porque ya pasó mucho tiempo, no sé quién, yo salí a un supermercado que estaba ahí a nada, de donde vivía y una señora me dice "! Ah!, ¿tú eres la nuera de A?, pues yo soy una de su pueblo, ay hijita que pena que me das, porque $A$. tiene un carácter, con esa mujer no se puede, por eso se murió el marido, del disgusto, porque tu suegro era un pan de dios ese hombre" $Y$ yo muda, y ahora yo quiero acordarme de la persona, de eso que te cogen desprevenido, pero no sé quien fue, sólo me acuerdo de las palabras, pero de la señora no me acuerdo, no me acuerdo

- (P) Pero ya te puso en antecedentes

- (R) Claro, me lo dijo

- (P) ¿Tú dirías que tu marido es una persona sometida a estrés por causas laborales, porque no tiene trabajo...?

- (R) Ahora sí. Sí, ahora sí

- (P) ¿Piensas que está estresado?

- (R) Ahora mismo, sí. Yo lo veo muy tenso..., muy preocupado... claro, es que ya lleva... ya...

- (P) ¿Y a eso se debe que te trate como te trata?

- (R) No, esto... antes estaba trabajando (contesta de forma automática, como un resorte) No

- (P) ¿Él consume alcohol u otras sustancias?

- (R) No, bebe una copa de vino a las horas de la comida y de la cena

- (P) No es un gran consumidor de alcohol, ni se emborracha...

- (R) No, nunca le he visto borracho, bueno... borracho, borracho cayéndose no, pero se toma sus copas cuando ha sido a una boda, o algo, pero no así... o que me llega a casa ebrio, no, nunca.

- (P) ¿Te costó contar lo que estás viviendo con tu marido a tu familia?

- (R) A mi hermana, me costó mucho, porque claro, ella lo conoció, como yo, de una manera y luego decirle tú a una persona como es realmente y ella dice "! Ay hombre, tú estás exagerando, lo que pasa es que tú tienes un carácter tan fuerte que no hay quién te aguante!" ¿Y cómo hacerle comprender que no es como ella piensa?, porque claro ella también lo conoció así. Y claro el hecho de cómo trasmitirle, cómo decirle las cosas para que lo entendiera, sí me costó mucho. Me daba hasta vergüenza decírselo.

- (P) ¿Nunca le has denunciado?

- (R) No, no. Es que no ha habido cosas como para denunciarlo...

- (P) Alguna vez, cuando le cuentas esto a tu hermana, o a alguna otra persona de tu confianza, ¿sientes la necesidad de exagerar para que te crean?

- (R) No, yo creo que no hay necesidad de exagerar, porque lo que me ha hecho ya es bastante... para mí por lo menos... bastante doloroso, como para exagerarlo. No creo que esté bien tampoco, poner a una persona así... se cuenta lo que realmente se ha vivido, porque exagerar para qué...

- (P) ¿Él considera que es él la víctima, que tú eres una maltratadora con respecto a él?

- (R) Sí, yo creo que sí. (Se ríe), muchas veces me lo ha hecho sentir, como que yo soy la mala, como que él es muy bueno, porque se llama $\mathrm{S}$. y se apellida $\mathrm{S}$. y yo soy la mala 
- (P) ¿Se llama S. S?

- (R) (Se ríe con carcajada) S. G. S. además.

- (P) ¡Ah, S. G. S!

- (R) (Continúa riéndose) Sí, entonces dice... "pero si yo soy un santo" "Lo serás, yo no sé tu madre tanta la redundancia de decir tanto S." porque yo no sé, si yo soy la mala, pienso mal o qué pasa. A veces, por eso te digo, de repente, es que yo soy un poco malilla con él, pero no, la realidad es esa.

- (P) Pero... ¿él te lo dice así?

- (R) No, así tal cual te lo dice "pero si yo no te hago nada, yo no sé cómo quieres que te trate, yo te trato como una reina" Le digo "Si la reina Sofía es tratada así, yo no creo que esté en el palacio 11 años aguantándole al rey, no lo sé"

- (P) A lo que yo me refería, es si él te decía, "Eres tú la que me maltratas a mí"

- (R) Yo soy la que siempre está encarándole las cosas, yo soy la que le está pinchando siempre, yo siempre soy la mala, soy la mala, según su punto de vista.

- (P) Dices que procuras, que tus hijos no vean nada

- (R) Siempre que discuto con él, es cuando no están los niños, prefiero y si en algún momento, yo que sé, levantas la voz... pero... yo que sé si la niña, bueno, ellos nunca nos han visto discutir, yo que sepa no. Siempre lo he hecho cuando están en el colegio, prefiero evitar que pasen malos ratos los niños

- (P) En su día pensaste, o quizás lo piensas ahora, que tu marido es tu complemento ideal

- (R) Cuando lo conocí sí

- (P) ¿Dijiste, "este es el hombre de mi vida"?

- (R) Este es el hombre de mi vida, no, tampoco fue así, dije, este se ve que está bien. Nunca dije que era el hombre de mi vida, pero pensé que... sabes que yo soy muy seria, siempre me decían que era demasiado centrada, que lo hago todo muy así... siempre me lo decían. En cambio él no, él es más..., a ver cómo te digo yo... como que no juguetón, es un poco... todo lo lleva un poco a no tanta seriedad ¿sabes? Entonces yo decía, mira va compensando, como yo soy muy seria y él no tanto, entonces como que hay un poco de... pero es que yo creo que mejor los dos serios está bien, porque hay veces que ya no puedo con él y le digo, "!ay dios mío! ¿por qué eres tan inmaduro hijo?" podía ser un poco más maduro, tengo tres niños en casa

- (P) ¿Cuántos años tiene él?

- (R) Va a cumplir 47 el 27 de Abril

- (P) ¿Qué piensas ahora?, ¿sigues pensando que equilibra?

- (R) No, mi vida no la equilibra para nada.

- (P) ¿No es tu complemento?

- (R) No es mi complemento, definitivamente, no. Es el padre de mis hijos, pero mi complemento no lo es. Yo no soy así, yo veo que... y pienso que la balanza debería estar así y no así (hace gestos con las manos como buscando el equilibrio) Entonces, yo a veces, estoy descompensada y siento que yo llevo mucho más la carga y que... si tú tienes un problema, se supone que es de los dos, pero como que te lo deja... ahora mismo la comunión de la niña mayor, y tenemos que ver lo del local, tenemos que ver esto, tenemos que... y soy yo, y él está bien tranquilo, como si no fuese con él y digo "¿tú no eres el padre?, yo que sepa, la has asentado, la has..." No lo entiendo

- (P) Bueno, él confía en que tú resuelvas bien, con lo cual, él ...

- (R) Pero es que así no es, él está acostumbrado a que su madre, todo se lo haga

- (P) ¿Piensas que la situación ideal de cualquier mujer es estar emparejada?

- (R) No, no, mi hermana no está casada, ni tiene pareja, y está más feliz que nadie ¿sabes?

- (P) ¿Y tú estuviste soltera y estabas bien?

- (R) Si, estuve soltera hasta treinta y tantos años y estaba perfectamente. No creo que porque estés sola, vayas a estar mal 
- (P) Por el contrario, ¿piensas que las mujeres sólo podemos amar a un hombre?

- (R) No, hombre, no, eso es una mentira. (Se ríe con grandes carcajadas). No, yo estuve enamorada otras veces y muy enamorada, y mucho más que esta vez, creo yo, pero oye... así es la vida ¡Que le vamos a hacer! No siempre se puede tener lo que uno quiere. Yo antes de él, estaba ya para casarme pues...Hombres, hombres...

- (P) ¿Qué opinas de los celos?¿piensas que tienen que formar parte de la pareja? ¿Son un componente más?

- (R) No, yo pienso que los celos..., yo no sé, no todo el mundo piensa lo mismo, pero para mí los celos son una tontería, si tu quieres a una persona y confías en ella, no tienes porqué sentir celos. Ahora que tú se lo digas para que la otra persona se sienta importante, pues se lo dices, pero no... sentir celos.... Si tú estás con una persona es porque confías en esa persona, porque la quieres, y porque sabes que esa persona es digna de tu confianza, si vas a sentir celos... no, yo no lo veo

- (P) ¿Piensas que el amor debería estar siempre en la misma intensidad, al $100 \%$ que dices tú?

- (R) No, yo creo que tiene sus altibajos, pero no tan bajos, hay que estar ahí, ahí, pero no tan bajo

- (P) ¿Fluctuando un poco, pero no esas caídas que tienes tú...?

- (R) No, eso no

- (P) ¿Piensas que el amor, realmente lo puede todo? ¿Que si verdaderamente, te quisiera este hombre, las cosas serían diferentes?

- (R) El amor lo puede todo, cuando es mutuo, si, pero cuando es sólo de una persona, yo creo que no. Es que yo mira, soy... es por mí, lo digo... porque yo he puesto todo de mi parte, al principio y lo sigo poniendo, pero bueno... Al principio yo estaba enamorada al $100 \%$ de él, estaba muy enamorada, es verdad. De esto que ay... estás ciega " ¿Tú como te vas a casar con un hombre que apenas conoces?" me decía mi hermana, "Pero lo tienes que pensar", pero mira que oye, que tal, yo no sé, entonces, vienes para aquí, das el $100 \%$ de ti y la otra persona nada, 25 o 20 y ya está

- (P) ¿Y te decepcionas?

- (R) Dices, pero... ¿esto qué es?, el amor no es así, el amor yo creo que es 50 y 50 , no más, pero si no, tú sola, tú sola, tú sola, tiras, tiras, tiras y el otro nada. Tiras de él también y sigues y sigues y no ves, no le veo. Tú sabes lo que es venir en Febrero, un 4 de Febrero que cumplía años de casada, el primer y luego hay el día de los enamorados, el día de San Valentín, yo preparo una cena romántica y tal y yo me siento a esperarlo, viene ¡Ah, que cansado estoy!, ¿qué has hecho y esas velas?, bueno voy a ducharme, yo no ceno que tengo sueño" $Y$ yo me quedé con mis velas prendidas, de novela (se ríe a la desesperada)

- (P) Bien, bien, bien.... No vamos a entrar en más valoraciones al respecto. ¿Piensas entonces que el amor es algo inevitable?, es decir tú te enamoras de alguien y no puedes hacer nada para controlar ese sentimiento.

- (R) Mira, mientras que tú no vives las cosas, mientras no experimentas las cosas, no sabes. Pero yo, ahora mismo, si yo me enamorara de una persona, más o menos, viendo las cosas, yo no me casaría. En el tiempo que me casé, yo no había pasado por esta experiencia, no lo sabía, yo pienso que... no sé cómo explicarlo, no sé, no sé cómo decirlo...

- (P) ¿Quizás quieres decir que no te enamorarías de esta persona si previamente lo hubieras conocido?

- (R) Yo creo que sí, que es todo

- (P) ¿Y de este hombre no te hubieras enamorado?

- (R) De saber cómo era, no, no, no, no, no. Definitivamente no. No por todo, porque aunque digan que el amor es ciego, no... el amor es el amor, pero no es ciego. El amor se da cuenta de las cosas. En mi caso, yo estaba ciega porque estaba allá y la realidad acá era muy diferente. Es que si hubiese sido así, me hubiese casado con cualquiera de mi país porque yo era muy selectiva y entonces de tan selectiva 
que soy tú mira a ver, pero si lo hubiese conocido yo aquí, de haberlo visto como era en su círculo, entonces definitivamente no, definitivamente no.

- (P) Y piensas que si dos personas se aman, ¿lo lógico es que acabe la cosa en matrimonio o en convivencia?

- (R) No necesariamente

- (P) Me decías que hubo varias intentonas de separación, pero nunca llegó a ser real

- (R) Lo he intentado yo, por él no. Entonces yo siempre lo he dejado ahí... porque digo "ya llegará el momento, ya llegará..." Yo espero que mis hijos crezcan y a ver...

- (P) ¿Estás ahí esperando?

- (R) Si

- (P) ¿Y es una de las cosas que te atan?

- (R) Que me mantienen

- (P) ¿Qué planes de futuro tienes en tu cabeza?

- (R) En primer lugar, yo tengo metido en la cabeza que tengo que conseguir un trabajo, pero un trabajo como debe de ser, sí, sí, sí, sí. Porque yo sé que el trabajo es la fuente de todo, de ahí ya puedes partir para muchas cosas. Mientras no tengas trabajo, y el trabajo hace que tengas dinero ¿no? Que lamentablemente, puedes pensar ique materialista!, pero es verdad, porque no sólo hay que mantenerse como persona, sino que te ayuda a salir a delante en muchas cosas y en mi caso a sacar a mis hijos a delante, entonces de ahí ya parte todo. Mira, teniendo yo trabajo ya me puedo separar, porque sé que yo sola voy a poder mantener a mis hijos, que no necesito... que no voy a estar esperanzada en que él me dé una mensualidad, yo siempre le digo "Si algún día nos separamos, yo no voy a decirte ah, no es que me tienes que dar una mensualidad ¿y si no me la quieres dar? ¿con qué le doy de comer a mis hijos?" Eso me detiene mucho también, porque ya te digo, estuve en P. y si no hubiese sido por mi familia... ¿qué hacía yo? Para mí lo primero que tengo en la mente es el trabajo y si tengo que hacer un curso de lo que sea, lo hago y.... si ese curso me va a hacer acceder a un trabajo... pues bien, hago el curso aunque me cueste un año o lo que sea, pero lo hago, no me importa, es que tengo que hacer algo, no me puedo quedar así estancada y te digo, estoy tratando y tratando y tratando, pero...

- (P) Ahí estás en el trabajo y formación. Esa es tu meta ahora mismo. Y mientras tanto que vayan creciendo las criaturinas.

- (R) Es que ellos son mi motor de cada día, si no fuese por ellos, yo no sé qué sería de mí, ellos son los que me motivan a seguir y a.... Me impulsan.

- (P) Yo por mi parte he acabado RP, no sé si tú me quieres contar algo más. A mí me ha parecido una charla muy amena y muy agradable

- (R) Pues mira, así me desahogué un poquitillo más, ya me conoces...

- (P) Yo te lo agradezco porque me proporcionas información muy valiosa para utilizar en mi trabajo. Te agradezco el tiempo que has estado compartiendo conmigo parte de tu vida

- (R) Gracias a ti, cuando quieras aquí estoy. 
- (P) ¿Cuántos años tienes M.J.?

- (R) 38

- (P) ¿Dónde naciste?

- (R) En L.

- (P) ¿Cuántos hijos tienes?

- (R) 3

- (P) ¿De qué edades?

- (R) 20, 15 y 8 años, el de 20 y el de 8 son chicos y la de 15 es una chica

- (P) ¿Con quién viven?

- (R) Conmigo

- (P) ¿Son hijos los tres, del mismo padre?

- (R) No, el primero no

- (P) Sin embargo lo tiene reconocido como hijo suyo

- (R) Si, de entrada salió de él, el querer reconocerlo

- (P) ¿Dónde vivís?

- (R) En L.

- (P) ¿Mantenéis el hogar familiar, la casa que compartías con él?

- (R) Sí

- (P) ¿Tu familia dónde vive?

- (R) Mi familia vive aquí, en $L$ también

- (P) ¿Tienes madre, padre, hermanas, hermanos...?

- (R) Tengo madre y 8 hermanos

- (P) ¿Son para ti un apoyo?

- (R) No, para nada

- (P) ¿Nunca lo han sido?

- (R) Nunca, nunca. No nos hemos criado juntos, entonces no sentimos los unos por los otros y mi madre.... Nunca.... El hecho de llamarla madre, porque me ha tenido, no por otra cosa

- (P) En este momento ¿Cuál es tu situación laboral?

- (R) Buena

- (P) Lo dices sonriendo (emocionada, todo un logro para ella el mantener un trabajo y tener una nómina)

- (R) Sí, sí, sí

- (P) ¿Lo has pasado mal, en este sentido?

- (R) Mucho

- (P) ¿Después de separarte?

- (R) Sí, y yo también trabajaba

- (P) Entonces ¿una vez te separas, las cosas económicamente, empezaron a ir peor?

- (R) Pues sí. Verdaderamente

- (P) ¿Has remontado?

- (R) Pues sí, me he mentalizado, he dicho, hay que levantar cabeza y lo he conseguido. (Lo dice con mucho orgullo)

- (P) Me dices que estás trabajando en un supermercado y te veo feliz, a juzgar por la sonrisa que luces en la cara.

- (R) Estoy feliz, estoy feliz

- (P) ¡Qué bien! 
- (R) Yo llevo toda la vida trabajando, pero esto para mí ha sido muy importante, el hecho de verme..., pues no sé.... ¿Me siento más crecida... igual?

- (P) No sabes cuánto me alegro, M.J., de verdad. ¿Qué estudios tienes?

- (R) Hasta 60

- (P) Hasta 60 de primaria

- (R) Sí

- (P) ¿Y cómo estás de salud?

- (R) Bueno..., de eso no ando muy bien

- (P) ¿Por qué?

- (R) Bueno, pues ahora mismo, tengo un fibroma en un pecho y células cancerígenas, que me detectaron hace poco.

- (P) ¿Ah sí? ¿Y eso? ¿Qué pasó?

- (R) Bueno, en el cuello del útero, entonces estoy ahí, estoy... en revisión cada 6 meses...

- (P) ¿Te lo tienen controlado?

- (R) Sí

- (P) ¿No te someten a operación? O ¿no es necesario?

- (R) Por el momento no, porque no saben si van a ir a más, si se van a desarrollar o no, entonces están ahí estancadas, por ahora

- (P) ¿Un buen susto eh?

- (R) Sí, sí. Procuro no pensar mucho en ello.

- (P) Esperemos que no vayan a más, que tengas suerte en ese sentido. ¿Cuánto hace que te separaste M.J.?

- (R) Dos años largos

- (P) Vamos si te parece a entrar de lleno, y es ahí donde yo quiero que tú cuentes, sobre el tema del maltrato ¿vale?

- (R) Sí

- (P) ¿Cuándo empiezas a ser consciente de que tu marido te está maltratando?

- (R) Mi marido no fue, nunca me maltrató mi marido, fue el padre de mi primer hijo. Desde los 13 años

- (P) ¿Tu historia de maltrato se remonta al padre biológico de tu primer hijo?

- (R) Sí, M., mi marido, nunca, en la vida me puso la mano encima. Sin embargo, esta persona, con el que tuve mi primer hijo, llevábamos tres meses saliendo cuando fue la primera paliza en la calle.

- (P) ¿Tres meses y de novios?

- (R) Si. Conmigo rompió una puerta de un trastero que había en la calle.

- (P) ¿Quieres decir con tu cuerpo?

- (R) Si, con mi cuerpo

- (P) ¿Rompió una puerta en la calle?

- (R) En la calle

- (P) ¿Eso fue la primera vez?

- (R) Sí, llevábamos tres meses. Bajó y todo una vecina a llamarle la atención. Eso son cosas que no se te olvidan nunca en la vida. $Y$ no se... siempre vas pensando que es tuya la culpa, igual... que algo habrás hecho, igual es que te lo mereces o no sé.... No que te lo merezcas, no sé... justificándole a él, que va a cambiar, de alguna manera lo justificas, pero con el tiempo ves que no. Yo hasta que no me quedé embarazada del niño, que ya llevábamos cuatro años... hasta que no me quedé embarazada, no me di cuenta que esto... que tenía que acabar

- (P) ¿Pero continuaste con él? Quiero decir, hay un primer incidente en la calle, te da una paliza, te golpea contra una puerta, rompe esa puerta, baja una vecina... todo lo que estás contando. ¿Continúa la relación y continúan los malos tratos?

- (R) Sí, sí, sí, sí....

- (P) Pero te quedas embarazada. ¿En ese momento te das cuenta de que eso no va a acabar, que no va a parar y te separas de él? 
- (R) Sí, yo más que nada fue el miedo, porque la última vez que me quiso pegar, estaba yo embarazada de 8 meses y me quiso tirar por unas escaleras y luego pegar, me amenazaba con la mano, levantándola y tal... y ya entonces me dio miedo por el niño... si no yo creo que... hubiera seguido

- (P) ¿Continuarías con él?

- (R) Sí, yo estaba muy ciega, es que no sé, no sé, de ninguna manera...

- (P) También es que eras muy joven

- (R) También, empecé con él con 13 años, y tenía casi 17 cuando...

- (P) ¿Cuándo te quedas embarazada?

- (R) Con 17 tuve al niño, estuvimos cuatro años

- (P) ¿Alguna vez abusó de ti sexualmente?

- (R) Si, muchas, muchas veces.

- (P) ¿Convivías con él?

- (R) Sí, nosotros cuando llevábamos... como un año saliendo juntos, nos fuimos a vivir a T., allí las palizas eran de continuo, de continuo... Me reventaba los morros... los ojos me los ponía como botijos... y sus padres, en alguna ocasión me lo vieron y.... y no sé lo que me habías preguntado, se me ha ido la olla

- (P) Te preguntaba acerca del abuso sexual y decías que sí... lo habías sufrido en T.

- (R) Estando ya en T. fue todo peor, las palizas de continuo..., violaciones....Sí, sí, sí. Yo llegó un momento que no he sido capaz de mirar a la gente a la cara hasta hace muy poco, porque siempre me he sentido inferior a todo el mundo, siempre.

- (P) ¿Y tú lo achacas al maltrato vivido en ese momento?

- (R) Todo, todo

- (P) ¿Te quedaron secuelas del maltrato físico?

- (R) Sí

- (P) ¿Tienes cicatrices o heridas...?

- (R) No, pero psicológicamente, sí, muchas secuelas, muchas secuelas.

- (P) ¿Qué pasó esa primera vez, cuando te tira contra esa puerta y la rompe a golpes contigo? ¿Cómo fue su reacción en ese momento y qué pasa después?

- (R) Nada, él... yo marché... yo recuerdo que ese día iba yo sangrando por las narices por la calle, pero en ese momento no piensas que vas sangrando, piensas en lo que te ha pasado, que te has sentido un poquitín..., es muy difícil explicarlo. Entonces yo recuerdo que sí, que al día siguiente él vino con un detalle..., que no recuerdo ahora cuál fue...

- (P) ¿Con un regalo?

- (R) Sí, con un regalo y dijo que.... Me echó a mí la culpa y bueno, que él no me iba a poner más la mano encima.... Que me quería muchísimo y todas esas cosas

- (P) Tú de aquella tenías 13 años ¿y él?

- (R) 13 años y él uno más que yo, 14

- (P) Tu entorno, tu familia, aunque dices que nunca te has sentido apoyada por tu familia por tu madre, hermanos y hermanas, ¿cómo reaccionaron? ¿qué pasó?

- (R) Nadie lo supo. Mi hermano el mayor que tenía muy buena relación con este chico, bueno se llamaban primos, se han apreciado... bueno es el día de hoy que todavía se llevan. Y mi hermano nunca.... Nunca hizo o dijo ningún comentario, ni nada, nada. Yo creo que lo apoyó

- (P) Lo apoyó. ¿Tú no se lo cuentas a nadie?

- (R) No, yo sentía vergüenza, un poquitín. Es que son muchos sentimientos ahí, que no sabes igual... mezclados, que no sabes especificarlos, no sé cómo decirte.

- (P) ¿Cuándo empiezas a contar lo que pasó?

- (R) No lo cuento hasta que tengo al niño, no lo cuento, tampoco me siento en ningún momento apoyada

- (P) ¿En aquel momento vivías con tu madre?

- (R) Cuándo ya tuve al niño, sí

- (P) Vivías con tu madre, y ella nunca te apoyó 
- (R) No, no, no, es más, no quería ni hablar del tema, yo se lo comentaba y ella saltaba con otra cosa que no venía ni a cuento

- (P) La reacción de él consistía en echarte a ti la culpa ¿Tú llegaste a creer que era culpa tuya?

- (R) Sí, sí, siempre, después de cada paliza, venía una manera de echarme la culpa a mí, siempre

- (P) ¿Por qué se enfadaba contigo? ¿Qué clase de cosas le ponían de mal humor?

- (R) Por cualquier cosa, yo recuerdo que estando viviendo juntos, él me pidió huevos fritos, ni le gustaban muy hechos ni poco hechos, tenía que ser un término medio y porque me pasé cuando vino me pegó una paliza que bueno.... Me agarró de los pelos, de últimas y me arrastró por el pasillo, se metió su hermano, ese día se metió también su hermano y le agredió también a él. Por pequeñeces, por cosas que no tenían sentido ninguno, pero él enseguida se encendía.

- (P) ¿Qué pasaba cuando se encendía? ¿Qué hacía?

- (R) Pues eso, me voceaba, no me daba ningún tipo de explicaciones, enseguida tenía la mano encima.

- (P) ¿Siempre contra ti?

- (R) Siempre

- (P) Después de la agresión, dices que la primera vez vuelve con un regalo, medio arrepentido, medio echándote a ti la culpa, ¿siguió pasando eso? ¿cada vez que te pegaba se arrepentía?

- (R) No, luego ya no, luego ya no, en ningún momento.

- (P) ¿No había periodos de calma en tu casa?

- (R) No, que va, que va

- (P) ¿Esto era continuo?

- (R) Sí, estando ya en T. era continuo, y lo mismo venía por la tarde y te daba, y venía por la noche, porque él marchaba, y andaba con unas y con otras... y venía por la noche y después de abusar de ti, te volvía a pegar otra vez

- (P) ¿Tú en esos momentos, cómo te sentías?

- (R) Pues muy sola, muy sola. No sé, yo veía que no podía hacer nada por solucionarlo, porque yo decía, si me voy de con él, ya sé dónde voy a acabar, en casa de mi madre, y yo sabía que con mi madre tampoco podía contar porque tampoco me quería

- (P) ¿Él era tu salida?

- (R) Yo era lo único que tenía, yo pensé que era lo único que tenía. Mi madre, pero es que mi madre nunca me quiso con ella, entonces yo tenía que quedarme con él.

- (P) ¿De haber tenido apoyos hubieras reaccionado de otra manera?

- (R) Igual sí, no sé. Yo creo que no hubiera aguantado todo lo que aguanté

- (P) Sin embargo, a los 8 meses de embarazo decidiste poner punto y final a esa relación

- (R) Sí, es que me tiraba por las escaleras, me tiraba por las escaleras. A él le llegó una carta que tenía que ir a la mili y él decía que a la mili no iba, que a la mili no iba, y que iba a decir que yo estaba embarazada y que nos íbamos a casar y que patatín y que patatán. Y yo le dije que yo me estaba planteando lo de casarme y me agarró y que él se tenía que librar, fuese como fuese, o por las buenas o por las malas y me tiraba, me tiraba y me tiraba. $Y$ después de que se calmó y marchó, me lo replanteé, yo sé que él ha venido por L. a verme y a ver a su hijo, pero dios quiera que no.... No... no quiero encontrármelo porque le tengo mucho miedo

- (P) A día de hoy, después de 20 años. ¿Nunca más le has vuelto a ver?

- (R) No. Sí, bueno, le vi poco después de que lo dejáramos, estaba con otra chica y estaban paseando por un parque y me lo crucé cara a cara, ya había nacido mi hijo y él dio la vuelta a la cabeza y... por una parte dije, "bendición que no quiere ni verlo", pero por otra parte te duele, pero...

- (P) En esos momentos, dices que te sentías sola ¿cómo te veías a ti misma? ¿qué imagen tenías de ti misma M.J.? 
- (R) Pues no sé, yo siempre pensé que fuese yo la mala, decía "bueno, es que yo no tenía que haber hecho esto, si yo hubiera ido por este otro camino, igual él no se hubiera enfadado..." Es que no sé. Responsable de todo, yo creo que era yo

- (P) Y ahora mismo ¿Cómo te ves?

- (R) Feliz, sí. Tengo unos hijos que me lo están dando todo y creo que tengo mucha fuerza para tirar durante mucho tiempo.

- (P) ¿Qué sentimientos tuviste hacia él cuando vivíais juntos? ¿Qué sentías por ese hombre?

- (R) Yo creo que estaba enamorada, pero quererlo no.

- (P) ¿Estabas enamorada, pero no le querías?

- (R) No, yo creo que son pasos diferentes. O sea, querer a una persona, no te importa como es físicamente esa persona, yo estaba enamorada de esta persona, lo veía muy guapo, veía que atraía a muchas chicas y a mí eso, el hecho de que se hubiera fijado en mí...

- (P) Te alagaba

- (R) Sí, sí, pero yo luego, después de haberlo dejado, no sentí, no sentí, o sea, no me dio pena, no me dio cosa de decir "!ay ya no estamos juntos, que tristeza!" No, no, no, nada, para nada.

- (P) A lo mejor fue una liberación para ti

- (R) Yo creo que sí, que el hecho de habérmelo quitado de encima para mí fue un peso muy grande, el decir me lo he quitado

- (P) ¿Estabas en T. en aquel momento?

- (R) No, yo cuando ya lo dejamos, bueno sí, me vine de T. porque me pegó una paliza, la última, me dejó los labios, me acuerdo que sangraba como un gocho y su padre ese día, sí se metió por medio y le dijo que me dejara ir, me trajo su hermano para L. y yo me quedé en S.A. que es donde vivía mi madre, y dos meses después él vino y yo ya estaba muy avanzada, ya estaba de 8 meses, y fue cuando habló de lo de casarnos, y claro... yo igual en esos meses que estuve aquí en $L$, sin que él estuviera conmigo, igual me replantee algo y yo estaba muy confundida, yo le dije que me diera más tiempo para pensármelo y fue cuando me quiso tirar por las escaleras

- (P) ¿Eso estando en casa de tu madre?

- (R) Si, estaba en casa de mi madre viviendo, pero eso no pasó en casa de mi madre, pasó en casa de una hermana.

- (P) ¿Qué pensabas en relación a ese niño que iba a nacer?

- (R) Yo pensaba que iba a ser para mí sola

- (P) ¿Lo tenías claro?

- (R) Si, pensaba que mi hijo no se merecía ver cada día lo que yo estaba viviendo y también tenía miedo, tenía miedo, decía "si me está pegando a mí, ¿quién le quita de pegar a su propio hijo?" Y tenía mucho miedo. Entonces yo eso, fue lo que me abrió las puertas, el hecho de que el día de mañana pudiera agredir a mi hijo, dije no, no

- (P) ¿Quién tomaba las decisiones importantes en esa relación?

- (R) Él siempre todo, él siempre

- (P) Él decidía...

- (R) Hasta lo que me tenía que poner de ropa, él era el que decía lo que había que comer, lo que había que beber, lo que había... lo que te tenías que poner.... Todo.

- (P) ¿Y el dinero?

- (R) El dinero, él trabajaba

- (P) ¿Y lo manejaba él o tú?

- (R) Él, él, él.

- (P) ¿Tú trabajabas fuera de casa?

- (R) Sí, yo también trabajaba

- (P) Y tu dinero ¿quién lo manejaba?

- (R) Lo manejaba él. 
- (P) Sin embargo de la casa, las compras,... Dices que te ocupabas tú, comentas que te monta un número porque cocinas unos huevos que no son de su agrado ¿eras tú la que te ocupabas de la casa y esas cosas?

- (R) Sí.

- (P) ¿En algún momento dudaste de ti misma? Decías que tenías la idea de que la culpa era tuya. ¿Dudabas de tus capacidades?

- (R) Sí, sí, sí. Siempre, siempre. Yo creo que me lo hizo creer él, porque yo después de un tiempo, te das cuenta de que son cosas sin sentido y que no... que hay otras maneras de solucionar las cosas.

- (P) ¿Qué clase de cosas le ponían de mal humor?

- (R) Pues eso, o que ibas por la calle, si dabas la vuelta a la cabeza, ya decía que si habías mirado a alguien... o yo que sé..., que si hablabas con su tío... que si a ti te gustaba su tío... que si yo que sé... Cosas que no...

- (P) ¿Qué te mantuvo a su lado? ¿por qué no cortaste antes esa relación?

- (R) Pues el hecho de no saber dónde ir y lo que hacer

- (P) ¿El no tener apoyos?

- (R) Sí

- (P) ¿Antes de conocer a esta persona, estuviste alguna vez a tratamiento psicológico?

- (R) No

- (P) ¿Y él antes de conocerte a ti?

- (R) No, que yo sepa, tampoco.

- (P) Me decías que te mantuvo a su lado, el no tener apoyos, ¿el dinero era un impedimento para separarte de él?

- (R) No

- (P) ¿Te hubieras separado igualmente, con o sin dinero?

- (R) Sí, sí, sí

- (P) Tu familia, aunque tú dices que es de esa manera, ¿te abre las puertas de casa cuando tú vienes?

- (R) Sí

- (P) Tu madre, en concreto

- (R) Sí, yo vengo embarazada, pero no vengo con intenciones de quedarme, yo vengo con intenciones de hacer una visita y ya es cuando le digo a mi madre que estoy embarazada y tal y al tiempo viene él y nos dejamos de seguido

- (P) En tu familia... dices que no tienes padre, ¿lo conociste?

- (R) Sí

- (P) ¿Entre tu padre y tu madre, tú viste alguna vez malos tratos $\mathrm{M} \mathrm{J}$ ?

- (R) Yo sé que entre ellos si los hubo, mi padre si pegaba a mi madre, pero a mí nunca me pegaron, ninguno de los dos.

- (P) ¿Y en la familia de este chico? ¿Tú sabes si había historia de malos tratos?

- (R) No

- (P) ¿No lo sabes o no había?

- (R) No había

- (P) ¿Tú conocías a su familia y no había?

- (R) Sí, sí. sí

- (P) ¿Él consumía alcohol drogas?

- (R) Él sí, él bebía bastante y luego empezó a fumar eso que se llama costo.

- (P) ¿Cuándo bebía o fumaba costo pasaba algo, quiero decir, era peor su actitud con respecto a ti, mejor...?

- (R) Era igual, él era lo mismo sin beber que bebiendo, era lo mismo, pegar, me pegaba, igual se levantaba de la cama e iba y me pegaba, o sea que...

- (P) ¿Cada día?

- (R) Sí, llegó un momento que sí, cuando estábamos en T, era casi a diario, no le importaba tampoco que hubiera gente delante, porque lo hizo delante su hermano y 
delante de su padre, o sea que... no le importaba, ni tampoco le importaba como me dejaba después, porque... vamos... yo salía a la calle y salía golpeada. A mí me preguntaban las amigas "qué te pasó" "me caí" Claro llegó un momento que las amigas ya...

- (P) ¡Tantas caídas...era un poco sospechoso!

- (R) Y una amiga mía, se ofreció, se ofreció a darme dinero para que yo me viniera para L. Y le dije que no, yo quería estar con él, porque yo sabía lo que me esperaba aquí en L. Yo pensaba, si me saco de Guatemala, igual me meto en Guatepeor. Entonces...

- (P) Una historia realmente dura, muy dura. No obstante creo que eres de admirar M.J., porque yo sé que todo esto sirve para que si a tu hija le pasara algo similar, creo que tú tendrías la capacidad, por lo que conozco de ti, de reaccionar de otra manera. De proteger de otra manera

- (R) Conmigo, sí, sí... son mis hijos, son mi vida. Yo vamos... si a mí me viene mi niña y me dice algo de eso... ipuf!... yo me muevo, yo me muevo. Yo no cierro la puerta a mi niña

- (P) Se te llenan los ojos de lágrimas

- (R) Es que... es que es muy fuerte. Yo ahora me pongo a pensar en el apoyo que tuve de mi madre y digo ¡es muy triste! ¡No sé porqué la llamo madre!

- (P) ¿Si fuera uno de tus hijos el que maltratara o golpeara a una chica?

- (R) No se lo consentiría, no se lo consentiría. Estaría del lado de ella. Un maltratador es un maltratador, sea tu hijo o sea lo que sea

- (P) ¿Por qué te costó tanto empezar a hablar de lo que estabas viviendo M.J.?

- (R) No lo sé, no lo sé y es que además fue algo tan repentino que no tenía intenciones de ello. Fue el día que tú me abriste las puertas y fue cuando lo solté. Porque yo... vamos... de igual.... Hablarle a mi madre y mi madre saltar con otro tema, tampoco se lo soltabas todo, quedabas... es que no sé, no sé cómo decirte...

- (P) Es que me estás diciendo que casi pasan 20 años antes de empezar a hablar de ello

- (R) Sí, sí, porque con mis hermanas no tuve nunca tampoco el apoyo. Si no te sientes... yo quería que alguien me extendiera la mano, sentir confianza en esa persona, sentir que esa persona me iba a apoyar, me iba a entender o me iba a escuchar como tú lo hiciste. Yo ya te digo, a mi madre intenté contárselo en alguna ocasión, un par de veces y te saltaba con otro tema, o sea... eso es que a ella no la importaba tampoco

- (P) O a lo mejor, ella no sabía cómo ayudarte, o estaba confundida, no lo sabemos

- (R) Me hubiera conformado con que me hubiera escuchado, eso es muy importarte, el dejarte echarlo todo, porque yo tenía algo ahí, un peso... que ... vamos....No te lo puedes ni imaginar, yo el día que hablé contigo por primera vez, salí de aquí casi como nueva, salí como nueva

- (P) Me alegro, me alegro mucho por ti, ¿Denunciaste a este hombre en alguna ocasión?

- (R) No

- (P) ¿Nunca?

- (R) No, no, no... (lo dice como asustada, reviviendo el miedo), ni se me pasó por la cabeza.

- (P) En alguna ocasión, ¿tuviste la necesidad de exagerar tu historia para que fuera creíble?

- (R) No, no, yo creo que no me ha hecho falta

- (P) No te ha hecho falta nunca

- (R) No, no,..., las cosas son como son y punto

- (P) ¿Estuviste en casa de acogida?

- (R) Sí, en F., estuve 10 días y verdaderamente, aquello me pareció catastrófico.

- (P) ¿Por qué? ¿cómo te sentías allí?

- (R) Muy mal 
- (P) ¿Ya había nacido el niño?

- (R) Sí, sí, sí,... yo fue por lo que me marché, porque yo veía que en casa de mi madre, mi madre no nos quería, o sea que...

- (P) Ni al niño, ni a tí

- (R) No, no, no... Entonces marché y aquello me pareció una casa de locos más que un centro de acogida y llamé a mi hermana, a una de mis hermanas y le dije que por favor hablara con mamá, a ver si podía acogerme... y sí, sí...

- (P) ¿Y tu madre vuelve a acogerte?

- (R) Sí, sí

- (P) ¿Cómo te sentías en esa casa?

- (R) Pues muy mal

- (P) ¿Por qué?

- (R) Pues mira, yo llegué, llamé al timbre, mi madre salió y lo primero que me dijo "¡Ah, eres tú! Y en la puerta me dejó, con todas las maletas, el niño y todo

- (P) No, me refería a la casa de acogida, discúlpame

- (R) ¡Ah en la casa de acogida! Muy mal en el sentido de que había cuatro chicas y una de ellas no estaba bien

- (P) ¿Quieres decir que tenía algún problema de salud mental?

- (R) Sí, sí, se le olvidaba que tenía un hijo, y a mí me decían que yo tenía que buscar trabajo, que a mí me parecía muy bien, que yo tenía que buscar trabajo y que mi hijo tenía que quedar al cuidado de esas personas, cuando a una se le olvidaba que tenía un hijo, la otra tenía dos hijas y las maltrataba a las dos ¿cómo iba a dejar yo a mi hijo con esa gente? Yo no..., yo no...

- (P) Aguantaste 10 días, a los 10 días te volviste y es donde dices que tu madre te abre la puerta y ahí te dejó... ¿ ¿pero tú entraste?

- (R) Sí, yo entré, pero ahí te das cuenta que no eres bienvenida, porque es que ni al niño me lo miró, te das cuenta de que no eres bienvenida. Yo enseguida me puse en manos de la asistenta social de P., M.J., muy maja, y sí, sí, me ayudó a conseguir una ayuda económica para independizarme yo

- (P) Poder empezar un poco... Este hombre, el padre de tu hijo, ¿sentía que eras tú la que le maltratabas? decías antes que él te culpaba

- (R) ¡Ah, sí, yo creo que sí!, que él se pensaba que yo le estaba maltratando psicológicamente, porque él te venía y te decía " $i E s$ que mira por lo que me haces pasar, has estado ahí toda la tarde hablando con mi tío y yo que sé, o vas en pantalón corto y estás toda la tarde hablando con mi tío!" Y yo decía "¡Jo... pues igual, pues igual yo estoy un poquitín..." Sí me lo hacía pensar, el hecho de que toda la culpa era mía y yo sí que llegué a pensar que igual psicológicamente le hacía daño.

- (P) Todo eso pasó, tú te separas, nace tu hijo y luego conoces al padre de tus otros dos hijos ¿cuánto tiempo pasó?

- (R) Tenía 4 años el niño

- (P) Tenía A. 4 años ¿y qué pasó después?

- (R) Pues nada, yo conocí a M., enseguida se encariñó con el niño, al niño siempre, siempre lo ha tenido en palmitas, y a mí eso, fue lo que me llamó la atención de él, que vamos... que tenía una paciencia con mi niño, un cariño, una ilusión que yo me cegué

- (P) ¿Te cegaste?

- (R) Sí

- (P) ¿Porque conquistó a tu hijo?

- (R) Sí, a ver, yo recuerdo que muchas noches yo me dormía llorando pidiéndole a dios que me mandara un padre para mi hijo, ya me daba igual que me maltratara a mí, yo quería un padre para mi hijo

- (P) ¿Alguien que fuera bueno con tu hijo?

- (R) Sí, porque yo recuerdo que íbamos a casa de mi madre, y el señor que está con mi madre, mi hijo lo llamaba papá, porque mis hermanos pequeños le llamaban 
papá y a mí me daba mucha penina y decía “iAy dios mío! ¿Cuándo me llegará a mí algo para mi niño?"

- (P) Y le conoces a él

- (R) Y conozco a M.

- (P) ¿Qué pasa después?

- (R) Pues nada, después de un tiempo nos decidimos a.... él me pide de salir, pero a mí no me llenaba como hombre, yo le veía como padre para mi hijo, pero no como marido para mí, como novio, como pareja, como lo que fuese...

- (P) ¿No lo veías?

- (R) No, no... pero bueno, yo tenía muy claro que yo quería un padre para mi hijo.

- (P) Era tu objetivo, conseguir un padre para ese niño

- (R) Sí, entonces pues eso... estuvimos 6 meses de noviazgo, y a los 6 meses nos casamos. Nos casamos y él es la persona... para mí buenísimo

- (P) Bueno con tu hijo, bueno contigo. ¿Qué pasa después? Nacen tus otros dos hijos...

- (R) Lo que pasa es que él es muy bueno, pero no sé cómo decirlo... es... No se da cuenta de las cosas, los desprecios que te hace la familia de él, a tus hijos y a ti, de los malos comentarios, de cosas así, empieza también un poquitín a darme de lado, ya no es tan cariñoso como al principio, o no te mima tanto, no tiene tantas atenciones y... (se le llenan los ojos de lágrimas) se afloja todo.

- (P) Pasan los años y decides separarte. ¿Tomas tú la decisión?

- (R) Sí

- (P) ¿Te has sentido maltratada psicológicamente por él?

- (R) No, no, no

- (P) ¿Físicamente?

- (R) Tampoco

- (P) ¿Sexualmente?

- (R) No

- (P) ¿Por qué te separas de él?

- (R) Porque veo que como pareja no, como pareja no

- (P) ¿Tus hijos han presenciado violencia entre vosotros?

- (R) No, nunca

- (P) Nunca han visto nada ¿discusiones fuertes con su padre?

- (R) Bueno, discusiones sí hemos tenido, pero de agredirnos y eso, no, nunca

- (P) Volvemos a tu relación anterior, al padre de A., si te parece. ¿Creíste que él era tu complemento ideal, en aquel momento? ¿En aquel momento lo pensabas así?

- (R) Sí, yo siempre, es que estaba muy ciega, estaba muy enamorada... era guapísimo... yo creo que era el prototipo de hombre.... Todas las chicas.....

- (P) ¿Estaban locas por él?

- (R) En el sentido de que era muy guapo, era muy guapo, era inteligente, era muy simpático, sabía estar... y vamos.... Y luego era muy importante en el círculo de amigos, o sea...

- (P) Era un poco líder

- (R) Sí, sí... entonces yo llegaba allí, llegaba también con él y también era un poco líder

- (P) Claro, el grupo te admiraba de alguna manera

- (R) Sí, sí... entonces claro... te creces un poco, no dejas de ser una niña también, y ves de otra manera las cosas, pero....

- (P) Hoy en día ¿cómo lo ves?

- (R) ¿A esa persona?

- (P) Sí, ¿Seguiría siendo ese complemento ideal para ti?

- (R) No, para nada, para nada, esa persona, y decirle persona, por decir algo, pero yo le veo como un animal, como un animal.... Yo, todo lo que viví con él, las agresiones de todas las maneras que viví, vamos... fue un trauma. Un trauma por llamarlo de alguna manera, creo que no se supera, bueno... lo superas si tienes 
mucha fuerza, tienes que tener mucha fuerza y pensar que se puede, que se puede.... Porque a mí... vamos yo..., mis fuerzas me las dio mi hijo, mis fuerzas.... Yo siempre lo he dicho, mi hijo...

- (P) Era tu motor

- (R) Si no, yo no hubiera.... Es que me veo como enclenque, me he visto siempre un poquitín como enclenque y como un poquitín floja, pero no, no... siempre supe por qué camino tirar para conseguir salir para arriba, a flote

- (P) ¿Piensas que la situación ideal, para cualquier mujer, es tener pareja?

- (R) No, pues no.

- (P) ¿Y crees que las mujeres cuando nos enamoramos de una persona, luego ya no podemos enamorarnos de nadie más?

- (R) Yo creo que no

- (P) ¿Qué piensas de los celos M.J., piensas que son buenos para la pareja?

- (R) No que va, es una desconfianza total

- (P) Antes hablabas de la intensidad en tu matrimonio, con el primer hombre no llegaste a casarte, con el segundo, y decías que las cosas fueron bajando en intensidad ¿piensas que el amor tiene que estar siempre al $100 \%$ ?

- (R) Bueno... no al 100\%, pero sí creo que... a ver...no sé lo que me preguntabas o como explicarlo

- (P) Inténtalo

- (R) A ver, yo pensé que siempre iba a ser tan especial como al principio, el hecho de ver... no sé cómo decirte...

- (P) Te estoy entendiendo

- (R) Es muy difícil, es muy difícil, yo creo que entre lo mucho y lo poco hay un término medio

- (P) ¿Y él pasó de un extremo a otro?

- (R) Abajo total, entonces...

- (P) No conociste el término medio.

- (R) No

- (P) ¿Pero, así, de repente?

- (R) Sí, yo reconozco también, pues eso, que yo soy muy refunfuñona, muy gruñona muy perfeccionista y eso daba margen a muchas broncas y las broncas también eran de muy seguido, igual él acabó también cansándose y dijo "pues... yo que se"

- (P) Que os desgastó la convivencia

- (R) Sí, yo creo que sí

- (P) La convivencia es dura. Tú piensas no obstante, que aunque la convivencia sea dura y todo esto que estamos comentando, ¿si hubiera sido un amor verdadero, hubiera podido con todo? ¿O a lo mejor aquí el problema era que no había amor de verdad?

- (R) Pudo haber sido que no hubiera amor de verdad, yo sabía que cuando me casaba con él, no sentía ese amor que siente una pareja cuando deciden casarse, entonces por mí parte yo sé lo que había, igual yo no puse mucho empeño en fortalecer esa cosa y acabar queriéndolo de esa manera, como pareja, pues igual la culpa fue mía, yo tampoco quiero echarle toda la culpa a él, pero... pero...

- (P) Bueno, es lo que tú viviste a su lado. ¿Tú piensas que se puede dejar de amar a una persona?

- (R) Yo pienso que se puede dejar de amar a una persona

- (P) ¿Y decidir amar a alguien?

- (R) También

- (P) Sin embargo en tu caso, dices que nuca decidiste amarle

- (R) Fue algo que no me nació, yo creo que es algo que tiene que nacer, porque tampoco puedes decir, bueno, pues voy a empezar a querer a esta persona como hombre, o voy a ... Yo por lo menos soy de esa manera

- (P) ¿O surge o no surge?

- (R) O surge o plof 
- (P) Piensas que si dos personas se quieren y tienen una buena relación ¿lo normal es que vivan juntas, o se casen o lo que sea?

- (R) Hombre, pues yo creo que sí.

- (P) ¿Sí?

- (R) Yo creo que sí

- (P) Por qué, volviendo al padre de A., ¿por qué te separas de él? ¿Cuál fue el detonante? Dices que ese día te quiso tirar por las escaleras, estabas embarazada de 8 meses ¿qué te pasó por la cabeza?

- (R) El miedo, el miedo...

- (P) ¿Miedo por ti o por el niño?

- (R) Miedo por mi hijo

- (P) ¿Pero a qué tenías miedo exactamente?

- (R) Pues yo tenía miedo a eso, a que la cosa fuera peor, a que luego ya no le fuese suficiente el hecho de pegarme a mí, a que luego...

- (P) ¿Pasara a pegar a tu hijo?

- (R) Sí. A mí se me encendió una bombilla y me dijo, "esto te va a seguir pasando a ti y a lo que venga también lo va a padecer, entonces... en todos los sentidos, los malos tratos físicos y psicológicos también, entonces fue cuando me mentalicé que no podía seguir la cosa para adelante.

- (P) ¿Ese fue el detonante?

- (R) Sí, sí, sí, sí. Fue una cosa muy rara, porque en casi 4 años en ningún momento lo piensas y luego, ese día, cuando te ves ahí, es como que de repente iplof! Se te aparece y dices "pues es que es cierto"

- (P) Puede ser que lo tuvieras en el subconsciente y por alguna razón, sale, por algún detalle, por alguna cosa que viste, por algo que te dijo... y en ese momento surge algo que estaba como aletargado, ahí, en tu cabeza.

- (R) Sí, sí, sí. Y luego ahí... el hecho de que te ves con tu bebé y dices "ya no estoy sola, lo tengo a él" Entonces... vamos...

- (P) ¿Temiste por tu vida alguna vez?

- (R) Muchas. Sí, ese día en concreto, ese día, ese día es que me tiraba, es que me tiraba por las escaleras

- (P) Lo viste claro

- (R) Lo vi claro, lo vi claro, ese día hubiera pasado de todo

- (P) ¿Tuviste muchos intentos de separación antes de ese día?

- (R) ¿De esta persona?

- (P) $\mathrm{Si}$

- (R) No

- (P) ¿Nunca se te había pasado por la mente?

- (R) No, no, no, que va... era como si yo, si dejara a esta persona, iba a dejar de ser, nada, o sea, no iba a ser nada

- (P) De repente dejabas de existir

- (R) Sí, yo vamos... como que esta persona me lo estuviera dando todo

- (P) ¿No hubo intentos de separación antes?

- (R) Una vez tuvimos una discusión y marché de casa, pero no sé si fueron 3 días lo que tardé en volver.

- (P) ¿Tú vida, después de separarte, cambió?

- (R) Sí

- (P) ¿En qué sentido, para mejor o para peor?

- (R) Para mejor

- (P) Cambió para mejor ¿por qué?

- (R) Hombre, para mejor entre comillas. A ver, yo... hasta hace poco, ya te digo, no me he empezado a sentir, casi como persona, me ha costado, pero... hombre, el hecho de no estar con una persona que te está pisando siempre la cabeza y diciendo que no eres nada, pues... te hace crecerte, empecé a considerarme, pues eso... una persona, pensar que valgo, que soy luchadora y que no le necesito a él. 
- (P) ¿Te marcó mucho esta relación?

- (R) Mucho, mucho, muchísimo, muchísimo... No te lo puedes ni imaginar

- (P) Volvemos a lo mismo, es que tú tenías 13 años cuando le conoces, estás sin formar, eras una niña

- (R) Sí

- (P) En la actualidad, ahora mismo, ¿con qué apoyos cuentas?

- (R) Con el de mis hijos

- (P) ¿Con el de los tres?

- (R) $\mathrm{Si}$

- (P) ¿Te ayudan a superar todo esto?

- (R) E. más, los otros... A. es un poco más... Yo el hecho de saber que llego y les tengo, o sea que los tengo ahí siempre, eso te da... a mí es que me da mucho, a mí me lo da todo (se le llena la boca de hijos e hija)

- (P) ¿Son tu tesoro?

- (R) Sí, sí, sí, sí.... Es que yo vivo para ellos, yo es que vamos.... Me levanto pensando en ellos y me acuesto pensando en ellos, es lo que me da fuerza para luchar cada día

- (P) ¿Cómo estás ahora mismo? De salud me decías que tenías ahí ese problema que te han detectado, que esperemos que no sea nada, sigues manteniendo tu casa, la que tenías antes de separarte del padre de los niños, una casa cómoda a tu medida, que la construiste para ti, laboralmente has mejorado un montón... ¿cómo estás con las relaciones sociales? ¿has hecho amigas/os?

- (R) Si... bueno..., me está costando bastante, además es que yo soy una persona que enseguida lo exteriorizo todo y no es bueno por una parte, porque a ver, parece que haces amigas porque les das un poquitín de pena, entonces yo quiero que me vean como soy, pero no se demostrarlo

- (P) ¿Dónde has conocido a estas amistades nuevas?

- (R) En el A. Trabajando. Yo es que lo pienso, digo igual es que las doy pena o yo que sé, lo piensas muchas veces

- (P) Y con tu gente, me refiero a tu familia ¿sigue siendo fría la relación?

- (R) Sí, sí, sí, mucho, eso no cambia, pienso que no va a cambiar nunca, es algo a lo que te habitúas y luego no lo hechas en falta tampoco, yo no lo echo de menos. Pienso que todo lo que tengo, lo tengo en mi casa, toda mi vida está en mi casa, lo demás, como nunca lo he tenido, no lo echo en falta. Sí te da, a veces, un poquitín de pelusa, cuando ves a alguna amiga que te dice, "marcho a pasar las navidades a casa de mi madre y vienen mis hermanos, y..." y yo ¡Jo!... eso nunca lo he tenido

- (P) A lo mejor, lo tendrás cuando tus hijos sean mayores

- (R) Sí, yo sí, yo todo lo que pueda hacer. Sí me gustaría, que lo que nunca he tenido yo para mí, que puedan tenerlo mis hijos para ellos

- (P) Proyectar en ellos, el tener siempre la puerta abierta para que cuando ellos se independicen puedan acudir a casa de su madre cuando les apetezca

- (R) Sí, las puertas de mi casa, para mis hijos, siempre estarán abiertas

- (P) ¿De nuevos amores y eso, ni hablamos?

- (R) No, nada

- (P) ¿Cómo te sientes respecto a ti misma? ¿te gustas o no te gustas? ¿En qué momento de tu vida estás?

- (R) Yo creo que me estoy superando, empiezo a gustarme, me veo luchadora, ahora empiezo a verme luchadora, digo "ijolines!, saqué a mi hijo a delante, tengo una casa, casi propia, bueno la estoy pagando, es del banco más que nada, pero bueno, la considero mía, tengo dos hijos más, no tienen falta de nada, de comer no nos falta, trabajo tengo ¿qué más quiero?"

- (P) Además tú ya sabes que la situación ideal no existe, cuando no cojeamos de un lado cojeamos de otro.

- (R) Claro, o sea que.... Vamos... yo me siento bien. 
- (P) ¿Qué planes de futuro tienes ahí, no sé si a corto, medio o largo plazo? ¿Cómo te ves en un futuro?

- (R) Pues... hombre.... Me apetecería verme querida... por un hombre

- (P) ¿Una pareja?

- (R) Sí, tener una pareja, una pareja que sepa tratar a mis hijos

- (P) Ya... pero también te tendrá que gustar a ti, a ver si volvemos a caer en los errores de antaño ¿o no?

- (R) Ya lo sé, bueno... que no me falte el trabajo y mis niños que estén siempre ahí

- (P) ¿Cada vez serán menos niños?

- (R) Ya, o más

- (P) ¡No fastidies!

- (R) Los míos ahí, pero si ellos tienen niños, para mí serán mis niños también

- (P) Con tus hijos cerca, con una pareja si pudiera ser, trabajo...

- (R) Que no me falte el trabajo y lo demás como hasta ahora

- (P) No le pides más a la vida

- (R) No, no, no

- (P) No es poco

- (R) Hombre, yo creo que ya pido mucho

- (P) Ahí está ese tema de salud, que se te arregle un poquitín

- (R) Sí, es verdad, eso también, eso es un puntín, procuro no pensar en ello para no hundirme

- (P) Pues mejor, las cosas se irán sucediendo, si te tienen controlada y tal, para qué preocuparse si no hay motivos, de momento.

- (R) No de momento no, ya me dijo la ginecóloga que de momento no había de qué preocuparse. Procuro no pensar mucho.

- (P) Pues bien. Yo por mi parte, ya he acabado de preguntarte todo lo que yo quería preguntar. ¿Tú quieres añadir alguna cosa a esta historia? ¿Piensas que se ha podido quedar algo interesante en el tintero?

- (R) Pues no sé, yo pienso que... la vida, es lo que uno quiera vivir, yo pienso que golpes llevamos todos y que se supera (se emociona)

- (P) No llores ahora que estamos acabando la entrevista

- (R) Hay que proponérselo porque si dices "estoy hundida y te hundes cada vez más, entonces no" hay que levantarse cada día con otra cara y decir "voy a subir para arriba"

- (P) Con mentalidad positiva, quieres decir

- (R) Sí

- (P) Pues muchísimas gracias M.J., te agradezco muchísimo este ratito que me has concedido y sabes que puedes charlar conmigo siempre que te apetezca

- (R) Me emociono toda

- (P) Muchas gracias, de verdad. 
- (P) ¿Cuántos años tienes A.M.?

- (R) 51

- (P) ¿Dónde naciste?

- (R) En V.

- (P) Hijos... ¿tienes dos verdad?

- (R) Si, dos

- (P) ¿Edades?

- (R) 18 y 19

- (P) ¿Con quién viven?

- (R) Pues actualmente, uno con su padre y otro conmigo, el mayor está conmigo y el pequeño con su padre. Hasta ahora estaban los dos conmigo

- (P) ¿Son hijos los dos del mismo hombre?

- (R) Sí, de A.

- (P) De A., ¿del que fue tu marido?

- (R) Sí

- (P) ¿Cuánto tiempo estuviste casada?

- (R) Pues con tanto jaleo que tengo en la cabeza,... veinte...., no sé decirte... veintiuno o veintidós años

- (P) ¿Cuánto tiempo llevas separada?

- (R) 7 años

- (P) ¿Dónde vives A.M.? ¿Aquí en L?

- (R) Sí

- (P) ¿Y tu familia?

- (R) Mi padre vive en un pueblo de la provincia y mi madre vive aquí en $L$.

- (P) ¿Tienes relación con ellos?

- (R) No, con mi madre no, con mi padre sí.

- (P) ¿Son toda tu familia?

- (R) Y un hermano que tampoco me habla, o no nos hablamos

- $(\mathrm{P})$ ¿Tu hermano está con tu madre y tu padre vive solo en un pueblo?

- (R) Sí, vive solo

- (P) ¿Cuál es tu situación económica en la actualidad?

- (R) Pues una... pensionista, o ¿qué te digo? Media baja o ¿cómo es?

- (P) No lo sé, ¿tú tienes una pensión de invalidez?

- (R) Sí

- (P) ¿Qué es una permanente?

- (R) Sí, creo que se llama así

- (P) ¿Y A. te pasa un dinero por estar con el niño mayor?

- (R) Sí

- (P) Bueno con el niño, ya 19 añazos

- (R) Sí, me pasa una cantidad, $100 €$

- (P) Y tu pensión que son $500 €$, me comentabas. Así que con $600 € \ldots$

- (R) Me tengo que arreglar

- (P) ¿Qué nivel de estudios tienes A.M.?

- (R) Hice el bachiller

- (P) ¿Y de salud cómo andas?

- (R) Bueno, pues ahí, ahí. Con mis depresiones..., luego tengo un problema en una cadera... de todo un poquito... la espalda...., osteoporosis... de todo un poco.

- (P) ¿Antes de estar enferma trabajabas fuera de casa? 
- (R) Sí

- (P) ¿Dónde trabajabas?

- (R) En una consulta privada

- (P) Antes de separarte

- (R) Sí, sí... bueno estuve de baja un tiempo, ya antes de separarme me habían jubilado

- (P) Y trabajabas en una consulta, creo recordar que de pediatría, me comentaste en alguna ocasión.

- (R) Sí, sí

- (P) ¿Te gustaba lo que hacías?

- (R) Mucho

- (P) Te dio pena dejarlo

- (R) Sí, mucho y luego es que estuve muchos años, muchos, los niños parece que te dan vida

- (P) Vamos a entrar en tu experiencia de maltrato ¿vale? El que fue tu marido, el padre de tus hijos, dices que te maltrataba, me has comentado en otras ocasiones, te maltrataba psicológicamente.

- (R) Sí

- (P) ¿Qué hacía exactamente?

- (R) Porque, a ver, yo no es que me diera cuenta, ni mucho menos..., yo me encontraba muy bien, jamás tuvimos ningún problema... pero por lo que me ha dicho gente, que me ha consultado, que me ha visto, me tenía, digamos, un poco anulada. Era como él decía, dónde él decía, lo que él quería. Si yo quería comprar unas sábanas, a pesar de estar trabajando,... "espera que este mes no se puede... o para el mes que viene... o no las necesitas" (él le decía). En cuanto a eso, en cuanto a ir por ahí un día a comer, pues tampoco se podía, el ir de vacaciones tampoco se podía, el salir con mis hijos un momento puntual a comerme una hamburguesa, te lo he contado yo en algunas ocasiones, ya les decía antes de entrar, que el postre era una taza de leche en casa, que no se podía,... Cuando en ese momento estábamos los dos trabajando. A pesar de pagar una hipoteca, teníamos una solvencia los dos y nos lo podíamos permitir

- (P) Pero él decidía que no

- (R) Eso es

- (P) ¿Alguna vez te maltrató físicamente A.M.?

- (R) No

- (P) Sexualmente ¿te obligaba a mantener relaciones con él sin tu consentimiento?

- (R) Bueno, pues lo típico que tenemos las mujeres, "hoy no me apetece, no me apetece..." Pues él insistía y había días...

- (P) ¿Tú cedías o te obligaba?

- (R) Cedía por no tener problemas. Soy una persona que no me gustan las voces y no quiero conflictos ni problemas

- $(\mathrm{P})$ ¿Cuándo es la primera vez que te das cuenta que A. está maltratándote psicológicamente? ¿Cuál es el primer incidente?

- (R) No... yo es que aunque me lo dicen ahora, no me lo creo, no, lo sigo defendiendo, si. No sé si es que estoy hecha a su forma de ser... no sé qué decirte Belén.

- (P) ¿Te cuesta trabajo, saber, o identificar en qué situaciones estabas siendo maltratada, aunque "sólo" fuera psicológicamente?

- (R) Sí, porque de hecho te dicen que eso es cosa tuya, que me tendría que haber hecho valer... Y ya que yo en aquel momento me lo ganaba... Porque yo una vez que dejé de trabajar, él todavía peor, claro según él no hacía nada, ni lo de casa ni nada, según él

- (P) ¿Eras responsable de tus hijos?

- (R) Sí claro y de mi casa y de la comida a su hora cuando él llegaba y... yo entonces hacía más que hago ahora. 
- (P) Con lo cual, ¿no puedes poner una fecha de inicio a ese maltrato?

- (R) No, no sé decirte

- (P) ¿Había broncas en tu casa, había discusiones?

- (R) No, nunca, no

- (P) ¿Él se alteraba?

- (R) Él sí

- (P) ¿Tú no entrabas a eso?

- (R) No, yo prefiero siempre perder de mi punto de vista, aunque bueno... en algún momento se lo decía o le exponía lo que yo creía, pero... por no llegar a más, yo siempre me he callado.

- (P) ¿Él por qué se alteraba? ¿Qué clase de cosas le molestaban?

- (R) La forma de enfocar, por ejemplo, la educación de nuestros hijos

- (P) Eso le irritaba

- (R) Sí

- (P) Pon un ejemplo

- (R) Pues no sé, yo... no sé como contarte. Pongamos que de hace tiempo, que yo estaba en activo, pues claro el ratito que yo les veía, tampoco me quería poner en plan duro con ellos y su padre era muy recto. Incluso el psicólogo del colegio le dijo que ni lo mío ni lo de él, que lo mío era por demasiado blando y lo de él por exagerado de duro. Entonces, ahí chocábamos un poco, y de hecho, todavía es el día de hoy, que dice que, toda la culpa de que mis hijos sean así es por mi culpa, y ya le he dicho, que sí, que la culpa la tenemos todos, pero que si él dice que la forma de educarlos en los primeros años es lo que les queda, en esos años era él el que estaba más tiempo con ellos, porque yo trabajaba de tardes y de mañanas, o sea que la primera educación que recibieron... sí... lo mío lo tenían digamos... en momentos o fines de semana, pero el resto del día estaban con él.

- (P) ¿Él llegó a golpear a tus hijos? ¿Pegaba a los niños como forma de educación?

- (R) Bueno... algún cachete.... Tampoco para decir maltratarlos. No. Sacarlos a la escalera con el plato de comida..., meterlos en la habitación..., pero vamos... pegarles un azote.... Como cualquier padre.

- (P) ¿Él sí tiene genio, es una persona con carácter?

- (R) Jura muchísimo y muchas voces

- (P) ¿Fue así siempre?

- (R) No, hombre, al principio no era así, pero poquito a poco, no sé hija...

- (P) La primera vez que te grita ¿cómo reaccionas?

- (R) Es que no lo recuerdo Belén, no

- (P) Y él, ¿qué pasaba después de que se ponía a gritar o montaba algún número de estos en casa? ¿Cómo reaccionaba? ¿Qué pasaba después?

- (R) Para él, es algo de lo más normal

- (P) Si tú te disgustabas ¿no te pedía perdón, no se arrepentía?

- (R) No

- (P) ¿Nunca?

- (R) No, que recuerde, tengo muy mala memoria, pero no, no es de las personas... por lo menos conmigo, yo de hecho le he visto con sus padres... yo no sé si yo es que he tenido otra educación, aunque es de mi edad, con sus padres, tenía el mismo papelote, la misma papeleta que conmigo, siempre han sido voces, voces y voces. $Y$ yo a mis padres por lo menos, aunque me fastidie me callo. No me gustan las voces

- (P) ¿De novios ya era así, A.M.? ¿O esto empieza a suceder después?

- (R) No, después

- (P) ¿Por qué motivos? Antes decías que por los niños sí se ponía alterado, pero qué clase de cosas...

- (R) Que me pasaba, según él, el día comprando. Pero es que eso lo hago ahora y comprar, comprar, no compro nada. Tú verás que ando siempre igual. El hecho de ir a pasear con los chicos o juntarte con otros padres en el parque... "iAh pues yo 
cuando pueda, ahora para el mes que viene voy a comprar no sé qué o no sé cual, o una colcha para las camas..." Ahí, él se rebotaba

- (P) El tema económico, sobre todo....

- (R) Pero que yo no era... el hecho de decir me compro, pero nunca me llegaba a comprar nada.

- (P) Tu lo planeabas, pero luego no...

- (R) Yo soy de esas personas que se conforman con verlo y decir, pues me lo compraré, pero no te digo ahora, algún día lo tendré, pero vamos, no...

- (P) ¿Y él ya se ponía como loco?

- (R) Si, es muy pesetero en ese sentido.

- (P) ¿Se enfadaba delante de la gente o cuando llegabais a casa?

- (R) En la calle creo que sabe... creo... mantener un poco.... Creo... da otro ¿perfil decís?

- (P) Otra imagen y luego en casa era distinto

- (R) Sí, en casa, en casa de su madre, con mis padres... o sea, lo suyo son las voces y yo eso no lo soporto

- (P) Cuando él se ponía así, a chillar, dices que luego, pasaba la bronca y no había, ni reconciliación, ni nada. ¿cuánto tiempo duraba la calma en tu casa?

- (R) Bueno... pues como yo no saltara por algo que a él le pareciera mal, no era para decir que tuviéramos... no, no pero porque yo me callaba, me conformo con cualquier cosa.

- (P) Y tú, después de escucharle reñir o dar voces ¿cómo te sentías?

- (R) Me metía mucho... o sea, me metía en mi trabajo en principio y luego con mis hijos, o sea como que....

- (P) Intentabas mantenerte ocupada ¿quieres decir?

- (R) Exacto, olvidar lo que pasaba, sí.

- (P) Era tu válvula de escape ¿podemos decirlo así?

- (R) Sí, sí.

- (P) ¿Cada cuánto pasaba esto?

- (R) No sé decirte, Belén

- (P) ¿Cada día se enfadaba por algo? O no, ¿teníais épocas buenas?

- (R) Sí, sí, teníamos épocas buenas. Pero bueno... él en cuanto yo dejé de trabajar, pues digamos que era un continuo, porque empezó a faltarme directamente. Yo tampoco me daba cuenta

- (P) ¿Empezó a insultarte?

- (R) Me llamaba gocha, me llamaba... pues de todo

- (P) ¿Y eso antes nunca había pasado?

- (R) Digamos que no. No porque yo era una tía que no paraba y luego cogí una depresión muy fuerte porque se separaron mis padres y me empecé a hundir, a hundir y a hundir, y sí, yo entiendo que él aguantó mucho conmigo, pero cuando empezó ya a faltarme, no, porque a mí me daban muchas pastillas y me pasaba el día dormida. Y me decía que eso de levantarme de la cama para echarme en el sillón... y gocha, marrana, de todo

- (P) Es decir, ¿coincide la separación de tus padres, con que tú te das de baja en el trabajo por motivos de salud?

- (R) Anteriormente, había tenido un par de operaciones. Entonces con la convalecencia de dos operaciones...

- (P) ¿De qué te operaron?

- (R) De un pecho y de un mioma

- (P) Entonces estabas convaleciente y coincide que se separan tus padres

- (R) Sí

- (P) Ahí entras en una depresión

- (R) Sí

- (P) Con lo cual, dejas de trabajar definitivamente, y él empieza a increparte de forma más continuada. 
- (R) Sí

- (P) Los niños, en ese momento, ¿Cuántos años tenían aproximadamente?

- (R) Pues... yo no sé si eran 10 años, 10, 11 años, por ahí. O quizás menos, menos, menos

- (P) Eran pequeños

- (R) Sí porque yo estuve, antes de separarme, igual llevaba yo 5 años o 6 jubilada.

- (P) ¿Cómo te sentías en ese momento? Tú dices que estabas con una gran depresión, bastante medicada y él insultándote. ¿Cómo te sentías?

- (R) Fatal, hundida. Hundida hasta el punto que me quise suicidar, vamos... yo ahora... me lo contó él, si es o no es cierto... porque en una sesión que tenía de psicólogo le dijeron que no me dejara de la vista, que procurara estar siempre conmigo, donde me viera, porque, pues eso... tenía una desesperación total.

- (P) ¿Y tuviste un intento de suicidio?

- (R) No exactamente el intento, si me pasaba por la cabeza

- (P) Lo pensabas

- (R) Sí

- (P) Pensabas en quitarte del medio, no llegaste a intentarlo, pero sí que lo pensaste

- (R) Eso ya fue cuando estuve yo sola, que tuve una temporada muy mala porque él me amenazó y mis hijos eran pequeños todavía... y estuve en la terraza... si voy o no voy

- (P) ¿Él te amenazó?

- (R) De esa época, ya estábamos separados y me amenazó de muerte.

- (P) ¿Por qué motivo A.M.? ¿Qué pasó?

- (R) No lo sé, estábamos separados, él en principio, antes de separarnos me estuvo engañando, yo lo pillé en varios renuncios

- (P) Engañando, quieres decir, siendo infiel con otra persona

- (R) Sí, siéndome infiel con otra persona, y bueno... yo estuve un tiempo, aguantando, aguantando, aguantando... hablándolo con él, procurando que mi matrimonio saliera arriba y bueno... él estaba ciego por esa chica y de hecho, pues... nos separamos. $Y$ esa chica, también me... digamos me mandó un mensaje, diciéndome muy parecido a lo que me decía A., que los coches subían mucho por las aceras en accidentes y que estuviera mirando siempre por mi hombro porque ella podía subirse en una acera sin querer. Cuando yo a esa muchacha, en mi vida le hice nada, fue ella la que se metió en medio de mi matrimonio.

- (P) Si vamos en el tiempo, un poco antes de separarte, tú ¿cómo te veías a ti misma estando a su lado? ¿Qué imagen tenías de ti misma después de que él te insultaba? ¿Cómo te veías?

- (R) Como un trapo, Belén. Porque para mí, ya no sé, si físicamente, o con estudios, yo sé que él, te hablo de novios, tenía chicas muy agradables a la vista, físicamente guapas y gente que supuestamente, tenía más dinero que yo podía tener. Y yo le decía que... vamos, que no podía creer que se hubiera casado conmigo con las chicas que tenía. Yo siempre me sentí bastante inferior a él, física e intelectualmente.

- (P) Y en este momento ¿cómo te sientes?

- (R) Igual

- (P) Igual, ¿no ha variado en nada esa sensación?

- (R) Pues igual, pero no sé si hizo después un año o dos de FP de ¿radio-electrónica se dice? Algo de eso. Pero es que es muy inteligente, lee mucho y yo por ejemplo leer, antes poco y ahora nada.

- (P) ¿Qué sentimientos tenías hacia él mientras estabais juntos? ¿Qué sentías tú por este hombre?

- (R) Me pasa ahora todavía, Belén

- (P) Así que la pregunta es ¿Qué sentías y qué sientes? 
- (R) Es como si fuera, no sé cómo explicarte... él el motor que me hace tirar para adelante.

- (P) ¿Y eso? Quiero decir ¿qué sentimiento está ahí funcionando?

- (R) Igual, por lo que me comentó el psicólogo, igual es una forma que yo adopté de comodidad, de tenerle siempre a él, que era el que miraba si llegaba el dinero, si había que comprar, si había que gastar, si no nos llegaba o lo que.... No sé como que adopté la postura cómoda que era él el que llevaba un poco el tema de la casa.

- (P) Entonces ¿te daba seguridad? No sé si lo estoy interpretando bien.

- (R) Sí

- (P) ¿Te daba como seguridad tenerle a tu lado?

- (R) Sí

- (P) Y a día de hoy, que no le tienes ¿cómo te sientes?

- (R) Muy mal, abandonada, no tengo en quién apoyarme.

- (P) En relación a tus hijos, mientras estabais juntos, ¿qué pensabas de él? ¿pensabas que era la situación ideal para tus hijos, que vivieran con él? ¿Qué sentimientos tenías?

- (R) ¿Cuándo nos separamos hablas?

- (P) O incluso estando juntos

- (R) No sé, yo es el día de hoy que le he dicho que no es la persona con la que me casé, no es ni su sombra, eso es cierto que se lo he dicho en varias ocasiones, porque era muchísimo más dulce de lo que es ahora, por lo menos conmigo y con mis hijos. Entiendo que hoy la gente joven, ve las cosas de otra manera, que te tienes que poner muy seria, pero... jolín, llega un momento que son tus hijos y te duele. Y en cambio sé que él está muy preocupado por los hijos de ciertas señoras con las que él ha estado y no le noto esa preocupación por los míos, que son suyos.

- (P) En aquel momento, cuando estabais juntos ¿quién tomaba las decisiones importantes en la pareja?

- (R) Él

- (P) ¿Siempre él?

- (R) Yo creo que sí

- (P) Y el dinero, me decías antes que también lo manejaba él, incluso el tuyo

- (R) $\mathrm{Si}$, "tú vas y sacas esta semana 100 o sacas 300" Era él el que decía...

- (P) ¿Tú no tenías dinero propio, aunque lo ganabas?

- (R) A mí nunca me faltó llevar dinero conmigo, pero vamos... el que decidía si había que gastar más o menos o sacar más o menos del banco era él. Hombre a mí no me quitaba, entre comillas, de que si necesitaba, ir y sacar para mí $20 €$, no me quitaba, pero vamos no.... No era el caso, porque tampoco soy una persona de gastar

- (P) ¿Quién se ocupaba de la casa, los niños, la comida, la compra? Esas cosas de casa ¿quién las hacía?

- (R) Pues cuando yo estaba trabajando, yo dejaba mi casa hecha, por la mañana, muy temprano, a las 8 salía con mis hijos de casa para dejarles en la guardería, los recogía él a las 5 de la tarde que yo volvía a estar en el trabajo, porque yo salía a las 20:30, llegaba a mi casa a las 21 y él a lo mejor se encargaba, pues eso... de recogerlos en la guardería, les daba un paseo por el parque o les estaba bañando cuando yo llegaba. Pero yo me encargaba de mi casa, de mi comida, de mi ropa, de todo.

- (P) Teníais las tareas un poco compartidas.

- (R) Sí, repartidas.

- (P) Él se ocupaba de los niños a partir de las 17

- (R) Porque él la tarde la tenía libre, él salía a las 15 de trabajar

- (P) ¿En algún momento, mientras estuviste a su lado, dudaste de tus capacidades como persona? Como buena madre, organizadora, como buena cocinera... ¿tuviste dudas como buena persona, trabajadora...?

- (R) Yo creo que no 
- (P) ¿No?

- (R) ¿De mí misma?

- (P) Sí

- (R) Creo que no, creo...

- (P) Tú sabías que lo estabas haciendo bien y...

- (R) Lo mejor que podía, sí

- (P) Cuando él te insultaba y empezó a faltarte al respeto... ¿Ahí empezaste a dudar o no?

- (R) Simplemente le decía que ¿qué era lo que pedía de mí? A ver... no sé... le tuve que fallar en algo para que buscara a otra persona ¿no?, pero yo era lo que él decía, tenía mi casa atendida, a mis hijos atendidos ¿qué me pedía? No lo entendía. No lo entiendo todavía.

- (P) Cuándo él te insulta, cuando él te increpa, te dice eres una gocha, no te levantas de la cama, no haces las cosas... ¿Tú empezaste a creerte que eras tan gocha como él decía, que no te ocupabas de tus hijos...?

- (R) Sí, en aquel momento sí

- (P) ¿En aquel momento sí que lo empezaste a creer?

- (R) Sí

- (P) Es decir, todo lo que él te decía, tú veías que era cierto. ¿lo veías así? A eso me refiero.

- (R) Sí, sí

- (P) ¿Qué clase de cosas de las que tú hacías o dejabas de hacer, le molestaban tanto?

- (R) No sé

- (P) Verte en la cama le molestaba ¿qué más le molestaba?

- (R) Sí, mi posición, de que como te he dicho, igual me volví cómoda, el hecho de que supuestamente ya no ganaba dinero. Que yo le decía, que bueno... ya no estaba en activo, pero una ayuda en casa, con lo que yo ganaba... teníamos para nuestra hipoteca, quedaba su sueldo libre. Pues él que no, que no valía para nada, vamos...

- (P) En el momento que dejas de trabajar, tú ahí sí que notas....

- (R) Fue a peor, fue a peor

- (P) La cosa cambió para peor, aunque él ¿ya tenía un poco de antes ese perfil?

- (R) Sí

- (P) ¿Puede ser que se agravara en ese momento?

- (R) Yo creo que sí porque él no era como es ahora mismo

- (P) A pesar de todo, continuaste a su lado varios años. ¿Qué te mantuvo a su lado? ¿por qué?

- (R) Yo es que sigo diciendo que lo necesito

- (P) Lo necesitas a tu lado, pero ¿por qué lo necesitas?

- (R) Pues es que no lo sé, Belén, porque me ha hecho mucho, mucho, mucho y muchas cosas, y bueno como que las tengo un poco olvidadas

- (P) Tú ahora dices que te encuentras a tratamiento psicológico, pero antes de haberle conocido ¿estuviste también?

- (R) No, nunca. Yo era una persona muy alegre

- (P) ¿Tú eras alegre antes de conocerle?

- (R) ¡Puf! Estaba el día bailando, estaba con la música, cantando a todo gas, muy, muy alegre. Y eso se fue apagando, se fue apagando. Yo cuando teníamos así, de juntarnos un grupo de parejas o de novios o luego ya de casados, digamos que yo era la chispa del grupo, la más fea, la más pequeña, pero la que daba un poco de chispa y con el paso del tiempo eso se apagó, no soy yo ni mi sombra

- (P) Y él ¿tuvo algún tratamiento psicológico antes de conocerte a ti?

- (R) Que yo sepa no, que yo sepa.

- (P) Hablabas antes de la cuestión económica, el dinero sí que importó en tu matrimonio, tenía un peso. 
- (R) Se ha vuelto... era y ahora más pesetero.

- (P) ¿El dinero dificultó la separación?, es decir, ¿tú dejas de separarte por una cuestión económica? ¿O por el contrario llegó un momento que daba igual?

- (R) ¿Qué si dejo de separarme?...

- (P) Sí, ¿retrasas un poco la separación por el tema económico?

- (R) No, nunca pensé en el dinero

- (P) ¿No pensaste en el dinero a la hora de separarte?

- (R) No, no

- (P) ¿Tu familia te sirvió de apoyo cuando te separaste?

- (R) Mi padre, que es el que digamos me está apoyando.

- (P) Te apoyó en ese momento y te sigue apoyando ahora

- (R) Sí, aunque él estaba mal también por su separación, pero bueno... ha estado ahí conmigo y está conmigo. Sí

- (P) ¿Tú viste alguna vez que tu padre maltratara a tu madre?

- (R) Nunca lo vi y mi madre sí lo alegó en su separación

- (P) Que era una mujer maltratada

- (R) Sí

- (P) Y los padres de A. ¿Tú sabes si entre ellos había maltrato?

- (R) De pegarla no, voces sí. Mi suegro también fue un hombre, de dar muchas voces.

- (P) Como su hijo

- (R) Sí

- (P) ¿Tú piensas que el padre de tus hijos, a lo mejor por su trabajo..., está sometido a mucho estrés y por eso se comporta como lo hace?

- (R) ¿Estrés? ¡qué va!, para nada. Él estaba solo en su trabajo, o sea, siempre tienes a alguien por encima, ¿no? pero no tenía a nadie allí continuamente chinchándole, no. Entraba y salía cuando le parecía, él teniendo su trabajo hecho....

- (P) ¿Consume alcohol o drogas?

- (R) Que yo sepa, no

- (P) ¿Y antes, tampoco?

- (R) No, nunca le vi borracho.., que te tomas una copa cuando sales, pero de verle borracho nunca

- (P) ¿Te costó o te cuesta hablar de todo esto A.M.?

- (R) Empezar a hablar, si, aunque yo después me desahogo mucho, aunque conozco mi historia, se mi historia, yo misma estoy muchos días "¿por qué? ¿por qué? ¿por qué? ¿por qué no hice esto? ¿por qué no hice aquello?”, pero bueno... luego estoy revuelta un par de días, pero a la par me desahogo

- (P) ¿Con quién?

- (R) Con mis amigas

- (P) Con las amigas, y ¿tardaste en empezar a contar esto o no, inmediatamente, en el momento que él empieza a insultarte, lo cuentas rápido?

- (R) No, no, no, yo... salvo a mi suegra que me decía "a ver ¿si tú quieres garbanzos, por qué vas a comprar lentejas?" Pero vamos.... Cosas así, puntuales, o "iAy! M., he visto una colcha para la cama" que además eso fue cierto y mi ex marido "ya estamos todo el día comprando" Cosa que es mentira, y bueno, mi suegra para no tener más follón, porque la cosa se subía de tono "no te preocupes que tengo yo aquí una que no uso, te la llevas" A mí sí me daban algo, yo aprovechaba eso, nunca compré cosas que no necesitara.

- (P) ¿Tu suegra, te apoyaba?

- (R) Digamos... cara a la galería

- (P) Y luego ¿no era sincero el apoyo?

- (R) Jamás vi que le dijera nada a su hijo, sí, sí, yo era muy buena... era fabulosa... una mujer muy limpia... una mujer que cocinaba que para qué... me querían y según ellos, me quieren mucho, pero nunca vi decirle a su hijo "oye que te estás pasando o ¿por qué le dices esto?" Nunca 
- (P) ¿Denunciaste alguna vez a tu marido?

- (R) En el momento que me dijo que los coches se subían por las aceras y que a él le sobraba dinero para pagar a unos gitanos para que vinieran a por mí a apuñalarme

- (P) ¿Pero eso una vez separada?

- (R) Sí

- (P) ¿Y ahí ya le denunciaste?

- (R) Sí

- (P) ¿Tuviste miedo o qué pasó? ¿por qué le denunciaste?

- (R) Por eso, porque me llamó diciéndome eso

- (P) ¿Surge de ti la idea de poner la denuncia o te lo sugiere alguien?

- (R) En ese momento que me llamó, sí ... tenía gente en casa que me dijeron que no lo dejara pasar, que era continuamente amenazas o groserías

- (P) ¿Qué gente tenías en casa en ese momento contigo?

- (R) Tenía a una amiga, estaba mi padre y una pareja que tenía mi padre entonces.

- (P) ¿Y te animaron un poco a denunciar?

- (R) Sí

- (P) ¿Tuviste en alguna ocasión, A.M., la necesidad de exagerar tu historia para hacerla más creíble?

- (R) No, no me gusta exagerar las cosas, no, no soy así.

- (P) ¿En algún momento tuviste la idea de acudir a una casa de acogida para resolver tu situación? ¿o no tuviste necesidad?

- (R) Nunca lo pensé, no, nunca lo pensé

- (P) Tú cuentas esta historia de malos tratos psicológicos y de amenazas de muerte, pero yo te pregunto ¿A. en alguna ocasión se sintió maltratado por ti, pensó que eras tú la que le maltratabas?

- (R) No

- (P) ¿Nunca te lo manifestó?

- (R) No

- (P) ¿Tus hijos presenciaban todo esto que estaba pasando, los insultos, las amenazas, etc.?

- (R) Sí, ellos lo vivieron y el día de la llamada estaban en casa. Y V. que era más vivo para eso..., incluso yo no quería que se enteraran de muchas cosas, o que entraran... y por narices, que nos bajaron en coche, de aquella misma, nos fuimos donde vive mi padre, estuvimos allí unos días, el mayor no, pero el pequeño insistió, insistió, llorando que no me dejaba y subió conmigo al juzgado a poner la denuncia. $Y$ en ningún momento quise que mis hijos entraran en nada de esto por no perjudicarles más

- (P) ¿Pero presenciaron cosas?

- (R) Sí

- (P) Sí que han vivido cosas. Vamos A.M., a lo que tú piensas sobre el amor y los sentimientos. ¿Tú piensas A.M. María, que tu pareja, A., en aquel momento era tu complemento ideal, la persona con la que ibas a envejecer?

- (R) Siempre

- (P) ¿Lo pensaste?

- (R) Siempre

- (P) ¿Y a día de hoy?

- (R) Hombre, lo veo imposible, pero sigo pensándolo

- (P) ¿Sigues pensando que es el hombre de tu vida?

- (R) Sí

- (P) ¿Piensas que la situación ideal para ti, es la de estar emparejada, que si no tienes una pareja como que no tienes valor?

- (R) A ver, una pareja cualquiera no. No, no, prefiero estar yo sola

- (P) ¿Te gustaría estar emparejada? 
- (R) Con mi marido sí

- (P) ¿Con él?

- (R) Sí

- (P) ¿Piensas que las mujeres somos de un solo hombre?

- (R) ¡Hombre!, mi educación me dice que sí, pero vamos... lo que ves alrededor... eso está muy pasado, no. Tienen el mismo derecho las mujeres que los hombres de tener una o varias relaciones, las cosas han cambiado, por supuesto.

- (P) ¿Qué opinas de los celos? ¿piensas que son necesarios en una pareja para que funcione la relación?

- (R) A ver, una cosa con color, como se suele decir, pero no, creo que no son buenos

- (P) ¿Y qué piensas sobre el amor? ¿Crees que tiene que mostrarse siempre con la misma intensidad en una pareja?

- (R) Yo pienso que hay momentos, pienso... mi forma de ser, y lo que te digo... la educación, y no es lo mismo, los dos primeros años que es todo vida y dulzura y de novios, que luego una vida constante, día a día, día a día, día a día. Pues tienes tus altos y tus bajos. Y días que tienes ganas de más carantoñas que otras. Ahora sí, claro que te gusta que te den una caricia, que te den un beso, o que tengan un detalle. Pero bueno... tienes tus altos y tus bajos

- (P) ¿El amor lo puede todo?

- (R) Eso creía yo

- (P) ¿Tú pensabas eso?

- (R) Sí

- (P) ¿Y ahora qué piensas?

- (R) Pues sigo opinando como la gente de antes, que tiran más dos tetas que dos carretas

- (P) ¿Ni amor, ni gaitas?

- (R) Es lo que creo

- (P) ¿Tú piensas que amar a una persona es involuntario, que no se puede hacer nada para evitarlo, que cuando surge el amor surgió y no depende de la voluntad?

- (R) Yo creo que sí

- (P) Que te enamoras y te enamoras, ¿sin saber por qué?

- (R) Exacto

- (P) Si te enamoras de alguien ¿lo ideal sería casarse con ese alguien o convivir?

- (R) ¡Hombre!, si la otra persona quiere como tú, sí.

- (P) ¿Sería la situación ideal?

- (R) Sí, yo soy muy de familia, muy de ... sí

- (P) ¿Quién toma la decisión de separarse? ¿la tomas tú o la toma él?

- (R) Pues no sabría decirte, yo sé que estuve aguantando un tiempo, igual un año o año y pico y vi que la situación no cambiaba, entonces, simplemente, él no puso ningún reparo, me imagino, pues no lo sé Belén, estuve tan mal, tan mal de aquella que igual él ya tenía su decisión tomada, pero yo recuerdo de cerrar él la puerta porque se iba a trabajar y decirle que en mi casa a la fuerza yo no quería a nadie, que si él no estaba a gusto conmigo que cogiera puerta, y vamos... él la cogió

- (P) ¿Cuál fue el detonante para la separación? ¿Cuál fue la gota que colmó el vaso? Porque después de haber aguantado un tiempo ¿qué pasó?

- (R) Pues llamadas a las dos o las tres de la mañana. de una señora, una carta que cogí yo sin querer, me la encontré, y bueno...

- (P) ¿Una carta de quién?

- (R) De ella dirigida a él

- (P) Una carta, como ¿de amor... cómo era la carta?

- (R) Amor, amor, no. Pero bueno... se entiende perfectamente que tienen una relación, que la madre de ella tapa mucho, porque ella tiene también dos hijas y que su madre la tapa mucho para que esté con mi marido, mientras el suyo está ciego perdido, el marido de ella. Entonces ya no pude más... Las llamadas, contestar 
delante de mí, de noche, hacerme la dormida y llamadas y mensajes, llamadas a mi fijo y saber que iba al trabajo y se veía con ella

- (P) ¿Cuántos intentos de separación tuviste antes del definitivo, si es que tuviste alguno?

- (R) No, el definitivo

- (P) ¿Después de separarte que cambios experimenta tu vida?

- (R) Me hundí muchísimo más, Belén

- (P) ¿Cambia para peor?

- (R) Sí, me hundí mucho

- (P) ¿Con qué apoyos contaste en ese momento?

- (R) Pues el de mis amigas, las que tenía más cercanas, claro. Porque mi padre no vive aquí y bueno, él... entiendo que es mayor y tiene sus problemas también, pero no... venía de vez en cuando, pero el apoyo, apoyo, las amigas.

- (P) Me decías antes que de salud, estabas pachucha ¿Cómo te encuentras ahora?

- (R) De momento como que me estabilicé, mi cabeza sólo daba vueltas a lo que había pasado con mi marido y luego me han dicho que todo esto va saliendo de la tensión que he tenido, empecé a cojear y he ido a más

- (P) ¿continúas viviendo en la casa familiar?

- (R) Sí

- (P) ¿Tú te haces cargo de la hipoteca?

- (R) La estoy pagando entera

- (P) ¿La pagas tú entera?

- (R) Sí

- (P) Económicamente cuentas que te estás arreglando con $600 €$

- (R) Sí

- (P) ¿Cómo estás de relaciones sociales? ¿Sigues manteniendo las amistades?

- (R) Las mantengo, pero ya no... a ver, por mi situación económica más que otra cosa, yo no puedo seguir un ritmo, que no es que ellas tengan un ritmo exagerado, porque te puedes gastar $2 €$, pero claro, a mí $2 €$ me suponen, el tomar un café o dos no va a ningún lado, pero a mí sí.

- (P) ¿Las relaciones familiares?

- (R) Siguen igual

- (P) ¿De hecho con tu madre no mantienes ningún tipo de relación?

- (R) No

- (P) ¿Y con tu padre?

- (R) Sí, o por ejemplo, ahora, cada 15 o 20 días, voy y le llevo comida para que congele y vaya sacando y le plancho y según como esté de espíritu, pues a lo mejor, le paso el baño un poco o... poco más

- (P) ¿Y la familia de A? ¿Tienes relación con esa familia?

- (R) Si nos vemos por la calle, me saludan, a ver "como estoy", "que tire para adelante", mis suegros hasta hace poco, de vez en cuando me llamaban para ver cómo estaba, pero vamos... apoyo, apoyo, no. De hecho a mi casa, digamos que ni mis cuñadas, ni... no, cuando antes era siempre, o una cena o una merienda, o una comida. Siempre estaban, para mi casa, para mi casa, para mi casa. $Y$ desde entonces allí no han ido. Y sí, sé que han salido de copas, con las supuestas amantes o queridas, o novias....

- (P) ¿De A.?

- (R) Exacto

- (P) En cuanto a la crianza de tus hijos, ¿tú te ocupas de uno de ellos? y...

- (R) Ahora de uno, siempre estuvieron los dos conmigo

- (P) ¿Siempre estuvieron los dos contigo, pero últimamente, uno de ellos se ha ido con su padre?

- (R) Sí

- $(\mathrm{P})$ ¿Por qué razón? 
- (R) Pues yo creo que por los estudios y porque igual... a ver, no es la palabra libertad, porque yo, no es que les haya quitado de nada ¿no?, pero... igual es eso, la libertad que tienen con él. Su padre... pues allí... por lo que me han contado ellos, yo no lo he visto, dice que sube a la media novieta, que se meten en la habitación, que están todos los días allí juntos, que... claro, yo en mi casa, que suba una chica y que se metan en la habitación... pues no.

- (P) ¿El que sube a la novia es el niño?

- (R) Sí

- (P) Creí que el padre

- (R) Bueno, los dos, allí es eso, jarana, por lo que me dicen

- (P) ¿Tienen una relación de colegas padre e hijo?

- (R) El vocabulario tampoco me gusta, el que adopta su padre con él, es mucho jurar, mucho jurar, mucha palabrota, pero bueno... no sé porque en realidad, si fue por eso, porque como tiene que ir donde él trabaja, lo lleva y lo trae

- (P) Un poco por comodidad

- (R) O por la libertad, esa que digo que tiene.

- (P) Que si van de vinos por el húmedo... me parece bien, pero vamos hay cosas que no, por mi educación.

- (P) V., es el que está con su padre ¿va a verte a casa?

- (R) Ahora menos porque está en exámenes, pero, sí, sí

- (P) Pasa por casa con normalidad

- (R) Sí, en un principio, incluso cada día. Ahora un poco más distanciado.

- (P) Él sigue considerando tu casa como su casa

- (R) Sí, sí, sí... sí porque ha habido días que a lo mejor ha coincidido que ha salido el mayor, que es muy puntual que salga, es de pascuas a ramos y se vienen los dos a dormir para casa y se queda a comer al día siguiente... Bien

- (P) ¿Y a ti te gusta?

- (R) Bueno... bueno, claro, además es que es de otra manera, lo que te digo, enseguida llega y empieza a contarte historias o te cuenta batallitas de él o pone música y se lía a bailar, como que te da vidilla

- (P) Con V., tienes buena relación

- (R) Sí, A. es más reservado, no te dice nada

- (P) Bueno, son distintos, A.M.

- (R) Sí, son distintos

- (P) Con todo lo que tú me has dicho, de nuevas parejas para ti ni hablamos

- (R) Ni me lo planteo, o me da un aire y me vuelvo loca por el primero que pase o no. No, mis hijos, mis hijos y se acabó

- (P) En este punto, donde ya llevas varios años separada ¿cómo te sientes? ¿Cómo te ves a ti misma?

- (R) Pues sola

- (P) ¿Te ves sola?

- (R) Sí

- (P) ¿Me lo dices como con pena?

- (R) Sí

- (P) Tienes dos hijos

- (R) Pero te ves sola

- (P) Y cuando piensas en un futuro ¿cómo te lo imaginas?

- (R) ¡Puf!, primero no pienso llegar muy lejos

- (P) ¿Cómo que no piensas llegar muy lejos? ¿eso qué significa?

- (R) Pues por la vida que tengo, la vida que llevo, sedentaria (su voz se entrecorta y se pone a llorar), de tabaco, café, tabaco, café

- (P) ¿Sigues tomando tanto café y fumando tanto por las noches?

- (R) Ahora me paso muchas noches de pies y me acuesto cuando se levanta mi hijo

- (P) Y hoy que yo te he hecho madrugar jmenuda faena! 
- (R) Pues me acosté a las cuatro de la mañana., no era capaz de dormir, seguían siendo las cinco y a las siete menos algo que se levantó A., yo desperté, pero me volví a quedar y le había dicho que de todos modos, me diera un toque cuando se fuera y si no me tiro de aquella, no me levanto

- (P) Pues ya lo siento, te he hecho una faena

- (R) No, no, no, en parte quiero salir, pero luego digo ¿para qué?

- (P) A lo mejor, necesitas tener un aliciente por las mañanas, que te ayude a tirarte de la cama

- (R) Alicientes tengo muchos, en mi casa para limpiar, Belén

- (P) Pero eso no es atractivo A.M.

- (R) No es que sea atractivo, es lo que te he dicho ¿para qué? ¿para quién? ¿quién te valora nada?

- (P) Para ti misma

- (R) Paso, te lo he dicho antes y te lo digo ahora

- (P) Total que de futuro, ¿me dices que no te ves llegando muy lejos?

- (R) No

- (P) A mí me estás dejando un poco asustada

- (R) No, o sea, la mentalidad que tengo es que no voy a llegar a ser muy mayor, quizás me muera antes y de repente y... y si vivo más sola, sola porque mis hijos, por lo que ahora hay con la juventud y por lo que a lo mejor han vivido, cada uno va a hacer su vida y por supuesto es ley de vida

- (P) Es lo normal, A.M.

- (R) Como es ley de vida, me voy a quedar sola

- (P) Bueno... mejor no anticipar cosas que no sabemos cómo van a suceder. Mi entrevista termina aquí, no sé si tú quieres contarme algo más A.M.

- (R) Pues no sé qué decirte Belén. Más o menos sabes mi vida, es lo que te he contado, sigo parecida y sigo, digamos tan tonta o gilipollas, hablando mal y claro. A. sigue chinchando

- (P) Sigue chinchando ¿a qué te refieres?

- (R) Pues... es raro el día que no llama, es raro el día que... si puedo ayudarle, es raro el día que... eso... que a ver... como que te da una de cal... a lo mejor lo veo así y no es, igual es que quiero ver yo eso, pero joer, es lo que le he dicho, que haga su vida y que me deje en paz, que está bien que hable con sus hijos, pero que pase de hablar conmigo. He tenido momentos en que le he colgado, no he querido hablar... y luego me siento mal, incluso conmigo misma, pero vamos no admito que me llame ahora mismo para decirme que si le ayudo con sus padres. Yo por mí, por mi forma de ser, sí, porque sus padres no tienen la culpa y porque soy una persona que me gustaría ayudarles y por otro lado digo, pero bueno eres idiota o qué, se han reído poco, que se rían más. En las navidades pasadas, yo no sé si esto... no, ya no venía a hablar contigo. ¿Te comenté en alguna ocasión que una de las novias de mi ex marido lo había echado de casa y se presentó en la mía? Estuvo en mi casa y me llenó la casa de cajas con sus pertenencias

- (P) ¿Pero él no tiene su propia casa?

- (R) Sí, pero la alquiló, digamos. Estaba en casa de la otra muchacha, la otra muchacha, por lo que fuera, él dice que fue por mi hijo...

- (P) ¿Y ahora recuperó su casa?

- (R) Tiene otra, esa la sigue teniendo alquilada

- $(\mathrm{P})$ ¿Y ahora qué vive en una casa de alquiler?

- (R) La compró

- (P) ¿Otra?

- (R) Sí

- (P) ¿O sea que ahora tiene dos?

- (R) Sí

- (P) Pues bien 
- (R) Para que veas la tontería de A.M., cuando a A. le pasa algo, viene y A.M. le abre la puerta

- (P) Es que eres como su madre A.M.

- (R) A lo mejor es lo que él piensa, que soy su madre

- (P) Claro que sí, es que tú tienes tres adolescentes, no tienes dos, tienes tres

- (R) Pues estuvo casi un mes, con mi casa que....

- (P) Como un almacén

- (R) Exacto. Y a él porque le dije, en cuestión de cuatro días que cogiera la puerta que mi hijo la tenía abierta, pero él no, porque él pensaba quedarse allí todo el mes hasta que arreglara los papeles del piso. Esa es mi vida Belén.

- (P) Bueno, tú eres así, tiempo al tiempo. Yo te agradezco muchísimo que me hayas concedido este ratito, porque estoy segura que de aquí sale un buen material

- (R) Gracias a ti, Belén

- (P) Gracias por haber colaborado de tan buena gana.

- (R) Tú me has apoyado mucho y me has ayudado mucho, muchas gracias.

- (P) Se hace lo que se puede. 


\section{ENTREVISTA № 6- A. (21/03/2011)}

- (P) Dime cuántos años tienes

- (R) ¿Es estrictamente necesario? (utiliza el sentido del humor)

- (P) Empezamos bien

- (R) Aunque no los aparente, tengo 55

- (P) Muy bien llevados, D.

- (R) Perfectamente, porque todo el mundo me echa 45, 45,47 y yo les digo que sí

- (P) ¿De dónde eres D.? ¿Dónde naciste?

- (R) Nací en V., un pueblecito cerca de aquí, de A.

- (P) ¿Cuántos hijos tienes?

- (R) Dos

- (P) ¿Chico y chica?

- (R) Chico y chica

- (P) ¿Edades?

- (R) 33 y 28, no 29, que hizo 29

- (P) ¿Con quién viven?

- (R) Independientes, con sus parejas, bueno mi hija, ahora acaba de dejar a la pareja, pero viven independientes

- (P) ¿Y son hijos del que fuera tu marido?

- (R) Sí, claro, evidentemente

- (P) Son hijos los dos de él. ¿Dónde vives ahora D.?

- (R) Aquí en A.

- (P) ¿Y tu familia?

- (R) También

- (P) ¿Vivís todos aquí en A?

- (R) Bueno, la única que vive aquí es mi madre, y me dedico a ella los sábados, es el día que le dedico a ella para comer y luego traigo el taper para comer yo al día siguiente, bueno... vuelvo a comer al día siguiente, pero para cenar, no me gusta cocinar.

- ¿Tienes hermanos/as?

- (R) Sí, tengo... somos cuatro hermanos, tengo dos hermanos y otra hermana. Lo que pasa es que tengo un hermano en $A$., en V. concretamente, un hermano viviendo en $\mathrm{L}$. y mi hermana que está viviendo en $\mathrm{M}$.

- (P) ¿Y tus hijos donde viven?

- (R) Mi hijo en O. y mi hija ahora irá a vivir para L., viene de M. para L.

- (P) ¿Qué situación laboral tienes en la actualidad, D.?

- (R) Estable, yo sigo estando en la empresa en la que estaba, con mi horario laboral como siempre, dependiendo del ayuntamiento como siempre y de la empresa privada y de administrativa como siempre y bueno...

- (P) ¿Cuántos años llevas en este trabajo?

- (R) 20 años aproximadamente, es que como estuve un año sin contrato y ese tipo de cosas, pues bueno...

- (P) ¿Qué estudios tienes D.?

- (R) Pues tengo, no sé, si te enseñara el currículum te quedarías un poco pasmada. Normalmente no suelo enseñarlo porque siempre me dicen que tengo excesiva... capacidad

- (P) Preparación

- (R) Excesiva preparación, que quieren algo con menos... sencillo. Yo tengo... bueno soy administrativo y luego soy licenciada, no diplomada, licenciada no, diplomada en técnico de medio ambiente, tengo varios cursos de informática a nivel de usuario, correo electrónico, programación tipo, lo que utilizas, luego tengo un montón de cursos hechos ya... de historia, sabes que a mí me encanta la historia, yo me meto en un museo, me meto en un archivo y el navegar por el mundo de lo desconocido, de la antigüedad, es mi mundo y bueno... pues publico muchas veces 
en el periódico muchísimas cosas, y me encanta investigar, la investigación es mi... soy muy polifacética, entonces acudo a muchos cursos de eso, voy a muchas conferencias, cuando hacen cursos que los dan en la escuela de A. participé, tengo la titulación de haber hecho el curso de la escuela de A., eh... te puedo decir del monacato $\mathrm{A}$. otro tanto, mujeres que han destacado en la historia por... pues por... cualquier materia, pues ahí estoy yo. Siempre un poco, el conocimiento, a mí me parece que todo lo que se sepa siempre es poco, es cuando te das cuenta que entre más sabes, menos sabes porque dices jolín lo que me queda por explorar y por saber. Es una de mis pasiones, la pintura también, cuando hay exposiciones, me encanta ver la gente, como se expresa, me gusta dialogar mucho, entonces voy a muchas conferencia, doy muchas conferencias, bueno... di más que doy, hablo mucho del tema, siempre destaco el valor de la mujer, pero ya no hablo del maltrato de la mujer, sino, una vez cerrada esa puerta, cómo te enfrentas a la nueva vida, una nueva vida que te han impuesto, que tú no has buscado, pero que te han impuesto y a la que te tienes que afrontar y cómo tienes que afrontarte. Entonces lo que trabajo son esas herramientas, por la experiencia que he vivido con la asociación (es la presidenta de la asociación de mujeres Concha Espina de A.), he dicho que hay que cerrar esa puerta y empezar a convivir con una nueva forma de vida

- (R) Hablas de la asociación, D. ¿Qué asociación es en la que tú estás colaborando?

- (P) Se llama, una asociación de autoayuda de A. y comarca, porque me parecía un pecado mortal que una mujer, por el simple hecho de que no fuera de A., no se le pudiera dar ayuda. Yo considero que todas las mujeres somos universales, porque España es la nación donde nacimos, pero si yo estoy viviendo en A. y conozco muchos casos de gente, como tú bien conoces, de gente que tiene problemas, de S. J., de S. R., de C., de estas zonas de los pueblos, que no tienen nada que ver con A., me llaman por teléfono, a las 5 de la mañana, a las 3, a las 4 de la tarde me vienen aquí, esto es muchas veces, casi una consulta. Es gente que termina marchándose para casa, pues con alimentos de la Cruz Roja, con un teléfono para un trabajo, todo este tipo de cosas... a cualquier hora del día y de la noche, o sea...

- (P) Estás permanente

- (R) Yo, no es la primera vez, que a las 5 de la mañana, me siento en la cama, ya sentada, relajada y digo, "bueno a ver, cuéntame, ¿qué te pasa?" "Es que me acaba de pegar mi marido" "Vamos a ver ¿ha sido una bronca?", porque yo soy un poco moderada, por una razón, porque yo he vivido la soledad tan de cerca y con tanto tiempo y a mí no me gusta, no creo que a nadie nos guste vivir en soledad, los que estamos solos, estamos solos porque no nos queda más remedio, yo además es que soy una persona que soy muy cariñosa, me encantan los mimos y todo ese tipo de cosas, no es que lo lleve, que me vaya la vida en ello, pero me encantaría tener pareja, porque a pesar de todos los pesares, para mí el amor es lo más bonito de este mundo. Entonces pues... "no..., es que nos enfadamos y cogió y pegó un portazo y marchó". Yo lo primero que le pregunto, vamos a ver, un arrebato lo tenemos cualquiera, uno o el otro, es frecuente, sucede con cierta frecuencia. "No..., pero es que me pilló mal, ya estoy harta, porque es siempre lo mismo" "Por qué no te sientas en la mesa y te pones a hablar con él del tema y decirle, vamos a ver, si esto tiene arreglo, lo arreglamos, pero civilizadamente, con la cabeza fría y a solas, si tiene arreglo, arreglarlo y si es reiteradamente, no hay amor, y lo que va a haber es sufrimiento, arreglarlo, pero por las buenas y separaros por las buenas, pero contándoselo a los niños

- (P) De todas las maneras, D., perdona que te corte, me estoy dando cuenta, de que yo te quiero preguntar sobre tu historia y tú por tu trayectoria....

- (R) Me voy

- (P) Te vas a otras historias

- (R) Claro, es que a fin de cuentas es mi historia, porque hasta las 5 de la mañana me está pasando esto

- (P) Es tu vida... forma parte de tu vida 
- (R) Sí, no sé si es por suerte o por desgracia, ahora es por suerte, ya no me llama mucha gente de noche

- (P) No, no... céntrate en tu vida, yo quiero que tú me cuentes tu vida, que es lo que tú has vivido y has experimentado

- (R) Pregunta, pregunta. Lo que yo he sentido

- (P) Sí, tus sentimientos, efectivamente

- (R) Precisamente me baso porque como yo lo he vivido, lo que intento es que la gente esa, no pase por lo que yo pasé si se puede evitar. Si no se puede evitar, no se puede evitar. Procuro siempre, “¿Hay arreglo? ¿Se puede arreglar? Arréglalo" Si no hay solución, vete a los medios, yo le indico donde tiene que ir y entonces buscar una solución, pero hacerlo de forma que sea... que no sean los niños moneda de cambio, eso me parece un pecado

- (P) ¿Cuánto tiempo hace que estás separada?

- (R) Pues siete años, hace este año ocho años, pero bueno en Julio que no queda tan lejos

- (P) Siete años y medio, más o menos

- (R) Sí

- (P) ¿Qué tipo de maltrato sufriste?

- (R) Vamos a ver... yo el maltrato que más sufrí fue el psicológico y la razón es muy clara, el nivel educacional de mi pareja, de mi ex marido, era totalmente diferente, yo era una persona de estar siempre comiéndome los libros, aprendiendo y descubriendo y él... vamos... lo acostumbré yo a leer el periódico digamos ¿no? Cuando quedó en paro le obligué a hacer el graduado escolar para que lo sacara, fui poco a poco, jugando con él para que intentara adquirir una cultura, que se pudiera defender. Entonces ahí chocábamos un poco, pero bueno, yo siempre sabía cómo sacarle de los apuros. Entonces eh.... Me perdí

- (P) Te estaba preguntando sobre el tipo de maltrato que sufriste tú a su lado

- (R) Primero educacional, porque si eres una persona educada, tienes otras formas, aunque sea maltrato psicológico son otras formas. Mi marido es alcohólico, entonces eh.... Él nunca consideró que es alcohólico, para él salir de trabajar y tomarse 6 ó 7 vinos y luego venir, comer e irse a jugar la partida, jugaba la partida y se tomaba a lo mejor dos o tres cubatas, luego venía a casa y cogía y... "que voy a hacer la compra, que voy yo, si te quedas pintando o cualquier cosa, ya voy yo" poco a poco me fue relegando y salía a tomarse los vinos, otra vez por la tarde, hasta las 9 de la noche. En un principio del matrimonio, como él trabajaba además en un pub, pues era muy cómodo porque... es que me salto un poco la cronología de la historia.... Al principio que trabajaba en un pub, se cerraba a las 5 de la mañana, a las 3 de la mañana, 3 ó 4, pero siempre venía a las 8 de la mañana o las 7, siempre, ¿dónde se iba? ¿qué está abierto a esas horas? Pues en los puticlubs. Yo ahora me he enterado de que lo conocían en todos, nunca pensé, es que tampoco lo sospeché, porque yo además... como yo soy confiada, pienso que no me miente nadie

- (P) ¿Hablas de la época de recién casada?

- (R) De recién casada, entonces, yo te puedo decir que en el viaje de novios, yo me casé embarazada, y... bueno de estos días que estás incómoda, que te encuentras mal, que estás cansada, que no tienes ganas de salir y se marchó con... estaba mi hermano viviendo allí, pues se marchó de fiesta con sus amigos y vino a las 8 ó las 9 de la mañana y yo me fui para el hotel porque yo me encontraba mal. Él venía siempre tarde, hacía su vida, claro con 20 años, se le apetecía marcharse a la discoteca, marcharse por ahí, claro a mí también, pero yo tenía un bebé y si no lo cuidaba yo a ver quién lo cuidaba. Con lo cual ahí sufrí muchísimo porque como todas mis amigas estaban en la discoteca... yo soy muy responsable de siempre, pues yo me tenía que quedar con mi niño. Ahí tuvimos muchas discusiones porque llegaba a tomarse la friolera de unos 25 cubatas por la noche, diarios, gin -tonic, que huelo a gin-tonic y me dan nauseas, hoy día, no lo puedo evitar. Entonces claro, tú imagínate, si se acuesta a las 8 de la mañana, a las 7 de la mañana, se levantaba a 
las 3 , o depende, se levantaba a las 12 o la 1, porque tenía que ir a llenar las cámaras, y a preparar, luego a tomar el vino con sus amigos, venía, comía y evidentemente tenía que dormir un rato la siesta porque claro estaba agotado, dormía la siesta hasta las 6 y media o las 7, yo siempre sola, en el parque, con los niños, domingos, festivos, fiestas, fiestas de guardar, fiestas de no guardar, siempre sola, y... él se levantaba, se duchaba, iba a trabajar, venía a cenar, cuando él venía a cenar, los niños estaban acostados, con lo cual, no los veía, cuando se levantaba, se marchaban al cole, tampoco los veía, entonces tomaba el vino y ya iba a trabajar, cenaba y cuando salía de trabajar, evidentemente, tenía que darse una vuelta, porque claro, llevaba todo el día trabajando, y pues... era cuando se tomaba... llegó a presumir delante de los amigos de tomarse 25 cubatas. Te voy a dar un detalle para que te hagas una idea, cuando hizo mi hija, la primera comunión, llegaba a gastarse tantísimo dinero, yo, de entrada, me puse a trabajar luego, en el momento que me quedé embarazada de mi hija y nació mi hija, a los dos años me puse a trabajar, porque yo veía que ganaba muy buen sueldo, podíamos vivir perfectamente, pero la mitad del sueldo se iba en alcohol, en alcohol y tabaco. Entonces llegó la comunión de mi hija y yo prácticamente no tenía ni para comprarle el vestido de la primera comunión a mi hija, y vendió un moto, tenía una moto de estas, pequeña, no recuerdo ahora, una moto pequeña. "Bueno si vendes la moto, por lo que te den de la moto tenemos para comprar el vestido y si quieres pues invitamos a los tíos para comer y celebramos la comunión, más que nada por los críos", y llegó el día y... que no vende la moto, entonces mis padres dijeron "a la niña le compramos nosotros el traje de la comunión y lo que sea" porque yo se lo pensaba pedir prestado a una vecina, a una prima y mi madre eso no lo permitía y al día siguiente... estando el mismo día de la comunión me dice me acaba de pagar..., porque se la compró un hermano curiosamente, "me acaba de pagar mi hermano la moto", "¿En cuanto se la vendiste?", "en 60.000 pesetas se la vendí. Entonces era un dineral, evidentemente. Dije, "bueno, ten en cuenta que hay muchos gastos y mis padres corren con todos, tampoco es cuestión de abusar" y dijo "no te preocupes que lo tengo todo en casa y miramos, hacemos cuentas", porque ese día trabajó, el día de la comunión de mi hija salió solamente a la ceremonia y a la comida, luego se marchó a trabajar, yo me quedé sola con mi hija, que era cuando por la tarde había que ir a la iglesia a no sé qué acto, mis hermanos como vinieron todos, y hacía mucho que no se veían, hacía buen tiempo, se quedó todo el mundo en la terraza, y yo me fui con mi hija y mi hijo, yo sola a la iglesia y de allí ya salimos tarde, al día siguiente había cole, entonces yo me tuve que marchar con los niños para casa, con lo cual fue una comunión, para mí tristísima. Todos los acontecimientos han sido para mí, siempre muy tristes. Él se marchó a trabajar y bueno... al día siguiente cuando vino dijo "hoy descanso" y dije "bueno por qué no salimos y celebramos un poco los cuatro la comunión de la niña, más íntima, yo que sé, vamos a algún sitio, tomamos un chocolate con churros con los niños o cualquier otra cosa, es decir, otro tipo de cosas, y dijo "si hombre si, de eso nada, me marcho con los amigos" “¿Cómo te vas a marchar con los amigos?"'Que sí, que sí que yo me voy con los amigos" Fueron al colegio, vinieron, hicieron los deberes, él se marchó y cuando vino, yo le dije "Vamos a ver P. ¿dónde está el dinero?" y se echó a reír y me dice "Querrás creer que me lo he fundido con los amigos celebrando la comunión de la niña" Le dije "No tienes vergüenza, no tienes vergüenza", yo me puse a llorar de frustración, de rabia, porque no puede haber un golpe más bajo, Belén, no puede haber un golpe más bajo. Sabiendo que mis padres me habían tenido que ayudar con todo, mi hermana pagó el restaurante para que invitáramos a los tíos y va y se funde las 60.000 pesetas en cubatas con los amigos, por ahí, sin ningún remordimiento. Eso me lo tuve que tragar y eso para mí era, siempre esa tortura diaria, venir y llegar borracho, yo decirle a mis hijos, a la niña sobre todo “¿Qué le pasa a papá?" "No, nada, está mal, pero no te preocupes, vete a jugar" Si hacía frío les ponía a ver la tele, siempre juegos infantiles, nunca les dejé ver la tele de noche, o les mandaba a su habitación a jugar y ahora me comentan " $\mathrm{Si}$, tú nos mandabas, y cogíamos y cerrábamos la puerta, pero luego 
escuchábamos detrás de la puerta" Porque yo jamás, delante de los niños, le hice ninguna recriminación, más que nada para que los niños respetaran a su padre, pero claro, cuando estábamos solos, sobre todo, íbamos al dormitorio a hablar, yo le decía "¿No te da vergüenza que tus hijos te vean como te ven?, es que tropiezas al entrar en casa y te caes al suelo y yo les tengo que estar diciendo que estás enfermo, no son tontos, que se dan cuenta, que son niños pequeños, pero se dan perfectamente cuenta" Ten en cuenta que mi hija y mi hijo, se llevan entre ellos cuatro años, mi hija tenía 2 años y mi hijo tenía 6 años y un día que vino muy, muy cargado, le dije "pero bueno, ¿no te da vergüenza?", llegó tropezando, dándose contra las paredes "¿qué le pasa a papá?" y yo "nada, no le pasa nada" y le dije a mi hijo "coge a la niña y sal a jugar a la calle un poco" porque vivíamos en un barrio que se podía salir a jugar, había como un parque que se podía jugar allí, y mi hijo se me quedó mirando, con 6 años, a ellos yo les había dado la comida, porque siempre comían antes, como él llegaba tarde, para que pudieran ir luego al colegio y mi hijo, se da media vuelta y coge un cuchillo, porque cuando entró en la puerta se puso sobre el marco de la puerta "a mí no me hables en mal tono" y me levantó la mano para pegarme, entonces mi hijo tuvo un acto reflejo, fue darse media vuelta, coger un cuchillo y ponérselo en el pecho a su padre y dijo "si tocas a mi madre te lo clavo". Yo pensé que lo había olvidado y lo recordó no hace mucho, pues el año pasado. Mira, volví a sentir la misma angustia cuando lo comentó que el mismo día que pasó, por el dolor que le tuvo que causar a mi hijo hacer eso.

- (P) ¿Y tú recordabas perfectamente ese día?

- (R) Es que de ese día, yo no me olvidaré en la vida, pero mi hijo tampoco. Sin embargo su padre, yo creo que ni se acuerda.

- (P) Hubo malos tratos psicológicos

- (R) Y empujones...

- (P) Ahí vamos a entrar, al mal trato físico

- (R) Mal trato físico, pues empujones... que decía que "te pintas mal, que estás gorda, que estás fea". Cuando yo estoy, como he estado ahora, "no te pongas vaqueros porque te quedan mal, intenta no dejarme en ridículo delante de los amigos" Por una razón, porque a mí no me gustaba beber, yo me bebía un mosto, o un butano, o un corto de cerveza con limón y ya estoy llena, porque no me gusta beber. Claro si vas aquí, sales a las 7 a tomarte vinos hasta las 9 de la noche, yo me tomaba 3 y no quiero más, es que yo reviento, yo no puedo, entonces llegué a la conclusión de no ir a tomar vinos y me dediqué a estudiar, cuando empecé la carrera universitaria, empecé a buscar mi mundo.

- (P) ¿Ya habían nacido tus hijos?

- (R) Sí, sí. Yo la carrera la saqué casada, estando estudiando mis hijos, mientras ellos hacían los deberes, yo estaba estudiando, yo tenía una casa más grande, evidentemente, tenía una habitación adecuada para el estudio y cada uno tenía su mesa con su estudio, estábamos estudiando todos y él venía, hacía su vida, comía, se iba, volvía. Cuando se enfadaba porque le recriminaba "P., estamos a 15 y no nos llega para acabar el mes" Yo cogí un bote de Cola-Cao e iba guardando el dinero, iba metiendo dinero allí, porque mi hija estudiaba en las escolapias y era un colegio de pago, quería que tuviera una buena educación, y decía para que su padre lo gaste en alcohol, lo invierto en una buena educación para mis hijos, e iba metiendo allí el dinero, lo iba guardando, porque a lo mejor mi hija me decía "mamá necesito un libro para mañana y tengo que bajar a comprarlo porque tengo que leerlo y mañana exponerlo en la clase" ¿De dónde sacaba yo el dinero? Entonces me las ingeniaba para guardar el dinero en el bote de cola-cao, siempre tenía yo allí mis fondos, hasta que un día lo descubrió, no sé por qué, lo descubrió y cogió el dinero. Entonces yo tenía que coger el dinero y guardarlo en sobres, debajo del colchón, en sitios en los que él no pensara que allí pudiera estar. Para estas cosas, para un libro "bueno, pues le dices a las monjas que no tenemos dinero para comprar un libro" "No le hables así a la niña, porque la niña va a decir mamá a la compra y tú estás por ahí, vienes de noche de tomar vinos y luego ¿no tengo yo 
para los libros?" Porque mi hija se lo tiraba un poco en cara, mi hijo me dijo un día, llorando, que había pasado mucha, mucha vergüenza de ver a su padre borracho, es triste, pero tener que esconderse de su padre porque lo ves borracho y no se rían de él. Mis hijos has sufrido mucho, dicen que los niños pequeños sufren mucho, no, sufren más los mayores, porque son conscientes de la vergüenza ajena y la propia, pero es lo que hay. Y luego pedirle cosas, pedirle una cosa y coger y tirármela, en lugar de dármela en la mano, o que yo gastaba mucho dinero, llegó un momento en que me relegó. "Salgo yo de compras", ya no me daba dinero, yo cobraba mi sueldo y me decía "ya cobraste" Yo tuve, como más de un año que no sabía ni lo que cobraba él, ni lo que cobraba yo. Yo a lo mejor iba a la peluquería, yo cuando iba a comprar pagaba con tarjeta y se lo comentaba y me decía "no utilices la tarjeta que no hay fondos, ¿cuánto quieres?" "Dame dinero, voy a ir a la peluquería, dame 5.000 pesetas por ejemplo" Yo iba a la peluquería y me costaba 3.000 , pero siempre le decía 5.000 , porque era la forma en la que yo iba guardando para los libros, me quedaba con dinero y... "¡Jolín lo que cuesta!"”¿Decías algo?”, porque yo no creas que me callaba, lo que pasa es que llegó un momento en que me salía económicamente más saludable el callar que el enfrentarme, porque yo fue cuando tuve que empezar a ir a psicólogos, porque yo tenía conmigo una angustia total, era una angustia, una angustia, una angustia. Porque claro yo tenía que fingir en la calle, fingir en el trabajo, delante de los niños fingir que no pasaba nada. De hecho ahora mis hijos me dicen "mamá te queremos ver reír, porque estamos tan cansados de verte llorar, queremos verte feliz"

- (P) Entonces tuviste que acudir a consultas terapéuticas ¿tuviste secuelas a nivel psicológico?

- (R) Estuve 5 años consecutivos yendo una vez al mes, cada 15 días, cada 3 meses, como muy tarde hasta 6 meses.

- (P) Y físicamente ¿tuviste alguna lesión, daños provocados por él?

- (R) Empujones, yo muchas veces le decía que prefería que me pegara una bofetada, antes de ese mal trato, porque es más cruel. Mira, al fumar y beber tanto, tenía... roncaba, era, era... eso es... es que no lo puedo describir, es algo que te rompe los nervios de tal forma, que fíjate, yo vivía en un chalet de dos plantas, yo me quedaba abajo en el salón viendo la tele y cerrábamos la puerta del salón, cerrábamos la del dormitorio y una puerta que había en el pasillo y con la tele abajo encendida oíamos los ronquidos de arriba del todo. Yo iba para la cama, y para mí era una tortura, porque es que yo le movía a P. "P. por favor", se daba la media vuelta y otra vez a roncar, entonces llegué a la conclusión, mi hija despertaba "mamá que no puedo dormir", de echarme con mi hija, quedarme con mi hija a dormir, al final cuando mi hija ya era mayor, la decisión que cogí, yo tenía una sala de estar pequeñita para mí que la tenía con estanterías con libros, con mis cosas, mis escritos, el ordenador para hacer los escritos, porque tengo muchos escritos publicados, y llegué a la conclusión de que el sofá era comodísimo y lo que hacía era dormir en el sofá, entonces cuando él se marchaba, empezaba a trabajar por las mañanas, en jardines, en la parrilla donde él trabajó, y... estuvo un año al paro. La indemnización que le dieron ,yo le decía que por qué no la invertíamos en un piso, que es la opción que teníamos, ahora podíamos comprarlo, damos la entrada y una cuota mensual, todos los meses, podemos librar y comprar un piso. Y dijo que no, que como íbamos a comprar un piso, que luego a ver si no encontraba trabajo, a ver cómo lo pagábamos. Y la solución fue que en lugar de alternar con vino normal, alternaba a Riojas, hasta que se fundió toda la pasta

- (P) ¿Toda la indemnización en Riojas?

- (R) En Riojas, claro, yo trabajando. Yo trabajaba con mi padre, mi padre tenía un negocio de arreglar electrodomésticos y le llevaba la contabilidad, pero también cogía una llave inglesa y un destornillador, o sea, que yo tenía mi sueldo y vivíamos prácticamente de mi sueldo, el de él era para vivir la vida él.

- (P) Para sus gastos 
- (R) Para vivir la vida él, porque yo si me quería comprar ropa, pues siempre iba a mi padre "¿qué te gusta? ¿Qué te quieres comprar?" y me lo pagaba mi padre, la ropa, o venía mi hermana y me traía ropa de M. y si no, cuando cogía la tarjeta y me compraba algo "¿cómo te compraste esto?"”porque no voy a andar desnuda, además tengo un sueldo, el cual me puede permitir vestirme" $Y$ ahí, bueno... no se metía tanto, porque a él le gustaba presumir, ir siempre con una mujer que fuera guapa, que le dijeran tienes una mujer guapa, por eso él presumía mucho de mujer, pero ante los amigos y cuando estaba borracho, pero luego quería estar a su bola y a su aire, un hombre que no compartía nada y de hecho cuando se levantaba por las mañanas, iba al salón y decía "iEh! Sube para la cama que yo ya marcho" palabras textuales. Yo ya subía y me acostaba, hasta que un día me pilló mi hijo y me dijo "mamá ¿desde hace cuanto tiempo llevas durmiendo en el sofá?"'”dije, no es que hoy roncaba mucho tu padre y no podía dormir y bajé" "Mira, he bajado al baño, te he visto durmiendo ahí muchos días, no me mientas, lo sé porque no dormimos nadie" le mandamos ir al médico y nunca quiso ir y decía que el que no estuviese a gusto que se fuera de casa, tanto a mis hijos como a mí y mi hijo es muy inteligente y lo que hizo fue empezar a trabajar por su cuenta con 14 años para comprar su ropa y no depender de su padre. Entonces mi hijo se distanció mucho de su padre, es hoy el día que le habla, porque les he dicho que no deja de ser su padre, pero no le perdona, porque claro, hizo cosas que no debería haber hecho, no tenía ninguna razón para hacerlas y ellos han vivido con esa amargura, yo... era hacer la comida, engullir la comida y marchar corriendo o dormir, marchar corriendo o dormir, estar sentado allí y "¿me ayudas a hacer algo?" y no, empujar yo sola los muebles para cambiarlos, un día me dio por pintar las puertas, toda, porque estaban feas y él llegar a las 3 y pico de la tarde, los niños ya estaban en el colegio, yo ya había comido y me dice "estás pintando la casa que parece el ambulatorio" y yo le dije "pues si hubieras venido tú, hubiéramos elegido un color que nos gustara y lo hubiéramos hecho entre los dos" y dice "Eso, dejo yo el vino para venir a pintarte la casa" O sea, es que eso es continuo, todos los días y a todas las horas, un día y otro y otro y si no era eso, era otra cosa, la casa a él nunca le importó, los hijos menos. Yo me acuerdo que cuando tuve que hablar con mi hijo de... lo normal es que fuera de hombre a hombre y no de madre a chico ¿no?, porque bueno, no por mí, porque yo no tenía problema, pero porque mi hijo se pudiera sentir más violento, entonces yo cuando veía que mi hijo tenía algún problema de adolescente, tenemos una sana costumbre y era coger y marchábamos a hacer footing, íbamos corriendo, hacíamos footing, cuando estábamos en mitad del campo, nos sentábamos en el suelo y le decía "¿qué problema hay?" y lo hablábamos, pero haciendo footing, corriendo. $Y$ con mi hija, pues un poco también lo mismo, pero siempre aislados, o sea, yo nunca censuré a su padre delante de ellos, pero mis hijos no eran tontos, porque es que se veía, lo que pasa es que cuando llegaban mis padres, o íbamos donde mis padres era el encanto en persona, llegaba P. y llegaba Dios, porque cuando le dio el infarto, mi padre le llevó una bata, le llevó, vamos... una bolsa de aseo, le llevó todo lo habido y por haber, comida especial para P., que no le faltara de nada a P., o sea, que si faltaba P., se acababa, más que a un hijo y mi padre a $P$. le quería mucho, pero mi padre cuando se estaba muriendo era consciente de que P. tenía a alguien detrás, que tenía un rollo, él dos días antes de morir, mi padre recuperó un poco... no la memoria, pero el conocimiento de saber que estaba muriéndose y dijo "yo marcho" y mi padre le dijo "sí, tú marcha porque aquí no pintas nada", con un Alzheimer que tenía mi padre y él se quedó blanco, de hecho no se atrevió a marchar y al ratín dijo "bueno marcho", yo de hecho el día que murió mi padre, con él no estuvo, porque vino su... con la que estaba enrollado al tanatorio, porque las familias éramos conocidos y vinieron todos a dar el pésame a la familia, y ella no entró, él se quedó con ella...

(P) ¿Estabais casados todavía?

- (R) Sí, él muy, muy nervioso, pero ya estaban juntos. Yo no lo sabía evidentemente y no... ella no se acercó a darme el pésame para nada, él no se acercó a mí para nada, sólo se acercó a mí cuando estábamos enterrando a mi padre, que me cogió 
por el hombro, pero... ese momento nada más y a mí es como si me hubiera puesto una mano de hierro que me hundiera a la vez que se hundía la caja de mi padre. Es cuando recordé y dije "ahora mismo estás cumpliendo un papel ante la sociedad, porque en ningún momento, me has venido a decir, ¿estás bien?" No lo preguntó nunca, y a los 6 meses es cuando me dijo que me tenía que ir de casa, que metía a su novia y que o me quedaba a dormir allí y compraba una cama porque la de él estaba ocupada o que me fuera, que yo allí no pintaba nada, yo no tenía dinero suficiente para pagar la hipoteca y dije "o pagas la hipoteca o comes", "como no te llega el dinero el que me quedo soy yo con mi novia y tú te vas de aquí", quedé en estado de shock dos días y luego mis hijos me llevaron para casa de mi madre y a los 15 días es cuando yo empecé un poco a reaccionar, ellos me subieron la ropa y es cuando estuve ida tal mente, 15 días, fui al médico a que me diera algo porque no podía... me llevó mi madre, fui a trabajar y me dijo el jefe, "cógete 15 días de vacaciones" y llamó a mi madre y le dijo "es que se sienta en la mesa y es que ... no sabe dónde está" Y a raíz de eso, lo que hacía era llorar, llorar, llorar de impotencia, rabia. Yo me culpaba de haberle dado toda la libertad del mundo, probablemente si yo, porque yo nunca le quitaba, vamos a ver, cuando estás con una pareja tienes que dejar que tenga también su libertad, su espacio, probablemente yo le dejé demasiado espacio, él tampoco respetó nunca el mío, porque él sí que podía salir, pero si yo salí tenía que dar explicaciones, entonces perdí todas mis amistades. Luego tuve la mala suerte de que las verdaderas amigas que yo tenía estaban fuera, entonces yo me encontré con las mujeres de los amigos de él que salíamos a cenar alguna vez que otra, pero los que eran los amigos, eran los maridos, entonces cuando nos separamos me dejaron de hablar todos, porque claro yo lo había denunciado por malos tratos, pero porque me había intentado matar y como no me mató, porque claro, a mí cuando me intentó matar fue al año, después de estar separados, no fue antes

- (P) Quería que me hablaras de esa experiencia, pero antes de eso... ¿fuiste agredida sexualmente alguna vez por él? ¿alguna vez mantuviste relaciones con él sin que tú consintieras?

- (R) Mira te puedo decir que yo nunca le negué el sexo, porque como además venía borracho, pues era llegar y como decimos, ya está, pin, pan, pun y fuego. Entonces estuvo un año sin tocarme, evidentemente, si estaba con unas y con otras, estaba por ahí, ¿Cómo iba a venir a casa con ganas de tener deseo sexual?, ninguno, yo te voy a contar que no lo echaba de menos, pero curiosamente el día que me dijo que me tenía que ir de casa, me lo dijo como comiendo, teníamos una sana costumbre que yo implanté en el momento que mis hijos ya fueron un poco mayores, era que cuando queríamos hablar de algo que concernía a la familia, lo que es al núcleo familiar decíamos, hoy hay quórum, después de comer, cuando se retira la mesa, decíamos, "mamá y yo hemos decidido que vamos a comprar un coche, habíamos mirado estos ¿qué os parece?" Siempre lo consultábamos con nuestros hijos, aunque luego tomáramos la decisión final, les hacíamos partícipes de todo lo que se acontecía en la casa. Entonces ese día, él dice, "hoy hay quórum" y bueno... "¿Qué pasa?", estábamos los cuatro allí y dice "qué bueno, que... voy a dejar a mamá" $Y$ yo le contesté "Como broma me parece de muy mal gusto", porque yo estaban mis hijos, que estaban empezando en la universidad, yo sabía que iba a terminar explotándonos en las manos en cualquier momento, pero yo quería llegar por lo menos a pagar la universidad, porque mi sueldo no me daba para ello, yo quería que mis hijos, porque son muy inteligentes, sacaran por lo menos la titulación, no tuvieran yo que trabajar como luego me tocó, trabajar mucho. Y... mi hijo se levantó de la mesa, cogió a N., mi hija de la mano y le dijo "N., vamos" y se marcharon para la habitación de mi hijo y se pusieron en el ordenador. Entonces yo, ya me quedé en la mesa con él y dije "A ver P. ¿qué me estás contando?, yo sé que yo te he abandonado una temporada porque mi padre ha estado mal y lo mismo que estuve cuidando de tu madre, que la única que cuidó de su madre, después de nueve hermanos, fui yo la que estuvo con ella hasta el último momento, hasta que murió, se ponía mala y yo dejaba todo para estar con ella, se ponía enferma en semana 
santa, la semana santa que se pasó en el hospital, era yo y los demás tomando limonadas, porque estaban cansados, no les dolía, no les dolía ni su propia madre, no me pesa y lo volvería a hacer y mi suegra a mí no me quiso nunca, me quiso cuando se vio mal y decía "yo te he tratado mal", porque claro yo no iba con chismes a nadie, no me gustan los chismes, el corre ve y dile no me gusta y al resto de la familia le gustaba ese rollo, entonces tú no cuentas nada de él, y es que no tengo nada que contar, pertenece a mi vida privada y punto, entonces no les gustaba a mis cuñadas el que yo no contara de mi marido como ellas contaban de los suyos. Entonces había un distanciamiento por esa parte, entonces cuando lo dije, que yo había dedicado a mi padre 6 meses, porque me necesitaba y era mi obligación, "que te conste que con tu madre he estado un año y nunca te lo he tirado en cara y nunca he dicho nada, y vosotros estabais todos a vinos, ibais la dejabais en el hospital, cuando la traían, luego la iban a buscar, "mamá está muy bien" a todo el mundo "iAh!, muy bien, muy bien, muy bien" Su madre se estaba muriendo y ellos no se preocuparon ni el día que se murió si quiera, la gente me daba el pésame a mí, los médicos me llamaban a mí, pensando que yo era su hija "no, no, no, es mi nuera" "¿Y los hijos?" "no es que trabajan..." luego me decía a mí mi suegra, me decía "yo conozco a mis hijos, soy su madre" Yo la entiendo, ella nunca lo sospechó, yo creo que nunca lo sospechó, que llegaran a ese límite, porque yo tampoco lo sospeché. Entonces lo que te decía, el día que nos dijo eso, lo del quórum de la mesa y tal, dije "como broma no tiene gracia" y me levanté y me puse a fregar, me agarra por un brazo, me lanzó contra la silla y me golpeó contra la mesa. Y le dije "vaya modales P., ¿qué pasa?" Y dice, "que te estoy hablando en serio, te voy a decir lo que nunca te he dicho y lo que pienso de ti, eres una gran hija de puta, no te he querido nunca, no te he podido jamás ver, no das la talla ni como persona, ni como mujer, ni como nada, no te puedo ver, te odio con toda mi alma, siempre me has avergonzado en todos los sitios y no te quiero ver delante." $Y$ cogió, escupió al suelo y marcho. Yo empecé a llorar evidentemente, ya era un hábito constante, ya no lloraba, simplemente se derramaban las lágrimas solas, me puse a fregar y dije "hoy además de borracho viene colérico" Me puse a fregar, porque no le creí, es curioso, yo no le creí, me puse a fregar, recogí todo, estuve por la tarde pintando, llegó a la hora de la cena, estaba la cena preparada y me dice "¿todavía sigues aquí? ¿cuándo te piensas marchar?" "No me voy a ir, cuando te pase el enfado hablamos"'es que no estoy enfadado, es que no te quiero ver ni delante" Le dije "¿qué es que hay otra persona?" Dijo "No, no hay nadie" "Si hay otra persona me puedes decir que estás enamorado de otra persona, somos civilizados y se puede hablar" "Que no te tengo que dar explicaciones de ningún tipo, pero tú ¿quién te piensas que eres? Pero tú ¿quién te crees que eres?, mira sepárate porque te daba" "no tienes valor, ni siquiera para eso porque eres un cobarde" $Y$ esa noche nos quedamos en casa, yo me acuerdo que él se fue a dormir para la cama, yo estuve viendo un rato la tele, luego me fui para la cama y cuando estaba en la cama, él me abrazó, y le dije "P., por favor" "Ni por favor, ni puñetas" y me violó (lo dice muy bajo, casi no se oye). Me sentí tan sucia, tan sucia, tan sucia que lo único que recuerdo fue humillación, me levanté, me duché, me acuerdo que cogí el escotch brite, no por la esponja, por la parte verde que araña y me froté tanto la piel que me la arañé entera, es como si quisiera arrancar la piel, el contacto de él ¿no?, cogí, me sequé, me metí en la cama, él como un tronco, más ancho que largo y por la mañana es cuando me levanté, desayuné y ya le dije a mis hijos, que iban para el colegio, vamos para casa de abuelita, ya me cogieron mis hijos y me llevaron para casa de mi madre y cuando fue mi madre, se lo conté, mi madre le llamó por teléfono, pero no cogió el teléfono, entonces cogió el teléfono de N., lo llamó y le dice "P. soy yo, ¿qué es lo que has hecho?" y le colgó y mi madre me dice, le volvió a llamar por el teléfono de mi hija otra vez, él pensó que era mi hija y le dijo "si tu padre viviera, no creo que te permitiera actuar como actúas, piensa lo que te dirían tus padres" Y le colgó, mi madre, nunca más habló con él, es el día de hoy que mi madre lo ve y agacha la cabeza, no quiere verle y mi madre le quería mucho y él ahora pregunta por mi madre, porque él si les quería, pero claro, 
él llegaba allí y daba una imagen que bueno... de hecho mi hermana, yo llegué a sospechar incluso que estaban liados, porque él me lo dio a demostrar muchas veces, él me lo decía. Yo soñaba constantemente, constantemente... que estaban liados, y un día me enfrenté a mi hermana, mi hermana y yo estuvimos sin hablarnos casi un año, porque yo un día le dije... yo se lo decía a P. "ijolín! Tengo unas pesadillas espantosas, sueño que estás con mi hermana y que yo voy y os reís de mí los dos, incluso que me empujáis de vuestro lado" Y él se reía y mi hermana cuando llamaba decía "que me vuelve a pasar esto de tal..." A mí me entraba una tensión espantosa, porque es que yo vivía el sueño y luego sucedía, tal y como yo lo vivía. Y le pregunté a él "¿Tú estás con mi hermana?" y se echaba a reír y me decía "Que ignorante eres, si te da 50.000 vueltas a ti, ipues claro que estoy con tu hermana!, ahora vete y cuéntaselo a la familia, no te van a creer, porque como estás zumbada" Él me llegó a decir, que yo estaba trastornada, de hecho en el juicio fue lo que dijo, que estaba loca. Y luego cuando me separé, sí que se lo dije a mi hermana "Tú estuviste liada con mi marido, con P." Y mi hermana se puso a llorar y se marchó para su habitación, dije "ya me lo has confirmado, porque no lloras como una cuñada dolida, sino como una amante resentida, por eso se que es cierto." Y mi madre dijo "yo no me lo creo, yo creo que lo ha dicho para enfrentaros" $Y$ yo a mi madre, por no hacerla sufrir, no la he dicho nunca nada más, pero a mí hermana luego la cogí y le dije "¿Cuéntame qué hacías con $P$., recién casados nosotros, que era P. chiquitín, hasta las 6 de la mañana con él tomando vinos en la gasolinera, tomando cubatas en la gasolinera, todos los días?, explícame qué hacías, porque bueno, un día sales de fiesta y os encontráis, bueno, es tu cuñado, vale, pero todos los día durante un año, tú tenías coche y marchabas para alli" "Es que me mandaba papá que estuviera con él para que no estuviera con otras" "¿Y tenías que ser tú la que lo cuidaras?, lo normal es que le dijeras, vete para casa que estás borracho" $Y$ ahí nos dejamos de hablar mi hermana y yo mucho tiempo, luego yo dije si es que con este rencor yo no puedo vivir. Yo la perdono y que dios nos juzgue, que dios nos juzgue, en un momento dado, dios tendrá que hacer justicia en esta vida, si no es ahora más adelante, pero yo no les voy a juzgar, por eso mi hermana y yo hemos tenido una relación, siempre bastante distante. Sin embargo, mi hermana ahora se apoya en mí porque se siente sola y he sido yo la valiente, la que la he sacado a ella de situaciones difíciles moralmente, y la he perdonado, la he perdonado.

- (P) Todo esto, yo supongo que es una trayectoria, de tiempo. ¿Tú recuerdas la primera vez que te saltó la alarma y dijiste, este hombre me está maltratando, esto es un maltrato? ¿Tú recuerdas esa primera vez?

- (R) Mira, es difícil porque fue muy sutil, porque es lo típico y lo característico, es muy sutil, porque va muy poco a poco y de forma muy constante y entonces no te das cuenta. Yo me di cuenta cuando yo quería disponer de dinero y no tenía, y yo decía "pero vamos a ver, si has cobrado ayer" Teníamos una caja de estas pequeñas metálicas "si ayer había aquí 60.000 pesetas y hoy hay 5.000 ¿Dónde has gastado el resto?" Entonces las justificaciones eran "es que le puse al coche esto..., porque tuve que pagar esto..., tuve que pagar lo otro..." Claro cuando me separé estábamos apuntados como a 25 asociaciones, yo solamente estaba con Marcelo Macías, que es el grupo este de literatura, de grandes literatos, que yo escribía en este grupo, que ahora tuve que dejarlo porque la cuota mensual, anual, que se paga al año, no me la podía permitir pagar porque a mí me dejó arruinada totalmente. De hecho me dijo mi hijo, "mamá, vete al banco mañana y saca el dinero que hay" Porque habíamos estado juntando dinero para la universidad de N., por lo menos el tener pagados los 6 primeros meses del año, libros, piso y todo este tipo de cosas. Habíamos ido juntando, con las pagas extras un dinero, tener ahí, si venían mal dadas, tener ahí un poco donde echar mano y tal. Fue mi hijo quien me lo dijo, "vete y saca el dinero mamá, que seguro que va papá y no tienes ni un duro" justo, cundo voy no había ni un duro. Yo salí de casa con $20 €$ porque los llevaba en el bolsillo y yo sentí que me había relegado, no tenía amigas, no tenía con quién salir, o salía con él o me quedaba en casa 
- (P) ¿Es ahí, donde tú te das cuenta de todo?

- (R) No, yo fue poco a poco que notaba mucho distanciamiento, él era muy sutil, cuando había gente delante, era un cielo y cuando estábamos solos, pues.... Simplemente no te hablaba, estaba en su mundo y no te hablaba, yo es que además soy educada en casa y en la calle, porque yo lo pillé muchas veces hablando por teléfono, en la habitación, sentado y a lo mejor, yo iba a entrar al dormitorio, y lo veía que estaba hablando por teléfono, sentado en la cama y... "iAy disculpa!, que estás hablando por teléfono" y cerraba y salía. Vamos a ver, si hay confianza, yo voy a lo que tenga que hacer en el dormitorio, lo haría sin más. Claro él se quedaba cortado, no sospeché. Tú fíjate, yo tenía una fe ciega en él, que será un borracho, pero no me maltrata con mujeres. Hasta que yo dije, "vamos a ver D., recapacita, el negarte la palabra durante una semana ya es maltrato, pero como eso yo lo recibí desde el primer día de la boda, para mí era normal

- (P) D., perdona que te corte, yo recuerdo, en entrevistas que hemos mantenido tú y yo a lo largo del tiempo, recuerdo que me llamó mucho la atención algo que te pasó en el cine con él, de novios. ¿no sé si recuerdas? Me dijiste que habíais ido al cine o que tú pretendías ir al cine, no lo recuerdo exactamente y él se enfadó y te sacudió un tortazo.

- (R) En la discoteca

- (P) Cuéntamelo

- (R) Yo siempre, nunca me quise casar, pero no sabía porque. Yo llegó el día antes de mi boda y pensaba en marcharme a $A$. que tengo unos tíos a los que adoro, ahora ya murió mi tío, mi tía vive, yo les adoraba, para mí eran como unos segundos padres. Y yo el día antes de la boda me quería marchar para A., yo sabía que mi madre no me lo iba a perdonar en la vida, con todo preparado, mi padre me iba a entender, pero mi madre no me lo iba a perdonar en la vida. De hecho se lo conté y me dijo "no te lo hubiera perdonado en la vida, el día antes de la boda, dejarnos plantados". Yo no quería casarme y decía ¿pero por qué no me quiero casar? ¿qué me ha pasado a mí que yo no recuerdo? Porque yo empecé a tener lagunas mentales. Claro era una forma de mitigar un poco el dolor. Yo tengo la costumbre, desde cría de escribir diarios, de hecho tengo ahí como 6 ó 7 libros que son las agendas que me quedaban así, las utilizaba para escribir diarios. Yo leo el diario ahora mismo y digo ¿he podido con todo esto?, es increíble. Entonces recuerdo que estaba la $A$.(una discoteca) abierta, imagínate, yo con 18 años, que entonces te ponían hora de 11 de la noche, no es como ahora que hay una libertad que es excesiva, entonces, yo tenía la gran suerte de que mis padres, siempre han sido muy comprensibles y entonces mi padre decía "vamos a ver, yo entiendo que si el baile empieza a las 7 , a las 11 de la noche que tenéis que cruzar la plaza" porque vivíamos en el centro, "tampoco es tanto, eso sí, yo quiero que vayáis por la vida con la cabeza alta, y no me la hagáis nunca avergonzar." Mi padre siempre nos decía eso. Entonces yo recuerdo que fuimos para la discoteca, yo estaba con las amigas, en grupo, bailando y todos en grupo bailando, lo típico, luego bailando con él, bailando con unos y con otros. A mí me llamaban el cuerpazo, estando en el instituto, porque yo tenía un cuerpo muy esbelto, muy proporcionado y... yo no lo supe, lo supe años más tarde, cuando la gente que iba conmigo al instituto de la clase, las hijas hablando con los padres, pues lo comentaban " $¿$ sabes que tu amiga, N., sabes cómo llamábamos a su madre en el insti? La llamábamos el cuerpazo" y yo me enteré, yo creo que de separada, yo nunca lo supe, ni me enteré. Yo hablo con todo el mundo y siempre me consideré fea, nunca me consideré un bellezón, y ahora todo el mundo me dice que soy guapísima, digo yo "a mis 50 años que me digan que soy guapa, esto es increíble, cuando siempre me han dicho que soy el patito feo" porque claro para mi marido era del montón, un patito feo que se pensaba que era algo, cuando yo soy lo más discreto del mundo, nunca me he pavoneado para nada, nunca he ido alardeando de nada, tú me conoces de sobra, y sabes que soy una persona sencilla y punto, nada más. Pues entonces ese día, yo me acuerdo que llevaba un vaquero que me quedaba muy bonito, yo me ponía la 
ropa y lo que me ponía me quedaba impecable, aunque fuera una bata, porque claro, te cogías como una trenza hacía un lado, te ponías unos pendientes, yo normalmente me daba brillo en los labios, no me solía pintar nunca, si ves la foto esa (señala una foto de ella cuando era joven que hay en un portarretratos), no estoy casi nada pintada, o sea, muy, muy discreta, maquillaje muy, muy pocas veces, muy natural, porque decía "si hay una belleza natural, no tienes porque mascararla". Cuando eres rematadamente fea, tienes que potenciar un poco, pero cuando yo me veía, que no me veía ni fea, ni guapa, me veía del montón, yo decía "vamos a ver, si con un brillín que me dé en los labios y una rayina que me haga para resalzar la mirada, con resalzarla me vale, pues... él tenía que entrar a trabajar a las 9 de la noche, claro, yo había entrado a las 8 a la discoteca y yo tenía el permiso de mis padres hasta las 11 , entonces como él se tenía que marchar a trabajar, que yo me tenía que ir para casa y yo "pero vamos a ver, P. ¿tú crees que yo puedo marcharme a las 9 de la noche para casa, cuando acabo de salir hace una hora?, que no voy a hacer el imbécil, que voy a estar bailando, además, están aquí, tus $20 \ldots$ los 9 hermanos o los 8 hermanos que tengas, 20 amigos tuyos de la pandilla... todo el mundo sabe que soy tu novia, no me dirige la palabra nadie porque todo el mundo, se encargó muy mucho de decirle "que no se os ocurra a nadie mirar a mi novia porque hay hostias por el medio" palabras textuales, a compañeros de trabajo amenazarles que no me mirara nadie a la cara que se las encontraban, no con él, con él y con 20 más. Yo cuando me enteré de todo esto, yo alucinaba en colores "estoy saliendo con un mafioso, es que esto parece de la mafia" yo decía "bueno... esto es una tontería" Pues me lo dijeron y era verdad, yo alucinaba, "¿Tú crees que algún chico se va a atrever a sacarme a bailar?, cuando a los 2 minutos tengo pegado a un hermano tuyo para que no me saque a bailar nadie", porque si llevaba un vestido con un poco de escote, venía el hermano y me decía "¿dónde vas con ese vestido tan escotado?" y yo decía "¿Y yo por qué tengo que darte a ti explicaciones?"'Es que vas enseñando todo" "¿Y a ti que más te da?"'pues ya se lo diré yo a mi hermano que no te permita andar con esas cosas" Eso me pasó a mí, claro que si es hoy, le meto el vestido por la boca, pero entonces...

- (P) Bueno total, tú estabas en la discoteca y él...

- (R) Eso, que me estoy yendo por las ramas, él se iba a trabajar y como no quería que yo... me agarró por un brazo, me subió a rastras, prácticamente las escaleras, que me golpee en las piernas, me llevó para casa, y fue desde la discoteca, hasta la puerta, de lo que es cruzando la P. E., yo vivía donde la virgen, más o menos, a bofetones todo el camino, pegándome. Yo llegué a casa, evidentemente, llegué llorando y me metí en mi habitación y claro mi madre ya me decía "¿qué te pasa?" "nada, nada" "¿Ya volviste a tener otra bronca con P.?, es que tienes todos los días broncas con él, pues dejarlo" De hecho, al poco tiempo, a los pocos días se casaba un cuñado, que yo estaba invitada a la boda y me dijo mi madre "no te dejo ir a esa boda, ayer viniste llorando porque no se qué te hizo ¿y hoy te quieres ir de boda?" "No, no, si es que tampoco quiero ir a la boda" Y no fui a esa boda. Al día siguiente, viene la cuñada y me dice "por no haber ido a la boda, estuvo con otra toda la boda" y dije "pues que se lo pase muy bien" Cortábamos mucho, íbamos al instituto y tenía amenazados a toda la clase, que no se acercara a mí nadie, entonces me decían, siempre me dijeron mis amigos ¿qué había visto yo en ese hombre para casarme con él? Pues no lo sé, no sé lo que vi en él. Claro después ya, concluyendo... él me conocía de cuando yo iba con mi padre al R., que era uno de los bares, pues más importantes de aquí, a tomar el vino, el vermut con él los domingos, y claro yo iba de niña mona, y él estaba allí, no de camarero, de ayudante de camarero, para quitar las cajas y limpiar y barrer y tal, y él me conocía de eso, entonces cuando me vio él, que yo vine a estudiar, pues él se encargó muy mucho, porque ya me conocía de verme con mi padre, de estar con los amigos de mi padre y tomando el vermut en un bar, y antes eso, era como que eras ya en la cúspide, era la alta sociedad ¿no? Y empezó por ahí, me engatusó, era guapo, porque P. es guapo, entonces, yo creo que él empezó un poco conmigo, pensando que ahí podía tener 
una boda y tener una buena vida, con tan mala suerte que mi padre se arruinó, entonces claro, empezaron a haber problemas, con lo cual él iba por el interés

- (P) En esa situación que tú comentas D....

- (R) Yo lloré muchas veces cuando él salía de bares y se ponía delante de mi balcón y decía "Nos marchamos ahora de fiesta a la B., que hay mucha tía buena por allí, para que alguna desgraciada llore toda la santa noche" Eso lo decía, a voces en la calle, en el balcón de mi casa, que mi habitación daba para la calle, para que yo lo oyera. Día uno y día otro, día uno y día otro. Y yo, yo decía "vamos a ver", yo sufría mucho y luego claro, venía y era una perita en dulce

- (P) Es lo que te iba a preguntar ¿tú como reaccionabas ante esas cosas? ¿Cuál era tu reacción?

- (R) Llorar, llorar y llorar. Llorar porque era decir, vamos a ver ¿por qué me hace esto?, que lo puede hacer, pero que no me lo diga a mí, que lo diga a voces en la calle y los amigos riéndose

- (P) Cuando te llevaba a bofetadas, desde la discoteca hasta tu casa ¿tú como reaccionabas? Llorar, llorar y llorar

- (R) No reaccionaba. Como el día que me intentó matar, no reaccioné

- (P) Esto me lo tienes que contar luego

- (R) Sí

- (P) Y él ¿Cómo reaccionaba él? ¿qué pasaba?

- (R) Que no podía quedarme en la discoteca, porque podía ligar con cualquiera y era suya. Un acto de posesión, total, total, total. Puro y duro

- (P) ¿Él en ningún momento se arrepentía o en algún momento te pedía disculpas?

- (R) No, vamos a ver "llevamos desde los 14 años, tú eres mía y no eres de nadie y si yo voy a trabajar, tú no pintas nada en la discoteca" Yo dije "vamos a ver, yo estoy bailando y pasándomelo bien con mis amigas y no te ofendo ni a ti, ni a nadie" Y él me decía "es que no me gusta que estés en la discoteca" Yo le decía "pero yo también tengo que disfrutar y pasármelo bien" Porque un día yo no fui porque me enfadé con él y luego me arrepentí y dije "¿me voy a quedar aquí en casa porque esté enfadada con él?, ique le den por saco! Yo voy a bailar". Y me lo encontré con una prima bailando en un plan que... fuera de lugar y cogí, fui y lo saludé. Le dije "¿Lo estáis pasando bien?, pues me alegro mucho" Me di media vuelta y me marché. Mi prima me dijo "lo tienes muy seguro" y yo dije "si lo quieres para ti", una prima mía y dijo "sabes tú de sobra que a mí no me va a hacer ni puñetero caso" $Y$ al día siguiente venía como que no había pasado nada y yo estaba enfadada evidentemente. Me decía "¿qué estás enfadada?" "Si quieres me pongo a bailar de alegría" "Bueno es que todo te lo tomas a mal, es que te estás volviendo una repugnante, se te está cambiando el carácter, cada día estás más repugnante, todo te lo tomas a mal, no se te puede hacer una broma" Dijo "ihombre!, si me vas a pegar una bofetada y me dices que es una broma... o yo estoy muy mal o tú estás muy mal, pero vamos, a mí no me cuadra nada" Se daba media vuelta, se marchaba, desaparecía, se ofendía, estaba 8 días que no lo veía

- (P) ¿Se ofendía él?

- (R) Sí, se ofendía, entonces claro, él lo que utilizaba era que él ofendido era él, para que yo me sintiera mal y fuera yo a pedirle perdón. Entonces yo salía de clase e iba a casa, se me presentaba por la mitad del camino y me decía "¿lo has pasado mal?, perdona, ijolín! Es que los amigos se lían y luego me lían" y yo le dije "es que tienes que empezar a ser conmigo... si eres mi pareja, cuando estás conmigo eres mi pareja y cuando estás con tus amigos, estás con tus amigos, no mezcles, no mezcles. Era un niño"

- (P) ¿Y tú esto lo contabas a tu madre a tus amigas, a tus primas, a tu hermana?

- (R) Se lo conté a mi hermana, se lo intenté contar en más de una ocasión y se rió de mí, dice "tú es que eres una repugnante, bastante aguante tiene $P$. con aguantarte con el carácter que tú tienes" Y nunca más le volvía a comentar nada

- (P) ¿Ni a ella ni a nadie? 
- (R) No, y como quedé embarazada, me casé, fui la deshonra de la familia, porque claro, un M. no puede deslizarse, tiene que tener una trayectoria.... Porque claro era una familia muy conocida en la ciudad, entonces claro, un M. no puede cometer ningún error, era un deshonor y una vergüenza pública que se supiera que yo estaba embarazada y me tenían que casar por narices. Entonces yo no me quiero casar, yo el día antes le decía a mi hermana Chus "yo no quiero casarme" y mi hermana diciéndome "¿tú estás loca? ¿qué haces con el crio que esperas?" Dije "mira, me marcho para O. y por dios te juro, que yo le saco y le doy de comer y no nos va a faltar pan ni para mi hijo, ni para mí, pero yo no me caso" "¿cómo no te vas a casar? ¿cómo no te vas a casar?" Yo había estado trabajando en el motel de P., lo inauguré yo y yo estaba de administrativo allí y claro... con los camareros que había allí, unos chavales encantadores, hacíamos un equipo... una unión... de maravilla" Los amenazó a todos uno por uno, que no se metieran ninguno en el medio que iban 20 por ellos. Me acuerdo que había un ayudante de cocina, que hoy es un gran cocinero, está en $Z$. o no sé dónde y es un chef de... era muy bueno y una gran persona, fíjate, no recuerdo su nombre, estaba enamorado de mí y fue el que me lo dijo, dijo "A, yo te quiero muchísimo, pero no nos podemos acercar a ti porque tu novio nos tiene amenazados a todos" Dije "Bueno, no digas bobadas" Yo decía, esto es de película, esto no es normal y no les creí y luego supe que era verdad. Yo estaba... no es que estuviera ciega, simplemente lo que hacía era ignorar esa realidad para no sufrir, porque yo lloré muchísimo de novia. De hecho me acostumbré a ir a la iglesia de S. B., hay un Sagrado Corazón, que desde el ángulo que te pongas te mira a los ojos, siempre que tengo un problema voy a él, desde muy cría, de hecho siempre que van dicen "el sagrado corazón de mi madre", mi hija cuando quiere pedirle algo a dios dice "yo voy al sagrado corazón de mi madre", de hecho, porque para mí es... yo iba y le decía "P. no me quiere, si es que P. no me quiere" Yo tenía claro que P. no me quería, P. estaba conmigo porque se acostumbró a estar conmigo, porque yo físicamente estaba muy bien, yo era muy moderna, hasta que mi padre se arruinó, pero cuando mi padre se arruinó, nos pusimos a trabajar todos, y empezó a entrar mucho dinero en casa, se pagó todo y empezamos a recuperarnos y a vivir como una familia más. Yo si antes tenía 20 pantalones, luego me acostumbré a tener 4 y estaba tan feliz, a mí cuando me vinieron a decir unos amigos, los hijos de unos amigos de mis padres, como diciéndome "¿A qué no sabes lo que pasa en tu casa?" Yo digo "Dios bendito dime, qué es lo que pasa en mi casa, que no me he enterado?" "Que tu padre se arruinó" Y yo le decía "¿No me digas? Entonces es porque teníamos mucho dinero..." y yo le di la vuelta a la situación, para mí no fue ninguna vergüenza, sin embargo mi madre y mi hermana lo llevaron muy mal porque para ellos fue como una vergüenza, para mí una vergüenza es cometer un delito, pero si mi padre trabajó toda la santa vida para que no nos faltara de nada, teníamos 3 coches, televisión, lavadora, teníamos de todo y vivíamos muy bien, a pasar a tener lo justo, pues no pasa nada, te adaptas a comer lo que se pueda comer, si en los danzantes te comías unos macarrones, una paella con pollo y mil cosas y luego te comes unos macarrones con chorizo y plato único y detrás comes una manzana, pues ya está. Pero es que siempre lo he visto así, para mí careció de valor, no le di más importancia y mi hermana y mi madre sí, tardaron mucho tiempo en asimilarlo, yo no le di importancia ninguna, porque dije "el dinero es papel"

(P) Volvemos a P., D.

- (R) Ahí es donde P. empezó a actuar de forma diferente, porque claro, D. ya no sacaba dinero, D. ya no iba con 200 ó 500 pelas un domingo. Es más, mira ahora hablando de lo de la propina, me acuerdo que salíamos los domingos, yo llevaba a lo mejor, 200 ó 300, porque yo no gastaba nada, como no bebía, lo único que fumaba un tabaco que fumaba sombra, negro, muy suavín, porque a mí el rubio nunca me gustó y... "¿no tendrás por ahí, no tendrás por ahí...?" y yo "Sí, toma que tengo aquí..." Y siempre por $\mathrm{H}$ o por $\mathrm{B}$, siempre, al final, terminaba cogiéndome la pasta. Pero como me decía "no he cobrado, no tengo, no sé qué..." "Toma, que a mí me da igual..." Si yo es que salía con 4 y volvía con $31 \frac{1}{2}$, o sea, te quiero decir, 
que me daba igual, porque yo he valorado siempre el dinero en su justa medida, y curiosamente, me acuerdo que fuimos a una boda, que me acuerdo que yo llevaba mil pelas, surgen compromisos y tal, y él yo no sé lo que llevaba, me dijo "dámelas que te lo guardo yo que tú igual lo pierdes" Yo como una ignorante, porque no tiene otro nombre, "bueno, pues tómalo" En esa boda nos juntamos con una chica con la que había estado enrolladlo él, pero que yo no lo sabía, pero coincide que a mi suegra se le escapó quién era "Ten cuidado que con esa es con la que se cambia, todos los días en la escalera, los cromos que te da a ti, porque está de patrona arriba" Yo dije "¡Anda! Esta es la presunta, con la que este me da a mí la sensación que..." Yo empecé a atar cabos y cogió tal borrachera que no estuvo ni con ella ni conmigo. Yo me quise marchar, porque además era en la B., me quise venir para A., yo tenía perfectamente para venir en un taxi, pero como le había dado el dinero a él y él tenía una borrachera que... me dijo "tú baila por ahí" A mí me dejó tirada y cómo le pido yo el dinero, si ya se lo habrá gastado en cubatas y tuve que aguantar hasta que unos amigos, con los que habíamos ido, que viniéramos, allí. Lloré en esa boda lo habido y por haber, y ahora digo... bueno era inocente, era inocencia total, era inocencia total, entonces esos pequeños detalles, es lo que me hicieron pensar que yo no me quería casar con él, porque sabía que iba a ser desgraciada y en la noche de bodas supe que mi vida iba a ser un desastre total

(P) ¿Por qué? ¿Qué pasó ahí?

- (R) Porque claro, el día antes, él ya había cogido una tajada impresionante, evidentemente. Cuando al día siguiente va... yo ya le vi la cara que... bueno... de haber estado (hace el gesto de beber, con su mano), y yo aguantando. Llegué yo la primera, o sea, la madrina era una... mi madrina, era la madrina, y tenía que ir a buscarla él, y mi tía para arreglarse, teníamos que darle como dos horas antes anticipadas, porque lo más pesado del mundo era ella, bueno es... que vive, y yo, llegamos ya tarde, esperando para llegar la última, y así todo, mi padre todo nervioso, "vamos y vamos y..." y yo, "tranquilos". Tuve que vestir a todos, estaban todos nerviosísimos y yo tan tranquila, yo, para mí era como que se fuera a casar otra persona, no era mi boda, porque claro, para qué vamos a comprar un traje, yo me marché dos días antes, cuando lo de la pedida, salí de fiesta con mis amigas y quedaron mis padres y mi suegra, mi suegro ya se había muerto, y unos tíos de P., preparándome la boda, ellos me eligieron el vestido, los zapatos, un tocado de mi suegra, que era así como una peinetina con unas florecinas aquí, que me lo pusieron al lado del revés de donde tenía que ir puesto. Estrené el sujetador de Belcor del corazoncito, lo que es el conjunto y las medias, lo demás todo fue prestado. Yo no preparé mi boda, a mí me la prepararon. Entonces yo me sentía... no es la boda que jay! Que me pongo esto, que llevo esto, que llevo lo otro. Yo no, yo, como no elegí nada y me casaron y encima yo no me quería casar y ese día dije yo, mi vida va a ser lo que marque hoy, es lo que va a ser mi vida y no me confundí en nada. Tenemos unos amigos, porque yo quería ir a dormir a S.M., P. que al N., ¿qué más te da?, ya empezamos con la historia, ya habían elegido el menú los mayores, como yo digo, "¿vosotros que decís?" "da igual, mira papá no te preocupes, a mí me despidieron del hotel, me marché..." porque además tuve la circunstancia de que tuve un acoso sexual en el motel, por el hijo del jefe, y yo no le hice ni puñetero caso, me dijo una empleada que dijo "de mi hijo no se ríe" me pagó lo que se me tuvo que pagar, una burrada de dinero, casi un millón de pesetas, que entonces era una burrada de dinero. $Y$ yo a mi padre le di la mitad para la boda, y la otra mitad me la quedé yo, que fue con lo que amueblé toda la casa. P. fue... hasta el traje de novio se lo compré yo, o sea, todo, todo y lo mío, todo prestado, mira si soy idiota... bueno las circunstancias de la vida. Nos casamos y a las 9 de la noche, que él se quería marchar, porque claro no podía con la vida, o sea, en pleno baile, cuando te lo estás pasando de puñetera madre, con todos allí de fiesta y de folclore, que yo es cuando empecé a decir... ya me casé, porque el cura estuvo toda la santa misa confundiéndome el nombre. "D. quieres por esposo..." y yo "Yo sí, D., quiero por esposo..." "E.", no "yo D." y yo decía, pero si hasta el cura se confunde, es que hasta el cura se confunde... bueno y bueno nada... al final salimos, él por la 
tarde ya había empezado a beber "es que mezclé y estoy mal, ahora la bobada del vaso de leche y la tontería de turno que entonces se hacía, a mí me parecía una grosería y una tontería, pero bueno... los amigos de él tenían que hacer la tontería de turno

- (P) ¿Qué era eso del vaso de leche?

- (R) Que después de comer se tenía que beber un vaso de leche y se suponía que eso a él de noche le iba a dar, para tener más esperma

- (P) ¡Ah, mira! Vale

- (R) A mí me parecía una grosería, una tontería y de muy mal gusto, pero como los amigos de él lo tenían que hacer...

- (P) Y se lo tomó, el vaso de leche

- (R) Él en ese momento abría la boca y lo que le echaran, como si le echan un cocodrilo, lo mismo. Luego dijo que lo que le había hecho daño era la leche. Pero no, el champan, el vino, los cubatas y todo lo que se montó. Con lo cual a las 9 de la noche, te imaginas, los dos en el tren para L., porque él se quería marchar a acostar porque estaba cansado. Claro, él estaba cansado de lo que había bebido y de la noche anterior. Yo que estaba en mi salsa, que era cuando empezaba a bailar y ya empezaba a olvidarme de que... esto.... Que nos vamos, ahí ya, muy fuerte... "pero que nos lleva cualquiera de la boda, nos llevan". No teníamos coche, pero nos podía llevar cualquiera a L., "a cualquiera que se lo digamos nos lleva" "Que no, que yo quiero marchar, que quiero marchar, si no vienes yo marcho" Digo "eso, tú te marchas a dormir al hotel y yo me quedo aquí y dirán... pero.... Bueno que es el día de la boda" Fui a casa, me quité el vestido, le dejé a mi hermana el ramo de novia encima de su cama y el vestido lo dejé colgado en la otra cama, me cambié y nos marchamos para L. Yo ya me olía la tostada y en la estación de autobuses me acuerdo que compré dos tebeos de tío vivo, porque ya me imaginé que la noche iba a ser... imagínate... acostarte a las 9 de la noche, penoso. Llegamos a la habitación, él cogió y se metió en la cama...

- (P) ¿Al final en el N. o en el S.M.?

- (R) En el N., porque en S.M. era más caro y no daba el dinero... que lo pagaba yo, que prácticamente la boda la pagué yo. Su madre se acababa de quedar viuda, se la había casado otro hijo un mes antes y al mes siguiente se iba a casar otro hijo, entonces claro, que el dinero ya lo tenía para las otras dos bodas repartido y como yo estaba embarazada, la mía había salido de rebote y que para la boda mía no tenía dinero. Resulta que luego tuvimos las tres los hijos a la vez, pero bueno, aquí la que era mala, fui yo, nada más, pero bueno eso es normal y lógico, yo ya no entro en temas... esto es ridículo, en fin... Llegamos allí y nada más que entramos en la habitación, que él va a vomitar, que va a vomitar, que se encuentra fatal, que va a vomitar. Estuvo vomitando un rato muy grande, muy mal, yo me voy a la cama, yo cogí, me había comprado un camisón, mi hermana, se había encargado de comprarme un camisón con una bata, en color verde manzana, no se me olvidará en la vida el color, al final, perdí el camisón y yo dije ¡menos mal!, es como si me hubiera quitado un lastre de encima, o sea, tú imagínate... y me puse a leer un tebeo, y yo escuchando abajo la discoteca del hotel y a mí con lo que me gusta bailar... "yo marcho y le dejo aquí solo dormido, con la borrachera que tiene, yo bajo a bailar y a distraerme, pero soy una novia... ¿qué pensarán de mí?" Claro, yo misma me decía... chica yo me mataba a preguntas porque decía, vamos a ver, esto es ilógico, pero jolín, yo a las 10 de la noche no tengo sueño, yo tengo ganas de bailar, este tío durmiendo la borrachera y yo aquí leyendo dos cuentos de pulgarcito. Dije, mi vida va a ser toda la santa vida, él borracho durmiendo, yo sin poder dormir, amargada y enfadada porque ni boda, ni puñetas y encima, el tío vomitando cada 10 minutos. Dije este es mi destino, va marcado así. Clavadito, clavadito. A mí me vomitó encima durmiendo en la cama porque no le daba tiempo a levantarse y yo levantarme, quitar las sábanas, lavarlo así como podía, yo lavarme, quitar todo, meterlo en la lavadora para que mis hijos no vieran nada... bueno, infinidad de veces, o escupirme, a él le daba igual, si tenía ganas de escupir 
y me caía encima, como si me caía en la cara. Yo llegó un momento en que intenté cambiar de cama, pero como tenía mi padre el taller, ahí pegando a donde yo vivía, si mi padre entraba y me veía en la otra cama decía ¿qué pasa? Y una de las sorpresas fue que un día me encontré... yo venía del baño y me encontré a mi padre con él y mi padre le estaba dando dinero para que no me pegara. Ese día mi padre, no puedo decir que lo odié, pero me decepcionó.

- (P) ¿Y tú padre le daba dinero a él para que no te pegara?

- (R) Para que no me pegara, le daba mil pesetas cada $x$ tiempo para que no me pegara y eso me dolió más porque yo pensé que mi padre podía haberle dicho... de hecho una vez, yo me marché de casa, tuvimos una bronca porque él vino muy borracho, al día siguiente descansaba y dije "hoy vas a quedarte tú con los niños y yo me marcho de casa" y me marché de casa, les dejé a los niños la comida, y comieron y todo, yo me marché y le dije "les das la cena y los acuestas" y me marché de casa. Se quedó en casa todo el día, y me encontré, porque claro en A. te encuentras... y me dice "¿qué te pasa?" y digo "nada" "reñiste con P. ¿verdad?" "es que ayer estaba"

- (P) ¿Tú padre?

- (R) No, un cuñado

- (P) ¡Ah, un cuñado!

- (R) Un cuñado y yo estuve sentada en el jardín de la muralla, si cogía y marchaba para donde mis hijos..., si voy y se lo digo a mi madre, mi madre me dijo "no te hubieras casado, si fuiste madura para quedar embarazada, ahora eres madura para aguantar las responsabilidades" Entonces no podía contar con esa ayuda. Mi padre no podía hacer nada, lo único que se le ocurrió, fue darle dinero para que no me pegara, por eso él la mano encima me la puso pocas veces, porque le pagaba mi padre, el día que yo lo descubrí le dije "no me quieres bien papá, si no te hubieras enfrentado a él" Entonces otro día cogió y bajó él y lo pilló de sorpresa y le dijo "Si no la quieres no te preocupes, porque en mi casa hay sitio para ella y para los niños, pero que no vuelva yo a..." entró mi padre y lo pilló con la mano levantada "que no, que no, hemos estado riñendo" "lleváis sin hablaros una semana, que yo vengo por aquí todos los días" Mi padre estuvo bajando por mi casa, todos los domingos, a las 9 de la mañana, durante un año, sabíamos que estaban los niños dormidos, salíamos, íbamos a desayunar y me tuvo que comprar unas gafas de sol porque yo no podía abrir los ojos de llorar, de pasarme las noches enteras llorando. Claro, en esa época, ¿dónde vas? ¿cómo dices que tu marido te pega? ¡qué vergüenza para la familia! $Y$ además un renombre, con el puñetero renombre, que vergüenza

- (P) Estamos hablando D. de hace treinta y tantos años

- (R) Entonces claro, yo me lo tenía que comer y callar, mi madre dijo "no te hubieras casado, no hubieras quedado embarazada, es tu problema, conmigo no cuentes." $Y$ mi hermana, si le comentaba algo... "tú que lo provocas, que eres una repugnante, porque $P$. viene aquí y es un cielo y tú siempre estás amargada y de mal humor, siempre vienes con una cara larga" Lo que mi hermana no sabía, ni mi cuñada, ni nadie, era que el día antes, a lo mejor me había pegado un empujón y me había tirado sobre la cama o me decía quita de ahí que no vales para nada o eres una puta mierda, no sirves para nada" $Y$ yo aguantando todo eso, tenía que ir y encima sonreía en casa de mi madre.

- (P) ¿Qué tipo de cosas le hacían ponerse agresivo contra ti? ¿qué es lo que no le gustaba?

- (R) El sentirse atado y yo tenía toda la libertad del mundo, porque él entraba y salía, tú fíjate que yo le decía, vamos a ver, cuando cojo vacaciones, que los críos ya eran mayores... dije "por qué no vas un mes por ahí de vacaciones a casa de tu hermana, o vas a G., pasas unos día, sal de este entorno" yo lo que intentaba era alejarlo de los amigotes que le llevaban a tomar el vino todos los días, que hay más vida que tomar el vino o una copa en un bar todos los días, hay más mundo para ver "No coincidimos para irnos unos días a la playa, pues vete tú, vas a la playa, ves 
que hay otro ambiente" Yo lo que quería era alejarlo un poco, que él viera que hay más vida que esa. No lo conseguí. Yo le decía "márchate un mes, vete y haz lo que te dé la gana, con quien te dé la gana, y vive tú solo la vida a tu aire, pero luego se un señor" No creo que muchas mujeres, les digan eso a sus maridos. $Y$ no quiso por no perder el ir a beber los vinos de por la mañana y por la tarde y por la noche, nunca quiso. Entonces claro... yo intenté modificar muchas cuestiones, pero no se dejaba él, cuando lo único se acercó un poco a mí, fue cuando le dio el infarto, que se asustó, porque claro, le dieron dos infartos y le dieron seguidos y uno en la UCI y en reposo, le dieron 42 horas de vida, ahí cogió miedo y entonces es cuando verdaderamente se acercó a mí y estuvo un año que rejuveneció, vamos, estaba guapísimo, claro... yo le tenía lo que tenía que comer, caminábamos mucho, él se apoyó en mí en todo momento, pero en el momento que se recuperó y estuvo muy bien, volvimos a las andadas. Entonces... bueno... cada vez se iba creciendo mucho más

- (P) ¿Qué pasaba cuando se ponía agresivo? ¿se crecía? ¿qué pasaba?

- (R) Sí, porque ¿sabes por qué? Porque él tenía un complejo de inferioridad muy grande, $P$. siempre me decía que él se sentía inferior a mí, porque yo tenía muchísima capacidad, yo había vivido una infancia con todo lujo de detalles y a él le daban de comer las vecinas porque su madre no hacía ni comida, ponía una... contado por él, yo no... por lo que me contó él..., "mi madre cocía una pota grande para todos y allí el primero que iba se servía lo que le daba la gana y comía y el último que llegara si no había comida, quedaba sin comer" No estoy diciendo que sea una mala madre, pero yo pienso que si yo pongo una pota de comida, si hay 10 platos, se sirven 10 platos, si no se toca a dos cucharadas, se toca a una, pero comen todos, no unos sí y otros no. Allí dormía... el último que llegaba a dormir, si no había sitio en la cama dormía en el suelo. Había un caos y un desorden en esa casa desde la infancia que eso repercutió en toda su vida

- (P) ¿Hubo malos tratos en esa familia? ¿Sabes si tu suegro... el padre de este hombre...

- (R) Mi suegro murió con 60 años, muy joven, del corazón

- (P) ¿Pero alguna vez agredió a su mujer?

- (R) No lo supe nunca, yo creo que más bien hubiera sido al contrario. Una mujer de un carácter muy fuerte, una mujer de que... vamos a ver... a mí me contaba $P$. que con 9 años había cogido una borrachera y que una gracia... porque el niño con 9 años se caía para todos los sitios porque estaba borracho. Cuando su madre, tenía que haberle dicho, esto no se hace. Dijo "yo con 9 años y con 10 años, iba para casa a las 2 y las 3 de la mañana. Si con 9 años lleva esa vida, yo no quiero pensar con 5 años qué hacía. Él tiene un trauma, y es que ... él vivía, y estando en la cuna, llovía y entró agua para su casa, entonces el agua le llegaba a la cuna, cuando su madre fue a cogerlo, el crio estaba aterrado, porque había una tormenta de estas de verano que en un momento te cae una tromba de agua y le llegaba el agua a la cuna y claro, él era pequeño y no podía saltar de la cuna, y eso le traumatizó mucho y él lo contaba muchas veces. De hecho cuando hay tormenta él se pone muy nervioso. Ese es uno de los traumas que le quedó, y luego me decía que cantidad de veces, él tenía que comer fuera porque cuando llegaba a casa no había comida, le decían que fuera a comer a casa de la vecina, que le daba de comer por lástima, porque su madre marchaba a atender el kiosko del jardín o lo que fuera, porque mi suegra tenía el kiosko y todos nacieron en el casino, porque mi suegro tenía el casino. Con 9 tíos como 9 castillos, en un casino en A., que había 3 cafeterías buenas, los mejores hoteles de A., hoy tenían que ser de ellos y ninguno ha salido de la puñetera miseria de ser asalariados y comprando una moto y el más... cuando empezó $P$. que la primera que le compró coche fui yo, le regalé un 600 , de lo que yo fui ahorrando para comprárselo a él, porque él no tenía ni espíritu de lucha

- (P) Hablas D. de una familia un poco desestructurada...

- (R) Totalmente desestructurada

- (P) ¿Tu familia era distinta, venías de un mundo diferente? 
- (R) Todo lo contrario

- (P) ¿Tú viste alguna vez agresiones de tu padre hacia tu madre?

- (R) En la vida

- (P) Nunca

- (R) No, no, no. Todo lo contrario. Mi madre decía "¡Ay la cantidad de ropa que tengo que lavar! Y no sé qué y no se cual” Al día siguiente tenía la lavadora en casa. Que venía la televisión... que yo que se... nosotros teníamos una furgoneta porque mi padre tenía una fábrica de mantas, entonces se manejaba muchísimo dinero, yo te estoy hablando de una venta, siendo yo muy pequeña, siempre se me han dado muy bien los negocios y me acuerdo que mi padre tenía que pagar una venta, porque nosotros comprábamos la lana, mi padre compraba la lana por camiones, te estoy hablando de pagos de 100, 200 mil, 300 mil pesetas de entonces. Yo me acuerdo que un domingo vino un señor de Barcelona, de la casa Rovira y venía buscando... comprando mantas y mi padre tenía una calidad de mantas muy buena, porque mi padre utilizaba siempre la mejor calidad y yo combinaba muy bien los colores, como soy pintora, se me dan muy bien los colores, entonces yo hacía unos colores y unos dibujos para las mantas que quedaban muy bonitos, de hecho nos los iban a copiar, cuando poníamos las mantas a secar, nos los iban a copiar, que a mí no me importaba, porque si no tenían imaginación, pues que los copiaran, pero mi padre a los tintes les echaba, no sé que les echaba y quedaban unos colores muy brillantes y muy bonitos y nadie conseguía esos colores, por eso el producto de mi padre se vendía muy bien. Y el señor vino y dijo que quería la friolera de 300 mantas y mi hermana, que era mayor que yo, decía "pues tenemos ahí..." y yo dije "tú déjame" Yo siempre he sido muy... y yo le digo "¿qué quiere? Tenemos 275 y nos quedan 5 mantas para doblar y preparar" y dijo "bueno pues si me las preparas os las llevo" no comimos, hasta que no se acabaron esas 5 mantas de doblar, de colocar y preparar... allí no comió nadie. Doblamos mantas y metimos mantas para el camión, cuando comimos, las 5 o las 6 de la tarde. Cuando vino mi padre, teníamos 800.000 pesetas en casa. Mi padre las vendía, cuando eran cantidades muy grandes, a 325 por unidad, yo se las vendí a 375, mi padre cuando llegó, le dijimos a mi abuela "icomo le digas algo abuela a mi padre y a mi madre, no te volvemos a hablar, que esta sorpresa se la tenemos que dar nosotras" $Y$ ya cuando llegó mi padre, yo es que siempre he sido como muy líder ¿me entiendes? Para estas cosas, decía "¿qué tal se os dio?" "fatal, no vendimos nada", habían ido a una feria y mal, era la forma de vender entonces. "No te preocupes papá, mira, toma, para que veas los hijos que tienes" y el señor dejó una tarjeta con una nota diciendo "no se preocupe que si usted marcha el negocio le queda funcionando" Luego llamó por teléfono y dijo "Mira, los vi trabajar y esa pequeñaja que tienes ahí, que no levanta ni medio metro, el desparpajo que tiene para vender, dijo fue lo que me convenció para comprar las mantas, y luego la calidad que tienes, pero el desparpajo de la chavalilla, que era la más pequeña, pero traía a los otros dos volando" Bueno, se hicieron íntimos amigos de mis padres, cogieron una amistad impresionante, siempre fueron clientes nuestros, clientes siempre, de toda la vida. $Y$ yo le di a mi padre las 800 mil pesetas como te puedo dar a ti ahora $5 €$ para que te tomes un café, para mí lo importante era que yo sabía que el lunes mi padre tenía que pagar una letra y que había que sacar dinero por donde fuera, por donde fuera y que yo tenía que comerle a este hombre la cabeza para que me comprara las mantas para que mi padre pudiera pagar la letra y lo conseguí. Quiero decir, que era muy fuerte y muy valiente para todo y luego para mí, eso es lo que te quiero decir, estas cosas yo las veía y es como si metiera la cabeza debajo... un avestruz y no quisiera arreglar la herida. Porque yo tenía el suficiente coraje para haberme enfrentado a él, entonces yo descubrí que P. tenía un complejo de inferioridad hacia mí terrible. Yo tenía una familia estructurada, una familia que vivía muy bien, tenemos relaciones muy buenas y gente de muy alto estanding, que entraban a casa allí, una educación muy formada, muy señorial, entonces claro, yo ver eso en contraste con lo otro... por eso a casa de mi suegra, yo casi nunca iba, porque yo 
veía que aquello era... a mí me parecía como los gitanos que vivían en el pueblo, las familias estas que no... que no... se dedican a nada, pero comen y si no hay para comer... pero se cantan y son felices... que tienen como mala reputación, pero que tampoco se preocupan por nada. Y a mí de hecho mi familia no me dejaban casar con él, mis tíos, sobre todo los de aquí, mi madre "Cómo te vas a casar tú con la familia que son los peores de toda A., la gente más baja de toda A., cuando tú puedes aspirar a alguien más" $Y$ yo le contesté "Vamos a ver... porque lo quiero, si yo no quiero el dinero de nadie, yo... con el sueldo de él me llega" ¿Entiendes hasta que punto...? Yo nunca miré el dinero en ese sentido. Lo que pasa que ellos veían la diferencia estructurada de una familia y de la otra y yo no la veía, yo le veía a él, que era la persona que me enamoró y que yo le quería y yo veía que yo me casaba por amor, hasta que descubrí que yo no me quería casar, pero que no sabía por qué. Y leyendo, fue cuando cogí y tiré del diario y es cuando dije, "mira por qué yo no me quería casar, ¿cómo fui tan imbécil que no me di cuenta?" pues no lo recuerdo, por eso tengo muchas lagunas y muchas cosas.

- (P) D., cuando él te hacía todas esas cosas, que antes describías, decías que había momentos de reconciliación...

- (R) Luna de miel, luna de hiel

- (P) ¿Eso cómo era? ¿Cómo funcionaba en tu pareja?

- (R) Pues al principio, de que pasaba todo esto, llegaba la etapa del arrepentimiento, procuraba..., me decía "he visto un vestido más bonito en R. (una tienda de moda), que si te lo compras y tal... te puede quedar muy bonito ¿por qué no te lo compras?" Yo le decía ,si me es igual, yo mi pasión, eran mis hijos, volqué mi vida en mis hijos

(P) ¿Pero él lo intentaba?

- (R) Pero me lo decía para quedar bien, como para quedar bien, de hecho un día me dijo "¿Por qué no vas a A. y conoces el pub de tu hermano que tiene muchas ganas de que vayas, la realidad es que no has salido de A. nunca más" "¿A dónde? ¿con quién? Si no me quedan con los niños, está todo el día borracho, con quién dejo yo a los niños" Totalmente difícil. Entonces me dijo "me quedo yo con ellos y vas a ver a tu hermano el pub y tal" y yo le dije "¿y no te enfadas?" Claro... yo me quedé muy extrañada porque como acababa de haber otra tormenta, evidentemente... pues... dijo "no, no, vete, pero vienes en dos día, estás hoy, lo ves y mañana te vienes" $Y$ para mí fue un aire fresco y puro de decir, me libero, me libero, de hecho estuve allí y en lugar de volver al día siguiente, volví al día siguiente. Claro cuando llego a la estación, lo primero que veo es una cara hasta el suelo "mira que cara traes, además te fuiste con esta zorra que es tu hermana que a saber lo que habrás estado haciendo" Ese fue el recibimiento. Y mi hermana le dijo "¡Oye guapo! A mí tú no me llames zorra" "Tú a callar" y mi hermana callaba. Claro, si había la historia que yo descubrí años más tarde, que no sé si es cierto, porque yo no les vi nunca y no puedo jurarlo, pero te das cuenta cuando hay algo, porque tonta no eres y luego él me dijo que sí, pero me lo dijo para hacerme todo el daño del mundo, porque me lo hubiera negado y yo me hubiera quedado... por lo menos no me había quedado a mí ese dolor, pero él me lo confirmó, para hacer daño o no, fuera mentira o fuera verdad, a mí me lo dijo, mi hermana siempre lo ha negado, pero yo cuando la vi llorar, lloraba como una amante resentida, no como una cuñada dolida. De hecho fue ella la que habló con la familia de él, yo no hablé con la familia de él, porque no le voy a dar explicaciones a nadie, porque no se las tengo que dar a nadie ¿Qué iba a decir si lo sabía todo el mundo menos yo? Entonces bueno, fue todo eso. Entonces cuando salí y tuve ese reproche, dije bueno, para qué vas a salir, si vas a pagar caro... ahora me va a costar una semana de sufrimiento, el haberme marchado dos días a $A$. a pasarlos con mi hermano que hacía un montón de tiempo que no le veía, cuando mi hermano de soltero se venía y no paraba en casa de mi madre, se venía para mi casa, para salir con mi marido de fiesta por ahí y venir a las tantas y si íbamos a dormir para casa de mi madre, era porque le había dejado las llaves porque mi hermano había ligado con una tía y se fuese a mi casa a dormir 
con ella, que a mí no me importaba, era mi hermano, había una habitación libre y no tenía problema, pero bueno... quiero decir... imagínate la relación que tienen tan estrecha. De hecho cuando a mi hermano le dije, y supo todo esto, se puso a llorar y me dijo "ahora entiendo lo que has sufrido", pero esto lo ha dicho mi hermano este año, después de 8 años, cuando lo vio, porque su niña lo adora y siempre que lo ve va corriendo y lo llama tío $P$., fue mi cuñada con ella, yo a mi cuñada le dije, a mi sobrina le dije "L., P. no es tu tío, porque ya no es mi marido y el hecho de que lo vayas a abrazar y a besar delante de mí, a mí eso me duele y $\mathrm{C} . .$. que tú le incites para que vaya a saludarle, me causa dolor porque estás dando una preferencia que no la tiene por qué tener, porque a quien tiene que venir a besar es a mí que soy su tía y es la única sobrina que tengo" Y mi hermano se enfadó, discutieron y mi hermano se puso "parece mentira, tú no sabes el daño que le causas" a mí hermano se le caían las lágrimas, cuando me vio a mí que me quedé tan aplanada, le cayeron las lágrimas y a mí me cayeron dos lágrimas y dije "se me pasa enseguida"

- (P) ¿Cómo eran las reconciliaciones con P?

- (R) Pues venía y decirte, "preciosa, guapa, hoy estás muy guapa ¿quieres que vayamos a tomar un vino?, ¿quieres que vayamos a tomar un vino?" Cuando yo es que, yo le decía "pues mira... no me apetece"

- (P) Tú en ese tiempo, mientras estuviste casada con él ¿cómo te sentías? ¿Qué sentimientos tenías?

- (R) Mira, trabajando me sentía... yo volqué mi vida en el trabajo, en el estudio y en mis hijos y en pintar. Entonces él era una persona que era el padre de mis hijos, él estaba ahí, tenía buenos ratos, porque cuando... para la fiesta el primero, lo pasas divina de la muerte, pero si yo salía... bueno de hecho un día me enfadé con él porque se puso a agarrarse de las manos con un camarero, se agarraron las manos y se dieron un pico y yo le dije "P., ¿qué te has vuelto homosexual?" "No, es una broma que estamos haciendo" Entonces mi cuñada, esta que está en A., dice "ya se enfadó, ya nos fastidia la noche porque mira qué cara tiene, mira que morros tiene" Ellos no había visto nada, lo había visto yo, yo la miré y le dije "tienes razón, tengo cara de amargada", pero no dije nada

- (P) ¿Y así es cómo te veías? ¿Te veías una mujer amargada?

- (R) Me veía una mujer que tenía que fingir delante de todo el mundo, porque mi padre sufría en silencio porque no podía hacer nada y me veía sufrir mucho a mí y mi padre sufría mucho, entonces yo tenía que fingir para que mi padre no sufriera aunque yo sabía que sufría. Mi madre no se enteró nunca, mi madre no se enteró nunca de lo que me pasaba, intenté hablarlo con ella una vez y no me quiso escuchar

- (P) ¿Y a día de hoy tampoco?

- (R) Hoy, sí, pero se ha tenido que morir mi padre y han tenido que pasar 8 años para que mi madre ahora ejerza de madre, eso es duro y ahora no puede vivir sin mí y ahora me da la vida, pero cuando la necesité nunca estuvo. Mi madre no me perdona que yo quedara embarazada porque fue una vergüenza

- (P) ¿En aquel momento te veías como una mujer amargada?

- (R) Desesperada

- (P) ¿Como una mujer desesperada?

- (R) Humillada, mi vida no tenía... tenía sentido por mis hijos. También te digo la verdad, que les preparé muy bien y les eduqué muy bien en el sentido de la tolerancia y que no juzgaran, que para eso había un dios

- (P) ¿Cómo te ves ahora?

- (R) Libre

- (P) ¿Libre? ¡Qué bonito!

- (R) Libre, se lo que quiero perfectamente y tengo muy claro lo que necesito

- (P) ¿Qué sentimientos tenías hacia P?

- (R) Yo creo que como empezamos de niños, tan jovencines... costumbre, porque si me dices... yo a P. le quise muchísimo, yo a P. lo adoraba, daba la vida por él, 
quizás por eso le perdoné tanto, porque yo decía, cambia, nunca mostró maldad, la maldad que yo empecé a ver fue a raíz de... porque para él eran prioritariamente sus amigos y su entorno de amigos, a mí me llegó a decir "para mí son más importantes mis amigos que mis hijos" A mí eso... son muchas puñaladas, muy dolorosas que te quedan clavadas, no se olvidan, no se olvidan, son puñales clavados. Como esa, muchas, decir que no vales para nada, que estás vieja y yo le decía "los años pasan para ti y para mí"'pero tú estás más vieja que nadie, tú estás fea, no vales para nada, no te va a mirar nadie a la cara, ya me encargaré yo de que no te mire nadie a la cara porque si no se la parto, te voy a enterrar y hasta que no pare..." Yo estuve, cuando me dejó, estuve durante 5 años, recibiendo en el móvil, mensajes de amenazas de muerte, hasta que un día me cogió mi hija el móvil y lo miró, tiene mucha costumbre y yo le digo que es de mala educación "¡Ah! Mamá, pero a ti te encanta" y me lo mira y fue cuando empezó a ver las amenazas, entonces tenía un amigo que su padre era procurador y se lo dijo "mi madre está pasando esto" y como entonces curiosamente...

- (P) ¿Sabías que esas amenazas venían de P. o eran anónimas?

- (R) No, no, me llamaban y decían "¿lo estás pasando mal verdad hija de puta?, pues no sabes lo que te espera, te vamos a enterrar, porque hasta que no te enterremos no vamos a parar"

- (P) ¿Pero eso quién te lo decía?

- (R) Ella

- (P) ¿La novia de P?

- (R) Sí, y luego rayarme el coche, me lo rayaron entero, me lo llenaron de pintura, me rasparon las cerraduras, me rompieron dos veces la luna, las matrículas ni te cuento, me rajaron las cuatro ruedas. O sea, un calvario hasta hace dos años que me han dejado en paz, hasta hace dos años. Y cuando mi hija vio los mensajes, me dijeron que no tenían validez, que eso no se consideraba delito, entonces que no cogiera el teléfono, hoy día se considera delito, entonces no se consideraba delito, y dijo "guárdalo ahí en el móvil por si un día... pasa algo, que haya unas pruebas" Y... y... bueno, yo los recibía y ya ni los miraba, cogía y los borraba, claro evidentemente cómo crees tú... yo estuve durmiendo durante más de tres años, dos, tres horas, dos, tres horas

- (P) Y en relación a tus hijos, D., ¿tú como te sentías cuando estabas atravesando ese momento en tu vida?

- (R) A mis hijos los mandé para la universidad, me cogí tres trabajos, el que tengo, entré a trabajar en una carnicería de 4 a 7:30 y después por la noche estaba pasando tesis doctoral en latín, en latín antiguo además, que es un rollo que no te imaginas, para el seminario y le mandaba un sueldo a mi hija para V., otro para mi hijo para $O$. que estaba en la Universidad, y el otro para vivir yo, hasta que terminaron de estudiar. $Y$ yo me dediqué a trabajar, a trabajar, a trabajar...

- (P) ¿Se puede decir que tu objetivo era ese, sacar a delante a tus hijos. La formación de tus hijos?

- (R) Mi objetivo es que mis hijos tuvieran un trabajo para que nunca tuvieran que depender de nadie, para que no pasaran por lo que yo pasé, tanto mi hija como mi hijo. Entonces... ¿cuál es la mejor forma? Preparación, les enseñé a cocinar, les enseñé a planchar, les enseñé a coser, les enseñé a hacer todo. Dije, tú puedes tener una pareja mañana, no porque te planche un pantalón porque tú lo sabes planchar, porque tú quieras tenerla, pero no porque la necesites para que te laven la ropa y a mi hija lo mismo y cocinan los dos de maravilla, mi hijo además es un cocinero excelente, entonces les preparé para que no necesitaran a nadie en ese sentido. Que luego quieren tener su pareja, salga bien o salga mal, es cosa de ellos, pero no porque la necesitaran como yo necesitaba a alguien porque mi sueldo no llegaba, para que no tuvieran que depender de nadie y eso fue mi objetivo principal y luego yo sobrevivir, porque yo dije, yo tengo que salir de esto, yo llamé a muchas puertas. Yo fui a P., la asistente social y le dije "me acaba de dejar P., ¿qué puedo hacer?" y me dijo... "no te quejes que tú tienes trabajo, que otras no lo tienen" "yo 
no vengo a pedir limosna, vengo a decir qué se puede hacer, porque es que no sé que tengo que hacer" Ni siquiera me dijo que había justicia gratuita, yo pagué el juicio, todo pagando, porque como no tenía ni idea, nadie me decía nada, yo tenía que ir a un abogado y pagando y pagando y pagando. Resulta que cuando vamos a mirar, a hacer la separación de bienes, veo que estamos apuntados en 25 asociaciones, del futbol, de la cruz roja... todas las que había, yo la única que tenía, ya te digo, era la de Marcelo Macías, el centro de estudios A. Marcelo Macías

- (P) ¿Que la tuviste que dejar, dijiste?

- (R) Que seguí pagándola, pero cuando tuve que mandar a mis hijos... yo dije "M, yo no puedo pagar, lo siento mucho, pero yo no puedo, a mí mil pesetas, dos mil..." para mí era un sacrificio, bueno... ahí ya empezamos a hablar de euros, porque claro, yo te puedo decir, cuando yo me separé, como hacía tantísimo tiempo que yo no utilizaba dinero... tenía que venir mi hija conmigo de compras porque no sabía pagar, no conocía los euros, no sabía distinguir los euros. Entonces claro... si yo pagaba con un billete de $5 €$ o con $1 €$, bien, pero como llegáramos a los céntimos ya me perdía, porque no manejaba el dinero, yo estuve un año sin tocar dinero, entonces tenía que venir mi hija conmigo y pagarme ella "mira mamá, esto con esto y con esto..." enseñarme como a una señora mayor, enseñarme como a una señora mayor y luego en casa practicarlo para hacerlo

- (P) Entonces ¿quién manejaba el dinero...?

- (R) Me anuló totalmente

- (P) ¿Las decisiones importantes quién las tomaba?

- (R) Él no tomaba decisiones, cuando yo quise comprar el piso, que es cuando nos fuimos de la E.G., yo fui a ver el piso, yo miré el precio, yo vi como estaban las condiciones y le dije a él" ¿Vamos a ver el piso?" y me dijo él "yo no voy, yo voy a tomar unos vinos con los amigos, lo que tú hagas bien hecho está" Él nunca tomaba decisiones

- (P) ¿Entonces las decisiones las tomabas tú aunque el dinero lo maneja él?

- (R) Sí, yo le decía "mira, cuesta tanto, tiene esto..." “¿te gusta a ti?" "Sí"”bueno pues entonces, vais para allí, yo me quedó todo el otoño aquí en la E.G. y luego ya..." y yo dije "no, aquí o nos vamos todos juntos o nos quedamos todos juntos, pero que tú te quedes aquí, no..." Ya estaba con ella, claro... y estar uno en cada lado, no, o nos vamos todos juntos o nos quedamos todos juntos. Él fue a ver el piso el día que nos daban las llaves, él no fue a ver el piso, fueron mis hijos, lo vieron, nos gustó y "papá nos encanta" "Bueno, bueno... si os gusta a vosotros, a mí me da igual" Nunca tomaba decisiones, era tan cobarde, es tan cobarde, que no es capaz de tomar una decisión, por eso ese complejo de inferioridad que tenía y el ver que yo tenía el arranque para todo, él me tenía unos celos profesionales impresionantes y fue una fusión de todo eso, porque como yo en el ayuntamiento siempre he tenido mucha mano, porque yo he ayudado mucho en el ayuntamiento, y la casa se la dieron por mí, eso a él lo envenenó, él eso no lo pudo soportar, porque cada poco me decía "la casa me la dieron a mí" y yo le decía "vamos a ver P., la casa se la dieron al jardinero, el jardinero eres tú, yo soy tu mujer ¿a mí cómo me la van a dar?, si el único que lo pone en duda eres tú" Lo que pasa es que luego la gente por la calle decía es que claro... si tu mujer está en fiestas, semana santa, carnavales, en navidad, preparando, haciendo, coordinando y nunca cobrando nada, siempre por altruismo haciendo todo, porque me encantaba organizar, me gustaba que las cosas se hicieran bien, ese tipo de cosas y nunca cobré dinero, jamás, pero claro, yo entraba en el ayuntamiento, yo entraba a hablar con el alcalde "alcalde, necesito..." "lo que quiera D." y me pagaban de otra manera, entonces yo, hoy todavía tengo mucha mano en el ayuntamiento porque me la gané a pulso, porque he trabajado mucho para la ciudad, dejando la piel y sin cobrar nada. Entonces qué pasa, que todo el mundo decía "a ti te han dado la casa porque tu mujer está todo el día trabajando en el ayuntamiento" A él eso le ponía... yo creo que ahí empezó él un poco como a odiarme, a decir "me la han dado por ella, no me la han dado por mí" ¿me entiendes? Y yo creo que ahí una cosa con la otra, un 
cúmulo de circunstancias y él cada poco me decía "que la casa es mía" y yo "P. que el que único que lo duda eres tú, si nadie te ha dicho nada, todo el mundo sabemos que te la dieron a ti" $Y$ eso me lo tiraba muchas veces en cara, yo me daba cuenta de que me tenía unos celos profesionales impresionantes

- (P) A lo largo de todo el tiempo que llevamos hablando, yo te oigo decir D., creo entender, que eras tú la que organizabas la casa, los niños, las comidas, las compras. Sin embargo ¿en algún momento dudaste de tu capacidad?

- (R) Para nada. Lo tuve muy claro, porque yo le decía "Vamos a ver, si no eres capaz, ni siquiera, para ir y comprarte un coche, porque no sabes qué coche coger, te conformas con una moto" Yo fui y le compré el coche, un 600, lo pagué en el momento, se lo puse en la puerta y le dije "ahí tienes un coche" feliz. Cuando cambiamos de coche, fue y cogió un coche y me dijo "¿Cuál te gusta?" y dije "Este" "bueno, si tú me dices que te gusta ese" Una persona que hay que ir tirando de ella, porque es muy cobarde, es tan cobarde, tan cobarde que era manipulado por los amigos. Por eso la mujer que tiene ahora, es una mujer, que no es educada, es grosera, es una persona poco digna, tiene... bueno.... Casi, casi, casi, de vida alegre, rompió muchas parejas, rompió muchas historias, a mí me rompió la vida. Pero vamos a ver, yo no la culpo a ella, ella va a su bola, él fue el que le hizo caso, con lo cual, ella tiró la caña y si caza, caza, y ya está, pero el culpable fue él y después de los mensajes, que es a lo que íbamos, pasó un año y estuvieron viviendo juntos en mi casa, yo vendí la casa como 4 veces por 16 millones y al final los tuve que denunciar porque no la vendían y ya lo metimos en manos del abogado y al final, la escrituraron por 11, le dieron 12 y a mí ni me dieron nada, nada... yo pagué la deuda que me correspondía, no quería ni un duro, lo que quería era quitarme la casa de encima y punto, y nada más que salió la ley del divorcio exprés, que salió en Enero, en Febrero se casaron y el día antes llama a mi hija y le dice "mira te llamo para decirte..." porque mi hija con su padre siempre ha tenido muy buena relación, yo nunca se la he querido cortar porque yo a mi padre le adoraba y mi hija a su padre le adora "yo sé como es mi padre y sé que no se ha portado bien contigo y no te llega ni a la altura del zapato, pero mamá yo necesito de papá" y yo le digo "es que tú tienes que pensar que es tu padre y para mí es mi pareja, entonces no mezcles, yo respeto, tú respeta y ya está, no hay ningún problema" De hecho estuvo cenando con él el día del padre, luego vino para aquí "¿qué tal tu padre? ¿bien?" "Estupendo, me preguntó qué tal estabas, qué tal el accidente y le dije, pues bien, muy bien", ahora él se ha volcado, porque la mujer le ha dejado solo, le han operado, le dejaron en el hospital solo y él ha tenido mucho tiempo para pensar, porque él ahora está al otro lado, a él ahora le están haciendo lo que él me ha hecho a mí y ahora lo está viviendo él en su propia carne ¿entiendes? Y eso es lo que... por eso se ha unido mucho a mi hija, entonces yo le he dicho a mi hija "vete con él, que menos" Y lo que te comentaba, que es lo que tú querías hablar un poco, lo del intento de asesinato, que fue absurdo

- (P) Sí, sí, eso me lo tienes que contar

- (R) Es que fue absurdo, la cosa más absurda...

- (P) Perdona, ahí fue donde le denunciaste ¿nunca antes le habías denunciado?

- (R) No, siempre hablé con él

- (P) ¿Qué pasó? Cuéntame

- (R) Pues mira, esto fue un sábado que llegó mi hija de la discoteca a las 5 de la mañana, llegó llorando con los amigos, que se había caído porque había resbalado en el suelo, que estaba mojado, cuatro gotas que habían caído y se resbaló y se sacó un hombro de su sitio, entonces tenía unos dolores espantosos y la cogieron unos amigos, la levantaron y la trajeron para casa, pero estaba allí su padre con la que era ya su mujer, y lo que hicieron fue reírse de ella, o sea, en vez de ir su padre a levantarla, que es lo menos que podía haber hecho, cogieron y se pusieron a reír y a ella le dolió más la risa de su padre que el dolor del hombro. Entonces llegó a casa destrozada, pero destrozada psicológicamente, la llevé al ambulatorio, se lo colocaron, bueno... lo típico, se lo arreglaron, de hecho todavía lo tiene mal, porque 
luego tuvo un accidente y le volvieron a dar en ese mismo hombro. Entonces mi hija dijo que iba a hablar con papá, mi hija está todavía a tratamiento como yo y llevamos 8 años separados, con ansiolíticos, el Alprazolán, lo que pasa es que yo lo tomo de un gramo y ella de 50 , desde entonces, y... bueno, yo intenté calmarla, "quiero hablar con papá" Yo cogí el móvil y le dije "P., tu hija quiere hablar contigo" y se la pasé "Me viste en el suelo y no me ayudaste" y se puso a llorar, le dijo "bueno hija no te preocupes, mañana hablamos" y le colgó el teléfono, claro, mi hija se puso a llorar más, yo le dije "Cuca, yo creo que no era el momento de hablarlo, pero bueno... si a ti te hizo bien, vale" porque yo a él no le he vuelto a dirigir la palabra, desde el juicio, nunca más. Y... esto el lunes, yo voy a correos a las 2 de la tarde, tenía que coger unos paquetes para la empresa, unos sobres, entonces yo a las dos voy a correos, cojo los sobres y me vengo y según me vengo, hay un bar que pone C. y C., que está justo en la calle S. O., que hace como esquina y hay un trozo así, la puerta y hay como una esquina así metida y tenía la moto allí, él. Entonces cuando me vio salió del bar, él había salido y estaba de vinos claro, yo seguía trabajando, llevaba los paquetes para la oficina y salió a preguntarme cómo estaba la cría, porque vino hacia mí, entonces claro, cuando llegué yo estaba pegando ya cerca de la moto, tenía la moto aparcada allí y... porque la moto la había comprado mi hija, que estuvimos todo el verano ahorrando para comprarla, y luego se quedó él con ella, que la moto era de mi hija, pero bueno y llegamos y le dije "Desde luego, ves a tu hija que la tiran en el suelo, que se hace daño en el hombro y no eres capaz, ni siquiera de levantarla y ayudarla, eres un... "con este tono y con estas palabras y cogió y me agarró y me tiró contra la moto, entonces cuando ve, que claro, que la moto se va a voltear, por temor a que se callera la moto, me agarró así por el cuello y me tiró contra la pared, en ese esquinazo que había entre la puerta y la cristalera del bar, me agarró ahí, me apoyó contra la pared y me agarró del cuello y me giró todo el cuello. Sabe que en esa posición me estaba ahogando, porque yo teniendo asma, esa posición a mí me ahoga, entonces yo... me sorprendió tanto, que lo único que hice fue quedarme parada, sujetando los... no sé si se me cayeron o no los paquetes, no lo recuerdo. Deduzco, porque yo dejé las manos caídas

- (P) ¿Te quedaste como floja?

- (R) Sí, me quedé con las manos así, (estira los brazos a lo largo del cuerpo) como diciéndole mátame de una vez, porque he sufrido ya tanto, que esto es una bendición, he sufrido tanto que esto es una bendición, no pensé nada más que en ... no pensé en nada, te juro, me quedó la mente en blanco, nada más como diciendo, esto es una bendición, dejo de sufrir, y él cuando vio que yo no me defendía, es cuando él se aterrorizó, es cuando me soltó, dice "eres una hija de puta", entonces yo es cuando reaccioné, cogí los papeles y..., es verdad, los cogí del suelo, el bolso y los papeles y cogí y le dije a la puerta del bar, que además salía gente, dos personas, dije "te voy a denunciar por malos tratos" y me contestó, no sé exactamente qué palabras, pero algo así como "vete a tomar por el culo", algo así. Yo cogí los papeles, yo iba andando por la costumbre de caminar, pero no veía, yo iba andando y no veía, yo estaba en estado de shock totalmente. De hecho me encontré con una amiga y me dice "D., no sé qué" y no le contesté, seguí andando para adelante, un día me preguntó, si es que me acababa de pasar algo, es que lo sabe. Llegué a la oficina, entré, llegué al jefe, le di los papeles y me dice "¿qué te pasa?" y digo "que mi marido me acaba de intentar matar" En ese momento llegó mi hermano y mi hija, claro, el jefe, me dijo "siéntate ahí, tranquila, ¿estás bien?" yo "sí", "D., ¿sabes dónde estás?" "en la oficina" Un zombi, un zombi. Entonces, claro, mi hija cuando me vio se puso a llorar "¿qué le pasa?"'siéntate ahí y relájate" y llamó a la policía. Dijo "miren, pasen por aquí que..."

- (P) ¿Quién llamó a la policía?

- (R) Mi jefe

- (P) Tu jefe

- (R) Vino la policía, que vinieron de paisanos con un coche privado, vinieron con... en estos casos suelen ser muy discretos y me llevaron a la comisaría y vinieron mi 
hija y mi hermano, que yo les decía que no quería que vinieran porque yo no quería que mi hija viviera lo que yo estaba contando o pudiera contar, porque claro, no dejaba de ser su padre y el motivo había sido porque a ella la habían tirado, entonces yo no quería que mi hija viviera eso. Entonces yo le dije al policía, "yo no quiero que esté aquí nadie, yo no quiero que estén" Entonces dijeron a mi hija y a mi hermano que esperaran en una salita, que no podían entrar. La verdad es que se portaron de maravilla, conmigo se portaron fenomenal. $Y$ ya poco a poco me relajaron, me dijeron "cuéntanos todo como fue pasando..." me tomaron declaración e inmediatamente ir a buscar a... y le traéis "pero ¿conocéis a mi marido?", me dicen "bueno hombre", como diciendo ¡vaya tela!, ¿no lo vamos a conocer? Excesivamente conocido por la policía, yo me llamó la atención el que dijeran "sí, hombre" pero "bueno hombre", esa expresión me llamó la atención como diciendo, ¡qué raro que haya esa expresión!, pero tampoco le di importancia, estaba muy ida, yo estuve ida muchos días, porque no reaccionaba ante nada. Hay que comer, comía; hay que dormir, dormía; o sea, autómata total, y me acuerdo que estuve declarando hasta las 5 de la tarde, me llevaron al ambulatorio, fui con una mujer policía en su coche privado y entramos en el ambulatorio y tuve tan mala suerte que el médico que había era un machista empedernido y le dijo "¿puedo pasar con ella?"'Si la paciente quiere"'sí, sí, quiero que venga ella, quiero que entre conmigo" Entró conmigo, además era un encanto de persona, la chica y tal... y me dice... "bueno ¿Qué ha pasado? "Pues... que mi marido me ha intentado estrangular y como yo tengo un poco de asma..." me auscultó y me dijo

"Bueno, tienes aquí un poco inflamada la garganta, te voy a dar unos antiinflamatorios, tampoco sería para tanto" Y dijo la policía "¿cómo que tampoco sería para tanto?, o sea, la ve que tiene la garganta inflamada, que casi no puede hablar" porque me quedé con afonía, " ¿y usted está diciendo que no tiene importancia?" "Bueno me dará los papeles" y dijo "No, los mando yo directamente para el juzgado, a usted no le voy a dar nada, ya puede marcharse" Pero con estos modales y yo con la policía, y la policía miraba para mí, me cogió así del brazo y me dice "vamos", volvimos para la policía, dijo uno "hemos ido a detener a tu marido y se ha dado a la fuga, no lo encontramos por ningún sitio, pero no te preocupes que esta noche queda detenido" $Y$ lo encontraron a las 5 de la tarde o cinco y media, lo localizaron y lo llevaron, porque yo estaba allí cuando lo cogieron, todavía declarando ¿eh?, estuve con la psicóloga de la policía, estuve un rato hablando con ella y cuando yo estaba hablando con ella decían "lo acaban de traer, viene para acá" Entonces yo, si soy un gato me clavo en el techo, pegué un sobresalto "que yo no lo quiero ver, que yo no lo quiero ver", claro aterrada "tranquila, que va a pasar al otro lado y tú no lo vas a ver, le vamos a tomar a él declaración, pero tú no le vas a ver, pero tú estate tranquila que a ti no te va a pasar nada" $Y$ bueno, al final yo no vi nada, creo que esa noche estuvo en el calabozo y me pusieron una orden de alejamiento de un año y yo marché y yo es que lo veía en todos los sitios, abría las ventanas y lo veía, me marché a $O$. a pasar unos días con mi hijo y yo le decía "P., está ahí papá" "Mamá que estamos en O. ¿qué va a estar ahí papá?

- (P) No es que lo vieras, es que creías verlo

- (R) Lo veía en todos los sitios, lo veía en todos los sitios y ver un jardinero vestido de verde y era P., o sea, fue una temporada horrorosa. Vinieron mis hijos y estuvieron conmigo un mes ahí, porque además como fue en Julio o por ahí, vinieron de vacaciones y estuvieron conmigo en casa. $Y$ al día siguiente de la orden de alejamiento me dijo mi hijo "vamos a sentarnos en la plaza a tomarnos una caña porque no ha pasado nada, la vida continúa y hasta dentro de 8 días no va a salir el juicio, así que estamos contigo" Yo iba por la calle e iba así, aterrada y el móvil en la mano. Entonces al día siguiente, justo, yo estoy en una terraza en la plaza y él va y se sienta en la otra, vio a la policía y se marchó, yo puedo decir muy alto que la policía nacional y la policía local, no me dejaron ni a sol ni a sombra durante un año, ni un momento. A donde quiera que miraba, ahí tenía yo un policía. Yo estuve trabajando para la policía 8 años, entonces se lo tomaron un poco, a título personal, como compañera, como diciendo... yo siempre que miraba, tenía un policía, para 
donde quiera que miraba. Pero a los tres días, yo iba con mi hija por la calle y me encontré con una cuñada y con la mujer de P. y P., como que estamos aquí nosotras, ahí las otras dos y P. ahí, cara a nosotras, y mi hija se agarró diciendo "mamá que nos vienen a pegar" a los tres o cuatro días, que no había salido el juicio, yo dije "ni te muevas" dije "es tan cobarde que no da la cara, pero estas dos a nosotras no nos van a tocar" Cogí, con una frialdad que no me explico, abrí el móvil, no marqué el número de la policía, porque de hecho no lo tenía metido todavía, como que hablaba con la policía, me paré y me puse de cara a ellas con el teléfono "si la policía ¿no?" se dieron la media vuelta y se marcharon y él riéndose. Mira, me vinieron a pegar, tanto ella como una cuñada que si hubiera parado en su casa y atender a su familia, ya le tocaba y le sobraba, cantidad de veces. Estaba sentada en una terraza, pasaba un hermano y me escupía, pasaba por la calle y tenía que bajar de la acera o cruzar de lado. Así durante 5 años día por día, con uno o con otro, o sea, porque claro, luego el día que salió el juicio, no me perdonaron que al salir el juicio él declaró que yo estaba loca porque iba a un psicólogo, entonces claro, la juez le dijo "¿y por qué tiene que ir su mujer a un psicólogo?, porque claro su mujer está yendo a un psicólogo hace tres años, ¿no será porque usted la está maltratando en casa?" Dijo "no, es que está loca, yo lo que quiero es internarla en Santa Isabel y que no salga de por vida" Mira, ahí me cayeron unos lagrimones, yo creo que ahí es cuando desperté, me cayeron unos lagrimones tan grandes que hasta la juez me dijo "¿Se encuentra bien?" Yo asentí con la cabeza porque... y dije "sí, sí" ¿Tan malo puede ser que está deseando que me encierren en un manicomio? Y desde ese día yo ya no le volví a dirigir la palabra, ya, claro, le cayeron 265 días de cárcel y su abogada apeló que como había pasado por un infarto y todo ese tipo de cosas, que había sido enajenación mental, locura transitoria, llámale x, que si le podía perdonar los 265 días de cárcel porque claro, entraba inmediatamente en prisión y yo me lo quedé pensando, porque en casa me habían dicho mis hijos y mi madre, me habían dicho "si lo mandan a la cárcel, por el amor de dios, no lo mandes a la cárcel, menuda vergüenza que vamos a pasar, que me digan que mi padre está en la cárcel" y yo dije "bueno, vale" y no les dije nada, cuando eso les dije "sí, sí, yo le perdono la cárcel" Cuando salí del juzgado, cogí a mi madre, a mi hermano, a mis hijos y les dije "¿preferís verme a mí en el cementerio y no a $P$. en la cárcel?, ¡cómo me queréis!" $Y$ mis hijos empezaron a llorar y dijeron "mamá no pensamos en ti, perdónanos" ¿Y qué hace una madre? Perdonar, pero no lo puedo olvidar, no lo puedo olvidar, preferían verme a mí... llevarme flores al cementerio y que no vaya papá a la cárcel, dije, es que yo no se lo hubiese... , pero sí que lo merece y a raíz de eso, ninguna relación, ninguno de mis hijos, ni con él, ni nada. Mi hijo dijo que no estaba preparado para hablar con su padre porque ahora estaba con la sangre muy caliente y podía decir cosas que luego le pesaran, pero el día que estuviera preparado que iba a hablar con su padre y habló hace dos años. Fue un día a hablar con él y le dijo "no tenías necesidad de hacer lo que has hecho, porque con decirle, me he enamorado de otra persona, mira nos vamos a separar porque yo la quiero, contigo ya no soy feliz, podemos ser tan amigos y no sufrimos nadie, no entiendo, porque mamá no te pidió ni un duro, no te reclamó nada, no te pidió ni paga para mí" porque $P$. ya era mayor de edad, no le pedí nada, nada, solamente que me dejaran en paz. Dijo "¿tuviste que ir a matarla? ¿a santo de qué?, si te puedes casar con la otra sin necesidad" Dijo "Es que la tenemos que matar" Dijo "Te puedo perdonar todo porque somos humanos, pero eso es lo que no te puedo perdonar" $Y$ mi hijo tiene una relación con él, ahora como tiene que firmar él porque la mujer de él no puede firmar cuando lo ingresan, porque por lo visto, según la seguridad social, la segunda mujer, no puede firmar y más en estos casos y tienen que llamar a mi hija o a mi hijo y firmar la autorización, si tienen que hacer una operación, haciéndose responsables de su vida. Y entonces claro, yo les digo que no deja de ser su padre, yo nunca, es curioso, porque yo nunca le he podido odiar, no sé odiar, no sé odiar, lo que sí no quiero es saber nada de él y ahora que estuvo grave, que estuvo grave, le pregunté a mi hija "¿qué tal está tu padre?" y dijo "está fastidiado, además, fueron, lo ingresaron y lo dejaron allí 
y la mujer marchó con todos los cuñados a tomar vinos por ahí, porque todos son de tomar vinos, allí lo dejaron solo, yo lo llamé y me dijo", "estoy solo, más deprimido, me han dejado aquí solo y estoy asustado" y dijo "si estuvieras con mamá estábamos todos ahí"

- (P) ¿Eso se lo dijo tu hija?

- (R) Porque mi hija cada vez que habla con él se las tira. "A veces hacemos cosas que... yo las he pensado y ahora me pesan y me arrepiento mucho de lo que he hecho" Y mi hijo le dijo "pues sigue pensando y sigue tragando lo que estás tragando porque ya es tarde, porque mamá contigo no va a volver en la vida, porque el primero que me voy a oponer soy yo, ya ha llorado mucho y no necesita llorar más". Yo lo que ahora les digo a mis hijos es que, si un día lo ven tirado en la calle, porque terminará tirado en la calle, porque esta mujer es muy mala persona, lo ha demostrado sobradamente, que su obligación es recogerlo y meterlo, por lo menos en un geriátrico o en algún sitio y que no muera como un perro en la calle, porque encima han comprado un piso, nada más se le ocurre a él comprar un piso, claro, lo puso a nombre de sus hijos y ella está, pues claro, molesta, también es verdad que la familia de ella no la han vuelto a dirigir la palabra, la desheredaron, lo hicieron todo, yo veo a su madre o veo a sus hermanos y yo les digo hola y adiós, porque no tiene porqué pagar la culpa de lo que... de lo sucedido, no son culpables de nada, ellos pasan vergüenza cada vez que me ven a mí, agachan la cabeza y yo pienso... no tienen por qué avergonzarse, a mí ellos no me han hecho nada, a mí si mi hermana hace cualquier cosa, yo no tengo porqué pagar las consecuencias de los actos que pueda tener mi hermana ¿entiendes?. Entonces, ellos se han sorprendido de... y mi hija me dice "mamá es que tú eres una señora y tú sabes estar" Digo "no, es que yo considero la justicia, como no juzgo... tampoco, como no me gusta que me juzguen, tampoco juzgo a nadie" $Y$ ahora él si me ve, se me queda mirando, cuando tuve el accidente le preguntó a mi hija "¿qué tal?, ¿qué tal mamá?" Al principio, cuando adelgacé tanto, le preguntó a mi hijo “¿Qué le pasa a mamá que está muy delgada?", claro mi hijo le dice "es gilipollas, con lo que has sufrido, después de la separación, del juicio y de todo, ¿qué no vas a adelgazar?, con lo que has padecido" O sea, es que es ignorante y le dijo "No, es que ahora marcha todos los días de fiesta y no para en casa, claro, no reposa, ni descansa, pues se ha quedado así, está delgadísima por eso, porque está todo el día de fiesta" Sólo por putearlo, sólo para... es decir, un poco, como diciendo... fastídiate, porque claro, ahora han dicho, porque no te lo pierdas, hoy encargué gasóleo curiosamente, y yo me llevo muy bien con el chico del gasóleo, yo me llevo bien con todo el mundo porque es que como no discuto y yo hablo con todo el mundo y doy confianza enseguida, que por eso después sufro muchas cosas, porque me como marrones que no me tenía que comer, pues llegó y me dijo "D., te voy a decir una cosa, porque es que hace unos cuantos meses que lo oí, estaba yo tomando un café y estaban hablando de ti en un bar aquí en A. y me llamó la atención, porque claro, yo te conozco, te llevo trayendo gasóleo para la calefacción desde que has venido para aquí y a mí me pareces una persona muy maja y por pura curiosidad, no es por otra cosa. Estaba tomando café y había allí dos o tres paisanos, que no te voy a contar quienes son ni nada" y dije "no, no, no, si tampoco me apetece" dice “¿has visto a la de P?"Dije, ¿Te das cuenta cómo sigue la de P? ¡Es que me da una rabia!, porque pueden decir, la ex de P. o D., simplemente, bueno, pero si no saben mi nombre "¿has visto a la de $P$ ? ¿sabes que me dijeron?, que se había retocado, que se había puesto más pecho, que se había quitado caderas" $Y$ yo dije "jay pobre de mí!, si hay meses que te digo, pásame el gasoil el día 5 que cobro que antes no cobro, que no tengo un duro, como para retocarme yo" Que bueno... muchas piden un crédito para retocarse, dije, "pero no, yo no es el caso, lo mío que tengo es natural, mira eres un hombre y no te voy a decir que toques para que veas que es natural evidentemente, pero vamos... lo mío, es todo mío, no hay nada extraño, lo que pasa es que tengo una buena alimentación, me cuido mucho, hago gimnasia, procuro cuidarme, entonces no aparento la edad que tengo, luego tengo un carácter muy juvenil, tengo una mentalidad muy abierta" Entonces, claro, todo el mundo 
piensa, como que he rejuvenecido 20 años y es cierto que he rejuvenecido 20 años, pero por mi forma de ser y porque me lo he currado, porque hoy yo me he comido una verdura a la plancha y detrás un yogur y después me pondré a hacer aquí una hora de aerobic y camino y salgo con este (el perro) a que corra un poquitín

- (P) ¿Este es el perro, verdad?

- (R) Este es el perro, M., para que también él haga un poco de ejercicio, un poquitín ahí enfrente. Y lo que te digo, y... con muchas ganas de vivir

- (P) Una historia dura, D...

- (R) Muy dura

- (P) Te voy a seguir preguntando ¿vale?

- (R) Sí, todo lo que quieras

- (P) No quiero cansarte, porque ya llevamos un rato largo hablando

- (R) Te canso yo a ti

- (P) No, nada de eso.

- (R) Mira, ahora mismo no me duele, si te das cuenta lo hablo desde la paz y yo creo que he aprendido en la vida, en 5 años, más que en toda mi vida junta. Yo he espabilado mucho, me he vuelto más pícara, me he vuelto más desconfiada, más precavida, un pelín cabrona, aunque la palabra no sea muy correcta, pero creo que es como hay que ir por la vida, porque o te pisan o te pisas. Entonces antes de que me pisen, como ya me han pisado tanto, tanto, tanto, ahora por si acaso ya me separo un poco.

- (P) Vas tú precavida

- (R) Sí y así y todo, todavía me siguen dando palos

- (P) Te voy a preguntar sobre P.

- (R) Dime

- (P) ¿Por qué se enfadaba contigo? Vamos a ver, yo te veo una mujer, como tú mismas te describes, con muchas cualidades, tanto a nivel físico como a otros niveles... a nivel intelectual, de valores... ¿Por qué se enfadaba contigo? ¿Qué cosas no le gustaban de ti?

- (R) Pues que yo estuviera en un estatus más alto, siendo su pareja y él en un estatus más inferior, porque se relacionaba con el mundo del vinoteo, del chateo, que lo único que hay en su mundo es el vino y el futbol y para de contar

- (P) ¿Que tú fueras de otro nivel cultural le molestaba?

- (R) Yo he estado cenando con Valentín García Yebra, con Gullón, con el hijo de Gullón, he estado cenando con grandes literatos de la Real Academia de la Lengua, en cantidad de... pues cuando vienen aquí... de la escuela de A., de... todo este tipo de gente.... He ido a cenar con ellos, yo he estado en conferencias con gente de muy... cultural de este país, yo escribo, yo publico en los periódicos, yo pinto, yo tengo cuadros en muchos sitios de casas de cultura de, de diferentes sitios. No presumo nunca de nada, porque todos tenemos cualidades y el presumir $i a$ qué te lleva?, a ser una tonta, porque dime de qué presumes y te diré de qué careces. $\mathrm{Si}$ dios me dio unas virtudes y yo las he desarrollado a medida de mis posibilidades, para mí ya es gratificante, no necesito que me den palmaditas en la espalda, porque yo lo hago porque me gusta

- (P) ¿Y eso es precisamente lo que le irritaba de ti?

- (R) Eso es lo que a él le irritaba, que yo fuera por la calle y me consideraban una persona que sabe estar...

- (P) ¿Cuándo él te conoció tú ya eras así?

- (R) Claro, pero es que él se consideraba como mi sombra. Él quería ser como... en el caso de la pareja yo creo que quería ser como él, el protagonista y que yo estuviera a su sombra. En este caso era al contrario y eso a él le molestaba, porque él, yo poco a poco le iba metiendo en el rol que yo me metía y yo di muchas conferencias, jamás fue a una y en una ocasión se lo dije, o sea, va toda $A$., que doy una conferencia en la que yo hablo, pues de un tema de medio ambiente, de cualquier cosa, de la mujer.... De mil cosas, y mi marido, que es el que tenía que 
estar en primera fila apoyándome, está en una barra, en la otra, en la otra y no fue jamás, mi marido no sabe como hablo en público

- (P) ¿Por qué permanecías a su lado, D.? ¿Qué te ataba a él?

- (R) Yo creo que en primer lugar los hijos y yo creo que en el fondo yo lo quería, pero llegó un momento que llegó el desamor y llegó el costumbrismo y como llegó un momento en que el objetivo era que yo necesitaba ese dinero para que mis hijos tuvieran una cultura, porque yo no quería que se quedaran... porque mira no valen para estudiar, le buscas un trabajo, porque cuando no hay capacidades, no se pueden sacar, pero cuando las hay se sacan, y yo quería que mis hijos... Yo les decía "¿no os da vergüenza que tenga yo muchos más estudios que vosotros?" Hombre, yo tiene mi madre más estudios más que yo y me comería, porque decía, vamos a ver, tengo inteligencia, no la voy a desperdiciar, si te la han dado es para que la utilices. Entonces yo a mis hijos, siempre les he educado en el razonamiento y en la forma de ver, no el hoy, sino el futuro. Porque claro, hoy, estamos en crisis y vienen mal dadas, pues te vas a tener que adaptar, como le digo yo a mi hija, vamos de vacaciones a lo pobre, a comernos un sándwich o un bocata y no ir de restaurante y te lo pasas fenomenal en la playa y punto, pero disfrutas de la playa que te viene muy bien. Entonces por eso lo llamo vacaciones a lo pobre, tirando de, $\ldots$ en vez de tomarte una cerveza, te la compras en el súper, la tomas en la terraza del hotel, en una silla, allí como que estás en una cafetería y te gastas, lo que te cuesta una cerveza, te compras una lata ¿entiendes? Es lo que llamo yo vacaciones a lo pobre, en este plan y te lo pasas fenomenal igual. Entonces yo creo que yo seguía un poco unida a él porque yo quería que mis hijos tuvieran una formación adecuada y hoy puedo presumir de que la tienen

- (P) ¿Podemos decir que el tema económico, dilata en el tiempo la separación?

- (R) Yo tuve preparados los papeles de separación, pues cuando mis hijos tenían 15 y 16 años, porque no soportaba más, yo no aguantaba más el hecho de.... Esa vida, es que yo he comido mucho pan con lágrimas, estar comiendo... yo estuve un año comiendo una barra de pan, una baguette concretamente, grande, la partía por la mitad, media barra de pan para comer con una manzana y media barra de pan para cenar con otra manzana, para que a mis hijos les llegara el dinero. No me da ninguna vergüenza decirlo, porque no he pasado hambre, he pasado necesidad de comprarme ropa, y tirar de ropa más vieja, o tirar más de ella, pero el día que me compro ropa, aunque sea en... barata, como que fuera de DG, la disfruto como tal, porque he aprendido a convivir con mucho dinero y con muy poco y lo disfruto igual. Porque es la ilusión de decir, me gusta ponerme guapa, aunque sea con una camiseta de $3 €$ que están en rebajas, porque antes valía 20 , pero yo espero a las rebajas y me la compro, me compro un par de ellas, así colores brillantes, me pinto los labios, me pongo unos pendientes largos y voy más guapa que otro poco. Que a lo mejor va una con un vestido de E. que no es caro, porque yo voy a Zara y me compro una falda o una camiseta y me cuesta $10 €$ y no me importa, pero entonces, esos $10 €$ a mí me suponía... vamos... el comer 10 días. Entonces ¿qué hacía? Repetir modelo, cambiaba una cosa con la otra, repetía al día siguiente, cambiaba una cosa

- (P) Combinabas

- (R) A mí eso de combinar se me da muy bien, o sea, yo he aprendido a combinar la ropa, vamos... a hacer maravillas, porque no me ha quedado más remedio que buscarme la vida de... porque soy presumida, en el buen sentido, es decir, no soy la ratita presumida, pero me gusta ir guapa

(P) Te gusta ir arreglada

- (R) Siempre voy, una barra de labios en los chinos vale... aunque se te quite al poco rato, pero sales de casa con los labios pintados, arreglados, con brillo, no con ojeras y con cara de dar pena, no , pena nunca, aunque la tenga dentro, cuidado, no mostrarla 
- (P) Antes decías que tuviste que visitar a un psicólogo y de hecho estás en tratamiento todavía, tanto tu hija como tú. ¿Antes de conocer a P., tú tuviste que visitar psicólogos?

- (R) No, para nada

- (P) ¿Y él?

- (R) Como ir al psicólogo significa estar loco ¿cómo iba a ir? Él era el que tenía que haber necesitado el psicólogo, pero bueno tenía que haberlo necesitado toda la familia, que era una familia desestructurada. Ahí es que no había por donde coger las cosas, yo... para mí era muy extraña, no... yo me eduqué de otra forma, entonces...

- (P) ¿Cómo se porta esa familia y la tuya propia, una vez te separas?

- (R) Vamos a ver, la familia de él me acosa, es cuando empiezan a acosarme, es cuando empiezan a... tengo que cambiar de acera, irme por otra calle, me intentan pegar, es cuando me rompen el coche reiteradamente, me lo rallan, me liman las cerraduras, me rompen dos veces la luna, me rajan las ruedas, me rompen las matrículas, me lo rallan por delante, por detrás, por el capó, me rompen los cristales, el espejo, los retrovisores, le han hecho de todo, porque claro, no me morí, así, es que me tenía que haber muerto y como hubo sangre y vivo ¡pues hija! No me perdonan que a $\mathrm{P}$. lo denunciara, tú imagínate si lo meto en la cárcel, me queman en la plaza por bruja, porque así y todo, perdonándolo, que ninguno a reparado... bueno, te puedo decir que hace 4 años coincidí en una boda con un cuñado, que estaba él de camarero y yo estaba en la boda y me dijo que si me encontraba sola que lo llamara que él venía conmigo ¡Es fuerte eh! Y le dije...

- (P) Pero ¿en qué sentido?, no entiendo

- (R) Vamos a ver, me dice, "cuñada estás guapísima" y le dije "perdona, pero tú y yo ya no somos cuñados"

- (P) ¿Un hermano de P?

- (R) Sí, "perdona, pero tú y yo ya no somos cuñados" "yo te quiero a ti como si fueras una cuñada" "pero yo a ti no", me dice "bueno, tú si quieres, voy un día y te hago compañía" Acariciándome el brazo y le dije "mira, ni es mi interés, sería con el último hombre que estuviera en este mundo, aparte de darme asco y vergüenza, estás hablando con una persona que fue tu cuñada, no sé cómo no se te cae la cara de vergüenza y a partir de ahora no me vuelvas a dirigir la palabra en tu vida"

- (P) O sea, que el apoyo que te presta esa familia es de este tipo

- (R) Es el único apoyo y lo demás es hacerme daño, todo el daño posible, de hecho fueron diciendo de ella (la mujer de P.) que estaba embarazada y mi hija lo pasó fatal, la tuve que llevar al psicólogo, muchas, muchas, muchas... veces

- (P) ¿Qué estaba embarazada quién, tú o ella?

- (R) Que estaba embarazada la mujer de su padre. Entonces se pone "jah que va a tener un bebe" y mi hijo le decía "vamos a ver, N., razona, si van a tener un bebé, va a ser medio hermano nuestro, el niño no va a tener la culpa" "Pero ya nos quita a papá del todo" decía ella "No, vamos a ver, razona, el niño no tiene la culpa, no le puedes odiar" Dice, "le digo que se lo cuido y lo ahogo", la rabia esta, vamos a ver, es normal, sufrió muchísimo y yo le dije "vamos a ver, no te preocupes que ya me enteré yo que ella no puede tener niños, lo han dicho para hacerte daño a ti y a tu hermano, así que no te preocupes" $Y$ ya mi hija se relajó, y mi hijo sin embargo, decía "a fin de cuentas, va a ser un medio hermano nuestro y él es un inocente, no tiene la culpa" Tú fíjate la educación que yo les he dado a mis hijos para que piensen de esta manera ique es duro!

- (P) Eso su familia, la tuya ¿Te apoyaron cuando te separas?

- (R) Ha sido muy variado, porque en un principio, mi hermano el de A., cuando vino dijo "Bueno antes de ayer también se separaron unos amigos nuestros y tampoco pasa nada, es normal que todo el mundo se separe" pero claro mi hermano no sabía... simplemente sabía que nos habíamos separado, no sabía de las amenazas, no sabía del intento de asesinato, no sabía nada de nada, simplemente que nos habíamos separado. Entonces, porque yo le dije "tampoco es que pase 
nada, simplemente es eso..." "Bueno vale, es normal, lleváis toda la vida, es normal que estés hecha polvo, pero no pasa nada" Pero qué pasa, que al poco tiempo, invitó a mi madre "por qué no te vienes unos días a A. y ... a pasar unos días en casa con nosotros", entonces empezaron a hablar el tema, entonces es cuando mi madre le contó a mi hermano todo lo que había pasado y mi hermano dijo "eso yo no me lo creó mamá" y le dijo mi madre "vamos a ver, te lo estoy diciendo yo que soy tu madre" Y ¿sabes cuándo lo comprendió? Cuando ese día que me vio llorar, cuando la niña fue corriendo a ver a P. Mi madre en un principio no sabía cómo tratarme, porque siempre era mi padre el que me ayudaba, fue un año difícil porque coincidió que mi padre muere en marzo y el 29 de septiembre, de julio es cuando yo me separo, en ese medio tiempo, a mi hermano, que está muy unido a mí, que es el más pequeño, que vive aquí en $\mathrm{A}$. con mi madre, tiene un cáncer maligno en un testículo, entonces la que se encarga de llevarlo a L. al hospital, con la operación y estar con las sesiones de quimio, dejarlo a las 7 de la mañana, volver a las 5 de la tarde y volver con él a las 11 de la noche, soy yo, la que estaba aquí, mis hijos estaban todos fuera, mi madre no podía con la vida. Tuve que hacer de tripas corazón y tirar para adelante con todo eso, 8 meses yendo a quimio, llevarlo por la mañana y lo iba a buscar por la tarde, cada vez que le tocaba. Entonces tienes tantas horas para pensar, libros para leer, darle vueltas a todo, que mi hermano es que el sufrió conmigo, la verdadera... mi madre "A. está llorando" "déjale, es bueno que llore, no te preocupes" A mi padre, no he podido ir a verle, el negocio de mi padre, soy incapaz de ir al cementerio, porque le dije "papá eras como un castillo de naipes, se cayó la carta que fortalecía toda la estructura y nos hemos venido todos a bajo" Entonces, lo que te quiero decir, mi hermano está con el cáncer, me quiere apoyar, está luchando contra un cáncer maligno, que se le infectan... tiene todo esto abierto, se le infectaron, hubo que volverle a operar, estuvo más tiempo por la infección que por el cáncer y luego claro... animándolo y sacándolo para arriba y salió arriba y hoy tiene una pareja y está montada su vida muy bien y todo

- (P) Mientras estuviste casada con P. ¿tú piensas que él estaba sometido a estrés y por eso reaccionaba así? ¿o no tenía nada que ver el trabajo con su forma de ser?

- (R) Vamos a ver, si con 12 años alterna a vinos, con 30 es lo más normal del mundo porque es lo que ha visto toda la vida, eso no le genera estrés, le genera estrés si no hay dinero para poder ir a tomar el vino y te explico, un día no había nada para comer, entonces, yo lo que le hice fue a mis hijos, una tortilla francesa, se la metí en un bocadillo y les di un bocadillo a mis hijos y para él y para mí no puse nada, llegó a comer y dice "¿Qué hay de comer?"'Nada"” ¿Cómo que nada?" "No, no hay nada, yo no tengo dinero, yo te he pedido, no me lo has dado, pues nada" "¿Y los niños qué comieron?", dije "a los niños les trajo mi padre un bocadillo, nosotros nos buscaremos la vida" pegó un portazo, se metió en la cama y se puso a dormir, claro como a él con el vino, le dan un pincho, ya venía comido, aunque tuviera hambre, venía alimentado, medio comido. Yo comí una manzana, como ya no me entraba ni la comida, porque es para no entrarte ni la comida, y punto. Al día siguiente apareció dinero para comer y es cuando dijo "voy a traer yo siempre la compra para que haya comida" y dije "Sí, perfecto" Yo le daba una lista de la compra con lo que necesitaba y ahí fue cuando empezó a comprar él, para controlar el dinero, para quedarse siempre él con dinero, era una artimaña

- (P) ¿Siempre que teníais esas broncas, era porque él había bebido previamente?

- (R) Evidentemente

- (P) ¿Si no bebía?

- (R) Si no bebía, tenía sus días muy buenos, o sea, cuando no bebía y cuando él estaba en su estado natural... un caballero y un señor. Yo le enseñé a estar en público, porque luego él se metió en una cofradía, la cofradía de la santa cena, que llegó a ser, es presidente, yo le enseñé a llevar los libros, le enseñé a saber estar, cuando iba a cenar con el obispo, cómo había que comportarse, siempre cómo había que vestir para cada acto, qué corbata había que poner, yo siempre se lo tenía todo combinado, cómo tenía que comer, nunca empezar antes que el señor 
obispo, siempre las autoridades hay que esperar que coman... lo que es la ética profesional a la hora de estar, no hablar con la boca llena, tragar, comer... saber estar ¿no?... saber estar a la altura y si tenía que hablar algo, hablar con sus propias palabras, que no buscara palabras rebuscadas porque iba a meter la pata, porque no iba a saber lo que tenía que decir. "Tú siempre habla con tus palabras, con tu lenguaje llano, normal, suave y lento, para que todo el mundo te comprenda, y no tienes por qué hacer... puedes hacer una gracia, pero no soltar una tontería", porque él era muy amigo de soltar muchas tonterías, porque era el cachondeo y la risa y la juerga, ese es el problema, si mañana hay problemas ¡bueno, da igual!, no había responsabilidad. Entonces yo lo que pretendí era hacer de él un señor, además lo he descrito muchas veces, yo lo saqué de una cloaca, lo convertí en un señor y ahora volvió otra vez a la cloaca. Yo creo que ahí queda claro... más o menos te queda un poco claro como era y como es

- (P) Cuando antes me hablabas, quisiera saber... ¿parte de ti la idea de denunciar o es alguien quién te anima a hacer la denuncia?

- (R) Directamente yo, la decisión, en el momento que me soltó, yo puse un pié, así dentro del bar y le dije "te voy a denunciar por malos tratos"

- (P) Parte de ti la idea, no hay nadie que te induzca

- (R) Estoy yo sola, me acaba de soltar y le digo "te voy a denunciar por malos tratos", él no me creyó, él pensó que era un farol, pero claro, cuando la policía lo detuvo, ahí él ya se arrugó, claro y nunca pensó que yo lo fuera a denunciar.

- (P) ¿Él consideró en alguna ocasión que el maltratado era él?

- (R) Para nada, "es que es mal bicho, no sé que le he hecho yo, ella lo que tiene es que está rebotada porque la he dejado por otra, porque claro yo quiero ir con una chica joven" porque ella es más joven que yo, ella tiene... no sé los años que tendrá, pero... no sé, cuarenta y algo, no sé los que puede tener, pero nos pones lado a lado y le hago yo sombra a ella y no es presumir, le hago yo sombra a ella, porque de hecho, ella se llegó a cortar el corte de pelo como yo, se tiñe de rubia como yo y empezó a imitarme como vestía yo. Y yo diciendo, "pero imbécil, si te ha dejado por mí, se tu misma, no me hagas una fotocopia, que ya la tuvo

- (P) Tus hijos vieron cosas, decías que tú intentabas que no se enteraran

- (R) Siempre lo oculté, todo lo que pude, pero luego me di cuenta, ellos me lo han contado, de que hacían que se iban y escuchaban todo

- (P) Sí, me lo comentabas antes. En aquel momento, cuando tú te casas, al principio de la relación ¿Piensas que este hombre, P. es tu pareja ideal, tu complemento? ¿Lo pensaste en aquel momento?

- (R) Yo pensé que iba a ser el hombre para toda mi vida

- (P) ¿Y ahora?

- (R) Me acuerdo muchas veces de él y digo... "me dejó, o sea, después de haber tragado tanto, de marchar con los amigos, de hacer todas las borracheras, cuando teníamos una estabilidad, que los chavales ya eran mayores y podíamos empezar a vivir un poco, vivir la vida ¿cómo me rompió la vida de tal forma? Que me dio una libertad que no deseaba, una soledad que no buscaba por un polvo". No me he sentido nunca culpable, porque yo pienso que a lo mejor, para él, yo pude cometer muchas cosas, porque vamos a ver, aquí nadie es perfecto y culpables pueden ser todos, yo creo que él se sentía presionado y aquí soy muy sincera y siempre lo digo... yo creo que él se sentía presionado porque yo le decía "sal y haz lo que quieras, pero no bebas, por favor, bébete un zumo de naranja, bébete yo qué sé... no bebas alcohol, si yo no te quito de que no salgas, que te apetece estar un rato con los amigos, que vayas, me parece estupendo porque no vas a quedar cerrado en casa", porque no es hombre de estar encerrado en casa, ahora porque no puede, porque anda medio cojo por una lesión, quiero decir... "pero no bebas" y cuando salía le decía "por favor, no bebas, no bebas, haz lo que te dé la gana, pero no bebas" Nunca le quité, lo único que le pedía, y a lo mejor a él eso le presionó mucho, puede que lo presionara, pero es que claro... a mí también me iba la vida en ello. Entonces, probablemente..., de hecho una prima le preguntó qué había 
pasado, se llevaba muy bien con ella y le dijo "es que me presionaba" Porque eso luego se lo comentaron a mi madre, es que dijo que D. lo presionaba, lo estuvimos observando, estábamos nosotros en un bar en la plaza, y estuvimos como 15 minutos y en 15 minutos recorrió todos los bares de la plaza, no me extraña que $D$. le presione, si es que hemos tomado nosotros un corto y él ya ha entrado en 4 bares, era coger... ras (hace el gesto de beber) ... posar y entrar a otro, eso conlleva que no hay dinero, que estás alcoholizado, que todo te parece mal, que te pones de mal humor, que vienes mal, tú que estás harta de que no haya dinero y que se lo gaste en vino y mil cosas, entonces claro, empieza a haber una presión, empieza a haber una presión, entonces evidentemente... yo claro que me rebotaba, cómo no me voy a rebotar si al día siguiente yo no sabía si tenía dinero para ir a la compra, cuando yo veía... mira en una ocasión... te voy a poner un ejemplo que me pasó que no olvidaré en mi vida y se lo tiré en cara y se rió de mí. Me acuerdo que viviendo yo en $V_{\text {., }}$ en una casa que vendimos, en el piso que vendimos, iba a misa, íbamos a misa y yo le digo "icaray! No llevo nada, no llevo dinero ni llevo nada" eran todavía pesetas, de eso me acuerdo porque cogió, abrió el... la cartera y me dio 25 pesetas y él se quedó con 5000 y cogí de rabia y se las tiré al suelo, dije "mira, eres de lo peor, tú crees que puedes... ¿tú te estás riendo de mí?, yo estoy aquí metiendo, como tú, un sueldo todos los meses, ¿tú crees que puedes hacer esto?" $Y$ dice "Anda tonta que es broma" Dije "pues yo no lo considero ninguna broma" $Y$ me acuerdo que cogí y marché para misa, di un portazo y marché para la iglesia, para misa y él vino detrás, y no le cogí dinero en todo el día. Me sentí tan burlada... me sentí tan mal, tan mal, que no he olvidado esas 25 pesetas en la vida, es que fue una burla

- (P) A día de hoy, D., ¿tú piensas que la situación ideal de cualquier mujer es estar emparejada?

- (R) Yo por ejemplo, te digo una cosa, yo... me encantaría tener pareja, yo soy mujer de vivir en pareja, vivo sola porque no me queda más remedio, pero si tuviera una pareja... eso sí... ahora sí que escojo muy mucho, tiene que tener unas cualidades muy especiales

- (P) ¿Tú piensas que las mujeres sólo podemos amar a un hombre y que después de haber amado a un hombre, todo lo que nos venga, ya no es válido?

- (R) No, no, no... para nada. Vamos a ver, yo creo en el amor, de hecho cuando hay una pareja que si puede haber una reconciliación y se puede unir una pareja y no se puede romper, soy partidaria de que se unan y no se rompa, porque no hay mejor cosa que compartir la vida con alguien, las alegrías y las penas

- $(\mathrm{P})$ De los celos ¿qué opinas? ¿Crees que son buenos en una relación?

- (R) Es un arma de doble filo, porque el que bien te quiere, te hace sufrir, me parece una tontería. El que bien te quiere no te hace sufrir, vamos a ver, el decir, es que me pega porque se cela porque me quiere mucho, eso es algo que nos han contado y nos han metido en la cabeza

- (P) ¿Pero tú eres consciente de que este discurso está en la calle?

- (R) Es que hoy en día es vigente, es vigente total. Yo conozco chicas, chavalillas del instituto, que le ha pegado el novio, el chaval que está con él una bofetada porque la miró un compañero y ella le sonrió. "Tú eres mía" Hoy en día. Que yo estuve a punto de decirle "chico... no eres dueño de nadie" Yo creo en el amor. De hecho yo estoy esperando el amor, estoy enamorada de V., sigo enamorada y estoy esperando y sé que va a ser mío, pero necesita tiempo, y le estoy esperando porque sigo enamorada de él, con todo lo que me haya hecho, yo creo en el amor y creo que en esta vida, los dos sentimientos más fuertes que hay son el amor y el dolor

- (P) ¿Piensas que el amor lo puede todo?

- (R) Sí. El amor mueve montañas

- (P) ¿Ha de mostrarse siempre con la misma intensidad? 
- (R) No siempre, no tiene porqué, pero sí demostrarse. A mí no me vale que me diga te quiero si no me lo demuestras, porque las palabras las lleva el viento, yo lo que quiero es demostraciones, eso es lo que he aprendido

- (P) ¿El amor es algo que no se puede dominar? ¿No se puede controlar?

- (R) No, es un sentimiento

- (P) ¿Es un sentimiento, qué no tiene nada que ver con la voluntad?

- (R) Evidentemente, tú un sentimiento lo tienes y no lo puedes controlar, hasta cierto punto se puede controlar, todo es controlable hasta cierto punto, pero claro, hay cosa que se te van de la mano, lo bueno está en tú llegar al punto de saber controlar la situación, porque yo, a mí, se me desbordó de las manos, y de eso he tenido que aprender a que no me vuelva a pasar. Aprendí que las cosas hay que controlarlas, el otro día leí una frase de un filósofo chino que decía que el no querer $y$ el querer demasiado no es bueno. Y es muy buena la frase, tan malo es no querer nada como querer demasiado y es cierto

- (P) ¿Piensas que si quieres a una persona hay que acabar en convivencia?

- (R) No, por qué. Yo mi hijo está con su pareja, no están casados y son más felices que nadie

- (P) ¿Conviven?

- (R) Conviven en pareja y tendrán sus rollos, como todos, no porque firmes un papel o te vistas de blanco vas a ser más feliz, eso no tiene nada que ver, eso simplemente es un acto simbólico

- (P) Vamos a recapitular un poco ¿vale?

- (R) Dime

- (P) ¿En tu separación la decisión la toma él?

- (R) Sí, a mí me la imponen

- (P) El detonante para esa separación ¿cuál es? ¿por qué en ese momento?

- (R) Porque ya había pasado el tiempo suficiente de que había muerto mi padre, y él debió de pensar que después de 6 meses, el dolor ya estaba amortiguado, de la muerte de mi padre, y creyó que era el momento oportuno. Pienso

- (P) ¿Hubo algún intento antes de separación?

- (R) Por parte de él fue el primero y el último, por mi parte, bastantes años antes yo tuve los papeles preparados, porque es que estaba liado con tres tías a la vez y lo descubrí yo y me hice amiga de ellas, las invité un día a casa a comer a las tres y cuando llegó él a comer y estábamos las cuatro comiendo juntas se rompió la relación. Vamos a ver, si no puedes con tu enemigo, hazte su amigo. Yo no podía ir contra ellas, pero sí me pude hacer amiga de ellas, íbamos a la cafetería, tomábamos un café con ellas, y un día digo, "os invito a comer "y cuando él llega a comer a casa, nos encuentra a las 4 en la mesa y digo "he invitado a unas amigas a comer" A partir de ahí se acabó la relación, ahí fui muy astuta

- (P) ¿Qué cambios experimenta tu vida una vez te separas?

- (R) Muchos

- (P) ¿Por ejemplo?

- (R) Ver la vida de otra manera totalmente diferente, crecer más como persona, el valorar mucho más las cosas, siempre las he valorado, pero ahora en su justa medida, el llanto me ha hecho conocer la desesperación y convivir con ella. De hecho el día que tuve el accidente yo pensé "no es un mal día para morirse, porque hoy están todos los muertos por ahí y nada más tengo que seguirles, seguir el camino" No me hubiera importado morirme ese día

- (P) ¿Fue el día de todos los Santos?

- (R) Fue el día de todos los santos, pero mi preocupación era el coche, no era mi vida, ya tengo a mis hijos encarrilados, ya lo tengo todo colocado, ahora no tengo responsabilidades, entonces qué pasa, si yo soy infeliz, mi vida no me gusta y sufro, ¿qué es lo que más me duele en este momento? El coche

- (P) Ahora mismo ¿qué apoyos tienes? ¿quién te apoya a ti? 
- (R) Ahora mismo, tengo el apoyo total de mi madre, por supuesto el de mis hijos, el de mi hermana, que la he recuperado porque la perdoné, mi hermano también está ahí, mis dos hermanos también están ahí y mis dos mejores amigas, una de ellas ha tenido un cáncer y he estado con ella día y noche hasta que lo ha pasado y lo ha superado y he estado ahí, para lo bueno y para lo malo, día, noche, verano, invierno, hemos llorado mucho juntas, pero lo ha sacado para adelante

- (P) ¿Tú de salud ahora cómo estás?

- (R) Yo creo que... bueno... todavía un poco golpeada por el accidente, al margen de lo del accidente y todo esto, estoy con... había quitado medicación, pero la he tenido que volver a poner, volver a subir un poco, me ha afectado mucho lo del coche, porque yo tenía mucha libertad y ahora no la tengo, entonces tengo que depender de gente, no me gusta depender de la gente, porque he tenido que aprender a vivir sola para no deber nunca favores a nadie, porque luego la vuelta, el tener que pagar el favor, estos favores morales, no se pagan nunca, son de por vida y yo no quiero depender, ni deber nada a nadie, me he vuelto un poco más egoísta

- (P) Muy rápidamente ahora. Vivienda ¿estás a gusto en tu casa?

- (R) Sí

- (P) ¿La pagas tú, con tu sueldo?

- (R) No dependo de nadie, yo me mantengo yo sola

- (P) Económicamente..., sigues manteniendo tu trabajo

- (R) El mismo que tenía, doy clases a alumnos para sacarme un sobre sueldo

- (P) ¿Las relaciones sociales, sin problemas?

- (R) Sí

- (P) Las relaciones familiares, dices que con tu madre y la familia has retomado relaciones

- (R) Me han empezado a conocer ahora, antes no me conocían

- (P) ¿Con tus hijos tienes muy buena relación?

- (P) Muy buena relación, bueno de hecho mi hija ya ves que me ha dejado todo, lleva aquí conmigo un mes y me dice "mamá si vas al armario y ves que te falta algún vestido, no lo busques es que te los llevé"

- (P) ¿Estás abierta a nuevas relaciones de pareja?

- (R) De hecho tengo mucha fe en que este hombre llegará a quererme, me tiene que llegar a querer, vamos a ver, el amor mueve montañas y yo tengo que mover ese corazón. El día que vi este móvil, dije ese móvil tiene que ser mío como V. tiene que ser mío, si conseguí el móvil... tiene que ser mío, me costará lo mío... ahora tiene que venir conmigo de rodillas porque me hizo sufrir mucho. Le perdono, pero tiene que venir de rodillas, con mucha humillación

- (P) ¿Cómo te sientes contigo misma?

- (R) A gusto, me gustaría tener una relación para sentirme completa, yo soy libra y tengo ahí la balanza desequilibrada, en ese campo, yo soy mujer de pareja

- (P) ¿Cómo te ves en un futuro?

- (R) Te puedo decir cómo me gustaría verme porque dios dispone, el hombre propone y dios dispone, pero yo me gustaría verme con este hombre, que le quiero, en pareja y disfrutando de la vida y olvidándonos del mundo, ya me toca y además yo creo que me lo merezco

- (P) D., por mi parte, he acabado, no sé si tú quieres contarme algo más, porque ha sido intenso, intenso. Hay mucha información aquí

- (R) Ya te dije que había para largo y tendido, tengo 5 tomos para hacer un best seller, sería muy ilustrativo para mucha gente, que aprendieran de los errores cometidos, para que no pasen por ahí

- (P) Tú que tienes esa vena creativa y artística, todo es que te lo propongas

- (R) Lo he pensado en hacerlo y además lo he puesto el título El grito silenciado que es el peor grito que puede haber, cuando gritas con toda tu alma en silencio, es como arañar un cristal, es la corona de espinas que llamo yo. Te describo en un momento dado lo que es una crisis de ansiedad, que ahora le tengo mucho miedo 
porque han sido tantas, que ahora tengo secuelas, cuando me pongo, sufro mucho, mucho, mucho. Ya no me puedo controlar, intento controlarlo y lo voy controlando, pero cuando ya no puedo controlar, ahora pierdo el conocimiento ya, del dolor, se me pone a pinchar la cabeza, por eso lo llamo yo la corona de espinas y me desvanezco y me caigo y pierdo el conocimiento y eso es grave porque entro en coma, soy muy fuerte, tengo que luchar, tengo que conseguir a V.

- Cuídate mucho D., yo te agradezco este tiempo de charla. 
- (P) ¿Cuántos años tienes?

- (R) 36

- (P) ¿Lugar de nacimiento?

- (R) T.B.

- (P) En T.B., vale, por tanto eres española. ¿№ de hijos/as?

- (R) Dos hijos y una hija

- (P) Dos niños y una niña y ¿edades?

- (R) B. va a cumplir 12 años, M. tiene 8 , va a cumplir 9 y D. tiene 4

- (P) Vale, 12, 8 y 4 ¿Con quién viven?

- (R) Conmigo

- (P) Los tres contigo

- (R) Si

- (P) ¿Son hijos del mismo padre?

- (R) Sí

- (P) Del hombre que te maltrató

- (R) Si

- (P) ¿Dónde vives ahora mismo?

- (R) En una casa de acogida

- (P) ¿Desde cuándo?

- (R) Desde el 29 de Marzo del 2010

- (P) ¿Tienes familia cerca?

- (R) Sí, pero aquí en L. no

- (P) En L. a nadie ¿Dónde está tu familia?

- (R) En A., donde yo vivía y en T.

- (P) ¿A quién tienes?

- (R) En A. tengo a mis tíos y en el pueblo tengo a mi abuela, a mi hermano y a mi padre, pero de él prefiero no hablar

- (P) ¿De tu padre prefieres no hablar?

- (R) No

- (P) Pues lo respetamos ¿No tienes madre C.?

- (P) No, mi madre murió de cáncer

- (P) ¿Hace mucho?

- (R) 13 años

- (P) Eras tú muy jovencita. Esta familia de la que me hablas, tus tíos de A., tu hermano... ¿te apoyan en esta situación por la que estás pasando?

- (R) Si

- (P) ¿Cuál es tu situación económica?

- (R) Ahora mismo acabo de empezar a trabajar y voy a remontar, voy a salir del agujero

- (P) ¿Tienes trabajo?

- (R) Si

- (P) Cuéntame un poco ¿dónde trabajas?

- (R) Pues de lunes a viernes, de 10 a 12 cuido a una señora y luego, menos los miércoles, de 12:45 hasta que cierre, que pueden ser las 15 ó $16 \mathrm{~h}$, depende y de 19 a 22 trabajo en un bar

- (P) ¿Entonces, cuentas con una independencia económica?

- (R) Sí, ahora sí

- (P) Tu objetivo ¿cuál es?

- (R) ¿Mi objetivo?, salir de la casa, que voy a salir ahora a primeros de mes y nada... vivir, vivir, empezar a vivir

- (P) ¿Qué estudios tienes, C.?

- (R) Soy auxiliar de enfermería 
- (P) ¿Alguna vez habías trabajado como auxiliar de enfermería?

- (R) De auxiliar de enfermería no, no me estaba permitido

- (P) ¿Y eso...?

- (R) Porque tenía que marcharme de A. o venir a L. o P. Eso era algo impensable

- (P) ¿Quién te lo prohibía?

- (R) El papá de los niños, eso era algo impensable, eso de tener que desplazarte para trabajar, no. Tenía que estar al alcance, eso no se podía ni plantear

- (P) ¿Cómo estás de salud?

- (R) Bien

- (P) ¿Gozas de buen estado físico? ¿no tienes nada físico que te impida llevar una vida normal?

- (R) No, bien, para nada

- (P) ¿Cuánto tiempo hace que te separaste?

- (R) Un año

- (P) Un año ya separada. ¿estabas casada con este hombre?

- (R) No

- (P) No estabas casada, pero sí convivíais ¿Cuánto tiempo llevabas conviviendo con él?

- (R) Con él llevaba desde los 16 años, conviviendo llevaba como 15 años

- (P) ¿Y hace un año, te separas?

- (R) Si

- (P) ¿A la casa de acogida llegas hace un año?

- (R) Va a hacer un año para la semana que viene

- (P) Te voy a preguntar sobre el maltrato ¿vale?

- (R) Vale

- (P) ¿Qué tipo de maltrato sufrías? ¿malos tratos físicos, psicológicos, sexuales..?

- Psicológicos principalmente, cuando el psicológico no funcionaba porque soy muy "turriona" (se refiere a machacona y testaruda) y muy cabezona y a mí no me calla nadie tampoco..., era el físico y luego el económico, el económico era el que más, también le gustaba utilizarlo mucho, el dejarte en casa toda la semana con los niños sin dinero. De hecho yo estuve con él conviviendo 15 años y yo no estaba en las cuentas del banco

- (P) ¿Él trabajaba?

- (R) Él es autónomo

- (P) ¿Tiene solvencia económica?

- (R) Si, tiene solvencia económica

- (P) ¿Alguna vez te maltrató sexualmente?

- (R) Si

- (P) ¿Te viste obligada a mantener relaciones sin tu consentimiento?

- (R) Sí

- (P) Descríbeme el primer incidente que a ti te lleva a pensar que no es normal el trato,... lo que hace contigo

- (R) Puf... yo qué sé

- (P) Echa la vista atrás en el tiempo

- (R) No sé, cuando más cuenta me di, yo creo que fue cuando mi madre estaba mala y exageradamente, le parecía algo impropio que yo quisiera marcharme el fin de semana y estar con mi madre en el hospital a preferir estarlo con él. Yo con mi madre, sólo podía estar cuando él no estaba en casa, si él estaba en casa no le podía dejar solo a él para ir con mi madre. Eso ya me parecía..., había cosas de antes que no me parecían...

- (P) ¿Ahí empezó?

- (R) No, yo creo que fue desde siempre, esos celos patológicos, el... yo que sé... que estuvieras trabajando y... le llamaras y le dijeras que ibas a salir un poco más tarde y llegara y te dijera que te había estado llamando 40 veces o tal y tú saber que 
no te había llamado ni una sola vez y él jurar y perjurar que si lo había hecho, que te había ido a buscar 40 veces y no estabas en casa, cuando tú sabías que estabas en casa, porque es que estabas, si estás en un sitio, no te puede decir nadie que no estás y que te había ido a buscar, porque es que no... y te lo hacía... y no poder hablar con nadie, no poder salir con tus amigas a ningún sitio y...

- (P) ¿Eso siempre lo hizo?

- (R) Siempre

- (P) A lo mejor, por lo que tú decías, la coincidencia en el tiempo, cuando enferma tu madre, ella está peor en el hospital. ¿Ahí es cuando se agrava la situación?

- (R) Yo creo que se agrava... cuando más se agrava es ahora... casi al final, que fue donde yo cogí un poco más de independencia y me... no se... me he revelado un poco más...., me he relacionado más por el tema de los niños, el colegio... porque antes te tenía más aislada, más... trabajabas y tal, pero era trabajar y salías y estabas con él o estabas en casa, estabas como más aislada, tampoco... tampoco te relacionabas mucho... yo... pero una vez que empiezan a ir los niños al cole, te tienes que relacionar con más mamás, con más papás, con más gente y empiezas a ver que la vida no es lo que él te dice, que las cosas no son como él dice, que por mucho que lleve toda la vida diciéndote eso es así, igual, no es igual

- (P) ¿Cómo reaccionaba él después de una agresión, C.?

- (R) Siempre era culpa mía, siempre era yo la que le calentaba, porque él siempre empezaba por el psicológico, pero siempre acababa soltando la mano, más o menos, pero siempre la soltaba y siempre... siempre era culpa mía, porque lo sacaba de quicio, porque contesto, porque las cosas no estaban bien hechas, porque... por mil cosas y luego ya el lloro empedernido, el sufrimiento total y ... lo buena persona que él era y lo mala que era yo

- (P) O sea, que él discutía contigo, llegaba a agredirte, te pegaba ¿y luego lloraba?

- (R) Claro, una vez que eso, a lo mejor de que se le pasaba el sofocón ese, venía llorando y es que era culpa mía, porque es que... no lo enciendo, porque lo encendía, porque le cabreaba, porque...

- (P) ¿No lloraba pidiendo perdón?

- (R) Y si lloraba pidiendo perdón, tampoco llegó a pedir perdón, perdón de verdad. Él pedía perdón, porque a lo mejor se había pasado, pero es que era culpa mía, yo lo sacaba de quicio (ese era el discurso que él mantenía con ella)

- (P) ¿Tú como reaccionabas ante eso?

- (R) Yo es que a veces, hasta me creía que tenía yo la culpa

- (P) ¿Llegaste a creértelo?

- (R) Sí, de hecho en la casa (se refiere a la casa de acogida), he tenido muchos problemas por ser tan quisquillosa, porque es que, yo creo que me he acostumbrado a tenerlo todo tan perfecto, he buscado siempre... porque es que si limpiabas aquí, él siempre encontraba una mancha y yo creo que te llegas hasta a obsesionar. $Y$ en la casa, al principio tuve muchos problemas por eso, porque era súper exigente, yo lo hacía, pero quería que todo el mundo lo hiciera igual, igual de bien y si alguien no lo hacía, me endemoniaba, pillaba un rebote de la leche, me rebotaba toda

- (P) ¿Son esas las secuelas que vienes arrastrando de tu relación de pareja?

- (R) Claro

- (P) ¿Te ha quedado alguna secuela física,...?

- $(R)$ No porque físicamente él tampoco te... él que se viera tampoco. Él te podía dar un guantazo, agarrarte del cuello, alguna patada o tal, pero... así a lo.... No, no eso no. No, la cara principalmente, no solía tocarla mucho. Morados por la espalda, las piernas, si, pero la cara no

- (P) ¿Se cuidaba de eso?

- (R) Yo ya no sé... yo creo que sí, porque él siempre sabía dónde te daba, en la espalda, que es donde más duele, cuando te da en la espalda, te machaca, agarrarte del cuello 
- (P) ¿Tú esto lo contabas C.?

- (R) No

- (P) ¿A nadie?

- (R) No, no. A nadie, nunca

- (P) ¿Cuándo lo empezaste a contar?

- (R) Al final, antes de venirme. Antes de ir al CEAS de A., que hablé con una amiga mía, pero jamás, jamás se lo he contado a nadie

- (P) ¿Cómo reacciona tu familia cuando lo supo?

- (R) Mi familia sabía que algo pasaba porque claro... él aparte de eso, luego te echaba de casa

- (P) ¿Esto de toda la vida?

- (R) De toda la vida, una vez al año, como digo yo tenías que salir, porque lo decía él, "o sales tú hija de puta o sales a hostias" (Ella recuerda sus palabras)

- (P) ¿Los niños y tú o sólo tú?

- (R) No, los niños y yo, a los niños les decía "vete con la puta de tu madre, a ver dónde te lleva". Todos..., marchábamos todos

- (P) ¿A dónde marchabais?

- (R) Claro... íbamos para casa de mi tía, una semana, 15 días y no se acordaba de nosotros para nada y luego ya era que tenía que volver para casa fuera como fuera, si iba a buscarte y le decías que no, le decías una vez que no o dos, pero a la tercera ya empezaba con las amenazas..., con el llorarte por la calle... en un cacho de 10 minutos te lo encontrabas 5 veces, a veces te lloraba, otras te amenazaba, otras te llamaba de todo, "que apareces en una cuneta muerta"(amenazas de él), era el pan nuestro de cada día

- (P) ¿Por qué se ponía agresivo contigo? ¿qué le hacía salirse de quicio?

- (R) A parte de que es una conducta aprendida, porque su padre era igual, sustancias no permitidas

- (P) ¿Varias?

- (R) Varias, y no era alcohol

- (P) ¿Consumía?

- (R) Consumía

- (P) ¿Y cuándo se "ponía" era más agresivo?

- (R) Sí, cuando se ponía de cocaína, al día siguiente estaba que no había quien...

- (P) ¿Y tú ya lo veías venir?

- (R) Lo veía venir, ese día ya lo sabía, pero había veces que venía de trabajar y ya sólo por la manera de llamar al timbre ya sabías... buf... cómo viene

- (P) ¿Y a lo mejor no se había puesto?

- (R) No, probablemente no porque venía de trabajar, pero ya sólo por la manera de llamar al timbre ya...

- (P) Ya sabías tú que algo iba a pasar

- (R) En casa se acojonaba hasta el tato

- (P) ¿Y los niños también?

- (R) También

- (P) ¿Vieron cosas?

- (R) Muchas

- (P) ¿Qué pasaba cuando él llegaba y tocaba el timbre de esa forma que vosotros cuatro identificabais?

- (R) Lo primero que nada más abrir la puerta, ya le veías la cara y ya... te acojonabas y a lo mejor, yo que sé..., estabas cenando y no le gustaba la cena y el plato salía volando y los insultos y el echar a todo el mundo de casa y el coger un cuchillo y amenazarte, o el tener que salir pitando de casa, aunque fueran las 11 de la noche

- (P) ¿Con lo puesto?

- (R) Con lo puesto, una vez M. salió en pañal la pobre, me la tuve que llevar en pañales en pleno verano 
- (P) Menos mal que era verano, ¿si llega a ser invierno hubiera sido igual?

- (R) Igual, igual

- (P) ¿Había periodos de calma en tu casa?

- (R) ¡Si hombre!, después de la tempestad, estaba muy tranquilo, muy enamorado y muy pacífico

- (P) ¿Cuánto duraba eso?

- (R) Ahora al final..., cada vez menos, era una calma muy... "yo te quiero mucho, pero es que eres una borde, eres una asquerosa, contigo no se puede ni hablar, es que yo lo intento, pero tú no haces nada, es que tú..., es que tú..., es que tú..."(repite las palabras de él)

- (P) ¿Cómo te sentías en ese momento? Cuando estabas conviviendo con él ¿qué pensabas de ti misma? ¿Qué sentías?

- (R) Que yo me quería ir de allí

- (P) ¿Tus sentimiento era de huida, de salir corriendo?

- (R) Sí, a veces hasta pensé que me quería morir y todo, porque ya no le aguantaba más, porque no me veía capaz de salir de allí, porque claro te llega a comer la cabeza. Yo llegué a pensar que a dónde vas a ir tú con los niños, a trabajar y a todo.... No, no, no

- (P) ¿Te lo creíste?

- (R) Sí

- (P) ¿Qué veías cuando te mirabas al espejo? ¿qué imagen tenías de ti misma?

- (R) Ninguna, no veía nada

- (P) ¿No eras capaz de reconocerte?

- (R) No, pero ni.... En eso, ni en la forma de ser, ¿sabes? Es que no era yo

- (P) No eras tú

- (R) No

- (P) ¿A esto te referías antes, cuando me decías que ahora vuelves a ser tú?

- (R) $\mathrm{Si}$

- (P) Vuelves a ser tú, ¿cómo, antes de conocerle a él o cómo?

- (R) A ver, antes de conocerle a él no sé porque tenía 16 años y tampoco, pero vuelvo a ser yo, vuelvo a vestirme como me da la gana, vuelvo a hablar cuando me da la gana, vuelvo a decir lo que pienso cuando quiero y vuelvo a pensar lo que quiero y ser como soy y no hay más. Tengo mis ideales, me gustan algunas cosas, otras no me gustan, me gusta vestir de una manera y no por eso me siento más "pendón", ni nada por el estilo

- (P) ¿Qué sentimientos tenías hacia él?

- (R) Miedo

- (P) ¿Le tenías miedo?

- (R) Mucho

- (P) Con respecto a tus hijos, a tu niña, a tus niños ¿qué pensabas?

- (R) ¿A ellos? Alguna vez llegué hasta pensar de si a ver si tenía suerte y me daba un palo bien dado, que me dejara allí en el sitio y que por lo menos no los iba a volver a ver en la vida, ni les iba a seguir haciendo daño

- (P) ¿Llegaste a pensar eso?

- (R) Si

- (P) ¿Quién tomaba las decisiones importantes en tu casa?

- (R) ¿Importantes en qué aspecto?

- (P) Pues bueno, las decisiones de compras, vacaciones,...

- (R) Él, de vacaciones no se iba en mi casa, eso era un derroche, se podía cambiar de coche cada dos años

- (P) ¿Y quién lo decidía?

- (R) Él, se podía comprar moto, se podía comprar televisiones, se podía hacerle al camión cualquier gilipollez que costara una fortuna, eso sí, era dinero invertido, él resto no. Las decisiones importantes, las económicas, las tomaba él

- (P) ¿Él manejaba el dinero? 
- (R) Sí

- (P) ¿Incluso el tuyo cuando tú lo ganabas?

- (R) No, es que cuando yo lo ganaba, no me daba ni un duro para nada, ni para comprar para comer, ni para vestir a los niños, ni para nada. O sea que...

- (P) ¿No eras dueña de tu propio dinero?

- (R) Si era dueña, pero para comer, para vestir a los niños y para llevar la casa y ya está, y no le dijeras que necesitabas dinero porque "¿a ver dónde has metido tu sueldo hija de puta?" (decía él cuando ella le pedía dinero)

- (P) No le podías pedir

- (R) No, no

- (P) ¿Quién se ocupaba de la casa, la comida, la compra, los niños?

- (R) Yo

- (P) ¿Siempre?

- (R) Siempre

- (P) ¿En alguna ocasión dudaste de tu capacidad para hacer ese trabajo?

- (R) Sí

- (P) ¿Pensaste que lo estabas haciendo mal?

- (R) Siempre lo he pensado, que lo estaba haciendo fatal, vamos que era una inútil perdida, lo tenía clarísimo. Todo estaba siempre mal hecho

- (P) ¿Qué clase de cosas le molestan a él? ¿por qué monta broncas?

- (R) Le molesta... todo, porque es que hay veces, bueno... estando con él no sabías ni siquiera lo que decir, porque probablemente abrieras la boca y le dijeras cualquier cosa, o la mal interpretara o fuera una broma, o lo que fuera, que él se lo tomara a la tremenda y ya estaba la de dios es Cristo preparada

- (P) ¿Le molestaba una cosa y justamente la contraria también?

- (R) Sí, todo, le molestaba todo, dependiendo del momento, es que le molestaba todo. Que es lo que te digo, porque ahora digo lo que pienso cuando lo pienso, entonces es que no podía ni hablar casi

- (P) ¿Qué te mantuvo a su lado? ¿Por qué tanto tiempo?

- (R) Primero porque se puso mala mi madre y bueno... tampoco aquel momento me parecía el concreto para... para sacar el bombazo, y bueno... me callé y seguí. Luego tuve al niño y dije "bueno cambiará"

- (P) ¿Al mayor?

- (R) Sí, pero no cambió nada y luego me quedé embarazada de la niña y seguimos igual. Empecé a trabajar y bueno... mi plan era... a ver... no era hacer esto, era trabajar y una vez que tuviera trabajo y tal y una independencia económica, dejarlo, pero luego claro... me quedé embarazada de D. y ahí la jorobamos, que de los 9 meses, estuve 7 llorando

- $(\mathrm{P})$ ¿Por qué?

- (R) Porque para mí, quedarme embarazada de D. fue lo peor, porque M. ya tenía 5 años, B. 8, ya me veía yo libre, con más tiempo para ir a trabajar, buscar un trabajo, para todo, los niños eran ya más mayores, D. me trastocaba todos los planes, todo lo que llevabas esperando, a que M. fuera mayor me lo... se me hundió todo

- (P) Bueno, pero ahora tienes un muñeco

- (R) Sí, claro, yo estoy encantada con mi D., pero en aquel momento lo pasé mal, lo pasé mal, ya te digo, los 7 primeros meses estuve llorando por eso, porque me había quedado embarazada y los dos últimos porque dejó de crecer y de comer, de engordar y de crecer y tenía que venir todas las semanas a $L$. a controlarme y no sé, creo que lo pasé peor, esos dos meses fueron peores todavía

- (P) ¿Estuviste alguna vez a tratamiento psicológico?

- (R) No

- (P) ¿Nunca tuviste ningún trastorno, ni ningún problema?

- (R) No

- (P) ¿Y él, antes de conocerte a ti? 
- (R) Ni antes ni después, porque él no tiene ningún problema, "la que estoy loca soy yo" (según él), bueno de hecho se lo dijo a... que yo tenía algún tipo de problema psicológico, que me iba de casa cuando se me antojaba y volvía cuando me daba la gana y como él era muy buena persona, ahí se quedaba esperándome, a que volviera

- (P) La cuestión económica ¿te frenó a la hora de separarte?

- (R) Sí

- (P) Te fuiste frenando esperando a tener...

- (R) Sí, porque claro, si me iba me iba con niños y no es lo mismo marcharte tú sola o marcharte con dos o tres niños

- (P) Cuando ya te separas ¿tienes apoyo de tu familia?

- (R) Sí, siempre los he tenido, lo que pasa, es que yo nunca me planteé... a parte nunca había ido al CEAS, yo siempre me iba para casa de mi tía y nunca quise volver, yo creo que la última vez volví porque estaba embarazada de D., si no, no hubiera vuelto. Lo que pasa es que él allí en A., te acosaba y te...

- (P) A. es muy pequeño, os conocéis todo el mundo...

- (R) Te encuentra en cualquier lado y él el día que te quiere encontrar te encuentra y aunque te quieras ir para casa, te encuentra 50 veces de camino a casa y te machaca y te machaca, te machaca y al final acabas cediendo

- (P) En su familia de origen ¿su padre maltrataba a su madre?

- (R) Sí

- (P) Yo sé que no quieres hablar de tu padre, ¿pero tú en tu familia de origen viste algún tipo de maltrato?

- (R) No, yo no lo sufrí, mi padre bueno... sí, pero era del alcohol, de la bebida (le incomoda hablar de su padre)

- (P) Vale, lo dejamos ahí. El padre de los niños, ¿sufre estrés por motivos laborales? ¿O por el contrario no le afecta?

- (R) A ver, ahora mismo tiene estrés por culpa del trabajo, pero es que he estado con él casi 20 años y hubo una época en la que no tenía estrés y era igual, porque yo ahora reconozco que las cosas... bueno... la situación en España... él tiene un negocio y no le va bien, como a la mayoría de la gente, autónomos pequeños, gente que tiene negocios pequeños, que no les va bien, pero no es cuestión de... él es así y punto y su hermana, ahora, se ha vuelto como él, porque a mí ahora no me tienen allí y no me hacen nada, pero a mis tíos constantemente los están insultando, tengo una amiga que la ha amenazado su hermana, la ha amenazado él..., está acosada totalmente

- (P) ¿Su familia, lejos de apoyarte...?

- (R) No, su familia, no, su hermana. Yo tengo tíos de él y demás que sé que me apoyan a mí y no se hablan con él y yo de hecho también lo dejé cuando su madre murió, su madre también, creo que lo veía como algo normal, como siempre lo sufrió ella, los niños tenían que criarse con su padre y con su madre y ella siempre se portó muy bien conmigo y reconocía lo que él hacía y todo, pero los niños tenían que estar con su padre y con su madre

- (P) Esa mentalidad

- (R) El qué dirán, es una familia que la conoce en $\mathrm{A}$. todo el mundo, fueron tal... y los conocen y el qué dirán es muy importante

- (P) Decías que él consumía ¿coincidía que él consumía y luego había follón contigo, te agredía? ¿Eso era así, matemático?

- (R) Ahora al final, si, antes no

- (P) ¿Te costó empezar a hablar del maltrato C.? Decías que durante mucho tiempo no se lo contaste a nadie

- (R) Me costó, si

- (P) ¿Por qué?

- (R) Porque consigue... no sé... sientes vergüenza, te sientes muy culpable, por miedo, por muchas cosas 
- (P) ¿Le denunciaste en alguna ocasión?

- (R) Cuando llevaba separada tres meses

- (P) ¿Ya estabas en la casa de acogida?

- (R) Llevaba en L. tres meses

- (P) ¿Qué pasó?

- (R) Que me convenció la abogada

- (P) ¿Denunciaste todo lo de atrás o pasó algo en ese momento?

- (R) No, no, no pasó nada porque yo llevaba tres meses en L., cuando fui al CEAS en $\mathrm{A}$. me dijeron que... a ver... que tenía que denunciar, que si no quería no pasaba nada y yo les dije que no quería, que le tenía muchísimo miedo y que no quería denunciarlo y no lo denuncié. Vine para aquí y me dijo $S$. (casa de acogida) y le dije que no, que no quería denunciarlo y luego cuando me dieron la abogada para la pensión de los niños y demás, estuvo hablando conmigo, me dijo que había hecho cursos de malos tratos y tal y que había que denunciarlo, que estando en L. en una casa de acogida y tal, que qué más pruebas quería, tenía a mis tíos, que siempre que me echaba de casa me habían recogido y tal y cual, que era lo mejor, que tin, tin, tin, $y$ tan, tan, tan y denuncié

- (P) O sea, que denunciaste un poco inducida por otra persona, de ti nunca hubiera salido esa idea

- (R) No, no quería cabrearlo más, ya estaba bastante cabreado

- (P) ¿Tuviste la necesidad, no sé si en el momento de la denuncia, o en alguna otra ocasión de exagerar la historia para que la gente te creyera?

- (R) No, me da igual que me crean o no, es algo que tampoco me importa mucho, el que me quiera creer que me crea y el que no que no me crea. Simplemente algún día se verá quién tiene razón y quién no y de hecho se está viendo. Yo no tengo ningún parte de incidencias en la policía, él ya tiene dos

- (P) ¿Desde qué te separaste?

- (R) Sí, de mi amiga, porque también la policía de A. la convenció a ella para que no lo denuncie, porque ella en dos ocasiones le ha querido denunciar y la policía le dice que no lo haga. Son partes de incidencia, pero ahí están. A mí nadie me ha denunciado por nada

- (P) ¿Cómo acabas en la casa de acogida, C.? Porque tú tienes familia, que en otras ocasiones te recogían en su casa ¿por qué una casa de acogida?

- (R) Porque estaba en A. y me iba a buscar

- (P) Necesitabas salir de A.

- (R) Yo creo que no lo dejé antes, porque nunca salí de A., a ver, me había ido al pueblo, pero cuando me iba al pueblo, cogía a los niños, se los llevaba y claro... él sabía que yo iba a volver, porque si él va y se lleva a los niños, sabe que matemáticamente, en cuanto entre por la puerta de casa en A., a la hora, estoy ahí, no voy a dejar a los niños con él, y eso... no te dejaba, no te dejaba, hasta que no volvías y volvías con miedo o acojonada o porque te había convencido o por mil cosas, pero era entrar por la puerta y decir "¿qué hago yo aquí? Si yo aquí no quiero estar"

- (P) ¿Entonces acudes a la casa de acogida...?

- (R) Acudo al CEAS de A. y me dicen que es un maltratador y que tengo que salir de la casa, que tengo que salir de allí, que me van a buscar una casa de acogida, espero tres semanas

- (P) ¿En tu casa, con él?

- (R) No, en casa de mi tía... pero bueno, las dos primeras nada, ni se inmutó, ni se acordó de mí, ni de sus hijos, ni de nada que se le pareciera. Luego ya la última sí, ya fue cuando fui otra vez al CEAS y les dije que miraran a ver si lo aligeraban porque ya me estaba... acosando ya... del todo y fue cuando me vine para $L$.

- (P) ¿Tuviste plaza de colegios y todo?

- (R) Sí, ya lo habían arreglado todo desde la casa de acogida, ya tenían el colegio para los niños, la guarde para D. y todo 
- (P) ¿Cómo te sientes en la casa?

- (R) Unas veces estás a gusto, otras veces no estás a gusto, es que es... comparto una habitación con mis hijos, llevo un año viviendo en una habitación con mis 3 hijos, los cuatro. Cada una tiene su habitación con sus hijos, la que tiene hijos, la que no, no y luego el resto de zonas son comunes, el día que te toca la limpieza la haces, el día que te toca hacer la comida la haces, si te toca hacer la cena la haces

- (P) Supongo que como todo, tiene sus pros y sus contras

- (R) Tiene sus pros y sus contras, hay gente con la que te llevas mejor, gente con la que te llevas peor, gente que cuando le toca hacer las cosas las hace, gente que cuando le toca hacer las cosas no las hace. Ahí chocamos y tenemos unas broncas de la leche. Que a mí, ahora mismo ya no me molesta que no lo hagan o que lo hagan mal, me molesta la falta de interés, la falta de respeto, la falta de... si tu cocinas C., nos sentamos todos y comemos muy bien, ahora el día que me toca a mí, no come nadie, porque no le pone ningún interés.

- (P) Volviendo al padre de tus hijos ¿Él se sintió en algún momento maltratado por ti?

- (R) Me imagino, no sé... yo creo que no, pero yo qué sé...

- (P) Alguna vez te verbalizó... Él te decía que la culpa era tuya

- (R) Sí, la culpa era mía, yo provoco, yo le sacaba de quicio, yo era muy mala, yo era un pendón, yo cien mil cosas

- (P) ¿Te sientes una mujer maltratadora?

- (R) No, creo que no, tengo muy mala leche, no lo voy a negar, tengo mala leche, es un defecto muy malo, pero vamos... maltratadora no, creo que no.

- (P) ¿Tus hijos presenciaron cosas?

- (R) Sí, de hecho M., fue una vez conmigo para el suelo, sí, fue cuando estaba mala su madre en la $\mathrm{UCl}$, fui con su hermana a verla a la $\mathrm{UCl}$, él se quedó con los niños con los tres, pero claro, tienes que venir desde A. a L., a la UCl, tienes que esperar que te dejen entrar, tienes que salir y esperar que te llame el médico, que te toque hablar con el médico y volver para A. Y cuando llegamos a $A$. eran las 21 y que ¿dónde había estado hija de puta, toda la tarde? Y tal y cual y ya empezó, yo estaba sentada en el sofá y la niña a mi lado, D. y B. en el sofá de enfrente y ya lo vimos que ya empezó y dijimos bueno... yo creo que la niña en un instinto de protección, como diciendo si estoy yo aquí a ella no le va a hacer nada, se sentó encima de mí y me agarró por aquí (señala su cuello) y fuimos las dos al suelo, salimos las dos volando del sofá, no le importó que estuviera la niña sentada encima de mí ni nada por el estilo y seguidamente nos echó de casa a los cuatro y había estado en el hospital visitando a su madre, a su madre que estaba en la $\mathrm{UCl}$

- (P) ¿A su madre, no a la tuya?

- (R) No, no, no, a su madre. Ni me había ido de paseo con las amigas, había ido a ver a su madre a la UCl

- (P) ¿Pensaste en algún momento que este hombre era el hombre de tu vida?

- (R) No

- (P) ¿Nunca lo pensaste?

- (R) Hombre lo pensé con 17 años, a lo mejor sí, pero yo con 20 ya sabía que no

- (P) ¿Piensas que la situación ideal de una mujer es tener pareja?

- (R) No, no

- (P) ¿No tienes esa idea romántica de...?

- (R) No

- (P) Continuamos con ideas románticas ¿Piensas que las mujeres sólo podemos amar a un hombre y después de ese, ya nada va a ser igual?

- (R) No, no

- (P) Dame tu opinión con respecto a los celos ¿qué piensas de ellos? ¿Son necesarios en una pareja para que funcione?

- (R) Hombre, yo pienso que no, yo pienso que una pareja para que funcione, lo principal es el respeto 
- (P) ¿Y el amor?

- (R) El amor también, pero si no hay respeto

- (P) ¿Piensas que el amor lo puede todo?

- (R) No, si no hay respeto, no. Me pueden querer mucho, pero como no me respeten, en este momento de mi vida, puedo querer mucho a una persona, pero como me falte al respeto una vez... se acabó

- (P) Respecto al amor ¿piensas que ha de mostrarse siempre con la misma intensidad?

- (R) Tenemos altos y bajos

- (P) ¿Piensas que es inevitable amar a una persona? ¿Es algo involuntario?

- (R) Pienso que sí, que es involuntario

- (P) No hay manera de arreglar esto, si te enamoras...

- (R) Yo creo que no

- (P) Si te enamoras de alguien ¿la situación ideal es la convivencia?

- (R) No, no

- (P) ¿Hay otras formas de relacionarse?

- (R) Sí, yo es que eso de la convivencia, ahora mismo lo veo muy...

- (P) ¿Qué pensaste cuando tomas la decisión de separarte? ¿Cuál es el detonante?

- (R) B.(su hijo mayor)

- (P) ¿Qué pasó?

- (R) El día que me dijo... estaba con mi tío... que él quería mucho a su padre, pero que estaba harto y que si yo volvía a casa, él no volvía, él que se quedaba a vivir con mi tío

- (P) ¿Cuantos años tenía?

- (R) 10

- (P) 10 años, te dice eso y a ti se te ilumina algo en el cerebro

- (R) Si, o mi hijo o ese personaje

- (P) ¿Lo tuviste claro?

- (R) Si

- (P) El detonante es ese, y por eso tomas la decisión ¿la tomas tú?

- (R) Si

- (P) ¿Qué pasa cuando él se entera?

- (R) No lo sé porque yo no estaba, bueno... si lo sé porque se puso hecho una fiera, pero yo como estaba aquí en $L$. ya, no... y desde que me vine a $L$. hasta que lo volví a ver, pasaron... yo vine en Marzo y nos vimos en Junio

- (P) ¿Tuviste más intentos de separación de él?

- (R) Si, muchos, pero era eso... que te iba a buscar y que te encontrabas en todos los lados y que ibas a salir de casa de tu tía y estaba en la puerta y estaba en la puerta del colegio, y dabas la vuelta a la esquina y allí estaba y unas veces te lloraba y otras era muy amoroso y otras veces era... "vas a aparecer en una cuneta muerta, tú tío va a aparecer no sé donde, mañana voy a por tu abuela, mañana voy a por..." llega un momento que...

- (P) ¿Qué cambios experimentó tu vida, una vez te separas?

- (R) Muchos, yo que sé... empecé a dormir, empecé a comer, porque yo a penas comía porque me dolía mucho el estómago, me di cuenta de que era verdad, ni me dolía el estómago, ni tenía nada malo, que era angustia

- (P) Te impedía comer, se te cerraba el estómago

- (R) Se me cerraba el estómago, tenía constantemente como un nudo en el estómago, un dolor, ganas de vomitar, que con el tiempo se me quitó y empecé a dormir, que era incapaz de dormir por las noches y yo que sé... empecé a ser yo misma, a vestirme como me da la gana, a cortarme el pelo como me da la gana, a despeinarme como él decía, a tratar con gente, a salir, a yo que sé... a relacionarme, a... vivir un poco

- (P) Ahora mismo ¿Qué apoyos tienes? 
- (R) Tengo, tengo a mis tíos, tengo la casa (de acogida), está S., está J., está la gente de la casa. Tengo a mis tíos, tengo a mi abuela, tengo a mis hijos y tengo algunos amigos que he hecho nuevos y a mis amigos de $A$. que eran mis amigos y lo siguen siendo, de hecho M., que la tiene acosadita total, la tiene aburrida de la vida, ahora hablamos una vez a la semana o dos veces, pero cuando me vine para L., yo creo que hablábamos todos los días, pero horas y horas por teléfono. Siguen siendo mis amigos

- (P) De salud me decías antes que estabas bien

- (R) Bien

- (P) Incluso ya no te duele el estómago. Tienes ahí apalabrada una casa decías ¿no? Para empezar a vivir con tus hijos

- (R) Es de alquiler, he solicitado a la Junta una de protección para comprar, pero de momento me voy de alquiler

- (P) Yo te veo ilusionada con el tema

- (R) Sí, estoy ilusionada, está muy bien la casa, los niños están encantados de la vida

- (P) Ya tenéis ganas de tener un espacio para vosotros

- (R) Ya es un año en la casa

- (P) Hablas de que tienes trabajo, incluso dos y que la economía... bueno.... Trabajando mucho, pero sales adelante, en cuanto a las relaciones sociales, has hecho amistades nuevas ¿Algún novio nuevo?

- (R) No

- (P) Con la familia sigues relacionándote con tus tíos, con tu abuela

- (R) Sí

- (P) La crianza de los niños, ahora mismo, la llevas tu sola

- (R) Sí

- (P) Al padre le ven una vez cada 15 días me decías, en APROME (Punto de encuentro)

- (R) Y se los lleva para A.

- (P) ¿Qué cuentan ellos?

- (R) Cuentan pues... Un día D. me dijo... yo no le hice mucho caso, tenía tres años. Vino un domingo y cuando le fui a acostar me dijo "quita que tú no eres mi mamá" digo "¿No?" y dice "No, mi mamá está matada" y digo “¿sí, quién la mató?" "la mató mi papá" "¿Quién te dijo eso?" "Mi tío", digo "Bueno, pues vale" Les compra muchas cosas, les tiene dicho que para L. no se trae nada, yo allí no soy su madre, soy la hija de puta, la cabrona, la zorra, el bicho...

- (P) No tienes nombre

- (R) Sí, muchos

- (P) Este tipo de calificativos

- (R) Y eso... a mis tíos cuando les ven con su padre, no les pueden hablar y eso... es muy guay... muy chachi.... Pero sigue siendo...teniendo su otra cara, que él con los niños, de momento no la da, pero yo tengo claro que la va a dar, si

- (P) ¿Cómo te sientes contigo misma?

- (R) Muy bien

- (P) ¿Estás a gusto, estás en paz?

- (R) Sí. Estoy encantada de haberme conocido

- (P) ¿Qué planes de futuro tienes?

- (R) ¿Planes? Yo que sé, trabajar y nada, intentar trabajar, vivir, sacar mis niños adelante y nada más, tampoco tengo muchos. Vivir, vivir tranquila, que mis niños vivan tranquilos

- (P) Y estás consiguiéndolo

- (R) Sí

- (P) Todo es proponérselo $C$.

- (R) Es duro, pero bueno, se sale

- (P) Claro que se sale 
- (P) Por mi parte nada más, sólo agradecerte la entrevista C. No sé si tú me quieres contar alguna otra cosa, bueno... habría tanto que contar

- (R) Te podría contar tanto, pero es que no tengo más tiempo

- (P) Gracias 
- (P) ¿Cuántos años tienes D.?

- (R) 26

- (P) ¿Dónde naciste?

- (R) En M.

- (P) ¿Qué haces tú en L? Cuéntame

- (R) Por la familia, yo vivía allí y... yo vivía allí hasta que ya me separé y estuve unos meses allí sola, con la niña, el trabajo, la casa... ya me tuve que venir.... Mi madre...

- (P) ¿Tu familia está aquí?

- (R) Sí, mi madre estuvo 22 años viviendo allí, pero mi abuela se puso mala, con cáncer y ya se vino ella para acá, para estar con ella, echarla una mano y ya me quedé yo allí sola

- (P) ¿Te viniste para acá porque tu familia es de L?

- (R) Sí

- (P) ¿O sólo tu madre?

- (R) Toda

- (P) Toda la familia, habían ido para allí y tú naciste en M. y te vienes una vez separada

- (R) Sí

- (P) ¿Cuántos hijos tienes?

- (R) Una

- (P) ¿Edad?

- (R) 4

- (P) Una de 4 años ¿cómo se llama?

- (R) A.

- (P) ¿Con quién vive A?

- (R) Con su madre, con su abuela, con su abuelo y con su tía.

- (P) ¿Cómo vivís en esa casa? Cuéntame

- (R) Pues mira, entre que es pequeña, dormimos... bien, porque la casa es pequeña, pero bueno bien... la verdad es que bastante bien, al principio un poco duro, porque date cuenta que yo ya vivía sola hace 5 años, independiente y te metes en casa de tus padres, que ya no es lo mismo, al principio es un poco duro, pero bueno... ahora estoy muy contenta, ahora no tengo ganas de irme

- (P) Estás a gusto en casa de tu madre

- (R) Sí, a parte que la niña, menudo cambio, genial

- (P) ¿Cuánto tiempo llevas en L?

- (R) Un año, un año y dos meses

- (P) ¿Te costó tomar la decisión de venir?

- (R) Sí porque como su padre estaba aquí

- (P) ¡Ah! ¿el padre de la niña es de aquí también?

- (R) Sí, porque yo viviendo allí, el padre se fue para vivir allí conmigo

- (P) O sea, que tú lo conoces aquí en L.

- (R) Yo lo conozco aquí en L., de vacaciones un año y estamos así saliendo un par de años, yo solamente venía en vacaciones y él a lo mejor iba allí en vacaciones, hasta que ya él dejó de trabajar aquí, se le acabó el contrato y se fue allí a trabajar y a vivir y estuvo viviendo dos años en casa de mi madre con nosotros y luego ya nos compramos un piso

- $(P)$ Y ya te pones a vivir con él

- (R) Sí, nos quedamos a vivir los dos juntos, estamos... creo que son tres años viviendo juntos, decido casarme, bueno... decidimos casarnos, me quedo embarazada pocos meses antes de la boda, me doy cuenta de... bueno me dicen que estoy embarazada y tuve la niña y ya justo fue tener la niña y mi abuela ponerse mala, mi madre marchó y ya yo me quedé allí, dos años y ya fue cuando la 
cosa... y ya luego me separé, yo estuve tres meses viviendo sola con la niña y cuando vi que no pude, pues ya... Él al separarse de mí, no se quedó en M., se vino para L. con sus padres, entonces claro... tener que tomar la decisión de venirme aquí... ya no solamente era por mí, es que tenía al bebé y...

- (P) Claro, que allí estabas sola

- (R) Yo allí tenía mi casa, mi trabajo, pero no tenía a la familia. La niña... no podía hacerme cargo de todo, tuve que decidir, pues... venirme

- (P) Así que vivís ahí un montón de gente. Tú con tu niña, tu madre, tu padre y...

- (R) Y mi hermana

- (P) ¿Tú hermana cuántos años tiene?

- (R) 14 años cumplidos de ahora

- (P) ¡Ah bueno!, está adolescente

- (R) Sí, sí... menudo bicho, pero bien, muy bien

- (P) Entonces vives aquí en L. y con tu familia. Vale. Tu situación económica y laboral es que has empezado a trabajar hace muy poquito en un ayuntamiento de auxiliar administrativo, ¿estarás feliz?

- (R) Sí, muy, muy feliz

- (P) ¿Qué estudios tienes, D.?

- (R) Tengo hecho auxiliar administrativo de grado medio y luego el curso que hice de cuidado de dependientes

- (P) ¿De salud cómo estás?

- (R) Con dolores en la espalda

- (P) ¿Qué te pasa?

- (R) Que tengo una contractura

- (P) ¿Desde cuándo?

- (R) Desde hace tiempo, también me dijo la psicóloga que las tensiones que yo tenía y todo el estrés y todo eso, que se me acumulaban en la espalda, a parte de la mala postura que tenga. Hago muchísimo deporte también, pero todas las tensiones que tengo, se me cargan en la espalda. Pero por el resto estoy bien.

- (P) ¿Cuánto tiempo separada?

- (R) Separada llevo, Noviembre, Diciembre... En Noviembre hizo un año, Diciembre, Enero, Febrero y Marzo. Un año y cuatro meses.

- (P) Vamos a empezar a hablar del maltrato. ¿Qué tipo de maltrato sufriste D.? ¿fue un maltrato psicológico, físico, sexual?

- (R) Empezó por el psicológico y terminó por físico

- (P) Cuéntame un poco, ¿cuándo te das cuenta?

- (R) Bueno... ahora que lo piensas, sí que vas atando cabos, porque al principio tampoco es que tú te des cuenta. Sí que mi madre había visto cosas, porque al estar dos años viviendo conmigo en casa, pues mi madre empezó a ver cosas... pero tampoco lo quieres ver. Ya me había advertido una vez "mira que hay cosas que no me gustan" o mentiras que él había dicho que mi madre había visto, a lo mejor se había roto algo y él decía que era mentira, que él no lo había roto, detalles pequeños, que luego tiene eso... que con mi madre todo estupendo, pero luego cuando no había nadie todo eso era mentira. Es decir, me daba una de cal y otra de arena o también como empecé desde muy joven, yo no sé porqué consentí tanto, porque ahora ya no consiento nada... y empezó así... primero por lo psicológico, muchos celos porque yo trabajaba, yo al trabajar con chicos..., porque donde yo trabajaba eran todo hombres y habíamos por lo menos 30 personas y éramos solamente dos mujeres. Empezó así con lo de los celos y no quería que tuviera contacto con nadie más que no fuera él, pero ni amigas, ni amigos, ni nada, no sé, yo que sé, piensas que es por lo que tú un día decías, porque te llaman y te llaman y tú piensas que es porque te quieren con locura y es todo luego "¿dónde estás? ¿con quién andas? ¿cuánto tardas? Y avísame"

- $(\mathrm{P})$ ¿Cuándo eres consciente de que empieza el maltrato? 
- (R) ¡Hombre!, soy consciente cuando ya llevo tiempo, pero yo una vez... un día que íbamos por la calle y no sé qué íbamos hablando... íbamos discutiendo y él me pegó un empujón y me tiró al suelo, quedé a esto del bordillo con mi cabeza (hace un gesto con los dedos de la mano indicando poca distancia) Pero luego yo qué sé... él te pide perdón, que no va a pasar nunca más y luego al verano siguiente, el hermano vino y se lo contaba como una risa ¿sabes?, yo me quedé así... "seré yo que no soy normal" Cuando en mi casa jamás se ha vivido ni malos tratos, jamás ha habido un grito y es a día de hoy que no se discute, en mi casa no, ni se dicen palabrotas, ni se insulta, ni se grita. Las cosas se hablan, eso es una cosa que yo dije... a mí eso nunca me va a pasar y me pasó. Luego yo qué sé, entre los hermanos era una cosa normal, los insultos, los empujones, los desprecios... era algo normal. Pero luego él llegaba a mi casa y le decía a mi madre "yo.., Ch., quiero a tu hija con locura, porque tu hija no come, porque tu hija no se qué , porque tu hija no se cuanto..." Claro tenía a mi madre, que si le hacía caso..., mi madre veía, pero claro por otro lado te trata bien... y como yo he sido muy reservada, no he querido nunca contar nada, pues... Y así empezó todo, todo fue a raíz de que él se fue a vivir allí, me acusaba de que él había dejado a su familia, de que yo no se lo tomaba en cuenta, no le echaba el mérito, que yo no valoraba eso. Entonces claro, tantas veces que te lo dice, tantas veces que te lo dice... y obsesionado... con el tema del sexo... obsesionado, porque claro yo en mi casa, yo decía, hombre, en mi casa yo no quería hacerlo y "que yo no lo quería y que yo no lo quería y que yo no lo quería" Y así empezó todo

- (P) ¿Te viste obligada a mantener relaciones sin consentir?

- (R) Eso fue... mira... empezó ahí la cosa y luego ahí, desde el día que me tiró en la calle, pasó un tiempo, dos años o así, que era más, todo psicológico, todo psicológico y bueno... yo no sé porqué tenía la habilidad, que en el momento que discutía a mí me dejaba, que no hablaba, me bloqueaba, yo era una cosa, que discutía, me decía y yo ni mu y ya está, pero tuve a la niña y después de tener a la niña, en la cuarentena... a mí me costó tener relaciones, bueno, pues el día que fuimos a tener relaciones, ¿tú sabes?, estaba agresivo, quería por narices tener y me vi obligada, pero para él eso es normal, yo le dije "parece que me siente como violada" y que yo exageraba, que yo es que claro...

- (P) ¿Te ha quedado alguna secuela del maltrato?

- (R) ¡Hombre!, ahora... sí que queda, te queda el hecho, sobre todo de cómo mirar a los hombres ¿cómo ves tú a un hombre ahora? Yo he tenido pareja después y es que eso es imposible, imposible, es el hecho a lo mejor, que te pones a discutir y yo ya estoy a la defensiva, porque ya no me ponen una mano encima, ya estoy a la defensiva

- (P) Te dicen porque yo estuve con un chico y me decía te quiero y yo le decía, pero... como me vas a querer, no. Te dicen que te quieren y no, luego no y... soy incapaz. Me gustaría tener una pareja, pero pienso, a pesar de estar mucho tiempo con una relación, que nunca he estado enamorada, estaba atrapada y no veía más y sí que le tenía cariño, pero ahí no había amor.

- (P) ¿Algo físico? ¿Te quedó alguna secuela física?

- (R) No, todo fue psicológico

- (P) Cuando ocurre esto, que él te tira contra el suelo y tu cabeza casi impacta contra el bordillo ¿Cómo reacciona él?

- (R) Pues es que él reaccionó, como una cosa natural, tampoco es que se pusiera...

- (P) ¿Ni se asustó, ni nada?

- (R) No, no, no... Al revés, si me pasaba algo, que a lo mejor me caía yo, un día que me caí por la escalera, él se reía y no veía que fuera nada malo, incluso, el tema de la violencia él no lo veía nada malo. El tema de la violencia, los amigos y la familia, que no tuviera amigos, que no tuviera familia, que no tuviera nada, así él podía... ¿sabes? Todo en la vida tenía que ser con él, entonces él cuando hacía algo así, pues no lo veía malo

- (P) ¿Entonces no se arrepentía? 
- (R) Sí, a lo mejor, perdóname... pero tampoco era una cosa que tú dijeras... oye se ha tirado un tiempo... porque yo pienso que la violencia, para mí no está justificada con nada y yo jamás me he pegado con nadie, pero bueno... yo qué sé... sin querer... pero esto no fue sin querer, eso fue con sentido, vamos con sus cinco sentidos él lo hizo

- (P) ¿Y tú cómo reaccionaste?

- (R) Pues yo me puse a llorar como una Magdalena

- (P) Allí en mitad de la calle

- (R) ¡Hombre claro! “¿yo qué he hecho?” Y sí que es verdad, que luego yo mucho tiempo, estuve pensando ¿seré yo una mujer maltratada? $Y$ yo decía, no, no, no, eso a mí no me puede pasar, eso será una cosa de hoy y ya está, nunca más

- (P) ¿Esto lo comentaste con tu madre o alguna amiga?

- (R) No, no, no... jamás Y a día de hoy tampoco se lo he dicho. No porque... ella ha sufrido también mucho con... ella lo ha pasado mal... y a hora volver al mismo tema y...

- (P) ¿Tu madre sabe que te separas y que hay violencia de género?

- (R) Sí, sí, sí

- (P) ¿Eso si lo sabe?

- (R) Sí

- (P) ¿Tardaste en contarlo en casa?

- (R) Pues mira tarde... esa fue la primera..., la segunda vez después de tener a mi hija, fue lo que me pasó el día ese después de la cuarentena que quiso tener sexo conmigo y no quise y él se puso muy violento. Luego a las dos semanas o al mes no sé que estábamos hablando de la madre y a él no le gustó, me agarró del cuello y me puso contra un armario que teníamos en la terraza, mira me dejó esto de aquí todo marcado (señalándose el cuello), un dolor de cuello que tuve una semana, pero él no lo veía malo, él no lo veía malo. "Es que tú me calientas la boca, es que tú sabes dónde hacerme daño, es que tú con mi madre no te metes..." "Bueno, pues será verdad ¿para qué digo nada?, ique tonta soy!, en vez de quedarme callada y así no me había dicho nada", pero no sé. Luego a lo mejor pasaba eso y se marchó de casa, porque yo tenía de aquella un perro, cogió al perro, a los 5 minutos vuelve y como si no hubiera pasado nada. Yo decía, iqué cosa más rara!, yo aquí destrozada y él viene muy bueno. No sé, es que es una cosa que no entendía, que no entendía

- (P) Cuando a tu madre le cuentas lo que te está pasando ¿ella cómo reacciona? ¿cómo reacciona tu entorno?

- (R) Bueno... pues yo llamé a mi madre, porque un día que yo salí con una amiga al cine, cuando volví a casa, no sé si era la una o así, yo le había avisado y al volver, me estaba esperando en el sofá y me dice "¿qué horas son de llegar?" y yo le dije "la hora que me da la gana" Bueno... de aquella se levantó, se puso a escupirme, a decirme que era una guarra, que a esas horas nada más que había putas por la calle, que yo qué pensaba, que tenía una niña, que me estaba gastando el dinero en fiestas... y me arreó una hostia en la cara, yo me senté en el sofá, bueno... me pegó en la cabeza..., me zarandeó para donde quiso..., bueno... todo eso a voces por la noche y se fue a trabajar y ahí me dejó, porque él trabajaba de noche y por la mañana aquello yo vi que no podía ser. Porque después que había pasado, antes del incidente físico había habido mucho más psicológico y eso fue ya el culmen total y ya dije, esto no puede ser, ya mucho atrás ya mi madre lo había notado, pero no le dije nada porque ella ya estaba aquí y yo estaba allí sola, entonces no le quise decir nada, porque bueno... yo qué sé... lo psicológico.... Cómo lo demuestras también, no sé... lo vas sobrellevando, pero yo creo que es más doloroso de quitar... pero aquel día fue... Yo a la mañana siguiente me levanté, llamé a mi madre y ya se lo conté lo que me había pasado, ya tenía que contárselo y me dijo ella que me fuera, que lo denunciara, que no fuera tonta, que si no estaba viendo la tele, que había casos de mujeres que los marido las mataban y ella no quería que yo fuera una más, y bueno... ya llamé a una amiga, la cosa es que él fue al rato 
para casa y volví con la niña... bueno, yo le dije que me separaba, que me separaba y que no le quería, pero él eso no lo consentía... ya empezó por la mañana, por la tarde y por la noche... que era una guarra, delante de la niña, ya le daba igual, que era una guarra, que nada más que quería salir, que nada más que quería entrar, que yo de mi casa no me ocupaba porque todo estaba lleno de mierda, eso era a diario, pero ya cuando me pegó la última vez fue en Septiembre, pues desde Septiembre hasta Noviembre, aguantando día y noche un acoso, pero masivo, de llamadas por teléfono, 10, 15 llamadas de teléfono, trabajando, de presentarse en el trabajo 3 ó 4 veces, luego en casa, porque yo dormía con mi niña ¡qué miedo! Y venía por la noche y venía y "acuéstate conmigo, acuéstate conmigo, acuéstate conmigo" y yo "no quiero", pero continuo, era una cosa continua, yo no he pasado peores momentos en mi vida que en esos dos meses, es que eso era continuo y ya un día que no pude aguantarle más, yo no sé qué estaba haciendo en la ventana, estaba limpiando y él seguía y seguía, seguía y seguía... y me dice "tú mantente ahí al filo que a lo mejor la que vas para abajo eres tú" y yo dije "¿Cómo?" yo ya vi que... una cosa, bueno, se levantaba por la noche a cogerme el móvil, a ver si tenía mensajes, a ver si tenía... bueno una noche que me desperté porque sentí que estaba a la vera mía yo pensé, que digo, aquí me mata iqué miedo!, eso te queda de por vida, ¿cómo voy a confiar yo en un hombre ahora?, ni loca, o sea, que va... no puedo, súper difícil, no sé si podría, muy difícil y así... claro mis amigas, yo ni comía, ni dormía. Mi niña era una cosa, una intranquilidad, mi niña con dos años, casi tres, tenía casi tres, era una cosa... que digo... esto se tiene que acabar y ya mi amiga me dijo "tú denúnciale" Porque claro yo a mi madre le conté aquella vez que me pegó en Septiembre, pero yo ya no le conté más y le dije que él me había dicho que no lo iba a hacer nunca más, pero yo ya no le quise contar más porque mi abuela estaba muy mala, mi madre estaba muy preocupada por mi abuela, tan lejos a mil km y mi madre todo el día llamándome y yo a lo mejor la decía, ahora no puedo que estoy acostada y a lo mejor no estaba acostada, pero ella nada más que me coge el teléfono me nota la voz y sabe que no estoy bien. $Y$ yo por evitar todo eso, evitar, evitar, evitar... hasta que ya... este va a acabar conmigo, tuve que dejarlo, pero hasta que no lo he dejado, reflexionas y lo ves, piensas que todo eso tenías que vivirlo así, yo decía ¿cómo me voy a separar con $1000 €$ de hipoteca?

- $(P)$ ¿Qué tipo de cosas le irritaban a este hombre? ¿qué es lo que no le gustaba de ti?

- (R) Pues no le gustaba de mí que tuviera amistades, que mi tiempo lo compartiera con alguien que no fuera él le molestaba, aunque fuera con mi hija, le daba igual, no quería. La familia, contra menos hablara con ella, mejor y luego sin ningún motivo, él llegaba a la casa y no había motivo ninguno. Yo no sé porqué, llegaba a la casa y... "esto está lleno de mierda, esa porquería no me la como..." tiraba la comida, decía que la ropa se la tenía que lavar él porque yo la dejaba sucia... no sé... trabajamos los dos... tenemos tanta carga, que no tenemos familia, nos tenemos que echar una mano los dos...todo lo contrario, bueno era un acoso conmigo constante. Lo que peor llevaba era que tuviera una amistad o tuviera algo, le volvía loco, es que no podía y me decía "tú sal, tú sal" Cuando llegaban 5 minutos antes de salir ya estaba... "¿A dónde vas?, porque a mí me dejas solo, porque yo para eso no vengo..." Lo de siempre "porque tú no ves lo que yo he hecho por ti, porque yo estoy aquí solo y tú tienes amigos, tienes a tu hermano y a R. "Y al final tenía que llamar a alguien para decir, "mira que no salgo"

- (P) ¿Qué pasaba cuando se ponía agresivo? ¿Qué tipo de reacciones tenía?

- (R) Pues insultos

- (P) ¿Empezaba insultando...?

- (R) Insultando, despreciando, haciéndome de menos, haciéndome de menos, no sé por qué, yo pensé que en ese momento a lo mejor por el trabajo, porque él trabajaba de noche, dormía poco...

- $(P)$ ¿En qué trabajaba él?

- (R) Panadero 
- (P) ¿Y tú en qué trabajabas?

- (R) Yo trabajaba de dependienta por la tarde de 2 a 9.

- (P) ¿Entonces cuando tú llegabas a casa y prácticamente se marchaba él?

- (R) Sí, bueno... él se marchaba a las 2 de la mañana, que bueno, llegaba, cenábamos y luego él marchaba para la cama y ya está

- (P) Después de que pasaba esto, después de una agresión, ¿Él mostraba arrepentimiento o había un periodo de calma en tu casa, intentaba conquistarte?

- (R) Sí, sí... además si eran regalos caros mejor. Sí, pero tampoco yo he visto un arrepentimiento... sí que tuvo mucho arrepentimiento cuando yo decidí separarme y cuando fue la última vez que me puso la mano encima, hasta que me separé, después de los dos meses esos que eran insultos constantes, pero no sé, te insultaba y a lo mejor al rato venía y te mostraba como que él quería ¿sabes? "yo te quiero", pero tampoco, él nunca me ha pedido perdón por el hecho de que me haya puesto la mano encima, a día de hoy nunca me ha pedido perdón por eso, nunca, nunca, él decía que sí... que no volvía a pasar, que ... pero pedir perdón, no lo ha pedido nunca

- (P) ¿Había periodos de calma?

- (R) Sí, había periodos, pero ya a lo último no, tuvimos un año, desde que mi madre se fue, que la cosa fue peor, cuando él vio que yo me quedé sola. Cuando él vio que mi madre se fue, él aprovecho esa oportunidad, ahí como si fuera el amo, tú en la casa, tú no te muevas de la casa, porque la casa es para ti y tenía que ir a comprar "no bajes, voy yo", pero bueno, "si voy ahí..." "no, no, no, voy yo" y yo "vale"

- (P) ¿Cómo te sentías mientras estuviste viviendo con él?

- (R) Mal, muy mal

- (P) ¿Mal, cómo?

- (R) ¡Puf... ¡¿cómo me sentía? ¿cómo explicarte?, pues me sentía que no era nada, estaba vacía por dentro, ni tenía amigos, ni podía expresarme con mi madre, tenía que llamar a mi madre a escondidas, yo me sentía vacía, es que nada me hacía ilusión, con lo alegre que yo soy, yo siempre he sido muy alegre, muy... con muchas ganas de vivir y mucha ilusión, y yo ahí no tenía ilusión, ni ganas de nada, yo tenía ganas de morirme

- $(P)$ ¿Cómo te veías a ti misma? ¿Qué imagen tenías de ti misma?

- (R) No sé, una mujer mayor, me veía vieja, vieja, fea, sosa, me veía fatal y es a día de hoy que mis amigas me dicen "¡lo que has cambiado, no pareces tú!" No sé, ni me arreglaba, ni nada, bueno eso de pintarme ni se me ocurriera porque " ¿dónde vas tú pintada al trabajo?, no, no, tú de pintarte no". Yo ni me pintaba ni me arreglaba, nada, era un levantarme y un empezar, bueno venga...

- (P) Había que sobrevivir

- (R) Exactamente

- (P) ¿Ahora cómo te ves?

- (R) Ahora me veo muy bien

- (P) ¿Has mejorado?

- (R) Sí, fue venir aquí y los dos o tres primeros meses muy mal, el adaptarme a la ciudad, a vivir con más gente en la casa, yo acostumbrada a vivir sola, el saber que él estaba aquí, que vivimos relativamente cerca

- (P) ¿Dónde vivís?

- (R) Yo vivo en la P. de T. y él vive por donde el C.. Entonces claro, eso a mí me ponía tensa, yo evitaba el salir a la calle, encima mi abuela se estaba muriendo, vamos que fue un cúmulo de cosas, fue duro, fue muy duro, pero bueno, luego yo que sé, va pasando el tiempo, yo luego hablé con él porque tenía una orden de alejamiento, la orden de alejamiento se acabó y él fue acabarse la orden de alejamiento y el día después me llamó por teléfono, me llamó al móvil, pero para pelearse, para decirme que si era una loca, que tenía que ponerme a trabajar porque yo había elegido el colegio, bueno entre otros, y él lo sabía y estaba de 
acuerdo, pero había que buscar un conflicto, había que buscar un conflicto y empezó ahí, venga y venga y venga, pero bueno, vas separando, vas intentando... fue un verano muy malo, conocí a un chico, pero la cosa no... porque yo no podía, porque eso era... yo terminé diciéndole "mira es que te pareces a él" yo creo que este chico con el que estuve también era muy agresivo, le faltaba al respeto a la madre y no sé... siempre estaba pegando puñetazos... yo ya vi, yo vi... yo en mi casa pasé cuatro meses muy malos, con una ansiedad terrible y digo... no, porque me pasa lo mismo y dije "mamá lo tengo que dejar" y me dijo "si, hija sí" yo ya no hago como antes, ya todo lo que me pasa a mi madre se lo comunico la primera porque no hay mejor consejo que el de una madre, por lo menos en mi caso y ya se lo dije "mira no, porque estoy viendo ciertas cosas y yo no quiero" y ya me dijo "pues venga, tú déjalo que no"

- (P) ¿Qué sentimientos tenías hacia él?

- (R) ¿Hacia quién de los dos?

- (P) Hacia tu marido

- (R) ¡Puf...! en principio de pena, no sé, al principio pensé que era yo y me sentí culpable, culpable por verle a él mal, no sé, no le veía tampoco agresivo, al principio no le vi, no sé... raro, porque lo ves raro...

- (P) ¿Cuándo te enamoras de él, qué sientes por este chico? ¿Cuándo inicias la relación?

- (R) Es que ahora yo creo que no me llegué nunca a enamorar, sí que le quise, le tuve mucho cariño, pero enamorarme no.

- (P) Cuando pasa todo esto, tú dices que empiezas a sentir pena, como que te sientes culpable

- (R) Sí, claro, cuando se termina siento mucha rabia, siento mucho coraje, mucho asco, en ese momento le tenía demasiado coraje, estaba yo demasiado alterada porque terminas cogiendo sus hábitos, me sentía agresiva... bueno estuve muchísimo tiempo sin poder decir su nombre, o sea, no quería ni verle, ni hablar de él, ni nada, pero luego ya... mira, no le guardo rencor, fue parte de mi vida pasada, que pasó y que merezco vivir otra

- (P) ¿Qué pensabas en relación a tu niña cuando te estaban pasando todas esas cosas?

- (R) Lo veía injusto, tan pequeña, "no, si no se entera" Su familia me decía "¿cómo vas a dejarlo si como él no vas a encontrar otro?, si esas cosas pasan, tú échatelo encima, ¿cómo te vas a separar con una niña?" Y mi madre me decía "sepárate, no seas boba, que mira lo que te está haciendo", era todo lo contrario. A mí mi hija, viene y me dice que ha pegado a alguien en el colegio y soy yo la primera que la regaño, que eso no se hace. La diferencia que hay, es que a él no le decían nada, no le decían que fuera malo, no porque en su casa se ha vivido eso, su padre ha pegado a la madre durante muchos años, psicológicamente lo sigue haciendo ahora, de puta para arriba, todos los días, por lo menos hasta el momento que yo dejé esa casa, entonces claro... yo ahora comprendo, él al decirme que si yo era una guarra, que si era una puta o si estaba sucio... yo ahora lo entiendo... no es que él lo viera mal, o lo viera bien, son los hábitos que ha aprendido en su casa ¿Qué me iba a decir?, pues lo que ha oído, ahora lo veo así, cuando antes no lo entendía, decía "pero bueno... ¿qué me está diciendo?, yo qué sé, voy a seguir limpiando porque se ve que esto no está bien" pero ahora me doy cuenta de que no, después de psicólogos y de charlas y de cosas que ya vas viendo, con gente que vas hablando... son patrones que se tienen y él los tenía, él los tiene, el hermano los tiene, el otro hermano los tiene porque todos son así, porque la hermana, al marido no, pero a las niñas, las tiene fritas y los otros tres hermanos son iguales que él, ¿Entonces qué va a hacer?

- (P) ¿Quién tomaba las decisiones importantes en la casa?

- (R) Él

- (P) ¿Y el manejo del dinero?

- (R) Él también 
- (P) ¿Incluso el tuyo?

- (R) Incluso el mío

- (P) ¿Tú no tenías tu propio dinero?

- (R) Y encima decía que yo lo malgastaba, cuando yo me separé la gente se sorprendía porque todo el mundo decía "Si tú eras la que mandabas, tú eras la que le ponías..." y yo decía "yo que le voy a poner, si yo no mando ni en mi casa" Yo no mandaba nada, yo solamente la niña y de la niña me ocupaba, la niña nunca ha querido ir con su padre, nunca, la niña era un bebé y era su padre cogerla en brazos y la niña berrear y lloraba y lloraba y decía que con el padre no quería y él decía que yo a la niña la malmetía, cuando a día de hoy, en mi casa, yo delante de la niña, de ese tema no se habla, no lo hemos hablado nunca, nunca, delante de la niña no se habla de ese tema, pero él decía que yo a la niña la malmetía

- (P) ¿Quién se ocupaba de las cosas de la casa, la compra, la comida, la niña...?

- (R) Mira, de las cosas de la casa me ocupaba yo, él hacía la cena, porque yo volvía tarde, pero bueno hacía la cena, pero muy restregado "porque yo hago la cena" y luego la compra, si podíamos hacerla los dos, para él mejor, porque es que yo no sabía comprar, yo no sabía comprar

- (P) ¿En algún momento te llegaste a creer o dudaste de tus capacidades para ser buena madre, buena trabajadora, buena...?

- (R) Sí, sí, sí, sobre todo de casa, yo pensé que no sabía ni fregar, bueno y el tema de la comida, ni hacer de comer, ni ir a la compra, que yo no tenía ni idea, de hacer la compra yo, ni idea. Llega un momento que tanto te lo repiten que al final te lo terminas creyendo, dices tú, "madre mía, si yo tan mal no compro, si tampoco..." Él llenaba el carro, lleno de porquerías, de bebida, de refrescos, de patatas fritas, de dulces, le daba igual que hubiera o no para comer la niña, él todo lo quería y yo, oye si la semana son siete días, voy más o menos a planificar la semana, sabiendo más o menos lo que voy a hacer de comer y si tengo poco dinero, los alimentos principales son para el bebé, no para mí, porque yo más o menos me puedo mantener, ¿pero a ella? a él eso le daba igual

- (P) ¿Qué clase de cosas le irritaban de ti? ¿Qué es lo que no soportaba?

- (R) Yo creo que de mí... no sé porque nunca me ha dicho, pero yo creo que a él lo que más le irritaba es que yo fuera independiente, el que yo quisiera también tener amigos, el que yo fuera familiar, o sea, él lo podía ser, yo no. El que dijeran de mi que yo en el trabajo era buena trabajadora, era buena niña, eso a él le molestaba, le irritaba, "¿Cómo va a ser ella mejor que yo?"

- (P) ¿Por qué permaneciste a su lado? ¿Qué era lo que te unía a él?

- (R) No sé... la independencia, él me creaba dependencia total, pero total, total, total

- (P) ¿Y tú te lo creías? ¿Estabas convencida?

- (R) Sí, por supuestísimo, sí, sí

- (P) ¿Antes de conocerle tuviste problemas psicológicos?

- (R) No, no

- (P) ¿Y él, sabes si los tuvo?

- (R) Yo creo que no, lo que pasa es que él no es que tenga problemas psicológicos, a ver... no lo sé, nunca fue al psicólogo, pero yo creo que el problema que él ha tenido es que ha visto eso en su casa, a lo mejor, no sé... porque yo nunca lo he vivido en mi casa, no sé como eso se puede filtrar, no sé como tú puedes ver a tus padres peleándose, no lo sé, pero yo pienso que eso te tiene que quedar un poco de marca porque tú vas creciendo y vas creciendo con esos patrones, pensando que todo eso es normal y viendo a tu madre llorar y sufrir. Yo a mi madre la he visto llorar, nada más, cuando se murió mi abuela, o sea, no la he visto llorar porque en mi casa se peleen y se digan palabrotas, es que no sé, no sé, no sé, es que hay cosas que no entiendo. Por eso cuando tengo amistades, me fijo mucho en el trato que tienen con la familia, una cosa que antes no hacía y ahora hago, porque mi teoría, pienso que si tú eres capaz de faltarle al respeto a tus seres más allegados, como por ejemplo hijos, padres, hermanos... si tú eres capaz de faltar el respeto así, eres capaz de faltar el respeto a tu pareja 
- (P) D., ¿la cuestión económica de alguna manera bloqueó tu separación, te dificultó?

- (R) Sí, porque cuando mi madre se va y yo me quedo sola en casa y voy viendo tantísimos detalles, porque es como que viviera en una cárcel, todo tenía que ser con su consentimiento, todo era a base de que él me dejara, o me diera dinero. Entonces claro, yo el verme querer salir y no poder... ¿qué era...?

- (P) Te decía que si el dinero...

- (R) ¡Ah, eso!, al yo quererme separar y ver que... ¿cómo me separo?, pagando dos coches, hipoteca y sin familia allí, porque mi hermano sí, pero mi hermano vive con su pareja y con los niños y no me voy a meter en su casa.

- (P) ¿Tenías a tu hermano allí también? O sea que sois tres

- (R) Sí, pero a él no le conté nada y todavía es el día de hoy que no le he contado nada, saben que me he separado, pero no saben los motivos reales

- (P) ¿Y tu madre tampoco se lo ha dicho?

- (R) No, porque no, ya no quiero más problemas, no porque no. Y claro ¿cómo me voy a separar? ¿qué hago yo? ¿A dónde voy?

- (P) ¿Económicamente te sentías atada a él?

- (R) Sí que me sentía atada, me sentía muy atada

- (P) ¿Tu familia te sirvió de apoyo cuando te separaste?

- (R) Sí

- (P) Una vez tomas la decisión, responden de forma positiva

- (R) Sí, sí, sí. Yo tomo la decisión por una compañera de trabajo, porque un día saliendo de casa, el día ese que me dijo que me tiraba por la ventana, ya yo salía con la niña, dije que iba a coger un taxi para ir al trabajo, bueno... dejarla a ella y luego ir para el trabajo y él dijo que yo me gastaba el dinero en tonterías y que yo me gastaba el dinero en tonterías y de eso que salía yo por la puerta de casa y él le dijo, ven Ainoa a darme un beso, yo la tenía en brazos, la cogió a ella en brazos y se metió para dentro de la casa y yo fui a abrir la puerta, se puso en el medio, me pegó una patada, pude coger a la niña y ya me fui. Claro cuando llegué al trabajo cómo estaba... llorando con la niña y me dijo mi compañera "se acabó, tú hoy lo denuncias, porque mañana no lo cuentas". Ya llamé a mi madre y me dijo que sí, que sí , que lo denunciara, que no fuera tonta, que por qué no le había contado nada, que ya había estado guardando muchas cosas y que ella tampoco sabía porque claro... tantos $\mathrm{km}$, si no le cuento yo...

- (P) No se entera

- (R) Y ya denuncié y desde el día que denuncié hasta hoy

- (P) ¿Qué pasa después de que denuncias?

- (R) Bueno, pues yo denuncié y me sentí fatal, me sentí la peor persona del mundo

- (P) ¿Tuviste que volver a tu casa?

- (R) Bueno yo denuncié en el juzgado, a él le llamaron, se puso... no se puso una medida, se puso unas medidas previas hasta que saliera el juicio, unas medidas previas que eran... había dinero en casa, la mitad lo tenía que coger él, había dos coches, uno lo cogía él, otro se dejaba en casa y él de la casa se tenía que ir. Él cogió sus pertenencias y hasta que no saliera el juicio, él a la casa no podía ir, yo no me quedé esos días en casa, porque yo cagada, pensé después de haberle denunciado, este viene, me mete aquí dos puñaladas y me deja frita y bueno,... me quedé en casa de una amiga con mi niña, mi madre la pobre aquí, porque mi abuela mala, no se podía ir, con mi hermana aquí en el cole... bueno un follón, pero mi madre me ofreció el irme para aquí, para L., lo que pasa es que yo tampoco quise, porque es como que... yo tampoco quería dar la espalda a todo porque al final tienes que dar la cara y prefería afrontar en ese momento y dejarlo todo listo... eso fue un viernes, hasta el lunes no se hizo el juicio y ya en el juicio, se dictaron las medidas previas, bueno... las medidas ya... a él le hicieron culpable, pero me costó alma, porque eso fue, porque ya a lo último..., porque la señora jueza, con él a tope, le apoyaba, yo no sé por qué razón, se ponen así, no es que apoyara... que tú vieras, pero la manera de hablar conmigo era dura y con él, tampoco le hizo 
preguntas, ni se dirigió mucho a él, todo era conmigo y muy dura, pero la última pregunta que me hizo fue que si tenía miedo a que él me hiciera algo, que si yo temía por mi vida, entonces claro, le dije que sí, le dije la verdad, mira, pues sí y de ahí me dio la orden de alejamiento porque a mí la abogada que me asistió me lo dijo, ella te da la orden de alejamiento porque si tú le dices que sí y ella te la niega, si mañana pasa algo la culpa es de ella, porque eso está escrito, vamos... está la mujer escribiendo, entonces te lo ha dado por eso. Digo, pues qué pena, porque una cosa que se ha sufrido de verdad y él ahí negándolo, que persona más falsa, yo me estaba quedando que fueron momentos durísimos, momentos duros de que ni tenía familia, ni tenía a nadie porque te quedas sin nadie, una compañera de trabajo, que era con la que salí aquel día al cine que me lió lo que me lió y me pegó, pero no tenía a nadie más, luego mi hermano como no sabía nada, porque claro yo que voy a decir, le digo a mi hermano que... yo quería evitar problemas, más que nada evitar problemas por lo que luego me pueda pasar a mí y ya luego cuando ya dictaron, que se acabó el juicio, a los pocos días ya me enteré que él se vino aquí a vivir a L. y yo ya fue cuando estuve allí tres meses

- (P) ¿Él estaba sometido a estrés en su trabajo? ¿Estaba presionado?

- (R) Él no, a ver, lo que tenía era un trabajo de noche, a lo mejor no descansaba las horas que tenía que descansar y luego el trabajo que tenía, no..., él estaba contento con su trabajo, se llevaba bien con su jefe... no sé, era una cosa que como era un negocio familiar y él estaba ahí, pues bien

- (P) ¿Él consume alcohol u otras sustancias?

- (R) Alcohol no, luego yo que se..., la gente es muy mala, me dijeron que fumaba, que fumaba porros..., no sé qué... en mí casa nunca ha hecho eso, pero... ¿te fías de lo que te diga la gente'

- (P) ¿Tú nunca lo viste?

- (R) No

- (P) Problemas de alcohol o drogas, ¿nunca observaste nada?

- (R) No

- (P) ¿Te costó comenzar a hablar del maltrato que estabas sufriendo? O por el contrario ¿después de todo lo que pasaste te resultó fácil?

- (R) No, me resultó dificilísimo. A mí me decían “¿tú por qué te has separado?", y yo decía, "no..., porque no nos llevábamos bien..., porque esto..." $Y$ ahora me preguntan, el otro día me preguntó la mamá de una amiga de mi niña, saliendo del cole, bueno... porque tengo muchos amigos... cosa que antes no tenía... y me preguntó que si estaba separada y dijo... "bueno, ¿pero te llevabas mal...?" y dije "mira le denuncié por malos tratos" y me dijo "Ah, lo siento" y dije "No, si no pasa nada, lo pasado, pasado está"... bueno...

- (P) ¿Antes nunca lo hubieras dicho?

- (R) No. Yo creo que el problema está en que si no te metes en este mundo, si no lo vives... no hay nadie. Cuanta gente lo sufre, lo pasa y no lo habla. Muchísima gente, muchísima, muchísima... Y claro, yo al decirle eso, a la chica esta, me dijo que la madre también se había separado, que había denunciado al padre por malos tratos... Pero si no eres tú... bueno... no... nadie lo habla

- (P) Es un tema todavía, un poco...

- (R) Un tabú, como el sexo. Es un tema que nadie quiere..., que no se saca, es que el pudor, pues si no se saca, nunca se supera

- (P) ¿Sentiste alguna vez la necesidad de exagerar tu historia para que te creyeran?

- (R) Yo es que nunca he querido contarlo, por no sé, que la gente me viera diciendo... "oye mira, que pena, pobrecilla, ha sufrido malos tratos" o porque no me crean. Por qué lo voy a contar si tampoco tengo fotos, no tengo fotos, ni nada que demuestre, es lo que te estoy contando...

- (P) Te pueden creer o no creer, ¿eso es lo que quieres decir?

- (R) Exactamente, y como que cada vez, yo me ponía a pensarlo... Si yo ahora lo cuento, pasas el mal rato de contarlo, revivirlo todo y encima para que luego a lo mejor, sientan pena o te critiquen o te pongan una etiqueta que no... 
- (P) ¿Nunca acudiste a una casa de acogida?

- (R) Yo no acudí a una casa de acogida, pero cuando yo empecé con un chico, el chico este que te contaba que era también agresivo, un día andando por la calle, me encontré con el padre de la niña, entonces se puso agresivo, iba con el coche, se puso a insultarnos, quería pegar al otro chico. Yo llamé a la policía, le denunciamos, entonces claro... ahí fue un poco violento, pero claro... qué haces en ese momento. $Y$ entonces yo pensé, yo necesito ayuda, necesito porque después de que me ha pasado esto, desde que me separé, hasta que me pasó este incidente, yo no lo hablé con nadie, entonces era una cosa como que la tenía aquí, la tenía aquí, la tenía aquí (se señala el pecho), necesito contarlo, necesito contarlo, necesito contarlo. En mi casa tampoco, porque a mí madre le puedo contar las cosas, pero yo sé que ella lo sufre y tampoco, para qué le voy a contar si ya pasó y yo tampoco quiero que ella se lleve un mal rato. Yo me dije, necesito ayuda ya y fui a la asociación que hay ahí en P.I.

- (P) ¿A la Oficina Municipal de Atención a las Mujeres?

- (R) Sí, y ya hablé con la psicóloga, bueno con S. y con V. y súper bien. Desde ahí, yo empecé a mejorar. Dejé al otro chico, porque le dije "mira, no puedo estar contigo, ni puedo estar con nadie, no" Fue dejarlo a él y empezar con V. (psicóloga del servicio de atención a las mujeres del Ayuntamiento de León) y mano de santo, fue una cosa...

- (P) Fenomenal

- (R) La verdad es que sí, luego con V., empecé el curso de ayuda a dependientes, empecé a conocer gente, porque todo mi miedo es "yo aquí, con 25 años, sin conocer a nadie, sin amigos", yo me sentía... sin trabajo, qué hago aquí. Peo luego fue viniendo todo, yo ya me sentía mejor, ya empecé a conocer gente, a abrirme yo, a saber que no estaba sola, que tenía el apoyo de mi familia, que mi niña iba mejorando, porque al principio mi niña estaba nerviosa, estaba inquieta, ella estaba mal, también yo estaba mal. Lo que tú transmites es lo que ellos te dan también, pero bueno... luego he ido mejorando, mejorando. Luego me apunté al teléfono de la esperanza a hacer... no son terapias, son unos talleres que hacen ellos y súper bien, me siento genial

- (P) ¿Quién te animó a apuntarte al teléfono de la esperanza?

- (R) Es que yo necesitaba... No me animó nadie, fue por lo del Instituto de la Mujer, que me dijo G., en el centro de Alzheimer que tenían voluntariado... y yo no sé, tenía la cosa de que necesitaba ayudar, que eso también a mí me llenaba, el hecho de poder ayudar a mí eso me llenaba y fui a hablar con J. que es el que lleva el tema del voluntariado y me involucré, me metí ahí y...

- (P) ¿Y estás fenomenal?

- (R) Sí, la verdad es que sí. Te quedan escollos, a ver, todavía me quedan cosas por superar, pero no sé, es como haberlo vivido otra vez, haber vivido toda mi vida otra vez, haberla analizado, haber visto que él fue el culpable, pero yo también lo fui por haberlo consentido, si a lo mejor yo me hubiera dado cuenta antes

- (P) ¿Responsable?

- (R) Exactamente, no culpable, yo me hago responsable de mis actos, de haberle aguantado y ahora lo veo de otra manera, no sé, lo he analizado de otra manera. Lo que pasa es que el tema de los hombres, es una cosa que la llevo... no me fío y luego la independencia que me ha creado, al miedo de decir no quiero verme sola, por eso él los amigos no los veía, porque los amigos no valen para nada. Claro ahora que tengo amigos, tengo miedo a quedarme sola, pero bueno yo creo que se mantendrán, si uno es bueno se mantienen

- (P) Y si no se mantienen, será que no eran tan amigos.

- (R) Ya, ya...

- (P) Decías que tu niña sí que había presenciado maltrato y sí que había visto cosas

- (R) Sí, ha visto cosas

- (P) Su padre ¿en alguna ocasión se ha considerado maltratado por ti?

- (R) No. ¿Él por mí? (muy extrañada) 
- (P) Sí

- (R) No, ¿qué dices?, demasiado bien me he portado yo. No, no, no. Yo después de que pasara todo esto, un día quedé con él, que hice mal, pero yo necesitaba, una de las cosas por las que estoy... porque nos sentamos en una cafetería y empecé a hablar con él "mira yo hay cosas..., quiero saber por qué, por qué lo hiciste ¿no?, tú no ves que esas cosas están mal hechas" y él por completo, o sea negó por completo, él me dijo "yo no he hecho nada malo, fueron situaciones que pasaron, que tú supiste llevarme al límite" Entonces digo, "mira no" Yo como ya llevaba tanto leído de casa, porque ya sabía, porque me he leído mucho sobre el maltrato, sobre el perfil del hombre, digo, "mira no, te equivocas completamente, yo estoy bien conmigo misma, sé que no he hecho nada malo, aguantarte, pero no he hecho nada malo, aquí el que ha hecho mal eres tú, las cosas que has hecho", pero como una persona cuando no quiere cambiar no cambia, tiene que ser ella misma, yo fui a hablar con él y mira... se acabó, ya no pierdo más mi tiempo. Pero era la necesidad que yo sentía, de expresarme, porque nos separamos y ya no volví a hablar más con él, a lo mejor alguna vez por teléfono, pero discutir por el tema de la niña o el colegio, pero nada más, el hecho de hablar ese día y en ese momento, fue ese día, incluso, luego me quedé bien, lo necesitaba yo el tenerle que decir...

- (P) ¿Creíste en algún momento que este hombre era tu pareja ideal, tu complemento, esa persona con la que envejecer?

- (R) En algún momento sí, fueron flases

- (P) ¿Ahora qué piensas?

- (R) Que no sabía lo que hacía

- (P) ¿Piensas que la situación ideal para una mujer es tener pareja?

- (R) No pienso que sea ideal, pienso que es un complemento de la vida, es decir... yo no creo en el amor eterno, ni creo en todas esas tonterías. Ahora no creo, es que no lo creo, pienso que es bueno tener una persona a tu lado, pero... que te transmite, que no acapare tu tiempo, yo que sé, que no sea celosa, que te entienda a ti y tú la entiendas a ella, el respeto... Pero que sea una cosa necesaria... yo estoy viviendo ahora sola, sin pareja y no pienso que sea una cosa necesaria de la muerte, es decir si me quedo... me quedaré, que le voy a hacer, que me guste, me gustaría tener una persona a mi lado, que fuera buena, pero no hay

- (P) No sabemos, igual hay alguno... (Utilizamos es sentido del humor)

- (R) Lo dudo

- (P) ¿Crees que las mujeres nos enamoramos una vez de un hombre y después de eso no somos capaces de amar a nadie más?

- (R) ¡Hombre!, yo no sé si lo que sentí por él fue amor, estoy todavía en proceso de estudio, pero creo que es muy difícil, no sé decirte ni un no, ni un sí, creo que es... Te queda el escollo, que te queda. Una vez que te entregas, yo en el caso me entregué tanto... y luego yo pienso que ya no te entregas igual... es la desconfianza, aunque supongo que con el tiempo pasará, no sé, es que tampoco te creas tú... yo he estudiado... he leído en el proceso ese, pero lo que pasa después ya no lo sé

- (P) Y los celos ¿son buenos o no para una relación de pareja?

- (R) No, que no, que no... cuando yo quiero a alguien, quiero en confianza, cuando yo quiero a alguien, yo pienso que si tu lo haces, ya me estás engañando a mí, pero también te estás engañando a ti mismo, si me estás diciendo que me quieres y te estás yendo con otra persona... antes era celosa, pero para qué, de qué te vale, los celos no te valen para nada, si tiene que estar contigo estará y si no que no esté

- (P) ¿Piensas que el amor se tiene que manifestar siempre con la misma intensidad?

- (R) Yo pienso que no, yo pienso, yo... que para querer tienes que dar sin pensar en recibir, porque si no... yo doy porque yo quiero dar, si luego recibo..., pero no el hecho de dar por recibir, por narices, es lo mismo que el voluntariado, es decir, yo doy porque quiero, si luego recibo cariño en ese caso, más agraciado eres y más bonito, yo pienso que se hace, más bonito, cuando yo recibo y no te lo esperas... es mucho más... obligar a que te quieran. 
- (P) ¿Piensas que es posible evitar amar a alguien, o no?, ¿es algo involuntario?, que de repente te enamoras y no se puede controlar

- (R) Es que para enamorarse, pienso que tiene que haber muchas cosas, no creo en un flechazo, pienso que cuando te enamoras de alguien, tiene que ser un proceso de cosas, de hechos, de convivencia, de..., no porque tú conozcas a alguien... el físico es físico, después del físico hay mucho más, hay muchos ámbitos

- (P) Si amas a una persona ¿lo mejor sería acabar en matrimonio o convivencia?

- (R) No, el matrimonio, por favor, eso es antiguo, no. Cuando tú amas, lo bonito es que estés a su lado y qué más da que te cases o que no

- (P) ¿Pero convivir?

- (R) ¡Hombre convivir!, a ver, no te vas a tirar toda la vida tú en un piso y él en otro. A ver, no sé... al principio... yo no dejaría todo de un día para otro por irme con una persona que no conozco, a lo largo de tu vida, van pasando cosas, vas evolucionando y vas viendo si tienes que convivir o no con esa persona, puedes amar y no convivir con ella. Hay muchas maneras de amar

- (P) En tu caso, estás casada durante un tiempo, tenéis a la niña y tomas la decisión de separarte ¿por un desgaste de la pareja o por esta situación de maltrato que se te presenta ese día cuando tu compañera te anima a denunciar?

- (R) Por un desgaste

- (P) ¿Cuál es el detonante?

- (R) La máxima agresividad que él tiene hacia mí, verbal y física

- (R) Ahí ya no puedes aguantar más

- (P) Sí, sí, claro, ya no. Era una cosa, vamos, que en la vida..., constante

- (P) ¿Tuviste intentos de separación antes del definitivo?

- (R) Sí, pero no le había dicho nada a él

- (P) ¿Sólo era un pensamiento tuyo?

- (R) Yo había cogido algunos teléfonos de asistentas, para informarme, esto a escondidas, después de que él me diera ese que salí en septiembre, que fui al cine, a partir de ese día sí que moví yo algún hijo ahí, fui llamando, pero cosas que él no sabía... yo tampoco estaba al $100 \%$ segura, quería ir tanteando, a ver cómo podía, hasta que... "vamos a ver me separo y se acabó, ya saldrá el sol por donde quiera"

- (P) ¿Qué cambios experimenta tu vida una vez separada? ¿Qué ves que ha cambiado para mejor o para peor?

- (R) ¡Hombre! al principio no sabes, es un poco una incertidumbre, más yo trabajando, decidiendo irme de M. para aquí para L., un cambio, al principio yo no sabía si estaba bien, si estaba mal, me sentía culpable, pero cuando ya me veo aquí y me veo estable, vamos... lo mejor que he hecho en toda mi vida. Yo la felicidad que tengo ahora, vamos... me siento como nunca y quiero seguir mejorando, pero yo, mejorando yo, intentando cambiar cosas que sé que no están bien por el hecho de todo lo que he sufrido, a lo mejor, que no pienso que sea agresiva, pero al principio, sí que me noté yo, como que era como él, yo me sentía un poco como él y me decían "D., pero si es que esto no es, esto no es así y tienes que cambiarlo y si no lo cambias a tiempo se te queda" $i$ La gente que no lo trata?

- (P) Hay muchos cambios en tu vida, pero supongo que también muchos apoyos, porque dices que el balance es positivo

- (R) Es positivo, sobre todo por mi familia, o sea, fue el mejor apoyo que tuve, porque cuando mi abuela se enteró que me separaba, que ya me venía para acá, ella me dejó dinero, mi madre se fue con mi padre, con mi hermana, fueron para allí, para M. con un camión de estos de transporte, vamos, cogí todo lo de la casa en cajas, me vine para acá, me ofrecieron la casa, vamos... qué más puedo pedir. Luego mi hermano cuando se enteró que me separaba, se hizo cargo, cuando yo no estuve allí en M., pues se hizo cargo de la casa, hasta que la pude dar al banco, vamos muy bien, mi balance, ha sido totalmente positivo, que yo pensé que no.

- (P) Apoyos todos 
- (R) Todos, sobre mi familia, la demás gente, habló mucho y mal, pero como me da igual, no eran sangre..., no eran mi gente con aprecio, ni eran amigos porque no tenía, el apoyo de mi familia lo tenía ahí, porque encima él quedó como que pobrecito

- (P) Por parte de su familia ¿te han apoyado?

- (R) No, ahí tiene un hermano que bueno, sí que me saluda o hablamos y él ve que lo que ha hecho el hermano no está bien, pero yo creo que él me lo dice, pero no me lo dice con toda la sinceridad, no es sincero, me lo dice por quedar bien ¿sabes? Yo pienso que no me lo dice con un sentido bueno.

- (P) Tu situación actual: la salud me decías que bien, te acompaña, eres una mujer muy joven, estás viviendo en casa de tus padres, economía y trabajo, ahora mismo parece que fenomenal, has iniciado un trabajo que te gusta, las relaciones sociales estás empezando a ampliarlas. Tienes muchas cosas a tu favor, las relaciones familiares parecen buenas... ¿cómo es la crianza de tu hija en solitario?

- (R) Bueno... yo me siento genial, me siento buena madre, siento que hago todo lo que puedo, el tema del padre... bueno... lo llevo un poco difícil porque ella tampoco es que quiera ir con su padre, tengo que andar ahí un poco... bueno... no la engaño, pero le digo "es que papá necesita verte, él te quiere" pero bueno, el fin de semana que se va con su padre, estoy a mi aire, pero es diferente, me falta algo también, pero tiene que estar con su padre. Luego su padre, bueno, que si sale los fines de semana, que si con la niña no está, que si la deja con la hermana, pero como es su padre y tiene que estar con ella, pues nada

- (P) Te habitúas a eso

- (R) Sí, me tengo que habituar

- (P) En relación a nuevas parejas, dices estar dispuesta a tener otras relaciones, pero tiene que ser una persona muy especial

- (R) Sí, sí, sí... muy especial. ¿Sabes lo que pasa? Que como este chico, el padre de mi niña estaba así gordito... como que le he cogido manía, no sé...

- (P) ¿A los gorditos?

- (R) Sí, y tengo amigos que son gorditos, pero no sé. Es que creo que el padre de la niña tenía algo de trauma por el tema del peso, entonces pensar en una persona a mi lado que tenga sobrepeso y que puede ser un conflicto en la pareja, yo ya pienso ya en futuro ¿no?, un hombre así gordito, para tener problemas, va a ser que no, no porque a él también eso le creó mucho... no sé, me hacía a mí culpable, que estaba gordo por mi culpa

- (P) ¿Y eso?

- (R) Pues yo que sé, decía que estaba... que yo le hacía gordo. Sí él estaba gordo yo era la culpable. No me cierro, pero muy marcado, tengo a los hombres muy marcados, a mí me ha dado algo con los hombres, el otro día hablaba con un amigo que tengo y le decía "para mí los hombres son todos malos, son unos guarros, nada más que quieren sexo" Yo se lo digo y él se ríe, yo qué sé, me ha quedado marcado.

- (P) ¿Qué planes de futuro tienes?

- (R) ¿Planes de futuro? Nada, seguir trabajando, seguir yo mejor, aunque tengo recaídas, pero ya me recupero, seguir con el trabajo como te he dicho, seguir con mi niña, tener mi casa y mi niña que me encantaría

- (P) ¿Te apetecería independizarte?

- (R) Sí, sí, me apetecería muchísimo. Tener mi perrillo, con mi niña, tener los animales que a ella le gustan, una tortuguita, pero bueno... algún día lo tendré, antes me ansiaba mucho la necesidad de tenerlo, pero ahora no me preocupa, yo pienso que las cosas vienen cuando tienen que venir, si no te las esperas van viniendo solas

- (P) ¿Cómo te ves a ti misma?

- (R) Me veo guapa, me veo bien, yo me veo feliz, me veo contenta, sé que estando así consigo el tener amigos, el relacionarme con la gente, porque yo era tímida y ahora no lo soy, puedo ayudar a alguien y antes no lo hacía, no sé, yo me veo bien. 
Como que he crecido, no soy tampoco ego centrista, pero también como que he trabajado mucho la autoestima

- (P) Yo por mi parte, D. ya he terminado la entrevista, no sé si tú quieres añadir algo más

- (R) No sé. Hablar se me da fatal. Muy bien, cuando me dijo G. (Oficina Municipal de Atención a las Mujeres) que ibas a hacer... yo vamos... encantada, dije sí por favor, contra más hablo de ese tema mejor me siento

- (P) Muchas gracias D.

- (R) A ti 
ENTREVISTA № 9: R. (28/03/2011)

- (P) Dime, ¿cuántos años tienes?

- (R) 47

- (P) ¿Lugar de nacimiento?

- (R) L.

- (P) № de hijos

- (R) 1, D.

- (P) ¿De cuántos años?

- (R) 20

- (P) ¿Con quién vive D.?

- (R) Vive conmigo, pero estudia en L.

- (P) ¿Es hijo de tu ex marido?

- (R) Sí

- (P) ¿Dónde vives en la actualidad?

- (R) En A.

- (P) ¿Y tu familia?

- (R) En L. y en A.

- (P) Tienes hermanos/as en $L$.

- (R) Mis hermanos en L., y mis sobrinos y mis tíos en A.

- (P) ¿Son para ti un apoyo, tu familia?

- (R) Sí

- (P) Los de L. y los de aquí

- (R) Sí, todos

- (P) ¿Económicamente, cómo estás?

- (R) Bien

- (P) ¿Trabajas fuera de casa?

- (R) Trabajo y me da para pagar los gastos, para un poquito más

- (P) Para vivir

- (R) Para no andar ahogada, que es bastante

- (P) Es mucho

- (R) Sí

- (P) ¿Qué estudios tienes R?

- (R) Tengo técnico superior administrativo, soy técnico en jardinería, informática administrativa, también tengo el título de ayuda a domicilio... no me acuerdo de más

- (P) Para, para... unas cuantas cosas, sin embargo no tiene nada que ver tu formación, con lo que estás haciendo ahora mismo

- (R) Nada, ahora estoy en un bar y haciendo trabajo de limpieza. Por las mañanas limpieza y por las tardes el bar.

- (P) Salud ¿cómo estás de salud?

- (R) Bien

- (P) No tienes nada...

- (R) Bueno... tengo problemas de huesos, de articulaciones, musculares... pero... no

- (P) Pero bien.

- (R) Sí, más o menos

- (P) Para ir tirando

- (R) Son temporadas

- (P) ¿Cuánto tiempo hace que te separaste, R?

- (R) Pues en Julio va a hacer 5 años, o sea que 4 años y...

- (P) 4 años largos. Vale. ¿Me podrías contar el primer incidente, la primera vez que tú te das cuenta que tu ex marido te está maltratando?

- (R) ¿El primer día que me pegó?

- (P) Cuéntame 
- (R) Pues... había hecho yo un curso de ebanistería, de 6 meses y teníamos la cena de fin de curso, entonces nos fuimos a comer y luego... bueno se alargó la cosa y bueno, dijeron... vamos a ir a cenar y tal... y le dije a él "venga vamos a cenar porque se está alargando la cosa y tal" "No, no quiero" Total, que a la una de la mañana apareció donde estaba yo con la otra gente, en el bar y ahí me pegó

- (P) ¿Delante de la gente?

- (R) Delante de la gente y me fue pegando luego hasta casa.

- (P) ¿Sin mediar palabra o hubo una bronca?

- (R) No, nada, nada...

- (P) Llegó al sitio donde tú estabas cenando

- (R) Yo no me enteré... yo noté un golpe, pero no sabía, ni lo vi entrar ni nada, me dio un tortazo que me arreó y luego me agarró así (del cuello) tampoco nadie hizo nada, entonces me agarró, me sacó y me llevó para casa

- (P) ¿Cómo reaccionó la gente?

- (R) No hizo nada

- (P) ¿Nadie, nada?

- (R) Nada, ni un comentario oí nunca jamás, ni hicieron nada, ni nada de nada, no hicieron nada

- (P) ¿Y tú cómo reaccionaste después?

- (R) ¡Puf...! yo... yo estaba en estado de shock, como quien dice, porque yo no llevaba ni un año casada con él y vamos... yo había puesto todo en esa relación, todo, todo. $Y$ de repente, una persona, que se supone que te quiere, que vas a pasar el resto de tu vida con él, que no hace ni un año que te has casado y esa reacción, claro, yo no me la esperaba, para nada, yo me quedé... bueno

- $(\mathrm{P})$ ¿Y él después cómo reaccionó?

- (R) Él, llegamos a casa y después cogió cosas en una bolsa y se marchó

- (P) ¿Sus cosas?

- (R) Sí y se marchó de casa y yo luego fui a la calle a buscarlo a él

- (P) ¿Y hablasteis?

- (R) No

- (R) ¿Volvió para casa?

- (R) Sí, cuando volvió a por las cosas que había dejado en la escalera, abajo, yo estaba esperando, a ver si volvía, porque vi las cosas allí y le dije que subiera, pero nunca lo hablamos

- (P) ¿Esa fue la primera vez?

- (R) Sí

- (P) ¿Nunca antes había pasado nada que te hubiera hecho sospechar?

- (R) Nada, nunca, nada

- (P) ¿Sexualmente abusó de ti en alguna ocasión, R?

- (R) Ahora, después del tiempo, que lo pienso, antes pensaba que no, pero ahora... sí que él me forzaba a tener relaciones con chantaje emocional. Me hacía ser culpable, si yo un día no tenía ganas, me hacía ser culpable... de... de que si no funcionaba sexualmente la relación era por mi culpa, porque yo estaba cansada, porque yo no tenía ganas. Si yo no tengo ganas, pues no tengo ganas. Eso lo sé ahora, pero en aquel momento consentía para no tener lío.

- (P) Esa vez, que cuentas que te fue a buscar a donde tú estabas cenando, fue la primera, pero ¿luego hubo otras?

- (R) Sí, sí

- (P) ¿Ahí no quedó la cosa?

- (R) ¡No, no, que va!

- (P) ¿En tu cuerpo tienes lesiones por el maltrato?

- (R) No

- (P) ¿Psicológicamente, te ha quedado algo?

- (R) Mucho

- (P) ¿Estás a tratamiento psicológico o estuviste? 
- (R) Ahora no, estuve en ADAVAS, pero hubiera necesitado un tratamiento psicológico prolongado

- (P) ¿Farmacológico, tomaste algo en aquel momento?

- (R) Sí, tuve que tomar porque fui un día a hablar con la psicóloga del ambulatorio, por otra cuestión y me vio tan mal que fue ella misma al médico de cabecera, a mi médico y le pidió una receta de lexatín y gracias a eso pude venir a L., porque muchas veces ni podía, a ADAVAS, que fue... vamos los primeros meses... que yo salía por ejemplo al banco o a un recado y tenía que volverme para casa, no podía hacer más, o sea, salir y volver, no podía hacer muchas cosas seguidas

- (P) ¿Pero por qué no podías?

- (R) Pues yo creo que era... no sé... era por miedo a encontrármelo, por angustia, era... no sé... tenía que venir a casa a sentirme segura

- (P) ¿Esto, una vez separada?

- (R) Sí, sí. Tenía que... y el coche siempre cerca, o sea, era...

- (P) Necesitabas tener esa seguridad

- (R) Sí, si no, no podía hacer nada.

- (P) ¿Tú esto lo contaste o tardaste tiempo en contarlo?

- (R) ¿Los malos tratos?

- (P) Sí, quiero decir, cuando te sucede, la primera vez, la segunda, ¿tú hablas con tus hermanos, con tus tíos...?

- (R) No se lo conté a nadie, no, no, no se lo conté a nadie

- (P) ¿Nunca?

- (R) No

- (P) ¿Y después, cuánto tardas en contarlo?

- (R) Una vez que ya hubo la denuncia y eso, sí, luego ya pude irme soltando y contando, y...

- (R) ¿Cómo reaccionaba la gente de tu alrededor cuando tú decías lo que habías vivido a su lado?

- (R) Pues la familia... a mis hermanos, poco... porque no quieres hacer sufrir más ¿no? Y él también era amigo de ellos, vamos, amigo. Y mis amigos, también andaban con él como amigo, pero bueno... luego me dijeron que era por mí, porque al principio, si..., bueno y tal, y luego... bueno... hubo una temporada que bien y tal... fueron muchos años también, fueron 20 años casi, y... claro... ellos también se sentían culpables de no haberse dado cuenta, de no haberlo podido parar o solucionar o lo que fuera y se sentían culpables de haber pasado buenos ratos con él, o sea... y yo me sentía culpable de haberlos engañado a ellos, por no haberles dicho nada, entonces es una situación un poco complicada

- (P) Las reacciones de tú alrededor, cuando ya salta todo por los aires ¿cómo son, tú te sientes apoyada o hay gente que se decanta por él?

- (R) Sí, sí, vamos, el 99\%, o sea, mis amigos, todos, estuve dos años como con guardaespaldas, o sea, conmigo, si salíamos algún fin de semana, íbamos a algún sitio, ellos conmigo, me iban a buscar, me llevaban a casa, hasta que no entraba en el portal, no marchaban, o sea, dos años súper controlada

- (P) ¿Qué clase de cosas le hacían enfadarse para que se pusiera así contigo?

- (R) Sobre todo, yo me he dado cuenta ahora, de que era, cuando empezaba yo a subir, a tener un trabajo bien..., después de sacar el carnet de conducir... Él te animaba, pero después... cuando él veía que tú ibas consiguiendo cosas, como que no.

- (P) ¿Le fastidiaban tus logros?

- (R) Sí, sí, sobre todo cuando él no los tenía

- (P) ¿Te veía a ti más capaz que a él?

- (R) Pues no lo sé, porque él es muy inteligente, y él puede hacer muchos trabajos, pero es muy cómodo, de hecho en 5 años ha trabajado en una escuela taller durante un año, es lo que ha hecho

- $(\mathrm{P})$ ¿Crees que es poca cosa para sus capacidades? 
- (R) Claro, puede trabajar de administrativo, de pintor, de delineante, de muchísimas cosas, pero no lo hace porque no le da la gana.

- (P) ¿Qué pasaba cuando se ponía agresivo? ¿Tú notabas que empezaba...?

- (R) Tú ya lo intuías, ya lo veías venir

- (P) ¿Por qué?

- (R) Por la mirada, por los gestos del cuerpo, la forma de hablar, el tono... sobre todo la forma de mirar... ya lo veías venir, ya sabías que te iba a caer de un momento a otro por lo que fuera

- (P) ¿Daba igual el motivo?

- (R) Daba igual, eso daba igual

- (P) Él, después de la agresión ¿mostraba arrepentimiento o intentaba camelarte o pedía disculpas?

- (R) No

- (P) ¿Jamás?

- (R) Una vez sólo, pidió disculpas, una vez y fue porque él, claro, cogió y se gastó todo el dinero que había en el banco, que había poquísimo, D. era pequeño, tenía 5 meses y me pidió perdón por eso, pero por pegarme a mí, no, jamás

- (P) ¿Nunca intentó luego camelarte o conquistarte de nuevo?

- (R) Sí, pero bueno, después de un tiempo, de que te hacía a ti ser culpable de esa agresión porque había sido por mi culpa todo, después de eso, sí, vamos, venía y me traía a mi amiga a casa, "venga que vamos a tomar café, o vamos a tal sitio" (pone el tono de voz que él utilizaba) o sea, estaba suave, pero ya sabías, que te iba..., al principio no lo sabías, creías que era el trabajo, que estaba mal, por mil cosas, siempre ponías excusas de que era por algo, pero luego los episodios son cada vez más cortos en el tiempo, más.., cada vez son más...

- (P) ¿Qué se repiten más, quieres decir?

- (R) Claro y cada vez ves que se encauza más hacia el hijo, entonces es ahí cuando empiezas tú a..., pero vamos a mí me costó un montón eh.

- (P) ¿Quieres decir que tú veías cómo su agresividad también la dirigía a D.?

- (R) Sí

- (P) Ya no sólo era contra ti, sino también con el niño.

- (R) De pequeño lo hacía, pues a lo mejor castigándole, o tal... pero bueno, cuando él veía que se pasaba "Ah, te levanto el castigo" ¿Sabes?, a lo mejor le decía "un mes sin tal..." y a lo mejor era una burrada, porque eso a un chaval no se le puede decir y siendo pequeño, "que te castigo un mes sin salir", eso es imposible, o le mandaba estar en su habitación estudiando, que ni estaba estudiando ni nada, estaba delante de un libro, pero no hacía nada

- (P) ¿A D. le pegaba?

- (R) De últimas, sí le pegó un puñetazo en el estómago, fue cuando D. quiso denunciarlo y yo no le dejé, yo le convencí para que no le denunciara, eso fue, creo yo, como un par de meses antes de lo que fue la denuncia. D. sí que me pedía que me separara de él

- (P) ¿Cuántos años tenía $\mathrm{D}$. de aquella?

- (R) Cuando nos separamos, 15, sí porque tiene ahora 20

- (P) Decías que había periodos de calma en tu casa, después de una agresión, él intentaba estar suave... ¿Cuánto duraba esa calma?

- (R) Pues al principio duraba más, ahora ya de últimas no..., no porque yo tampoco consentía, yo además llevaba más de un año durmiendo en otra habitación, bueno... durmiendo... intentando dormir

- $(\mathrm{P})$ ¿Intentando dormir, por qué?

- (R) Porque él a lo mejor, de repente, abría la puerta así, se te quedaba así... mirando, no sabías si iba a ir a por ti...

- (P) ¿A cualquier hora de la noche?

- (R) Sí

- (P) ¿Te abría de repente la puerta? 
- (R) Sí y no sabías si iba a ir o no... no sabías. Yo dormía con un cuchillo debajo de la almohada y decía si viene... algo hay que tener aquí

- (P) Al que más pueda

- (R) Sí, sí ,pero yo creía que salir de esa casa iba a ser mucho peor que quedarme dentro, sí

- (P) ¿Por qué creías eso?

- (R) Porque le tenía muchísimo miedo y tenía más miedo a estar fuera que dentro, porque dentro yo creía que todavía controlaba las cosas, pero... ya de últimas no controlaba nada, nada, ninguna filtración, nada, nada, nada

- (P) ¿Cómo te sentías en aquel momento?

- (R) ¡Puf...! es que llegas a no sentir

- (P) ¿No sentías?

- (R) No

- (P) Nada. ¿Cómo te veías...? Se te llenan los ojos de lágrimas $R$.

- (R) Es que eso fue...Terrible, el no sentir

- (P) ¿Cómo te veías a ti misma cuando te mirabas al espejo?

- (R) ¡Puf...! me veía como me veía él, me veía inútil, me veía mala madre, me veía fea, me veía... todo

- (P) ¿Ese era el discurso que él te enviaba a ti? ¿Llegaste a creértelo?

- (R) Sí (contesta con un hijo de voz, no puede hablar al recordarlo)

- (P) Te lo creías, lo hiciste tuyo, dijiste, ¡bueno será verdad! Ahora mismo ¿cómo te ves?

- (R) Tengo días, hay días que estás más arriba o más abajo, pero bueno... la montaña es cada vez más... se va haciendo más lineal, ya no es ni tan arriba ni tan abajo

- (P) ¿Se van acercando los extremos?

- (R) Sí, ya no estoy ni tan arriba, ni tan abajo. Bueno, bien, ya me voy viendo a mí misma, ya me voy encontrando

- (P) ¿Qué sentimientos tenías hacia él, a lo largo de la relación? Porque claro, os conocéis jóvenes

- (R) Sí, yo 23 y él 28

- (P) Cuéntame un poco

- (R) Yo es que puse todo, todo, todo, todo... es que no podía poner ya más, porque no tenía más y yo que sé... a mí me parecía lo mejor del mundo, lo mejor que me había pasado, él me lo hacía ver de esa manera y luego, de repente, desde la primera vez que me dio... yo ahí luego ya... siempre estuve alerta, pero claro, siempre piensas que las cosas se van a solucionar, que van a cambiar, que... siempre piensas que las cosas van a cambiar, entonces en esos periodos en que las cosas van bien, crees que están cambiando y no está cambiando nada, nada, no cambia nada, simplemente hay un periodo de descanso y luego viene otra cosa peor

- (P) ¿Vuelta a empezar?

- (R) Sí, pero peor a la anterior, siempre es peor, porque como ya te conoce más y ya sabe tus puntos débiles, te hace todavía más daño, porque puede hacértelo, entonces cada vez va haciendo más daño y va minándote cada vez más

- (P) ¿Qué pasaba en relación a D.? ¿Qué sentimientos tenías con respecto a ese niño y lo que estabais viviendo?

- (R) ¡Puf...! yo no quería que se perdiera muchas cosas que él... yo que sé, si le apuntabas a los scouts no le parecía bien, te dejaba, pero luego ya no le parecía bien, ya había que sacar al chaval de ahí, entonces claro, en ese periodo, que tú estás tratando de que el niño disfrute de lo que le gusta, de lo que... y el otro tira para atrás, o sea, él siempre utilizaba esas cosas para desarmar la tranquilidad, porque ya ves que daño podía hacer D. perteneciendo a los scouts o yo que sé que decirte... otra cosa que le gustara..., ya no me acuerdo, pero bueno..., él decía que no y tenía que ser que no, entonces yo estaba ahí siempre intentando alargar para 
que no... para que $D$. pudiera disfrutar de lo que... de eso... y a la vez luchando con él, entonces era agotador, todo el día, todo el día, todo el día así, cuando no era una cosa, era otra, todo el día desgastándote..., en la comida, si ibas al súper mercado, o sea, lo que fuera. Cuando veía ese periodo en el que te iba a machacar, lo sabías que te venía, tenías que estar sentada en el sofá, así (se cruza de brazos) y sin moverte. Bueno, yo me bloqueaba, yo me quedaba sentada en el sofá y arreando, procuraba ir a comprar cuando él no estaba, para que no supiera que iba a comprar, o... para que él me viera en casa y hacer de ama de casa. Si estaba trabajando en alguna cosa ipuf...!, cuando fue lo del gas, tenía que hacer reuniones de vecinos y a veces se alargaban por la noche, pues que de dónde venía, de estar con alguno, de yo qué sé, de lo que fuera, le daba igual, le daba lo mismo

- (P) ¿Quién tomaba las decisiones importantes en la casa?

- (R) Yo las proponía y él las decidía, o por lo menos yo intentaba que fuera así, para que él se viera que era él el que tomaba las decisiones, por ejemplo, cuando se compró la casa, la idea fue mía y toda la labor fue mía, hasta el dinero fue mío, pero como que era él el que lo conseguía

- (P) ¿Le dabas importancia a él, el mérito a él, para que no se sintiera menos que tú?

- (R) Sí, para que hubiera tranquilidad sobre todo

- (P) ¿Y eso funcionaba, o así y todo montaba jaleo?

- (R) Sí, siempre montaba follón y siempre era culpa mía todo

- (P) ¿El dinero, quién lo manejaba?

- (R) Desde siempre yo, pero claro, relativamente. A él le gustaba decir que yo manejaba el dinero, pero él todos los días me pedía y cuando no había, que donde había metido el dinero, dónde te lo has gastado. Él me pedía todos los días, para salir, 20 ó 30 todos los días, todos los días y claro de un sueldo de nada, bueno... pues claro, tú lo manejas, pero claro, si te lo piden todos los días, ¿qué manejas?, no manejas nada. El último año, su dinero, él sólo pagaba lo que era la hipoteca, 300 y pico, pero el resto lo pagaba yo, estaba haciendo lo del gas por la calle, cobraba un sueldo y el resto lo pagaba yo todo y fue el único año que él manejaba el dinero, vamos su dinero, yo manejaba el mío, pero era para casa, él pagaba la hipoteca

- (P) ¿Incluso de tu dinero le tenías que dar a él?

- (R) Yo..., si yo ingresaba en una cuenta..., daba igual, si él me pedía, yo tenía que sacarlo de donde fuera, "¿Cómo es que no hay?, pues eso es que lo... tal" Comprabas una cosa "claro si es que te gastas en una lavadora tanto" "oye es que las lavadoras es lo que cuestan", o sea, eso sí, él decía "Tú cómprate lo que quieras"' ¿Con qué? Si no hay un duro, ¿Con qué me lo compro si no tenemos ni un duro? ¿cómo me lo voy a comprar?" Claro yo manejaba y yo todo, sí, pero él era el que se lo gastaba

- (P) ¿Quién se ocupaba de la casa, de la compra, del niño...?

- (R) Yo

- (P) ¿Siempre?

- (R) Sí, porque las pocas veces que se tuvo que ocupar él, era "Sí, sí, yo, yo" Dos días

- (P) Sin embargo decías que sí que te hizo dudar de tu labor de madre, de ama de casa...

- (R) Sí, si él hacía un día la comida, eso era la leche y había que pregonarlo, no te decía hazlo así, pero te lo daba a entender, fíjate, no había un dios que comiera aquello, pero bueno, había encima que... Yo sí, yo bueno, cuando empezó, "mira yo trabajo, tú no trabajas, pues haces la comida..." pero no hacía nada, lo hacía yo todo

- (P) ¿Qué clase de cosas le molestaban? ¿Cuándo se ponía de mal humor por qué era?

- (R) Porque le tocaba, él tenía periodos en que le tocaba, y sobre todo si a mí me veía subir, más todavía 
- (P) ¿Era como cíclico?

- (R) Sí

- (P) ¿Tú sabías que llegaba un momento que...?

- (R) Sí, yo ya sabía que llegaba

- (P) ¿Sin que sucediera nada?

- (R) Sí, yo ya sabía que me tocaba

- (P) ¿La tensión, la palpabas?

- (R) Sí, sí, ya como te hablaba, el tonito y las miradas...

- (P) ¿Y se precipitaba rápido, después de que tú te percatabas de esos signos? ¿Se precipitaba rápido la agresión o tardaba?

- (R) No, lo prolongaba, ¡hombre!, había veces que era una agresión directa, sobre todo si yo salía a cenar con amigos, yo sola, yo sola, que fueron cuatro veces en 20 años, vamos, si salí 5, 4 me dio. De llegar y darte, una vez casi me tira por las escaleras, por la barandilla para abajo, porque yo me agarré, si no... cuatro metros para abajo, hubiera caído, o sea, de meter la llave en la puerta y jzis, zas y zis, zas! y sin saber porqué, porque yo se lo decía "mira voy a salir con... a cenar con amigos" que él sabía quiénes eran, eran todo parejas, matrimonios, que nos conocemos desde hace treinta y tantos años, que no iba con nadie extraño, o sea, es que fíjate, me estoy todavía excusando yo

- (P) Justificándote

- (R) Me estoy justificando, manda narices. Bueno, pues eso, e igual si, de eso que llegas a casa y ipun, pun!, un mes sin hablarte, eso era normal, lo de un mes sin hablarte, era lo más normal del mundo. D. llevaba un año sin hablarle

- (P) Con 15 años

- (R) De los 14 a los 15

- (P) No se hablaron

- (R) No, no le hablaba

- (P) ¿Cuánto tiempo estuviste a su lado?

- (R) 20 años

- (P) 20 años, ¿cuánto de casada y cuanto...?

- (R) Empecé con 19 y de novios estuvimos un año, un año y algo

- (P) ¿Qué te hacía mantenerte a su lado?

- (R) Yo había proyectado toda mi vida en él, toda. Yo creo que fue eso, y yo qué sé que empiezas de joven, haces la vida ya con él, o sea, yo ya no me veía en otro lado que no fuera con él y como pensaba que las cosas iban a cambiar y que él iba... y luego claro dicen "la bebida hace...", pero no la bebida no hace eso

- (P) ¿Él bebía?

- (R) Sí, la bebida no hace eso, porque cuando estaba calmado era cuando estaba pedo, es cuando estaba tranquilo, y claro, al día siguiente, era cuando había que prepararse, por si no había dinero para salir él, había que prepararse también

- (P) ¿A ti te agredía estando sereno?

- (R) Sí, siempre, sí, sí, sí

- (P) ¿Tuviste algún tratamiento psicológico antes de conocerle a él?

- (R) No

- (P) Porque después, dices que en ADAVAS estuviste algún tiempo

- (R) Sí

- (P) ¿Y él antes de conocerte a ti, tuvo algún tratamiento psicológico?

- (R) Sí

- (P) ¿Qué le pasaba?

- (R) Tenía crisis de ansiedad, tenía crisis de pánico

- (P) ¿Pero esto antes de conocerte a ti?

- (R) No, bueno eso no lo sé, eso no lo sé

- (P) Esto que dices que tenía crisis de ansiedad y ataques de pánico

- (R) Eso le pasó estando conmigo, sí, pero es porque tenía mucho miedo a la muerte 
- (P) ¿Y eso, algo que él tenía en su cabeza?

- (R) Eso son cosas de él, yo me pasaba las noches hablando con él, calmándole, claro, para eso yo era maravillosa, en esos momentos, yo era la única persona que le podía ayudar. Una vez que se le pasaba... ancha es Castilla

- (P) Es decir, que antes de conocerte tú no sabes, pero sí que mientras estuviste casada con él, tuvo que visitar... ¿hizo terapia?

- (R) Bueno sí, vino a L. un par de veces, le dieron una cinta, pero él luego no hizo nada, realmente no hizo nada

- (P) ¿La cuestión económica dificultó tu separación? ¿Tú pensaste mucho en el dinero a la hora de separarte?

- (R) Sí, vamos... mucho no, pensé que era un problema añadido al problema que ya tenía, pero vamos, para mí el dinero no era importante, yo sabía que tenía familia y que no me iba a faltar ni un techo, ni comida y a mi hijo tampoco. O sea, que no tenía problema, que podía trabajar en cualquier cosa, lo he hecho siempre, en lo que me dejó él trabajar, porque había que... entonces claro, normalmente eran pequeños trabajos, que no requirieran mucho tiempo, que...

- (P) En horario compatible con sus necesidades

- (R) Claro

- (P) El dinero no resultó problema, tanto en cuanto que a ti llegó un momento que te da igual, dices me separo y ya está ¿no?

- (R) No, fue D. el que me dijo... fue D....

- (P) ¿Cuál fue el detonante? ¿Por qué te separas?

- (R) Porque D. vio como me pegaba él

- (P) ¿Nunca antes lo había visto?

- (R) No, lo intuía, pero no lo había visto

- (P) Y ese día lo vio ¿qué pasó ese día?

- (R) Ese día tenía yo la cena del curso de jardinería, llevaba un año haciendo el curso de jardinería, que te pagaban un sueldo y bueno..., un año, claro, era el cumpleaños de uno de los del curso y nos invitó al pueblo a comer con la familia de él, la mujer, los hijos y los del curso. Bueno pues ya vamos a provechar y... pues me amenazó por teléfono "ya verás cuando vengas para casa, te vas a preparar" (lo recuerda con miedo). Al niño le dijo que yo estaba por ahí, con uno y cuando llegué a casa, le di la cena a D. y él no estaba y cuando llegó vino directo a mí, me dio un puñetazo y me agarró así (por la pechera) y me dio un puñetazo en la cara, claro, el chaval fue cuando lo vio y sacó un cuchillo del cajón

- (P) ¿D. sacó el cuchillo del cajón?

- (R) Sí, un cuchillo grande y lo fue a amenazar a él y claro, D. era delgadito, con 15 años, entonces cuando yo lo vi, los dos intentamos quitarle el cuchillo porque yo dije, aquí va a pasar algo muy, muy gordo, bueno... casi ni te da tiempo. Yo cuando lo vi tenía el cuchillo echado para otro lado, pero él empezó a agarrar a D. y a darle puñetazos en la espalda, entonces intenté separarle, entonces saqué a D. y nos marchamos los dos corriendo

- (P) ¿A dónde fuisteis? ¿Qué pasó?

- (R) Pues como D. salió descalzo, fuimos a casa de su amigo, D. con un ataque de nervios, a por unas zapatillas, nos fuimos, yo no sabía qué hacer, él decía que fuéramos a la policía y bueno... bajó la madre del niño

- (P) De su amigo

- (R) También la conozco, es amiga de toda la vida, no amiga íntima, pero bueno, y... "sube y tal", allí ya me convencieron de que tenía que ir a denunciar, ya fuimos todos y le denuncié, y...

- $(\mathrm{P})$ ¿Después qué pasó?

- (R) Yo después..., hace un par de años, ella me dijo que yo quería volver para casa ese día, yo estaba diciendo que ya se le pasaría. Yo no me acuerdo de haber dicho eso, dijo "si tú querías ir para casa", pero ¿Cómo iba a querer ir para casa?, "sí, 
dijiste que ya se le pasaría que ibais para casa" Yo porque me lo dice ella, pero no...

- (P) La cuestión es que vais a la comisaría, denunciáis y luego ¿dónde te vas, R., con tu hijo?

- (R) Pues en ese momento, pasaron un matrimonio, también de los del grupo de amigos, que tienen allí la cochera, en esa plaza y vieron a este amigo "¿Qué haces aquí?" "Bueno... que está R." y le contó todo, entonces ya empezaron a llamar, vinieron todos los amigos, yo cuando acabé de declarar salí y allí estaban todos, no sé si serían 12 o por ahí y entonces ya me dijo la que era más amiga mía que me fuera a su casa. Me fui allí a dormir, no le dije nada a mi tía hasta el día siguiente para que no me viera como estaba, D. también se quedó a dormir allí y bueno... al día siguiente llamé a mis hermanos, vinieron por la tarde, a mi tía...

- (P) ¿Cómo reacciona tu familia en ese momento?

- (R) ¡Puf...! no me acuerdo (se pone a llorar)

- (P) Tranquilina, tranquila. Lo tienes todavía muy fresco en la memoria, lo vives como si hubiera sido ayer mismo (no puede parar de llorar)

- (R) Fue muy doloroso

- (P) Claro, es que no es fácil, romper una relación de tantos años

- (R) No, muy doloroso, fue muy doloroso, ahora lo veo de otra manera, fue muy doloroso que mis hermanos sufrieran eso, verles sufrir de esa manera, a mí me dolió mucho

- (P) Sin embargo, sí que te apoyaron ¿verdad R?

- (R) Sí, bueno, yo tuve que llamarles, coger el coche, que estaban de vacaciones y venir corriendo, mi hermano y mi hermana, vinieron, vamos... fue coger el coche y venirse (suspira muy profundamente para poder seguir hablando) Me cuesta todavía pensar en el dolor que sufrieron ellos, me cuesta mucho

- (P) Todo pasa, R., todo pasa, Y la peor parte te la llevaste tú, no lo dudes

- (R) Ya

- (P) ¿Cómo reaccionan tus tíos, con los que tienes una relación muy estrecha?

- (R) Pues también con dolor, mucho dolor, pero bueno, yo intenté hacérselo suave para... no hablar mucho, no contar mucho porque no hay que hacer más daño que el imprescindible

- (P) ¿En tu familia habías visto alguna vez malos tratos?

- (R) Jamás, no. No, ni insultos tampoco

- (P) ¿Y en la familia de él?

- (R) En la de él luego me enteré, que su hermana y su cuñado... pero claro intentaban taparlo, y su madre y..., o sea, sus padres, ahora me enteré fíjate, por un señor, que el padre también era como él, así de... que había que esconderle lo que se compraba y cosas de esas

- (P) ¿Pero tú eso nunca lo supiste?

- (R) No, no me enteré hasta este año, que lo dijo un vecino mío de toda la vida

- (P) Después de pasados muchos años te enteras de que él, a lo mejor, ha tenido experiencias...

- (R) Pero a él nunca le maltrataron, fue un niño tardío y lo tuvieron siempre muy mimado y muy consentido

- (P) Sí, pero la pregunta es ¿él presenció ese maltrato? ¿él vio como su padre maltrataba a su madre?

- (R) Pues... seguramente. Maltrato de palabra sobre todo, de palabra a lo mejor, sí

- (P) Maltrato psicológico

- (R) Sí, lo que pasa que mi suegra era una mujer tan... "va, no pasa nada" y siempre tapaba y tapaba

- (P) Era también otra mentalidad

- (R) Sí, tapaba mucho

- (P) ¿Fue un hombre sometido a estrés por problemas laborales? Que tú puedas achacar todo esto a ese motivo.... 
- (R) Yo lo achacaba, pero no, porque he estado yo en estos 5 años mucho más sometida a estrés que él en 20

- (P) Y decías con el consumo lo mismo, que también intentaste justificarlo en alguna ocasión

- (R) No dicen que él decía la verdad, y él siempre me decía "no es que tú hermano es un gitano" "es que me ha valido esto, me ha valido tres, aunque tú creas que me ha valido 10 , me ha valido 3 , porque es que no hay dinero para más, no hay" Yo siempre le decía la verdad

- (P) Él consumía alcohol y aunque en ese momento no agredía, cuando se le pasaba el efecto, era cuando tú te echabas a temblar. A parte del alcohol ¿consumía otras sustancias?

- (R) No

- (P) Era alcohol, sobre todo ¿Lo consumía habitualmente?

- (R) Sí, a diario

- (P) ¿Cuándo consumía él estaba tranquilo?

- (R) El día que se emborrachaba y eso, sí

- (P) ¿Bebía fuera de casa?

- (R) Sí, sí, siempre fuera

- (P) Bebía fuera, venía para casa y no pasaba nada. ¿Y al día siguiente qué pasaba?

- (R) "Dame dinero para salir" (le pedía él a ella) "No tengo" (ella le contestaba) “¿Cómo que no hay?"( él se enfadaba) y ya..., no podías decir que no hay, había que sacarlo de donde fuera

- (P) ¿Te costó comenzar a hablar de todo esto que te estaba pasando?

- (R) ¡Puf...! muchísimo

- (P) ¿Te costó?

- (R) Mucho, mucho

- (P) Hablabas antes de la denuncia, la denuncia la provoca, cuando tú ves que también entra en el juego tu hijo D. ¿De no haber sido así, lo hubieras denunciado?

- (R) Pues no lo sé, yo tenía muchísimo miedo

- (P) ¿Sólo fue una denuncia?

- (R) Una

- (P) Y a partir de ahí la separación

- (R) Sí, yo nunca más tuve contacto con él para nada, ni una palabra

- (P) Le denunciaste por esto que pasó, y acto seguido la separación

- (R) Él, por el policía me llamó, que si fue un mal momento, que si no se qué, que le perdonara, que fue un mal momento

- (P) Llevabais muchos años de mal momento

- (R) Claro después de hablar toda la noche, sí, toda la noche y tal y bueno... Cuando ya ves a tu hijo, pero vamos, yo lo de subirme para casa, es que todavía lo tengo aquí metido, ¿cómo diría yo eso?, irme para casa después de lo que pasó, no lo entiendo

- (P) Pues no lo sé, R., pero a lo mejor era la fuerza de la costumbre, tú estabas acostumbrada a que a él se le pasaba al cabo de un rato o al día siguiente, y estabas en esa dinámica

- (R) Pero un hecho tan grave como ese, no sé cómo pude decir eso. No lo sé

- (P) ¿Te culpas por ello, R? O ¿Te parece vergonzoso?

- (R) Sí, me parece... ¿Cómo podría decir eso? No me parece que yo, después de lo que pasó, pudiera decirlo

- (P) Ni te culpes, ni lo pienses, fue una reacción y ya está

- (R) Yo creo que fue algo...

- (P) ¿Te anima tu amiga a denunciar?

- (R) Sí 
- (P) Te vas a la comisaría acompañada por ella, luego aparecen tus amigos. ¿Te has sentido, no sé si en aquel momento o ahora al revivirlo, sientes la necesidad de exagerar tu historia para que la gente te crea?

- (R) No, yo muchas veces, muchas cosas he tenido que no contarlas porque dirán, esta está loca, ¿cómo le pudo pasar eso y estar ahí?, porque lo que más rabia me da es cuando dicen ¿cómo pudiste seguir?, eso me da una rabia que no puedo con ello, a ti te quería yo haber visto ahí, a ver si hubieras seguido o no. Bueno... pues infórmate de a ver cómo es la cosa, yo lo entiendo porque me lo tuvisteis que explicar el porqué yo seguía ahí, pero no sé, no es tan fácil, no es fácil

- (P) No es fácil, de hecho las mujeres que salís adelante sois unas valientes, eso está clarísimo

- (R) No lo sé, a veces, te sientes cobarde por haber estado allí tanto tiempo

- (P) Eso es una cuestión de cada una, cada persona tiene su momento y las cosas suceden cuando tienen que suceder. ¿No tuviste la necesidad de ir a una casa de acogida?

- (R) No

- (P) ¿Tu ex marido, se consideraba en aquel entonces un hombre maltratado por ti? ¿Pensaba que tú eras la maltratadora?

- (R) Sí, sí, sí

- (P) ¿Te echó a ti la culpa en alguna ocasión?

- (R) Sí, sí, sí

- (P) ¿D. sólo presenció ese episodio de violencia o hubo más?

- (R) ¡Hombre!, presenció... él desde la habitación oía

- (P) ¿Tú le metías allí dentro?

- (R) No, como él le castigaba siempre

- (P) Estaba siempre en la habitación, el pobre

- (R) Estaba siempre en la habitación el pobre, pues ahí estaba

- (P) ¿Él ha recuperado la relación con su padre?

- (R) No, no puede verlo, no, ni la va a recuperar. Yo he intentado decirle que no viva con ese rencor, que le va a hacer daño, pero él la verdad, como que no lo necesitara

- (P) Y ahora que él ya es mayor, ¿tú observas en él reacciones como las de su padre, en el trato con las chicas?

- (R) ¡No, hombre!, con otra novia que tuvo, a veces, pues de esto que te das y yo le decía " $D$. no juguéis a eso, que acabáis haciéndoos daño, no juguéis porque eso es un juego muy malo, que de tanto daros, al final os hacéis daño y esto se vuelve costumbre" $\mathrm{Y}$ bueno, con esta le veo más tranquilo que con la otra chica y era muy maja, majísima, pero bueno... son cosas de ellos

- (P) ¿Tú pensaste en algún momento, sobre todo cuando conoces a tu ex marido, que él era el hombre de tu vida?

- (R) No, en principio no, pero luego ya sí

- (P) ¿Creíste que era tu complemento?

- (R) Vamos, es que cualquier película de estas románticas, no se puede comparar con el año de noviazgo, o sea, insuperable, o sea...

- (P) ¿ldeal?

- (R) Bueno... impresionante

- (P) ¿Y ahora qué piensas de todo eso?

- (R) Pues que fue bonito mientras duró, un año y se acabó, de veinte, uno

- (P) Bueno R., al menos tuviste uno (utilizamos la ironía para descargar la tensión anterior)

- (P) ¿Piensas que la situación ideal de las mujeres es tener una pareja?

- (R) No, no

- (P) ¿Crees que las mujeres cuando amamos a un hombre, después de ese ya no hay más?

- (R) No 
- (P) ¿Tenemos capacidad para...?

- (R) Sí, sí

- (P) Cuéntame ¿qué opinas de los celos?

- (R) Los celos, es envidia, es...

- (P) ¿Son buenos en una relación?

- (R) No, no, no

- (P) ¿Mejor no?

- (R) No, no. Eso es que no hay confianza, no hay... no hay esto... ¿cómo se dice?... no hay respeto, no hay nada, nada. Tiene que haber total libertad de todo

- (P) ¿Qué piensas R. de la intensidad con la que se ama? ¿Tenemos que amar siempre con la misma intensidad?

- (R) No, yo tengo que amar con menos intensidad

- (P) Tú es que amas mucho

- (R) Demasiado, lo doy todo, no dejo nada para mí, entonces ahí es cuando la cago, entonces prefiero no tener nada

- (P) ¿Piensas que el amor tiene que manifestarse siempre con la misma intensidad? $¿ \mathrm{O}$ crees que tiene altos y bajos?

- (R) Sí, sí, todas las relaciones empiezan... todas las relaciones tienen una intensidad al principio, pero luego se va relajando, siempre igual más o menos

- (P) ¿Y el amor lo puede todo?

- (R) (Se ríe) A los hijos, quizá, pero a una pareja

- (P) ¿A un hombre?

- (R) No

- (P) Quiero decir, que si nos queremos, pues, sólo con eso, podemos vivir tranquilos ¿o no?

- (R) No, no, tiene que haber más cosas

- (P) ¿Piensas que podemos evitar amar a una persona? $\mathrm{O}$ ¿El amor es algo involuntario?, te llega y te llegó y tienes que amar porque te llegó el amor

- (R) No, no, se puede evitar, sí

- (P) ¿Por el simple hecho de amar a alguien, lo ideal sería convivir con esa persona?

- (R) No

- (P) ¿Se puede amar cada uno en su casa?

- (R) Que no traiga el cepillo de dientes nunca

- (P) ¿Jamás?

- (R) Jamás

- (P) Cualquier cosa, menos el cepillo de dientes

- (R) Tú en tu casa y yo en la mía y ya está

- (P) En tu caso, ¿la decisión de separarte es tuya?

- (R) Sí, sí, total

- (P) Fue el día de la denuncia, y no hay marcha atrás

- (R) No, no, yo ahí sabía que no había marcha atrás, porque era, vamos..

- (P) ¿El detonante es la agresión a tu hijo?

- (R) Sí, sí, sí

- (P) ¿Porque le agrede a él o porque él ve como te agrede a ti?

- (R) Porque le agrede a él

- (P) ¿Y ese día por qué lo vio?, no estaba castigado

- (R) Estábamos en la cocina, yo dándole la cena y el otro entró como un toro y directo a mí. Bueno me dijo "márchate" y yo le dije "no, yo de aquí no me marcho", él quería que me fuera de casa sin el niño, pero yo no le iba a dejar allí, al chaval, para qué, vamos no

- (P) Y entonces como no marchaste...

- (R) Cogió y jala...!

- (P) ¿Tuviste intentos de separación antes de ese?

- (R) No 
- (P) ¿Nunca se te había pasado por la mente?

- (R) ¡Hombre! si le dije "oye como no sigan mejor las cosas, tal...", pero nunca, nunca porque me hubiera pegado, o porque... por su forma de estar conmigo o de cómo llevábamos la relación, pero nunca por haberme agredido a mí

- (P) Si no por el tipo de relación que teníais. ¿Qué cambios experimenta tu vida desde el momento que te separas? ¿Qué cosas cambian para mejor o para peor?

- (R) Todo para mejor, te das cuenta de la familia que tienes, de los amigos, de tu hijo, de lo que eres capaz de hacer, de lo que eres capaz de no hacer, de lo que te quiere la gente, de los prejuicios que hay, de las diferencias que hay, de cómo nos ven los hombres y las mujeres, te das cuenta de muchas cosas

- (P) ¿Se puede decir, R. que tú creciste como persona después de salir del matrimonio?

- (R) Sí, sí

- (P) ¿Es cuando tú empiezas a desarrollar tú...?

- (R) Sí

- (P) De alguna manera tu vida, a nivel profesional, a nivel personal

- (R) Yo pasé de los 24 a los 42

- (P) Así, de un plumazo

- (R) Sí, sí

- (P) ¿Con qué apoyos cuentas en este momento?

- (R) Mi hijo, mi familia, mis amigos, mis nuevos amigos

- (P) Te iba a preguntar por tus nuevas amistades

- (R) Esta amiga es de un trabajillo que tuve, he tenido muchas amigas buenas

- (P) Ampliaste la red

- (R) Sí, sí, he ganado, a raíz de eso, pues mucha gente y muy bien

- (P) ¿De salud estás bien?

- (R) Sí

- (P) Con esos achaques tontos que me decías antes, pero bien, la vivienda, sigues en el mismo piso y la economía te va incluso mejor que estando con él

- (R) Bueno... no hemos tenido, ya sabes que yo soy muy ahorradora

- (P) Organizada

- (R) No hemos vivido tan bien nunca, económicamente... me he comprado hasta un coche

- (P) Fíjate y ¿qué coche te compraste?

- (R) Un Ibiza de segunda mano, porque el otro se me murió y estoy feliz

- (P) Feliz con tu coche

- (R) Sí, sí

- (P) Las relaciones sociales las amplías

- (R) Sí

- (P) Las relaciones familiares las conservas

- (R) Bueno, con una amiga... yo creo que le vino el problema mío, un poco grande, o a lo mejor es que ella tiene sus propios problemas y tuvo que dejar los míos, pero bueno seguimos siendo amigas aunque la relación no es tan estrecha

- (P) Bueno, se enfrió un poco

- (R) Sí, se enfrió un poco

- (P) La crianza de D., la asumes tu sola, tú eres padre y madre y todo a la vez

- (R) Sí ,pero bueno, tiene la figura paterna en mi hermano, que es muy buena, y mi cuñado también le da de vez en cuando un repasín, cuando se desviaba "habla con

D."(le pide ella a su cuñado), le daba un repaso y ya parecía que...

- (P) De nuevas parejas me decías antes que no quieres ni oír hablar

- (R) No, de momento no, además es que me da mucho miedo

- (P) Te ha quedado ahí un punto

- (R) ¡Puf...!, tendría que ser un santo varón y no los hay

- (P) Eso en los altares 
- (R) En los altares nada más

- (P) ¿Cómo te sientes ahora con respecto a ti misma?

- (R) Bien, bien, tengo que adelgazar, pero bien

- (P) ¿Qué planes de futuro tienes? ¿Cómo te ves de aquí a un tiempo?

- (R) Pues en cuanto D. ya se encauce un poco, trabajo, estudios o lo que sea, me voy a buscar un trabajo que me satisfaga un poco, que lo necesito

- (P) ¿No te gusta lo que haces?

- (R) No, no. Estoy muy a gusto porque hago lo que quiero en todos los trabajos, o sea que no hay nadie detrás de mí, que tengo total libertad, pero claro me apetece un trabajo un poquito más..., me apetece un trabajo... otro trabajo que me satisfaga a mí

- (P) ¿Que te permita un horario más organizado... o más...?

- (R) Y que me guste

- (P) Estabas muy contenta en el CTR

- (R) Bueno... en aquel momento... luego estuve en el reciclaje, mira esta amiga es de allí, y bueno bien... estuve allí en la gloria, pero bueno... eso se acabó, y luego estuve en el asilo y bien

- (P) Por mi parte, ya acabo, si tú quieres contarme alguna cosa más que te parezca importante

- (R) Si ya te lo he contado todo

- (P) Seguro que habrá por ahí más episodios, pero similares a lo que me has contado

- (R) Si, parecidos

- (P) Muchas gracias R.

- (R) Cualquier cosa me llamas.

- (P) Gracias 
